\title{
Influencia de las instalaciones de suministro de agua de edificios sobre el comportamiento hidráulico en régimen permanente $y$ transitorio de la red general de distribución
}




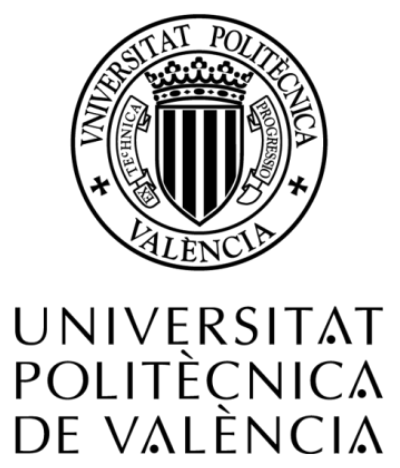

DEPARTAMENTO DE INGENIERÍA HIDRÁULICA Y MEDIO AMBIENTE

INFLUENCIA DE LAS INSTALACIONES DE SUMINISTRO DE AGUA DE EDIFICIOS SOBRE EL COMPORTAMIENTO HIDRÁULICO EN RÉGIMEN PERMANENTE Y TRANSITORIO DE LA RED GENERAL DE DISTRIBUCIÓN

\section{TESIS DOCTORAL}

Presentada por:

JAVIER SORIANO OLIVARES

Dirigida por:

FRANCISCO ARREGUI DE LA CRUZ 

nacional e internacional.

\section{(c) J avier Soriano Olivares}

Primera edición, 2012

(c) de la presente edición:

Editorial Universitat Politècnica de València

www. editorial. upv. es

ISBN: 978-84-8363-845-3 (versión impresa)

Queda prohibida la reproducción, distribución, comercialización, transformación, y en general, cualquier otra forma de explotación, por cualquier procedimiento, de todo o parte de los contenidos de esta obra sin autorización expresa y por escrito de sus autores. 
Dedicado a mi abuela Carmen

y a mis padres 


\section{AGRADECIMIENTOS}

Llegar a escribir estas líneas no es nada sencillo, y gran parte te lo debo a ti Paco, muchas gracias por tu valioso apoyo técnico, por tu apuesta y por todos esos consejos que como Director, amigo y compañero me has ido dando. Gracias.

A los miembros del ITA, y en especial a Vicent por el desarrollo del programa Allievi, y por todas las consultas que desinteresadamente me has aclarado. También te debo mucho a ti Jorge, por todo ese fundamento técnico que desde el primer momento me has facilitado. Y como no, al resto de profesores Enrique, Quique y Ricardo por vuestra accesibilidad y apoyo. También a Paco Valero por tu valiosa compañía, y a tantos otros compañeros con los que he compartido unos muy buenos momentos durante el desarrollo de la Tesis.

A la empresa EMASESA, y en especial a Camilo Veiga por acogerme como uno más, y por facilitarme toda la parte experimental de la Tesis.

A los miembros del Comité Técnico de Normalización 149-SC2 de AENOR, por su confianza para implementar los resultados de la Tesis en la Norma UNE 149202, y por el valioso apoyo técnico que me han brindado.

A Buchberger por darme la oportunidad de incorporarme a su grupo de trabajo en Cincinnati.

Y finalmente, pero con el más merecido cariño, a mis padres Encarnita y Juan, y a mis hermanos Juan Jesús y Luis, y a Elena. Simplemente gracias por el día a día. 


\section{RESUMEN}

El crecimiento urbanístico ha propiciado un aumento de la demanda de agua de los usuarios de un abastecimiento. Frecuentemente, debido principalmente a la falta de inversión, este crecimiento no ha ido acompañado de una adecuación de la infraestructura hidráulica. Esta situación ha mermado progresivamente la capacidad de la red y ello ha favorecido un uso extendido de depósitos atmosféricos interpuestos entre la red general y la propia instalación interior de los edificios, que no solo la protegen de variaciones repentinas de los caudales demandados sino que, además, protegen a los usuarios frente a hipotéticos cortes de suministro.

A pesar de estas ventajas el almacenamiento de agua en estos depósitos introduce en el sistema graves inconvenientes asociados principalmente a la garantía de la salubridad del agua, y otros asociados a la reducción de la eficiencia energética del suministro. Estos inconvenientes tienen suficiente envergadura para reducir, e incluso anular, las ventajas asociadas al uso de depósitos. Por tanto, resulta conveniente plantear estrategias que permitan una eliminación progresiva de los mismos.

En cualquier caso, la eliminación de los depósitos parte por garantizar un correcto funcionamiento y protección de la red general de abastecimiento. En esta línea, el conocimiento de las exigencias hidráulicas, tanto en régimen permanente como en régimen transitorio, a las que se va a someter a la red general de distribución, asociadas a los esquemas de suministro más usuales adoptados en la instalación interior, adquiere un ineludible protagonismo. 
En previsión de una instalación generalizada de grupos de presión en las instalaciones interiores, resulta conveniente analizar pormenorizadamente los efectos transitorios generados por este tipo de elementos, en aras de proteger la instalación interior, y el tramo de la red general ubicado en las proximidades de ésta.

Conocidos los efectos transitorios generados en la instalación interior, se procede a establecer los mecanismos y sistemas que permitan reducirlos y proteger la red de suministro adecuadamente ante variaciones de presión excesivas. Conviene recordar que el deterioro de las tuberías se puede producir no solo por una única depresión, sino por la ocurrencia sistemática y continua de depresiones. Es en este contexto donde la utilización de grupos de presión equipados con variador de velocidad y la instalación de depósitos presurizados en la aspiración de los grupos de presión han demostrado que permiten obtener una adecuada protección de la red. 


\section{RESUM}

El creixement urbanístic ha propiciat un augment de la demanda d'aigua dels usuaris d'un abastiment. Sovint, degut principalment a la falta d'inversió, aquest creixement no ha anat acompanyat d'una adequació de la infraestructura hidràulica. Esta situació ha minvat progressivament la capacitat de la xarxa i això ha afavorit ha afavorit un ús estés de depòsits atmosfèrics interposats entre la xarxa general i la pròpia instal-lació interior dels edificis, que no sols la protegeixen de variacions sobtades dels cabals demandats sinó que, a més, protegeixen als usuaris enfront d'hipotètics talls de subministrament.

A pesar d'estos avantatges l'emmagatzemament d'aigua en estos depòsits introduïx en el sistema greus inconvenients associats principalment a la garantia de la salubritat de l'aigua, i altres associats a la reducció de l'eficiència energètica del subministrament. Estos inconvenients tenen prou envergadura per a reduir, i inclús (fins i tot) anul·lar (anular), els avantatges associades(associats) a l'ús de depòsits. Per tant, resulta convenient plantejar estratègies que permeten una eliminació progressiva dels mateixos.

En qualsevol cas, l'eliminació dels depòsits part per garantir un funcionament correcte i protecció de la xarxa general d'abastiment. En esta línia, el coneixement de les exigències hidràuliques, tant en règim permanent com en règim transitori, a les que es va a sotmetre a la xarxa general de distribució, associades als esquemes de subministrament més usuals adoptats en la instal·lació interior, adquireix un ineludible protagonisme. 
En previsió d'una instal·lació generalitzada de grups de pressió en les instal-lacions interiors, resulta convenient analitzar detalladament els efectes transitoris generats per aquest element, a fi de protegir la instal·lació interior, i el tram de la xarxa general ubicat en les seues proximitats.

Coneguts els efectes transitoris generats en la instal·lació interior, es procedeix a establir els mecanismes i sistemes que permeten reduir-los i protegir la xarxa de subministrament adequadament davant de variacions de pressió excessives. Convé recordar que el deteriorament de les canonades es pot produir no sols per una única depressió, sinó per la idea sistemàtica i contínua de depressions. És en aquest context on la utilització de grups de pressió equipats amb variador de velocitat i la instal·lació de depòsits pressuritzats en l'aspiració dels grups de pressió han demostrat que permeten obtindre una adequada protecció de la xarxa. 


\section{ABSTRACT}

Urban growth has led to an increased demand for water supply. Frequently, mainly due to a lack of investment, this growth has not come along with an adjustment of the hydraulic infrastructure. This situation has gradually diminished the network's capacity and favored the use of atmospheric storage tanks - located between the main network and the building's network - because not only do they protect from sudden changes in demand, but also from water outages.

Despite these advantages, water storage in these tanks creates serious problems in the system - water health and system energy efficiency being the main. The magnitude of these drawbacks is big enough to mitigate, or even disregard, the benefits associated to the use of these storage tanks. It is therefore crucial to suggest strategies for their progressive removal.

However, assuring an adequate operation and protection of the supply network is compulsory to the removal of storage tanks. Knowing the increasing hydraulic requirements of buildings, both for steady and transients states, by which the main water supply network is unavoidably affected, acquires, therefore, a key role.

In anticipation of the widespread installation of indoor pressure groups, it is worth examining in detail the transient effects generated by such elements, in order to protect the internal equipment and the network segment located in its vicinity. 
Once the transient effects generated by indoor installations are known, mechanisms and systems which aim at reducing and protecting the main network from pressure surges can be established. It should be noted that pipe deterioration is not only a consequence of a single pressure drop but also of the cyclic appearance of this surges. It is in this context where the use of pressure groups along with variable speed drives and pressurized tanks in the suction lines have proven very effective towards attaining a satisfactory network protection. 


\section{Índice de los capítulos}

AGRADECIMIENTOS ......................................................................................................... I

RESUMEN..........................................................................................................................II

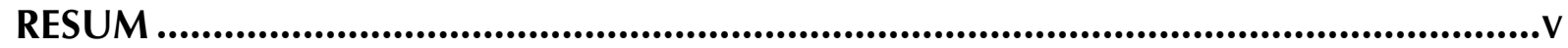

ABSTRACT........................................................................................................................

Capítulo 1. Introducción. Aspiración directa en instalaciones interiores De EDIFICIOS

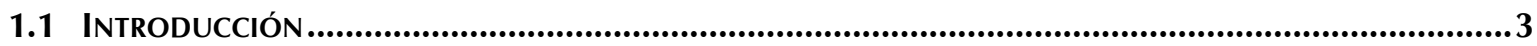

1.2 ASPIRACIÓN DE GRUPOS DE PRESIÓN EN INSTALACIONES INTERIORES ...................................................5

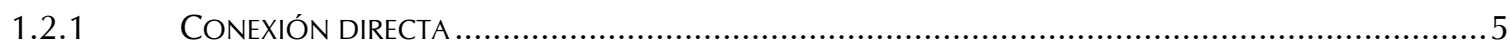

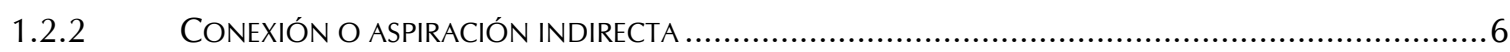

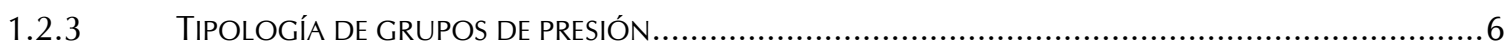

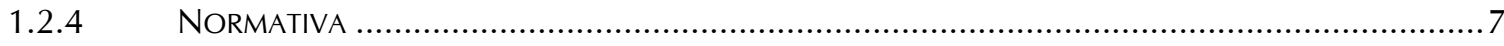

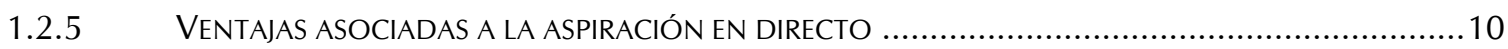

1.2.6 INCONVENIENTES ASOCIADOS A LA ASPIRACIÓN EN DIRECTO ...................................................15

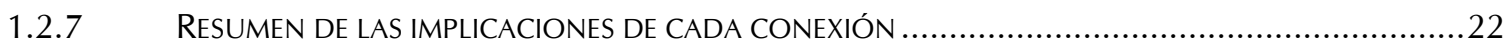

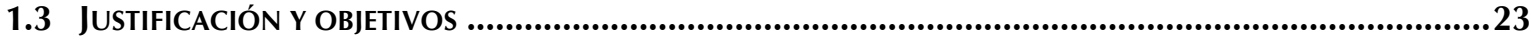

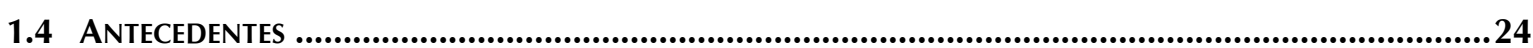

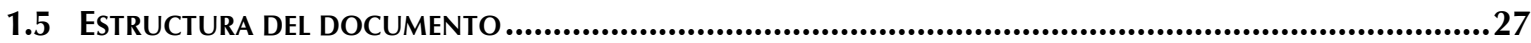

CAPÍtUlo 2. CARACTERIZACIÓN DEL MODELO hidRÁUliCo DE UNA RED DE DISTRIBUCIÓN.... 29

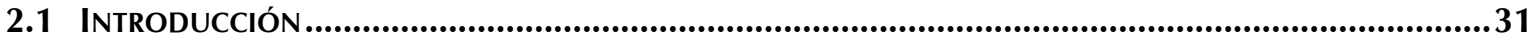

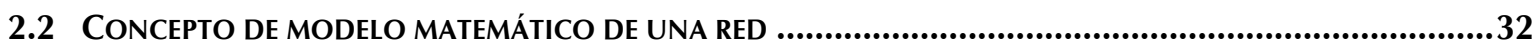

2.2.1 CLASIFICACIÓN DE LOS MODELOS DE ANÁLISIS DINÁMICOS ...................................................33 


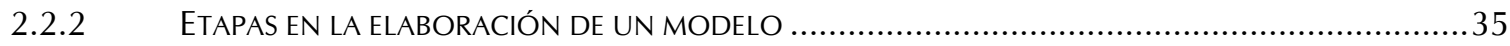

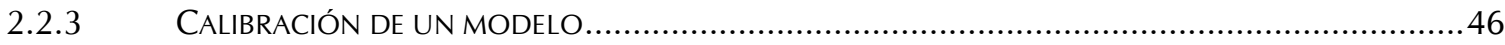

2.3 EJEMPLO de CARACTERIZACIÓN DEL MODELO HIDRÁUliCo DE UN SECTOR DE RED PARA SU ANÁLISIS EN

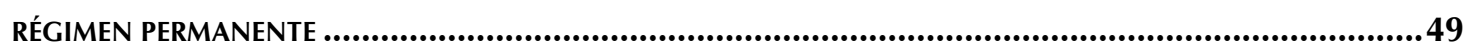

2.3.1 DESCRIPCIÓN GENERAL DEL PROCEDIMIENTO DESARROLLADO .......................................49

2.3.2 CARACTERIZACIÓN DE LA RED GENERAL DE DISTRIBUCIÓN ........................................51

2.3.3 CARACTERIZACIÓN DE LAS PAUTAS DE CONSUMO DE LOS USUARIOS.....................................55

2.3.4 CARACTERIZACIÓN DE LA INSTALACIÓN INTERIOR DE LOS EDIFICIOS ....................................58

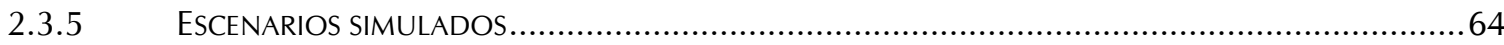

2.4 EJEMPLO DE CARACTERIZACIÓN DEL MODELO HIDRÁULICO DE UN EDIFICIO PARA SU ANÁLISIS EN RÉGIMEN

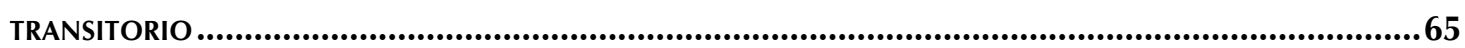

2.4.1 DESCRIPCIÓN GENERAL DEL PROCEDIMIENTO DESARROLLADO ........................................65

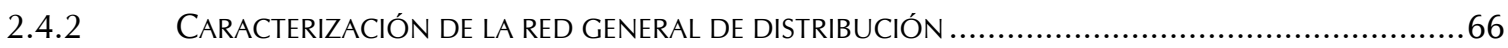

2.4.3 CARACTERIZACIÓN DE LA INSTALACIÓN INTERIOR DEL EDIFICIO .........................................69

2.4.4 IMPLEMENTACIÓN DE LOS ESQUEMAS DE CONEXIÓN DIRECTA...........................................70

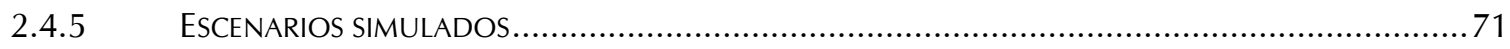

\section{CAPítulo 3. ANÁLISIS DE lOS EFECTOS DE LA CONEXIÓN DIRECTA EN RÉGIMEN PERMANENTE ... 73}

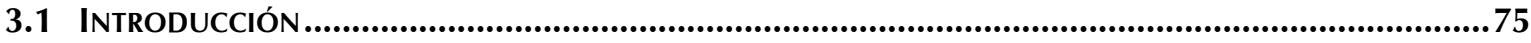

3.2 DESCRIPCIÓN DEL PROCEDIMIENTO PARA LA GENERACIÓN DEL MODELO ..........................................76

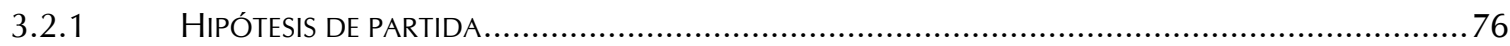

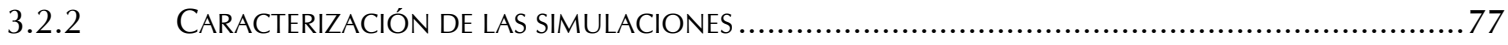

3.2.3 COMPARACIÓN DE LOS COMPORTAMIENTOS DE LOS DIFERENTES ESQUEMAS ..........................84

3.3 RESULTADOS EN RÉGIMEN PERMANENTE PARA EL ESQUEMA TIPO I...................................................91

3.3.1 ANÁLISIS ESTADÍSTICO DE LOS RESULTADOS EN RÉGIMEN PERMANENTE ................................94

3.3.2 APLICACIÓN DE LOS RESULTADOS DE LAS SIMULACIONES ..........................................97

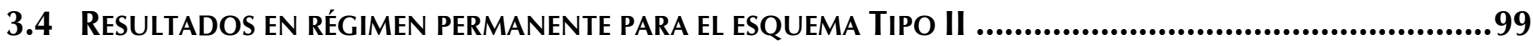

3.4.1 ANÁLISIS ESTADÍSTICO DE LOS RESULTADOS PARA EL ESQUEMA TIPO II ..............................100

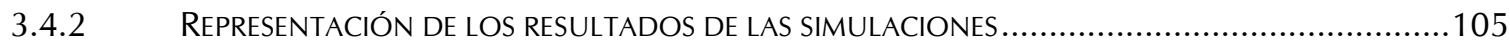

3.5 Resultados en RÉGIMEN PERMANENTE PARA El ESQUEMA TIPO III ..........................................106

3.5.1 ANÁLISIS ESTADÍSTICO DE LOS RESULTADOS EN RÉGIMEN PERMANENTE ...............................106

3.5.2 REPRESENTACIÓN DE LOS RESULTADOS DE LAS SIMULACIONES.......................................110

3.6 COMPARACIÓN DE LAS RESPUESTAS DE LOS ESQUEMAS DE SUMINISTRO ..........................................111

3.7 EJEMPLO DE APLICACIÓN ....................................................................................................112

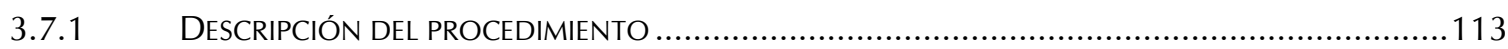

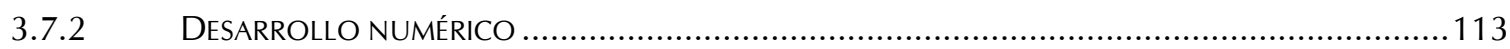

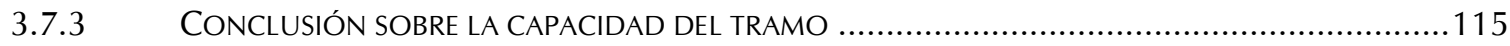


CAPÍtUlO 4. ANÁLISIS DE LOS EFECTOS DE LA CONEXIÓN DIRECTA EN RÉGIMEN TRANSITORIO 117

4.1 INTRODUCCIÓN 119

4.2 DESCRIPCIÓN DE LAS SOLICITACIONES TRANSITORIAS EN UNA INSTALACIÓN MONITORIZADA 120

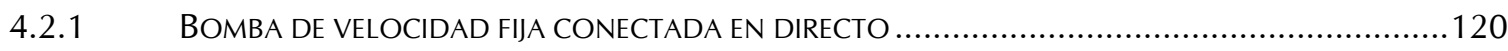

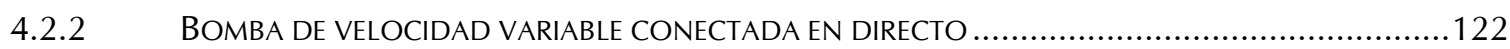

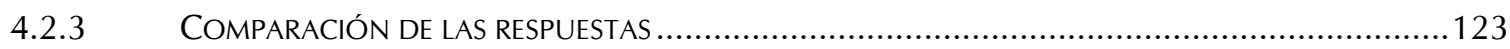

4.3 RESPUESTA DE LA INSTALACIÓN OBTENIDA MEDIANTE SU MODELO HIDRÁULICO...................................124

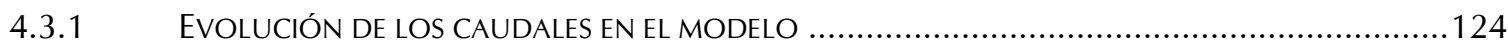

4.3.2 EVOLUCIÓN DE LA PRESIÓN EN LOS DIFERENTES PUNTOS DEL MODELO ……............................126

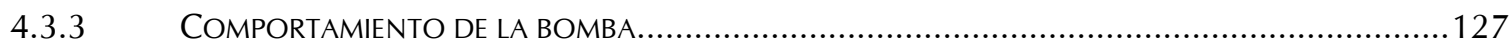

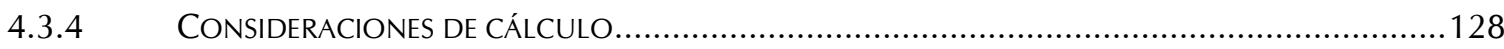

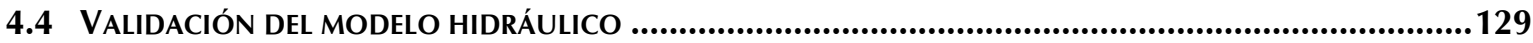

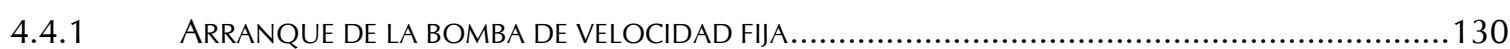

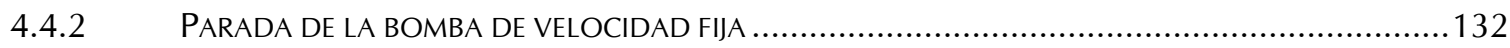

4.4.3 VALIDACIÓN DEL MODELO DE LA BOMBA DE VELOCIDAD VARIABLE ....................................134

4.5 ANÁLISIS DE SENSIBILIDAD DE LAS CARACTERÍSTICAS DEL TRAMO ………..............................................136

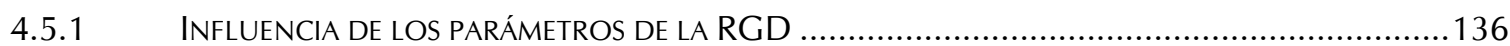

4.5.2 INFLUENCIA DE LOS PARÁMETROS DE LA INSTALACIÓN INTERIOR ...........................................145

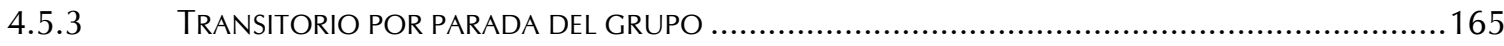

4.6 CONCLUSIONES

\section{Capítulo 5. MeCanismos de protección para la Reducción de los efectos} TRANSITORIOS POR LA CONEXIÓN DIRECTA ......................................................... 169

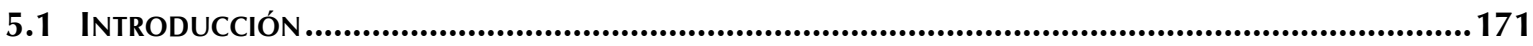

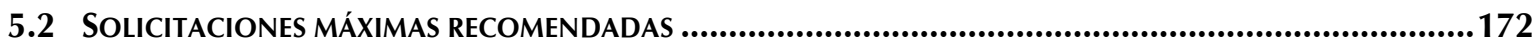

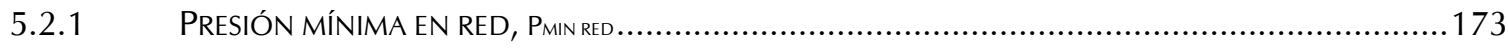

5.2.2 CAÍDA MÁXIMA ASOCIADA AL TRANSITORIO DE ARRANQUE O EQUIVALENTE, APTA ...................173

5.2.3 CAÍDA DE PRESIÓN MÁXIMA EN RÉGIMEN PERMANENTE, APRP .............................................. 174

5.2.4 SOBREPRESIÓN MÁXIMA ASOCIADA AL TRANSITORIO DE PARO O EQUIVALENTE ..........................174

5.2.5 PRESIÓN MÁXIMA ASOCIADA AL TRANSITORIO DE PARO O EQUIVALENTE..................................174

5.3 UTILIZACIÓN DE DEPÓSITO HIDRONEUMÁTICO EN ASPIRACIÓN …………………….................................175

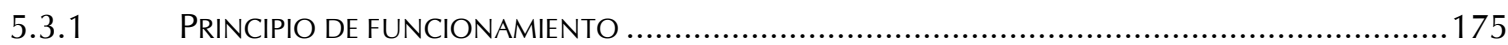

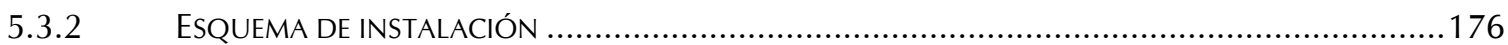

5.3.3 MONITORIZACIÓN DEL COMPORTAMIENTO DE UN CALDERÍN EN ASPIRACIÓN ..........................176

5.3.4 MEJORAS OBTENIDAS EN LA INSTALACIÓN DE REFERENCIA CON CALDERÍN DE ASPIRACIÓN...........177

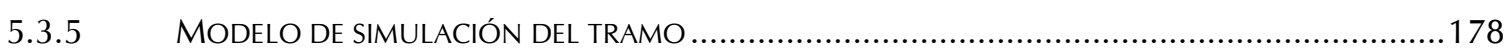


5.3.6 ANÁLISIS DEL COMPORTAMIENTO DE LA INSTALACIÓN EQUIPADA CON CALDERÍN ....................179

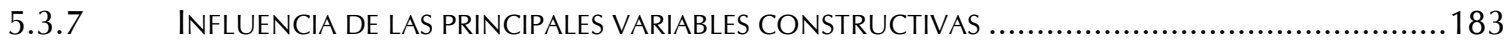

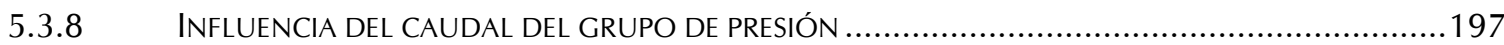

5.4 DiMENSIONADO DE LA PROTECCIÓN................................................................................204

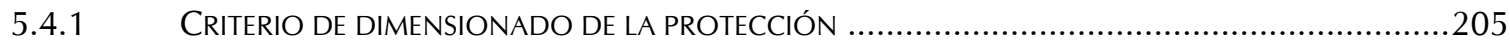

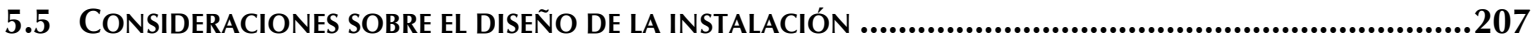

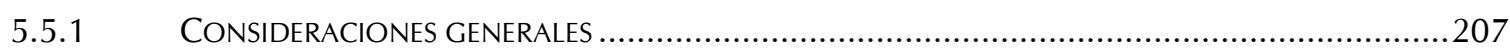

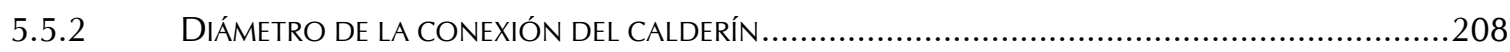

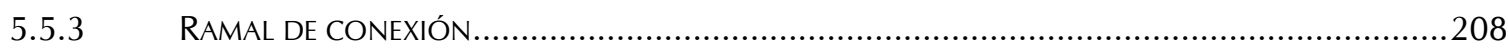

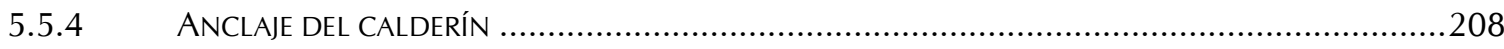

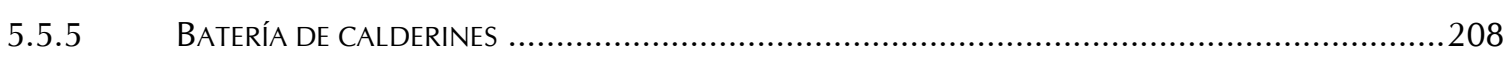

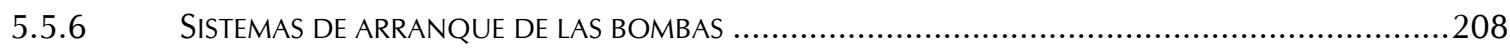

5.6 CONSIDERACIONES SOBRE El MANTENIMIENTO DE LA INSTALACIÓN ...........................................209

CAPÍtulo 6. ConclusioneS y deSARrollos futuros............................................ 211

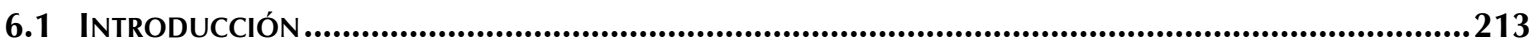

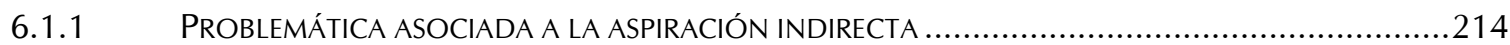

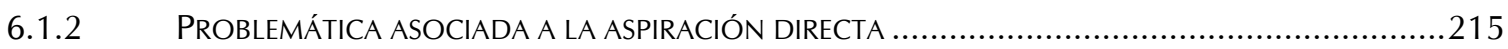

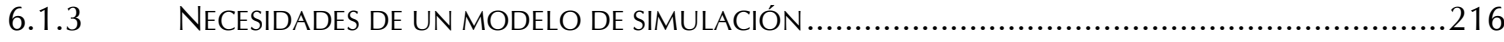

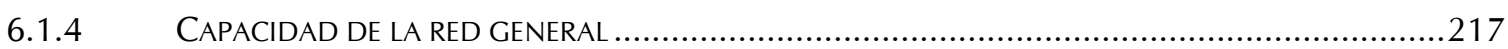

6.1.5 SOLICITACIONES TRANSITORIAS ASOCIADAS A LA CONEXIÓN DIRECTA ................................222

6.1.6 ALTERNATIVAS PARA LA PROTECCIÓN DE INSTALACIONES PARA LA CONEXIÓN DIRECTA .............223

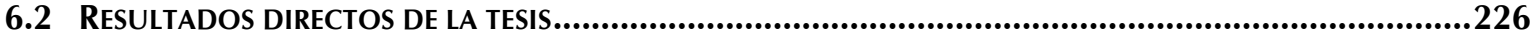

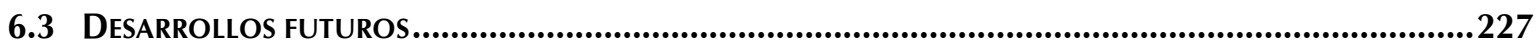

ÍNDICE DE LOS ANEXOS

\section{ANeXo 1. DesCripCión de los elementos QUe fORMAN PARTE DE UNA INSTALACión}

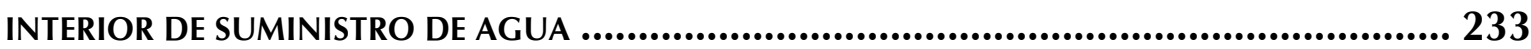

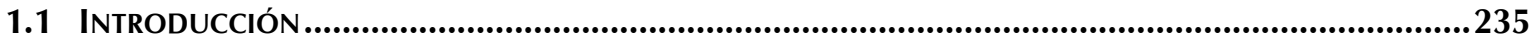

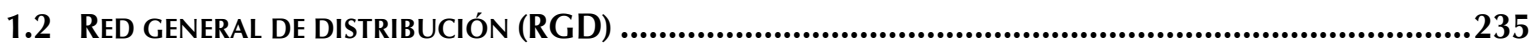

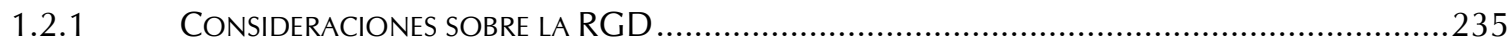

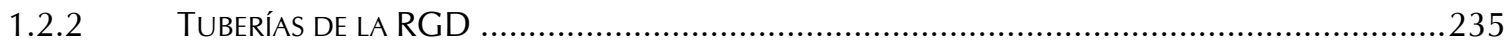

1.2.3 VÁLVULAS Y ELEMENTOS DE CONTROL RGD .....................................................236

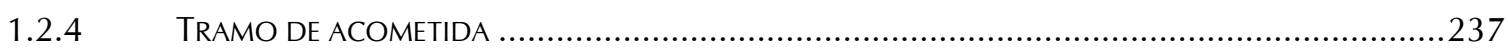


1.3 INSTALACIÓN GENERAL DEL EDIFICIO

1.3.1 LLAVE DE PASO O DE CORTE GENERAL (SITUADA EN EL INTERIOR DEL EDIFICIO) .........................240

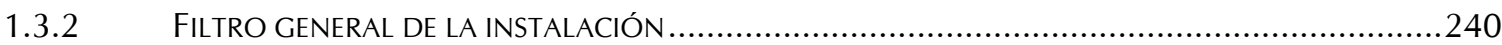

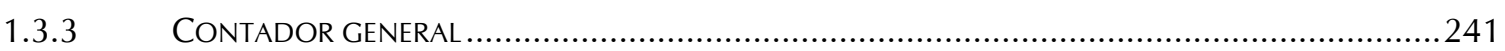

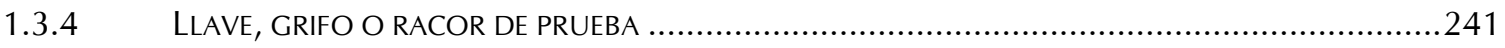

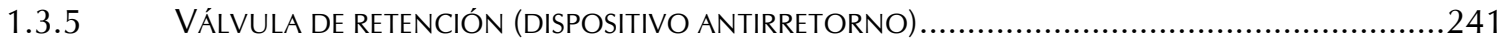

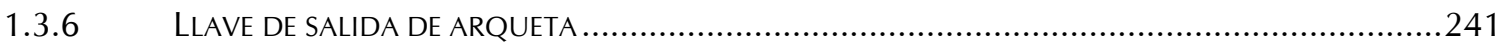

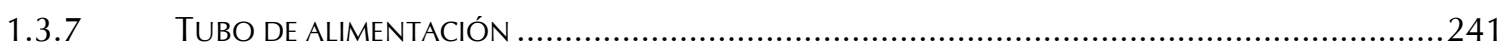

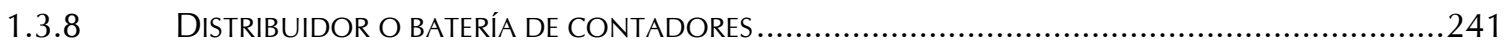

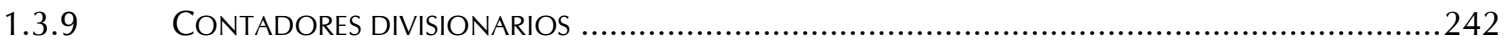

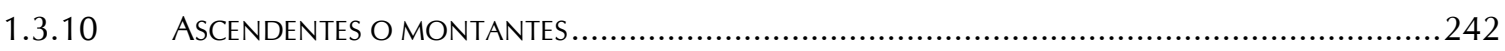

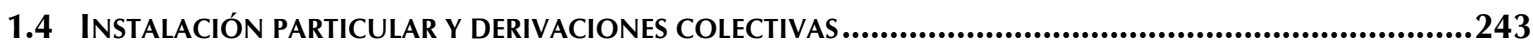

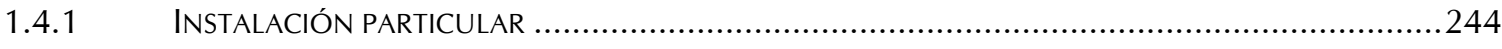

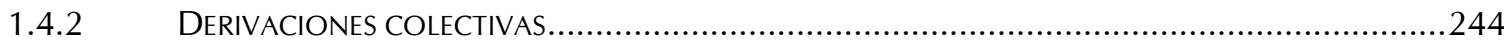

ANEXO 2. ESQUEMAS DE SUMINISTRO ADOPTADOS EN LAS INSTALACIONES INTERIORES ......... 245

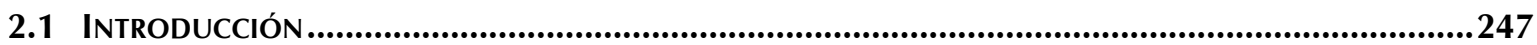

2.2 SUMINISTRO EN DIRECTO SIN GRUPO DE PRESIÓN (TIPO I) ..............................................................247

2.3 SuMINISTRO EN DIRECTO CON BOMBA DE VELOCIDAD FIJA (TIPO II) ....................................................249

2.4 SUMINISTRO EN DIRECTO Y CON GRUPO DE VELOCIDAD FIJA (TIPO III) ...........................................250

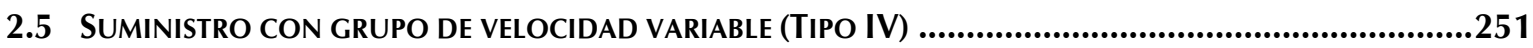

2.6 SUMINISTRO CON GRUPO DE VELOCIDAD FIJA Y DEPÓSITO ATMOSFÉRICO (CONVENCIONAL) ..................252

2.7 SUMINISTRO CON DEPÓSITO EN LA PARTE SUPERIOR DEL EDIFICIO .......................................................253

\section{ANEXo 3. Estimación DE LA DEMANDA DE AGUA EN VIVIENDAS EN EL ENTORNO}

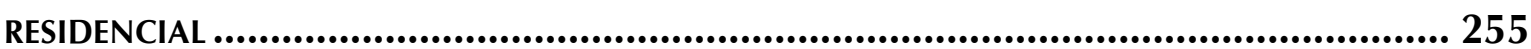

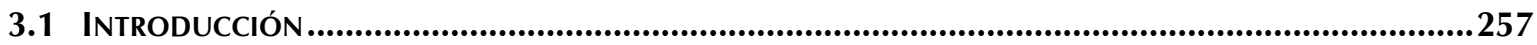

3.2 Metodologías para el CálCulo del CaUdal simultáneo en Un tramo …...................................258

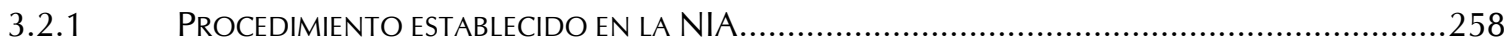

3.2.2 ProcedimIENTO ESTABLECIDO POR LAS NORMAS FranCESAS (NF P 41-204).........................261

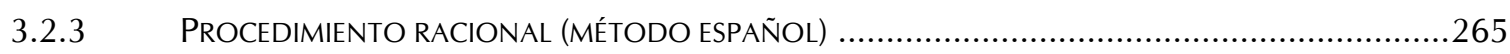

3.2.4 PROCEDIMIENTO ESTABLECIDO EN EL CÓDIGO TÉCNICO DE LA EDIFICACIÓN ...........................266

3.2.5 PROCEDIMIENTO ESTABLECIDO POR LAS NORMAS ESPAÑOLAS (UNE 149201) ........................267

3.3 RESULTADOS OBTENIDOS A PARTIR DE LA BASE DE DATOS DE CONSUMOS ..............................................270

3.4 CompaRACIÓN CON LAS SIMULACIONES DE LOS CONSUMOS DE LA BASE DE DATOS ................................273

3.4.1 COMPARACIÓN CON LA METODOLOGÍA DERIVADA DE LA NIA ...........................................274 
3.4.2 COMPARACIÓN CON LA METODOLOGÍA ESTABLECIDA EN LA NF P 41-204 .........................275

3.5 Comparación CON El MÉTOdo RaCiOnAL ......................................................................276

3.5.1 COMPARACIÓN CON LA METODOLOGÍA ESTABLECIDA EN LA UNE 149201 _.......................277

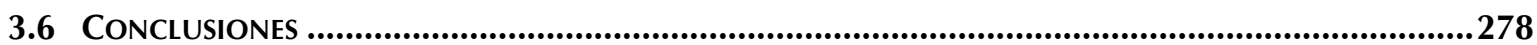

ANEXo 4. MONITORIZACIÓN DE UN EDIFICIO PARA REGISTRAR LOS EFECTOS TRANSITORIOS GENERADOS EN CONEXIÓN DIRECTA........................................................................... 279

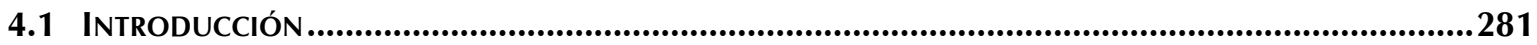

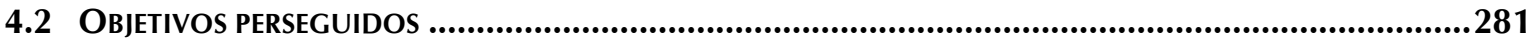

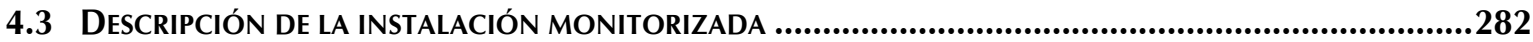

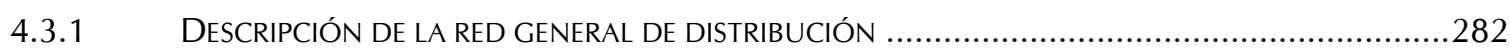

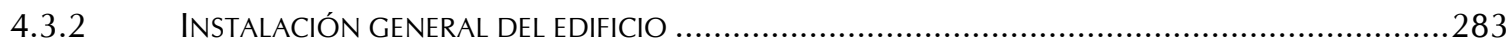

4.3.3 DESCRIPCIÓN DE LAS INSTALACIONES INDIVIDUALES ...........................................288

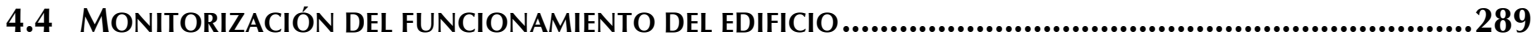

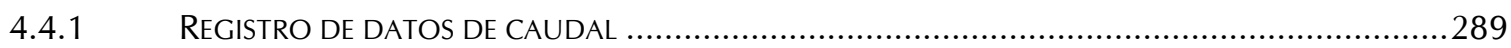

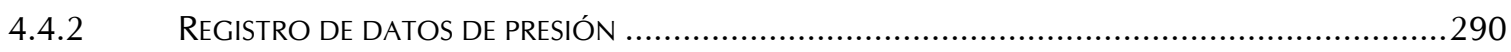

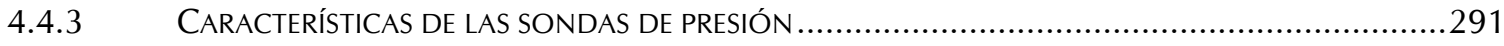

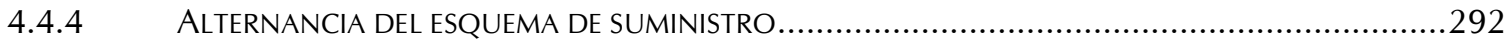

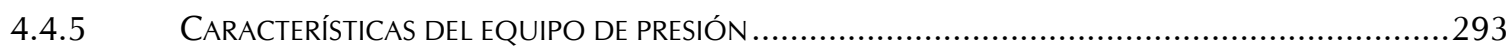

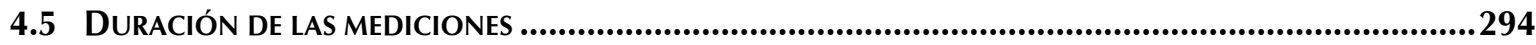

4.6 ReSUltados De LA MONITORIZACIÓN DEL EDIFICIO ...............................................................295

4.6.1 REGISTROS DEL GRUPO DE VELOCIDAD FIJA CONECTADO EN DIRECTO ................................295

4.6.2 REGISTROS DEL GRUPO DE VELOCIDAD VARIABLE CONECTADO EN DIRECTO .........................297

4.6.3 RESPUESTA ANTE MEDIDAS DE PROTECCIÓN .......................................................298

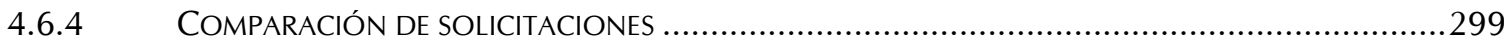

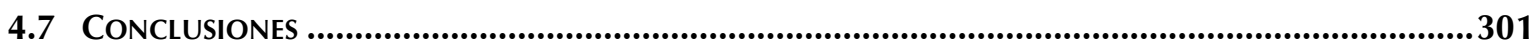

ANEXO 5. CONSIDERACIONES SOBRE LA CONEXIÓN INDIRECTA CON DEPÓSITO ATMOSFÉRICO 303

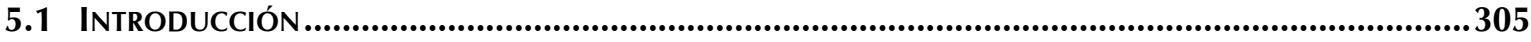

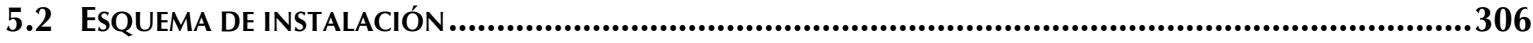

5.2.1 SOLICITACIONES ASOCIADAS AL LLENADO DEL DEPÓSITO ATMOSFÉRICO ..............................306

5.3 SimulaCión DE LAS SOliCitACIONES DE UNA VÁLVULA DE CONTROL DE LLENAdO.............................309

5.3.1 MANIOBRAS EN RÉGIMEN TRANSITORIO DE LA VÁLVULA ....................................................

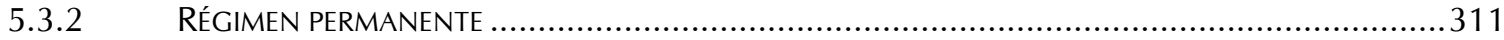

5.4 DimenSiONADO DE LOS ELEMENTOS DE LA INSTALACIÓN ...........................................................311

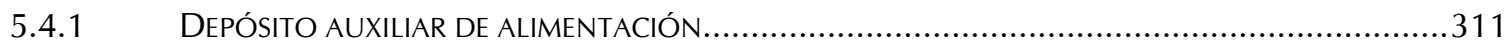


5.4.2 VÁLVULA DE CONTROL DE LLENADO

5.5 Situaciones ACONSEJAdAS de USO COMO ElEMENTO DE PROTECCIÓN .........................................312

5.6 RECOMENDACIONES DE INSTALACIÓN DEL DEPÓSITO ATMOSFÉRICO

ANEXO 6. FundAMENTOS DEL CÁlCULO TRANSITORIO DE ALLIEVI

6.1 INTRODUCCIÓN

6.2 Fundamentos del CálCulo transitorio de AllieVı

6.2.1 ECUACIONES FUNDAMENTALES DEL MODELO ELÁSTICO ............................................317

6.3 MODELACIÓN DE LAS CONDICIONES DE CONTORNO ..............................................................319

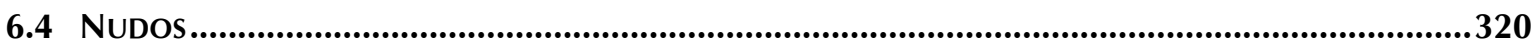

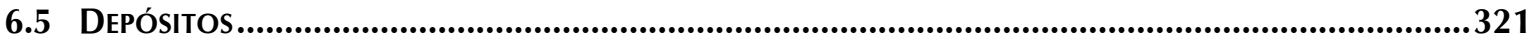

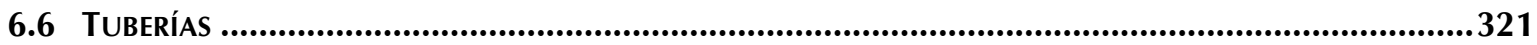

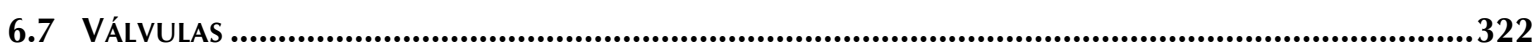

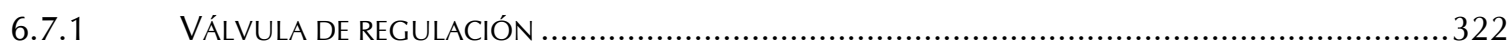

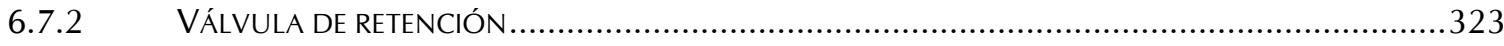

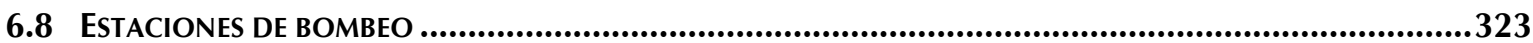

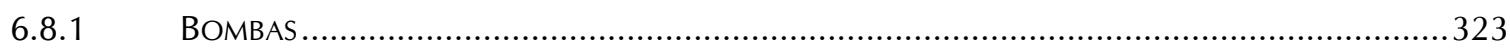

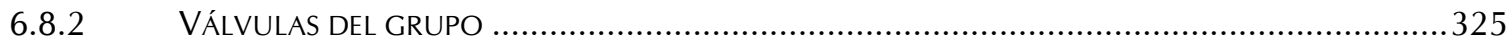

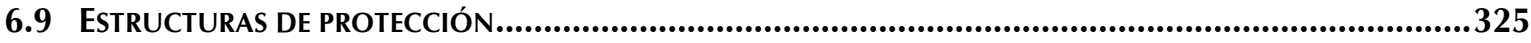

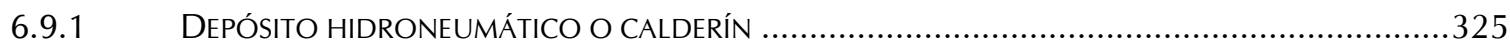

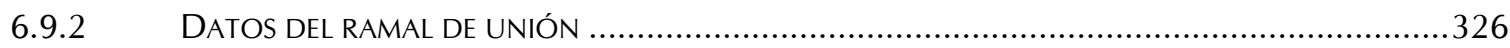

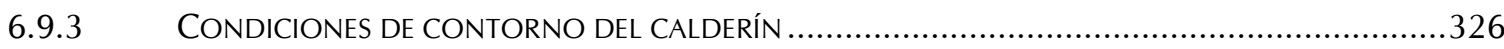

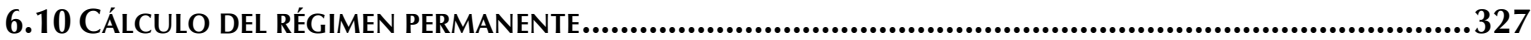

ANEXO 7. NOTACIÓN, DEFINICIONES Y SIMBOLOGÍA ..................................................... 329

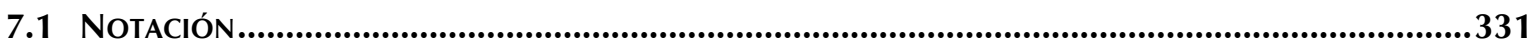

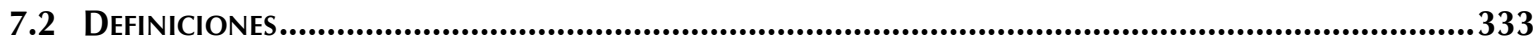

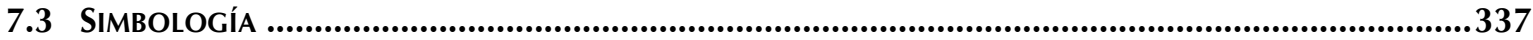

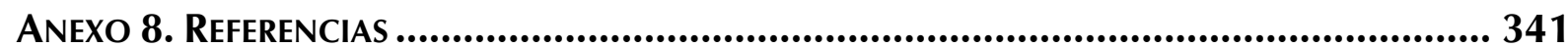




\section{ÍNDICE DE LAS FIGURAS}

\section{CAPÍtULO 1}

FIGURA C1-1. ESQUEMA DE CONEXIÓN EN DIRECTO DEL EQUIPO DE PRESIÓN EN UNA INSTALACIÓN INTERIOR.......... 5

FIGURA C1-2. ESQUEMA DE CONEXIÓN INDIRECTA DEL EQUIPO DE PRESIÓN EN UNA INSTALACIÓN INTERIOR............ 6

FIGURA C1-3. ESQUEMAS DE CONEXIÓN CONTEMPLADOS POR EL CTE …......................................................... 7

FIGURA C1-4. ESQUEMAS GRUPO CONVENCIONAL (IZQDA.) Y ACCIONAMIENTO REGULABLE (DCHA.) SEGÚN CTE ... 8

FIGURA C1-5. DEPÓSITO ATMOSFÉRICO SIN TAPA DE PROTECCIÓN 11

FIGURA C1-6. COMPORTAMIENTO TíPICO DE UNA VÁLVULA DE BOYA PROPORCIONAL. VOLUMEN NO REGISTRADO

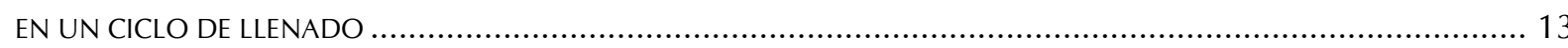

FIGURA C1-7. SIMPLIFICACIÓN DE LOS EFECTOS ORIGINADOS POR LA ASPIRACIÓN EN DIRECTO DE UNA BOMBA..... 16 FIGURA C1-8. SALIDA DE CURVA (IZQDA.) Y RESPUESTA ACEPTABLE (DCHA.) ANTE UNA BAJADA DE PRESIÓN ........... 20

\section{CAPítULO 2}

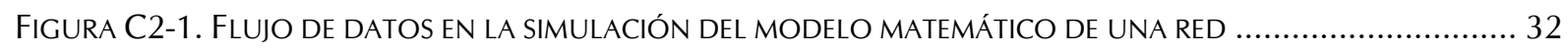

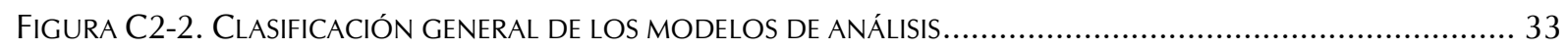

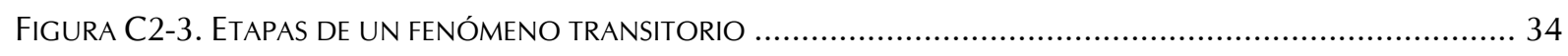

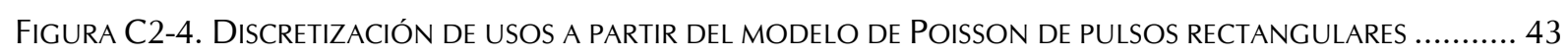

Figura C2-5. Flujo PARA LA ADECUACIÓN DEL MODELO MATEMÁtICO DE UNA RED ....................................... 48

FIGURA C2-6. ESQUEMA DE UNA RED DE DISTRIBUCIÓN EN SUS INMEDIACIONES AL TRAMO DE ACOMETIDA ........... 49

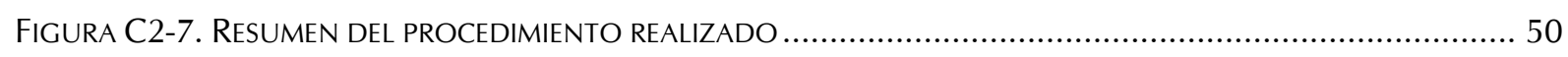

FIGURA C2-8. REPRESENTACIÓN ESQUEMÁTICA DEL SECTOR DE RED MODELADO .............................................. 51

Figura C2-9. CURVA DE MODULACIÓN DE LA DEMANDA DE LAS VIVIENDAS DE LA BASE DE DATOS...................... 56

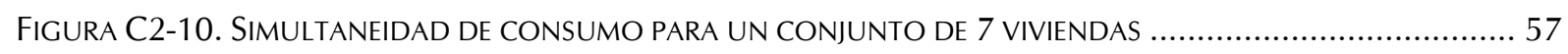

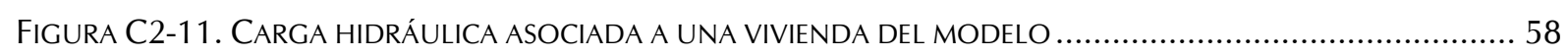

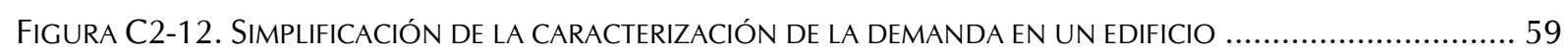

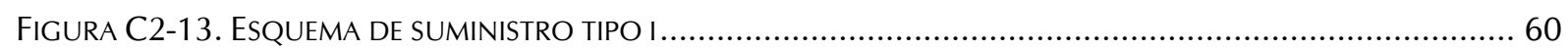

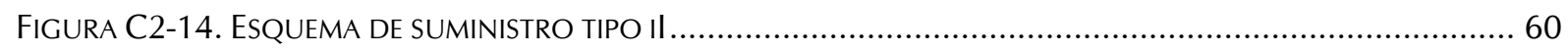

FIGURA C2-15. ESQUEMA DE UN SUMINISTRO MIXTO (COMBINACIÓN DIRECTO Y CON GRUPO DE BOMBEO) .......... 63

FIGURA C2-16. COMPARACIÓN DE LA DEMANDA AGREGADA DE UN CONJUNTO DE VIVIENDAS Y LA CORRESPONDIENTE DEL CONTADOR GENERAL (INSTALACIÓN EQUIPADA CON VARIADOR DE FRECUENCIA) .............. 64

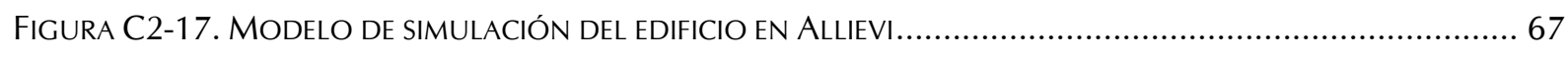

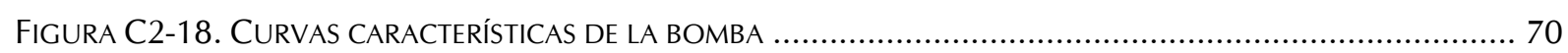




\section{CAPítulo 3}

FIGURA C3-1. REPRESENTACIÓN ESQUEMÁTICA DEL MODELO HIDRÁULICO ANALIZADO

Figura C3-2. VARIACIÓN DE LA PRESIÓN EN EL NUDO N, PARA EL ESCENARIO DE REFERENCIA (ESQUEMA TIPO I) .... 78

Figura C3-3. Resultado de 200 SIMULACIONES PARA EL ESCENARIO DE REFERENCIA (ESQUEMA TIPO I) .............. 80

FIGURA C3-4. PENDIENTE HIDRÁULICA MÁXIMA Y RANGO DE VARIACIÓN PARA EL ESCENARIO DE REFERENCIA......... 81

FiguRA C3-5. VARIACIÓN DEL CAUDAL PROMEDIO EN FUNCIÓN DEL INTERVALO TEMPORAL DE CÁLCULO .............. 82

FIGURA C3-6. INFLUENCIA DEL TIEMPO ENTRE REGISTROS PARA EL ESCENARIO DE REFERENCIA.............................. 83

FIGURA C3-7. VARIACIÓN DE PRESIÓN EN FUNCIÓN DEL ESQUEMA ADOPTADO EN LA INSTALACIÓN INTERIOR ........ 84

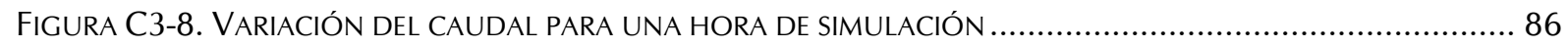

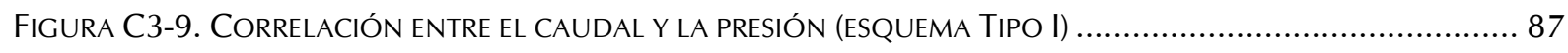

FIGURA C3-10. CORRELACIÓN ENTRE EL CAUDAL Y LA PRESIÓN (ESQUEMA TIPO II) ……..................................... 88

FIGURA C3-11. HISTOGRAMA DE FRECUENCIA ASOCIADO A LOS DIFERENTES ESQUEMAS DE SUMINISTRO ............... 89

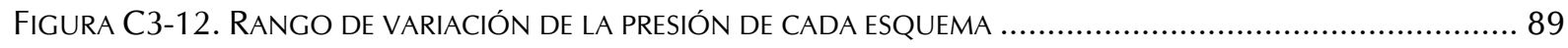

Figura C3-13. AJUSTE de LA PRESIÓN A UNA SERIE WEIBULL (ESCENARIO DE REFERENCIA, ESQUEMA TIPO I) .......... 90

Figura C3-14. AJuste de La PRESIÓN A UNA SERIE Weibull (ESCENARIO DE REFERENCIA, ESQUEMA TIPO II) ......... 90

Figura C3-15. AJuSTE de LA PRESIÓN A UNA SERIE Weibull (ESCENARIO DE REFERENCIA, ESQUEMA TIPO III) ........ 91

FIGURA C3-16. REPRESENTACIÓN DE LAS PÉRDIDAS UNITARIAS EN FUNCIÓN DE LA CARGA TOTAL DEL TRAMO

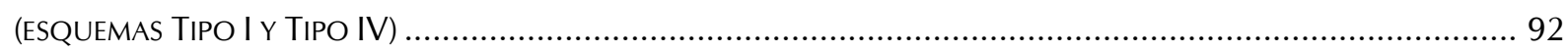

Figura C3-17. AJUSTE DE LA SERIE DE PENDIENTES HIDRÁULICAS MÁXIMAS PARA UNA TUBERÍA DE 79 MM............. 93

FIGURA C3-18. HistOGRAMA DE FRECUENCIAS DE LA SERIE DE PRESIÓN MíNIMA (ESQUEMA TIPO I) ...................... 95

FIGURA C3-19. HISTOGRAMA DE FRECUENCIAS ACUMULATIVAS DE LA SERIE PRESIÓN MÍNIMA Y APROXIMACIÓN CON

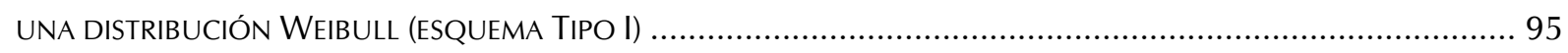

Figura C3-20. AJUSTE DE LOS DATOS A UNA DISTRIBUCIÓN WEIBULL PARA EL ESCENARIO DE REFERENCIA ............ 96

FIGURA C3-21. RANGO DE PÉRDIDAS UNITARIAS MÁXIMAS EN FUNCIÓN DEL DIÁMETRO (ESQ. TIPO I) ................... 97

FIGURA C3-22. CURVAS DE PENDIENTES UNITARIAS MÁXIMAS (ESQUEMA TIPO I) …….................................... 98

FIGURA C3-23. REPRESENTACIÓN DEL VALOR PROMEDIO DE LA PÉRDIDA UNITARIA EN FUNCIÓN DEL DIÁMETRO (T-II)

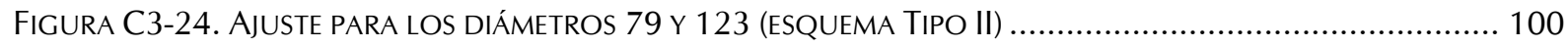

Figura C3-25. Histograma de fReCUenCIAS de LA PRESIÓN MÍNIMA (ESCENARIO DE REFERENCIA, ESQ. TIPO II) 101 FIGURA C3-26. HISTOGRAMA DE FRECUENCIAS ACUMULATIVAS DE LA SERIE DE PRESIÓN MÍNIMA Y APROXIMACIÓN

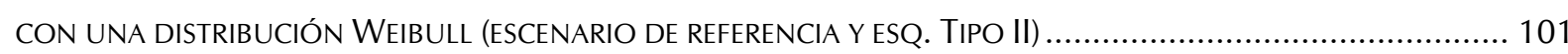

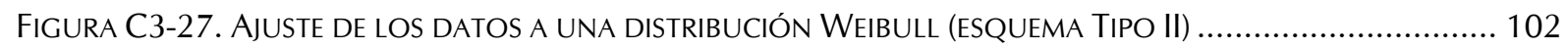

FIGURA C3-28. VALOR MÁXIMO DE LA PÉRDIDA UNITARIA EN FUNCIÓN DEL DIÁMETRO (TIPO II) ....................... 102

Figura C3-29. DetALLE DE LA PENDIENTE HIDRÁULICA MEDIA Y VARIACIÓN DEL VALOR MÁXIMO (D=123 MM) . 103

FIGURA C3-30. VARIACIÓN DE LA PENDIENTE HIDRÁULICA PARA UN ESQUEMA TIPO II Y DIÁMETRO 123 MM........ 103

FIGURA C3-31. RANGOS DE PENDIENTES UNITARIAS MÁXIMAS (ESQUEMA TIPO II) ......................................... 105

Figura C3-32. Histograma de FRECUENCIAS DE LA SERIE PRESIÓN MÍNIMA (ESC. REFERENCIA Y ESQ. TIPO III) ... 107 
FIGURA C3-33. HistOGRAMA DE FRECUENCIAS ACUMULATIVAS DE LA SERIE DE PRESIÓN MÍNIMA Y APROXIMACIÓN CON UNA DISTRIBUCIÓN WEIBULL (ESCENARIO DE REFERENCIA Y ESQ. TIPO III) ............................................. 107

FIGURA C3-34. AJUSTE DE LOS DATOS A UNA DISTRIBUCIÓN WEIBULL (ESQUEMA TIPO III) ............................... 108

FIGURA C3-35. REPRESENTACIÓN DEL VALOR MÁXIMO DE LA PÉRDIDA UNITARIA (ESQUEMA TIPO III) .................. 108

FIGURA C3-36. DETALLE DE PÉRDIDAS UNITARIAS CON SUMINISTRO TIPO III Y DIÁMETRO 123 MM.................... 109

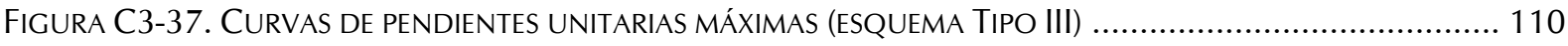

FIGURA C3-38. PÉRDIDAS UNITARIAS MÁXIMAS EN FUNCIÓN DEL ESQUEMA DE SUMINISTRO (D 123 MM) ............ 111

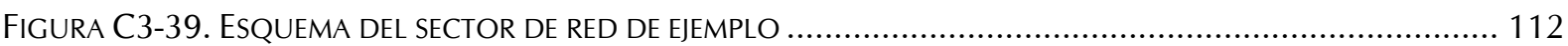

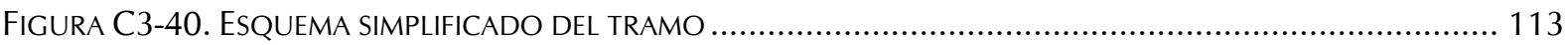

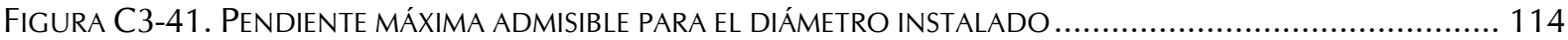

\section{CAPítULO 4}

FIGURA C4-1. REGISTRO DE PRESIÓN DURANTE EL FUNCIONAMIENTO EN DIRECTO DE LA BVF.......................... 120

FIGURA C4-2. REGISTROS DE PRESIÓN DURANTE EL FUNCIONAMIENTO EN DIRECTO DE LA BVV ........................ 122

FIGURA C4-3. COMPARACIÓN ENTRE LAS SOLICITACIONES CON BVF Y BVV (INSTALACIÓN MONITORIZADA) ....... 123

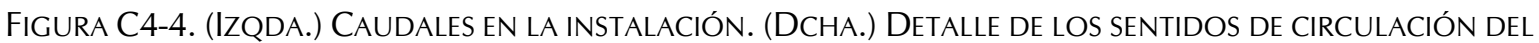
AGUA EN EL MODELO DE SIMULACIÓN

FIGURA C4-5. SimULACIÓN DE LOS CAUdALES EN LAS TUBERÍAS CONECTADAS A LA ACOMETIDA......................... 125

FIGURA C4-6. SIMULACIÓN DE LA EVOLUCIÓN DE LA PRESIÓN EN DIFERENTES PUNTOS DE LA INSTALACIÓN.......... 126

FIGURA C4-7. SIMULACIÓN DEL COMPORTAMIENTO DE LA BOMBA DEL MODELO............................................. 128

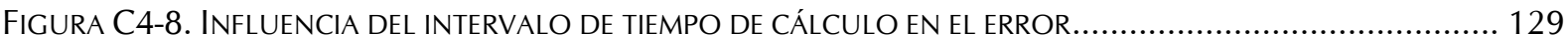

FIGURA C4-9. COMPARACIÓN DE LA PRESIÓN EN LA ACOMETIDA DURANTE EL ARRANQUE …............................ 130

FIGURA C4-10. COMPARACIÓN DE LA PRESIÓN EN EL PUNTO INTERMEDIO DE CONTROL DURANTE EL ARRANQUE 131

FIGURA C4-11. COMPARACIÓN DE LA PRESIÓN EN LA ASPIRACIÓN DURANTE EL ARRANQUE …........................... 132

FIGURA C4-12. COMPARACIÓN DE LA PRESIÓN EN LA ACOMETIDA DURANTE LA PARADA …….......................... 132

FIGURA C4-13. COMPARACIÓN DE LA PRESIÓN EN LA ASPIRACIÓN DURANTE LA PARADA …................................ 133

FIGURA C4-14. COMPARACIÓN DE LA PRESIÓN EN LA ACOMETIDA DURANTE EL ARRANQUE DE UNA BVV ............ 134

FIGURA C4-15. COMPARACIÓN DE LA PRESIÓN EN LA ASPIRACIÓN DURANTE EL ARRANQUE DE UNA BVV ............ 135

FIGURA C4-16. DEPRESIÓN EN FUNCIÓN DE LA VELOCIDAD DEL AGUA POR LA RGD. DIÁMETRO RED =150 MM. 137

FIGURA C4-17. DEPRESIÓN EN FUNCIÓN DE LA PRESIÓN DE ENTREGA (DRED = 150 MM) …............................... 138

FIGURA C4-18. RESPUESTA DE LA BOMBA EN EL ARRANQUE ANTE UNA BAJADA DE PRESIÓN EN ASPIRACIÓN ......... 139

FIGURA C4-19. RESPUESTA DE LA BOMBA PARA DIFERENTES PRESIONES EN ACOMETIDA................................... 140

FIGURA C4-20. EVOLUCIÓN DE LA CINÉTICA EN LAS PROXIMIDADES DE LA BOMBA …...................................... 141

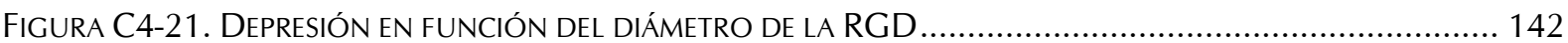

FIGURA C4-22. EVALUACIÓN DE LA INCIDENCIA DE LA PERTURBACIÓN EN EL NUDO DE CONEXIÓN DE LA RGD ... 143

FIGURA C4-22. RELACIÓN ENTRE EL COEFICIENTE DE REFLEXIÓN Y LA DEPRESIÓN EN ACOMETIDA ........................ 145

FIGURA C4-24. VARIACIÓN DE LA INTENSIDAD ELÉCTRICA CONSUMIDA EN FUNCIÓN DEL TIPO DE BOMBA ........... 146 
Figura C4-25. DePRESIÓN EN FUnCIÓN DEL TIEMPO DE ARRANQUE DE LA BOMBA ..... 147

FIGURA C4-26. CURVAS DE BOMBEO PARA DIFERENTES ALTERNATIVAS DE GRUPOS DE PRESIÓN 148

FIGURA C4-27. DEPRESIÓN EN FUNCIÓN DEL CAUDAL DE LA BOMBA PARA LA INSTALACIÓN DE REFERENCIA. 150

FIGURA C4-28. ARRANQUE ESCALONADO EN UNA INSTALACIÓN CON 3 BOMBAS EN PARALELO 151

FIGURA C4-29. EFECTOS DERIVADOS DEL ARRANQUE DE DOS BOMBAS EN PARALELO (DESFASE = $2 \mathrm{~S}$ ). 152

FIGURA C4-31. EFECTOS DERIVADOS DEL ARRANQUE DE DOS BOMBAS EN PARALELO (DESFASE =0,25 S). 153

FIGURA C4-30. INFLUENCIA EN EL DESFASE ENTRE LOS ARRANQUES.

FIGURA C4-32. DEPRESIÓN PARA LA ASOCIACIÓN DE VARIAS BOMBAS EN FUNCIÓN DEL CAUDAL. D ASP. 74 MM. 154 FIGURA C4-33. DEPRESIÓN EN ASPIRACIÓN EN FUNCIÓN DEL CAUDAL DE LA BOMBA EN RÉGIMEN TRANSITORIO.. 155 FIGURA C4-34. DEPRESIÓN EN FUNCIÓN DEL CAUDAL DE LA BOMBA EN RÉGIMEN TRANSITORIO EN ACOMETIDA.. 156 FIGURA C4-35. RELACIÓN ENTRE LA VARIACIÓN DE VELOCIDAD EN LA ASPIRACIÓN Y LA DEPRESIÓN................... 157 FIGURA C4-36. DEPRESIÓN EN FUNCIÓN DEL CAUDAL DE LA BOMBA EN RÉGIMEN PERMANENTE ...................... 158 FIGURA C4-37. DIFERENCIA DE COMPORTAMIENTO ENTRE BOMBAS CON DIFERENTE TIPO DE CURVA ................. 159 FIGURA C4-38. DEPRESIÓN EN FUNCIÓN DE LA LONGITUD DEL TRAMO DE ASPIRACIÓN.................................. 160 FIGURA C4-39. (IZDA.) VARIACIÓN DE LA PRESIÓN EN LA ASPIRACIÓN DE LA BOMBA. (DCHA.) COMPARACIÓN DE LA VELOCIDAD EN LA CONDUCCIÓN DE ACOMETIDA 161

FIGURA C4-40. DEPRESIÓN EN FUNCIÓN DE LAS PÉRDIDAS MENORES EN EL TRAMO...................................... 162

FIGURA C4-39. INFLUENCA DE LA CELERIDAD SOBRE LA PRESIÓN ........................................................... 162

FIGURA C4-42. DEPRESIÓN EN FUNCIÓN DE LA CELERIDAD EN EL TRAMO DE ASPIRACIÓN ................................ 163

FIGURA C4-43. DEPRESIÓN EN FUNCIÓN DE LA PRESIÓN DE ARRANQUE DEL GRUPO ................................... 163

Figura C4-44. COMPARACIÓN DE LA VELOCIDAD Y ACELERACIÓN EN LAS PROXIMIDADES DE LA BOMBA............ 164

FIGURA C4-45. VARIACIÓN DE PRESIÓN POR PARADA Y ARRANQUE DE UN GRUPO (INST. REFERENCIA) ............... 165

\section{Capítulo 5}

FIGURA C5-1. SOLICITACIONES MÁXIMAS PROPUESTAS PARA LA CONEXIÓN EN DIRECTO DE UN GRUPO .............. 172

FIGURA C5-2. FLUJO DE CAUDALES EN LA FASE DE ARRANQUE DE LA BOMBA ......................................... 175

FIGURA C5-3. INSTALACIÓN CON CONEXIÓN DIRECTA CON CALDERÍN EN ASPIRACIÓN ................................. 176

FIGURA C5-4. REGISTRO DE PRESIONES PARA LA BVF EQUIPADA CON CALDERÍN EN ASPIRACIÓN ......................177

FIGURA C5-5. COMPARACIÓN DE LAS SOLICITACIONES DE UNA BVF (CON Y SIN CALDERÍN) EN ASPIRACIÓN DE LA

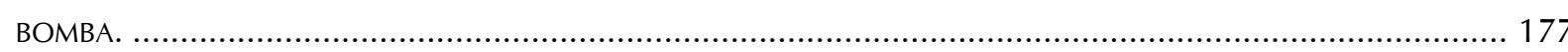

Figura C5-6. COMPARACIÓN DE LAS SOLICITACIONES DE UNA BVF (CON Y SIN CALDERÍN) EN LA ACOMETIDA. .. 178 FIGURA C5-7. MODELO DE SIMULACIÓN EN ALLIEVI CON CALDERÍN EN ASPIRACIÓN (C2) ............................. 178

FIGURA C5-8. COMPARACIÓN DE LA RESPUESTA DEL MODELO Y LA REGISTRADA ....................................... 179

FIGURA C5-9. CAUDALES EN LOS DIFERENTES TRAMOS DE LA INSTALACIÓN PARA LOS ESQUEMAS CC Y SC .......... 180

FIGURA C5-10. COMPORTAMIENTO DEL CALDERÍN EN ASPIRACIÓN DURANTE EL ARRANQUE DEL GRUPO ............. 181

FIGURA C5-12. VARIACIÓN DE PRESIONES EN LAS PROXIMIDADES DE LA BOMBA Y EN EL CALDERÍN ..................... 182

FIGURA C5-13. EVOLUCIÓN DEL CAUDAL Y LA PRESIÓN EN EL CALDERÍN EN UN CICLO DE FUNCIONAMIENTO...... 182 
FIGURA C5-13. COMPORTAMIENTO DE LA BOMBA DURANTE EL INSTANTE DE ARRANQUE 183

FIGURA C5-14. INFLUENCIA DEL VOLUMEN DEL CALDERÍN DE ASPIRACIÓN EN LA INSTALACIÓN DE REFERENCIA .... 184

FIGURA C5-15. COMPARACIÓN DEL COMPORTAMIENTO DEL CALDERÍN PARA DIFERENTES VOLÚMENES ................ 185

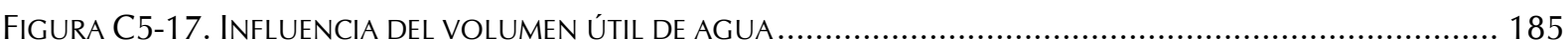

Figura C5-18. ReSPUESTA DE UN CALDERÍN DE 25 L CON UNA MASA DE AIRE PRÁCTICAMENTE NULA ................. 186

FIGURA C5-18. INFLUENCIA DE LA PRESIÓN DE HINCHADO Y EL VOLUMEN DEL CALDERÍN ….............................. 187

FIGURA C5-20. RESPUESTA ANTE VALORES REDUCIDOS DE PRESIÓN DE HINCHADO DEL CALDERÍN ...................... 188

FIGURA C5-20. INFLUENCIA DE LA DISTANCIA DEL CALDERÍN A LA ASPIRACIÓN DE LA BOMBA (VC=25 L) ........... 189

FIGURA C5-21. INFLUENCIA DE LA LONGITUD DEL RAMAL DE CONEXIÓN DEL CALDERÍN (VC=25 L)................... 190

FIGURA C5-22. INFLUENCIA DEL DIÁMETRO INTERIOR DEL RAMAL DE CONEXIÓN DEL CALDERÍN (VC=25 L) ......... 191

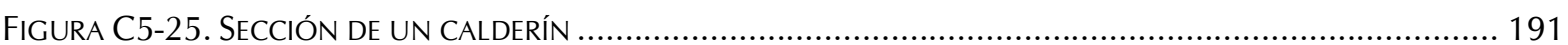

FIGURA C5-26. COEFICIENTE DE PÉRDIAS Ks EN FUNCIÓN DEL DIÁMETRO NOMINAL DE LA CONEXIÓN .................. 193

Figura C5-27. INFLUENCIA DEL COEFICIENTE DE PÉRDIDAS EN LA DESCARGA DEL CALDERÍN (VC=25 L) ............. 193

FIGURA C5-26. COMPARACIÓN ENTRE EL COMPORTAMIENTO DE UNO O DOS VASOS DE EXPANSIÓN................... 195

FIGURA C5-27. INFLUENCIA DEL NÚMERO DE CALDERINES EN LA ASPIRACIÓN (V=25 LITROS) ............................ 195

FIGURA C5-29.INFLUENCIA DEL COEFICIENTE POLITRÓPICO DE EXPANSIÓN DEL GAS (V=25 LITROS) ................... 196

FIGURA C5-30. SIMULACIÓN DE LA RESPUESTA DE LA INSTALACIÓN CON UNA BATERÍA DE 4 CALDERINES DE 25 L 196

FIGURA C5-30. INFLUENCIA DEL CAUDAL DE LA BOMBA EN LA PROTECCIÓN CON UN CALDERÍN DE 25 L.............. 198

FIGURA C5-31. INFLUENCIA DEL CAUDAL DE LA BOMBA PARA DIFERENTES PROTECCIONES EN ASPIRACIÓN ........... 199

Figura C5-32. EFECTOS DERIVADOS DEL ARRANQUE DE DOS BOMBAS EN PARALELO (DESFASE $=2$ S).................. 200

Figura C5-33. EFECTOS DeRIVAdOS DEL ARRANQUE DE dOS BOMBAS EN PARALELO (DESFASE = 2 s), CC ........... 200

FIGURA C5-35. EFECTOS DERIVADOS DEL ARRANQUE DE DOS BOMBAS EN PARALELO (DESFASE $=0,25$ S) ............ 201

FIGURA C5-36. EVOLUCIÓN DEL VOLUMEN DE AGUA EN EL CALDERÍN Y DE LA PRESIÓN EN LA ASPIRACIÓN .......... 201

FIGURA C5-36. INFLUENCIA DEL CAUDAL Y NÚMERO DE BOMBAS PARA LA PROTECCIÓN CON CALDERÍN DE 50 L . 202

FIGURA C5-37. INFLUENCIA DEL CAUDAL Y NÚMERO DE BOMBAS PARA DIFERENTES ESQUEMAS DE PROTECCIÓN.. 203

FIGURA C5-40. CAÍDA DE PRESIÓN EN RÉGIMEN PERMANENTE PARA UN DIÁMETRO DE 74 MM............................ 203

FIGURA C5-39. INSTALACIÓN EQUIPADA CON CONEXIÓN DIRECTA Y PROTEGIDA CON CALDERÍN EN ASPIRACIÓN 207

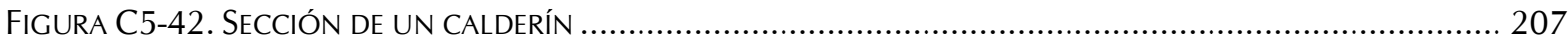

FIGURA C5-41. ESQUEMA DE CONEXIÓN DEL CALDERÍN EN ASPIRACIÓN AL GRUPO DE BOMBEO ......................... 209

\section{ANEXO1}

FIGURA A1-1. ESQUEMA DE ACOMETIDA Y ELEMENTOS

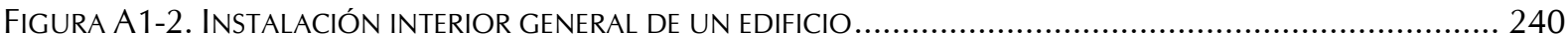

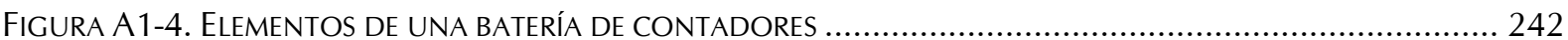

FIGURA A1-5. ESQUEMA DE INSTALACIÓN CON MONTANTES COLECTIVOS ...................................................... 243

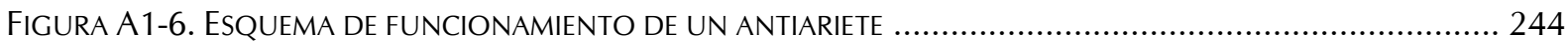




\section{Anexo 2}

FIGURA A2-1. ESQUEMA DE UNA INSTALACIÓN CON SUMINISTRO EN DIRECTO SIN GRUPO DE PRESIÓN................ 248

FIGURA A2-2. ESQUEMA DE UNA INSTALACIÓN CON SUMINISTRO CON BVF EN DIRECTO …............................. 249

FIGURA A2-3. ESQUEMA DE UNA INSTALACIÓN CON SUMINISTRO DIRECTO Y BOMBAS DE VELOCIDAD FIJA........... 250

FIGURA A2-4. ESQUEMA DE UNA INSTALACIÓN CON SUMINISTRO CON BOMBAS DE VELOCIDAD VARIABLE ........... 251

FigURA A2-5. ESQUEMA DE UNA INSTALACIÓN CON BOMBA DE VELOCIDAD FIJA Y DEPÓSITO AUXILIAR ............... 253

FIGURA A2-6. ESQUEMA DE UNA INSTALACIÓN CON DEPÓSITO SUPERIOR................................................... 254

\section{Anexo 3}

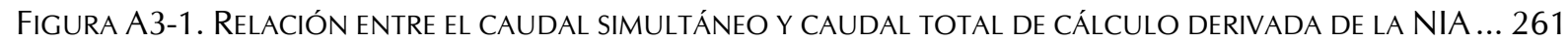

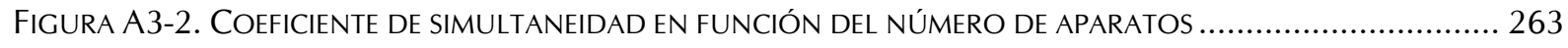

Figura A3-3. CURVAS PARA EL COEFICIENTE DE SIMULTANEIDAD DEL USO DE APARATOS ................................. 263

Figura A3-4. RELACIÓN ENTRE EL CAUDAL SIMULTÁNEO Y CAUDAL TOTAL DE CÁLCULO SEGÚN NF 41-204 ...... 264

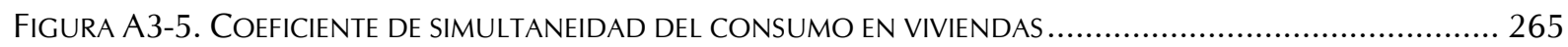

FiguRA A3-6. RELACIÓN ENTRE EL CAUDAL SIMULTÁNEO Y CAUDAL TOTAL SEGÚN EL PROC. RACIONAL .............. 266

FIGURA A3-7. RELACIÓN ENTRE El CAUDAL SIMULTÁNEO Y CAUDAL TOTAL SEGÚN LA NORMA UNE 149201 ..... 268

FIGURA A3-8. RELACIÓN ENTRE EL CAUDAL SIMULTÁNEO Y CAUDAL TOTAL DE CÁLCULO DE LA INSTALACIÓN

(DIN 1988-5, FigURE 3. PEAK FLOW RATE, AS FUnCTION OF TOTAL FLOW RATE) ........................................... 269

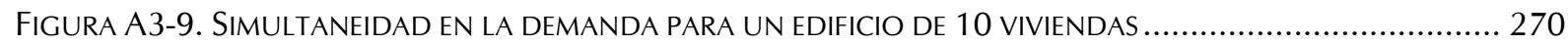

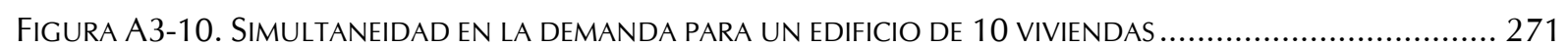

FigURA A3-11. RELACIÓN ENTRE EL CAUDAL SIMULTÁNEO Y CAUDAL TOTAL DE SEGÚN EL RESULTADO DE LAS

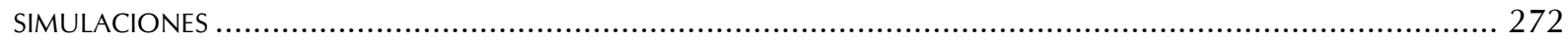

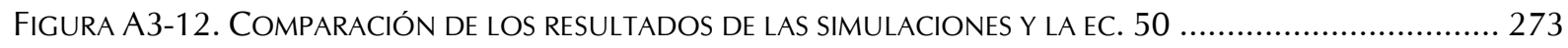

FIGURA A3-13. COMPARACIÓN DE LOS RESULTADOS DE LAS SIMULACIONES Y EL PROCEDIMIENTO DE LA NIA ..... 274

FIGURA A3-14. COMPARACIÓN DE LOS RESULTADOS DE LAS SIMULACIONES Y DE LA NF P 41-204 ................... 275

FiguRA A3-15. COMPARACIÓN DE LOS RESULTADOS DE LAS SIMULACIONES Y EL MÉTODO RACIONAL ................ 276

FIGURA A3-16. COMPARACIÓN DE LOS RESULTADOS DE LAS SIMULACIONES Y EL PROCEDIMIENTO DE LA UNE 149201

FIGURA A3-17. DETALLE DE CAUDALES SUPERIORES A 150 L/S

\section{Anexo 4}

FIGURA A4-1. DETALLE RED GENERAL DE DISTRIBUCIÓN Y CONEXIÓN DEL EDIFICIO MONITORIZADO .................... 282

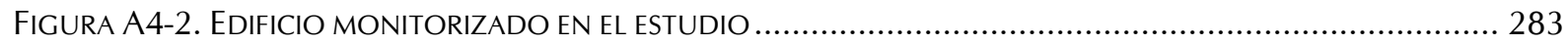

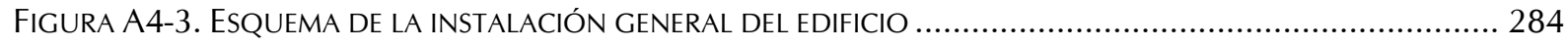

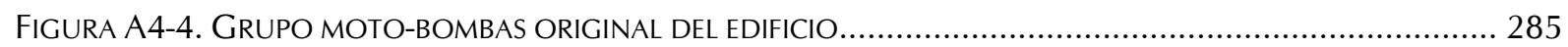

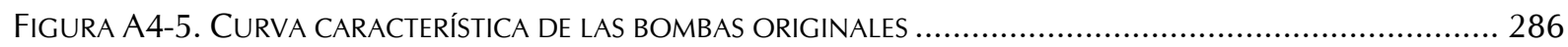


FIGURA A4-6. CONEXIÓN DEL GRUPO DE BOMBEO AL DEPÓSITO ATMOSFÉRICO 286

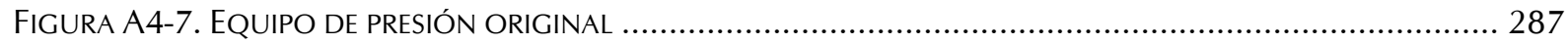

FIGURA A4-8. CONTADORES INDIVIDUALES CON SISTEMA DE CONTABILIZACIÓN DE PULSOS .......................... 289

FIGURA A4-9. DETALLE CONTADOR GENERAL Y SONDA DE PRESIÓN CON DATA LOGGER ................................ 290

FIGURA A4-10. ESQUEMA CON LA ZONA APROXIMADA DE INSTALACIÓN DE LAS SONDAS DE PRESIÓN ................ 291

FIGURA A4-11. GRUPO DE PRESIÓN CON VARIADOR E INSTALACIÓN ORIGINAL (BOMBAS AZULES) .................... 292

FIGURA A4-12. DETALLE DE CONEXIONES PARA LA MODIFICACIÓN DEL ESQUEMA DE SUMINISTRO ..................... 293

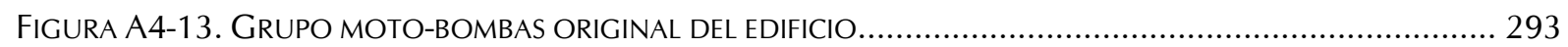

FIGURA A4-14. CURVA CARACTERÍSTICA Y DE RENDIMIENTO DE LAS BOMBAS ........................................... 294

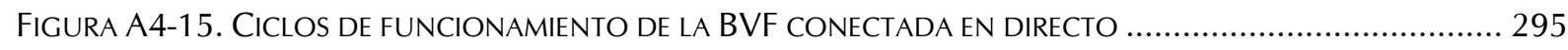

Figura A4-16. DetAlLE DEL FUnCIONAMIENTO DEL GRUPO DE PRESIÓN DE VELOCIDAD FIJA CONECTADO EN

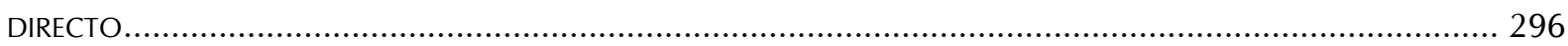

FIGURA A4-17. FUNCIONAMIENTO DEL GRUPO DE PRESIÓN CON VARIADOR CONECTADO EN DIRECTO .............. 297

FIGURA A4-18. FUnCIONAMIENTO DE LA BVF CONECTADA EN DIRECTO CON CALDERÍN EN ASPIRACIÓN ............ 298

FIGURA A4-19. FUNCIONAMIENTO DE LA BVV CONECTADA EN DIRECTO CON CALDERÍN EN ASPIRACIÓN ............ 298

FIGURA A4-20. COMPARACIÓN DE LAS SOLICITACIONES EN ASPIRACIÓN PARA DIFERENTES ESQUEMA ................. 299

FIGURA A4-21. COMPARACIÓN DE LAS SOLICITACIONES EN ACOMETIDA PARA DIFERENTES ESQUEMAS ................ 300

\section{Anexo 5}

FIGURA A5-1. INSTALACIÓN INDIRECTA CON DEPÓSITO ATMOSFÉRICO DE ALIMENTACIÓN 306

Figura A5-2. COMPARACIÓN DE LAS MANIOBRAS DE UNA VÁLVULA TODO/NADA Y DE UNA PROPORCIONAL..... 307

FIGURA A5-3. VARIACIÓN DE PRESIÓN EN LA ENTRADA DE LA VÁLVULA PROPORCIONAL ................................. 307

FIGURA A5-4. VARIACIÓN DE PRESIÓN EN LA ENTRADA DE LA VÁLVULA TODO/NADA ......................................309

Figura A5-5. MODELO DE SIMULACIÓN DE LA INST. DE REFERENCIA CON CONEXIÓN INDIRECTA EN ALLIEVI ........ 310

FIGURA A5-6. VARIACIÓN DE PRESIÓN ORIGINADA POR LA MANIOBRA DE UNA VÁLVULA DE LLENADO ............... 310

\section{Anexo 6}

Figura A6-1. REPRESENTACIÓN DE Un NUDO EN EL QUE CONFLUYEN 4 TUBERÍAS 320

FIGURA A6-2. SECCIÓN DE UN CALDERÍN 


\section{$\underline{\text { Índice de las tablas }}$}

\section{CAPÍTULO 1}

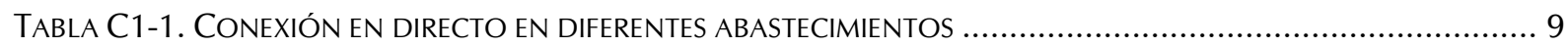

TABLA C1-2. COMPARACIÓN DE LAS IMPLICACIONES SEGÚN EL TIPO DE CONEXIÓN ……..................................... 22

\section{CAPÍTULO 2}

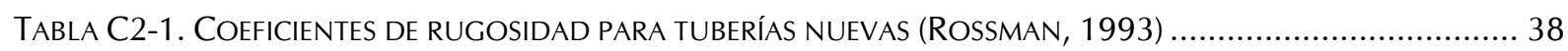

TABLA C2-2. INFORMACIÓN GENERAL PARA LA CARACTERIZACIÓN DE LOS ELEMENTOS DE UN MODELO .................. 45

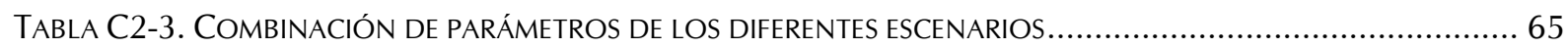

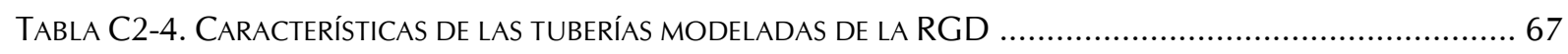

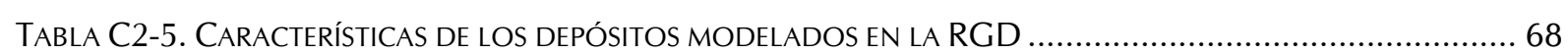

TABLA C2-6. CARACTERÍSTICAS DE LAS TUBERÍAS DE LA ACOMETIDA Y LA RED INTERIOR ....................................... 69

\section{CAPÍTULO 3}

TABLA C3-1. TRAZABILIDAD DE LOS PUNTOS ANALIZADOS (ESQUEMA TIPO II, DIÁMETRO 123 MM)...................... 104

TABLA C3-2. TRAZABILIDAD DE LOS PUNTOS ANALIZADOS (ESQUEMA TIPO III, DIÁMETRO 123 MM)................... 109

\section{CAPÍTULO 4}

TABLA C4-1. VARIACIÓN DE LAS PRESIONES EN DIFERENTES NUDOS DEL MODELO ......................................... 127

TABLA C4-2. NúMERO de BOMBAS EN FUNCIÓN DEL CAUDAL DE DISEÑO (PR UNE 149202) ........................... 148

\section{CAPÍtulo 5}

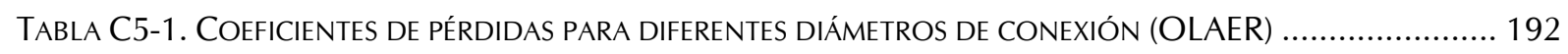

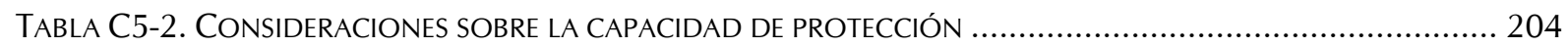

TABLA C5-3. PROTECCIÓN NECESARIA EN FUNCIÓN DEL CAUDAL DE LA BOMBAY DIÁMETRO DE ASPIRACIÓN ........ 206

\section{Anexo 1}

TABLA A1-1. Diámetros de aCometida (CANAL DE ISABEL II) 239

\section{Anexo 3}

TABLA A3-1. DESCRIPCIÓN DE LOS TIPOS DE VIVIENDA DEFINIDOS POR LA NIA

TABla A3-2. TABla PARA El DIMENSIONADO DEL tUBO DE ALIMENTACIÓN DE UN EDIFICIO SEGÚN LA NIA. 
Índice

TABLA A3-3. DEFINICIÓN DE SUBTIPOS DE VIVIENDA.

260

TABLA A3-4. RELACIÓN ENTRE EL CAUDAL INSTALADO Y CAUDAL DE CÁLCULO PARA DIFERENTES TAMAÑO DE EDIFICIO 260

TABLA A3-5. AJUSTE DEL COEFICIENTE DE SIMULTANEIDAD DE APARATOS 264

TABLA A3-6. CAUDALES MÍNIMOS INSTANTÁNEOS DE DIFERENTES APARATOS SEGÚN EL CTE (AGUA FRÍA) 267

TABLA A3-7. VALORES CARACTERÍSTICOS PARA LA SIMULACIÓN DEL EDIFICIO DE 10 VIVIENDAS 271 
Capítulo 1

\section{Introducción. Aspiración directa en instalaciones interiores de edificios}




\subsection{INTRODUCCIÓN}

La incorporación de depósitos atmosféricos de almacenamiento está ampliamente generalizada en el ámbito de las instalaciones interiores de suministro de agua. Con frecuencia, su utilización está justificada por las deficiencias que presenta la red, principalmente asociadas a la falta de continuidad en el servicio, o a la limitada capacidad hidráulica en algunas zonas. $Y$ es que el continuo crecimiento de la población y el aumento de las exigencias hidráulicas han mermado sensiblemente la capacidad de transporte de algunas redes, siendo precisa la incorporación de elementos de almacenamiento que aporten una mínima fiabilidad en el suministro.

En tantas otras situaciones, la utilización de estos elementos atiende a la severidad con la que demandan agua las instalaciones. En esta línea, una mayor densidad de población en el ámbito urbano, acompañado de un incremento del tamaño medio de los edificios, ha favorecido la incorporación de grupos de presión de forma generalizada en las instalaciones interiores, exigencia necesaria si se atiende a los estándares mínimos de suministro fijados en la reglamentación vigente. A su vez, las exigencias de funcionamiento de estos equipos de presión sobrecargan en mayor medida unas redes de capacidad finita. Estas condiciones de operación precisan la utilización de un elemento de aislamiento entre la instalación general de abastecimiento y la propia instalación interior del edificio, que impida que las alteraciones de presión generadas en la instalación interior condicionen el normal suministro del edificio, o afecten de forma negativa al correcto funcionamiento de instalaciones próximas.

Por otro lado, la dificultad de conocer la capacidad real de un tramo bajo una determinada demanda, ha propiciado la incorporación de esquemas de suministro con conexión indirecta de forma generalizada, ya que aparentemente reduce las solicitaciones en red. Del mismo modo, el diseño de instalaciones interiores atiende frecuentemente a la simplicidad de procedimientos, en esta línea la casuística derivada del análisis de esta instalación ha favorecido la adopción de esquemas que simplifiquen los cálculos de dimensionado. 
De lo que no hay duda es de que los depósitos de almacenamiento realizan eficazmente la función para la que están diseñados, pero colateralmente esta solución introduce severos problemas en aspectos relacionados con la eficiencia de suministro y con la propia calidad del agua servida, y es que hoy día no hay duda sobre la alteración de la garantía de la salubridad del agua almacenada en este tipo de elementos. Este mismo problema inquieta al propio gestor del servicio que ve peligrar su capacidad de garantizar un agua de calidad en el punto de consumo, situación que ha llevado a algunos abastecimientos y al comité de normalización correspondiente, a centrar esfuerzos para su eliminación.

El desarrollo realizado trata de acudir a esquemas de suministro que presenten una mayor bondad operativa, reduciendo los inconvenientes que presenta el esquema de suministro con conexión indirecta. Los esquemas analizados acuden a una alimentación directa de red (sin la interposición de depósitos atmosféricos). Tal como se muestra en el presente trabajo, si bien la utilización de estos elementos en muchas situaciones está justificada, la necesidad de estos depósitos en tantas otras es cuestionable y prescindir de este elemento no supondría una alteración significativa del comportamiento de la red.

En cualquier caso, la eliminación de los depósitos no es directa ni evidente. El desconocimiento del funcionamiento global de la red, y lo que es más importante, la incógnita sobre la respuesta de la red al prescindir de este elemento laminador, suscita una incertidumbre que obstaculiza en gran medida la adopción de esquemas de suministro alternativos. Este escenario además se ve favorecido por la dificultad en el conocimiento de las solicitaciones de los equipos de presión en aspiración directa. Y es que no sólo es suficiente caracterizar la respuesta en régimen permanente de la red para una carga hidráulica más o menos severa, además es necesario conocer las afecciones transitorias introducidas por los esquemas alternativos en la instalación interior.

En esta línea, se muestra los resultados de un procedimiento para analizar la capacidad hidráulica de una red bajo diferentes esquemas de funcionamiento con conexión directa, en aras de aportar un mayor conocimiento asociado a las solicitaciones de diferentes esquemas. De forma complementaria se ha realizado el análisis en régimen transitorio para comprobar las exigencias asociadas al funcionamiento de grupos de presión con alimentación directa. Los resultados pretenden aportar un mayor conocimiento de los efectos asociados a la aspiración directa, y una guía para el dimensionado de la protección que permita la conexión directa en función de las características particulares de la red y de la instalación interior del edificio. 


\subsection{ASPIRACIÓN DE GRUPOS DE PRESIÓN EN INSTALACIONES INTERIORES}

\subsubsection{Conexión directa}

Se conoce como conexión directa o aspiración en directo, al esquema de la instalación general interior del edificio que conecta la tubería de entrada de la red general de distribución (RGD), directamente con el equipo de presión (a través del tubo de alimentación), sin la interposición de ningún elemento de aislamiento como el depósito auxiliar de alimentación (depósito atmosférico).

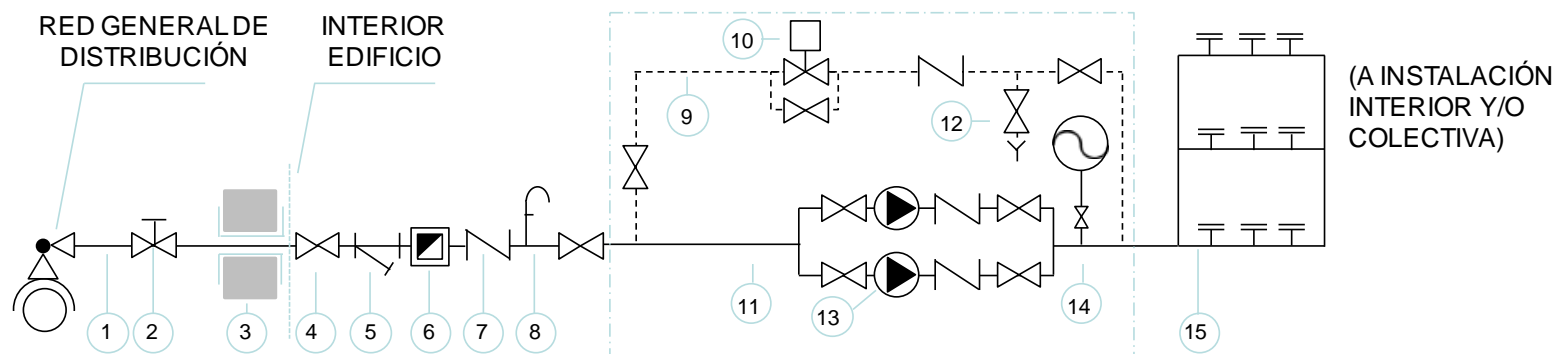

\begin{tabular}{l|ll}
\hline ACOMETIDA & \multicolumn{1}{|c}{ INSTALACIÓN INTERIOR GENERAL } \\
\hline & & \\
\hline 1. Tubo de acometida & 6. Contador general & 11. Tubería de aspiración \\
2. Válvula de aislamiento (registro) & 7. Válvula antirretorno & 12. Llave a desagüe \\
3. Pasamuros & 8. Toma auxiliar & 13. Bomba \\
4. Llave de paso & 9. By-pass & 14. Depósito hidroneumático (impulsión) \\
5. Filtro general & 10.Válvula de dos vías motorizada & 15. Batería de contadores (distribuidor)
\end{tabular}

FIGURA C1-1. ESQUEMA DE CONEXIÓN EN DIRECTO DEL EQUIPO DE PRESIÓN EN UNA INSTALACIÓN INTERIOR

La conexión directa está supeditada a la disponibilidad de presión suficiente en red (en el punto de entrega del edificio), a la capacidad de la red de soportar la extracción de caudal en régimen permanente de la bomba, y a la limitación de las afecciones en régimen transitorio por el arranque y parada del grupo. Estas consideraciones incluirían además la continuidad del suministro, ya que la red debe ser capaz de garantizar un suministro adecuado de forma permanente.

En el caso de instalaciones o tramos que no precisen de grupo de presión (por la existencia de presión suficiente en red), el esquema de conexión también se realiza de forma directa (alimentación directa sin grupo de presión). Para esta situación y, atendiendo a las pautas usuales de simultaneidad de la demanda, las solicitaciones transitorias generadas no suele ser elevadas en comparación con instalaciones equipadas con grupos de presión, ya que de forma instantánea no se suelen generar variaciones significativas de velocidad en la acometida del edificio. 


\subsubsection{Conexión o aspiración indirecta}

La conexión indirecta interpone un depósito auxiliar de alimentación (depósito atmosférico), entre la conducción conectada a la red general de distribución y la aspiración de la bomba. La finalidad perseguida con el depósito atmosférico es aislar la red general de la instalación interior del edificio, laminando las solicitaciones a la red y evitando la transmisión de efectos transitorios generados durante el funcionamiento del grupo, al mismo tiempo que se dispone de un volumen de agua auxiliar a modo de reserva.

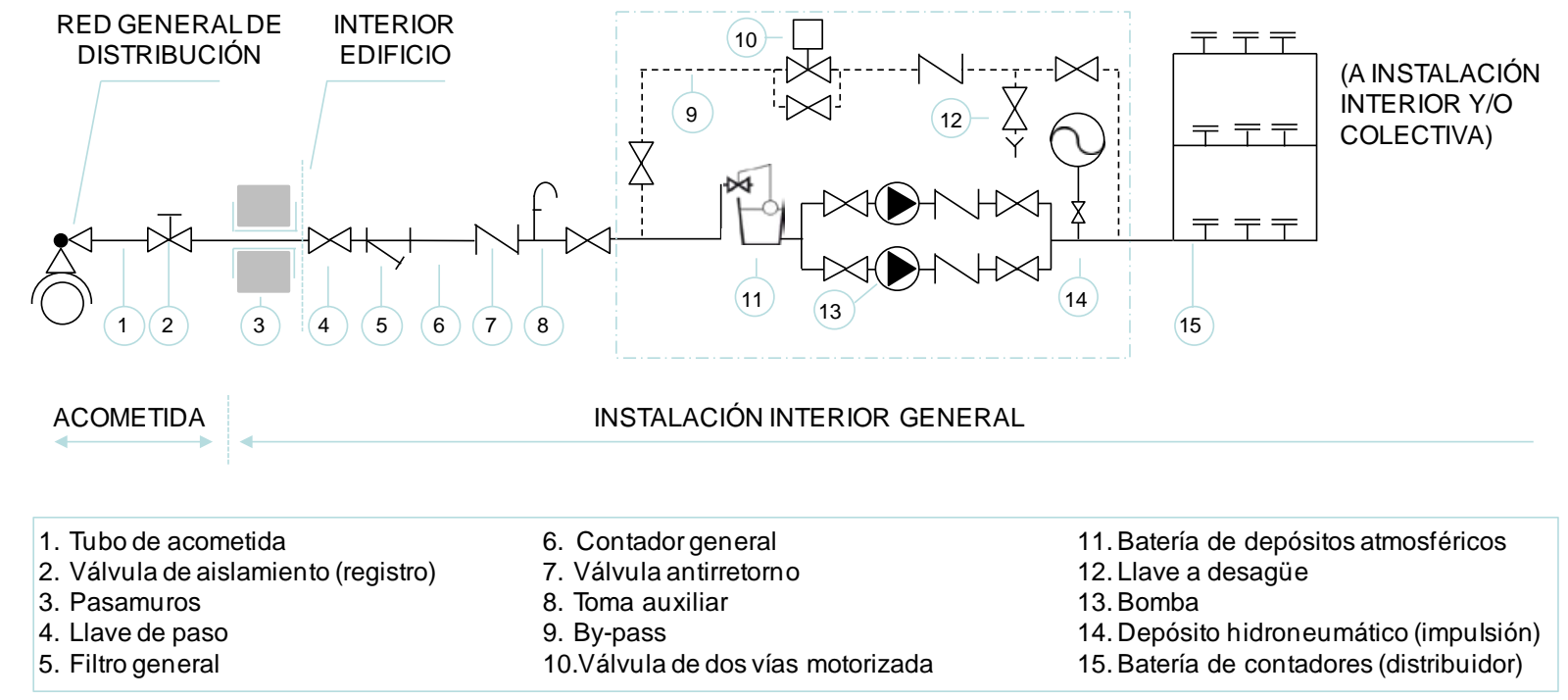

FIGURA C1-2. ESQUEMA DE CONEXIÓN INDIRECTA DEL EQUIPO DE PRESIÓN EN UNA INSTALACIÓN INTERIOR

\subsubsection{Tipología de grupos de presión}

Generalmente, los grupos de presión en instalaciones interiores de suministro de agua en edificios están formados por:

- Bombas de velocidad fija (BVF). Grupo moto-bomba sin variador de frecuencia.

- Bombas de velocidad variable (BVV). Grupo moto-bomba con variador.

En instalaciones que cuentan con varias bombas, es posible que no todas sean del mismo tipo. En el caso de que alguna de ellas esté equipada con variador se considera como grupo de presión de velocidad variable, ya que durante la regulación la bomba equipada con variador realiza siempre el ajuste fino, mientras que las bombas de velocidad fija arrancan de forma escalonada cuando la primera alcanza su velocidad nominal. La funcionalidad introducida por el variador de frecuencia permite la regulación de la velocidad rotacional de la bomba, y por tanto, aporta un mayor control durante su funcionamiento, principalmente durante los instantes de arranque y paro del grupo, originando arranques más suaves y progresivos que las bombas de velocidad fija. 


\subsubsection{Normativa}

A continuación se describen las principales consideraciones reglamentarias referentes a los esquemas de conexión en las instalaciones interiores de abastecimiento en el entorno residencial.

\subsubsection{Código Técnico de la Edificación}

El reglamento de referencia en el ámbito de las instalaciones interiores de suministro de agua es el Código Técnico de la Edificación (en adelante CTE), en su Documento Básico de Salubridad, sección HS4 Suministro de Agua (CTE, 2006), y sustituye a las antiguas normas Básicas para las Instalaciones Interiores de Suministro de Agua (NIA, 1975).

Este reglamento contempla la posible conexión de grupos de presión de velocidad variable en aspiración directa, pero no así la correspondiente a los grupos sin variador. Para el primero de los casos no se indica nada relacionado con las limitaciones para implementar este esquema. Sólo considera tres esquemas de alimentación para sistemas con sobreelevación (Figura C1-3, pto. 3.2.1.5.1 HS4):

- Grupo convencional (grupo con BVF en aspiración indirecta). Esquema equipado con depósito auxiliar de alimentación y grupo de presión de velocidad fija.

- Grupo de accionamiento regulable (caudal variable). Esquema con bombas equipadas con variador de frecuencia conectadas en directo. A su vez, este esquema puede derivar en un tercero si se interpone un depósito atmosférico en aspiración.

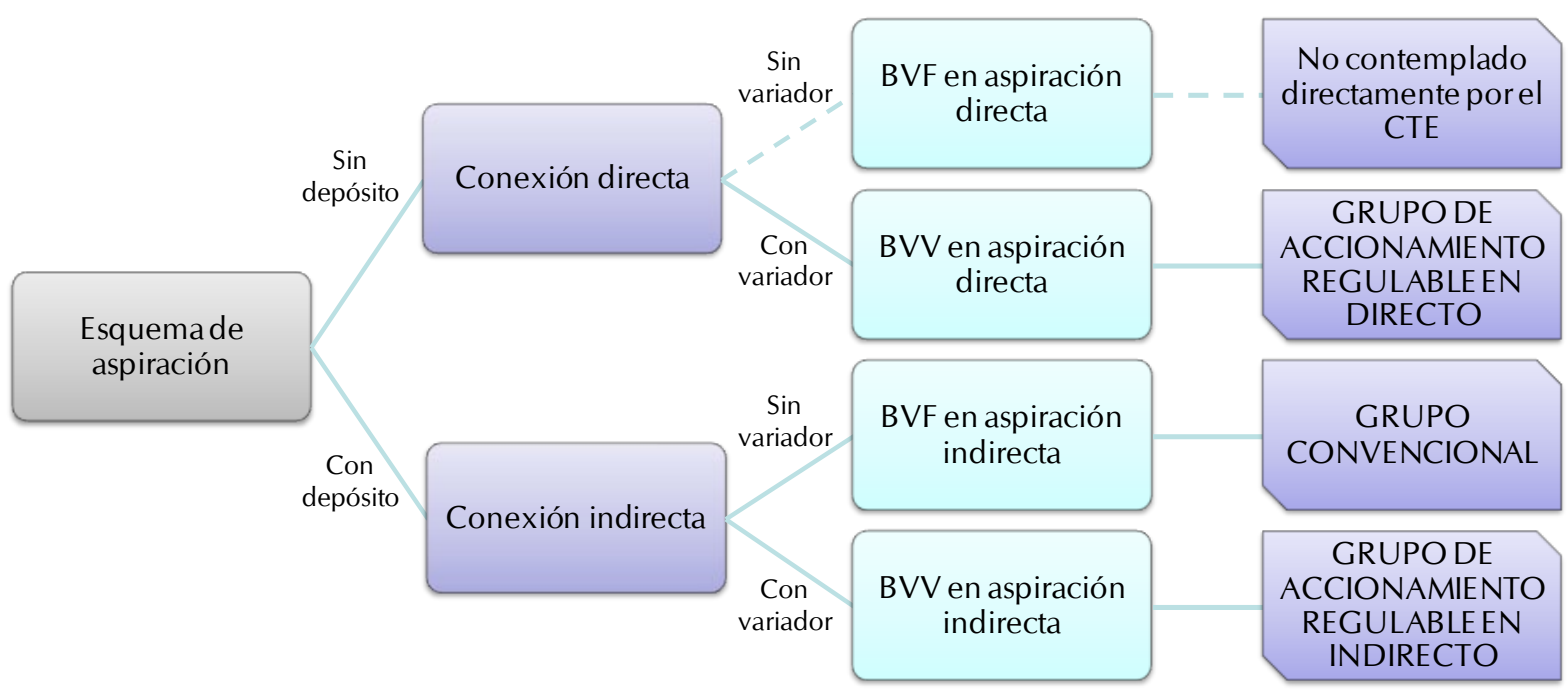

FIGURA C1-3. ESQUEMAS DE CONEXIÓN CONTEMPLADOS POR EL CTE 
Sin embargo, esta misma normativa indica además lo siguiente "Las bombas no deben conectarse directamente a las tuberías de llegada del agua de suministro, sino que deben alimentarse desde un depósito, excepto cuando vayan equipadas con los dispositivos de protección y aislamiento que impidan que se produzca depresión en la red" (pto. 3.3.6 $1^{\circ}$ ), añadiendo a continuación (pto. 3.3.6 $2^{\circ}$ ) "Esta protección debe alcanzar también a las bombas de caudal variable que se instalen en los grupos de presión de acción regulable...". Por tanto, aparece una clara ambigüedad sobre la posibilidad de conectar grupos de velocidad fija sin la interposición de un depósito auxiliar de alimentación cuando se prevea la protección y aislamiento suficiente. Además no es sencillo desde el punto de vista del instalador conocer las posibilidades de conexión directa con bombas de velocidad fija.

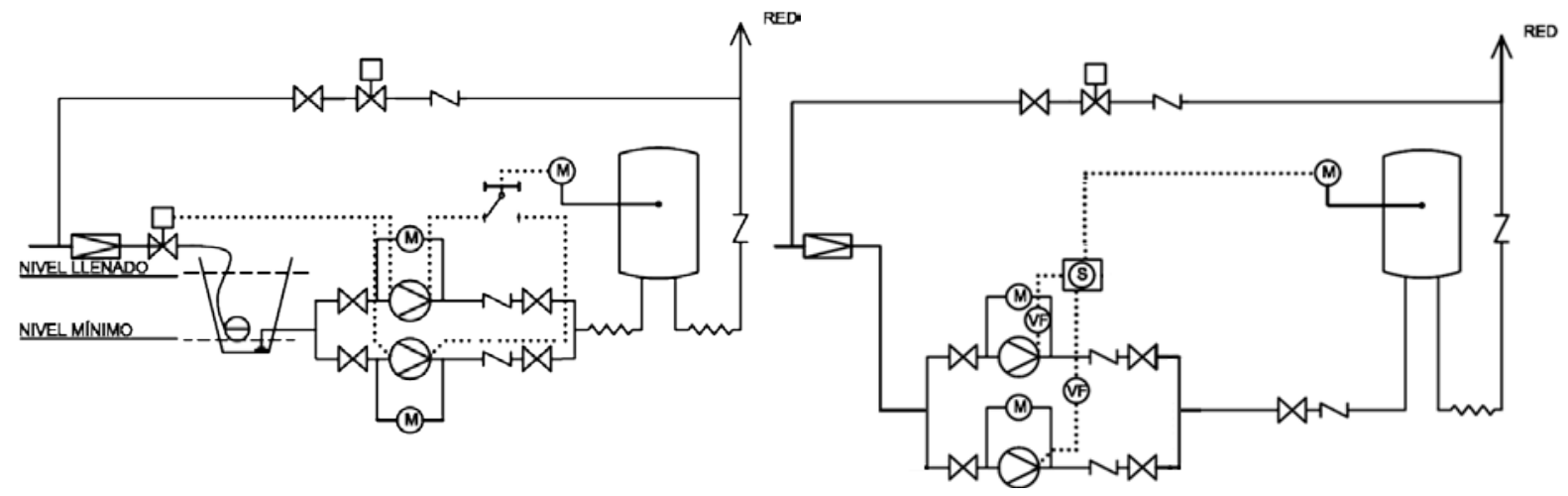

FIGURA C1-4. ESQUEMAS GRUPO CONVENCIONAL (IZQDA.) Y ACCIONAMIENTO REGULABLE (DCHA.) SEGÚN CTE

\subsubsection{Normas tecnológicas UNE}

Por un lado, la norma UNE-EN 806-2 (vigente en el momento de redacción del presente estudio), en el apartado 1.5.3 Dispositivos elevadores de la presión, indica lo siguiente "Dado que en un sistema cerrado no existe riesgo de una contaminación del agua potable que sea peligrosa para la salud, es preferible una conexión directa a una conexión indirecta". Abogando por tanto, por los esquemas en directo frente aquéllos que incorporan un depósito auxiliar de alimentación.

De la misma forma, el proyecto de norma Pr-UNE 149 202. Grupos de presión, completa la normativa actual en lo relacionado con los grupos de presión, estableciendo diferentes alternativas para la conexión directa, así como las medidas de protección necesarias para garantizar una conexión directa en función de las características de la instalación interior y de la red general de abastecimiento. En esta línea se destaca la inclusión de calderines en aspiración como medida de protección para reducir los efectos derivados de la aspiración en directo. 


\subsubsection{Reglamentos de Servicio de las Empresas Suministradoras}

Por otro lado, la empresa suministradora o el ayuntamiento gestor del servicio en su defecto, es la que fija en su Reglamento de Servicio o documentos análogos, los esquemas de conexión de los grupos de presión permitidos, ya que esta entidad es la que conoce generalmente la capacidad de su red. En este punto, existe discrepancia en cuanto a la posibilidad de conectar grupos en directo (sin depósito de alimentación).

Algunos abastecimientos como en la Ciudad de Valencia, gestionado por la empresa Aguas de Valencia, permiten la conexión directa tanto para bombas de velocidad fija como bombas de velocidad variable. En la mayoría de casos, la instalación debe contar con la aprobación del técnico de la empresa. Las características operativas de la mencionada red mantienen, en condiciones normales, un rango de presión acotado y con valor elevado en los diferentes puntos de entrega; $2,5 \mathrm{Kp} / \mathrm{cm}^{2}$ y 5 $\mathrm{Kp} / \mathrm{m}^{2}$ para la presión mínima y máxima respectivamente (Reglamento de Servicio de Abastecimiento de Agua Potable de la Ciudad de Valencia, 2004).

Otros abastecimientos, por ejemplo en la Ciudad de Madrid, abastecimiento gestionado por el Canal de Isabel II, no permite este esquema de conexión (Reglamento para el servicio y distribución de las aguas del Canal de Isabel II, 1975). Además, la empresa no contempla presiones mínimas garantizadas, existiendo en algunos casos rangos de presión que oscilan desde 1 a $7 \mathrm{Kp} / \mathrm{cm}^{2}$.

TABLA C1-1. CONEXIÓN EN DIRECTO EN DIFERENTES ABASTECIMIENTOS

\begin{tabular}{|c|c|c|c|}
\hline Ciudad & $\begin{array}{c}\text { Empresa } \\
\text { Suministradora }\end{array}$ & $\begin{array}{l}\text { Permite la conexión } \\
\text { en directo }\end{array}$ & Consideraciones \\
\hline Cádiz & Aguas del Puerto & No & \\
\hline Cartagena & Aguas de Cartagena & No & \\
\hline Castellón & FACSA & No & \\
\hline Huesca & Ayto. Huesca & No & \\
\hline Madrid & Canal de Isabel II & No & \\
\hline Sevilla & EMASESA & Sí & Bombas con variador \\
\hline Valencia & Aguas de Valencia & Sí & Potencias menores de $3 \mathrm{CV}$ \\
\hline Vitoria & AMVISA & Sí & Sólo con depósito cerrado \\
\hline Zaragoza & Aguas de Zaragoza & Sí & Uso de depósitos atmosféricos no permitido \\
\hline
\end{tabular}

Una situación más estricta se establece en la ciudad de Zaragoza, este abastecimiento en su ordenanza municipal prohíbe directamente la utilización de depósitos atmosféricos en la nueva edificación, debiéndose acudir a la utilización de grupos en conexión directa equipados con depósitos estancos a presión (Ayto. de Zaragoza, 2011). 
En otros casos, algunos abastecimientos muestran un evidente interés en la eliminación de los depósitos auxiliares, es el caso del abastecimiento de la Ciudad se Sevilla (gestionado por la empresa municipal EMASESA), y para ello ha desarrollado estudios internos para la eliminación de estos elementos, posibilitando además el uso de sus instalaciones como campo de trabajo para analizar diferentes alternativas de protección (Veiga y Soriano, 2010). En una primera iteración, este abastecimiento aboga por la aspiración en directo con grupos de velocidad variable equipados y protección.

\subsubsection{Ventajas asociadas a la aspiración en directo}

\subsubsection{Garantía de las condiciones de salubridad del agua}

Entre las ventajas que presenta una conexión en directo la más importante está relacionada con la calidad del agua. Son ampliamente conocidos los problemas derivados del uso de depósitos atmosféricos de almacenamiento de agua, imposibilitándose en muchos casos la capacidad de garantizar un agua perfectamente salubre (Grayman y Kirmeyer, 1999). El aumento del tiempo de residencia del agua tratada en el depósito reduce exponencialmente la concentración de desinfectante (Clark et al., 1993, 1994; Vasconcelos et al., 1997; Fang Hua, et al., 1999), por tanto aun suministrando agua desinfectada, puede no ser posible garantizar la correcta salubridad del agua servida según las exigencias del Real Decreto 140/2003, que regula los criterios sanitarios de la calidad del agua de consumo humano (documento de referencia en las instalaciones interiores). Estudios muestran que en periodos prolongados sin reposición del recurso, fácilmente se alcanzarían concentraciones de cloro libre residual por debajo de los estándares mínimos de $0,2 \mathrm{mg} / \mathrm{l}$ (Reynolds y Richards, 1996; American Water Works Association, 1982). Esta disminución del desinfectante posibilita la proliferación de bacterias que colonizan los sistemas de abastecimiento de agua, y por tanto la posible contaminación de las instalaciones interiores. Este efecto es mucho más sensible para los depósitos cuyo diseño favorece la aparición de zonas muertas, y destinos con claras connotaciones estivales.

En esta misma línea, el Real Decreto 865/2003 para la prevención y control de la legionelosis cataloga las instalaciones interiores de agua fría de consumo humano como de "menor probabilidad de proliferación y dispersión de la Legionella", dejando esta instalación fuera del ámbito de aplicación del Real Decreto, si bien y dado que este tipo de depósitos favorece el micro hábitat de esta familia de bacterias (a saber temperaturas entre $25-40{ }^{\circ} \mathrm{C}$, estancamiento de agua y disponibilidad de nutrientes), recomienda realizar operaciones periódicas de mantenimiento y control en este tipo de instalaciones, ya que un reducido mantenimiento puede favorecer la proliferación de esta familia de bacterias en el interior del depósito. 
De forma análoga, en abastecimientos con concentraciones elevadas de materia orgánica y que incorporan depósitos atmosféricos aumenta la posibilidad de proliferación de subproductos de desinfección (DBP), como trihalometanos (THM) y ácidos haloacéticos (HAAs), esta situación se ve favorecida por el contacto de este tipo de sustancias con los propios agentes de desinfección, y las condiciones de hábitat aportadas por el depósito (Boorman, 1999; Trusell y Umphres, 1978; Clark, 1998; Levesque et al., 2006; Nieuwenhuijsen et al., 1999). Este efecto es principalmente importante en algunas cuencas del mediterráneo en las que se puede llegar a concentraciones en torno a $80 \mu \mathrm{g} / \mathrm{I}$ de THM (Villanueva, 2003). Como es conocido, este tipo de compuestos está incluido dentro de los carcinógenos para personas en ciertas condiciones de exposición (OMS, 1985; Cantor et al., 1998). Adicionalmente otros problemas de calidad que deben ser considerados son: el incremento del nivel de $\mathrm{pH}$, el crecimiento de algas y otros organismo biológicos por la pérdida de cloro, la presencia de sedimentos, crecimiento de biofilm, etc. (Hassan y Ali, 2011).

Por otro lado, la aspiración en directo evita un punto de entrada de agentes contaminantes. Los depósitos atmosféricos, aun contando con tapas y rejillas para evitar la entrada de elementos, acaban incorporando compuestos que pueden poner en riesgo la salubridad del agua almacenada, efecto más sensible en el caso de que esta agua haya perdido la concentración mínima de agente desinfectante. Este efecto también se favorece si la instalación no cuenta con elementos de filtración aguas arriba del depósito (como mayoritariamente sucede).

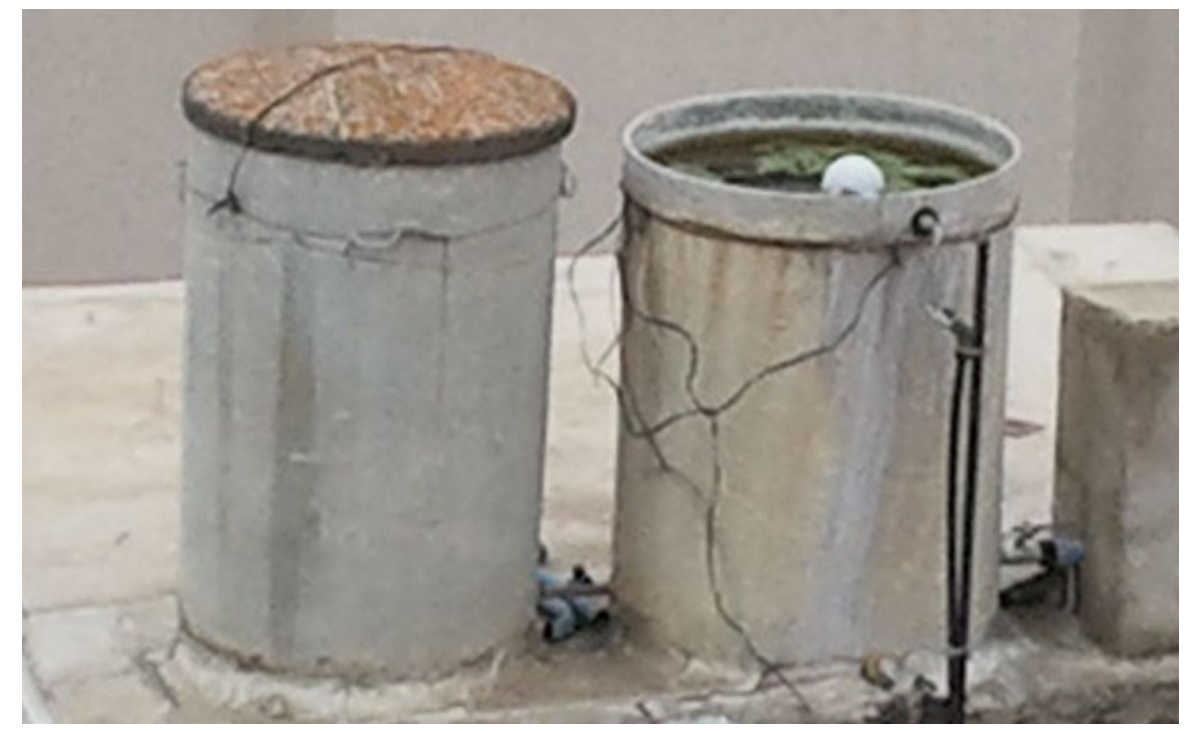

FIGURA C1-5. DEPÓSITO ATMOSFÉRICO SIN TAPA DE PROTECCIÓN

Las alteraciones descritas junto con la dificultad que presenta la realización y el control de tareas de mantenimiento de depósitos domésticos, cuestiona la correcta conservación de la salubridad en esquemas con conexión indirecta, justificándose el 
interés de algunos abastecimientos para reducir su adopción. El RD 140/2003, en su artículo 4 Responsabilidades y competencias, establece que "los gestores del servicio (municipios o gestores indirectos) son los responsables de asegurar que el agua suministrada a través de cualquier red de distribución, cisterna o depósito móvil en su ámbito territorial sea apta para el consumo en el punto de entrega al consumidor y, por tanto, son ellos los que deben velar por el correcto mantenimiento de los elementos de la instalación". Por ello algunas compañías incluyen en su reglamento de servicio la necesidad de realizar de análisis de calidad del agua en instalaciones interiores.

\subsubsection{Aumento de la eficiencia energética del suministro}

La conexión de la red general de distribución al depósito atmosférico de almacenamiento origina una despresurización del agua suministrada por la red, con la correspondiente pérdida de energía en forma de presión que disponía el agua antes de arribar al depósito. Una vez despresurizada el agua en la instalación general del edificio es necesario, en la mayoría de instalaciones, volver a presurizarla para garantizar las presiones mínimas exigidas por la reglamentación vigente, acción que implica un consumo energético adicional. Una situación más eficiente partiría del aprovechamiento energético de la presión disponible en red, tal como sucede en la aspiración en directo (Soriano et al., 2010; Cobacho et al., 2007). Téngase en cuenta que en algunas situaciones incluso la nueva presurización aporta valores de presión próximos a la presión que ya se dispone en la acometida. Este efecto es mucho más sensible en el caso de redes que presenten menores fluctuaciones de presión de entrega (presión en acometida), ya que en tal caso es posible incluso optimizar el punto de funcionamiento del grupo de presión manteniendo rendimientos elevados durante el funcionamiento normal de la bomba. En el caso contrario, aun aprovechando la presión en red puede darse la situación de operar fuera de zonas con buen rendimiento del grupo, y por tanto, restar eficiencia al suministro.

\subsubsection{Mejora del rendimiento hidráulico de la red}

\section{Problemática en el registro de caudales bajos}

La utilización de válvulas de control de llenado en los depósitos principalmente de tipo boya proporcional (elemento ampliamente extendido en el entorno residencial), origina el trasiego frecuente de caudales bajos, correspondientes a las posiciones finales de cierre de la válvula. La utilización de contadores aguas arriba del depósito conlleva generalmente subcontaje (Rizzo y Cilia, 2005; Charalambous et al., 2007; Crimisini et al., 2009; Cobacho et al., 2007), derivado de la dificultad de contabilizar estos volúmenes de agua, aumentando de este modo el caudal incontrolado del 
abastecimiento y reduciéndose por tanto, el rendimiento del mismo (en el caso de facturar con el registro de este contador, o realizar balances de volúmenes consumidos).

En la Figura C1-6 se observa el comportamiento típico de una válvula de boya tipo proporcional, y el nivel de caudal por debajo del cual el contador no registra el volumen trasegado (aproximadamente un $5 \%$ para el ejemplo). En esta línea, la utilización de válvulas de boya tipo todo/nada (válvula que opera totalmente abierta o cerrada) reduce la aparición de caudales bajos, favoreciendo la mejora del rendimiento de las

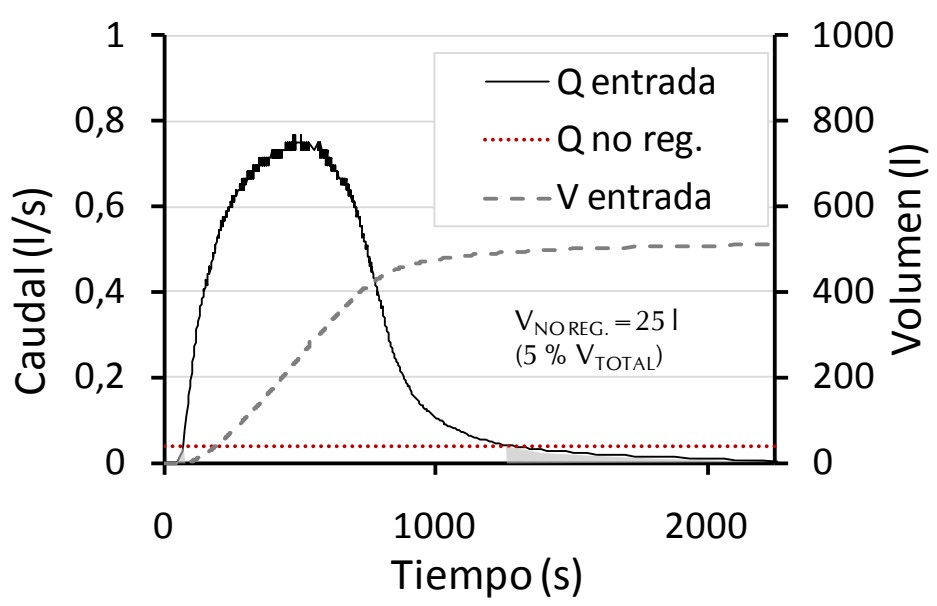

FIGURA C1-6. COMPORTAMIENTO TÍPICO DE UNA VÁLVULA DE BOYA PROPORCIONAL. VOLUMEN NO REGISTRADO EN UN CICLO DE LLENADO mediciones.

Problemática asociada a los fraudes (usos intencionados no registrados)

Los depósitos de almacenamiento privados permiten en muchas instalaciones un acceso directo al recurso sin proceder a la contabilización del mismo (instalaciones que cuentan sólo con contadores individuales aguas abajo del depósito). En tal caso, además de no realizarse un registro de volúmenes utilizados en ciertas actividades, como las dedicadas al mantenimiento y limpieza de elementos como el depósito atmosférico, se aumenta la posible extracción y uso del recurso sin la previa contabilización (Veiga y Soriano, 2010). Con la aspiración directa, la facilidad de acceso al recurso se reduce, así como los volúmenes de agua utilizados en tareas de mantenimiento y limpieza.

\subsubsection{Reducción del coste de la instalación}

El aprovechamiento de la presión en red generalmente propicia la necesidad de menores alturas de bombeo, y por ello, para un mismo caudal de diseño de la instalación, menores potencias de grupos. Esto reduce no sólo el coste de instalación y material, también el de operación al repercutir directamente en una menor potencia contratada y en un menor consumo energético (característica siempre condicionada a los puntos de funcionamiento del grupo de presión).

En cuanto al coste de instalación, también existe un ahorro sobre el propio depósito y en los elementos de control de Ilenado (válvula de boya), aislamiento, conexiones, rebosadero, etc. Este inconveniente no se ve favorecido por las 
disposiciones de algunas normativas, ya que se persigue la incorporación de varios vasos que totalicen el volumen de cálculo de la instalación (Pr-UNE 149202). Del mismo modo, el ahorro es tanto más sensible en instalaciones con obra in situ, ya que este tipo de elementos encarece sensiblemente el coste final.

\subsubsection{Reducción del coste de mantenimiento}

La eliminación de los depósitos por un lado evitaría la necesidad de realizar las tareas de limpieza de los depósitos, e incluso los análisis químicos del agua almacenada (exigencia contemplada en la normativa de algunos abastecimientos).

Por otro lado se evitan los problemas derivados de la asignación de competencias de estas tareas, ya que si bien la comunidad de vecinos es por lo general responsable del mantenimiento de esta instalación, la compañía de suministro puede verse perjudicada ante la aparición de problemas de salubridad en la instalación interior de sus usuarios.

\subsubsection{Reducción del espacio en planta necesario}

Es usual la reserva de espacios reducidos en planta de los edificios para la ubicación de las instalaciones comunes del inmueble, lo que generalmente lleva a realizar instalaciones en las que se dificulta las tareas de mantenimiento. El elemento que mayor espacio suele requerir en estos casos es el depósito atmosférico (del orden de $2 \mathrm{~m}^{2}$ para un volumen medio de $1 \mathrm{~m}^{3}$ ), por tanto, favorecería la disponibilidad de espacio si se prescinde del depósito además de conseguir instalaciones más compactas.

De la misma forma, otra repercusión constructiva del depósito está relacionada con la necesidad de espacio suficiente para introducir el depósito atmosférico. Esta necesidad suele precisar la instalación de puertas de acceso de dimensiones diferentes a las convencionales, o incluso acudir a varios tanques de menor volumen, con el correspondiente encarecimiento de la instalación y aumento del espacio requerido. Todo ello sin perder de vistas las implicaciones correspondientes al cálculo de cargas estructurales asociadas al volumen de agua almacena. En este sentido, la sobrecarga asociada al cuarto de bombas no siempre está convenientemente calculada, ya que de forma similar a otras zonas del edificio en el entorno residencial, se suele mantener una sobrecarga de uso de $2 \mathrm{kN} / \mathrm{m}^{2}$ (CTE, Documento Básico Seguridad Estructural. Acciones en la edificación), valor que puede ser superado por la carga concentrada que supone el depósito completamente lleno de agua. 


\subsubsection{Mejora en la conservación del recurso}

Tras periodos sin servicio, es necesario proceder al vaciado y limpieza de los depósitos de almacenamiento. Esta agua no suele ser aprovechada, pasando directamente a la red de evacuación por el desagüe que incorpora el recipiente. Si bien no es un volumen elevado, su desperdicio no favorece la preservación del recurso.

Otra de las situaciones que favorecería este mismo problema está relacionada con las pérdidas de agua en el desagüe del depósito, derivado del cierre defectuoso de las válvulas de control de Ilenado. Actualmente esta situación no se detecta de forma inmediata, y se prolonga hasta la realización de operaciones periódicas de mantenimiento en el mejor de los casos, lo que implica la pérdida de importantes volúmenes de agua. La importancia de esta detección temprana ha llevado a abogar por la incorporación de sistemas automáticos de detección de fugas ( $\operatorname{Pr}$ UNE 149202). Dentro de este volumen de agua también debe considerarse las fugas del propio depósito, favorecidas por la falta de mantenimiento.

Adicionalmente se destacan los problemas usuales derivados del bloqueo total o parcial de algunos contadores mecánicos (por la incidencia de partículas que obstruyen el giro normal de la turbina). Si la instalación cuenta con depósito aguas abajo del contador, generalmente se puede mantener el suministro a partir de menores caudales, pero el depósito oculta el incidente al usuario. Situación diferente tendría lugar con el suministro en directo, ya que en este caso el usuario experimentaría una reducción de la capacidad de suministro en su instalación, y con ella, procedería a una revisión del elemento de lectura.

\subsubsection{Inconvenientes asociados a la aspiración en directo}

Si bien no siempre es posible proceder a la conexión directa por las características funcionales de la red general de distribución, en el caso de que sí sea posible, hay que tener presente una serie de inconvenientes asociados a este tipo de esquema, principalmente en lo que respecta a las alteraciones de presión en el punto de entrega durante el arranque y parada de la bomba.

\subsubsection{Alteración de la presión en red por el funcionamiento de la bomba}

Existen varios efectos a considerar asociados al funcionamiento de un grupo de presión conectado en directo, y concretamente relacionado con las variaciones de presión que experimenta el fluido aguas arriba de la bomba, y que incluso pueden transmitirse al exterior del edificio. Estos fenómenos aparecen en las tres etapas en las que se ha dividido el funcionamiento del grupo, y son más sensibles en instalaciones 
que cuentan con bomba de velocidad fija (sin variador de frecuencia) dada la mayor severidad en el funcionamiento mostrada por estos equipos.

- Arranque del grupo (caracterizado por su instante inicial y final, $T_{i a}-T_{f a}$ ).

- Funcionamiento en régimen permanente $\left(T_{f a}-T_{i p}\right)$

- Parada del grupo $\left(T_{i p}-T_{f p}\right)$

La Figura C1-7 simplifica los efectos asociados al funcionamiento de un grupo de presión en aspiración directa en diferentes puntos de la red general de distribución. Como puede entenderse, las implicaciones del funcionamiento del grupo serán más o menos significativas en función de las características de la instalación interior de la red exterior al edificio.

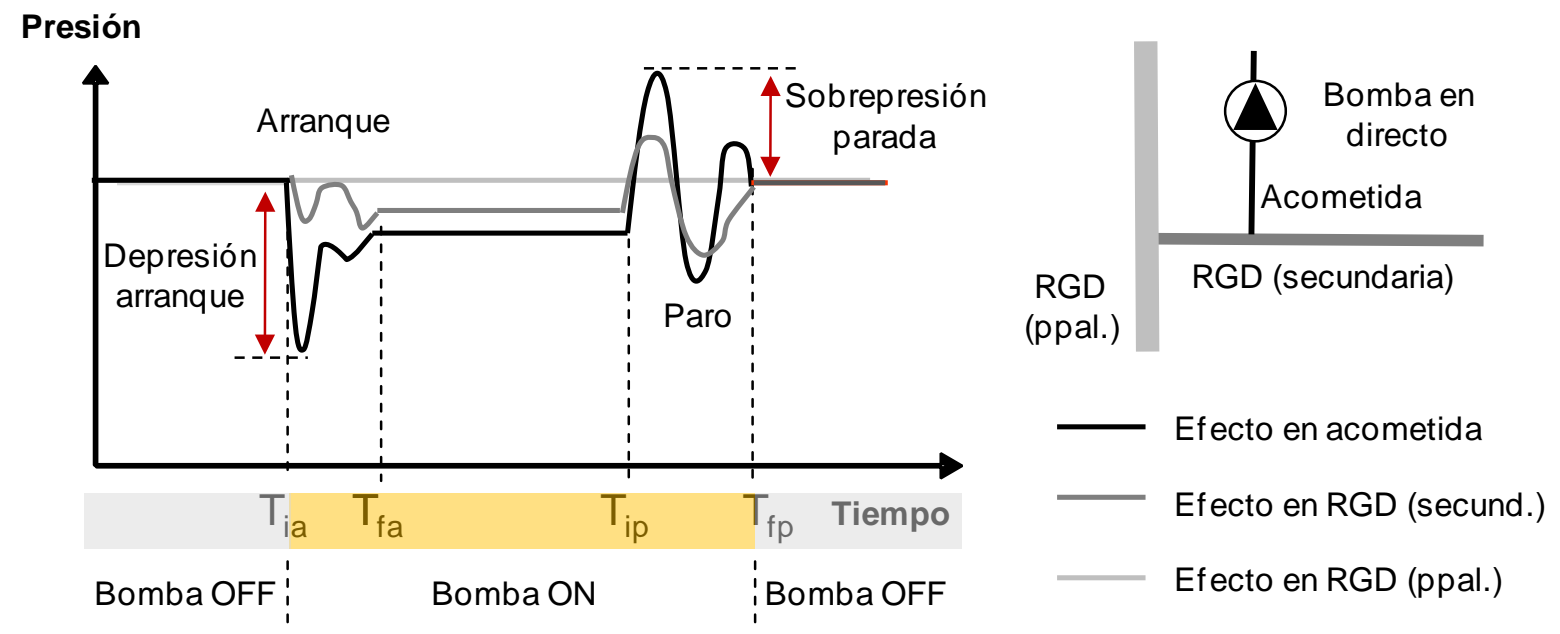

FIGURA C1-7. SIMPLIFICACIÓN DE LOS EFECTOS ORIGINADOS POR LA ASPIRACIÓN EN DIRECTO DE UNA BOMBA

Perturbación originada por el arranque del grupo

Durante el arranque del grupo de bombeo el fluido en la aspiración de la bomba experimenta una succión que deriva en una reducción puntual de la presión. Esta dinámica va arrastrando a las partículas de agua a las proximidades de la aspiración de la bomba, cambiando su estado de equilibrio y generando una onda de depresión que se transmite aguas arriba de la instalación, recorriendo en este desplazamiento el tubo de alimentación de la instalación interior y la acometida del edificio.

Una vez que la onda de perturbación alcanza el punto de conexión de la acometida se origina una transmisión de la onda hacia la RGD, pudiendo alterar las condiciones normales de funcionamiento que se dan en esta instalación, o incluso alterar la presión de entrega en instalaciones próximas. La transmisión de la onda a la RGD puede ser más o menos significativa, dependiendo de las características de la instalación y de la magnitud de la perturbación generada en el edificio. 
Del mismo modo, la perturbación que llega a la conexión de la acometida sufre la reflexión de la onda que viajará en sentido contrario, volviendo de nuevo hacia la instalación interior del edificio. En todo este trayecto se produce una atenuación de la onda de depresión, favorecida por la disipación de energía en los elementos de la instalación interior, con la correspondiente reducción de la magnitud de la perturbación.

Esta perturbación puede originar una caída notable de la presión en el punto de aspiración de la bomba (punto donde se registra el valor más bajo respecto al resto de conducción de alimentación), con la correspondiente posibilidad de colapso de alguna tubería, o incluso disparar los elementos de protección que impiden el funcionamiento en seco de las bombas (presostato de mínima), originando una secuencia de arranques y paros consecutivos que podrían impedir el normal suministro o dañar los componentes de la instalación.

En cuanto a la duración del fenómeno (periodo comprendido desde el inicio de la alimentación eléctrica del motor, hasta el establecimiento de la depresión para el funcionamiento a velocidad nominal del grupo), cabe comentar que va a influir directamente en el posible solapamiento de efectos en instalaciones contiguas, ya que si esta duración es elevada pueden coincidir de forma simultánea los arranques de varios grupos, y en tal caso, la coexistencia de varias ondas perturbadoras. La magnitud de la perturbación y el alcance de la misma están condicionados a las características tanto de la instalación interior como de la red general de distribución, siendo en cualquier caso más desfavorable aquellos puntos situados próximos a la aspiración del grupo.

Perturbación originada durante el régimen permanente del grupo

Después del arranque del grupo de presión y, cuando éste ha alcanzado condiciones de régimen (función del tiempo de estabilización del transitorio de arranque), éste continúa detrayendo caudal de la red y manteniendo una caída de presión asociada a las pérdidas de carga que se dan en el tramo. El caudal máximo trasegado por la bomba durante este periodo es próximo al caudal de cálculo necesario en la instalación, y dada una velocidad de diseño, el diámetro de la conducción debe limitar las pérdidas originadas. Esta componente también se verá afectada por las pérdidas de carga asociada a los diferentes elementos instalados en el tramo.

La depresión originada durante este periodo, si bien es mucho más reducida en magnitud que la correspondiente al arranque del grupo, puede limitar la posibilidad de conexión en directo de grupos de presión, ya que la caída de presión en régimen permanente puede alcanzar valores elevados por un infradimensionado de la instalación interior, o por una reducida capacidad de la red general (téngase en cuenta la función de laminación que realiza el depósito atmosférico y su efecto sobre el caudal detraído). 
En instalaciones con conexión indirecta la válvula de control de llenado fija el caudal detraído de la red para cada nivel de agua en el depósito, y por tanto es posible reducir sensiblemente las alteraciones de presión respecto a la situación anterior (sin perder de vista que una mala selección de este elemento puede inducir depresiones incluso superiores a las originadas por el arranque de una bomba).

\section{Perturbación originada por la parada del grupo}

El paro del grupo de presión, bien durante el funcionamiento normal, o bien debido a un fallo eléctrico, provoca una sobrepresión puntual en el punto de aspiración de la bomba similar a la derivada del cierre rápido de una válvula. Esta sobrepresión se origina a medida que las partículas del agua se ven frenadas por la obstrucción del paso que genera el paro de la bomba, y es más sensible cuando entran en juego mayores masas de agua en movimiento junto con maniobras más rápidas de parada. El tiempo de paro de la bomba (periodo comprendido desde la reducción del caudal trasegado hasta su completa anulación), está directamente relacionado con la inercia del conjunto motor más bomba hidráulica bajo las características de operación propias de la instalación, ya que una vez que cesa la alimentación eléctrica a la bomba ésta no bloquea inmediatamente el paso del agua.

Ante este fenómeno, la onda de sobrepresión generada se propaga aguas arriba del foco perturbador, alcanzando la RGD. Si bien una depresión puede poner en riesgo el normal suministro de una instalación, el caso de la sobrepresión el efecto derivado es el inverso al anterior, ya que principalmente aumenta la presión en los diferentes puntos del tramo.

Aunque en el entorno residencial la magnitud de esta sobrepresión no suele originar problemas dado que las paradas de los grupos como se ha comentado no son instantáneas, y el valor de las velocidades que entran en juego no son elevadas en los instantes de parada (generalmente se programa una regulación escalonada, y por tanto una parada desfasada de las bombas), en algunas situaciones la perturbación puede dar lugar a una sobrepresión que supere el timbraje de la conducción o los elementos conectados en la aspiración de la bomba. Y, aunque la protección ante este efecto tiene mayor trayectoria en instalaciones singulares, es conveniente recurrir a elementos que reduzcan las solicitaciones originadas en esta fase (por ejemplo un calderín presurizado o una válvula de alivio, ambos en las proximidades de la aspiración del grupo).

En el caso de bombas equipadas con variador, este fenómeno puede ser incluso imperceptible, ya que este tipo de controladores suelen programar una rampa de paro con frecuencias descendentes que origina una deceleración suave del flujo trasegado por la bomba, reduciendo significativamente las sobrepresiones alcanzadas. En el caso de parada por fallo en la alimentación eléctrica, además de las consideraciones 
comentadas anteriormente, la posibilidad de que la bomba gire a una velocidad inferior a la velocidad nominal favorece la aparición de caudales trasegamos menores, y por tanto, menores variaciones de presión en el transitorio.

\subsubsection{Aumento del caudal detraído de la red}

La aspiración indirecta generalmente conlleva la extracción de menores caudales de red en el caso de contar el depósito con una válvula de control de llenado tipo proporcional, ya que en esta situación la propia válvula regula el caudal detraído en función del nivel de agua en el depósito. Esta particularidad no siempre se cumple, ya que una mala selección e instalación de la válvula puede originar caudales muy elevados con depresiones incluso superiores a las originadas con grupos de presión. Esto muchas veces obliga a los instaladores a incorporar válvulas de reducido diámetro o tuberías de sección pequeña para introducir mayores pérdidas de carga al mismo tiempo que reducen el caudal detraído (no hay que perder de vista que estas válvulas operan a modo de descarga a la atmósfera cuando se encuentran abiertas).

Adicionalmente, la conexión en directo elimina la laminación de la demanda realizada por el depósito atmosférico. La laminación consigue reducir los picos máximos de caudal demandado y desfasar la demanda real en la instalación interior. De esta forma, sin el depósito podría aumentar la simultaneidad en los arranques de grupos de presión en determinados periodos, acrecentando la probabilidad de que varios funcionen de forma simultánea en una misma zona, principalmente en horas en las que la demanda sea mayor.

Estas alteraciones afectan principalmente al funcionamiento de la red general y por ello puede verse limitada su capacidad en aquellas situaciones en las que la red opere bajo una elevada carga, por ejemplo asociada a un crecimiento demográfico no seguido de una adecuación de las conducciones, o en zonas con una elevada dependencia estacional.

\subsubsection{Problemática en la regulación de la instalación}

Otro de los problemas que presenta la aspiración en directo es la variación del punto de funcionamiento del grupo de presión por el cambio de presión en red. Esto puede llevar a la bomba a operar en condiciones alejadas de la nominal.

Este efecto es principalmente importante en redes que presentan fluctuaciones significativas de presión a lo largo del día. En el caso de redes estabilizadas, o en aquéllas en las que la curva característica del grupo de presión presente un comportamiento aceptable ante variaciones controladas de presión de red, este efecto 
pierde relevancia, si bien se debe tener presente los puntos de funcionamiento que alcanza la bomba en las diferentes situaciones.

En el caso de instalaciones equipadas con bombas de velocidad variable, este fenómeno también puede presentar problemas, principalmente en lo referente al rendimiento de la bomba en los diferentes puntos de funcionamiento, o incluso el trabajo de la bomba en zonas en las que la curva no está completamente definida, fenómeno conocido coloquialmente como salida de curva. En esta línea la Figura C1-8 muestra dos respuestas para una misma bajada de presión en red y dos curvas de bombeo. Como puede observarse la variación de la curva resistente puede dar lugar a puntos de funcionamiento problemáticos.
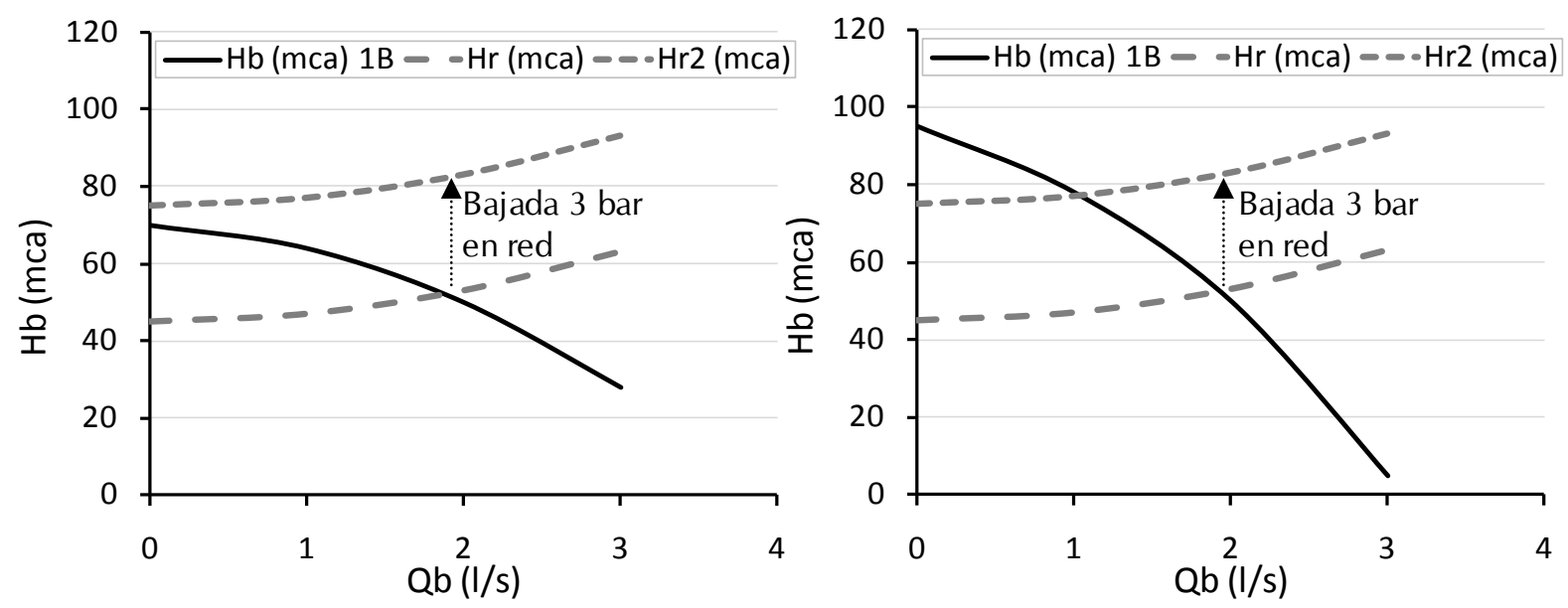

FIGURA C1-8. SALIDA DE CURVA (IZQDA.) Y RESPUESTA ACEPTABLE (DCHA.) ANTE UNA BAIADA DE PRESIÓN

Disminución de la presión en red

En la aspiración en directo, una disminución de la presión en red implica una mayor necesidad de altura de bombeo aportada por el grupo de presión para cumplir las necesidades de presión de la instalación. Los principales inconvenientes que presenta esta variación son el alejamiento del punto de funcionamiento nominal del grupo, la posible salida de la curva de la bomba, y la reducción del caudal aportado, pudiendo incluso poner en riesgo el correcto funcionamiento de la instalación por desajuste de los sensores de presión (efecto más importante en instalaciones que cuentan con varias bombas y en las que la regulación se realiza de forma escalonada).

En tal situación, podría resultar conveniente acudir a la aspiración indirecta a partir de un depósito atmosférico, o bien acudir a un mecanismo de control que garantice el correcto funcionamiento de la instalación, como por ejemplo un sistema de sondas que ajustara la actuación de los sensores en función de la presión disponible en la aspiración de la bomba, junto con algún controlador externo tipo PLC. 


\section{Aumento de la presión en red}

Por el contrario, un aumento de la presión en red implica una disminución de la altura de bombeo necesaria. Esta situación conlleva de modo similar al del caso anterior, a un alejamiento del punto nominal de funcionamiento, con la correspondiente reducción de la eficiencia del bombeo (reducción del rendimiento), pudiendo incluso tratar de operar en punto con altura y rendimiento en el bombeo excesivamente bajo.

En cualquier caso, la solución para esta situación resulta más sencilla, ya que es posible acudir a la instalación de una válvula reductora de presión aguas arriba del grupo para mantener una determinada presión constante, o una caída de presión variable con válvulas convencionales, de esta forma automáticamente se corregiría el exceso de presión sin alterar el funcionamiento del grupo.

\subsubsection{Influencia de las pérdidas menores en la aspiración en directo}

La conexión en directo de la bomba implica que la presión en la aspiración de ésta va a estar condicionada a las pérdidas de carga del tramo de aspiración. Esto significa que todas las pérdidas inducidas en el tramo van a influir en el funcionamiento de la bomba. En el caso de la aspiración indirecta este fenómeno prácticamente carece de relevancia, ya que al interponer un depósito atmosférico en la aspiración de la bomba ésta sólo se ve influida por la variación del nivel de agua en el mismo, junto con las pérdidas en los elementos de aspiración (mucho menos significativas por tratarse de tramos cortos y con pocos accesorios).

Por tanto, en la aspiración en directo se deberán tener presentes durante el dimensionado las pérdidas que se dan en el tramo de acometida, y principalmente en algunos elementos que inducen mayores pérdidas, como el filtro general (de instalación obligatoria según el CTE), el contador general y la válvula antirretorno. Del mismo modo, este efecto será mucho más significativo a medida que se suministran mayores caudales. Las pérdidas en la aspiración además de poder obligar a trabajar a la bomba en puntos de bajo rendimiento, pueden poner incluso en riesgo el correcto funcionamiento del grupo favoreciendo la aparición del fenómeno de cavitación.

\subsubsection{Imposibilidad de suministro con bajas presiones en red}

En algunos abastecimientos se originan fluctuaciones significativas de presión a diferentes horas del día, coincidiendo las horas de máxima demanda con instantes en los que la presión en red es más baja. Si la instalación cuenta con depósito de alimentación, es posible que el llenado de éste se realice a niveles de presión en los que la bomba no puede funcionar (por la entrada en funcionamiento del presostato de 
mínima), y por tanto garantizar el suministro en determinadas situaciones excepcionales. En cualquier caso, estas situaciones de funcionamiento no son convenientes en los abastecimientos, y deberían originarse sólo de forma esporádica y puntualmente como en situación de incendio, avería o rotura de alguna conducción.

\subsubsection{Pérdida del volumen de reserva}

Otra de las ventajas que aporta el almacenamiento de agua es la de disponer de un volumen de emergencia que pueda utilizarse en determinadas situaciones sin necesidad de dejar sin servicio a los usuarios. Esta situación contemplaría sólo pequeñas interrupciones como las derivadas de tareas de mantenimiento en la instalación o averías en la red general de corta duración.

\subsubsection{Resumen de las implicaciones de cada conexión}

La Tabla C1-2 muestra un resumen comparativo sobre la influencia que ejerce el tipo de conexión, según ésta sea en directo, o de forma indirecta a partir de la interposición de un depósito atmosférico.

TABLA C1-2. COMPARACIÓN DE LAS IMPLICACIONES SEGÚN EL TIPO DE CONEXIÓN

\begin{tabular}{lcc}
\hline ( $\uparrow$ aumenta; $\downarrow$ disminuye) & $\begin{array}{c}\text { Conexión } \\
\text { en directo }\end{array}$ & $\begin{array}{c}\text { Conexión } \\
\text { indirecta }\end{array}$ \\
\hline Característica & $\uparrow$ & $\downarrow$ \\
Alteraciones transitorias & $\downarrow$ & $\uparrow$ \\
Laminación del caudal de red & $\uparrow$ & $\downarrow$ \\
Conservación del recurso & $\downarrow$ & $\uparrow$ \\
Coste de la instalación & $\uparrow$ & $\downarrow$ \\
Eficiencia energética & $\uparrow$ & $\downarrow$ \\
Garantía de la calidad del & $\uparrow$ & $\downarrow$ \\
agua suministrada & $\uparrow$ & $\downarrow$ \\
Influencia de la caída de las pérdidas & & \\
en la instalación interior & $\uparrow$ & $\uparrow$ \\
Influencia variaciones en la red & & $\uparrow$ \\
(caudal, presión, continuidad) & $\downarrow$ & $\uparrow$ \\
Coste de mantenimiento & $\downarrow$ & $\downarrow$ \\
de la instalación & $\downarrow$ & $\downarrow$ \\
Ocupación de espacio en planta & $\downarrow$ & $\downarrow$ \\
Posibilidad de fraude & $\uparrow$ & $\downarrow$ \\
Dificultad de regulación & $\downarrow$ & $\downarrow$ \\
Rendimiento hidráulico & & $\downarrow$ \\
Reserva de volumen & & $\downarrow$ \\
\hline
\end{tabular}




\subsection{JUSTIFICACIÓN Y OBJETIVOS}

A la vista de la problemática asociada al uso de depósitos de almacenamiento atmosférico, principalmente en aquellos usos que interfieren en el suministro de agua dirigida al consumo humano, no es de extrañar el interés mostrado por empresas de abastecimiento para su eliminación. En esta línea se destaca el desarrollo del proyecto estatal CGL2005-03666 titulado: "Ordenación y valoración de estrategias orientadas a la progresiva eliminación de los depósitos de almacenamiento de los usuarios en los abastecimientos de agua urbanos", y los desarrollos realizados conjuntamente con el abastecimiento de la Ciudad de Sevilla (gestionado por la empresa municipal EMASESA), y cuyo propósito es establecer unas directrices para la eliminación de depósitos atmosféricos.

Como extensión a los desarrollos anteriores y, atendiendo a la magnitud del problema, el Comité Técnico de Normalización de AENOR CTN 149 (Ingeniería de Agua y en el que el doctorando participa activamente), ha considerado oportuno la inclusión de los resultados de la presente Tesis Doctoral en el contenido de la norma UNE 149202 (actualmente en desarrollo), para favorecer la eliminación gradual de depósitos en las instalaciones interiores, al mismo tiempo que se propicie la adopción de esquemas de conexión directa para su progresiva implementación.

La necesidad de proponer esquemas alternativos y el cambio significativo de operación que puede experimentar la red de suministro, precisa un análisis sobre la capacidad hidráulica de un tramo de red, y los fenómenos transitorios asociados al funcionamiento con conexión directa en la instalación interior. Estos resultados pueden servir para mejorar el conocimiento sobre las exigencias asociadas al uso de los diferentes esquemas de suministro, al mismo tiempo que orientan sobre la conveniencia de acudir a un determinado esquema en función de las características del edificio de la propia red. En esta línea, la materialización de los resultados en diferentes gráficas pueden aportar una herramienta de dimensionado complementaria a las comúnmente utilizadas.

Por otro lado se muestra un procedimiento para el análisis en régimen permanente de la capacidad de un sector de red, en el que se emplean de forma directa datos reales de consumo. La incorporación de este tipo de información en los modelos hidráulicos no es usual por la necesidad de una cuantía considerable de registros, y al mismo tiempo deben disponer de una resolución suficiente (en el análisis en régimen permanente se ha mantenido una discretización entre consumos de 10 segundos). Por el contrario, puede presentar una alternativa interesante a los procedimientos convencionales cuyos análisis suelen acudir a series sintéticas de demanda, o basarse en el establecimiento de caudales promedio demandados con una reducida resolución, próxima en muchas situaciones incluso a la hora. 


\subsection{ANTECEDENTES}

El análisis de la conexión directa en instalaciones interiores en el entorno de la edificación, aun siendo un problema palpable y con una considerable repercusión, no presenta una trayectoria importante, y principalmente se cuenta con recomendaciones establecidas en normas de referencia (tanto de carácter nacional como internacional), junto con contribuciones de algunas empresas de suministro de agua o empresas privadas. En esta línea se destaca la aportación de Corts en 1990 con el desarrollo de un estudio para la incorporación de un depósito auxiliar presurizable con ventosa en la aspiración de los equipos, y cuya utilización se promovió con la ampliación de las Normas Básicas para las instalaciones interiores de suministro de agua (NIA, 1990). Si bien su difusión no es significativa dado por un lado la necesidad de elevados volúmenes y la reducida fiabilidad de algunos componentes, presenta una alternativa interesante a los depósitos atmosféricos en aquellas situaciones en las que se originen fluctuaciones significativas en la presión de entrega de la compañía.

En el ámbito del análisis de la demanda urbana, íntimamente relacionado con la carga hidráulica de modelos, encontramos una extensa producción dentro de las cuales se destaca los primeros esfuerzos encaminados a la caracterización de la demanda de agua residencial desarrollados por Wells (1994), quien analizó estadísticamente los pulsos generados en viviendas proponiendo distribuciones de probabilidad para la intensidad, la duración y el volumen para los diferentes consumos medidos. En esta misma línea, Buchberger y Wu (1995) caracterizan el consumo en instalaciones interiores según pulsos rectangulares de Poisson derivados de un modelo estocástico definido por variables aleatorias, para posteriormente generar funciones de probabilidad que aportan una aproximación a los caudales punta que pueden darse en este tipo de instalaciones. Un año después, Buchberger y Wells (1996) aprueban algunas de las hipótesis tomadas para la caracterización de la demanda de agua residencial, validando la representación de los consumos como pulsos rectangulares aleatorios.

Posteriormente, en Buchberger y Lee (1999) se comprueba que la aplicación de la teoría de pulsos rectangulares de Poisson para la caracterización de la demanda de agua residencial es válida, demostrándose que los caudales de los pulsos son aditivos, requisito para asumir la validez del empleo de un proceso de pulsos rectangulares de Poisson para la caracterización de los usos residenciales del agua. En esta misma línea García (2003) y García et al. (2003) desarrolla un modelo estocástico para simular el comportamiento de los consumos domésticos de agua, suponiendo que los consumos se comportan como pulsos rectangulares de Poisson. Para ello se buscan formulaciones (funciones) para las tres variables: duración, intensidad y ocurrencia de pulsos. 
La disponibilidad de gran cantidad de datos de demanda de agua en el entorno residencial, y en aras a contribuir con la aportación de un procedimiento diferente y particularmente aplicado al estudio de las solicitaciones en la conexión directa, se optó por la utilización directa de esta información, siguiendo algunos desarrollos como los realizados por DeOreo et al. (1996) quién destacó la importancia de disponer de mediciones en viviendas en continuo, y su posible aplicación entre otros ámbitos en el campo de la identificación de usos. DeOreo en su estudio utilizó datos de consumo de viviendas y fue capaz de identificar el funcionamiento de hasta nueve aparatos diferentes. La utilización de datos de consumo de viviendas también fue llevado a cabo por Arregui F. (1998) en su Tesis Doctoral, en ella recoge las principales características de los datos de consumo utilizados en el estudio, y establece el procedimiento para la caracterización de las medidas de consumo de agua. Otros desarrollos como el primer libro publicado sobre el análisis de los usos residenciales del agua, "Residencial End Uses of Water" (Mayer et al., 1999), aporta datos específicos sobre consumo doméstico de agua, usos finales del consumo, influencia de factores ambientales y desarrolla un modelo de predicción de la demanda.

Respecto al análisis sobre la simultaneidad de la demanda para un conjunto de usuarios, se destacan las aportaciones de Arizmendi (1985), junto con los diferentes procedimientos de cálculo de caudales simultáneos establecidos en las normas nacionales e internacionales y que se detallan en el Anexo 3. Estimación de la demanda de agua en viviendas en el entorno residencial.

Respecto al estudio sobre la influencia de los depósitos atmosféricos sobre la calidad del agua y la problemática derivada de su utilización, también se cuenta con una amplia bibliografía asociada. Mayoritariamente los estudios se centran en los depósitos de almacenamiento de la red de distribución, principalmente enfocados en los modelos de mezcla más usuales en depósitos de grandes dimensiones, la cinética de los agentes desinfectantes, y a la dificultad que presenta la garantía de una concentración mínima de éstos (Rossman, 1993; Clark et al., 1996; Grayman et al., 1996; Grayman y Kirmeyer, 1999). Pero también encontramos contribuciones orientadas a los depósitos domiciliarios, cuya carga y descarga generalmente simultánea muestran un comportamiento ligeramente dispar que los depósitos de gran tamaño. En esta línea en Iglesias et al. (1998), se analiza la reducción de la concentración del agente desinfectante del agua con el aumento del tiempo de permanencia o retención de ésta en el depósito, junto con el efecto de modulación horaria en la demanda, y por tanto la dificultad de garantizar las condiciones mínimas de calidad exigidas por la normativa vigente. 
Por otro lado un estudio más reciente (Hassan y Ali, 2011), incluye la monitorización de la instalación de un edificio en el entorno residencial, estando equipado este edificio con depósitos atmosféricos. En este estudio se controla diferentes parámetros de calidad antes y después de los depósitos, y se establece una importante relación entre la duración de los periodos de llenado del depósito, y el correspondiente aumento de la concentración de desinfectante, al mismo tiempo que predice una considerable reducción del agente desinfectante (cloro en el caso del estudio) en periodos en los que la demanda es más baja y por tanto aumenta el tiempo de residencia del agua, posibilitando la contaminación del recurso en la propia instalación interior del edificio.

En el análisis de la problemática asociada a la utilización de depósitos en instalaciones interiores se destaca la contribución de Cobacho et al. (2007), en la media que se aporta una visión generalizada sobre las ventajas e inconvenientes de su uso, y se destaca la reducción del rendimiento global de la red por una menor capacidad de detectar los caudales bajos asociados a las válvulas de control de llenado. 


\subsection{ESTRUCTURA DEL DOCUMENTO}

La Tesis se ha estructurado en cinco partes bien diferenciadas. Primeramente con el presente capítulo se ha tratado de situar en contexto la problemática asociada a la utilización de depósitos atmosféricos en la instalación interior de edificios, avalada por los inconvenientes introducidos por su uso. Como se ha mostrado, algunos de estos inconvenientes son especialmente significativos en la medida que se almacena agua destinada al consumo humano, ya que este elemento propicia una falta de garantía de salubridad por la pérdida gradual de desinfectante. Al mismo tiempo se han descrito otros problemas que pueden adquirir una mayor o menor relevancia, y que en cualquier caso deben tenerse presentes. Adicionalmente, se han mostrado las ventajas de incorporar este elemento en la instalación interior, ventajas que muchas veces se convierten en necesidades al no disponer de una red con capacidad hidráulica suficiente, o por la severidad operativa inherente a los requerimientos del edificio.

En el Capítulo 2. Caracterización del modelo hidráulico de una red de distribución de agua, se presentan algunos fundamentos básicos para la elaboración del modelo de simulación de una red o sector de abastecimiento, en aras de analizar tanto la capacidad de la red como los requerimientos de funcionamiento de la instalación interior. De forma particularizada se describen las consideraciones tomadas para abordar este estudio, previa reflexión sobre la dificultad que presenta la modelación precisa del comportamiento global de la red. En la misma dirección se ha incluido los fundamentos de un análisis en régimen transitorio, encaminado a conocer la severidad operativa de los diferentes esquemas de conexión directa. Por tanto, sirva este capítulo como prólogo para el desarrollo de los capítulos posteriores.

Para el análisis de la capacidad de la red, y dada la alteración de su comportamiento cuando se adoptan esquemas con conexión indirecta, en el Capítulo 3. Análisis de los efectos de la conexión directa en régimen permanente se ha evaluado la respuesta de un sector de red bajo esta conexión. Para ello se han analizado las exigencias de los esquemas más comunes en los que se prescinde de depósito, mostrando una comparación de las solicitaciones asociadas a cada esquema. Al mismo tiempo se pone de manifiesto aquellas situaciones de funcionamiento más críticas, describiendo los escenarios de operación más desfavorables. Este capítulo contribuye a un mejor conocimiento de las capacidades de un sector de red función lógica de las características constructivas del mismo, y a la influencia ejercida por los esquemas adoptados en las instalaciones servidas. Como resultado se aportan unas gráficas sencillas que pueden ser útiles para un técnico en tareas de diseño y dimensionado de un tramo de red. Con todo ello, esta información orienta sobre las posibilidades de eliminación de los depósitos domiciliarios, y la selección del esquema alternativo más conveniente. 
Complementariamente y derivado de los efectos introducidos por los equipos de presión que prescinden de depósito atmosférico en el Capítulo 4. Análisis de los efectos de la conexión directa en régimen transitorio, se han analizado las exigencias asociadas al fenómeno transitorio tanto en la instalación interior del edificio como en las proximidades de éste. En esta línea, las variaciones bruscas de flujo provocadas por el funcionamiento de los grupos de presión generan perturbaciones que pueden poner en riesgo el normal suministro en la instalación. Al mismo tiempo los resultados de las simulaciones mostrarán la severidad operativa introducida por las bombas de velocidad fija, y la conveniencia de acudir a grupos equipados con variador de frecuencia. Un análisis de sensibilidad sobre la influencia de las variables que definen el modelo de simulación pondrá de manifiesto de nuevo aquellos escenarios de operación más rigurosos, y orientará sobre la posibilidad de adoptar una conexión directa bajo condiciones de funcionamiento menos severas.

Finalmente y dada la importancia de limitar las solicitaciones generadas por el equipo de presión en directo, en el Capítulo 5. Mecanismos de protección para la reducción de los efectos transitorios por la conexión directa se ha analizado la protección de la instalación en aras de reducir la magnitud de los efectos transitorios generados. Para ello, se ha evaluado las mejoras introducidas por la incorporación de un depósito hidroneumático en aspiración. Este elemento como se comprobará atenúa de forma significativa las solicitaciones cuando el grupo de presión aspira directamente de red, y puede ser un complemento perfecto al variador de frecuencia para reducir la severidad operativa de los grupos. Para ello se ha analizado en primera instancia cómo afectan las variables más importantes que intervienen en la instalación y principalmente en lo relacionado con la protección. Como resultado del análisis se propone un dimensionado que oriente al técnico a la hora de seleccionar la protección más conveniente en función de las características propias de cada instalación. 
Capítulo 2

\section{Caracterización del modelo hidráulico de una red de distribución de agua}




\subsection{INTRODUCCIÓN}

El suministro en cualquier tramo de una red de abastecimiento puede ser simulado a partir de su correspondiente modelo matemático, sin más que programar la estructura que representa los diferentes elementos que lo componen y sus condiciones normales de operación. Siguiendo esta premisa, el presente capítulo se centra en la elaboración de los modelos de simulación para aproximar el comportamiento hidráulico de un tramo de la red pública de suministro, así como el comportamiento de las instalaciones interiores de los edificios conectados a la red general, y de forma particularizada cuando éstas tienen carácter residencial.

El interés final perseguido es analizar las implicaciones asociadas a la conexión directa de las instalaciones interiores de los usuarios y la red general de distribución. En esta línea, es importante conocer la capacidad hidráulica de un tramo de red, y la respuesta que éste presenta cuando las instalaciones de los edificios prescinden de los depósitos atmosféricos de almacenamiento, condicionado principalmente por la problemática asociada a su uso.

Desde el punto de vista hidráulico, se ha discernido entre el comportamiento de la instalación en régimen permanente y régimen transitorio. En el primero de los casos, la simultaneidad en la demanda de diferentes usuarios altera la respuesta de un determinado sector, efecto mucho más sensible en la medida que las instalaciones interiores de los edificios cuentan con grupos de presión. Bajo esta configuración, el arranque simultáneo de varios grupos puede limitar la capacidad de la red, pudiendo incluso poner en riesgo el normal suministro de los usuarios. Por otro lado, en régimen transitorio es importante conocer los factores que favorecen el origen de perturbaciones en el interior de una instalación interior, y el grado de influencia de cada una de las variables implicadas en el desarrollo y posterior propagación de estos efectos al exterior del edificio.

En los capítulos posteriores se mostrarán los resultados obtenidos del análisis de cada uno de los modelos construidos, y concretamente cómo responde un sector de red a la conexión directa de las instalaciones interiores de los edificios. 


\subsection{CONCEPTO DE MODELO MATEMÁtICO DE UNA RED}

El modelo matemático de simulación aproxima el comportamiento real de una red hidráulica. Este modelo está formado por un conjunto de ecuaciones que, de forma simplificada tratan de representar los datos hidráulicos, geométricos y funcionales que caracterizan la red real y su respuesta.

Generalmente, la complejidad analítica asociada a la resolución del sistema de ecuaciones resultantes, precisa del apoyo de un sistema computacional capaz de desarrollar multitud de cálculos que aproximen la respuesta del modelo, es por ello que esta herramienta adquiere un destacado protagonismo tal como ya apuntaba Walski en 1983, evidenciando que el programa computacional no deja de ser una parte indispensable para el desarrollo del modelo matemático de un sistema de distribución. Siguiendo el flujo usual de información a partir de unos datos de partida del sistema, el programa aproxima el valor de las principales variables de cálculo (Figura C2-1).

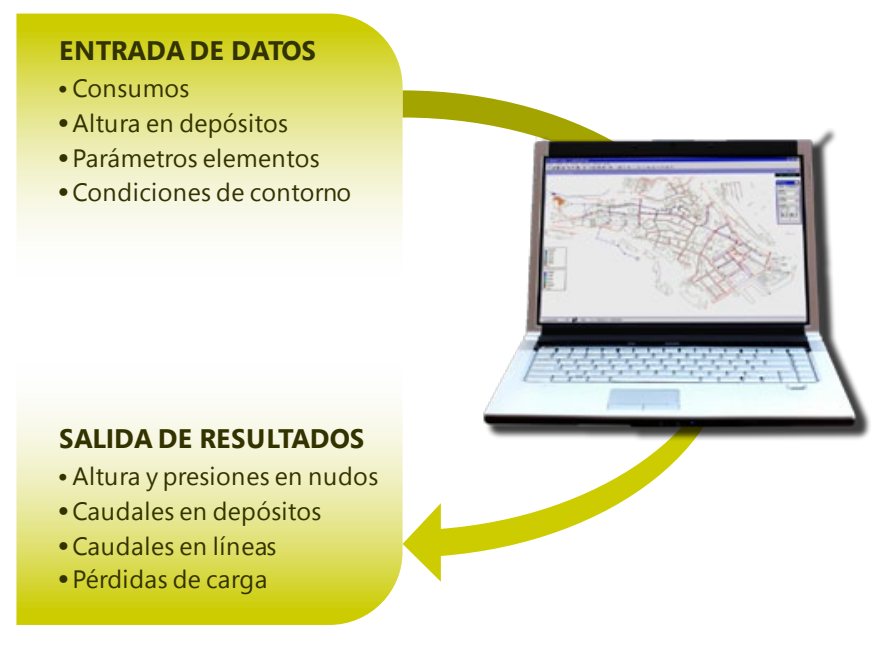

FIGURA C2-1. FLUJO DE DATOS EN LA SIMULACIÓN DEL MODELO MATEMÁTICO DE UNA RED

En cualquier caso, se debe tener presente que la respuesta aportada por un modelo matemático no deja de ser una aproximación a la situación real, y que ésta distará en mayor o menor medida de la realidad en función principalmente de la calidad de los datos de partida, y de la precisión con la que son modelados cada uno de los elementos y propiedades del sistema. En esta línea, no puede dejar de mencionarse la dificultad que presenta la obtención de algunas propiedades del modelo, no sólo por el coste asociado, también debido otros factores como el tiempo de dedicación, o incluso la disponibilidad de información en el abastecimiento. Por todo ello, resulta conveniente establecer unas pautas básicas sobre la elaboración del modelo, y principalmente en aras de obtener un equilibrio entre el esfuerzo necesario y la aproximación perseguida. 


\subsubsection{Clasificación de los modelos de análisis dinámicos}

Durante el suministro en una red de distribución, tiene lugar una alteración de las diferentes variables del sistema condicionadas por los cambios que se originan en los diferentes puntos; por un lado, los usuarios modifican sus pautas de consumo, y por otro lado la red varía sus características funcionales para adaptarse a dichos cambios, es por ello que la variable temporal juega un papel determinante en la resolución de los modelos matemáticos.

Atendiendo a la variable temporal, comúnmente se clasifican los modelos de análisis en modelos estáticos y dinámicos. Este último grupo a su vez se clasifica en (Abreu et al, 2012):

- Modelo no inerciales (modelos cuasi estáticos)

- Modelos inerciales

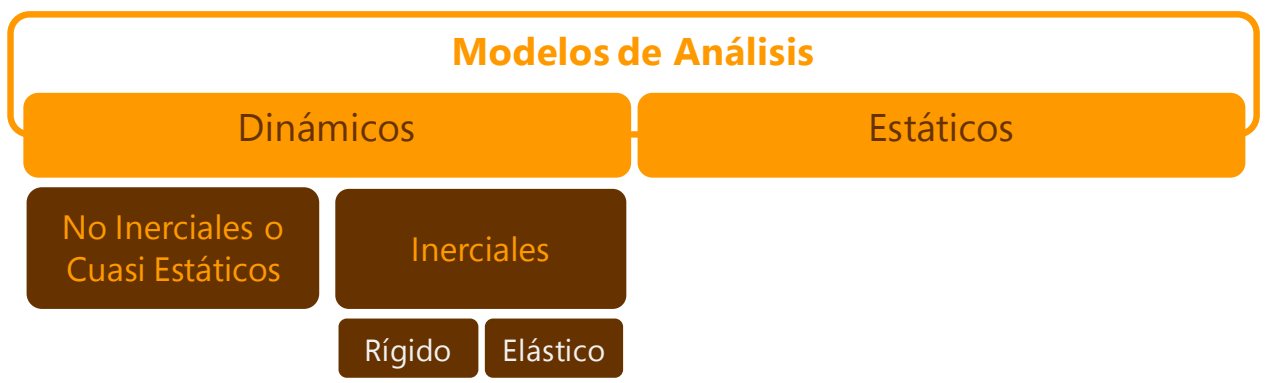

FIGURA C2-2. ClasificaCIÓN GENERAL DE LOS MODELOS DE ANÁLISIS

\subsubsection{Modelos no inerciales}

Los modelos no inerciales se caracterizan por una variación lenta de las variables significativas del flujo, principalmente los caudales y presiones. Como característica particular dentro de los modelos de análisis dinámicos, este tipo de modelo desprecia la inercia y elasticidad de los flujos y elementos del sistema, comportándose como una sucesión de modelos estáticos en los que las variaciones que suceden no se consideran significativas, es por ello que estos modelos también son conocido como modelos cuasiestáticos (Iglesias, 2001).

De forma generalizada, la utilización de estos modelos predomina en el análisis de las redes hidráulicas de los abastecimientos, ya que aporta una aproximación al comportamiento de la red con un predominio del flujo en régimen permanente, dado que las variaciones temporales no son significativas. Del mismo modo, su caracterización no es excesivamente compleja, debido principalmente a que las condiciones de contorno varían de forma lenta. 


\subsubsection{Modelos inerciales}

Esta clasificación engloba todos aquellos modelos cuyas características funcionales precisan de incrementos de tiempo de cálculo más reducidos que en el caso anterior. Concretamente, la consideración de los términos inerciales del sistema hace necesario acudir a menores incrementos temporales para contemplar los flujos energéticos asociados a los cambios de velocidad que se dan en el sistema. Bajo estas condiciones de operación, las variaciones de las condiciones de contorno pueden ser significativas, y por tanto la respuesta aportada por un modelo no inercial podría resultar insuficiente.

La utilización de modelos inerciales en abastecimientos no es representativa en comparación con los modelos de carácter cuasi-estático. Su uso suele limitarse al estudio de instalaciones con tamaño más reducido, pero con entidad suficiente como para valorar situaciones derivadas de perturbaciones en su funcionamiento. Estas perturbaciones, como pudiera ser la resultante de un fallo de alimentación eléctrica a un grupo de presión o del cierre instantáneo de un elemento de control, originan un régimen transitorio que altera las condiciones normales de funcionamiento (generalmente el equilibrio inicial en el sistema), y es en esta situación en la que los cambios temporales de las variables son significativos, y pueden originar variaciones de velocidad y presión con valores muy alejados de los correspondientes al régimen permanente.

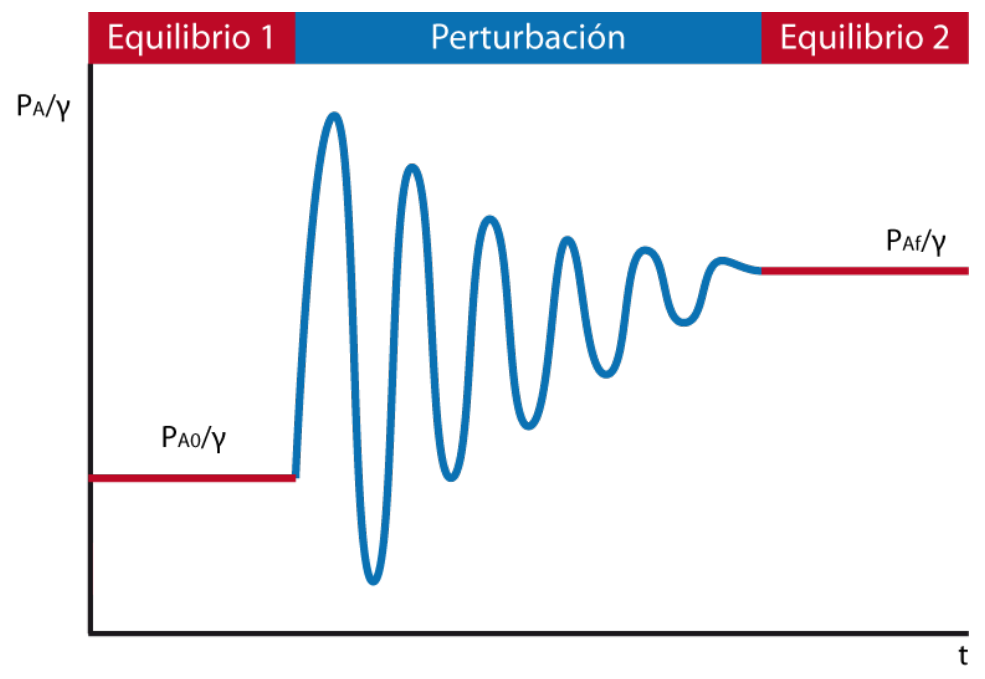

FIGURA C2-3. ETAPAS DE UN FENÓMENO TRANSITORIO

A su vez, los modelos inerciales se clasifican en modelos elásticos y modelos rígidos en función de la consideración o no de la variación de la energía elástica almacenada en el fluido y en las paredes de las tuberías. 


\section{Modelo rígido}

El modelo rígido, también conocido como modelo de oscilación en masa, considera una variación rápida de las variables del sistema, pero no contempla las implicaciones asociadas a la elasticidad de los materiales y la del fluido. En estos modelos, las variaciones de presión no llegan a modificar significativamente la energía elástica almacenada en el fluido, y por ello esta energía no es considerada.

\section{Modelo elástico}

Por el contrario, el modelo elástico (también conocido como golpe de ariete) considera la compresibilidad del agua y la elasticidad de las paredes de las conducciones. Bajo algunas condiciones de funcionamiento, la violencia de la perturbación introducida en el sistema genera cambios de presión importantes, variando significativamente la energía elástica almacenada en el fluido y en la tubería.

Como puede entenderse, la brusquedad con la que se originan los cambios en el sistema origina una variación temporal de las diferentes variables muy rápida, siendo preciso disponer de información sobre cómo varían las condiciones de contorno del sistema en cada uno de los intervalos de cálculo. Esta característica hace necesaria una capacidad computacional nada despreciable, mucho más significativa en la medida que aumenta la complejidad de la red y se reduce el intervalo temporal de cálculo.

\subsubsection{Etapas en la elaboración de un modelo}

La complejidad que adquiere la elaboración del modelo de una red hace necesario establecer diferentes etapas que encaminen hacia su consecución. Del mismo modo, es necesario reflexionar sobre la continua evolución del mismo, y sobre las necesarias tareas de seguimiento que deben hacerse para adaptarlo progresivamente a los continuos cambios. En adelante, y de forma simplificada se indican algunas de las consideraciones asociadas a las etapas de elaboración del modelo hidráulico de una red.

\subsubsection{Definición del alcance del modelo}

Como bien es conocido, la fase previa para la elaboración de un modelo de simulación trata de establecer el alcance u objetivo último que se persigue con el modelo. Una buena definición de esta fase facilita en gran medida la distribución de recursos para abordar su elaboración, por el contrario una definición insuficiente compromete la confianza de los resultados derivados. En esta fase se decide qué modelo de análisis utilizar de los descritos anteriormente, y las características básicas de la red a modelar. 


\subsubsection{Recopilación de la información sobre los elementos del modelo}

Una vez definido el objeto del modelo se precisa la obtención de información suficiente para caracterizarlo, para ello se debe recopilar los datos de los diferentes elementos de la red, e información técnica complementaria. En esta fase no puede dejar de mencionarse la importancia de disponer de datos fiables, es por ello que la posibilidad de involucrar a los técnicos de la red adquiere una relevancia nada despreciable. En cualquier caso, debe tenerse presente que la bondad de los resultado obtenidos con el modelo va a depender en gran medida de la calidad de los datos de partida.

La información básica a obtener trata de fijar las propiedades y condiciones de contorno asociadas a cada elemento del sistema, tratando de definir físicamente con ésta su comportamiento. Como es lógico, la información para cada modelo de análisis puede ser diferente, y por lo general aquellos modelos cuyas variaciones temporales son más significativas precisarán una caracterización a mayor nivel de detalle. Por el contrario, una excesiva caracterización puede derivar en un consumo de recursos elevado, sin que su aporte práctico sea significativo.

En esta fase, suele ser de gran ayuda la disponibilidad de un modelo GIS o similar que integre planos de la red, y una base de datos con la información asociada a los diferentes elementos. A continuación se detalla la información básica para la elaboración de un modelo.

Información sobre la topología de la red

La topología tiene en cuenta los elementos que forman parte de la red y la interconexión que tiene lugar entre ellos. Una decisión importante que debe tomarse en este punto es el nivel de detalle con el que se desea describir la red. De manera general se tiene que tener presente que una red muy simplificada puede aportar valores aproximados. Por el contrario, elevados niveles de detalle pueden aproximar en mayor medida la respuesta (aunque esta afirmación no siempre es cierta), pero con un consumo mayor de recursos.

Respecto a la tipología de red, entre las configuraciones más comunes es posible trabajar con redes ramificadas, malladas o una combinación de ambas disposiciones. La primera se caracteriza por tener definido el sentido de circulación del caudal en cada tubería, mientras que en una red mallada el agua puede circular de forma continuada en un sentido, en otro, o variando éste en función de sus características operativas. 


\section{Información sobre la topografía de la red}

La topografía permite definir la localización concreta de cada elemento del modelo, y en esta línea obtener la información para la caracterización de la elevación de los elementos quizá adquiera una complejidad adicional.

En muchos programas de simulación lo topografía está materializada a partir de los nudos del sistema, siendo una de las propiedades básicas de éstos las coordenadas que definen su ubicación. Estos nudos a su vez sirven como base de conexión del conjunto de elementos de la red, generalmente líneas, de forma que dotan al conjunto de información básica sobre su localización.

En cuanto a los nudos del sistema, debe tenerse presente que no se trata de elementos físicos como tal, como pudiera ser una tubería o una válvula, y por ende muchas veces tienen difícil materialización. De forma generalizada, la localización de estos elementos se resuelve en las propias conexiones entre componentes de la red, por ejemplo en la conexión de un depósito con una tubería de salida. Del mismo modo, también suelen hacerse coincidir con algunos cambios de las propiedades de las líneas: cambio de material o sección, cambios de dirección de las tuberías, etc.

Información sobre las conducciones

Como se ha comentado, el modelo de una red está formado por un conjunto de nudos y líneas. En este último caso, la línea característica es la tubería, al mismo tiempo que se trata del elemento mayoritario en cualquier red de abastecimiento. Generalmente la información básica que se debe disponer de una tubería es su diámetro, longitud, espesor, conectividad, rugosidad, pérdida de carga (continua y localizada), y adicionalmente, su material, edad, etc. Respecto a la longitud de la tubería, ésta indirectamente viene determinada por la topografía de los nudos extremos asociados.

La determinación exacta del diámetro interior de una conducción no siempre es inmediata; por un lado debido a la existencia de diferentes materiales y normas de diseño, y por otro lado debido al no despreciable efecto del paso del tiempo y las deposiciones en la cara interna de la conducción. Si a estos factores se une la dificultad de medir o explorar el interior de la tubería, se entiende la lógica incertidumbre a la hora de caracterizar este parámetro. La reducción de la sección útil de una conducción no sería un problema si la influencia con otras variables no se viera afectada (como puede ser las pérdidas de carga de la conducción). En cualquier caso, el error asociado a la incertidumbre en la determinación del diámetro no es tan significativo como el error en la estimación de otras condiciones de contorno del sistema, es por ello que el ajuste de la mayoría de modelos no requiere de una precisión excesiva en su determinación. 
Adicionalmente es necesario definir la fórmula de pérdidas de carga que incorpora el modelo de resolución y el coeficiente de rugosidad asociado. Entre las expresiones de cálculo de pérdidas más comunes se destaca el uso de la expresión propuesta por Darcy Weisbach (1875), ya que suele ser la que mejor aproximación aporta en redes a presión. Respecto al coeficiente de rugosidad, no es posible establecer un valor que resulte válido para un amplio espectro de funcionamiento derivado del cambio de diámetro y caudal circulante (Martínez, 2005), por ello es conveniente acudir a valores estimados propuestos por diferentes autores, y que en todo caso son función del material instalado.

TABLA C2-1. COEFICIENTES DE RUGOSIDAD PARA TUBERÍAS NUEVAS (ROSSMAN, 1993)

\begin{tabular}{cccc}
\hline Material & $\begin{array}{c}\text { Hazen-Williams } \boldsymbol{C} \\
\text { (adimensional) }\end{array}$ & $\begin{array}{c}\text { Darcy-Weisbach } \boldsymbol{\varepsilon} \\
(\mathbf{m m})\end{array}$ & $\begin{array}{c}\text { Manning's } \boldsymbol{n} \\
\text { (adimensional) }\end{array}$ \\
\hline Hierro colado & $130-140$ & 0,26 & $0,012-0,015$ \\
$\begin{array}{c}\text { Hormigón o } \\
\text { revestido } \\
\text { Hierro }\end{array}$ & $120-140$ & $0,3-3$ & $0,012-0,017$ \\
galvanizado & 120 & 0,15 & $0,015-0,017$ \\
\hline Plástico & $140-150$ & 0,0015 & $0,011-0,015$ \\
\hline Acero & $140-150$ & 0,046 & $0,015-0,017$ \\
\hline
\end{tabular}

En la medida que se trata de resolver el modelo de análisis con mayor dependencia de la variable temporal será necesario adquirir más información sobre la conducción, y concretamente sobre el material y espesor de ésta. En régimen transitorio, el material de la tubería condiciona la velocidad con la que las ondas se transmiten tras una perturbación, y en mayor medida si se considera el comportamiento elástico de los materiales.

Información sobre los puntos de captación y almacenamiento

Otro elemento existente en toda red de suministro es el punto de captación del recurso, o los puntos de almacenamiento de éste. Generalmente suelen ser pozos de los que se extrae el agua mediante grupos de presión, o directamente depósitos donde ésta es almacenada previa distribución. La información necesaria de estos elementos es referente a su elevación, forma, dimensiones, fluctuaciones de nivel si las hubiera, existencia de dispositivos de regulación y control, etc.

La modelización más común de estos elementos se realiza a partir de un depósito de nivel variable, del que se debe conocer los niveles de variación del agua y sus dimensiones. También puede ser útil la modelación a partir de un depósito de grandes dimensiones (GD), considerando que la variación del nivel del agua es despreciable durante la simulación. Este procedimiento es muy usual en modelos simplificados tanto en régimen transitorio como en permanente. 
Información sobre los equipos de presión

Gran número de instalaciones disponen de equipos de bombeo. Estos elementos aportan al fluido una energía adicional para aumentar su presión. El equipo de bombeo está formado por un conjunto de elementos que no sólo abarca el grupo moto-bomba, a su vez suelen considerarse otros elementos adicionales como los sistemas de regulación, dispositivos de control y elementos de protección. Por ello, es conveniente adquirir información en su conjunto en aras de disponer de conocimiento suficiente sobre su modo de operación.

De forma general, la información básica necesaria para caracterizar el funcionamiento de un equipo de presión se limita al conocimiento de sus curvas características (curva de altura, curva de potencia y curva de rendimiento), y el modo de operación (maniobra de arranque y paro, régimen de giro, tiempo de funcionamiento, etc.). De forma similar al envejecimiento de las conducciones, los grupos de presión pueden ver variadas sus curvas de funcionamiento teóricas a lo largo de su vida útil, por ello en algunas situaciones es necesario realizar ensayos específicos para tener convenientemente caracterizado su comportamiento.

En ocasiones, la obtención de las características funcionales de los elementos del equipo de presión puede ser compleja, por ello es usual acudir a las curvas características a partir de un punto de funcionamiento conocido (definido por una altura y caudal aportado por la bomba) o a curvas adimensionales. Si bien la precisión del procedimiento no es elevada, puede aportar una aproximación suficiente en algunas situaciones. En esta línea, es usual que el fabricante no disponga de información asociada al comportamiento de la bomba en cualquier región de trabajo, y por ello es necesario acudir a curvas universales como las propuestas por Marchal, Flesch y Suter (1965), y por Thorley y Chaudry (1996). Este procedimiento adquiere una mayor relevancia cuando se trata de modelar una instalación en régimen transitorio en el que alguna modificación en el sistema puede llevar al grupo a trabajar fuera del primer cuadrante.

De forma similar, y en el caso de utilizar modelos de análisis dinámicos, el proceso de arranque y paro de las bombas condiciona en gran medida la evolución de la respuesta del sistema, ya que este elemento puede ser fuente de perturbaciones, y por ello es necesario disponer de información asociada a estas fases de funcionamiento, junto con el valor de la inercia del grupo. Sin duda se trata de una información compleja de obtener y que rara vez es facilitada por los fabricantes, pero al mismo tiempo necesaria para realizar una correcta modelación en estas situaciones. 
Información sobre los elementos de regulación

La utilización de válvulas automáticas es cada vez más habitual en los actuales sistemas hidráulicos, favorecido principalmente por un mayor conocimiento de la capacidad de regulación y control que aporta este tipo de elementos, junto con los desarrollos técnicos realizados por los diferentes fabricantes. Es por ello que debe ser convenientemente modelado su funcionamiento, ya que en caso contrario la respuesta simulada puede alejarse significativamente de la realidad.

De estos elementos es necesario disponer de información tan básica como puede ser la determinación del tipo de válvula. La materialización de diferentes tipos funcionales con un mismo cuerpo a partir de la modificación del pilotaje, puede originar diferentes comportamientos dificultando por ello su identificación. Generalmente se suele clasificar las válvulas dependiendo de la función que realizan en el sistema donde están instaladas (Garcia-Serra et al., 1996):

- Válvulas de control de variables fluidas (también denominadas válvulas automáticas e hidráulicas). Funcionan generalmente de manera autónoma tratando de mantener una determinada consigna (presión, caudal, pérdida de carga, nivel, etc.). Se incluye bajo esta clasificación algunas válvulas como las reductoras de presión, sostenedoras, limitadoras de caudal, válvulas de control de llenado, etc.

- Válvulas de operación. Realizan las operaciones usuales de mantenimiento y operación de una instalación, como el corte del servicio o la reposición de éste. Dentro de este grupo se incluyen las válvulas de seccionamiento, las llaves de purga, los hidrantes de riego o incendio, etc.

- Válvulas de regulación. El principal cometido de este tipo de válvulas es realizar labores de regulación de un sistema, actuando directamente sobre el flujo que circula por su interior, con la variación de la sección de paso. Es usual acudir a las válvulas de operación para realizar esta función.

- Válvulas de protección. Su entrada en funcionamiento es ocasional y derivada en algunos casos de una situación anómala en la instalación, como pudiera ser una presión excesiva, un flujo en sentido diferente al usual, etc. Dentro de esta clasificación se incluirían las válvulas de retención, las válvulas limitadoras de presión (alivio), anticipadoras de onda, ventosas, desconectores, etc.

Además de la tipología es importante conocer su diámetro, característica resistente, consigna y su ley de actuación (directamente asociada al tipo de válvula; regulación, reductora de presión, sostenedora, etc.). Del mismo modo, conviene disponer de información adicional como marca y modelo, evolución temporal de su posición de regulación, evolución temporal de su consigna de regulación (si es automática), material, edad, estado de conservación, historial de averías, etc. 


\subsubsection{Carga hidráulica del modelo}

Sin duda una de las labores más complejas en la elaboración del modelo matemático de una red se basa en la conocida como carga hidráulica del modelo. Esta fase persigue asignar la demanda de agua a cada uno de los usos, al mismo tiempo que presta atención a todos aquellos flujos de agua asociados al volumen incontrolado del sistema.

Demanda de los diferentes usuarios

Se trata de una información básica sobre los volúmenes y pautas de consumo asociadas a los diferentes usos. De manera general la demanda de una vivienda o nudo del modelo puede ser caracterizada por el valor de su demanda base $\bar{q}$ y de su modulación temporal.

\section{Demanda base}

Se trata del volumen de agua consumido por un uso por unidad de tiempo. Dependiendo del nivel de detalle con el que se modela la red o sector de ésta, puede coincidir con el consumo de un único uso, o de varios usos asignados a un mismo punto (piénsese en la modelación a nivel de acometida de edificio, Figura C2-12, en la que se asigna a dicho punto todo el consumo originado aguas abajo). En el caso extremo, algunos modelos tratan de asignar la demanda a nivel de punto de consumo.

Para la caracterización de un único usuario es posible acudir a su historial de consumo formado por registros volumétricos, el análisis estadístico de los volúmenes consumidos puede aportar una buena aproximación de la demanda base asociada (esta metodología está especialmente indicada para la caracterización de la demanda de grandes consumidores). Si no se dispone de datos históricos de consumo es necesario acudir a su estimación. Para ello, es posible acudir a expresiones asociadas a análisis estadísticos de otros usos similares, y que se utilizan en el dimensionado de instalaciones. En esta línea gran número de autores y documentos técnicos proponen valores y expresiones asociados a las demandas usuales en función del tipo de usuario (doméstico, industrial, oficinas, etc.).

Cuando varios usuarios están conectados en un mismo punto de la red, es necesario considerar la lógica simultaneidad en los consumos. Ésta tiene en cuenta la probabilidad de que varios consumidores o usos puedan concurrir en el tiempo. Una muestra de ello, y particularizado para viviendas en el ámbito urbano, se describe en el Anexo 3, donde se comparan diferentes procedimientos seguidos para la estimación de la demanda de un conjunto de usuarios domésticos, al mismo tiempo que se propone una expresión para el cálculo de esta demanda en función del tamaño del edificio. 
Modulación temporal de la demanda

Como puede intuirse, la demanda no tiene por qué ser estática y puede presentar una lógica variación temporal. Es el caso de la demanda de agua doméstica para una misma vivienda, su variación se ve comúnmente alterada en función de parámetros como la hora del día, el día de la semana o incluso la estación del año. La forma más sencilla de caracterizar la modulación de la demanda parte de la utilización de curvas patrón para diferentes usos, resultado de diferentes estudios estadísticos desarrollados.

Las curvas de modulación están formadas por coeficientes temporales de forma que, para un nudo $i$ del modelo el caudal demandado se obtiene como producto del coeficiente de modulación correspondiente y el caudal medio del nudo $\bar{q}_{i}$. Por tanto la demanda temporal $q(t)$ resultante se evalúa según:

$$
q_{i}(t)=k_{i}(t) \cdot \bar{q}_{i}
$$

Donde $t$ representa el conjunto de intervalos temporales en los que se ha dicretizado el periodo (atendiendo a un incremento temporal de cálculo $\Delta t$ ).

Por otro lado, el volumen total consumido en un periodo, por ejemplo un día, discretizado en $n$ intervalos es evaluado por la Ec. 2. Téngase en cuenta que en función de la resolución considerada $n$ puede valer 24 (para un intervalo horario), 86400 (para un intervalo de 1 segundo), etc.:

$$
V_{d}=\bar{q}_{i} \cdot \sum_{t=1}^{n} k_{i}(t)
$$

Del mismo modo, algunos autores han enfocado sus esfuerzos en la determinación de modelos estocásticos para la generación de series sintéticas de consumo. Entre éstos se destaca el modelo de Poisson de pulsos rectangulares (Wells, 1994; Buchberger y Wells, 1996), a partir del cual es posible representar un proceso de series de ocurrencias de pulsos de consumo con un instante de inicio determinado $\tau_{\text {i, }}$ cada uno de los cuales tiene asociado una duración $T_{i}$, e intensidad independientes $l_{i}$ y aleatorias. De esta forma, el consumo total a lo largo del día $V_{d}$ vendría representado por una secuencia de $C_{j}$ pulsos rectangulares tal como aproxima siguiente expresión:

$$
V_{d}=\sum_{j=1}^{C_{i}} T_{i}\left(\tau_{i}\right) \cdot l_{i}\left(\tau_{i}\right)
$$


Continuando con los desarrollos anteriores, en García et al. (2003) se muestra una metodología para la obtención de series temporales de demanda a partir de la superposición de pulsos de consumo en el ámbito doméstico.
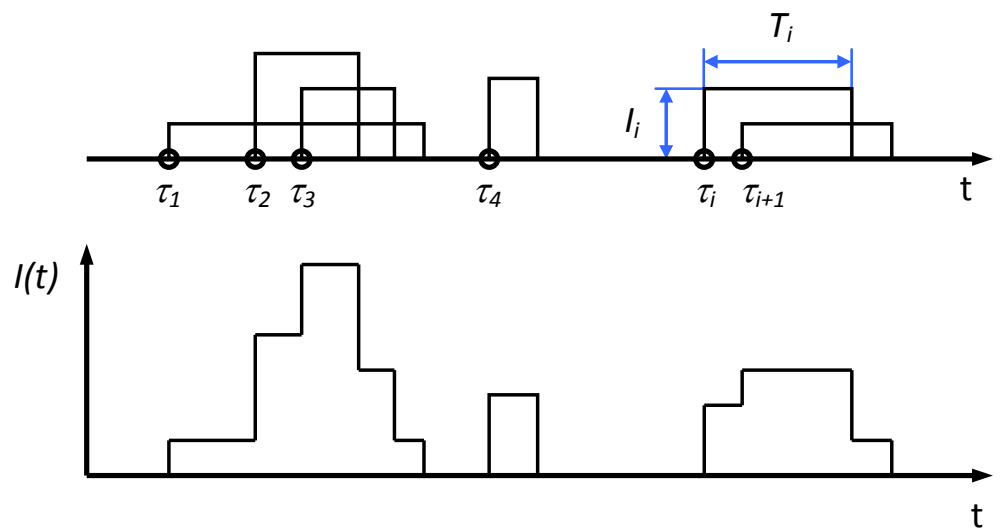

FIGURA C2-4. DisCRETIZACIÓN DE USOS A PARTIR DEL MODELO DE POISSON DE PULSOS RECTANGULARES

Otro procedimiento para contemplar la modulación temporal de la demanda consiste en utilizar directamente datos reales de consumo con suficiente discretización temporal. La carga directa del modelo con esta información para un conjunto de usuarios puede aportar una precisión elevada de la respuesta del modelo, pero generalmente la disponibilidad de esta información junto con la carga computacional asociada, limita la adopción de este procedimiento.

Asignación de la demanda

Una vez determinados estos datos característicos de consumo es necesario asignarlos convenientemente en el modelo. En esta línea existen diferentes propuestas, siendo las más usuales la asignación punto a punto, la asignación por mallas del modelo, la asignación por derivaciones de líneas y nudos (Vela, 1988; López, 1994) y la asignación de consumos unitarios por calle (García-Serra, 1988).

\section{Volumen incontrolado}

Bajo esta designación algunos autores incluyen tanto las fugas reales en el sistema (pérdidas reales asociadas al volumen de agua fugado debido a defectos en la red), como las pérdidas aparentes (caudal consumido no medido), asociadas estas últimas a errores de los elementos de contabilización y consumos no medidos por no disponer de sistema de contabilización, por ejemplo flujos por hidrantes, o tomas ilegales, entre otras (Almandoz et al., 2005). En la mayoría de modelaciones estos volúmenes deben ser considerados ya que en ambos casos el agua es inyectada en el sistema y pueden presentar valores nada despreciables. 
Fugas reales

Las fugas reales suelen representar el porcentaje más alto del volumen incontrolado, y su determinación no es sencilla si bien existen diferentes métodos que tratan de aproximar sus valores, siendo el procedimiento más utilizado la metodología de análisis de caudales mínimos nocturnos (UK Water Industry, 1994). Esta metodología estima el volumen fugado a partir de la respuesta en periodos de mínima demanda.

En cuanto a la asignación del volumen fugado, el procedimiento de modelación más usual trata de repartir el volumen bien de forma homogénea en todos los puntos de consumo, o de forma particularizada en función de las características de cada zona (antigüedad de las conducciones, presión media, número de acometidas, etc.).

En otras situaciones es posible acudir a expresiones que determinen de forma aproximada el valor del caudal fugado Qfuga, si bien su utilización precisa del conocimiento de la zona concreta en la que se origina ésta y sus características dimensionales.

$$
Q_{\text {fuga }}=C_{d} \cdot A \cdot \sqrt{2 \cdot g \cdot h}
$$

Siendo, para unidades de caudal en el Sistema Internacional $\left(\mathrm{m}^{3} / \mathrm{s}\right)$ :

$C_{d}$ : coeficiente de descarga.

A: sección de la fuga $\left(\mathrm{m}^{2}\right)$.

g: aceleración de la gravedad $\left(\mathrm{m} / \mathrm{s}^{2}\right)$.

$h$ : altura piezométrica en el interior de la tubería (mca).

Pérdidas aparentes

En el caso de las pérdidas aparentes, éstas pueden representar un volumen significativo que puede estar comprendido en la horquilla $0-10 \%$ del volumen inyectado en redes de distribución de agua urbana (Farley y Trow, 2003), si bien pueden alcanzar valores mucho mayores. Como puede entenderse, la determinación e incluso asignación de estas pérdidas no resulta sencilla.

En el caso de los volúmenes de pérdida asociados a los errores de contador es posible mayorar el caudal asociado a la demanda de los diferentes usos, en función por ejemplo de las características del contador si éstas son conocidas. Otra posibilidad es considerarlas directamente como fugas reales del sistema. El procedimiento más usual para la evaluación de esta componente parte de la obtención del patrón de demanda de los usuarios (evalúa el peso de cada rango de caudales sobre el volumen total demandado), junto con las curvas características del parque de contadores (evalúa el error asociado a cada rango de caudales), para realizar una estimación de las pérdidas asociadas. 
2.2.2.4 Resumen sobre la información necesaria para la caracterización de un modelo

De manera general se resume la información necesaria para la elaboración del modelo de una red. En cualquier caso se debe tener presente que el alcance perseguido condicionará la necesidad de obtener más o menos información al respecto.

TABLA C2-2. INFORMACIÓN GENERAL PARA LA CARACTERIZACIÓN DE LOS ELEMENTOS DE UN MODELO

\begin{tabular}{|c|c|}
\hline Componente & Propiedades \\
\hline Nudos & $\begin{array}{c}\text { Topología (conectividad) } \\
\text { Topografía }\end{array}$ \\
\hline Tuberías & $\begin{array}{c}\text { Topología } \\
\text { Diámetro } \\
\text { Longitud } \\
\text { Coeficiente de rugosidad } \\
\text { Pérdidas localizadas } \\
\text { Material } \\
\text { Espesor }\end{array}$ \\
\hline Bombas & $\begin{array}{c}\text { Topología } \\
\text { Curvas características } \\
\text { Información sobre su regulación } \\
\text { Control del funcionamiento } \\
\text { Información sobre la fase de arranque } \\
\text { Información sobre la fase de paro } \\
\text { Inercia }\end{array}$ \\
\hline Válvulas & $\begin{array}{c}\text { Topología } \\
\text { Tipo (VRP, VSP, VLQ, etc.) } \\
\text { Consigna y su evolución } \\
\text { Característica resistente } \\
\text { Diámetro } \\
\text { Características de operación }\end{array}$ \\
\hline Depósitos & $\begin{array}{l}\text { Cota del fondo } \\
\text { Rango de variación del nivel de agua } \\
\text { Forma y dimensiones } \\
\text { Sistema de control de llenado }\end{array}$ \\
\hline $\begin{array}{c}\text { Carga } \\
\text { hidráulica }\end{array}$ & $\begin{array}{c}\text { Demandas } \\
\text { Tipo/s de uso/s } \\
\text { Modulación de las demandas } \\
\text { Fugas } \\
\text { Localización }\end{array}$ \\
\hline
\end{tabular}




\subsubsection{Calibración de un modelo}

La calibración de un modelo trata de comparar las condiciones reales de funcionamiento con las teóricas obtenidas con el modelo de simulación. Para ello, es necesario contar con registros medidos en campo sobre las variables más significativas. De forma general, en la medida que se disponga de más información sobre el modelo, y concretamente sobre su respuesta bajo diferentes condiciones de funcionamiento, será posible conseguir un mejor ajuste.

En la calibración se modifican algunos de los parámetros que caracterizan el modelo, entre ellos los asociados a la carga hidráulica suelen ser los que mayor incertidumbre presentan (Bhave, 1988), aunque también es usual alterar otros como las rugosidades de las conducciones, las pérdidas localizadas, las cotas de los nudos, o incluso el valor de los diámetros interiores. Generalmente esta etapa de elaboración del modelo suele realizarse en varias fases, éstas se describen a continuación.

\subsubsection{Obtención de mediciones en campo}

Se deben realizar diferentes campañas de medición directamente en la instalación que se ha modelado, generalmente la información recogida se limita a los caudales y presiones que se originan en diferentes puntos, aunque también se puede incluir otros registros para un conocimiento más detallado de algunas zonas del modelo, como pudiera ser estaciones de bombeo o puntos de captación y almacenamiento. Complementariamente, conviene acudir a registros históricos de funcionamiento, y extender el muestreo en diferentes periodos de forma que se disponga de información bajo distintas condiciones de operación.

Respecto a la cantidad de información a registrar dependerá de las características particulares de la red, y especialmente de la homogeneidad de la misma, entendida ésta como la existencia dentro de la red de zonas cuyas características funcionales presentan una marcada igualdad. Algunos autores proponen una cuantificación de los puntos de registro comprendida entre el 15 y $20 \%$ de los nudos del modelo (Allen, 1987).

La decisión de dónde ubicar los puntos de registro adquiere una complejidad adicional, ya que además de los puntos característicos del sistema (puntos de inyección, puntos próximos a grandes consumidores o zonas singulares), es preciso determinar otros puntos que ayuden a ajustar el modelo. En esta línea, el conocimiento de la red adquiere una notoriedad importante, ya que puede aportar información sobre la posibilidad de definir áreas con comportamientos similares. Como complemento, es posible acudir a diferentes técnicas de optimización que mejoran la eficiencia a la hora de establecer puntos de muestreo (Bush y Uber, 1998). 


\subsubsection{Evaluación del modelo}

Una vez se dispone de registros reales de funcionamiento se evalúa la discrepancia existente entre la respuesta real de la red y la aportada por el modelo. En esta fase se advierte de los funcionamientos anómalos asociados a un defecto en la caracterización de elementos, como pueda ser el nivel de operación de un equipo de presión, o los errores en la edición de tuberías o conexiones.

En un segundo nivel se valora el error absoluto o relativo del caudal y presión en los puntos característicos del sistema, para ello es conveniente fijar el grado de ajuste perseguido en la calibración. En algunos casos se toma como desviaciones de referencia en torno al 5 y 10\% para modelos de análisis estáticos (Water Research Center, 1989), pero en todo caso el valor máximo fijado para este error promedio depende de las características particulares de cada modelo de simulación.

Esta medida también aporta el conocimiento sobre la incertidumbre asociada al modelo, indispensable a la hora de tomar decisiones siguiendo los resultados obtenidos con éste. Téngase en cuenta que el conocimiento de las limitaciones es un valor añadido en la fiabilidad del mismo.

\subsubsection{Ajuste del modelo}

En el ajuste del modelo se realiza una nueva edición de aquellos elementos y propiedades de la red que no han sido convenientemente caracterizados. De forma similar a la evaluación del modelo, el ajuste se realiza en dos niveles; un primer nivel trata de ajustar los defectos más importantes introducidos en la modelación (conexiones, modo de regulación, diámetros, etc.), y un segundo nivel persigue aproximar en mayor medida los resultados del modelo (principalmente caudal y presión).

Es quizá este segundo nivel el que adquiere una mayor complejidad. El ajuste preciso de las variables requiere como es lógico de un conocimiento muy detallado de la red, situación que rara vez es alcanzable, principalmente en lo referente a la carga hidráulica por la incertidumbre asociada, tanto en el conocimiento exacto de los datos de partida como en su edición.

Además de editar con mayor detalle los elementos de la red (principalmente en aquellas zonas en las que existe una mayor discrepancia), los parámetros que usualmente suelen alterarse son: la rugosidad de las tuberías, las pérdidas localizadas, las demandas de los usuarios y los caudales de fuga. Para el desarrollo de esta fase es necesario acudir a un proceso en el que se modifican las características mencionadas de forma iterativa. 


\subsubsection{Ajuste fino del modelo}

Tras diferentes iteraciones para el ajuste del modelo se entra en una dinámica que persigue reducir los errores de éste, se trata de la fase del ajuste fino, sin que exista una frontera bien definida entre esta fase y la anterior. En el desarrollo de esta fase debe tenerse presente la complejidad en el ajuste dada la incertidumbre asociada a la caracterización de los elementos, junto con las simplificaciones realizadas del modelo.

En el ajuste fino es importante conocer el grado de implicación de cada variable, caracterizando el grado de influencia de su modificación. Un análisis de sensibilidad puede orientar sobre las variables a modificar y el grado de dependencia de las mismas. Para el desarrollo de esta fase es común acudir al método de prueba y error, aunque también se cuenta con diferentes técnicas de optimización que tratan de minimizar una función objetivo sujeta a una serie de restricciones (Meredith D., 1983; García-Serra, 1988; Lansey, 1988; Ormsbee y Chase, 1988; Ormsbee y Lingireddy, 2000).

\subsubsection{Mantenimiento del modelo}

Del mismo modo que las características de la red cambian con el paso del tiempo (averías, renovaciones, ampliaciones en el servicio, envejecimiento de los elementos, etc.), es necesario mantener una calibración continua de la red a partir de la actualización de la información de los elementos que van cambiando, junto a la realización de diferentes campañas de medición que permitan chequear el estado del sistema de forma periódica.

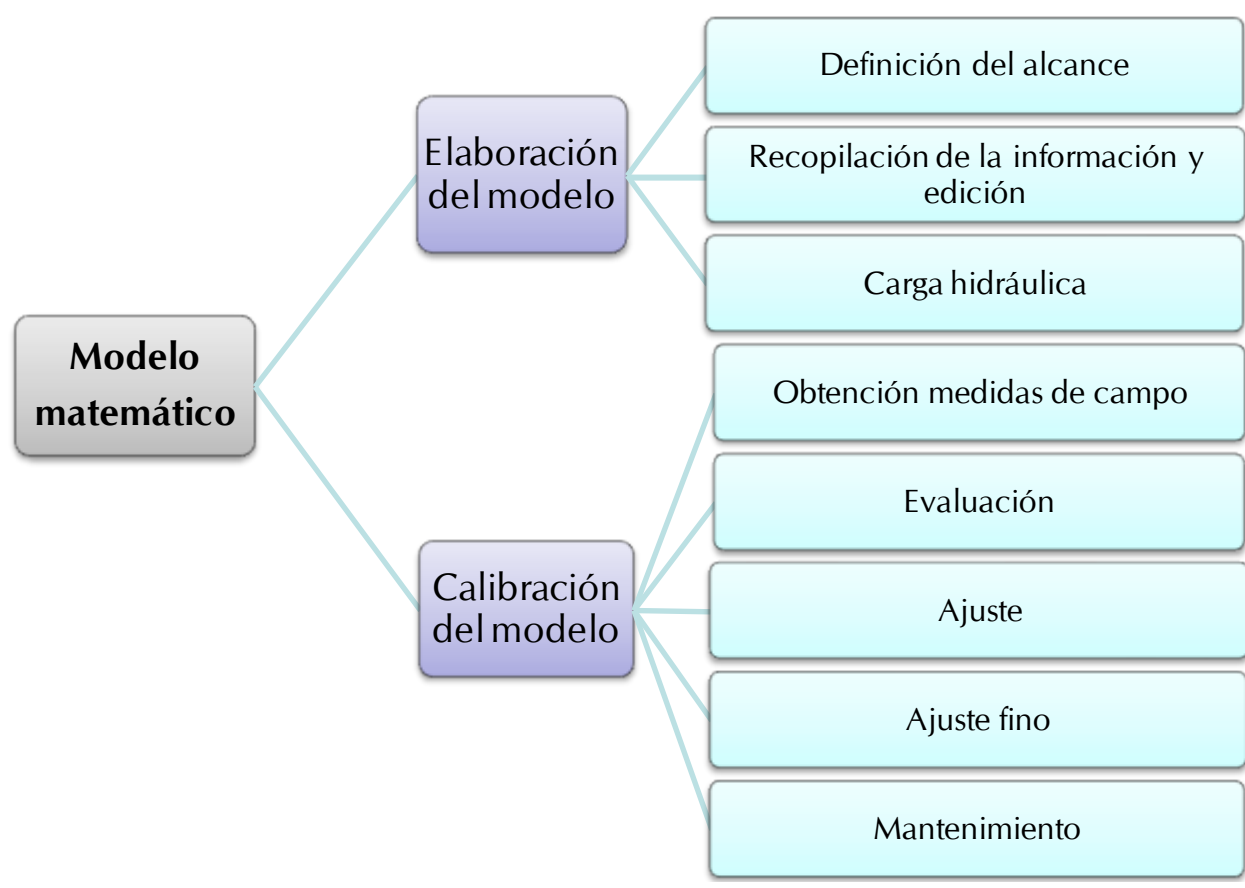

FIGURA C2-5. FLUJO PARA LA ADECUACIÓN DEL MODELO MATEMÁTICO DE UNA RED 


\subsection{EJEMPLO DE CARACTERIZACIÓN DEL MODELO HIDRÁULICO DE UN SECTOR DE RED PARA SU ANÁLISIS EN RÉGIMEN PERMANENTE}

\subsubsection{Descripción general del procedimiento desarrollado}

Introducidas las consideraciones generales asociadas a la elaboración del modelo hidráulico de una red, a continuación se describen las hipótesis seguidas para la construcción del modelo de simulación para el análisis en régimen permanente. Con este análisis se persigue evaluar las exigencias asociadas a la conexión en directo de las acometidas de los edificios, como una primera exploración para comprobar los efectos derivados de la eliminación de los depósitos atmosféricos de las instalaciones.

Como es lógico, para elaborar un modelo generalista es necesario establecer una serie de simplificaciones sobre el modelo real, de forma que los resultados obtenidos aporten una aproximación de los efectos asociados a la aspiración en directo. En esta línea se ha tratado de analizar un sector de red que suministra a un conjunto de edificios. El sector modelado bien podría coincidir con una determinada calle de mayor o menor entidad, en la que coexisten diferentes usuarios en el ámbito residencial conectados a través de sus respectivas acometidas (Figura C2-6).

Bajo diferentes escenarios de operación, los resultados mostrarán la capacidad del sector para funcionar bajo una conexión directa, atendiendo a las condiciones reales de suministro, a la influencia de las principales variables constructivas que lo caracterizan, así como a la implicación sobre la simultaneidad en el consumo.

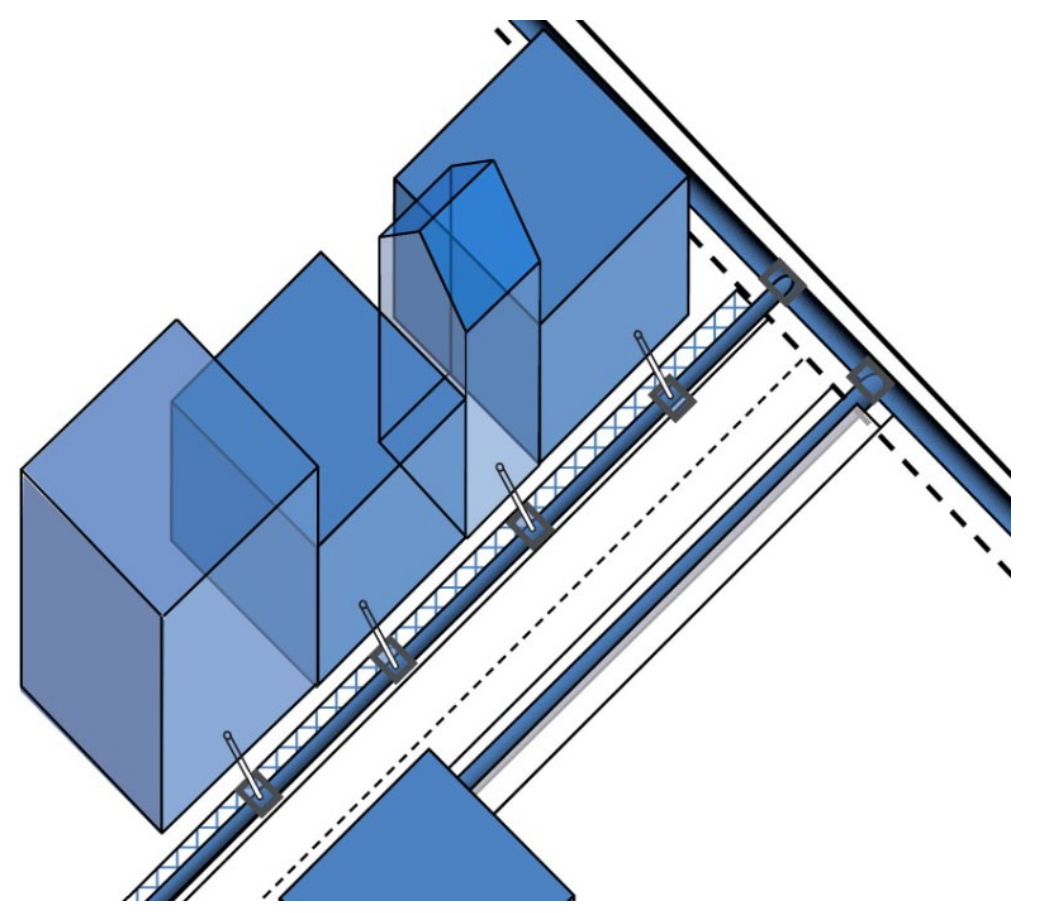

FIGURA C2-6. ESQUEMA DE UNA RED DE DISTRIBUCIÓN EN SUS INMEDIACIONES AL TRAMO DE ACOMETIDA 
Las simulaciones realizadas utilizan el modelo de cálculo del programa hidráulico Epanet, y se apoyan en un entorno de programación de Visual Basic (VB), sirviendo de plataforma de conexión la herramienta Toolkit de Epanet. A partir de este entorno es posible modificar sistemáticamente las propiedades de los elementos y construir los mencionados escenarios de cálculo. Para la carga hidráulica de los consumidores se conecta el modelo con una base de datos que incorpora datos reales de consumo con una resolución de 10 segundos, obteniendo la carga de 1 hora asociada a un hipotético conjunto de edificios del sector. Una vez construido un escenario se realiza la simulación para obtener la respuesta del mismo, y el grado de implicación de cada variable del modelo.

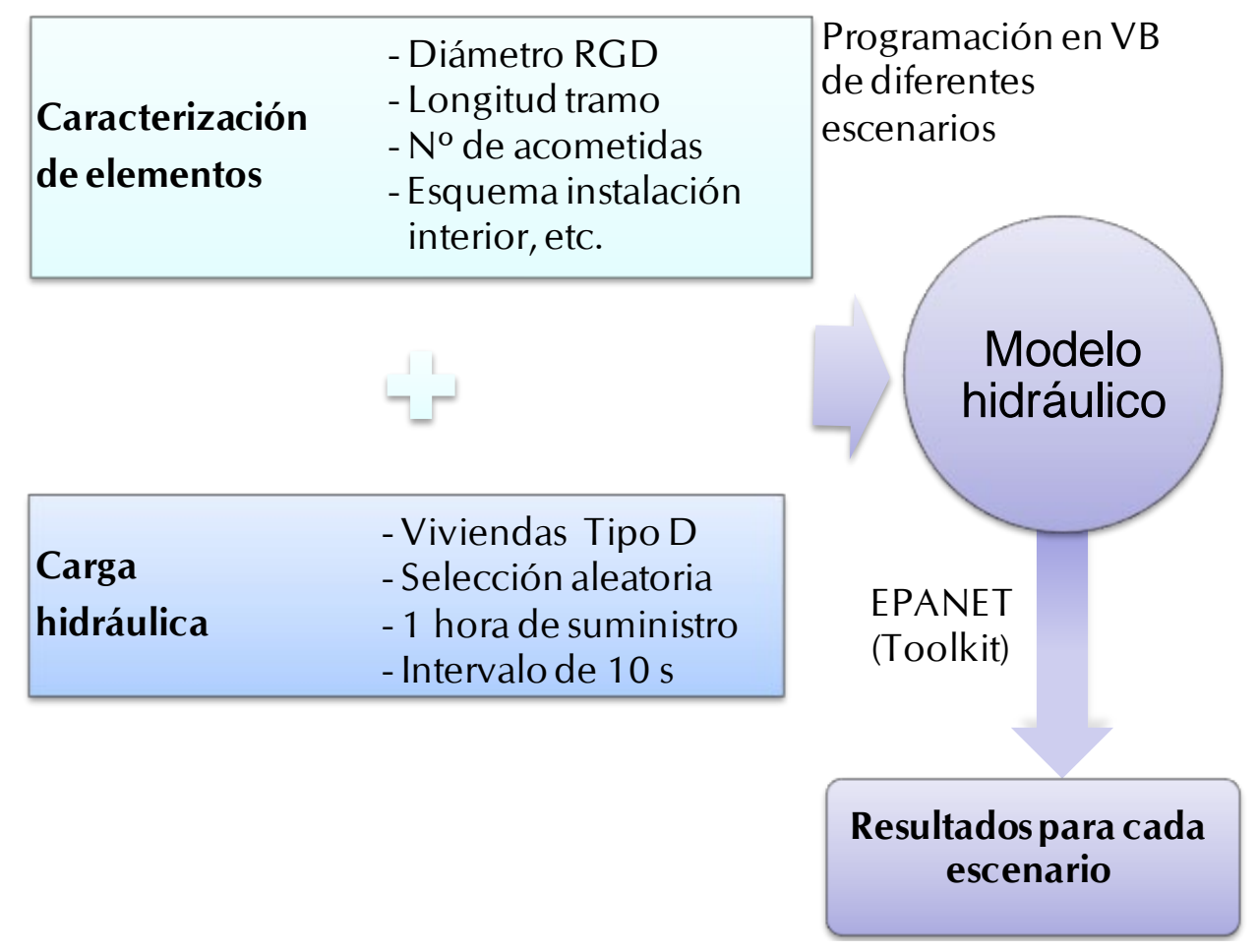

FIGURA C2-7. RESUMEN DEL PROCEDIMIENTO REALIZADO

El interés aportado por el procedimiento propuesto se basa en la posibilidad de alterar reiteradamente las propiedades del modelo, y así construir diferentes escenarios de cálculo. Adicionalmente posibilita asignar la carga hidráulica utilizando datos reales de consumo.

A continuación se muestra las consideraciones tomadas para la elaboración de los modelos de simulación. En cualquier caso, en el Anexo 1 se puede encontrar más información sobre los tramos que forman parte del estudio, y las características básicas de éstos. 


\subsubsection{Caracterización de la red general de distribución}

La conducción principal considerada en el modelo representa el tramo de la red general de distribución (RGD) más inmediato a los edificios, y se corresponde con el conjunto de tuberías que discurren por una o varias calles de la red y a las que se conectan las diferentes acometidas de los edificios suministrados.

El tramo queda delimitado entre un nudo inicial no, coincidente con el nudo de conexión a una tubería de mayor entidad y de la que se conocen las principales propiedades físicas e hidráulicas, y otro final $n_{j}$ (Figura C2-8). El nudo final puede simplificar una prolongación de la red si aguas abajo del mismo existen más zonas de consumo. El nivel de detalle optado fija la carga hidráulica del modelo directamente sobre los nudos que representan las acometidas.

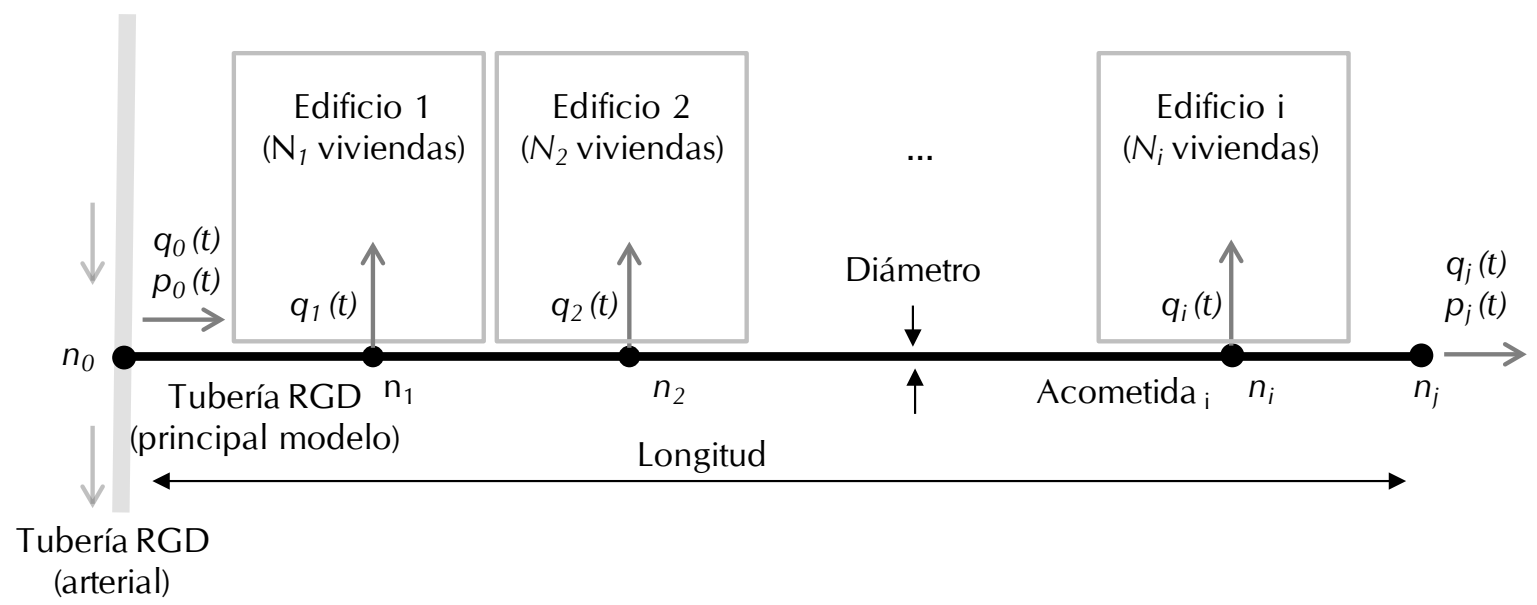

FIGURA C2-8. REPRESENTACIÓN ESQUEMÁTICA DEL SECTOR DE RED MODELADO

El esquema representativo del sector está definido a partir de sus características físicas (longitudes parciales de las conducciones, diámetros interiores de las tuberías, materiales empleados, cotas, etc.), y a partir de los diferentes caudales (por un lado los caudales de consumo asociados a cada acometida $q_{i}(t)$, función del número de viviendas $N_{i}(t)$ del edificio i) y por otro lado los caudales por los nudos extremos del modelo).

Para analizar las solicitaciones de la instalación bajo diferentes características constructivas y de consumo, se comprobará la caída de presión que tiene lugar en el sector evaluada ésta como diferencia entre la presión en el nudo de entrada, y el nudo final de tramo. Esta caída de presión es función de la presión $p_{i}(t)$ en los nudos correspondientes.

\subsubsection{Conducción principal del tramo}

Las propiedades de la conducción dependen del sector modelado. En el caso concreto del análisis realizado, éstas pueden ser programadas durante el proceso de 
construcción del modelo permitiendo de esta forma construir diferentes escenarios. Si se pretende simular un sector concreto, es posible conocer las características físicas de esta conducción (o conducciones) con una elevada precisión.

Respecto a la longitud de la conducción principal, ésta es suma de las longitudes parciales de cada una de las conducciones que forman el sector, pudiéndose incluso trabajar con una longitud equivalente de tubería (para la consideración de las pérdidas menores). Al mismo tiempo, el tamaño total de la conducción está delimitado por un nudo de entrada y otro de salida convenientemente caracterizados en plano, función de la extensión del modelo elaborado.

La segmentación de la conducción principal se asocia a la ubicación de los nudos correspondientes a las acometidas. Un parámetro importante asociado es la densidad de acometida, variable que muestra el número de acometidas por unidad de longitud. En el modelo desarrollado se programan indirectamente diferentes densidades para analizar la influencia que esta variable presenta en la respuesta del tramo. Una mayor densidad podría derivar en unas mayores solicitaciones, ya que un arranque simultáneo de grupos de bombeo de velocidad fija puede causar un descenso de la presión en la conducción pública, efecto que quizá no se hubiera originado bajo otra distribución menos exigente.

El diámetro interior de la conducción principal debe introducirse con suficiente precisión en el modelo. Su determinación tiene sentido a este nivel de detalle dada la reducida extensión del tramo. De forma general, en las simulaciones realizadas se mantiene un valor constante para toda la conducción principal, al mismo tiempo que se programan diferentes diámetros interiores en aras de comprobar la respuesta de cada uno. Se ha acudido a valores comerciales de tuberías de polietileno ya que es uno de los materiales más comunes en este tramo de la red general.

Respecto a la caracterización de las pérdidas de carga en la conducción, se ha acudido a la expresión de Darcy Weisbach, y se ha fijado un coeficiente de rugosidad promedio de $0,1 \mathrm{~mm}$, téngase en cuenta que es un valor razonable en condiciones normales de operación de una red, principalmente en el caso de tuberías con cierta edad, y teniendo presente que con el modelo se persigue una aproximación de la respuesta.

\subsubsection{Punto de entrada del tramo}

El nudo de entrada de agua en el sector no se materializa en un punto de la red del que se conocen sus características normales de funcionamiento, y que se puede hacer coincidir con la conexión entre dos conducciones de igual o mayor entidad, o simplemente en un punto determinado de la tubería. 
La modelación de este elemento se ha realizado como si se tratase de un embalse situado a una cota determinada. Mediante la implementación del embalse, y fijado un nivel de agua disponible, es posible mantener unas condiciones constantes de presión en tal nudo durante toda la simulación. La existencia de las lógicas fluctuaciones de presión en la red asociadas a la variabilidad horaria de la demanda, puede ser considerada en el modelo a partir de un embalse al que se le asigna su correspondiente curva de modulación. En este caso, la presión, o lo que es lo mismo, el nivel de agua en el embalse dependería del instante de simulación, y por tanto sería posible ajustar la respuesta real de la red a partir del comportamiento de dicho embalse de nivel variable.

En las simulaciones programadas se ha simplificado las propiedades de este elemento, mantenido el nivel del embalse constante de forma similar a la cota del resto de nudos. Se ha establecido una diferencia de elevación entre la entrada y los nudos de acometida de 30 metros de columna de agua en condiciones estáticas. Se considera que se trata de un valor aceptable para el análisis, en cualquier caso al simularse el comportamiento del sector utilizando el programa Epanet, asociando una demanda determinada a cada nudo independiente de la presión, la variación de nivel del nudo de entrada sólo repercute alterando la presión en el resto de nudos, manteniendo un caudal en circulación constante (de forma análoga a las pérdidas de carga).

Respecto al caudal asociado, el volumen inyectado en el sector para cada instante de tiempo $q_{0}(\mathrm{t})$, es función del consumo cargado en cada uno de los nudos y del caudal de salida del tramo $q_{i}(\mathrm{t})$.

\subsubsection{Punto de salida del tramo (nudo final)}

El nudo final del modelo $n_{j}$ se corresponde con el punto de control de la presión, ya que se trata del punto más alejado del nudo de suministro, y por tanto el nudo más crítico por experimentar las condiciones mínimas de presión durante el régimen permanente (todos los nudos del modelo salvo el de entrada mantienen una misma elevación).

Respecto a los parámetros relacionados con la demanda, no se ha asignado ninguna acometida al nudo $n_{i}$, y sólo se ha impuesto un caudal constante de salida. La finalidad es mantener un determinado caudal mínimo en circulación por el sector independiente de los caudales consumidos en los edificios. Este caudal puede estar asociado al caudal demandado por puntos de consumo situados aguas abajo del tramo, al mismo tiempo que puede ser introducido para representar el posible volumen incontrolado que se da en el modelo. El valor del caudal demandado por este nudo se fija a partir de una velocidad mínima del flujo para afectar de forma idéntica a cualquier diámetro de conducción, para el estudio se ha establecido una velocidad de $0,5 \mathrm{~m} / \mathrm{s}$ (independientemente de los caudales demandados por los nudos). 
Respecto a las fluctuaciones de demanda que pudiera experimentar este nudo debidas al consumo de los usos aguas abajo del sector modelado, es posible establecer una curva de modulación asociada al caudal detraído. Pero en el caso concreto del modelo, al simularse una única hora de suministro se simplifica manteniendo un caudal detraído constante.

\subsubsection{Conexiones de las acometidas}

Las acometidas en el modelo se han representado mediante nudos de consumo. La información necesaria para definir estos elementos se reduce a las condiciones topográficas del mismo (a partir de las coordenadas de su ubicación), y a la caracterización del consumo asociado.

Topografía de los nudos de consumo (acometidas)

Las coordenadas marcarán la distancia entre los diferentes elementos y dependen directamente de la longitud del tramo y la densidad de acometidas fijada. En lo referente a las cotas o elevación de los nudos, y tal como se ha comentado, todos los nudos se situarán con una misma elevación, de forma que representen el perfil topográfico del tramo de una calle sin desniveles, de esta forma se consigue que la influencia del desnivel físico de una calle en los valores de presiones sea nula. En el caso de representar el comportamiento de una conducción que discurre por un trazado escarpado, es posible alterar las cotas de cada uno de los nudos e imponer los valores correspondientes.

Del mismo modo también es posible modificar el número de nudos de la red, posibilitando la representación de sectores de diferente tamaño y con una mayor o menor densidad de acometidas.

Carga hidráulica de los nudos de consumo

A cada acometida del modelo debe asignarse un caudal variable en el tiempo $q^{\prime}{ }_{i}(t)$ según la Ec. 2, que tenga en cuenta por un lado el esquema de suministro adoptado en la instalación interior del edificio y por otro lado, la demanda de agua correspondiente a cada una de las viviendas conectadas (Figura C2-12).

Para el primero de los casos, se han programado los esquemas interiores más comunes adoptados en edificios de viviendas, de forma que se traslade a los nudos de acometida la alteración originada por cada esquema. Los esquemas tratan de evaluar principalmente la aspiración en directo de las instalaciones interiores de los edificios, bien por un uso directo del recurso (sin la interposición de grupos de presión o depósitos), o a partir de grupos de presión conectado de forma directa. 
Respecto a la demanda se cuenta con datos de consumo almacenados en una base de datos con información acerca de las pautas de uso en viviendas en el ámbito residencial. A continuación se muestra el detalle sobre el análisis de los datos de consumo y sobre la caracterización de los esquemas interiores modelados.

\subsubsection{Caracterización de las pautas de consumo de los usuarios}

Dado un modelo hidráulico de un sector es preciso considerar los consumos en cada una de las viviendas que integran cada edificio conectado a éste. Para ello el procedimiento utiliza para la carga hidráulica del modelo datos reales de viviendas para "alimentar" los hipotéticos edificios del tramo.

La etapa previa a la caracterización de las pautas de consumo es la generación de una base de datos que concentre toda la información organizada de los consumos de las viviendas. Los datos de consumo utilizados han sido obtenidos en diferentes campañas de mediciones, éstas se realizaron en el marco del proyecto Propuestas metodológicas para el cálculo de la vida útil de los contadores de agua en un abastecimiento (DPI2000-0657), y del proyecto Ordenación y valoración de estrategias orientadas a la progresiva eliminación de los depósitos de almacenamiento de los usuarios en los abastecimientos de agua urbanos (CGL2005-03666).

La caracterización de las pautas de consumo de usuarios trata de identificar el modo con el que los abonados demandan agua en sus instalaciones particulares. Concretamente, interesa conocer cuál es la demanda media $\bar{q}$ que puede darse en una vivienda en una determinada hora de consumo, así como la distribución temporal del consumo durante los intervalos en los que se discretiza dicha hora.

\subsubsection{Obtención de la demanda media por hora}

Se persigue determinar el volumen de agua consumido por una vivienda en una hora, este valor será el que caracterice el consumo medio en cada una de las viviendas de los edificios del sector. De esta forma, el volumen total consumido durante una hora por un determinado número de viviendas será el producto de la demanda media establecida por el número de viviendas.

Para su determinación se acude a la base de datos de consumos de viviendas y se trata de analizar el consumo normal de cada hora. Puesto que la base de datos cuenta con días de consumo no usuales (por ejemplo volúmenes muy reducidos), se analizan sólo aquellos días en los que el volumen consumido toma valores aceptables, estableciéndose un rango que va desde los 200 litros hasta los 800 litros (téngase en cuenta que la dotación usual es próxima a los 200 litros por habitante y día). Del mismo 
modo sólo se seleccionan aquellas viviendas que tienen carácter de vivienda tipo piso, dejando fuera de la consulta otras como chalets o bungalós.

La siguiente figura muestra el resultado de la consulta relativa al caudal horario promedio consumido para cada una de las horas de un día.

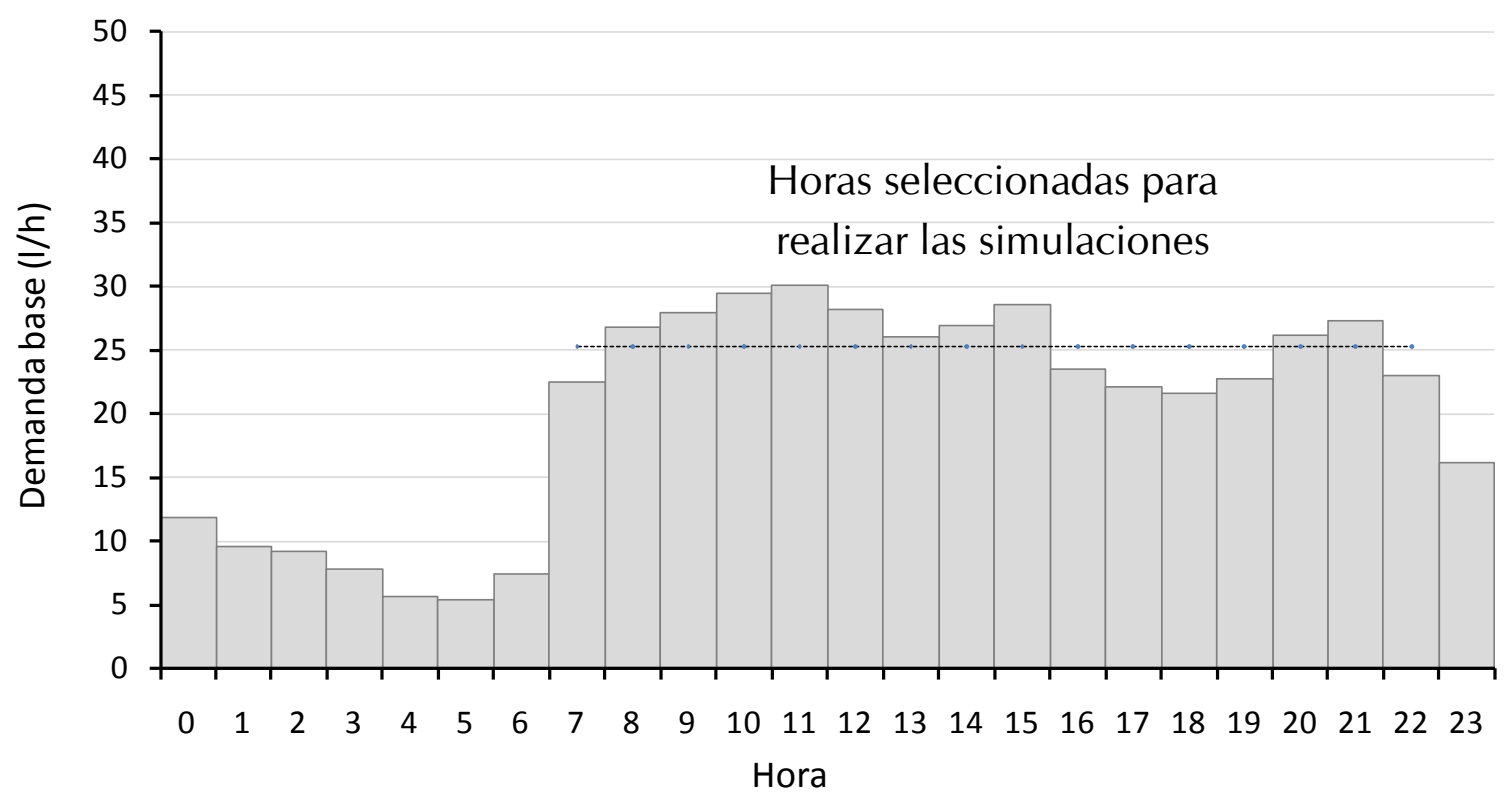

Figura C2-9. CuRVA DE MODULACIÓN DE LA DEMANDA DE LAS VIVIENDAS DE LA BASE DE DATOS

Como se observa el mayor consumo se origina a las 11 de la mañana con un valor aproximado de 31 litros. La demanda para las horas posteriores es muy similar, de forma que la tendencia de consumo se mantiene durante un periodo de tiempo considerable (a partir de las 7 de la mañana los volúmenes promedios consumidos están comprendidos entre 23 y 31 litros por hora).

\subsubsection{Discretización de la demanda horaria}

Para representar el comportamiento de las viviendas de un sector además de utilizar los datos de consumo promedio en una hora de funcionamiento, es necesario considerar la distribución de la demanda durante la hora de consumo, ya que el ritmo con el que los abonados consumen agua marcará el instante de arranque de un grupo de bombeo, y posibilitará la simultaneidad de usos.

En esta línea, la ocurrencia de consumos en cada una de las viviendas sigue un comportamiento estocástico. La siguiente figura muestra un ejemplo de una posible simultaneidad en la demanda de agua de un conjunto de viviendas de un edificio de 7 viviendas para un determinado periodo, evidenciando la aleatoriedad de los usos de forma más significativa en la medida que se cuenta con un mayor número de viviendas y se establece una discretización temporal más reducida. 


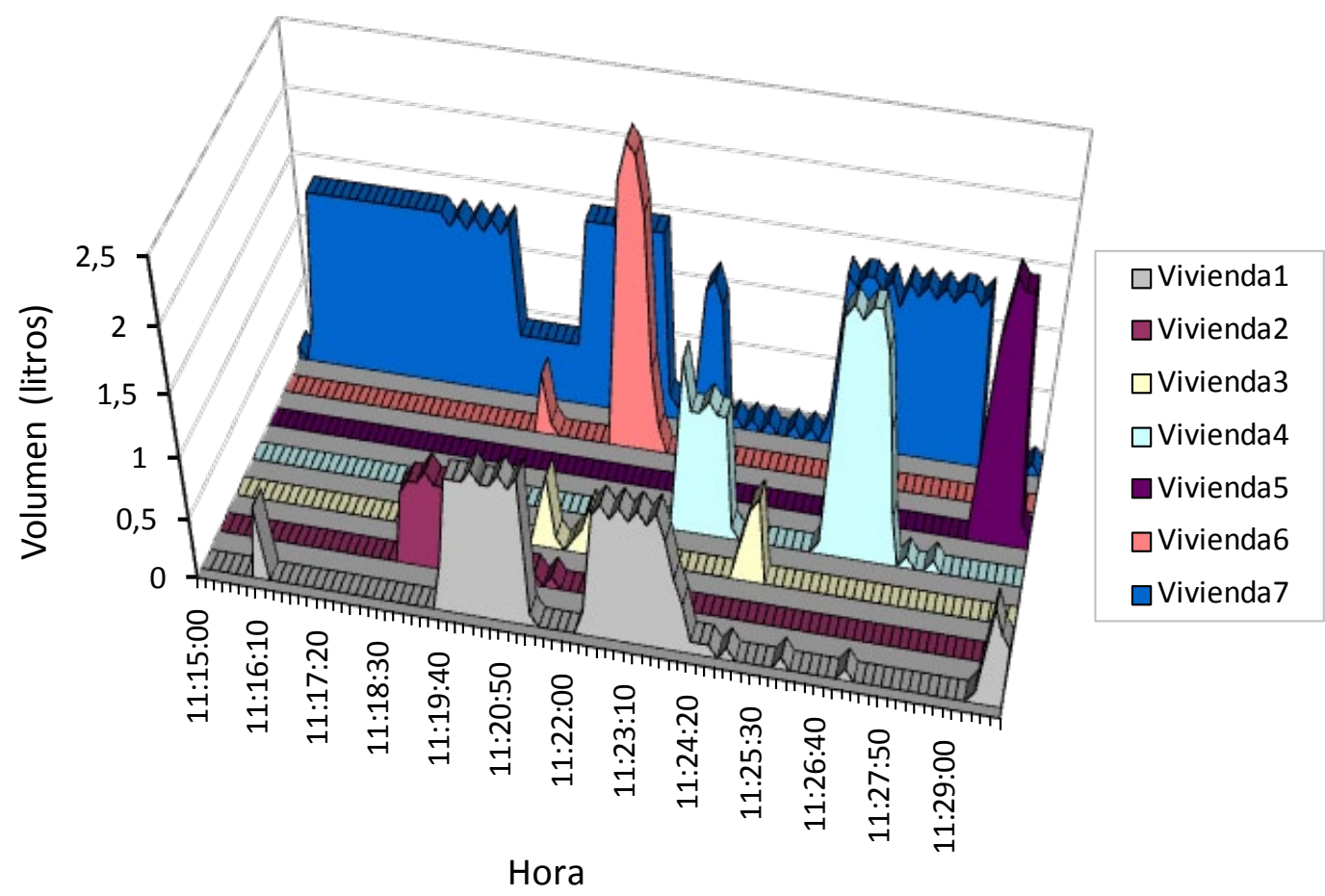

FIGURA C2-10. SiMULTANEIDAD DE CONSUMO PARA UN CONJUNTO DE 7 VIVIENDAS

En lugar de acudir a series sintéticas de consumo para cargar el modelo, el procedimiento utilizado acude a la carga directa de datos reales de viviendas, de forma que para un edificio del tramo conectado en una determinada acometida y formado por un conjunto de viviendas, la distribución que se le asignará a cada vivienda se obtiene a partir de los registros particulares de una de las viviendas integrantes de la base de datos. Las viviendas son tipo piso de diferentes municipios de Valencia y Sevilla. En total la base de datos dispone de aproximadamente 6000 días efectivos de mediciones con una discretización de 10 segundos, contando con unas 250 viviendas tipo piso. Las características de los registros pueden consultarse en Soriano (2008).

Otro de los detalles que se debe tener presente durante la carga hidráulica es la selección de las viviendas de la base de datos para una determinada simulación. Para que la carga se aproxime a la demanda base impuesta en la simulación el volumen consumido por la vivienda en una hora debe ser próximo al volumen promedio fijado $\bar{q}$ (nótese que en horas nocturnas la demanda de agua es muy baja, y los instantes de uso son muy limitados). Por tanto, para la carga de los modelos hidráulicos se han fijado las siguientes consideraciones:

- La hora de análisis se discretiza cada 10 segundos (360 intervalos)

- El consumo promedio de las viviendas asociadas a una acometida está en torno a los 30 litros (se establece un rango entre 25 y 35 litros)

- Los datos de consumo de las viviendas cargadas en el modelo están comprendidos entre las 7 de la mañana y las 11 de la noche 
- Las viviendas seleccionadas en la carga tienen consumo no nulo

La siguiente figura muestra de forma simplificada el resumen sobre la carga hidráulica asociada a una vivienda. Establecido el valor promedio de variación del volumen horario consumido (el consumo medio por vivienda y hora está comprendido en la horquilla entre 25 y 35 litros), junto con la variación temporal real asociada a una vivienda de la base de datos, se obtiene una evolución del caudal demandado por la vivienda para una hora de suministro. Este procedimiento se realiza para la cada una de las viviendas del modelo, acudiendo a diferentes registros de la base de datos de consumo, y por tanto se simula el consumo hipotético en un edificio de viviendas.

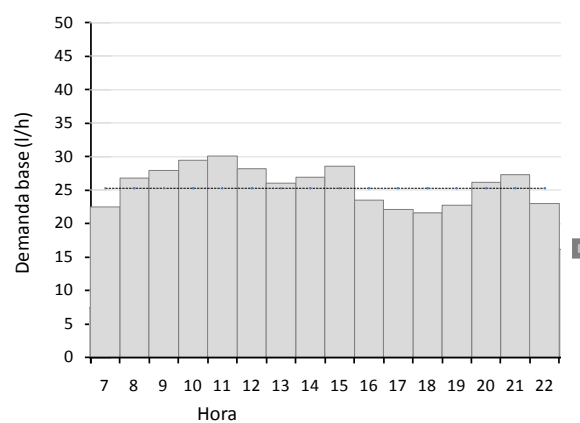

Demanda base en una hora

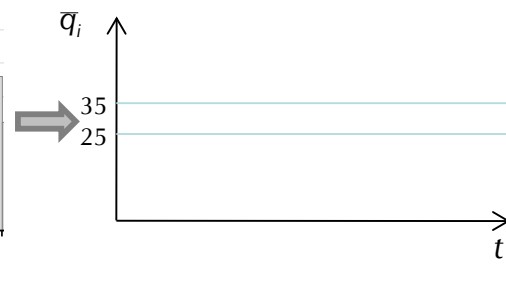

Demanda temporal vivienda
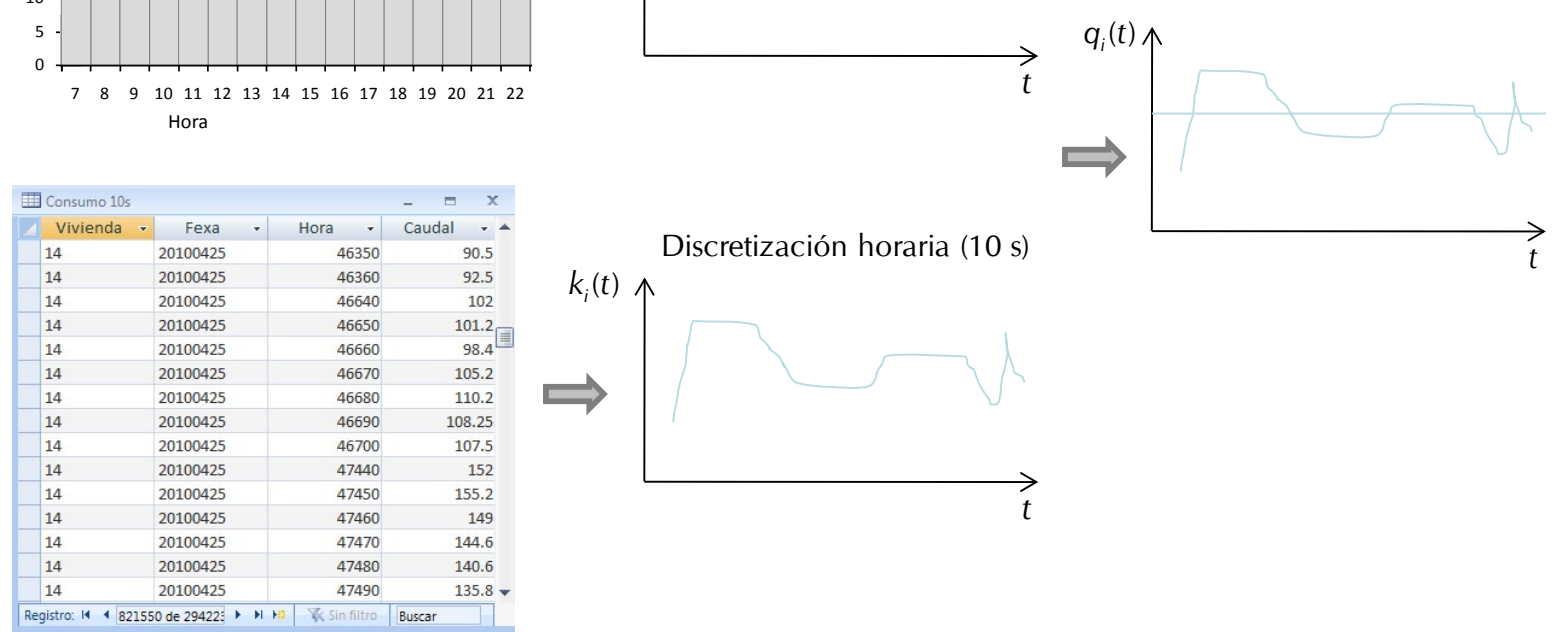

FIGURA C2-11. CARGA HIDRÁULICA ASOCIADA A UNA VIVIENDA DEL MODELO

\subsubsection{Caracterización de la instalación interior de los edificios}

El procedimiento propuesto permite simplificar la representación del sector de forma que no sea necesaria la implementación de las instalaciones interiores conectadas aguas abajo de la acometida, ya que si se dispone de la información sobre el consumo de los usuarios de cada edificio y dado un esquema de suministro, es posible trasladar dicha información al nudo situado aguas arriba (nudo de acometida) mediante la conveniente conversión de los datos asociados a cada esquema, asignando a este nudo la demanda temporal tal como un caudalímetro general la advertiría.

Como puede entenderse, la modulación temporal de la demanda aguas abajo de la acometida $q_{i}(t)$ está asociada a la agregación directa de las modulaciones temporales de las viviendas, pero en el momento que existe algún elemento que interfiera en esa 
modulación (como sucedería en caso de existir un depósito o una bomba) se altera dicha evolución siendo necesario obtener la serie temporal correspondiente $q_{i}^{\prime}(t)$. La asignación de los requerimientos a cada una de las acometidas parte del análisis de los esquemas de la instalación interior de un edificio. Para cada esquema se crea un módulo que calcula los factores de modulación que tienen en cuenta la distribución temporal de la demanda y el caudal instantáneo asociado a cada intervalo de cálculo.

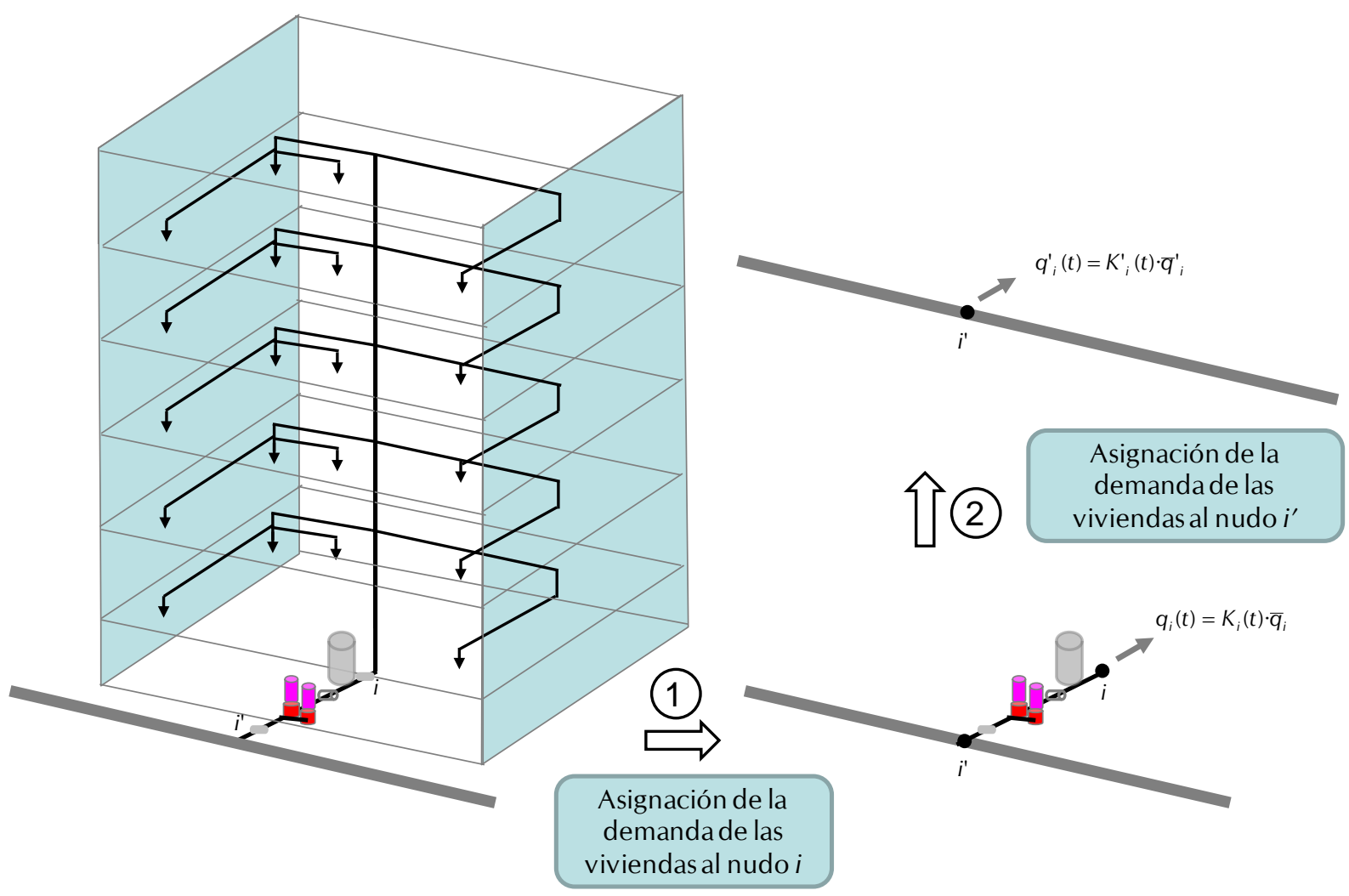

FIGURA C2-12. SIMPLIFICACIÓN DE LA CARACTERIZACIÓN DE LA DEMANDA EN UN EDIFICIO

En el Anexo 2 se describen los esquemas interiores de suministro más usuales adoptados en edificios, especificándose sus principales características y consideraciones funcionales. Entre ellos sólo se han modelado aquéllos que realizan una conexión directa, diferenciándose entre:

- Esquema Tipo I. Suministro en directo sin bomba ni depósito.

- Esquema Tipo II. Suministro en directo con grupo de bombeo de velocidad fija (para todas las viviendas).

- Esquema Tipo III. Suministro mixto; en directo con grupo de bombeo de velocidad fija una parte de las viviendas y suministro directo sin bomba para el resto.

- Esquema Tipo IV. Suministro en directo con grupo de bombeo equipado con variador de frecuencia (para todas las viviendas). 


\subsubsection{Esquema de suministro Tipo I}

El suministro en directo prescinde de elementos de impulsión y almacenamiento, de forma que la demanda de los usuarios es trasladada directamente al punto de entrada de agua en la instalación. Bajo este esquema la asignación a la acometida se realiza a partir de la agregación de cada una de las demandas temporales de las diferentes viviendas $v$ del edificio, para cada uno de los instantes discretizados. El factor temporal de demanda se obtiene por división del valor anterior entre el

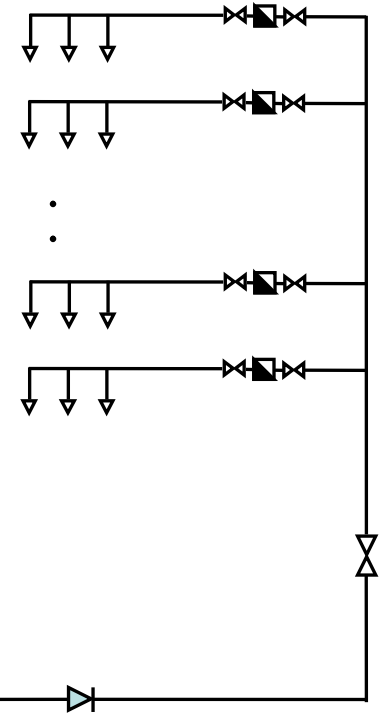

FIGURA C2-13. ESQUEMA DE SUMINISTRO TIPO I caudal del edificio $Q_{i}$.

$$
q_{i_{-} \prime}^{\prime}(t)=q_{\left.i_{-}\right\lrcorner}(t)=\frac{\sum_{v \in N} q_{v}(t)}{Q_{i}}=\frac{\sum_{v \in N} q_{v}(t)}{N \cdot \bar{q}_{i}} \forall t=1 \ldots N_{\text {fact }}
$$

Donde $N$ representa el número total de viviendas del edificio y $N_{\text {fact }}$ el número de intervalos de análisis (360 para la discretización de una hora en periodos de 10 segundos), y $q_{v}(t)$ la serie de caudal registrado en una de las viviendas de la base de datos con la discretización fijada.

\subsubsection{Esquema de suministro Tipo II}

El esquema de suministro Tipo II incorpora un equipo de presión de velocidad fija formado por un grupo moto-bomba y un calderín en impulsión. Se trata de un esquema exigente desde el punto de vista hidráulico, ya que todo el caudal bombeado se corresponde con el caudal máximo simultáneo del edificio (caudal que no suele coincidir con el caudal instantáneo demandado por un conjunto de usuarios).

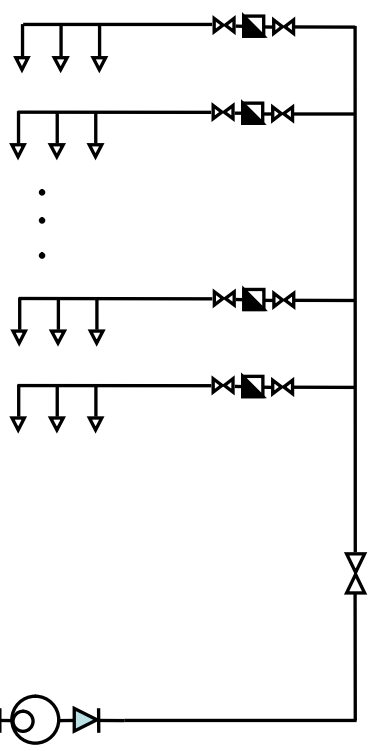

FIGURA C2-14. ESQUEMA DE SUMINISTRO TIPO II 
Respecto al cálculo de factores de modulación, es necesario tener en cuenta el comportamiento del grupo de bombeo; puede darse la situación de que la bomba esté parada y el suministro se realice únicamente a partir del agua a presión almacenada en el acumulador, en tal caso el factor de modulación que se debería cargar al nudo principal sería nulo (nótese que no se detrae agua de la acometida del edificio). Y la otra posibilidad se daría cuando el grupo de bombeo está activo y aporta agua al calderín y a las viviendas. En estas condiciones el factor se corresponde con el caudal bombeado por el grupo dividido por el caudal total consumido por las viviendas. Las siguientes expresiones representan las series de caudal temporal en el nudo de acometida:

$$
\left\{\begin{array}{llll}
q_{i_{-} I l}^{\prime}(t)=0 & \text { si } V_{\text {cal }}(t)>0 \quad \text { (en ciclo de vaciado) } & \forall t=1 \ldots N_{\text {fact }} \\
q_{i_{-} \_l}^{\prime}(t)=\frac{q_{b}}{Q_{i}} & \text { si } V_{\text {cal }}(t) \geq 0 \quad \text { (en ciclo de llenado) } & \forall t=1 \ldots N_{\text {fact }}
\end{array}\right.
$$

Siendo $q_{b}$ el caudal asociado a la bomba en marcha y $V_{c a l}(t)$ el volumen útil de agua acumulado en el calderín para cada instante de tiempo. Como se observa en la expresión anterior, el valor del factor de modulación es función del ciclo que está realizando el calderín; en un caso se producirá el vaciado de éste suministrando a la instalación con la bomba parada, y en otro caso se suministrará a partir del grupo de bombeo, procediendo además al Ilenado del depósito a presión. La anulación del volumen útil del calderín activa el arranque de la bomba.

Respecto al caudal de bombeo es necesario remarcar que en condiciones normales de funcionamiento éste no permanece constante ya que es función entre otras variables de la presión en el interior del calderín, y del número de bombas en funcionamiento. En cualquier caso, para simplificar el modelo se mantiene fijo su valor pudiendo coincidir con el caudal medio aportado por el grupo, o con el caudal de máximo de éste.

\section{Cálculo del caudal del grupo de presión}

Los cálculos para modelar el caudal de la bomba se han realizado siguiendo las directrices impuestas por el Código Técnico de la Edificación (CTE) en la materia de suministro de agua. A partir de este documento, el caudal que deberá ser capaz de aportar la bomba debe ser como mínimo el caudal máximo simultáneo del edificio (caudal de cálculo). Este caudal se ha programado a partir del Método Racional (ver Anexo 3), considerando los coeficientes de simultaneidad asociados al número de aparatos de una vivienda tipo, y el número de viviendas del edificio (se ha considerado una vivienda Tipo D según la clasificación de la NIA, que corresponden a viviendas con dos cuartos de baño completos, lavadora, lavavajillas, fregadera y office, con un caudal promedio instalado de $1,75 \mathrm{l} / \mathrm{s}$ ). 


\section{Cálculo del volumen del calderín}

El cálculo del volumen útil del calderín se realiza a partir de la expresión propuesta por la UNE 149 201, aproximando el caudal útil del calderín como un 25 \% del caudal total del depósito presurizado, y simplificando para un número de ciclos de arranque de 12, y una diferencia entre la presión de arranque y paro de 20 mca.

$$
\forall_{\text {cal }}(\mathrm{l})=0.25 \cdot \mathrm{K} \cdot \frac{6,25 \cdot \mathrm{q}_{\mathrm{b}} \cdot\left(\mathrm{p}_{\mathrm{p}}+10,33\right)}{100 \cdot \mathrm{N}_{\mathrm{b}}}
$$

Donde $K$ tiene en cuenta el tipo de renovación de aire: 1 para calderines de membrana, 2 para calderines con compresor y 2,5 para calderines de contacto (siguiendo las exigencias del CTE se consideran sólo calderines de membrana). qb es el caudal de la bomba en litros por minuto, $N_{b}$ es el número de bombas que trabajan en alternancia y $p_{p}$ es la presión de paro del grupo de bombeo en mca. Para simplificar se considera que la instalación cuenta con una única bomba que totaliza el volumen del edificio y que la presión de paro es de 60 mca.

\subsubsection{Esquema de suministro Tipo III (instalación mixta)}

Se trata de una combinación de las tipologías anteriores (Tipo I y Tipo II), el edificio resultante está formado por un conjunto de viviendas que son alimentadas en directo (si la red dispone de presión suficiente), mientras que el resto de viviendas precisan de grupo de bombeo para elevar la presión del agua a un valor suficiente. Para las simulaciones se ha considerado que bajo esta tipología el $33 \%$ de las viviendas se suministra a partir de grupos de bombeo y el resto se suministrarían en directo (nótese que para otros porcentajes las solicitaciones deben estar limitadas por la respuesta de un edificio que cuenta con el $100 \%$ de viviendas con grupo de presión, coincidente con el esquema Tipo II, y por otro lado por las solicitaciones correspondientes a un edificio en el que todas las viviendas se suministran sin bomba, esquema Tipo I).

La determinación de la distribución temporal de la demanda en el nudo de acometida vendrá condicionada por una combinación de las expresiones para los Tipos I y II. Asociado al caudal de bombeo, la componente será nula en aquellos instantes $t$ en los que el calderín se está en ciclo de vaciado, mientras que en el resto de situaciones esta variable toma directamente un valor constante asociado al caudal de la bomba. Adicionalmente, se debe considerar la contribución asociada al consumo en directo sin bomba.

$$
q_{i_{-} I I I}^{\prime}(t)=\frac{\sum_{v \in N} q_{v}(t)+q_{b}(t)}{Q_{i}}=\frac{\sum_{v \in N} q_{v}(t)+q_{b}(t)}{N \cdot \bar{q}_{i}} \forall t=1 \ldots N_{\text {fact }}
$$


La siguiente figura muestra un esquema típico de este esquema de instalación en la que se puede apreciar dos ramales de alimentación; uno de ellos alimentaría en directo a la parte baja de la instalación, mientras que otro de los ramales conectaría el grupo de bombeo con la instalación de las viviendas situadas en la parte alta del edificio (o con mayores necesidades de presión).

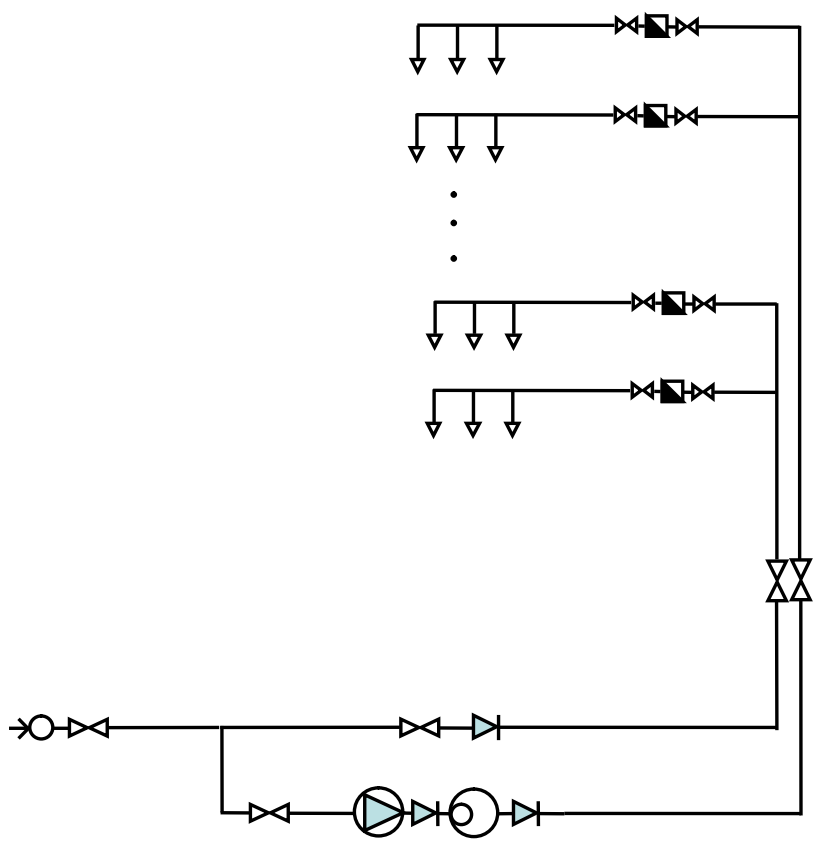

FIGURA C2-15. ESQUEMA DE UN SUMINISTRO MIXTO (COMBINACIÓN DIRECTO Y CON GRUPO DE BOMBEO)

El cálculo de los componentes del equipo de presión se realiza de forma similar a la mostrada para el esquema anterior, en cualquier caso tanto el volumen del calderín como el caudal de la bomba será menor que en el esquema Tipo II, ya que para un mismo tamaño de edificio es menor el número de viviendas que suministradas mediante el grupo.

\subsubsection{Esquema de suministro Tipo IV}

El esquema de suministro Tipo IV es similar al esquema Tipo II pero el equipo de presión cuenta con un variador de frecuencia que permite a la bomba modificar su régimen de giro en función de la demanda de agua en la instalación.

En las mediciones realizadas en campo (Figura C2-16), salvo el instante de arranque el resto de tiempo de funcionamiento la bomba mantiene un caudal muy aproximado al promedio del caudal instantáneo demandado por las viviendas con consumo (téngase en cuenta que el reducido volumen útil del calderín en aspiración favorece un Ilenado rápido durante el arranque del grupo, y a partir de este instante la bomba trata de seguir la consigna de presión directamente relacionada con la demanda instantánea de los usuarios). 
Tal como se ha comprobado este ajuste es más o menos preciso en función de la programación del controlador asociado al PID del variador. Bajo esta premisa, se asimila el comportamiento de la bomba de velocidad variable al suministro en directo sin grupo de presión (Tipo I). Al mismo tiempo, la simplificación tiene sentido dada la complejidad en la modelación del comportamiento del controlador, y de los diferentes ajustes realizados por los fabricantes e instaladores. En cualquier caso es necesario remarcar que la asimilación entre los esquemas anteriores está supeditada a una adecuada programación de las variables del PID del controlador, ya que es posible reducir en gran medida el pico máximo de la bomba y aproximarlo a la demanda instantánea.

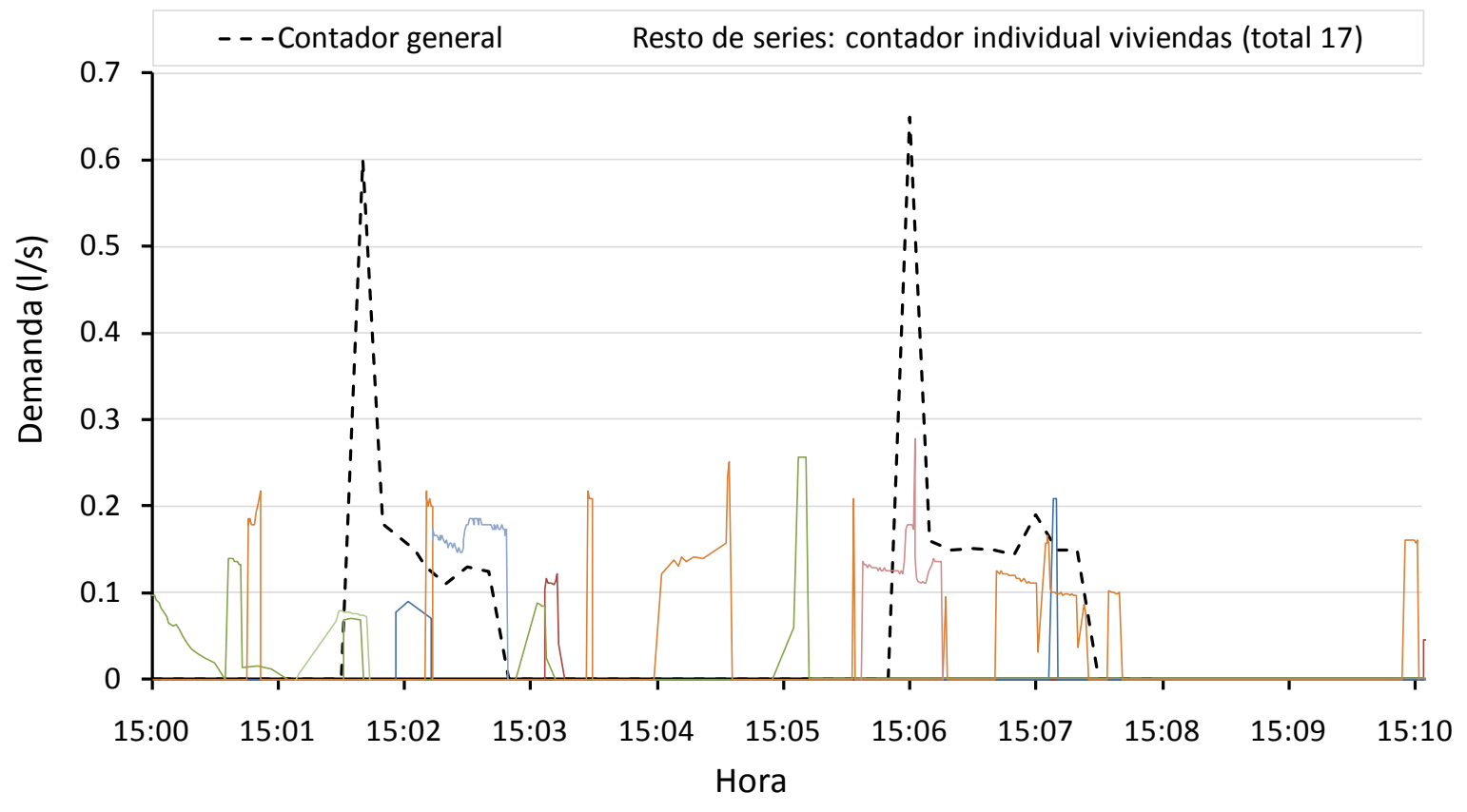

FIGURA C2-16. COMPARACIÓN DE LA DEMANDA AGREGADA DE UN CONIUNTO DE VIVIENDAS Y LA CORRESPONDIENTE DEL CONTADOR GENERAL (INSTALACIÓN EQUIPADA CON VARIADOR DE FRECUENCIA)

\subsubsection{Escenarios simulados}

Comentadas las características básicas de los elementos hidráulicos que integran el sector así como los esquemas de las instalaciones interiores de los edificios, el procedimiento programado trata de construir diferentes escenarios de simulación. Cada uno de estos escenarios está caracterizado a partir de unas determinadas propiedades de los elementos integrantes, ya que a partir de la programación en VB se han modificado las características físicas del sector (diámetros, longitudes, etc.), la carga hidráulica de cada modelo y los esquemas de las instalaciones interiores de los edificios, dando lugar a diferentes escenarios de cálculo.

La siguiente tabla resume los valores utilizados de cada parámetro para elaborar los escenarios sobre los que se han realizado simulaciones en el estudio. Cada 
escenario está constituido como una combinación de los valores indicados. Los resultados de las simulaciones y resto de consideraciones se detallan en el Capítulo 3.

TABLA C2-3. COMBINACIÓN DE PARÁMETROS DE LOS DIFERENTES ESCENARIOS

\begin{tabular}{ccccc}
\hline $\begin{array}{c}\text { Nudos totales } \\
\text { del tramo }\end{array}$ & $\begin{array}{c}\text { Distancia } \\
\text { nudos }(\mathbf{m})\end{array}$ & $\begin{array}{c}\text { Viviendas } \\
\text { por nudo }\end{array}$ & $\begin{array}{c}\text { Demanda } \\
(\mathbf{l} / \mathbf{h})\end{array}$ & $\begin{array}{c}\text { Diámetro } \\
(\mathbf{m m})\end{array}$ \\
\hline $\mathbf{1 0}$ & $20-40$ & $5-15-25-35$ & $25-35$ & $79-96-110-123-141-158$ \\
$\mathbf{1 5}$ & $20-40$ & $5-15-25-35$ & $25-35$ & $79-96-110-123-141-158$ \\
$\mathbf{2 0}$ & $20-40$ & $5-15-25-35$ & $25-35$ & $79-96-110-123-141-158$ \\
\hline
\end{tabular}

El campo nudos representa el número de nudos del tramo de red $\left(n_{i}\right)$. Del total de nudos hay dos que no son de consumo (el nudo de entrada y el nudo de control), por tanto se corresponde con el número de acometidas o edificios del sistema más dos. Para la distancia entre nudos se han tomado dos valores; edificios separados 20 metros y edificios separados 40 metros. La programación de diferentes números posibilita diferentes longitudes de la conducción principal del sector. Respecto al campo Diámetro, se ha acudido a una gama comercial de conducciones de polietileno, con valores de diámetros interiores comprendidos entre 79 y 158 mm (serie PE100 - PN10). De esta forma, se obtendrá la respuesta de un mismo tramo de red en el que únicamente varía el diámetro de la conducción principal que lo forma.

El número de viviendas por nudo indica el tamaño del edificio, para ello se han construido edificios de 5,15, 25 y 35 viviendas. Como se ha comentado, la demanda media de cada una de las viviendas de los edificios varía entre 25 y 35 litros por hora, valor que deriva de las conclusiones obtenidas de la gráfica de la Figura C2-9.

\subsection{EJEMPLO DE CARACTERIZACIÓN DEL MODELO HIDRÁULICO DE UN EDIFICIO PARA SU ANÁLISIS EN RÉGIMEN TRANSITORIO}

\subsubsection{Descripción general del procedimiento desarrollado}

Además del análisis sobre la respuesta de la red bajo conexión directa en régimen permanente, deben evaluarse las implicaciones asociadas a su funcionamiento en régimen transitorio, principalmente en los instantes en los que se originan variaciones bruscas de caudal detraído (por ejemplo durante el arranque o paro de un grupo de bombeo). En esta situación es posible que la instalación mantenga un comportamiento correcto en régimen permanente, pero en el instante de entrada en funcionamiento de uno o varios grupos se origine una reducción puntual de la presión en la red que ponga en riesgo su normal suministro, y por tanto condicione la adopción de esta conexión. 
El estudio en régimen transitorio se ha enfocado a un volumen de control de menor extensión que en el estudio en régimen permanente. Éste contempla la instalación interior de un único edificio junto con el tramo de la red general más inmediato conectado a la acometida domiciliaria. La reducción de la extensión del modelo permite enfocar el estudio a un mayor conocimiento de la instalación donde se origina la perturbación (instalación interior del edificio), y que al mismo tiempo es la zona donde los efectos alcanzan su valor máximo. Una vez se origina la perturbación ésta se propaga a las inmediaciones del edificio atenuando su efecto, pero pudiendo alcanzar la red general de distribución o incluso la instalación interior de otro edificio próximo.

Tal como se comprobará, las características físicas y operacionales de la instalación interior del edificio condicionan en gran medida la magnitud de los efectos transitorios. Como es lógico, y dada la gran casuística inherente a este tramo de la instalación, es necesaria la modelación de una instalación piloto que fije las condiciones de referencia a partir de las cuales, es posible realizar un análisis de sensibilidad sobre la influencia de las principales variables. Esta instalación se corresponde con el edificio monitorizado en la presente Tesis y cuyas características se describen en el Anexo 4. Al mismo tiempo se han modificado las características constructivas y funcionales del modelo de este edificio en aras de analizar cómo afecta su variación en la magnitud de la perturbación transitoria.

Para el análisis del fenómeno transitorio se ha utilizado el programa de cálculo hidráulico Allievi. El programa, si bien ha sido ampliamente testeado en gran cantidad de instalaciones singulares, es la primera vez que se utiliza como plataforma para modelar el comportamiento en el interior de un edificio, instalación que aparentemente reporta una menor complejidad de modelación frente a otro tipo de proyectos. Las características particulares de este programa se describen en el Anexo 6.

\subsubsection{Caracterización de la red general de distribución}

Dada la vinculación entre la red general de distribución (RGD) y la instalación interior del edificio, en el modelo se ha contemplado parcialmente este elemento y su conexión a la instalación del edificio a través de su acometida (T7 en Figura C2-17). Respecto al esquema de la RGD se ha modelado por un lado la tubería a la que está conectada la acometida (se trata en la instalación de la conducción que discurre por la acera próxima al inmueble). Esta conducción en el modelo se materializa con las tuberías T3 y T4, y sus características básicas se detallan en la Tabla C2-4.

Se han modelado otras conducciones y elementos de la RGD, entre ellos 4 depósitos (D1-D4) y las conducciones T1, T2, T5 y T6. Se persigue mantener diferentes flujos de caudal (a partir de la variación de los niveles en los depósitos), tal como en 
una red mallada sucede, de esta forma es posible analizar cómo influyen los flujos y diferentes niveles de presión en los puntos próximos a la acometida. En el caso concreto del modelo, los niveles de los depósitos se han fijado para mantener una velocidad por las conducciones T2 y T4 de $0,7 \mathrm{~m} / \mathrm{s}$ (no se dispone de esta información para la instalación, por tanto en el análisis se comprobará la influencia de este término).

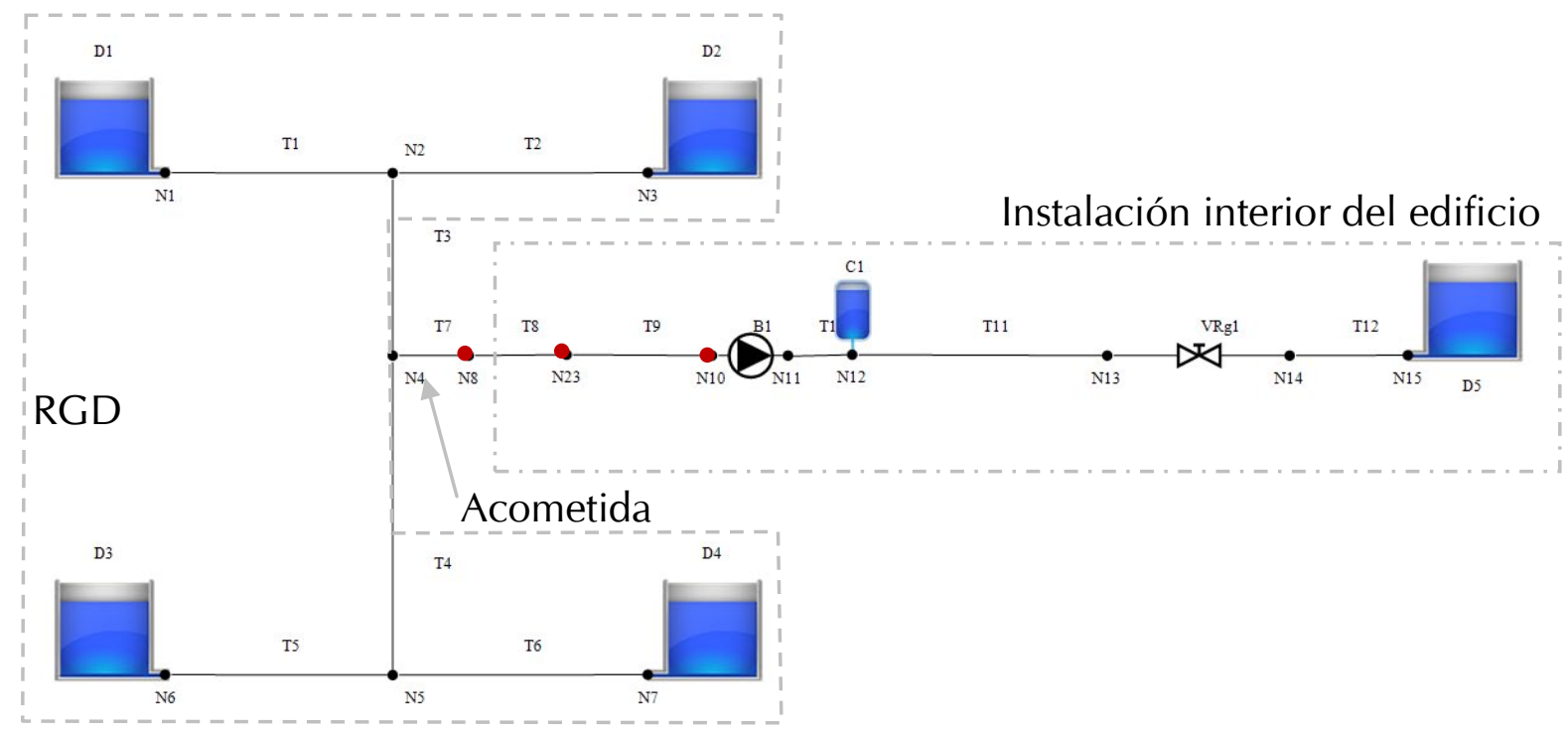

FIGURA C2-17. MODELO DE SIMULACIÓN DEL EDIFICIO EN ALLIEVI

TABLA C2-4. CARACTERÍSTICAS DE LAS TUBERÍAS MODELADAS DE LA RGD

\begin{tabular}{cccccc}
\hline $\begin{array}{c}\text { Id } \\
\text { tubería }\end{array}$ & $\begin{array}{c}\text { Diámetro } \\
\text { interior }\end{array}$ & $\begin{array}{c}\text { Espesor } \\
\mathbf{e}\end{array}$ & $\begin{array}{c}\text { Longitud } \\
\boldsymbol{L}\end{array}$ & $\begin{array}{c}\text { Celeridad } \\
\mathbf{a}\end{array}$ & $\begin{array}{c}\text { Rugosidad } \\
\boldsymbol{\varepsilon}\end{array}$ \\
\hline & $\mathbf{( m m )}$ & $\mathbf{( m m )}$ & $\mathbf{( m )}$ & $\mathbf{( m / s )}$ & $\mathbf{( m m )}$ \\
T1 & 150 & 6 & 30 & 1161,9 & 0,1 \\
T2 & 150 & 6 & 30 & 1161,9 & 0,1 \\
T3 & 150 & 6 & 50 & 1161,9 & 0,1 \\
T4 & 150 & 6 & 50 & 1161,9 & 0,1 \\
T5 & 200 & 6,3 & 30 & 1111,4 & 0,1 \\
T6 & 200 & 6,3 & 30 & 1111,4 & 0,1 \\
\hline
\end{tabular}

\subsubsection{Tuberías de la RGD (T1-T6)}

En el caso de la red modelada, las tuberías son de fundición dúctil de diferentes diámetros nominales (para este material el diámetro interior es prácticamente coincidente con este valor (CEDEX, 2006)). Respecto al espesor, se ha considerado un tubo de clase K9, y unas dimensiones según UNE-EN 545:1995. Para la determinación de la celeridad de estas conducciones se ha considerado un módulo de elasticidad del material $\mathrm{E}=1,25 \cdot 10^{5} \mathrm{~N} / \mathrm{mm}^{2}$. En cuanto a la rugosidad, al no disponer de datos reales se ha acudido a un valor usual para este material. 


\subsubsection{Válvulas y elementos de control de la RGD}

No se consideran estos elementos en el modelo, ya que las válvulas de seccionamiento próximas se encuentran completamente abiertas, y se estima una influencia despreciable.

\subsubsection{Presión de entrega en acometida}

Para el escenario de simulación y puesto que se dispone de datos reales sobre la presión de entrega en acometida de la instalación monitorizada, se ha establecido una presión estacionaria de 33 mca (función de los niveles de los depósitos que simulan la RGD y resto de características de la misma). En la instalación se ha observado un valor suficientemente estable en la instalación monitorizada para no introducir una evolución temporal de esta presión. En cualquier caso, se debe realizar un análisis de la incidencia originada por la variación de la presión. Respecto a la variación de esta presión en la acometida del edificio, La Tabla C2-5 resume las características básicas de los depósitos del modelo (asociados a las RGD).

\begin{tabular}{|c|c|c|}
\hline $\begin{array}{c}\text { Id } \\
\text { depósito }\end{array}$ & Tipo & Nivel \\
\hline & & (mca) \\
\hline D1 & GD & 34 \\
\hline D2 & GD & 34,9 \\
\hline D3 & GD & 33,9 \\
\hline D4 & GD & 33,8 \\
\hline
\end{tabular}

\subsubsection{Modelo del tramo de acometida (T7)}

Desde el punto de vista de la afección por una perturbación originada en la red interior del edificio la acometida es el tramo de la RGD más solicitado, ya que está directamente conectada al edificio y mantiene unas características funcionales similares a las propias del tubo de alimentación. Es por ello que a diferencia del resto de elementos de la RGD conviene realizar una modelación lo más próxima a la realidad posible.

Para la modelación se ha considerado un tramo de 3,2 metros de tubería recta de polietileno (PE100), con las características que se indican en la Tabla C2-4. Respecto a las válvulas y elementos que incorpora esta conducción, no se estima que introduzcan pérdidas de carga que deban ser tratadas individualmente (las válvulas son de 
seccionamiento tipo compuerta), en cualquier caso se ha calculado la longitud equivalente como usualmente se hace estableciendo ésta como un $25 \%$ de la longitud de tubería (los procedimientos usuales fijan un 20 ó 30\% dependiendo del tramo).

Esta conducción aun siendo perteneciente a la red general de distribución, se define junto con el resto de elementos de la instalación interior del edificio por la similitud de sus características constructivas respecto a la conducción de alimentación de la instalación interior.

\subsubsection{Caracterización de la instalación interior del edificio}

La representación de la impulsión de la bomba se ha realizado a partir de la modelación de un depósito (D5) y una válvula de regulación (VRg1). Con estos elementos se ha caracterizado el punto de funcionamiento de la bomba, impuesto éste a partir del nivel del agua en D5 y el grado de apertura de la válvula. El caudal que se ha fijado aguas abajo del calderín C1 es próximo a 0,5 l/s (caudal usual registrado en la monitorización del edificio). Esta representación aproxima el instante de arranque de la bomba de velocidad fija. En condiciones normales de suministro un interruptor de presión (generalmente un presostato) ordena el arranque de la bomba cuando la presión en el calderín alcanza un determinado valor. A partir de este instante se inicia el relleno del calderín de impulsión al mismo tiempo que se mantiene el suministro a los usuarios activos.

\subsubsection{Tuberías de la acometida y la instalación interior (T7-T12)}

En la instalación interior del edificio se combinan tuberías de acero galvanizado y polietileno de diferentes longitudes, y cuyos diámetros interiores y resto de propiedades se muestran en la siguiente tabla. En cuanto a las pérdidas de carga, se han considerado las pérdidas menores y las pérdidas de carga más representativas correspondientes a accesorios incluidos en este tramo (reducciones, acoples, antirretorno, etc.).

TABLA C2-6. CARACTERÍSTICAS DE LAS TUBERÍAS DE LA ACOMETIDA Y LA RED INTERIOR

\begin{tabular}{ccccccc}
\hline $\begin{array}{c}\text { Id } \\
\text { tubería }\end{array}$ & $\begin{array}{c}\text { Diámetro } \\
\text { interior }\end{array}$ & $\begin{array}{c}\text { Espesor } \\
\mathbf{e}\end{array}$ & $\begin{array}{c}\text { Longitud } \\
\text { equivalente }\end{array}$ & $\begin{array}{c}\text { Celeridad } \\
\mathbf{a}\end{array}$ & $\begin{array}{c}\text { Rugosidad } \\
\boldsymbol{\varepsilon}\end{array}$ & $\begin{array}{c}\text { Pérdidas } \\
\boldsymbol{k}\end{array}$ \\
\hline & $\mathbf{( m m )}$ & $\mathbf{( m m )}$ & $\mathbf{( m )}$ & $\mathbf{( m / s )}$ & $\mathbf{( m m )}$ & \\
T7 & 44 & 3 & 4 & 800 & 0,1 & 0 \\
T8 & 52,8 & 3,6 & 14 & 1285,25 & 0,1 & 8 \\
T9 & 55,4 & 3,8 & 5 & 800 & 0,1 & 16 \\
T10 & 50 & 6 & 2 & 1161,9 & 0,1 & 0 \\
T11 & 40 & 5 & 2 & 1100 & 0,1 & 0 \\
T12 & 40 & 5 & 2 & 1100 & 0,1 & 0 \\
\hline
\end{tabular}




\subsubsection{Implementación de los esquemas de conexión directa}

Sólo se analizan los esquemas con grupo de presión tanto de velocidad fija (esquema Tipo II) como de velocidad variable (esquema Tipo IV), ya que son los esquemas que mayores solicitaciones presentan en régimen transitorio, y de los que se tiene referencias.

\subsubsection{Esquema de suministro Tipo II}

En Allievi se han implementado las curvas características de la bomba de velocidad fija a partir de los datos disponibles del fabricante (altura, potencia y rendimiento). La duración del arranque del grupo se ha fijado en 0,55 segundos, valor estimado a partir de los datos registrados en la instalación del edificio.

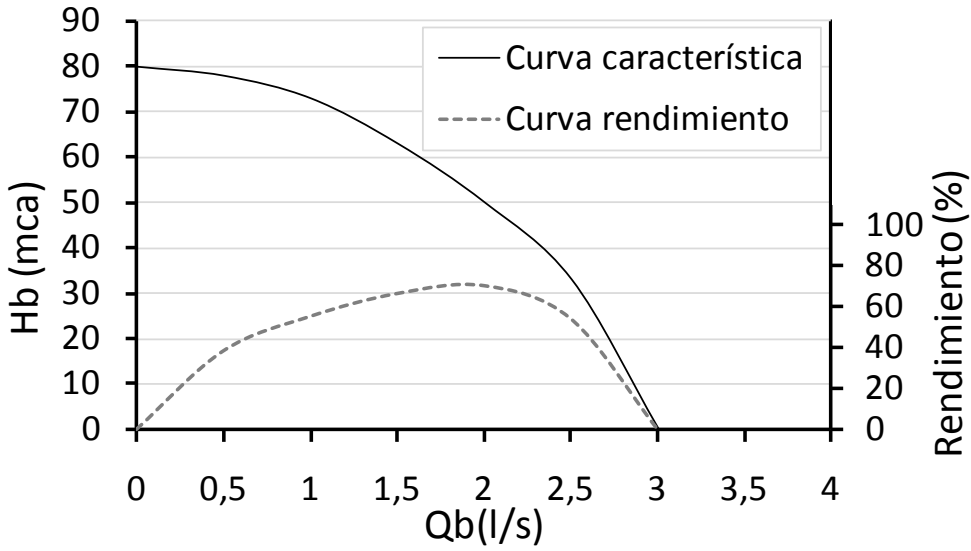

FIGURA C2-18. CURVAS CARACTERÍSTICAS DE LA BOMBA

Del mismo modo se han incorporado el resto de elementos del equipo de presión (válvula de retención a la salida de la bomba y el depósito presurizado aguas abajo de ésta). El calderín modelado es de vejiga, con posición vertical y con un volumen total de 650 litros. Sus dimensiones son de $1,4 \mathrm{~m}$ de altura y $0,77 \mathrm{~m}$ de diámetro. Se ha considerado una evolución politrópica del aire en el interior del calderín de coeficiente 1,2 , puesto que los tiempos de llenado y vaciado son suficientemente rápidos para no darse condiciones isotermas.

\subsubsection{Esquema de suministro Tipo IV}

En el caso de la instalación con bomba de velocidad variable, las características operacionales de ésta se han modelado a partir de la curva característica de la bomba, junto con un tiempo de arranque de 3 segundos (valor programado para la rampa de arranque del PID del equipo monitorizado). Esta simplificación atiende a la imposibilidad de modelar el controlador en el programa Allievi.

El calderín instalado aguas abajo de la bomba se ha modelado de tipo vejiga, y de 50 litros de volumen, atendiendo a las características dimensionales del depósito instalado en el edificio monitorizado (el resto de características son análogas al calderín descrito en el esquema anterior). 


\subsubsection{Puntos de control (N8-N10)}

Se han establecido tres puntos donde se realiza el control de las evoluciones de presión en la instalación. Estos puntos se corresponden con las sondas de presión instaladas en el edificio monitorizado.

Por un lado, el nudo N8 coindice con la sonda colocada en las proximidades de la acometida. Esta sonda no está directamente instalada en la RGD, sino que se sitúa en la toma de incendios ubicada en la misma fachada del edificio (al ser un punto terminal, no puede representarse en Allievi como tal, y se representa como un punto de unión entre el final de la acometida y el inicio de la instalación interior del edificio). Este punto de control aportará una aproximación de la transmisión de la perturbación al exterior del edificio.

El nudo N9 es un punto intermedio de la instalación interior aguas arriba de la bomba. Su modelación ha permitido ajustar los datos del modelo en dicha zona, pero en los resultados del análisis no se referenciará, ya que en cualquier caso las solicitaciones máximas y mínimas vendrán dadas por los puntos de control extremos (N10 y N8 respectivamente).

Por último el nudo N10 representa la sonda instalada en las proximidades de la aspiración de la bomba. Ésta será la que represente las solicitaciones máximas que se registran en la instalación.

\subsubsection{Escenarios simulados}

Presentadas las consideraciones asociadas al análisis en régimen transitorio, se realizan una serie de simulaciones con objeto de aproximar los efectos derivados de la conexión directa para los dos esquemas de suministro considerados. Los resultados de las simulaciones y resto de consideraciones se muestran en el Capítulo 4.

Tal como se comprobará en el análisis de resultados se han variado las características físicas y funcionales de los elementos que integran el modelo en aras de conocer su grado de influencia. La modificación de las características propias de la red general de distribución trata de ubicar los edificios modelados en diferentes zonas de la red (por ejemplo sectores en los que el diámetro de la tubería principal varía su valor), o en instantes en los que cambian las condiciones de suministro (presión de entrega, caudal que circula por la tubería de la RGD, etc.). Estas modificaciones sobre las características particulares de la instalación piloto originan diferentes escenarios de simulación que bien podrían corresponderse con el modelo asociado a diferentes edificios con aspiración directa. 
Capítulo 3

\section{Análisis de los efectos de la conexión directa en régimen permanente}




\subsection{INTRODUCCIÓN}

El flujo de agua normal por un sector de red genera una caída de presión variable en el tiempo, y es función de las propiedades de los elementos que lo caracterizan y la carga hidráulica que soporta. En una primera iteración, variables como la longitud y diámetro del tramo, y la carga hidráulica de éste parecen ser críticos a la hora de establecer las posibles afecciones que puede soportar durante su suministro normal, pero otras consideraciones asociadas a las propias instalaciones interiores de los edificios pueden condicionar su capacidad.

En esta línea, la severidad con la que puede operar un grupo de presión conectado en directo limita en gran medida la adopción de este esquema en determinados sectores de una red de abastecimiento. Durante su funcionamiento aumentan sensiblemente los caudales que circulan por tramos de la red, situación que puede originar caídas de presión significativas, e incluso puede poner en riesgo el correcto suministro de la totalidad de usuarios. Por el contrario, sectores que muestren un dimensionado y características funcionales apropiadas reducirían la afección por la conexión directa de los grupos, y mantendrían una respuesta aceptable bajo ésta.

Como puede entenderse, el análisis del comportamiento de un tramo de red no es una tarea sencilla. Esta afirmación toma consistencia cuando se visualiza el sector dentro de un entorno mayor como es una red de abastecimiento, y por propia condición de pertenencia, la alteración de cualquier condición en ésta modifica en mayor o menor medida su comportamiento. Al mismo tiempo, las características de cada red difícilmente pueden ser extensibles para la totalidad de zonas que la integran, y menos aun se puede generalizar entre diferentes redes.

Teniendo presente estas premisas, con el presente estudio se persigue aproximar las implicaciones asociadas al suministro normal de un sector de red, simplificado éste por una conducción principal a la que se conectan las acometidas de los edificios, y en lo que respecta a su capacidad de suministro bajo diferentes esquemas de las instalaciones de los edificios, en aras de comprobar qué parámetros son susceptibles de aumentar la severidad con la que opera. 
Los resultados directos del estudio pueden advertir sobre la conveniencia de modificar incluso las propiedades actuales de los elementos de la instalación general con vistas a la eliminación de los depósitos atmosféricos, o la posibilidad de adoptar una alimentación directa de las instalaciones interiores en aquellas situaciones en las que sea factible. En cualquier caso, aportarán una aproximación sobre la capacidad de la conducción principal de un tramo para soportar un esquema u otro en función de sus características particulares.

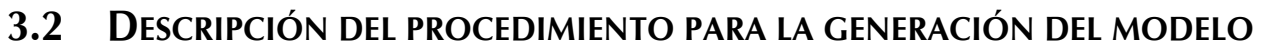

\subsubsection{Hipótesis de partida}

Si bien en el Capítulo 2 se introdujeron las consideraciones básicas asociadas a la elaboración de un modelo de simulación para el análisis de su capacidad en régimen permanente, es necesario atender a una serie de reflexiones sobre las consideraciones tomadas para desarrollar el presente capítulo.

Como se ha indicado, dada la complejidad inherente a la consideración de una red de forma global, en el análisis se ha aislado un sector característico con el propósito de simplificar el problema. Esta segregación puede aportar una aproximación sobre los efectos originados en una red de menor tamaño. En cualquier caso, en la interpretación de resultados no se debe perder de vista las implicaciones asociadas a la pertenencia del sector a un entorno mayor.

Por otro lado, y dado que se dispone de datos de consumo asociados al suministro en el entorno residencial (principalmente de viviendas unifamiliares tipo piso), los resultados de los modelos no contemplan aquellos usos diferentes a los domésticos (tales como oficinas, locales comerciales, etc.). Si bien las pautas de consumo pueden diferir en mayor o menor medida, la extrapolación de resultados a sectores con una contribución elevada de consumo no doméstico puede no resultar directa. Adicionalmente, asociado a los datos de consumo utilizados, y dadas las notables diferencias que pueden darse sobre las pautas de consumo doméstico en diferentes ámbitos, se debe atender a los patrones propios de cada emplazamiento.

Asociado a las instalaciones interiores modeladas, la simplificación realizada mantiene un mismo esquema y número de viviendas por edificio. Debe tenerse presente que esta situación dista de lo que comúnmente sucede en cualquier sector de red, pero el procedimiento reduce notablemente la obtención y análisis de resultados. Del mismo modo, los procedimientos de dimensionado de los componentes de la instalación se han realizado siguiendo los requisitos fijados en la normativa vigente, pudiendo variar respecto a las soluciones adoptadas por cada instalador. 


\subsubsection{Caracterización de las simulaciones}

Tal como se introdujo en el capítulo anterior, para comprobar el efecto asociado a la aspiración en directo de un conjunto de instalaciones se ha modelado un sector genérico de una red de distribución (Figura C3-1). Al mismo tiempo se han construido diferentes escenarios a partir de la variación de las características constructivas de los elementos integrantes, en aras de conocer cómo afecta el cambio de sus propiedades y su influencia respecto a los diferentes esquemas que se adoptan en la instalación interior.

Atendiendo a la Tabla C2-3, cada escenario está caracterizado por unas determinadas propiedades, por tanto la modificación de alguna de las variables que definen el sector da lugar a un nuevo escenario. Las variables modificadas son:

- Diámetro de la tubería principal del tramo

- Número de edificios del tramo

- Distancia entre acometidas (valor constante en todos los escenarios y que interviene en el tamaño final del tramo)

Por otro lado, y en lo referente a la carga hidráulica del sector se han variado las características de los edificios conectados a partir de las siguientes variables:

- Número de viviendas por edificio

- Demanda base de una vivienda (litros consumidos por hora)

- Variación temporal de la demanda (función del esquema adoptado en las instalaciones interiores y de las viviendas seleccionadas de la base de datos de consumo)

La severidad asociada a la carga hidráulica de cada edificio es función del propio esquema de suministro adoptado en su instalación interior, por ello se evalúan para un mismo escenario de red y una misma carga hidráulica, las solicitaciones asociadas a diferentes esquemas. Esta media permite realizar una comparación directa de las implicaciones asociadas a la adopción de un tipo de esquema u otro en la instalación interior del edificio.

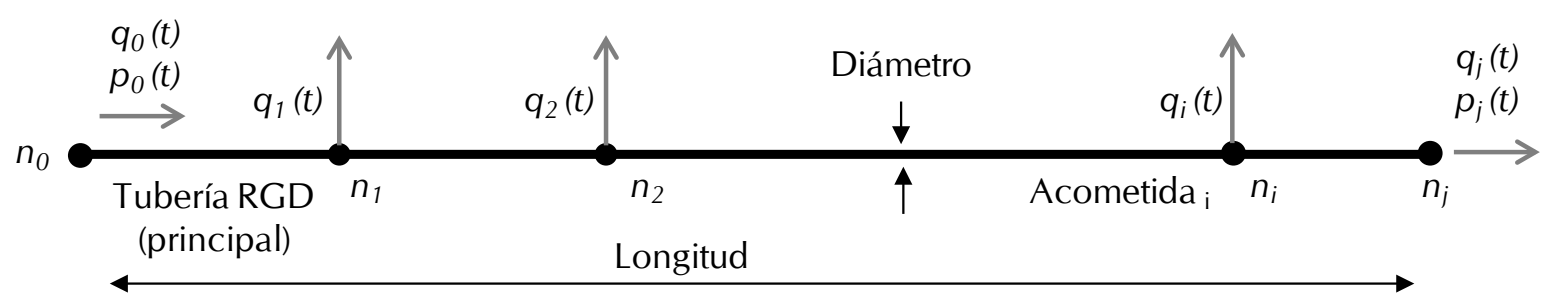

FIGURA C3-1. REPRESENTACIÓN ESQUEMÁTICA DEL MODELO HIDRÁULICO ANALIZADO 
De cada escenario construido se realiza la simulación de una hora completa de suministro. Para representar la variabilidad en la demanda de los usuarios y su efecto, se ha discretizado la hora de simulación en intervalos de 10 segundos, obteniendo la respuesta del modelo para cada uno de estos instantes (téngase en cuenta que los datos de consumo de las viviendas de la base de datos presentan una discretización de este valor).

La respuesta de cada simulación se materializada a partir de la serie temporal de presiones $p(t)$ que se origina en el nudo final de tramo $n_{j}$. A continuación se muestra como ejemplo ilustrativo algunos resultados parciales del estudio para un escenario referencia. Éste está constituido por 15 nudos (13 acometidas), un valor fijo de 35 viviendas por acometida, un diámetro interior de la conducción principal de $96 \mathrm{~mm}$, una demanda media horaria por vivienda de 35 litros, y una longitud total del tramo de 560 metros (función del número de acometidas y su equidistancia). La Figura C3-2 muestra los resultados para el escenario de referencia bajo una conexión en directo sin grupo de presión (Tipo I). Cada registro de la serie se corresponde con el resultado de la simulación obtenido con Epanet para cada instante discretizado.

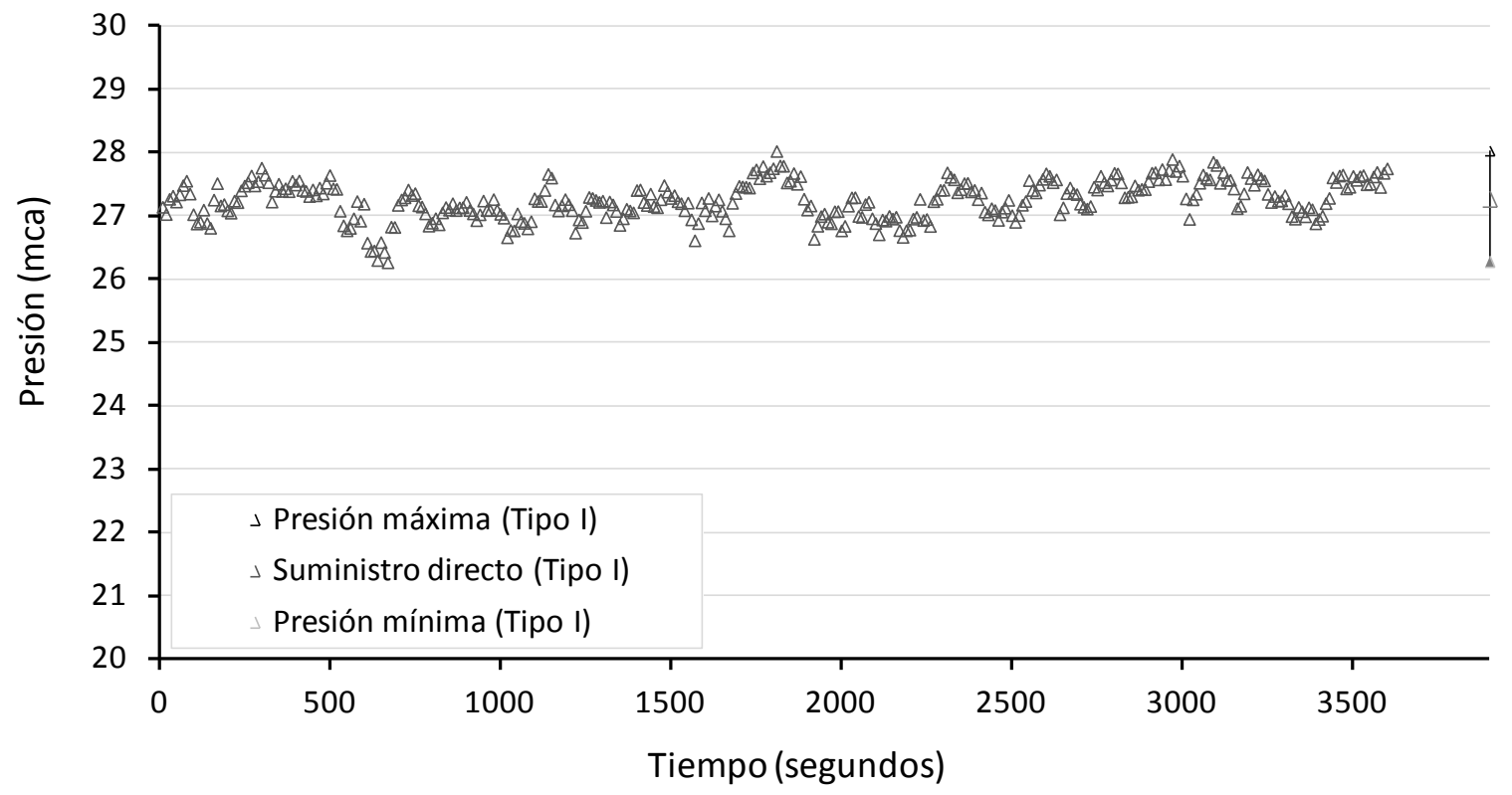

FIGURA C3-2. VARIACIÓN DE LA PRESIÓN EN EL NUDO NI PARA EL ESCENARIO DE REFERENCIA (ESQUEMA TIPO I)

De cada simulación y cada esquema de suministro es posible almacenar los datos correspondientes a las presiones extremas originadas en el nudo $n_{j}$, así como la presión media característica de la simulación. Es importante considerar que de los valores anteriores (valores extremos y valor medio) el correspondiente a la presión mínima en el tramo $p_{i}^{\min }$ es el valor que se asocia a la situación más crítica de suministro, y se corresponde con la disposición que mayor caída de presión origina para el escenario modelado. 
Por otro lado y dado el condicionamiento que puede experimentar la respuesta del sector en función de los datos de consumo de las viviendas seleccionadas, se realiza un total de 200 simulaciones por escenario, seleccionando en cada una de ellas datos de diferentes viviendas de forma aleatoria (cada simulación acude a los registros de una determinada vivienda, para un determinado día y hora en la que la vivienda tiene consumo). Si bien es posible realizar un mayor número de simulaciones, el tiempo computacional requerido, y dadas las simplificaciones realizadas para analizar la respuesta del sector, no se estima que los resultados derivados puedan contribuir de forma significativa a las conclusiones del estudio. Del mismo modo, no debe perderse de vista que el objeto del presente capítulo además de proponer esta metodología, fija las 200 simulaciones como un número razonable para obtener una respuesta aproximada de la influencia asociada a los datos de las viviendas.

Respecto a los resultados analizados, la variable utilizada para caracterizar la respuesta de cada simulación es la pendiente hidráulica máxima en el tramo. Para el modelo de estudio la pendiente hidráulica valora las pérdidas de carga asociadas al suministro, y tiene en cuenta el mayor o menor descenso de presión que se da en el nudo más desfavorable del sector, así como la longitud total de éste. Para cada simulación la pendiente hidráulica se evalúa como diferencia entre la presión a la entrada del tramo po (se mantiene constante a lo largo de la simulación) y la presión mínima en el punto más desfavorable $p_{i}^{\text {min }}$.

$$
j=\frac{p_{0}(t)-p_{j}(t)}{L} \rightarrow j_{\max }=\frac{p_{0}-p_{j}^{\min }}{L}
$$

Una mayor o menor pendiente hidráulica en un tramo puede advertir sobre una excesiva carga hidráulica soportada por la conducción principal, favoreciendo al mismo tiempo el desarrollo de velocidades de circulación excesivas. A su vez, las pérdidas de carga originadas en la conducción reducen el valor de presión disponible en los diferentes puntos de consumo, repercutiendo de forma directa sobre la vertiente energética. Por ello los valores obtenidos de la pendiente hidráulica asociados a cada escenario pueden orientar sobre la capacidad de la conducción bajo unas determinadas condiciones de operación, o por el contrario evidenciar su insuficiencia.

De forma orientativa es posible establecer un límite máximo de la pendiente hidráulica en redes de distribución en el entorno residencial no superior a los 10 $\mathrm{mca} / \mathrm{km}$ de tubería. Si bien es posible operar con niveles más elevados, la limitación de su valor puede favorecer la mejora del rendimiento energético en el suministro. 
La Figura C3-3 muestra para el escenario de referencia y bajo el esquema Tipo I los resultados asociados a un conjunto de 200 simulaciones. Para un instante determinado se cuenta con una terna formada por la presión máxima $p_{\max }$, media $p_{\operatorname{med}} \mathrm{y}$ mínima $p_{\min }$ correspondiente a la simulación, de forma similar a la Figura C3-2 pero en este caso para un conjunto de simulaciones.

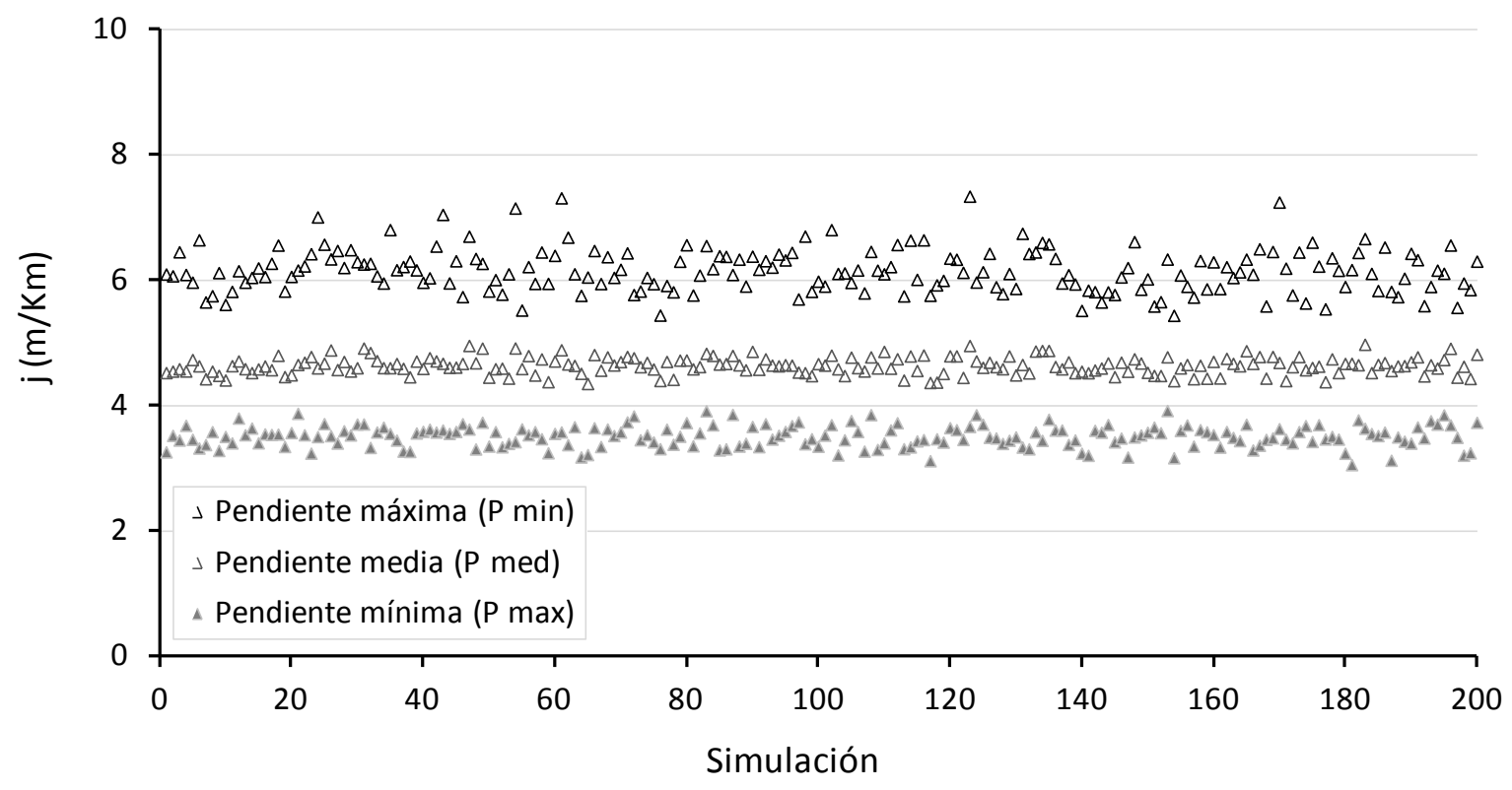

FIGURA C3-3. RESULTADO DE 200 SIMULACIONES PARA EL ESCENARIO DE REFERENCIA (ESQUEMA TIPO I)

Como se observa cada serie de 200 simulaciones tiene un valor de pendiente hidráulica diferente debido a la variación de la carga hidráulica en cada periodo de muestreo. A diferencia de la situación anterior, esta variación no sólo depende de la carga hidráulica asociada a cada edificio, influye notablemente la localización de los puntos de consumo en el sector y la simultaneidad que se origina en el consumo de la totalidad de viviendas. En esta línea la localización de edificios con elevada simultaneidad de demanda en las acometidas terminales del sector puede dar lugar a una situación hidráulica más desfavorable tal como se comprobará más adelante.

En cualquier caso debe tenerse presente que el análisis sobre la localización de las viviendas con mayor frecuencia de consumo, y su casuística relacionada con su vinculación a una determinada acometida es complejo dado el carácter estocástico del fenómeno. Por ello en el estudio se analiza el comportamiento del sector a partir de la carga aleatoria de viviendas, y de la evaluación de la pendiente hidráulica máxima alcanzada en cada una de las simulaciones, ya que esta serie indirectamente tiene en cuenta las situaciones de suministro más desfavorables que se pueden dar en el sector, asociadas tanto a la posible simultaneidad en la demanda como en la localización de las viviendas y edificios dentro del sector. 
La siguiente gráfica incluye la variación que experimente la serie de pendientes hidráulicas máximas obtenidas en las diferentes simulaciones para el escenario de referencia. Esta serie está asociada a la presión mínima que se alcanza en cada simulación $\left(p_{\min }\right)$ y por tanto tiene en cuenta las condiciones más desfavorables alcanzadas en el escenario para el conjunto de simulaciones. El valor característico de la serie es su valor promedio ya que representa el conjunto de respuestas críticas en el nudo $n_{j}$. Más adelante se realiza un análisis sobre la dispersión de valores de la serie en aras de ajustar su comportamiento a una distribución tipo que permita construir unos intervalos de confianza adecuados.

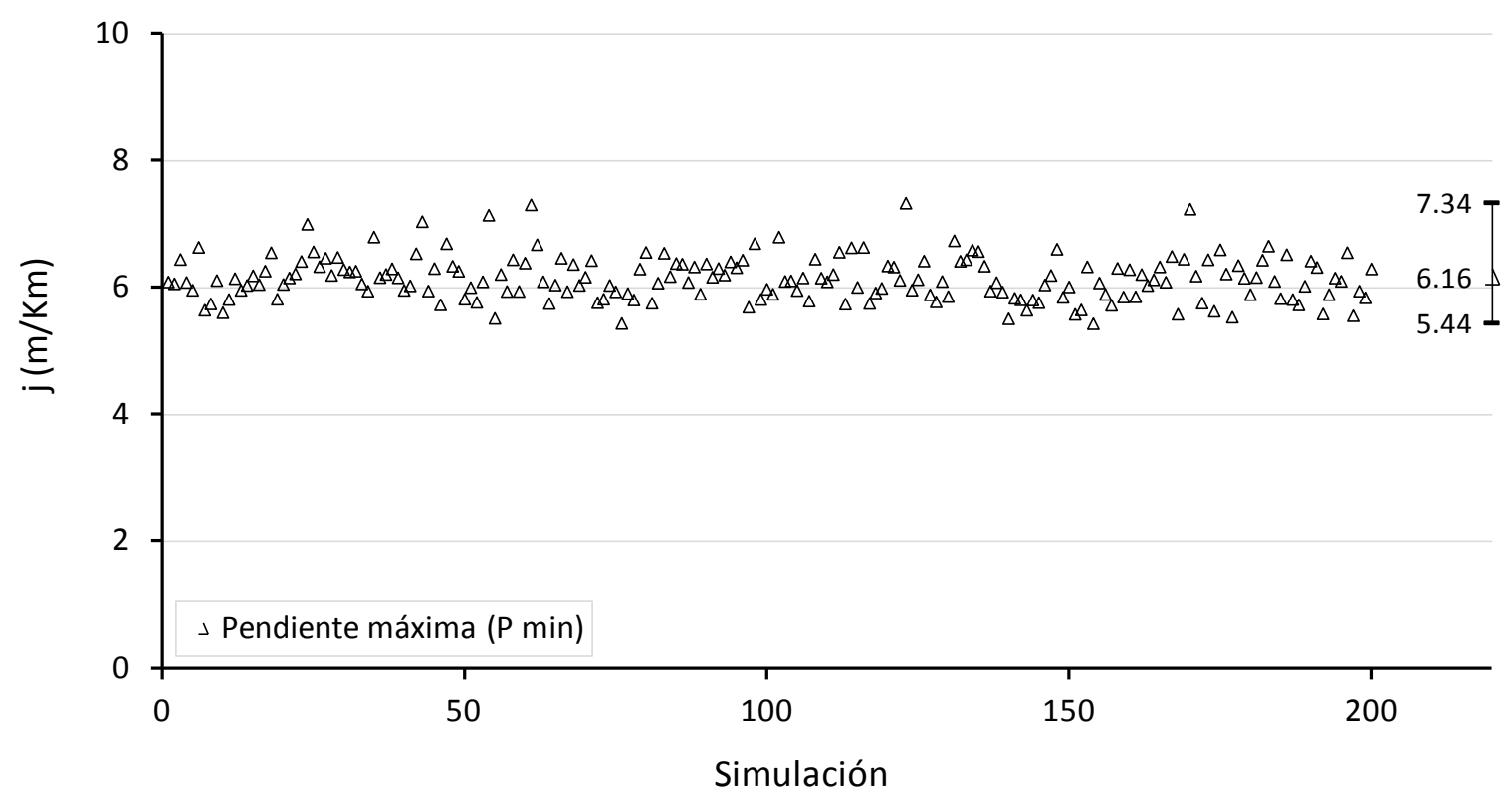

FIGURA C3-4. PENDIENTE HIDRÁULICA MÁXIMA Y RANGO DE VARIACIÓN PARA EL ESCENARIO DE REFERENCIA

En cualquier caso y de forma estricta, la probabilidad de ocurrencia de la máxima pendiente hidráulica de un conjunto de simulaciones se corresponde con 200 horas de suministro en el periodo de máxima demanda del día. En la práctica la probabilidad de ocurrencia de dicha pérdida de carga es significativamente menor puesto que los niveles de carga de consumo utilizados en las simulaciones atienden a una situación de demanda desfavorable, en la que todas las viviendas mantienen un uso severo del recurso (en los escenarios simulados se ha considerado una demanda próxima a 30 litros por vivienda y hora).

Del mismo modo se ha considerado que en la hora de suministro todas las viviendas del sector hacen uso del recurso. Situación ilógica si se atiende a los valores usuales de simultaneidad en el uso, y por tanto deberá ser considerada una vez se evalúe la carga hidráulica asociada a cada simulación. 
Por otro lado, si se atiende al tiempo de muestreo (la carga hidráulica del modelo presenta una frecuencia entre registros mínima de 10 segundos), se puede comprobar que los resultados obtenidos estarían asociados a caídas de presión que se originan en la red en un periodo de 10 segundos. Tal y como puede entenderse, la aparición de una caída de presión máxima con esta duración de forma puntual no tiene por qué suponer ningún riesgo significativo en el tramo. En esta línea son fácilmente admitidas las fluctuaciones de presión de corta duración que experimenta cualquier red (sin atender a las variaciones originadas por fenómenos transitorios).

Si en la carga hidráulica del modelo se considera un intervalo de tiempo entre registros de volumen mayor a 10 segundos, por ejemplo 30 segundos, el caudal instantáneo experimenta una reducción de su magnitud. El efecto puede ser fácilmente asimilable a partir de la Figura C3-5 en la que se evalúa cómo se reduce el caudal instantáneo demandado de una vivienda a medida que aumenta el intervalo temporal entre registros. Este efecto es mucho más sensible cuando se considera una agrupación de viviendas dada la lógica simultaneidad asociada al uso. Por lo general, el análisis con un mayor intervalo temporal $d t$ entre registros de consumo redunda en una reducción del caudal promedio simultáneo de una vivienda para dicho periodo, y por tanto menores solicitaciones en el tramo.

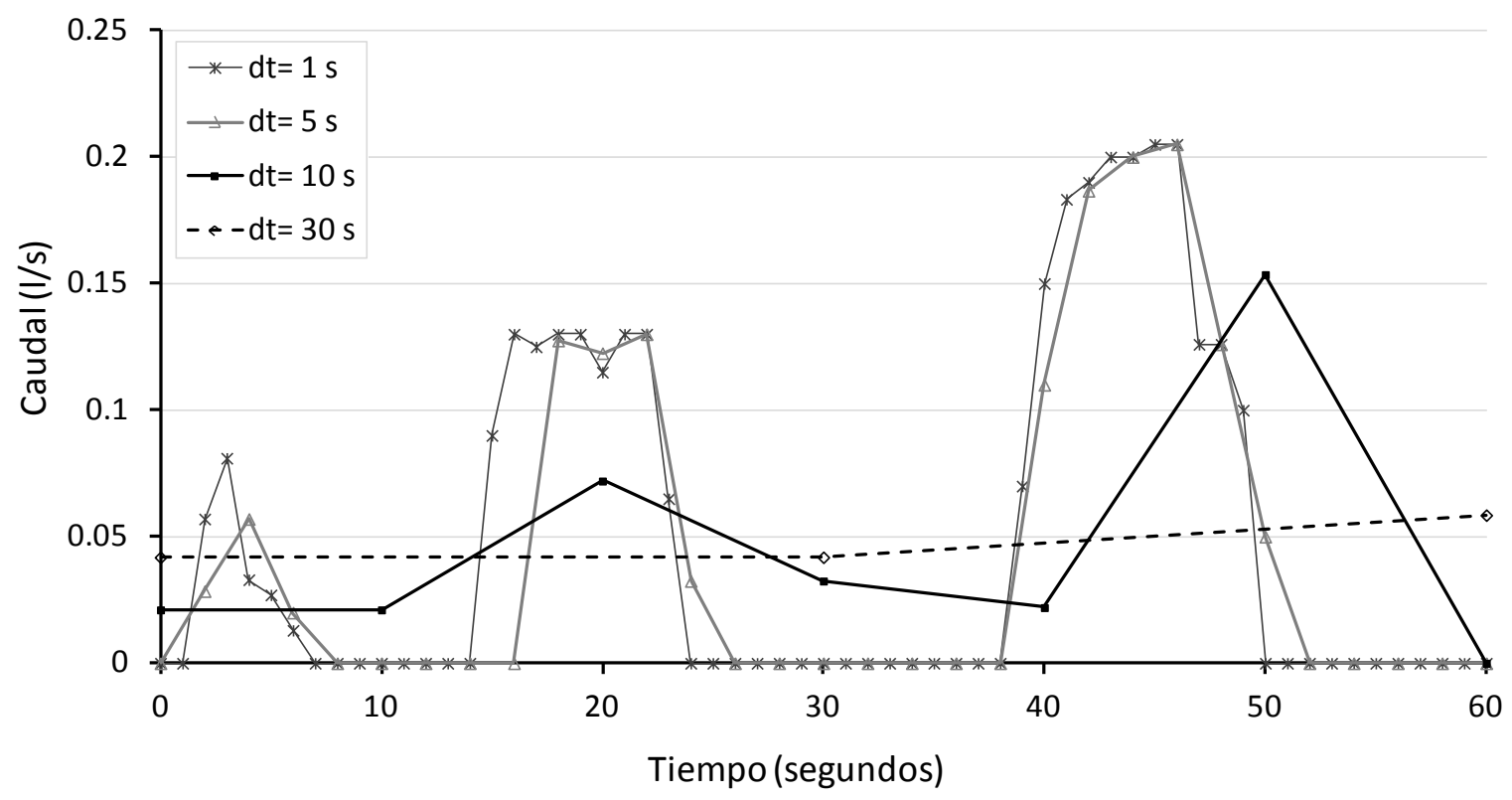

FIGURA C3-5. VARIACIÓN DEL CAUDAL PROMEDIO EN FUNCIÓN DEL INTERVALO TEMPORAL DE CÁLCULO

Este efecto es especialmente significativo cuando el esquema de la instalación interior del edificio cuenta con viviendas suministradas en directo sin grupo de presión (Tipo I y Tipo III), ya que los factores de modulación temporal máximos asociados a las viviendas reducirían significativamente su valor, y por tanto la carga hidráulica en los nudos correspondientes sería menos severa. 
Como muestra de lo anterior, para el escenario de referencia se han realizado simulaciones modificando el incremento de tiempo entre registros de caudal, y se ha representado la variación porcentual de la presión experimentada en el nudo final (considerándose como referencia los resultados de la simulación para dt =10 s).

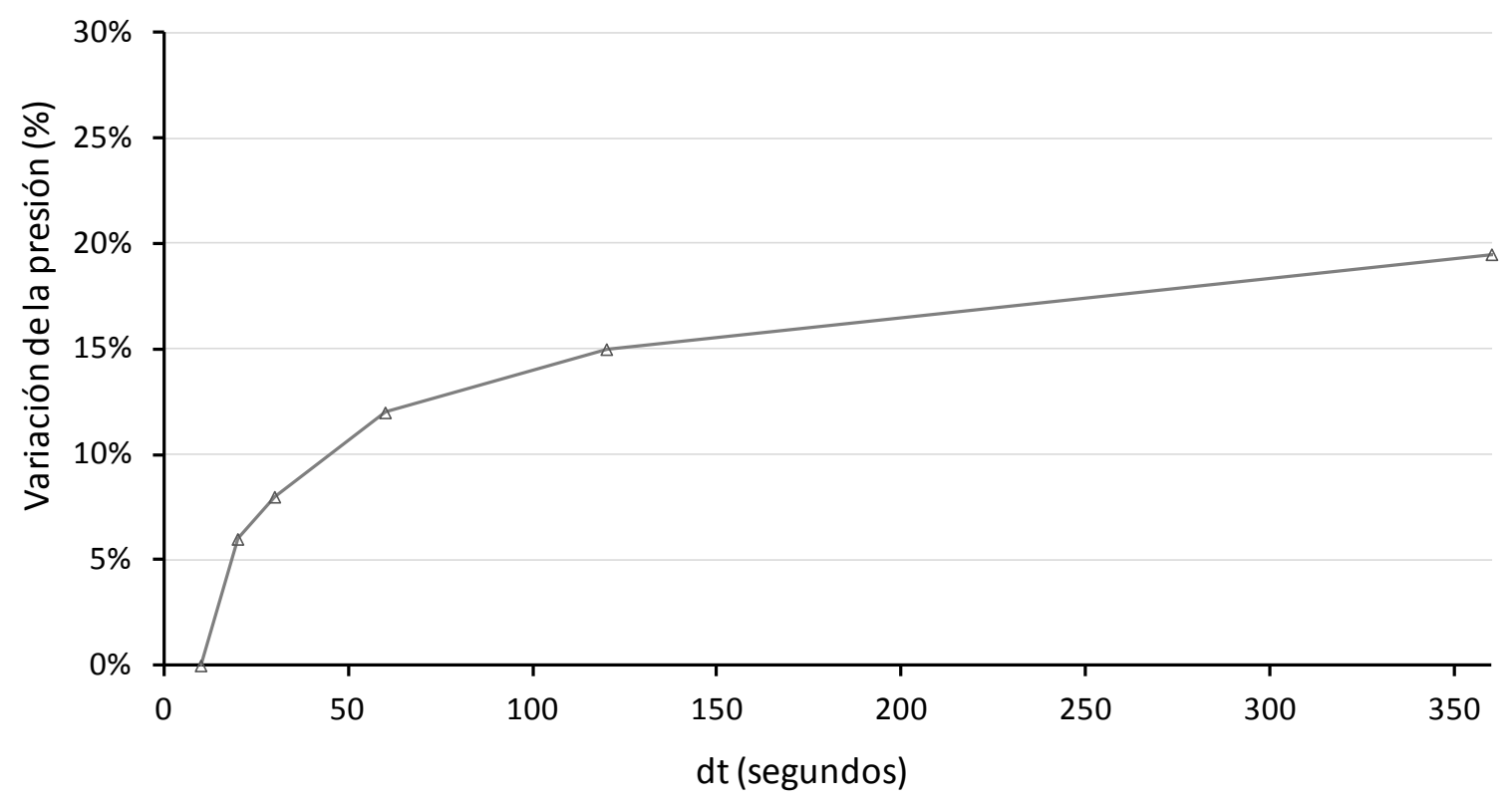

FIGURA C3-6. INFLUENCIA DEL TIEMPO ENTRE REGISTROS PARA EL ESCENARIO DE REFERENCIA

Como puede observarse un aumento del incremento del tiempo de muestreo origina menores caídas de presión en el nudo extremo, derivado de menores caudales instantáneos asociados a los consumidores. Este efecto es principalmente notable en los valores extremos de presión (presión mínima), pero en el caso de las presiones promedio de un conjunto de 200 simulaciones se mantiene prácticamente inalterable. Del mismo modo, las características particulares del escenario condicionan las solicitaciones en la instalación (dada la relación entre las pérdidas originadas en el tramo y el caudal demandado). En cualquier caso conviene tener presente este efecto.

En el caso de instalaciones con grupos de presión de velocidad fija, el llenado y vaciado del depósito de presión forzará el arranque de las bombas de la instalación en función de la presión alcanzada en el interior del depósito, siendo los caudales demandados independientes del intervalo de tiempo considerado. Por tanto este fenómeno no presentaría una influencia tan importante como en el caso anterior, si bien pueden verse alterados los instantes de arranque de los grupos, y con éste la posible simultaneidad en el arranque de varios equipos de un mismo sector.

En el esquema Tipo III los factores de modulación asociados a la carga hidráulica de las viviendas conectadas en directo verían variado su valor con un aumento del tiempo de muestreo, reduciéndose con ello las solicitaciones extremas. El efecto es menos sensible a medida que aumenta la proporción de viviendas con grupo. 


\subsubsection{Comparación de los comportamientos de los diferentes esquemas}

El descenso de presión originado en el sector en régimen permanente está condicionado por las propiedades de los elementos del modelo, y por la carga hidráulica que soporta el sector. A su vez la carga hidráulica depende de las pautas de consumo de los usuarios y del esquema de suministro.

Para comprobar lo anterior se ha simulado la respuesta del sector de referencia bajo diferentes esquemas con conexión directa, adoptados éstos de forma generalizada por todos los edificios del sector. En estas simulaciones se ha mantenido la misma demanda temporal de las viviendas conectadas para los diferentes esquemas (en cada instante las viviendas y periodos seleccionados de la base de datos son los mismos).

\subsubsection{Influencia del esquema de suministro sobre la presión en $n_{j}$}

La Figura C3-7 muestra para cada uno de los esquemas de suministro comentados la variación temporal de la presión $p_{j}(t)$ en el nudo extremo, para una simulación de 1 hora de duración. Como puede comprobarse la incorporación de un esquema u otro influye de forma significativa sobre el rango de variación de la presión mínima en el tramo.

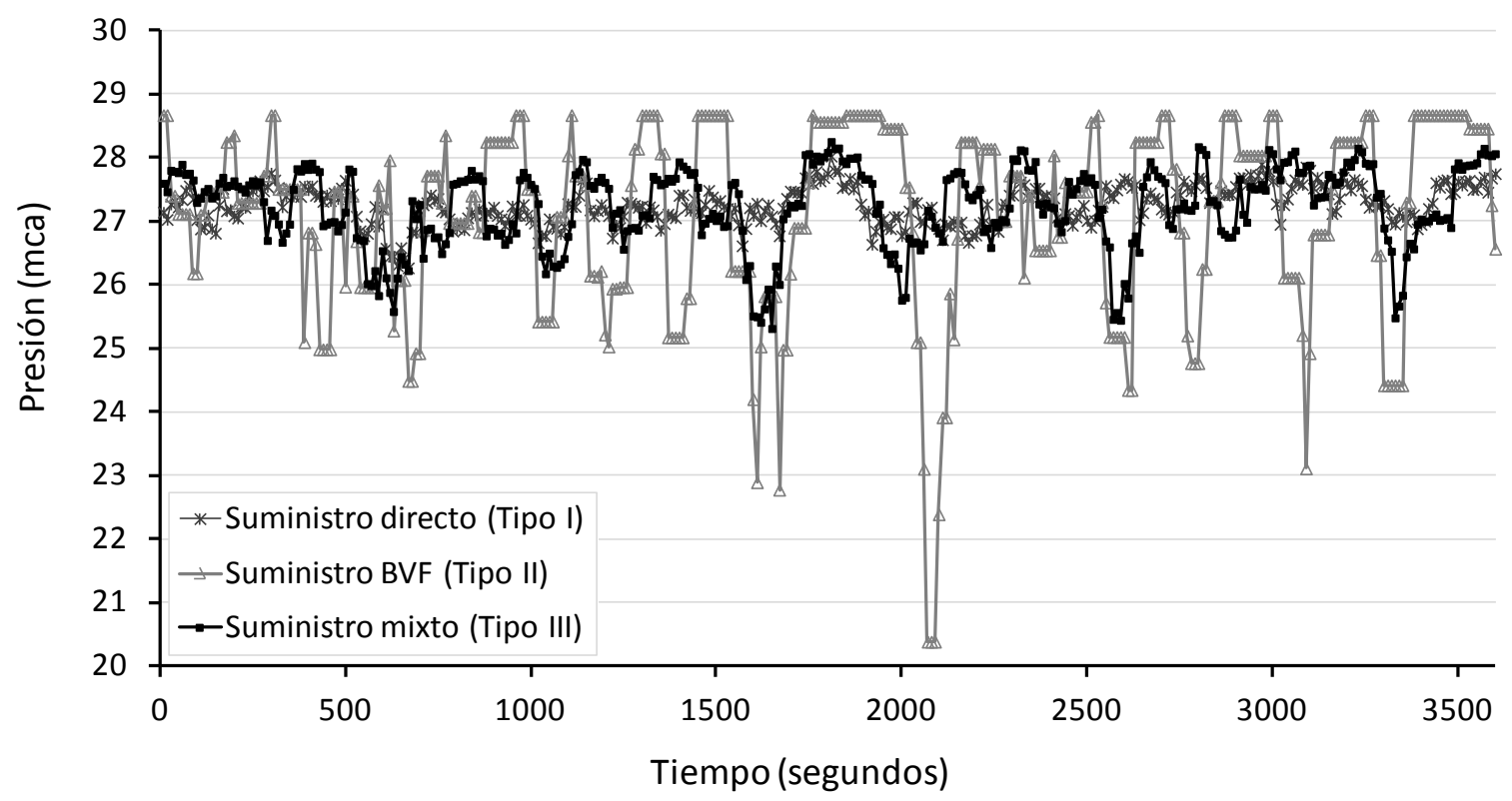

FIGURA C3-7. VARIACIÓN DE PRESIÓN EN FUNCIÓN DEL ESQUEMA ADOPTADO EN LA INSTALACIÓN INTERIOR

El esquema con un funcionamiento más leve es aquél que mantiene el suministro de la totalidad de viviendas conectadas en directo sin grupo de presión (Tipo I). Para este esquema se puede observar cómo la presión mínima alcanzada mantiene un valor ligeramente superior que el resto de esquemas. Del mismo modo se origina una ligera oscilación de la presión en el nudo final debido a una variación continua de la demanda 
instantánea de las viviendas. La presión máxima se corresponde con instantes en los que la demanda es más baja, y por tanto el caudal asociado a mantener una velocidad mínima de $0,5 \mathrm{~m} / \mathrm{s}$ en el tramo adquiriría un notable protagonismo. Respecto al esquema de suministro equipado con bombas de velocidad variable (Tipo IV) y tal como se apuntó en el capítulo anterior, la respuesta sería próxima a la originada con un suministro Tipo I, originándose una ligera variación de la presión durante los primeros instantes de arranque de la bomba función de la calidad del ajuste del controlador.

Por el contrario el esquema con funcionamiento más severo es aquél que mantiene un suministro de la totalidad de viviendas mediante grupo de presión de velocidad fija (Tipo II). En esta situación la caída de presión originada en el tramo es función del caudal total demandado por las diferentes acometidas, condicionado por el número de bombas con funcionamiento simultáneo. Concretamente la presión mínima tiene lugar para una concurrencia en el arranque de 5 grupos de presión (ver Figura C38). También se destaca una considerable oscilación de los valores de presión en cada instante debido al funcionamiento alternativo y de variable localización de los grupos. Al mismo tiempo este esquema origina la mínima caída de presión cuando no hay ningún grupo de bombeo en funcionamiento (suministro desde calderín), y la caída de presión es sólo función del flujo constante fijado en el sector.

Por otro lado cuando se simula la variación de presión para un suministro mixto Tipo III (en el que el 33\% se corresponde con viviendas suministradas con bomba de velocidad fija y el resto suministro en directo sin grupo), se puede observar cómo las solicitaciones mínimas son ligeramente inferiores a las del Tipo I. Esto se debe a que redunda un menor número de viviendas conectadas en directo con consumo simultáneo, situación que tiene lugar cuando no hay grupos en funcionamiento. Por el contrario el arranque de grupos de presión aumenta sensiblemente la caída de presión en el tramo respecto a este esquema, pero las solicitaciones resultan inferiores que las correspondientes al esquema Tipo II al disponer de grupos de presión de menor tamaño.

\subsubsection{Influencia del esquema de suministro sobre el caudal de entrada al tramo}

Si se analizan los caudales totales demandados por el conjunto de acometidas del tramo (caudal de entrada al tramo eliminando la componente de velocidad de 0,5 $\mathrm{m} / \mathrm{s}$ ), puede comprobarse del mismo modo un comportamiento dispar entre los diferentes esquemas de suministro, siendo el comportamiento más severo aquél que mantiene un mayor número de viviendas suministradas con bomba de velocidad fija.

Para el esquema Tipo II se alternan situaciones en las que el caudal demandado por las acometidas es nulo, o bien adquiere un valor máximo asociado a varias bombas funcionando de forma simultánea. Para este esquema es fácil conocer el número de grupos con funcionamiento simultáneo; para el caso simulado, el número máximo de 
bombas que solapan su funcionamiento es de 5 (evidenciado a partir del número de escalones de caudal que presenta la serie). Una variación en el número de bombas en funcionamiento origina una variación significativa del caudal inyectado en el tramo, al mismo tiempo que genera una caída de presión que puede ser más o menos sensible en función de las características particulares del escenario y la localización de éstas.

Por otro lado, parte de los instantes de suministro están asociados a un caudal de bombeo nulo (aproximadamente un $20 \%$ ), situación en la que la presión en el tramo toma valores máximos. La variación del número de edificios del tramo puede implicar una variación del porcentaje anterior, ya que altera la simultaneidad en funcionamiento concurrente de bombas. Analizando un histograma de frecuencias se puede observar que la situación de máxima demanda tiene una repetibilidad reducida $(2,2 \%$ del tiempo de simulación para el escenario de referencia), y la generación de una presión mínima reduce incluso la frecuencia de aparición (aproximadamente un 0,8\%).

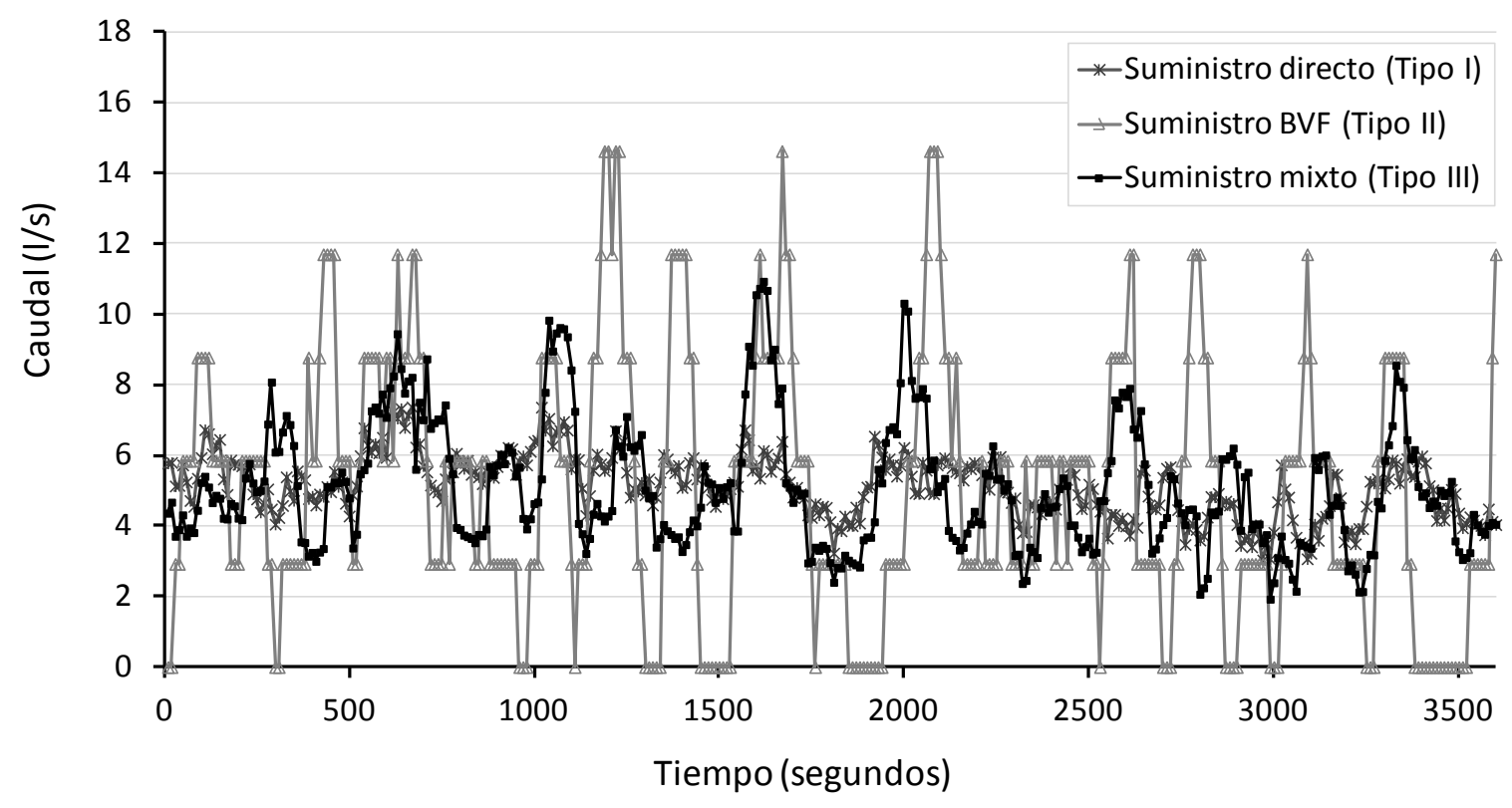

FIGURA C3-8. VARIACIÓN DEL CAUDAL PARA UNA HORA DE SIMULACIÓN

Para un suministro directo sin bomba la variación de caudal es más limitada y oscila entre 3 y $7 \mathrm{l} / \mathrm{s}$ para el escenario modelado, frente a los 14,8 l/s correspondientes a 5 bombas con funcionamiento simultáneo (Tipo II). En el caso del suministro Tipo III el caudal mínimo es de $1,9 \mathrm{l} / \mathrm{s}$ y el caudal máximo es próximo a $11 \mathrm{l} / \mathrm{s}$, coincidiendo con la suma de varios grupos con funcionamiento simultáneo y consumo directo. En cualquier caso es posible que bajo este esquema se origine en un determinado instante un caudal demandado nulo, correspondiente a un número nulo de bombas en funcionamiento y a una demanda nula de las viviendas (piénsese en un periodo nocturno en el que se reduce significativamente el caudal demandado de forma intencionada). 
Por otro lado y tal como puede observarse en las figuras anteriores, para un determinado escenario y esquema de suministro, un mismo caudal demandado no siempre origina una misma caída de presión, ésta es función de la distribución de flujo que se da en el tramo. En esta línea no es lo mismo que los grupos de presión se localicen al principio del tramo, que en la parte final del mismo. Esta última situación originaría una mayor caída de presión al darse mayores pérdidas en régimen permanente. Este fenómeno es menos sensible en escenarios con variaciones más reducidas de caudal, como los correspondientes a esquemas sin grupos de presión, y en los que las características dimensionales favorecen la aparición de menores caídas de presión. En esta línea se ha observado que bajo el esquema Tipo I, las variaciones de caudal originadas de forma continua (prácticamente sin variaciones bruscas en la demanda) favorecen la aparición de caídas de presión que mantienen una correlación elevada con la serie de caudales (Figura C3-9).

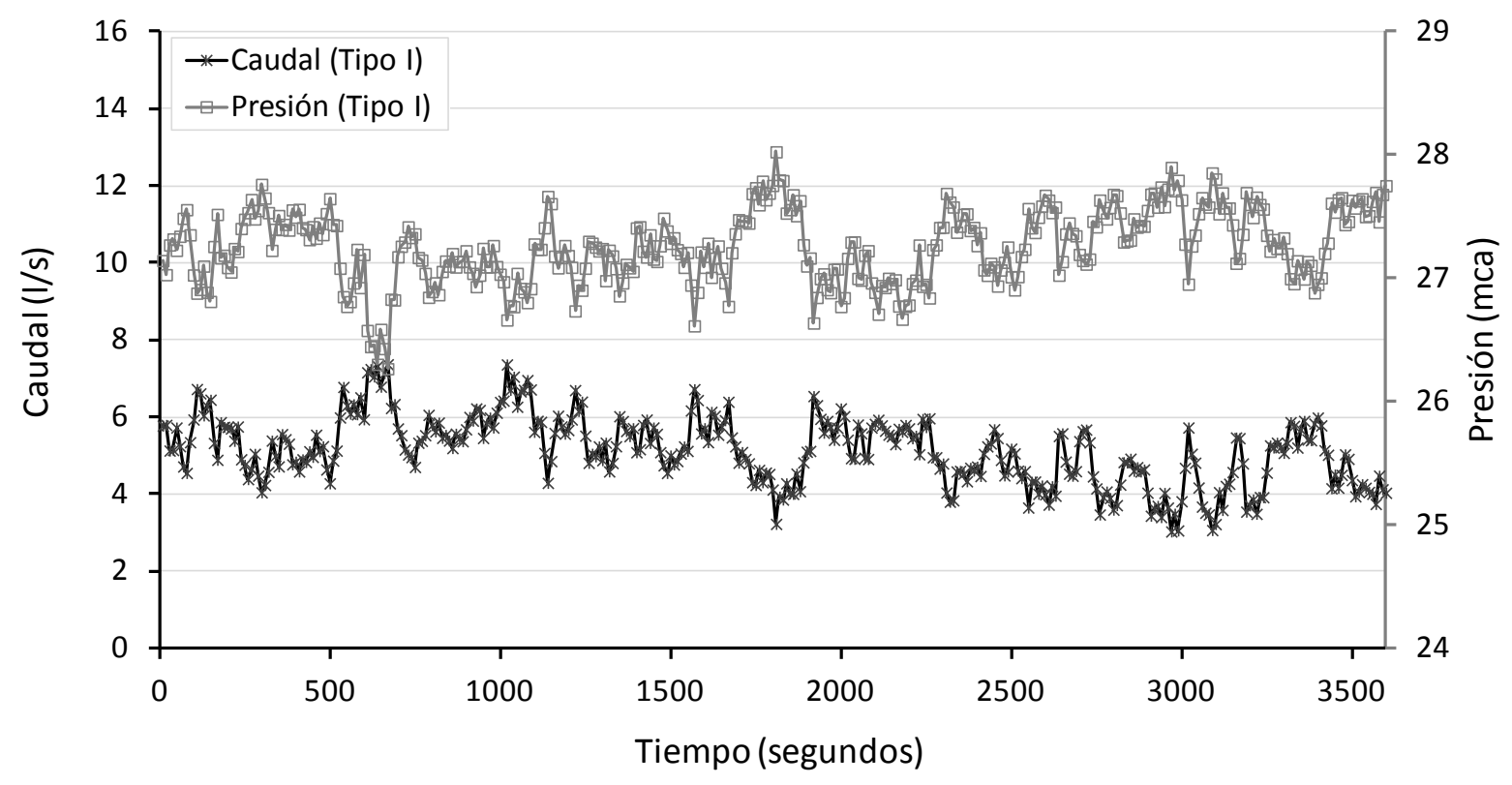

FIGURA C3-9. CORRELACIÓN ENTRE EL CAUDAL Y LA PRESIÓN (ESQUEMA TIPO I)

Esta situación se modifica ligeramente en aquellos esquemas que cuentan con grupo de presión y por tanto generan caudales mayores para el mismo escenario. En el caso de que todas las viviendas estén suministradas con grupos de presión de velocidad fija el caudal demandado en el tramo no siempre origina una misma caída de presión, ya que el efecto sobre la localización de los grupos en funcionamiento presenta una mayor influencia (como puede entenderse esta influencia en cualquier caso es función de las características de la red). En la siguiente figura puede apreciarse situaciones en las que el caudal total circulante por el tramo presenta un valor elevado por coincidir varios grupos de presión en funcionamiento simultáneo (aproximadamente en los instantes $\mathrm{t}=1200 \mathrm{~s}, \mathrm{t}=1600 \mathrm{~s}$ y $\mathrm{t}=2000 \mathrm{~s}$ ), pero aun siendo el caudal punta coincidente la presión mínima registrada no toma un valor homogéneo. 


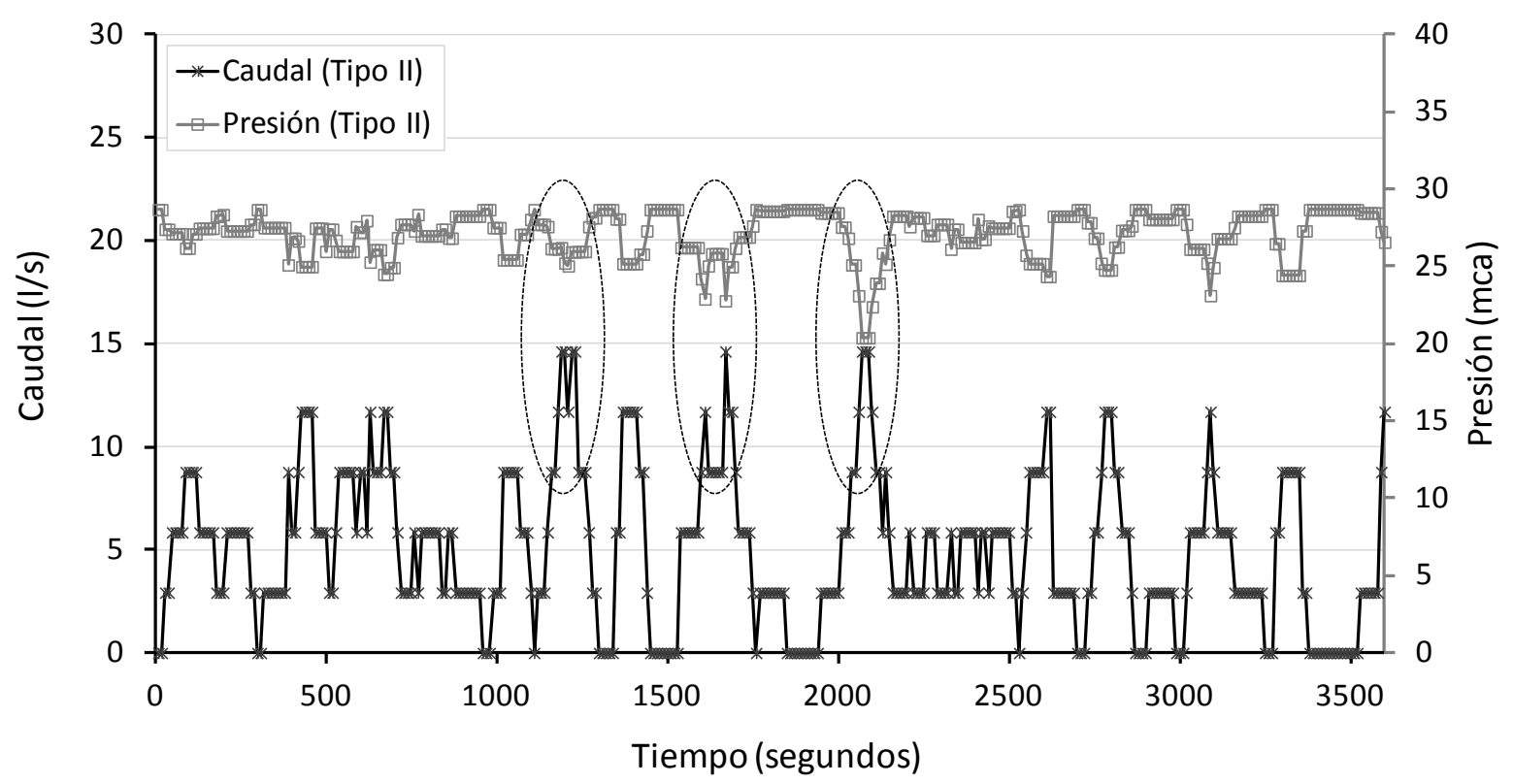

FIGURA C3-10. CORRELACIÓN ENTRE EL CAUDAL Y LA PRESIÓN (ESQUEMA TIPO II)

A la vista de los resultados anteriores se puede concluir que el esquema Tipo II de forma generalizada presenta un comportamiento más severo que aquellos esquemas que mantienen el suministro a viviendas sin grupo o con equipo de velocidad variable, al mismo tiempo que presentan una influencia más significativa de la localización de los edificios con consumo. Adicionalmente, la relación entre el caudal y la presión muestra una menor concordancia que en aquellos esquemas que se suministra sin grupo de presión, condicionado por las características particulares del tramo.

\subsubsection{Análisis estadístico de la caída de presión de cada esquema}

Si para una simulación de 3600 s de duración en intervalos de 10 s se analiza la dispersión de la presión para cada uno de los esquemas, se puede comprobar que para una conexión directa (con o sin bombas) el esquema que mayor dispersión genera es aquél que cuenta con un mayor número y tamaño de grupos de bombeo, reduciéndose la amplitud de esta variación a medida que aumenta el número de viviendas que se alimentan en directo. Estas conclusiones se desprenden de los histogramas de frecuencias de los diferentes esquemas de suministro para una simulación de $3600 \mathrm{~s}$ de duración para el escenario de referencia (Figura C3-11). El histograma representa la función de densidad asociada a la pérdida de carga máxima provocada en cada simulación, siendo el número máximo de intervalos de cálculo para cada periodo simulado de 360. 


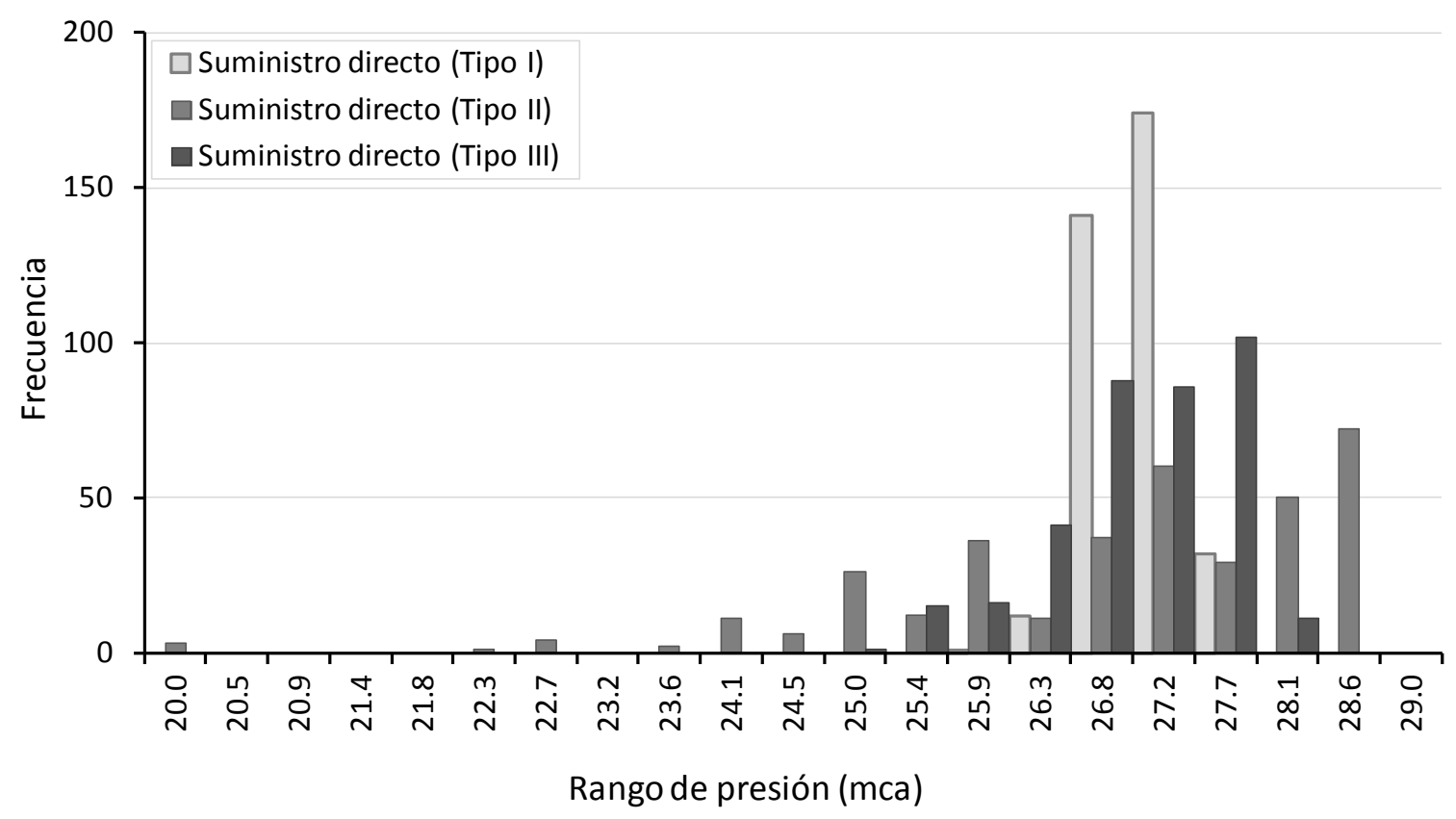

FIGURA C3-11. HISTOGRAMA DE FRECUENCIA ASOCIADO A LOS DIFERENTES ESQUEMAS DE SUMINISTRO

Como es de esperar la dispersión de presiones más significativa se da para el esquema Tipo II, observándose una dispersión no muy significativa en el esquema Tipo III, favorecida por la reducción del número de viviendas suministradas con grupo de presión $(33 \%)$. A medida que la proporción sea mayor la dispersión tenderá a los resultados del esquema Tipo II.

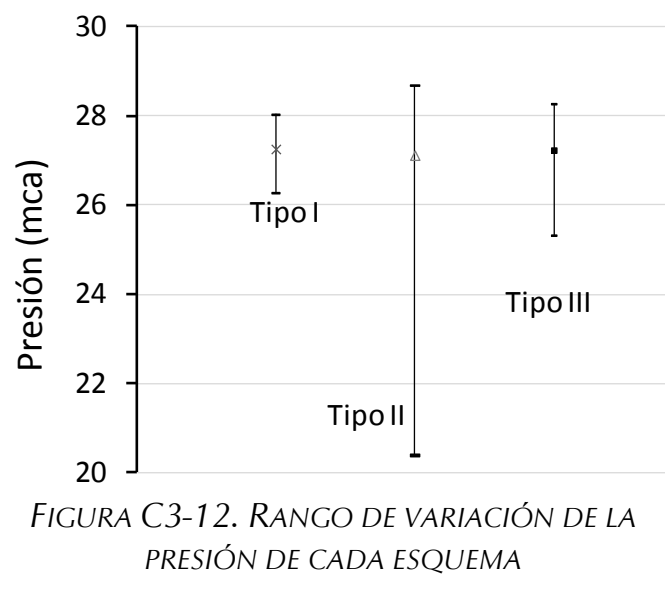

Ajuste esquema Tipo I

Las series de presiones para un suministro en directo sin grupo de bombeo aproximan a una serie de extremos, siendo la que mayor ajuste presenta la distribución tipo Weibull (Figura C3-13). Del mismo modo y tal como se comprueba, la calidad del ajuste se reduce en los extremos (principalmente en el correspondiente a la presión máxima) y en la parte intermedia de la serie.

\section{Ajuste esquema Tipo II}

En el caso de analizar el ajustar de la serie correspondiente al esquema de suministro Tipo II (Figura C3-14) se observa que este ajuste a la distribución Weibull u otras similares es complejo, principalmente en los extremos debido a los diferentes rangos caudales que se originan (función del número de grupos con funcionamiento simultáneo y localización de éstos, ya que las diferentes distribuciones espaciales de las 
bombas en funcionamiento originan flujos y caídas de presión variables que difícilmente son ajustables a una distribución convencional).

En el extremo asociado a las presiones máximas puede comprobarse que se concentra gran número de instantes en los que la bomba está parada y se mantiene la presión correspondiente al flujo constante fijado en el tramo. De nuevo esta situación no favorece el posible ajuste a una distribución convencional.

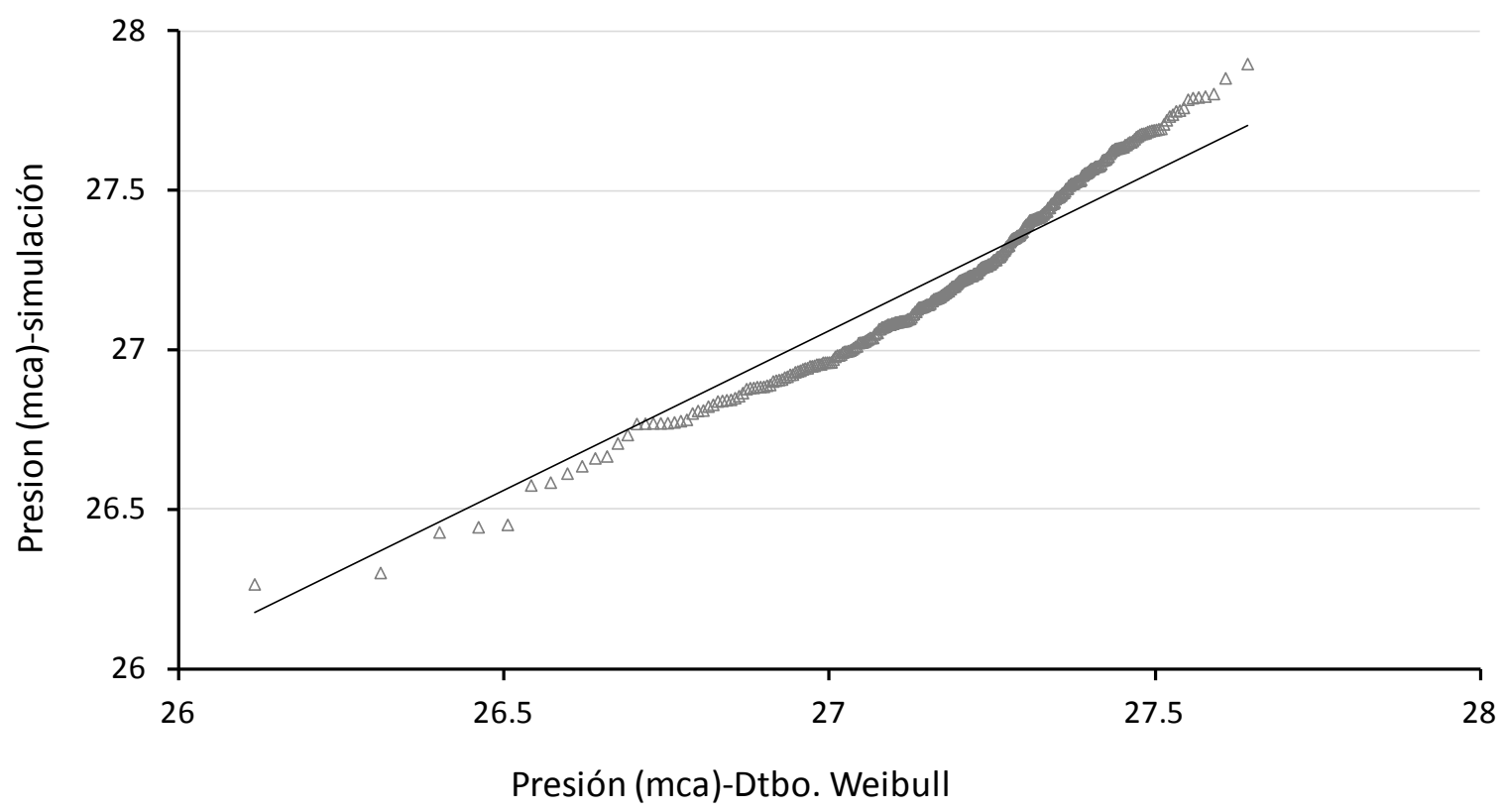

FIGURA C3-13. AJUSTE DE LA PRESIÓN A UNA SERIE WEIBULL (ESCENARIO DE REFERENCIA, ESQUEMA TIPO I)

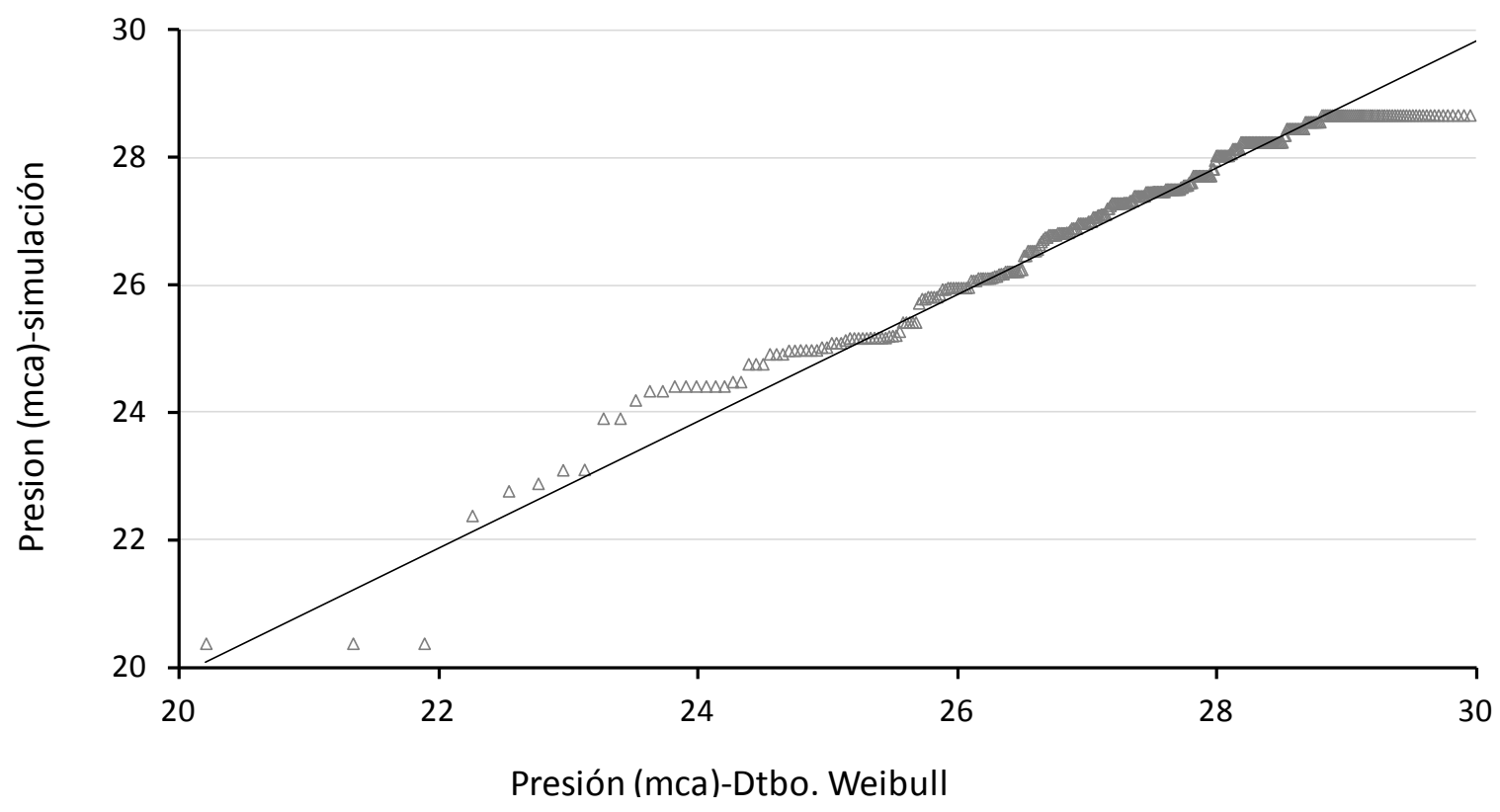

FIGURA C3-14. AJUSTE DE LA PRESIÓN A UNA SERIE WEIBULL (ESCENARIO DE REFERENCIA, ESQUEMA TIPO II) 


\section{Ajuste esquema Tipo III}

En el caso de tratar de ajustar la serie de presiones asociada al esquema que comporte el suministro con bombas y en directo (en una proporción 1:3), es posible comprobar que mejora sensiblemente el ajuste respecto al caso anterior, principalmente en el extremo superior de la serie, obteniéndose un ajuste intermedio de los esquemas anteriores (Figura C3-15). Esto se debe por un lado a la eliminación de las situaciones en las que el caudal demandado es nulo (por la contribución de las viviendas con suministro directo sin bomba), y por otro lado a la reducción del tamaño de los grupos de presión y por tanto, la generación de variaciones de caudal menos importantes.

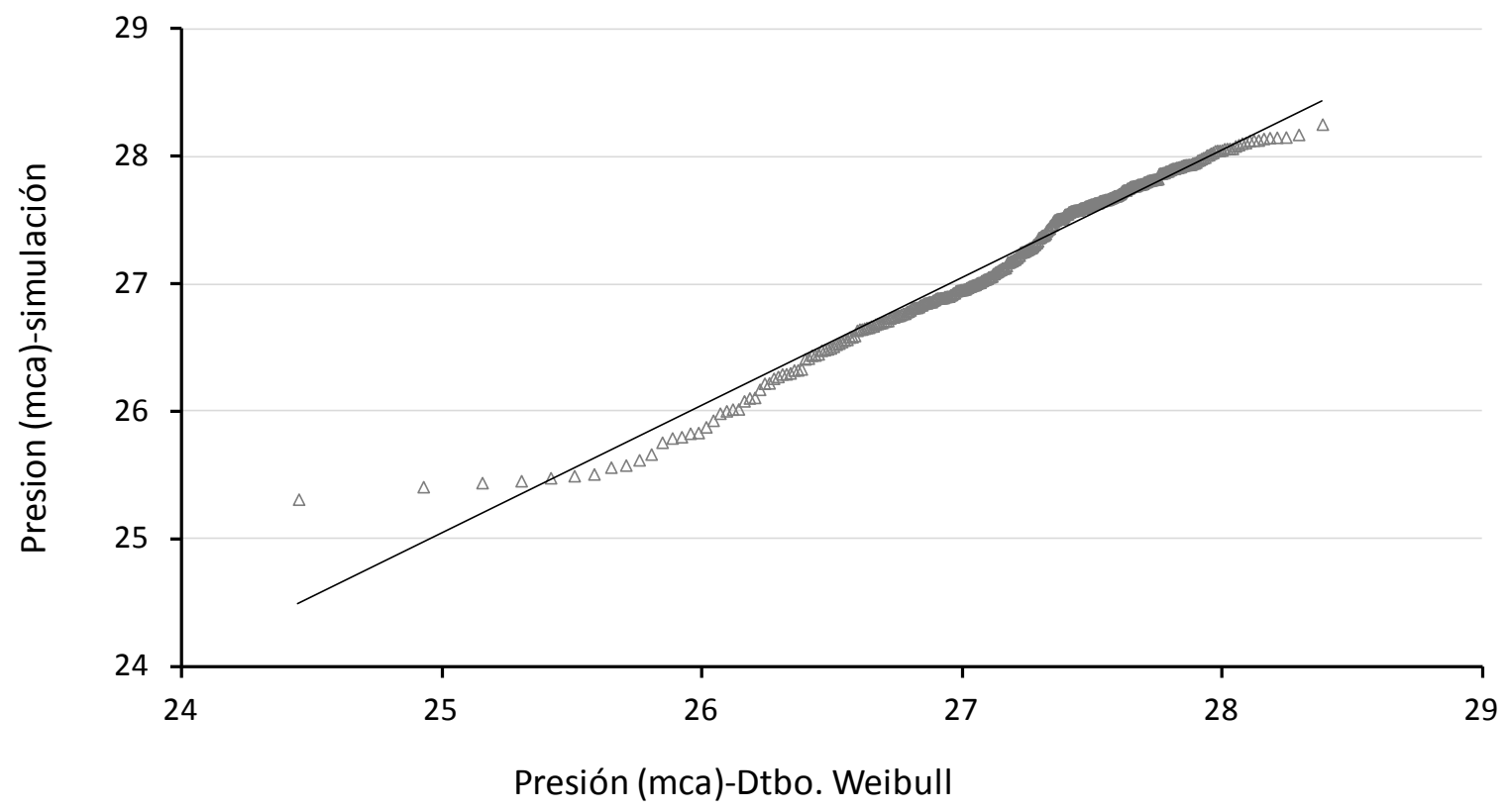

FIGURA C3-15. AJUSTE DE LA PRESIÓN A UNA SERIE WEIBULL (ESCENARIO DE REFERENCIA, ESQUEMA TIPO III)

\subsection{Resultados en RÉGIMen PeRMANeNTE PARA El eSQUema TIPO I}

Si de la serie de pendientes hidráulicas máximas de cada escenario se acude al valor promedio del conjunto de 200 simulaciones, es posible caracterizar cada uno de los escenarios a partir de este valor y evaluar las solicitaciones asociadas a falta de incluir la dispersión de esta serie (ver Figura C3-4). Procediendo de forma similar para el conjunto de escenarios modelados (en total se representan 324 puntos asociados a las diferentes combinaciones de parámetros), es posible comprobar una elevada dependencia de la pendiente hidráulica máxima originada en el sector con dos de las variables que caracterizan cada simulación: la carga hidráulica y el diámetro del tramo. 


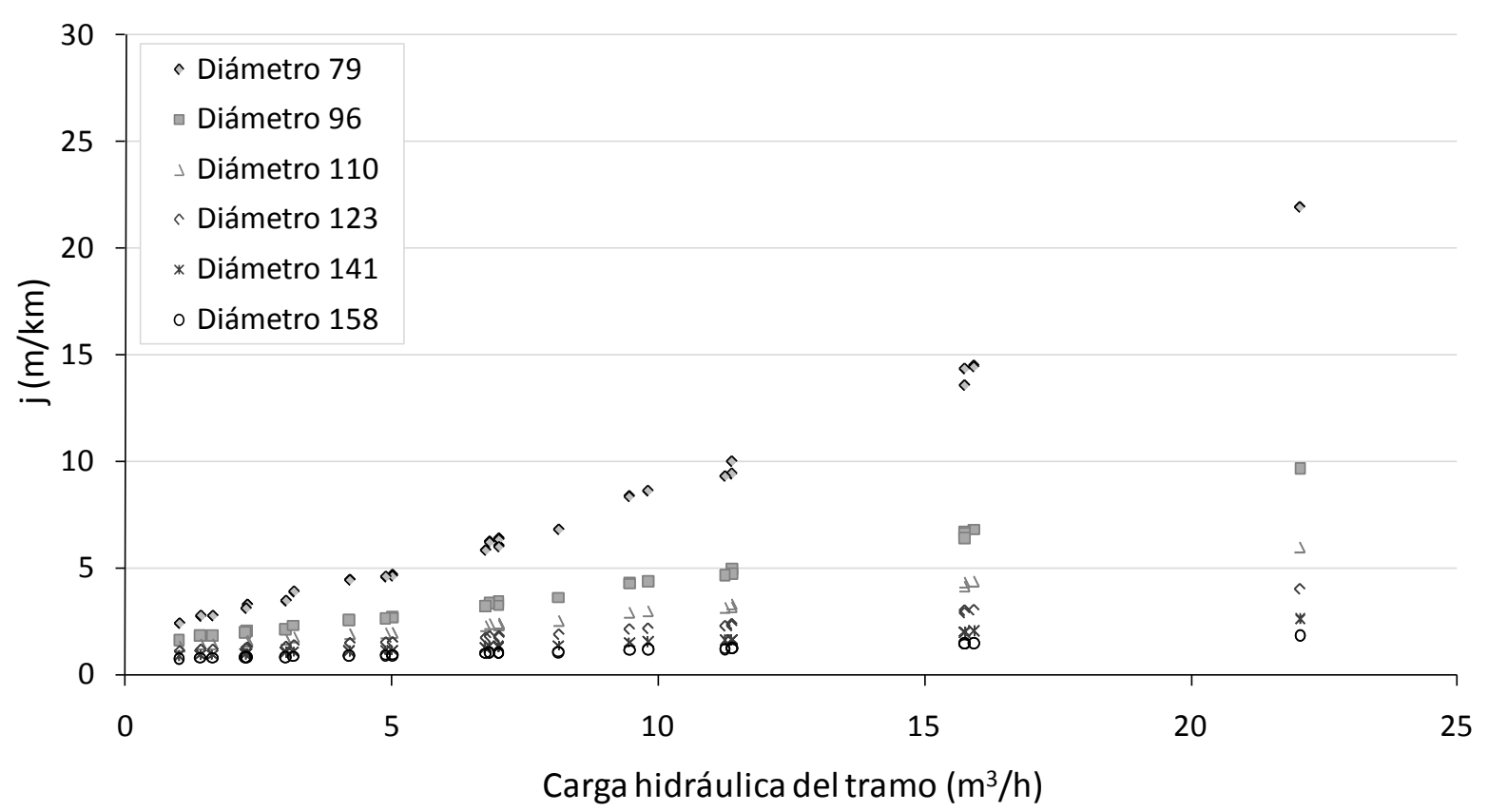

FIGURA C3-16. REPRESENTACIÓN DE LAS PÉRDIDAS UNITARIAS EN FUNCIÓN DE LA CARGA TOTAL DEL TRAMO (ESQUEMAS TIPO I Y TIPO IV)

Para el primero de los casos, la carga hidráulica se ha obtenido en función de los parámetros que caracterizan el escenario (coincidente con el valor medio consumido en la hora de simulación por el conjunto de viviendas), junto con el caudal residual mantenido constante (aunque este término aumenta la severidad con la que opera el tramo, se ha considerado oportuno mantenerlo ya que puede asociarse a un caudal incontrolado en el sector, al mismo tiempo que permite que los resultados obtenidos con la gráfica estén del lado de la seguridad).

Respecto al diámetro del tramo y tal como puede observarse, para un mismo diámetro instalado la pendiente hidráulica resultante mantiene una lógica tendencia creciente, generándose mayores caídas de presión a medida que aumenta el caudal que circula por el sector.

Por otro lado puede comprobarse que para un determinado diámetro, los valores promedio de la pérdida de carga unitaria máxima siguen una función polinómica con elevada fidelidad. En esta línea la Figura C3-17 muestra el ajuste para un diámetro interior de conducción de $79 \mathrm{~mm}$ sin advertir una elevada dispersión del valor para las diferentes cargas. Respecto al término constante de la ecuación, puede establecerse su relación con el caudal mínimo fijado en el tramo (asociado a la velocidad de 0,5 m/s), y por tanto la consideración de valores diferentes al utilizado desplazaría la curva anterior. 


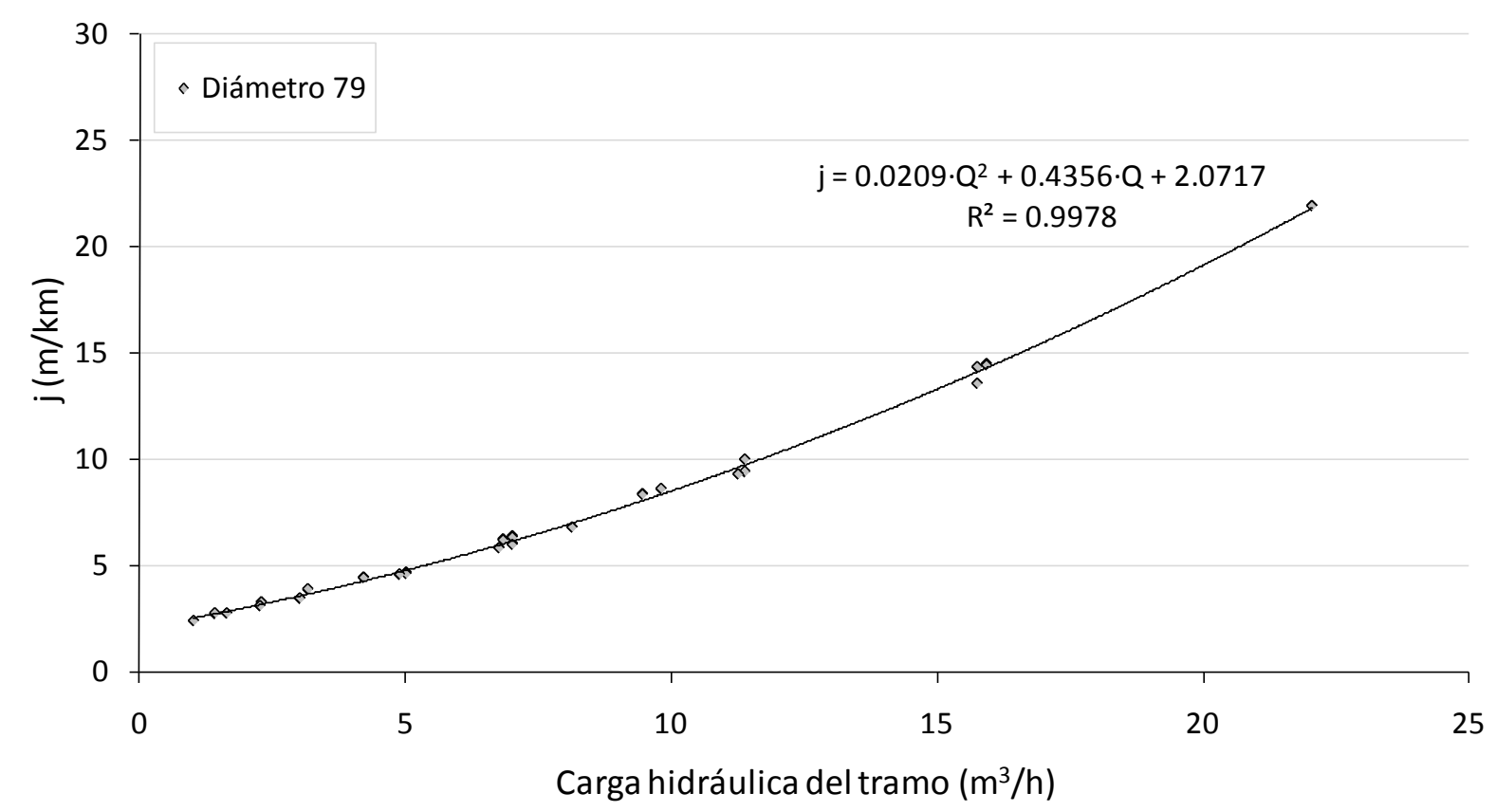

FIGURA C3-17. AJUSTE DE LA SERIE DE PENDIENTES HIDRÁULICAS MÁXIMAS PARA UNA TUBERÍA DE 79 MM

Una de las conclusiones importantes que se puede obtener de los resultados para el esquema Tipo I sugiere una reducida influencia de algunas de las variables que caracterizan el modelo del tramo, principalmente en lo que respecta al número de viviendas por edificio (tamaño del edificio) o número de edificios por tramo. Esto se fundamenta por la concurrencia de cargas hidráulicas próximas para diferentes escenarios, y la obtención de solicitaciones similares para estas cargas. Por ejemplo, la configuración de escenarios asociados a un mayor tamaño de edificio (y por ende menor número de acometidas), no presenta una influencia elevada frente a los escenarios asociados a menores tamaños de edificio (menor número de viviendas y mayor número de acometidas), siempre y cuando totalicen un mismo número de viviendas en el sector (téngase en cuenta que en la combinación de parámetros coinciden diferentes escenarios con una misma carga total).

Por otro lado la influencia que presenta otra de las características del escenario como es la distancia entre edificios estaría directamente considerada en el valor de la pendiente hidráulica, ya que en el cálculo de ésta interviene dicha variable junto con el número de acometidas del modelo. Por tanto instalaciones que presenten una mayor longitud de tramo dispondrán de una mayor reducción de la presión disponible en el nudo extremo para unas mismas características de suministro.

En el caso concreto de la demanda media horaria asociada a cada vivienda, un mayor volumen horario consumido exige por lo general un mayor ritmo de consumo de forma independiente a la intensidad de uso (caudal instantáneo demandado), esta situación propicia un aumento de la demanda simultáneo de varias viviendas del tramo. Esto se deduce de una mayor pendiente hidráulica para un aumento de la carga 
hidráulica del tramo, al calcularse como producto de la demanda medida horaria por el número de viviendas totales asociadas a cada acometida. Por tanto se aprecia una dependencia de este volumen horario en las solicitaciones del tramo. Derivado de lo anterior, y tal como puede entenderse, horas en las que la demanda sea menor se originarán solicitaciones más reducidas que en horas con mayor consumo horario, al reducirse la probabilidad de ocurrencia de usos simultáneos (nótese que el análisis realizado contempla sólo las horas con consumo más exigente).

\subsubsection{Análisis estadístico de los resultados en régimen permanente}

Conocido el valor promedio de las solicitaciones máximas asociadas a cada diámetro y carga, y dada la variabilidad que se observó en el conjunto de simulaciones (Figura C3-4), resulta interesante obtener el rango de variación probable. Este rango aproximará el valor de las pérdidas de carga unitaria que pueden originarse con cierta probabilidad alrededor del valor medio representado. En cualquier caso es el valor máximo de la pendiente hidráulica el que adquiere una mayor significación en el análisis (considérese que las series graficadas en la Figura C3-16 están asociadas al valor promedio de la serie y lo que se persigue caracterizar es el valor extremo superior, y la posible eliminación de aquellos puntos con solicitaciones extremas que pudieran resultar anómalos).

Para ello, si se trata los resultados de cada escenario como un proceso estocástico independiente e idénticamente distribuido, es posible describir cada serie como una función de distribución de probabilidades PDF (Probability Distribution Function). A partir de una distribución tipo y del conocimiento de los parámetros característicos para cada conjunto de 200 simulaciones (escenario) es posible construir la correspondiente función de probabilidad de la serie, obteniendo los valores extremos de la misma con la confiabilidad deseada. En concreto se trabaja con una confiabilidad del $99,5 \%$.

Para tal propósito se acude al histograma de frecuencias para una primera exploración de los datos (de forma similar al análisis realizado para los 360 registros asociados al comportamiento de cada esquema). De nuevo el histograma de la serie de presión mínima en el tramo de un conjunto de 200 simulaciones sugiere un ajuste a una distribución de extremos tal como se puede comprobar a partir de los resultados del escenario de referencia (Figura C3-18), y entre las funciones analizadas la que mayor aproximación presenta es la distribución tipo Weibull (Figura C3-19).

La función de distribución acumulativa Weibull se define a partir de la siguiente expresión, siendo los parámetros característicos de la misma $\alpha$ y $\beta$. El primero de ellos es el parámetro de escala, mientras que el segundo es el de forma. 


$$
F(x, \alpha, \beta)=\left(\frac{1-\exp \left[-\left(\frac{x}{\beta}\right)^{\alpha}\right]}{1-\exp \left[-\left(\frac{x}{\beta}\right)^{\alpha}\right]}\right) \quad x \geq 0
$$

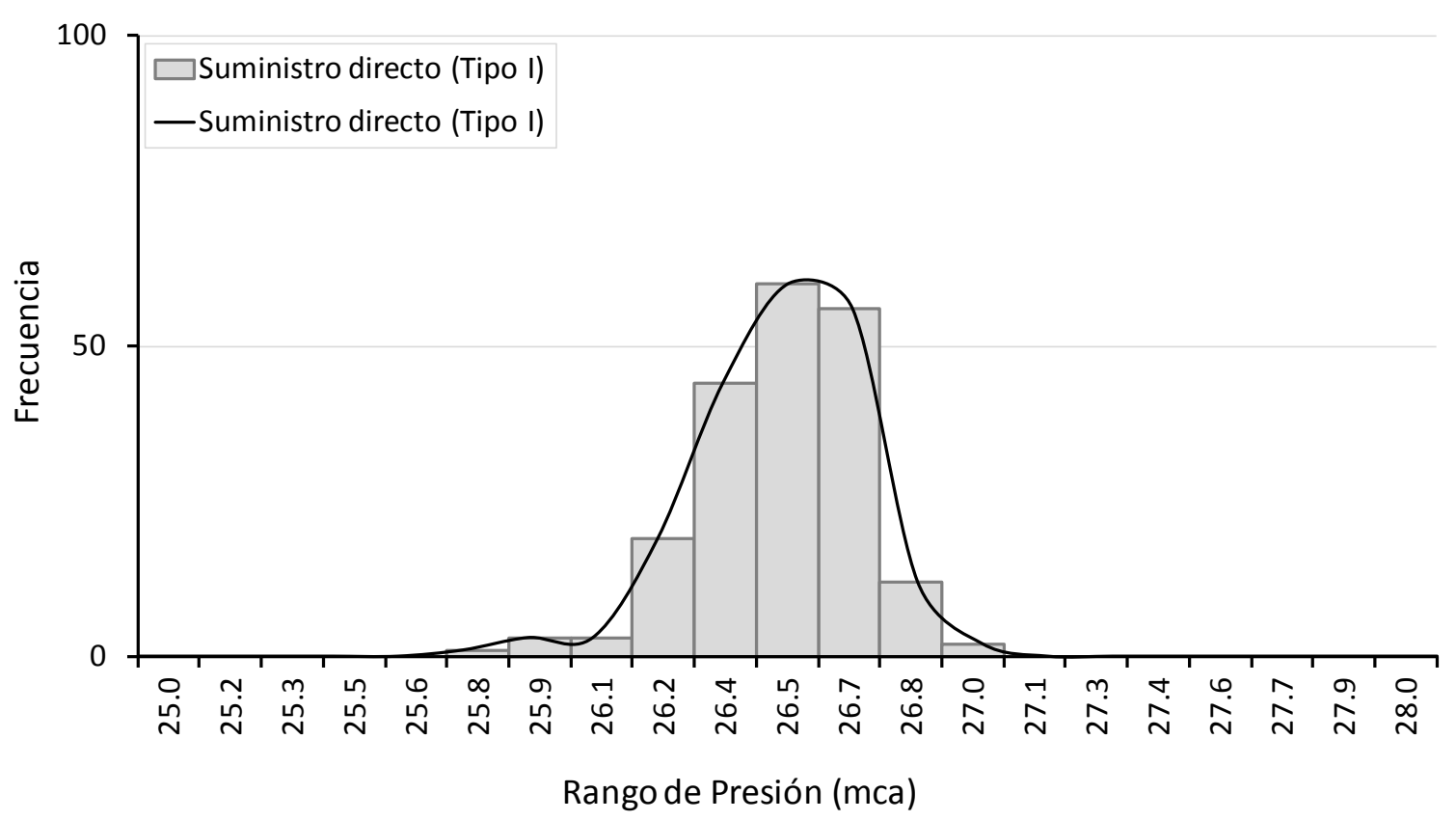

FIGURA C3-18. HISTOGRAMA DE FRECUENCIAS DE LA SERIE DE PRESIÓN MÍNIMA (ESQUEMA TIPO I)

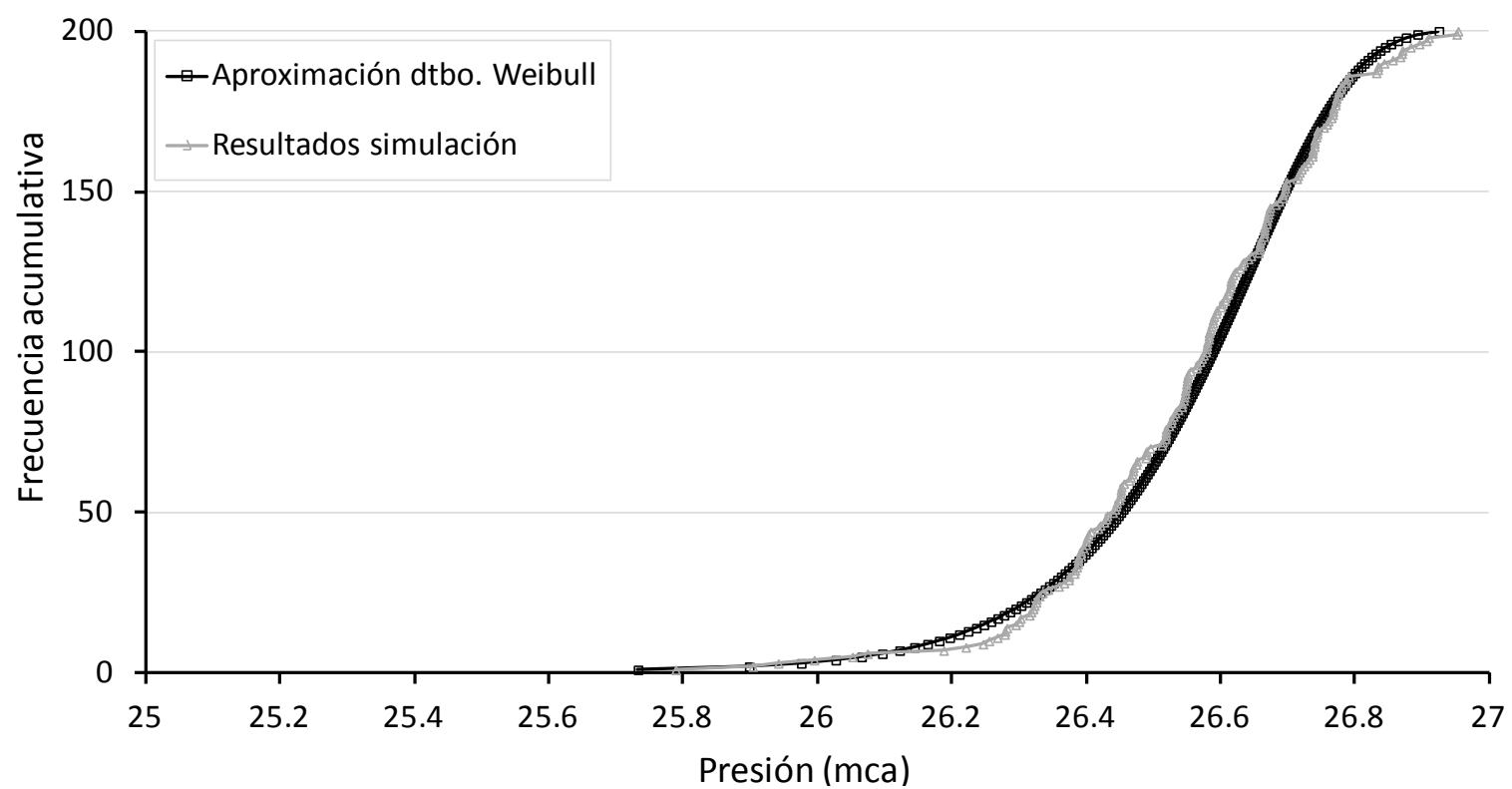

FIGURA C3-19. HISTOGRAMA DE FRECUENCIAS ACUMULATIVAS DE LA SERIE PRESIÓN MÍNIMA Y APROXIMACIÓN CON UNA DISTRIBUCIÓN WEIBULL (ESQUEMA TIPO I) 
Para cada escenario estos parámetros se han obtenido por medio de una regresión entre los valores de la variable y su probabilidad acumulativa, utilizando la transformación logarítmica y el método de mínimos cuadrados. La técnica consiste en comparar los cuantiles teóricos que seguiría la distribución Weibull versus los cuantiles asociados a la serie de pendientes máximas, de tal forma que si es posible caracterizar linealmente ambas series bajo una determinada distribución tipo, es aceptable representar la serie de la simulación con la correspondiente distribución.

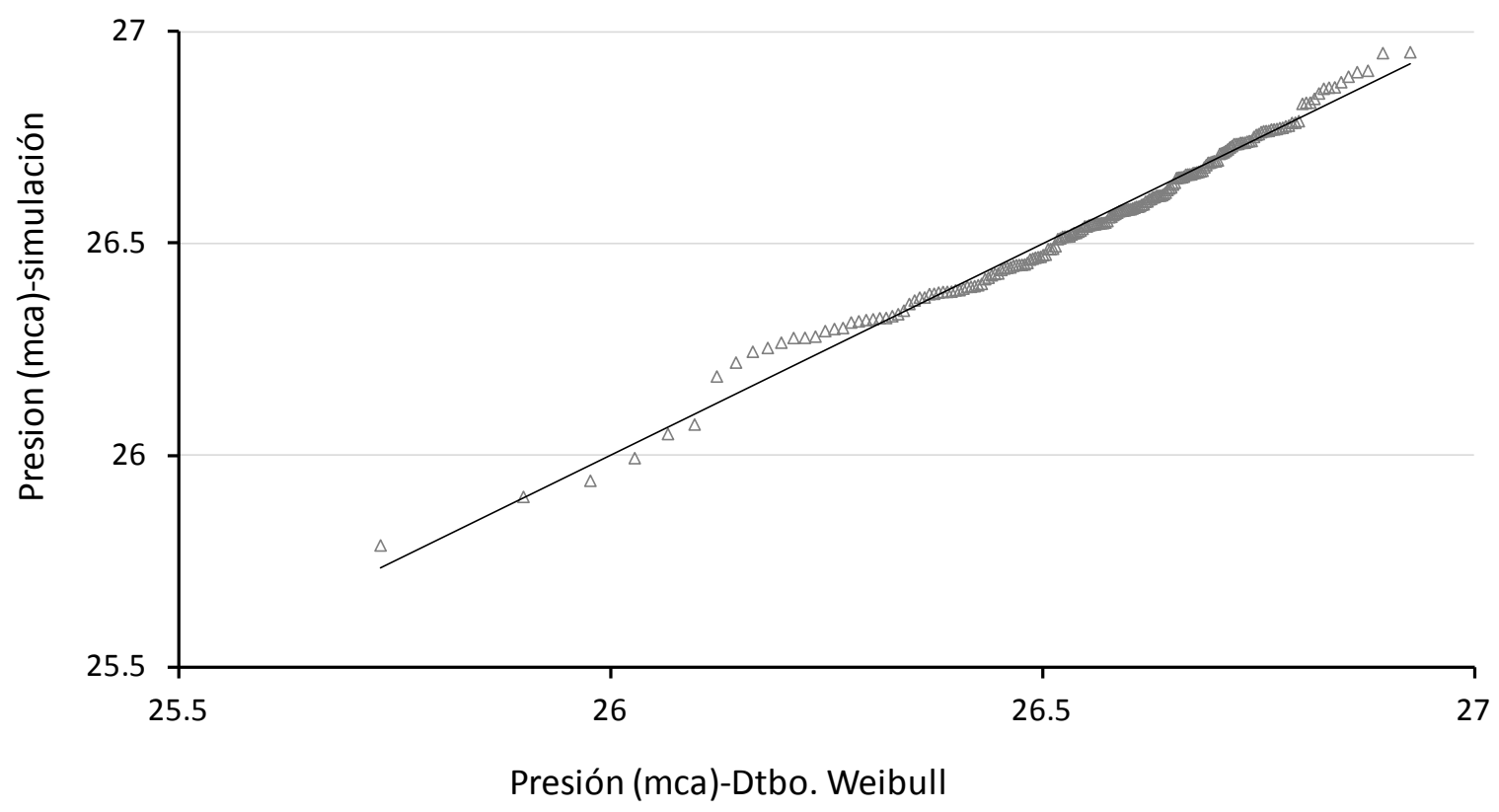

FIGURA C3-20. AJUSTE DE LOS DATOS A UNA DISTRIBUCIÓN WEIBULL PARA EL ESCENARIO DE REFERENCIA

Tal como se aprecia en la Figura C3-20 la distribución tipo Weibull muestra un grado de ajuste elevado para la mayoría de datos de la serie. También se ha obtenido ajustes similares para los datos asociados a otros escenarios. Existe únicamente una pequeña proporción en zonas intermedias de las series y menos sensible en los puntos situados en la cola inferior. Se concluye que la distribución aporta para esta serie una representación aceptable ya que mantiene con un elevado ajuste del conjunto de valores, y por tanto se procede a construir los intervalos de confianza sobre las series de pendientes hidráulicas máximas.

Dado el ajuste de la distribución y siguiendo las indicaciones comentadas, la Figura C3-21 muestra una representación del valor promedio y de los valores extremos de la serie de pendientes hidráulicas máximas para cada una de las cargas y diámetros analizados (con un grado de confiabilidad del 99,5\%). 


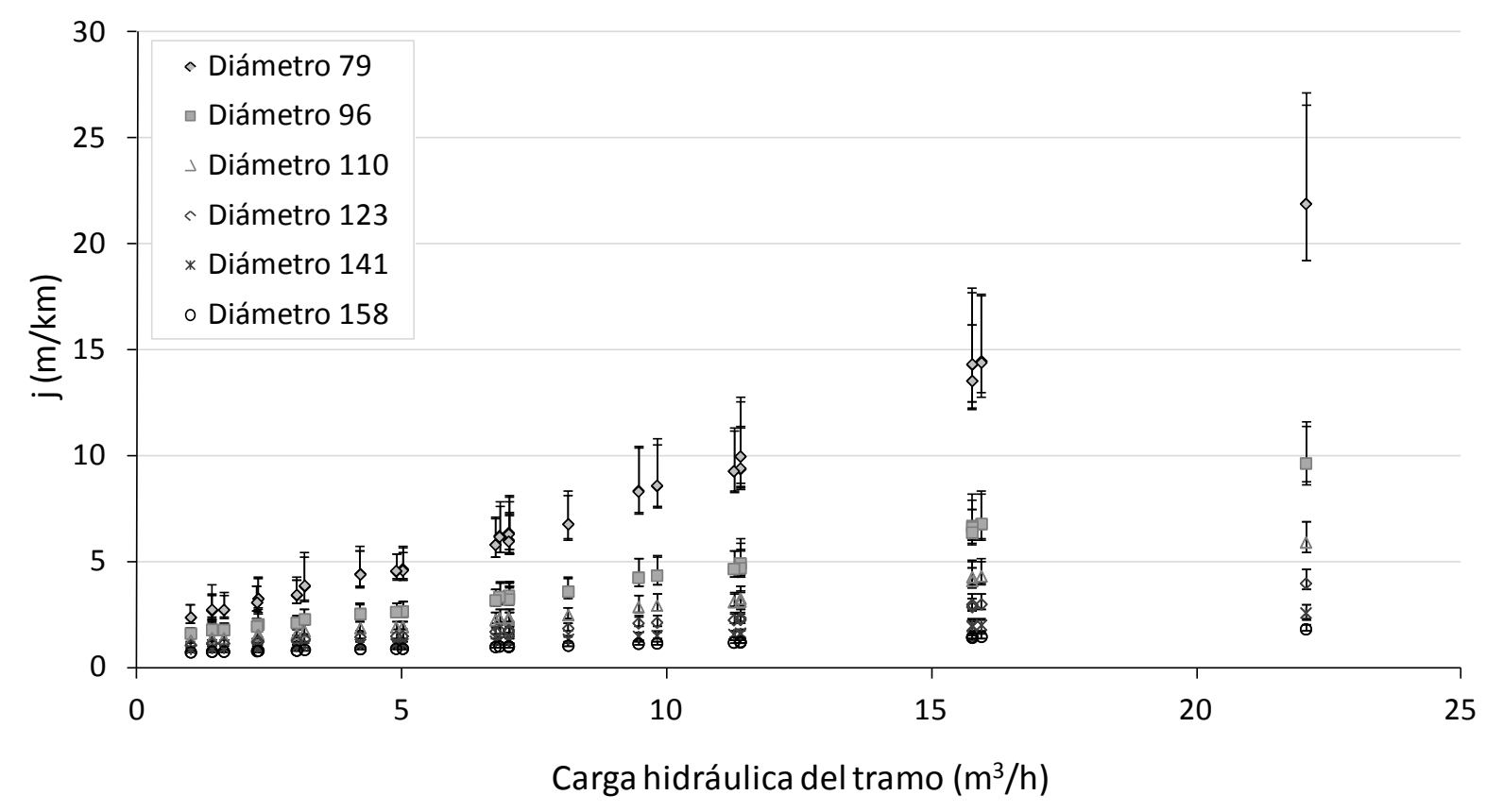

FIGURA C3-21. RANGO DE PÉRDIDAS UNITARIAS MÁXIMAS EN FUNCIÓN DEL DIÁMETRO (ESQ. TIPO I)

Por tanto, a partir de la gráfica anterior y para un escenario dado, es posible aproximar la pendiente hidráulica máxima esperable. Este comportamiento caracterizaría los esquemas con suministro en directo sin grupo de presión (Tipo I) y el suministro en instalaciones que cuentan total o parcialmente con grupos de velocidad variable (Tipo IV).

\subsubsection{Aplicación de los resultados de las simulaciones}

Si se quiere ser conservador es posible establecer una curva correspondiente con el límite superior de los rangos anteriores, de forma que la pérdida unitaria máxima para una determinada carga y diámetro se encuentra fielmente definida por un punto ubicado sobre una curva (Figura C3-22).

Con ello es posible estimar la caída de presión máxima que puede experimentar un tramo de red. En esta línea, el acceso al gráfico y la localización del punto de operación se realiza tomadas las siguientes consideraciones:

- La carga hidráulica en el tramo se ha simplificado como producto de la demanda media horaria por vivienda, el número de viviendas por nudo (tamaño del edificio) y el número de nudos de consumo (acometidas).

- La pendiente hidráulica es la diferencia entre la presión de referencia y la presión mínima en el tramo, evaluada para la longitud total de éste (función del número de acometidas y la distancia entre acometidas). 
- Respecto al diámetro se ha mantenido un valor constante. Para valores diferentes a los indicados o para un diámetro equivalente de tramo, es posible extrapolar valores entre las series graficadas.

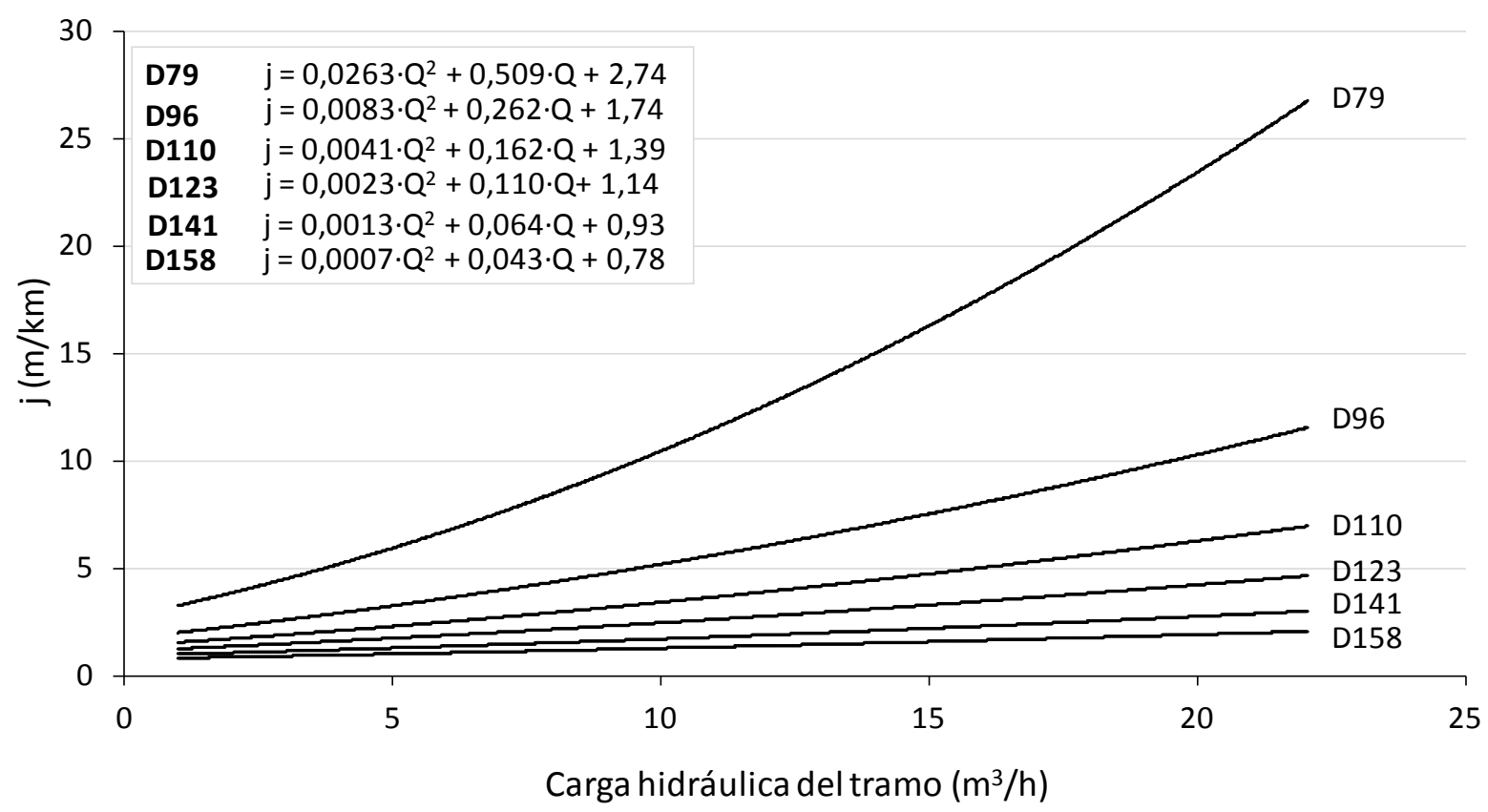

FIGURA C3-22. CuRVAS DE PENDIENTES UNITARIAS MÁXIMAS (ESQUEMA TIPO I)

Derivado de lo anterior, la gráfica permite estimar la capacidad de un tramo si se eliminan los depósitos domiciliarios y se asume una conexión directa de las diferentes instalaciones interiores (según los esquemas especificados). Para ello la determinación del punto de operación correspondiente debe originar una pendiente hidráulica inferior a un valor máximo fijado, o bien asegurar que la presión mínima en todas las acometidas mantienen un valor razonable. En esta línea, en el estudio se ha considerado un valor razonable de presión de servicio próxima a los 2 bar. Respecto a los valores de pendiente hidráulica máxima aconsejada, se consideran valores aceptables aquéllos próximos a 5 metros por kilómetro de tubería (y nunca superiores a $10 \mathrm{~m} / \mathrm{km}$ ), de forma que no se originen pérdidas de carga en el tramo elevadas, al mismo tiempo que se favorezca la mejora del rendimiento energético global de la red.

Para una carga hidráulica en abscisas es posible trabajar con un número equivalente de viviendas función del volumen de agua promedio asociado a cada vivienda o uso del sector, y así ajustar la carga hidráulica para un número de viviendas superior a las simuladas (teniendo en cuenta la lógica simultaneidad en los usos). De esta forma es posible adaptarse a situaciones en las que no todas las viviendas consumen o bien el caudal demandado por hora es diferente al considerado.

Con todo ello se destacan dos posibles utilidades del gráfico anterior, diferenciándose de si se trata de una fase que analiza la capacidad del tramo en función 
del diseño de las instalaciones conectadas (selección de un tipo de esquema u otro), o de una fase de dimensionado para la determinación de las características dimensionales de la conducción principal. Para cada utilidad la filosofía es la siguiente:

1. Diseño: para una determinada carga y dada una presión mínima en la entrada del tramo, es posible estimar la caída de presión que se puede originar bajo una conexión directa, y por tanto obtener una aproximación sobre el valor de la presión que puede alcanzarse en el punto más desfavorable del sector.

2. Dimensionado: para una determinada carga (real o futura) e impuesta una determinada pendiente máxima admisible (o presión mínima de entrega en acometida), es posible estimar el diámetro mínimo que debe instalarse de forma que se garantice la presión mínima de suministro en todas las conexiones.

\subsection{Resultados en RÉGIMEN PERMANeNTE PARA EL ESQUeMA TIPO II}

Si bien a partir de los resultados anteriores se aproxima la respuesta de un sector de red bajo una conexión directa (sin grupos de presión o con bomba de velocidad variable), es posible que la red bajo algunas configuraciones sea capaz de mantener un suministro aceptable con la conexión en directo de grupos de presión de velocidad fija (de forma total o parcial). Para ello se realiza un procedimiento similar al mostrado para el esquema Tipo I, pero en el que las viviendas están en su totalidad conectadas en directo a través de un grupo de velocidad fija (Figura C3-23).

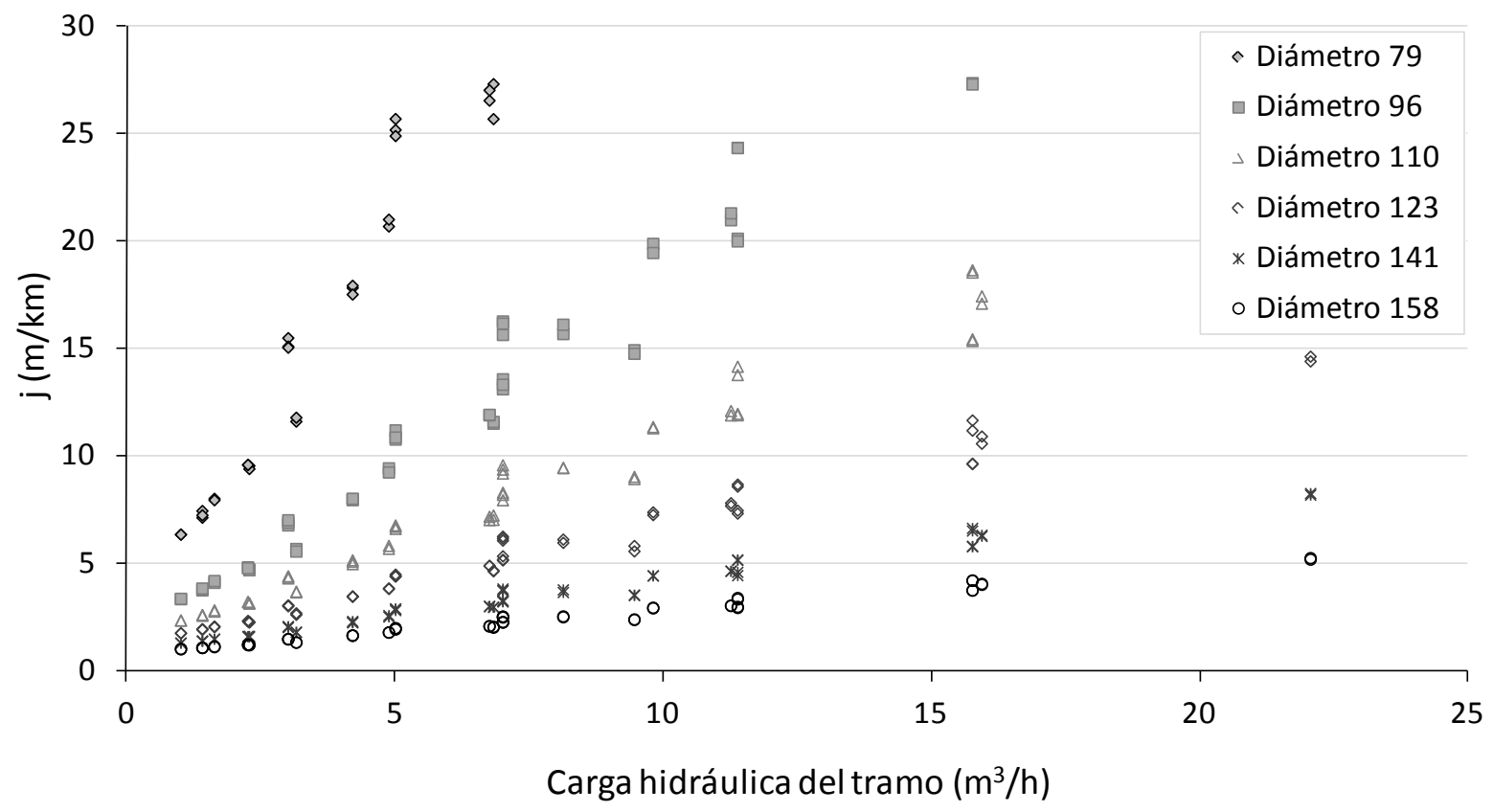

FIGURA C3-23. REPRESENTACIÓN DEL VALOR PROMEDIO DE LA PÉRDIDA UNITARIA EN FUNCIÓN DEL DIÁMETRO (T-II) 
Para el esquema Tipo II y tal como se comprobó en la Figura C3-12, la dispersión de la presión mínima en el tramo para una simulación de 1 hora adquiere una magnitud considerable respecto al resto de esquemas. Este efecto es mucho más notable cuando se realizan 200 simulaciones de un mismo escenario. Por ello, a diferencia del suministro con bombas de velocidad variable o en directo, al representar el valor promedio de la pendiente hidráulica máxima para cada carga no se aprecia un ajuste polinómico tan riguroso a los diferentes diámetros. En su lugar la nube de puntos asociada a cada valor se encuentra incluida sobre un área más o menos extensa en función del diámetro de la conducción; para una misma carga, la variabilidad de la pendiente es significativa. En esta línea menores diámetros muestran una dispersión mayor de esta variable debido a una mayor influencia de las pérdidas de carga en el tramo al disponer éste de menor capacidad hidráulica.

A modo de ejemplo la siguiente figura detalla el ajuste para dos de los diámetros analizados, como puede observarse una mayor pendiente de la curva que ajusta al diámetro menor posibilita una franja de variación de $j$ considerable para una misma carga.

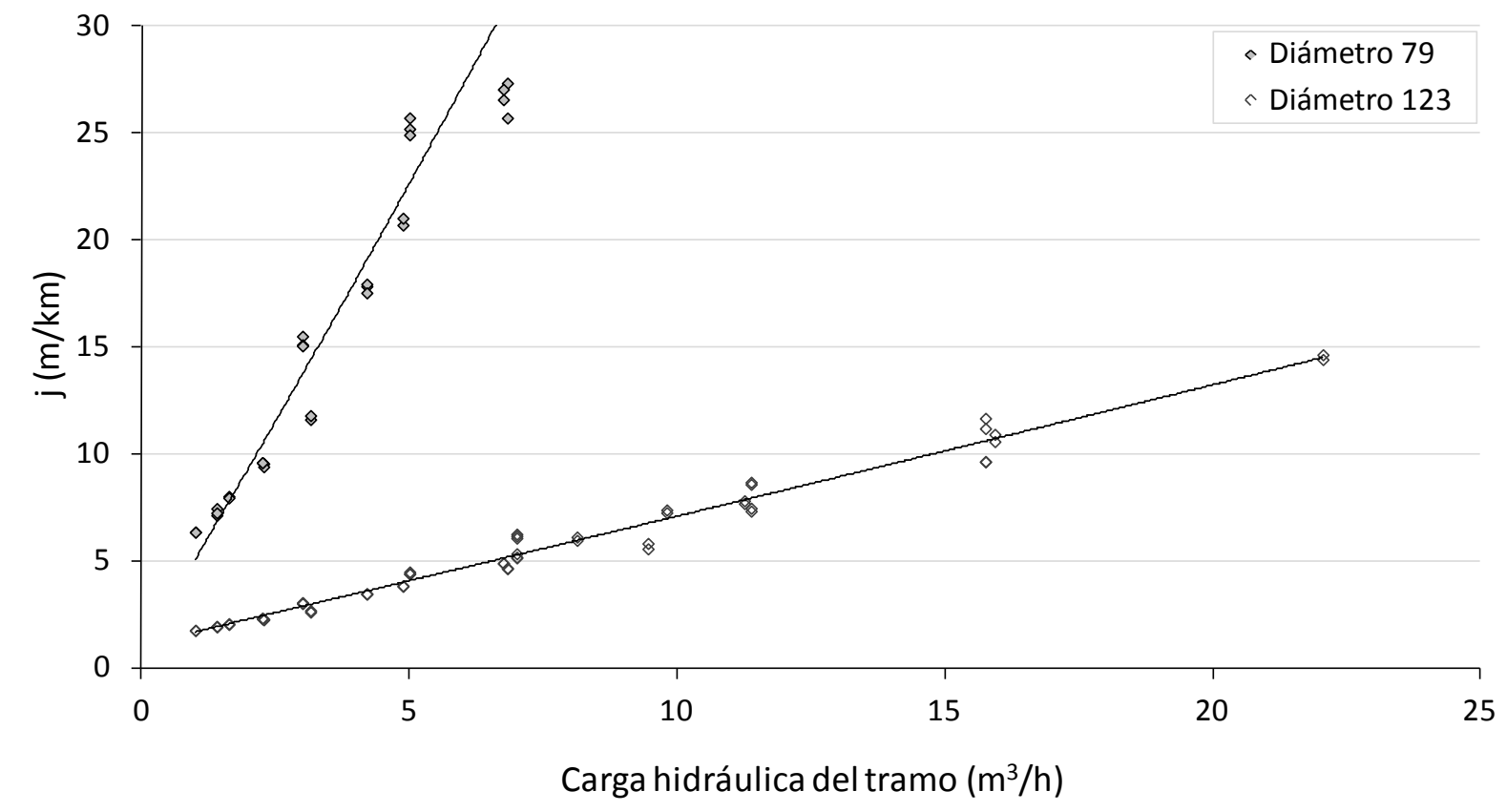

FIGURA C3-24. AJUSTE PARA LOS DIÁMETROS 79 Y 123 (ESQUEMA TIPO II)

\subsubsection{Análisis estadístico de los resultados para el esquema Tipo II}

El histograma de frecuencias de la serie de presiones mínimas de 200 simulaciones muestra una notable asimetría para el escenario de referencia. Del mismo modo el ajuste a una distribución de extremos convencional resulta complejo al existir puntos aislados en la cola inferior de la serie según el histograma de frecuencias. 


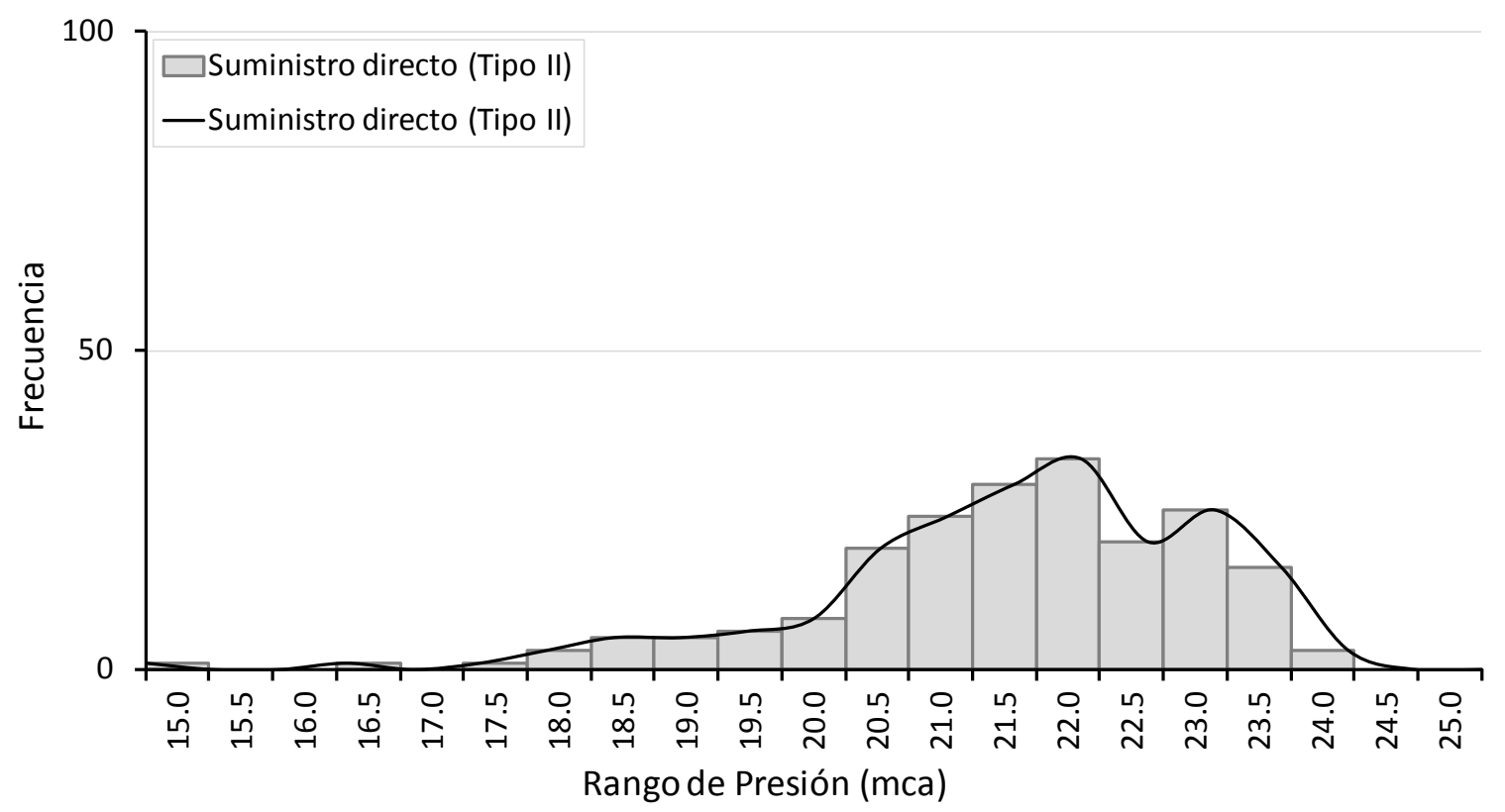

FIGURA C3-25. HISTOGRAMA DE FRECUENCIAS DE LA PRESIÓN MÍNIMA (ESCENARIO DE REFERENCIA, ESQ. TIPO II)

Tal como se ha comentado la dispersión se ve favorecida por la existencia de grupos de presión, ya que la concurrencia de diferente número de grupos en funcionamiento y su localización en el tramo origina variaciones de presión más severas que en esquemas con suministro en directo sin grupo. Para el escenario de referencia la aproximación de la presión mínima alcanzada se aleja sensiblemente del valor de la presión simulada, siendo este efecto más notable en los escenarios que favorecen una mayor variabilidad de la serie.

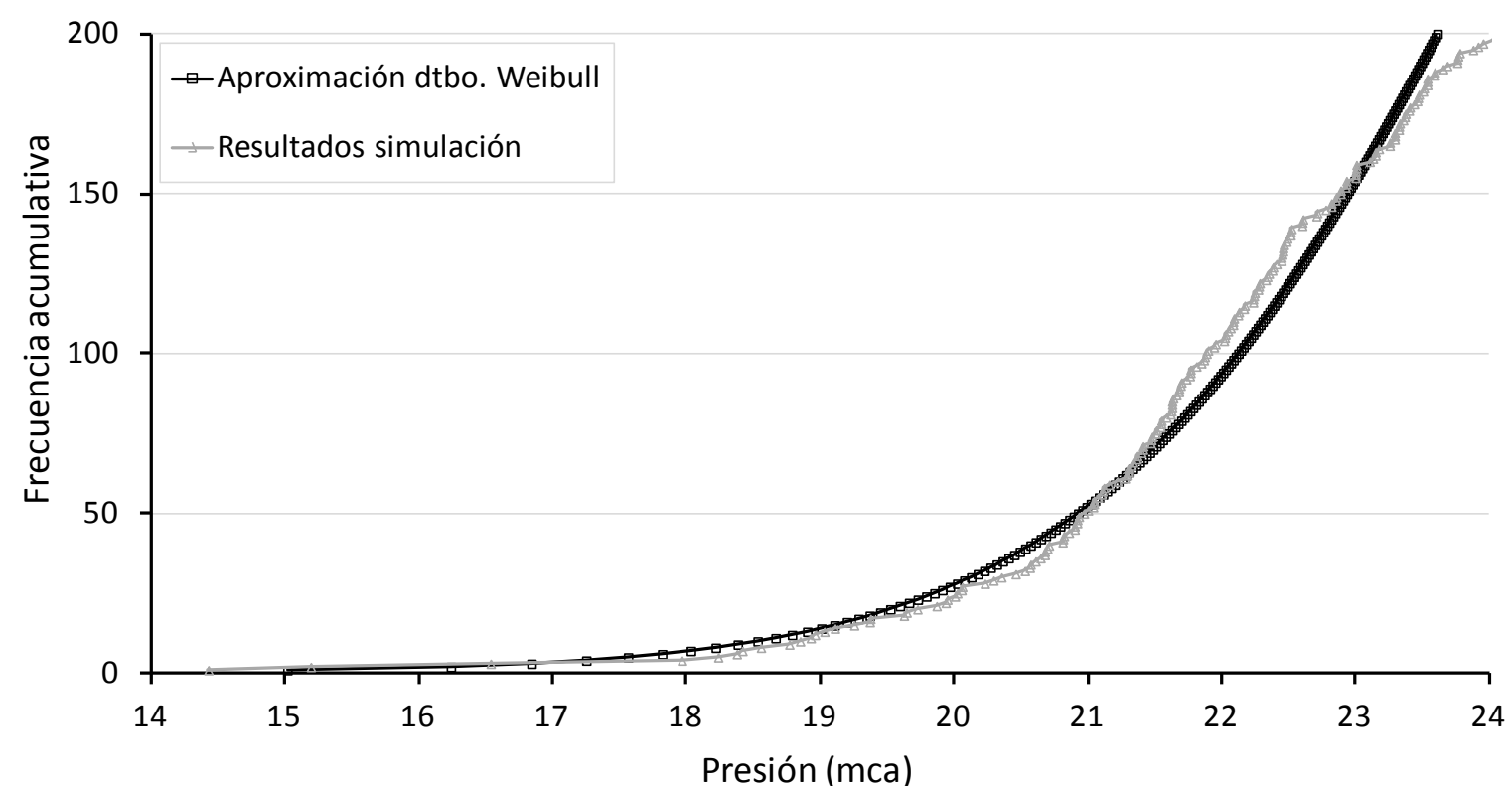

FIGURA C3-26. HISTOGRAMA DE FRECUENCIAS ACUMULATIVAS DE LA SERIE DE PRESIÓN MÍNIMA Y APROXIMACIÓN CON UNA DISTRIBUCIÓN WEIBULL (ESCENARIO DE REFERENCIA Y ESQ. TIPO II) 
De las distribuciones analizadas la que mejor ajuste presenta es la distribución Weibull, pero se destaca que en algunos casos el ajuste en extremos podría resultar insuficiente.

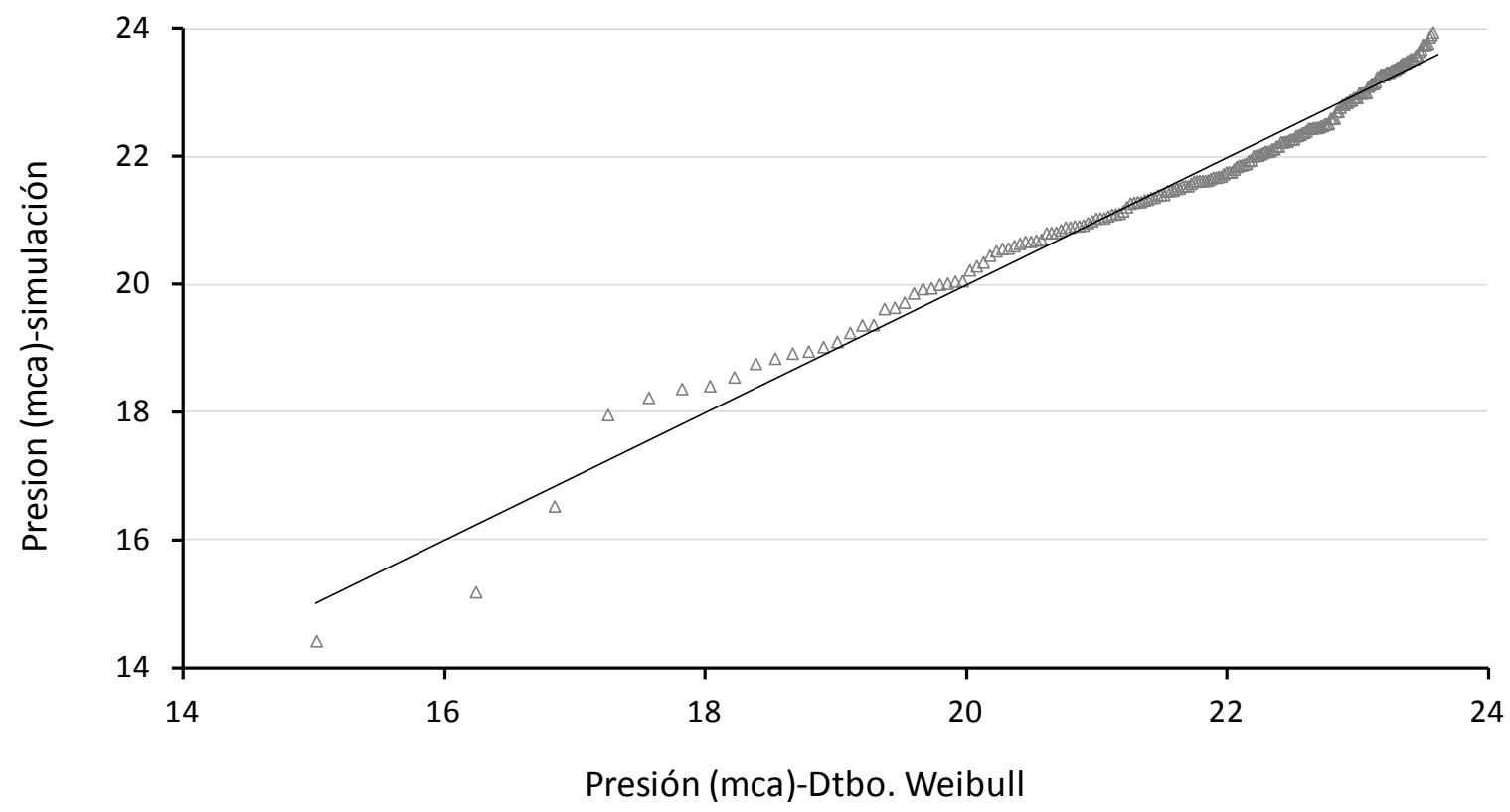

Figura C3-27. AJUSTE DE LOS DATOS A UNA DISTRIBUCIÓN WEIBULL (ESQUEMA TIPO II)

Dado el vago ajuste obtenido con la distribución tipo Weibull se muestra a modo de referencia los valores máximos de las pendientes hidráulicas obtenidas durante las simulaciones para cada uno de los escenarios (en lugar de construir los intervalos de confianza). Del mismo modo, se detalla el valor promedio y máximo de la serie para una diámetro concreto para ilustrar el efecto asociado a la variabilidad de los resultados (Figura C3-29).

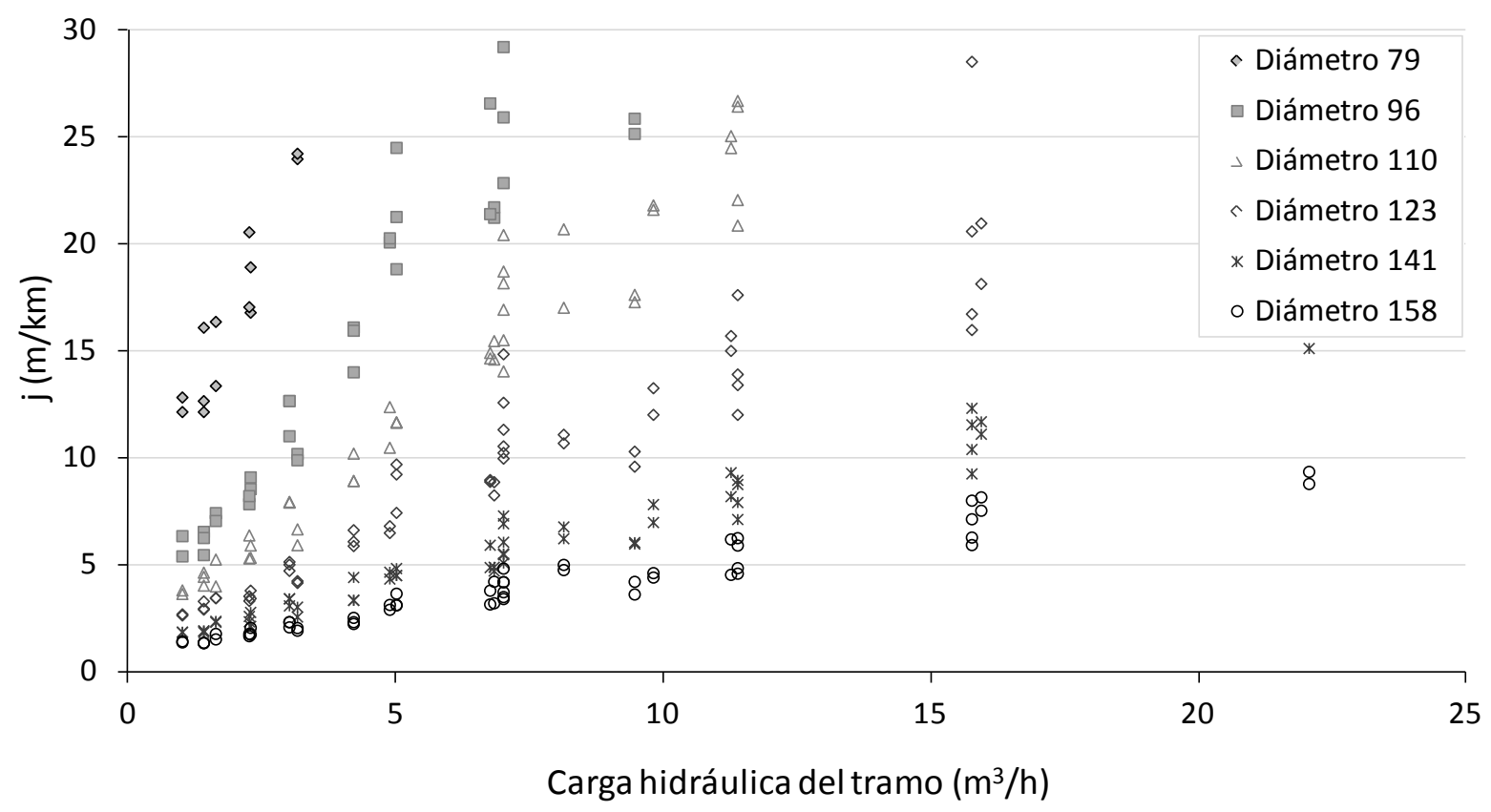

FIGURA C3-28. VALOR MÁXIMO DE LA PÉRDIDA UNITARIA EN FUNCIÓN DEL DIÁMETRO (TIPO II) 


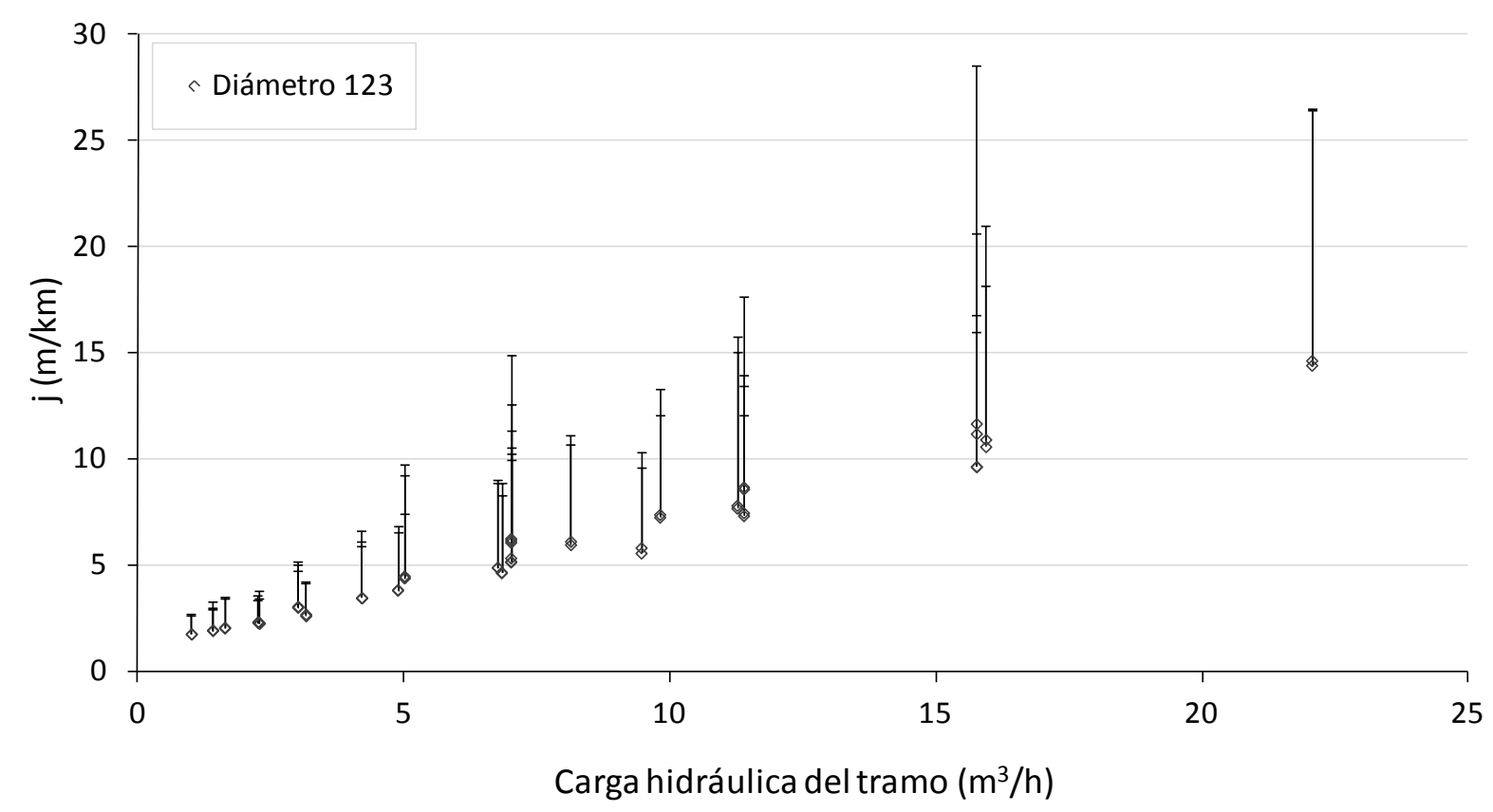

FIGURA C3-29. DETALLE DE LA PENDIENTE HIDRÁULICA MEDIA Y VARIACIÓN DEL VALOR MÁXIMO (D=123 MM)

Si se centra el análisis a una determinada carga y diámetro, aparece un rango de variación de la pendiente hidráulica máxima alcanzada para los diferentes escenarios asociados. Como se puede apreciar en la siguiente figura para una carga aproximada de $16 \mathrm{~m}^{3} / \mathrm{h}$ y para un diámetro de $123 \mathrm{~mm}$ la variabilidad es muy elevada, frente a una menor dispersión en el caso de prestar atención a la caída de presión medida característica de cada escenario.

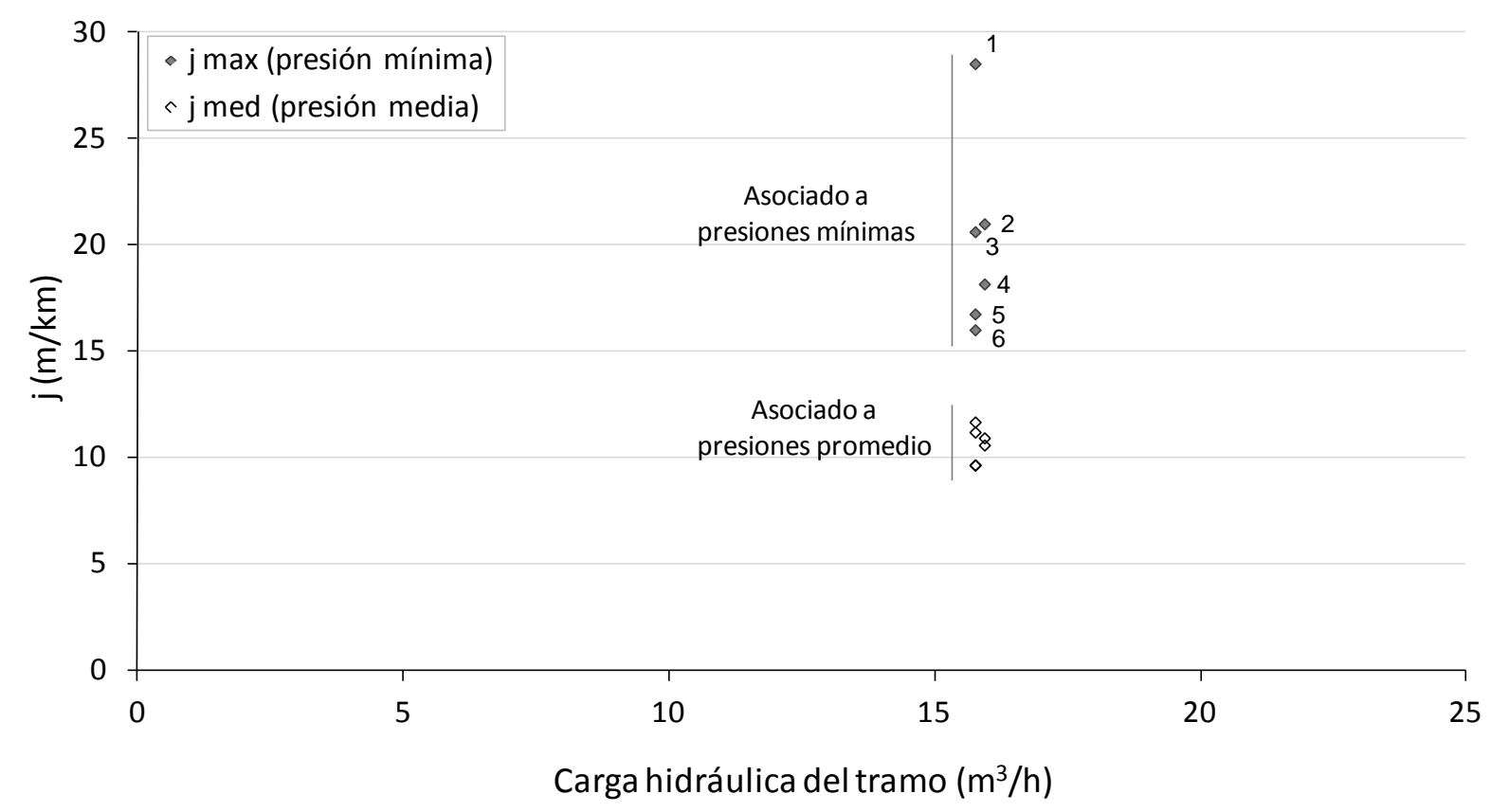

FIGURA C3-30. VARIACIÓN DE LA PENDIENTE HIDRÁULICA PARA UN ESQUEMA TIPO II Y DIÁMETRO 123 MM 
Analizando la posible influencia de las diferentes variables para el caudal y diámetro anterior, es posible comprobar que no existe una influencia predominante de ninguna de las variables que definen el tramo, si bien parece que el número de viviendas por nudo pudiera ser una de las variables críticas que favorecen la aparición de mayores caídas de presión. La siguiente tabla resume las características asociadas a las series graficadas (Figura C3-30), ordenadas éstas de forma descendente en solicitaciones.

TABLA C3-1. TRAZABILIDAD DE LOS PUNTOS ANALIZADOS (ESQUEMA TIPO II, DIÁMETRO 123 MM)

\begin{tabular}{|c|c|c|c|c|c|c|c|c|c|c|}
\hline Serie & $\begin{array}{c}C \\
\left(m^{3} / h\right)\end{array}$ & $\begin{array}{c}\mathbf{j}_{\max } \\
(\mathrm{mca} / \mathrm{km})\end{array}$ & $\begin{array}{c}\text { jed } \\
(\mathrm{mca} / \mathrm{km})\end{array}$ & $\begin{array}{c}L \\
(\mathrm{~m})\end{array}$ & $\mathbf{n}$ & $\begin{array}{c}d \\
(m)\end{array}$ & $\begin{array}{c}\text { viv. } \\
\text { nudo }\end{array}$ & $\begin{array}{l}\text { qmed } \\
(\mathrm{I} / \mathrm{h})\end{array}$ & $\begin{array}{c}\text { Simult. } \\
\text { Máx. }\end{array}$ & $\begin{array}{c}\text { Simult. } \\
\text { Med. }\end{array}$ \\
\hline 1 & 15,75 & 28,54 & 11,68 & 760 & 20 & 40 & 35 & 25 & 10 & 4,99 \\
\hline 2 & 15,925 & 21,01 & 10,93 & 280 & 15 & 20 & 35 & 35 & 7 & 4,825 \\
\hline 3 & 15,75 & 20,63 & 11,21 & 380 & 20 & 20 & 35 & 25 & 7 & 4,62 \\
\hline 4 & 15,925 & 18,17 & 10,60 & 560 & 15 & 40 & 35 & 35 & 8 & 4,96 \\
\hline 5 & 15,75 & 16,76 & 9,65 & 760 & 20 & 40 & 25 & 35 & 9 & 5,42 \\
\hline 6 & 15,75 & 16,02 & 9,67 & 380 & 20 & 20 & 25 & 35 & 9 & 5,48 \\
\hline
\end{tabular}

Donde $C$ representa la carga hidráulica del tramo, $j_{\max }$ la pendiente hidráulica máxima (asociada a la presión mínima registrada en las simulaciones), jmed la pendiente hidráulica promedio característica de la simulación (asociada a la caída de presión media), $L$ la longitud total del tramo, $n$ el número de nudos totales del modelo, $d$ la distancia entre acometidas del modelo, $q_{\text {med }}$ la demanda media por hora y vivienda, Simult. Máx. representa el número de bombas con funcionamiento simultáneo asociadas a $j_{\max }$ y Simult. Med. el número promedio de grupos con funcionamiento simultáneo de cada escenario.

La situación más desfavorable se corresponde con el funcionamiento simultáneo de 10 bombas (de las 18 que integran el escenario más desfavorable), al mismo tiempo que el tamaño del edificio es el máximo de los simulados, de forma similar al tamaño del tramo. Esta configuración origina un caudal bombeado elevado, y previsiblemente localiza la mayoría de las bombas en funcionamiento al final del tramo, generando una elevada caída de presión. La respuesta promedio de esa misma configuración origina una caída de presión con una reducción en torno al $60 \%$ respecto al valor anterior, para un funcionamiento simultáneo de 5 bombas.

Por otro lado un mayor número de bombas en funcionamiento simultáneo (para un mismo número de viviendas y nudos) no siempre origina una mayor caída de presión en el tramo, ya que es posible alcanzar mayores caídas de presión reduciendo 
el número de grupos simultáneos, pero localizando éstos en zonas más alejadas del punto de inyección.

Tal como se apuntaba, se observa una influencia significativa del tamaño del edificio, como puede entenderse a mayor número de viviendas por nudo el tamaño del grupo de presión instalado es mayor y por tanto se le asigna un caudal de bombeo proporcional a este dato. Respecto al caudal medio demandado, éste puede influir aumentando la simultaneidad en el arranque de grupos, ya que la vivienda presenta una mayor frecuencia de uso (o un mayor volumen consumo) reduciendo los ciclos de vaciado de los calderines.

Siguiendo los resultados anteriores se puede concluir que cuando la instalación cuenta con un suministro directo con bombas de velocidad fija, la aleatoriedad en la demanda de las diferentes viviendas de la instalación puede originar diferentes combinaciones en el arranque de los grupos de presión, y por tanto es complejo establecer un rango de solicitaciones máximas próximo al comportamiento promedio.

\subsubsection{Representación de los resultados de las simulaciones}

A partir de los resultados anteriores se ha construido una zona asociada a la pendiente hidráulica máxima para diferentes cargas y diámetros. Se ha prescindido de los resultados de los diámetros menores por las elevadas pérdidas que generan y la elevada dispersión asociada (Figura C3-31).

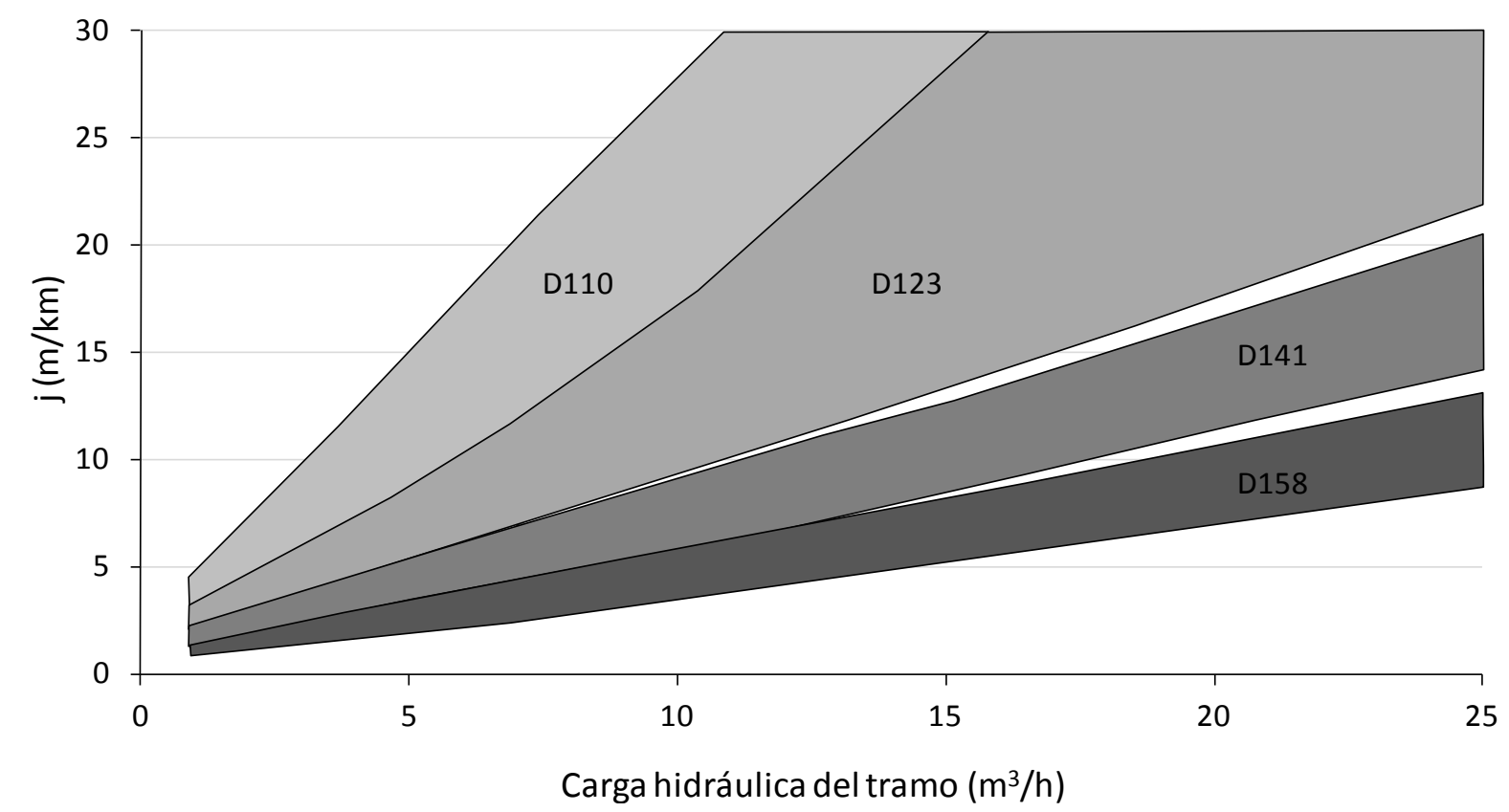

FIGURA C3-31. RANGOS DE PENDIENTES UNITARIAS MÁXIMAS (ESQUEMA TIPO II) 
Si se fija una pendiente hidráulica máxima aceptable es posible aproximar la caída de presión esperada en el tramo si se acude a un esquema en el que todas las viviendas se suministran a partir de grupos de velocidad fija. A medida que aumenta el diámetro es posible permitir una mayor carga hidráulica conectada y la dispersión es menor. Respecto a esta última consideración, y tal como se ha mostrado en el análisis particular de una determinada carga, debe tenerse en cuenta la influencia de las variables a la hora de establecer el punto de funcionamiento aproximado dentro del área marcada. En esta línea un mayor tamaño de edificio favorece la generación de mayores caídas de presión al aumentar el tamaño de los grupos.

En cuanto a la posibilidad de eliminar los depósitos manteniendo todos los grupos de presión de la instalación conectados en directo, es importante limitar el tamaño mínimo de la conducción de la red, ya que como se ha observado, esta variable presenta una dependencia significativa y puede derivar en unas pérdidas excesivas. Por el contrario, en determinadas circunstancias la respuesta del tramo con la conexión directa de grupos de velocidad fija puede ser aceptable, manteniendo pérdidas unitarias que no alteran el comportamiento de la red (esta situación es la que actualmente se da el algunos abastecimientos que permiten esta conexión).

\subsection{ResUltados en RÉGIMEN PERMANENTE PARA EL ESQUEMA TIPO III}

\subsubsection{Análisis estadístico de los resultados en régimen permanente}

Cuando las instalaciones de los edificios cuentan con un suministro compartido entre viviendas conectadas en directo y viviendas suministradas con grupo de presión de velocidad fija, la dispersión de los resultados se mantiene como efecto de la influencia del funcionamiento del grupo de presión, pero su magnitud es mucho menor tal como se pudo comprobar en el análisis particularizado del escenario de referencia (Figura C3-12).

El histograma de frecuencias de la serie para el esquema Tipo III aproxima a una distribución de extremos, reduciéndose la dispersión de valores aislados y por tanto facilitando el ajuste a una distribución tipo. La distribución Weibull es de nuevo la que mejor ajuste consigue a la mayoría de los escenarios analizados (el ajuste es menor para diámetros más pequeños ya que la afección de las pérdidas resulta más significativa). A modo de ejemplo a continuación se muestra el ajuste del escenario de referencia para 200 simulaciones. 


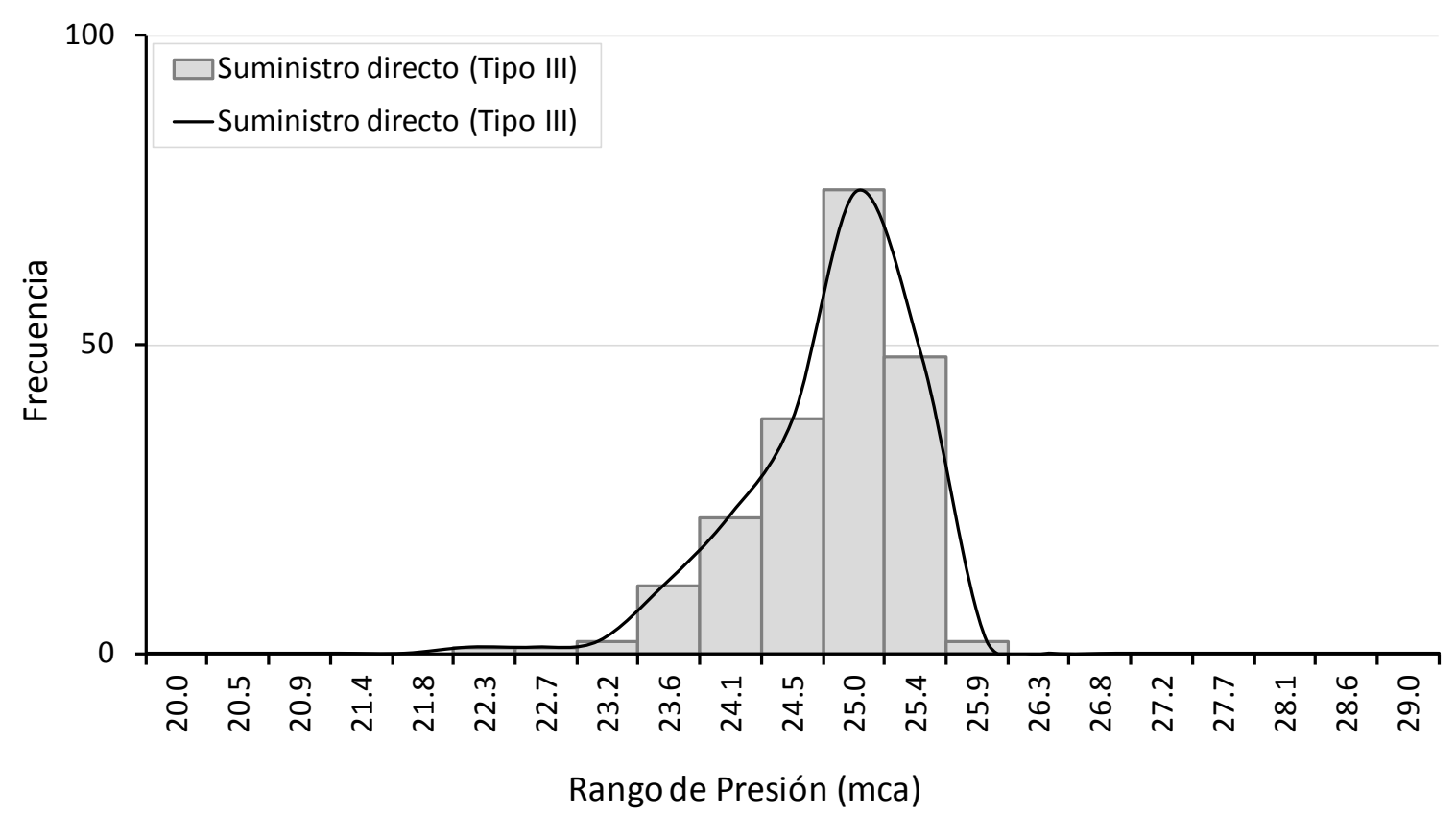

FIGURA C3-32. HISTOGRAMA DE FRECUENCIAS DE LA SERIE PRESIÓN MÍNIMA (ESC. REFERENCIA Y ESQ. TIPO III)

Para este escenario es posible aproximar con suficiente precisión los valores extremos de la serie, y por tanto se utiliza esta distribución para obtener el intervalo de confianza sobre el valor promedio de la pendiente hidráulica máxima con una confiabilidad del 99,5\%.

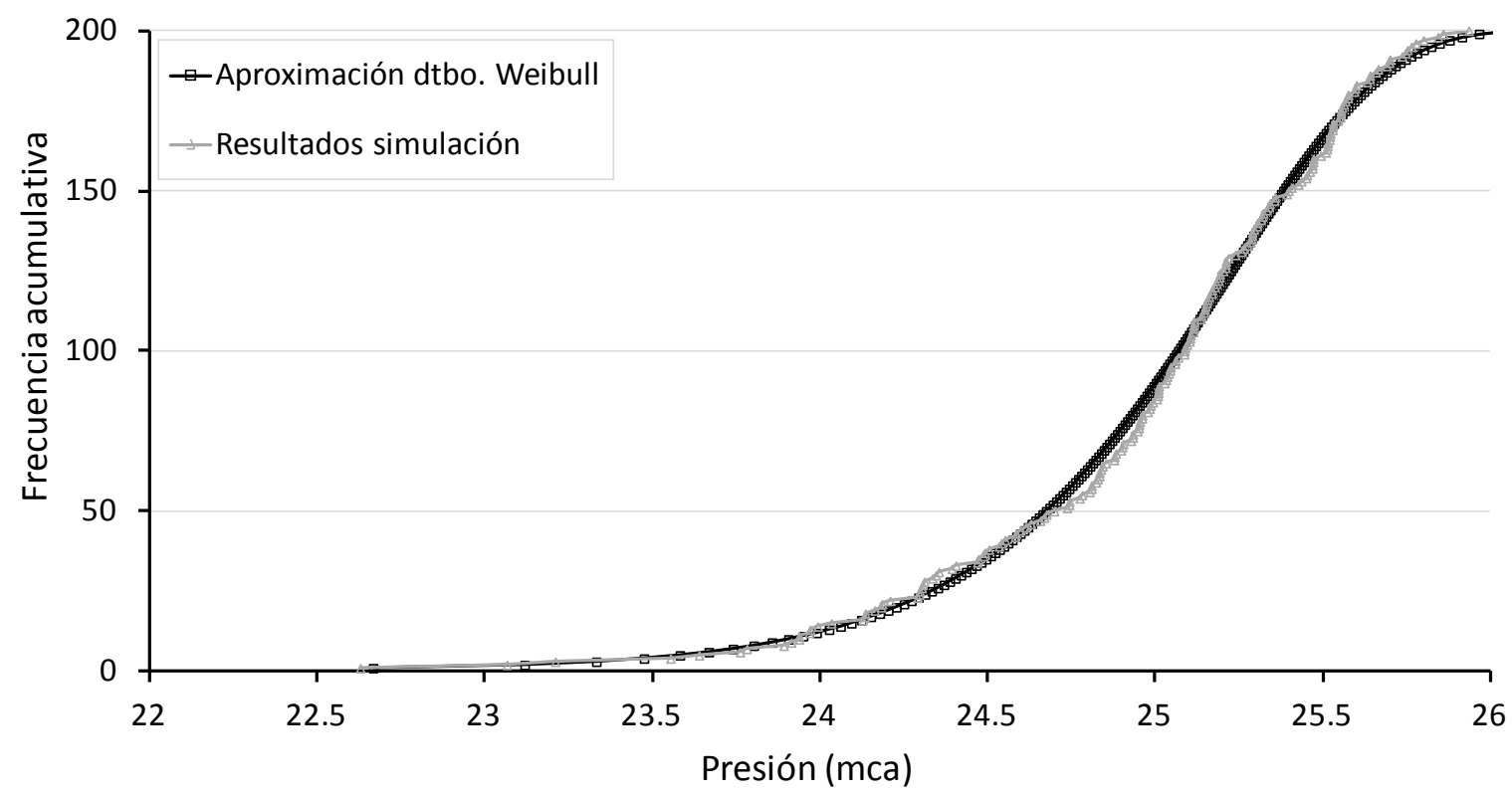

FIGURA C3-33. HISTOGRAMA DE FRECUENCIAS ACUMULATIVAS DE LA SERIE DE PRESIÓN MÍNIMA Y APROXIMACIÓN CON UNA DISTRIBUCIÓN WEIBULL (ESCENARIO DE REFERENCIA Y ESQ. TIPO III) 


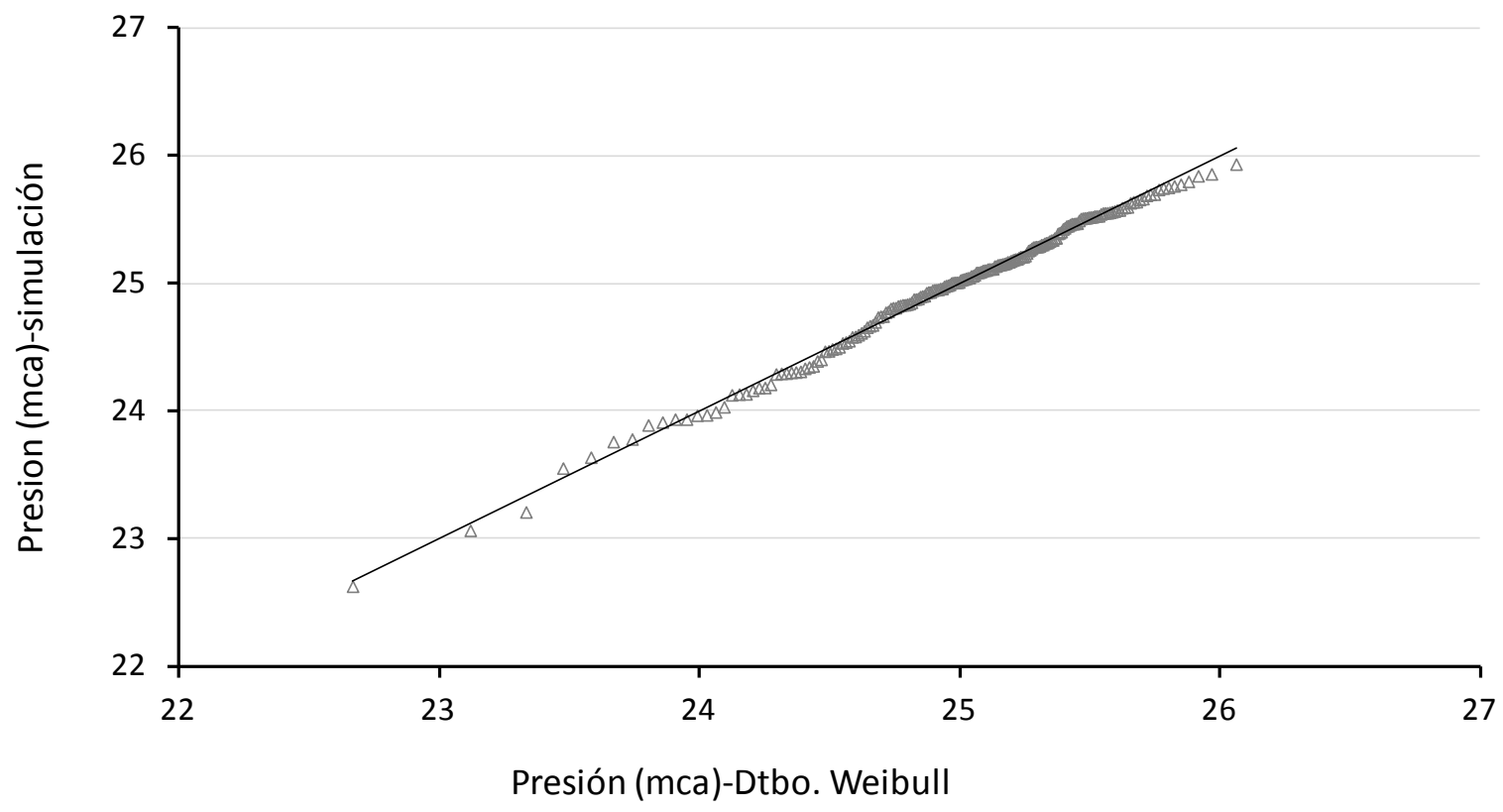

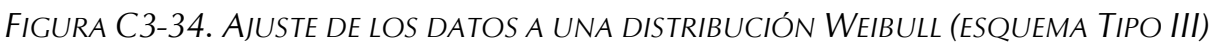

La siguiente gráfica incluye los valores de las pendientes hidráulicas máximas esperables para cada diámetro y carga hidráulica para el esquema Tipo III (atendiendo al grado de confiabilidad fijado).

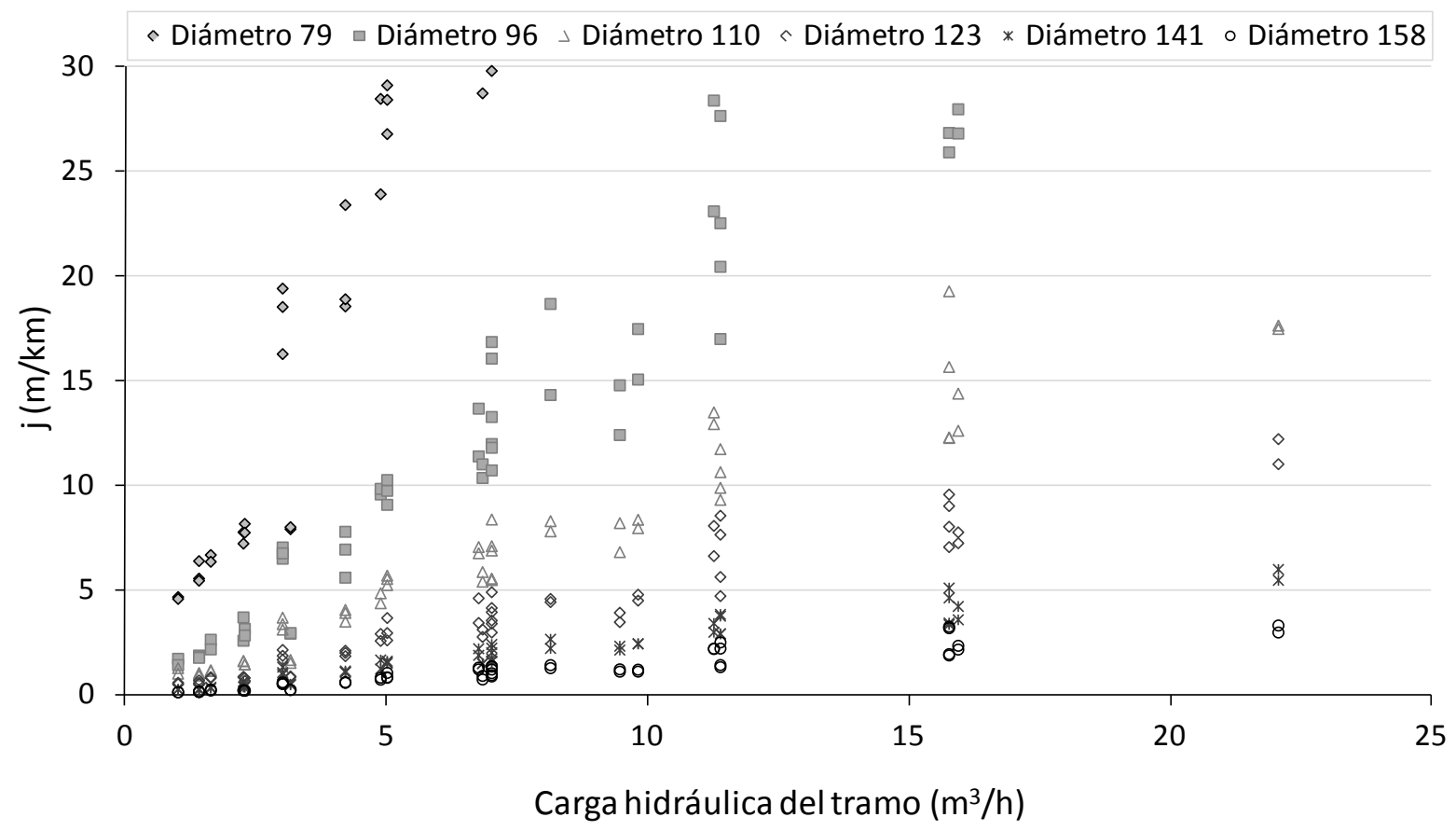

FIGURA C3-35. REPRESENTACIÓN DEL VALOR MÁXIMO DE LA PÉRDIDA UNITARIA (ESQUEMA TIPO III)

Si se analiza de forma particularizada una serie para una determinada carga se observa que se reduce la variabilidad con respecto a la causada por el esquema Tipo II. 


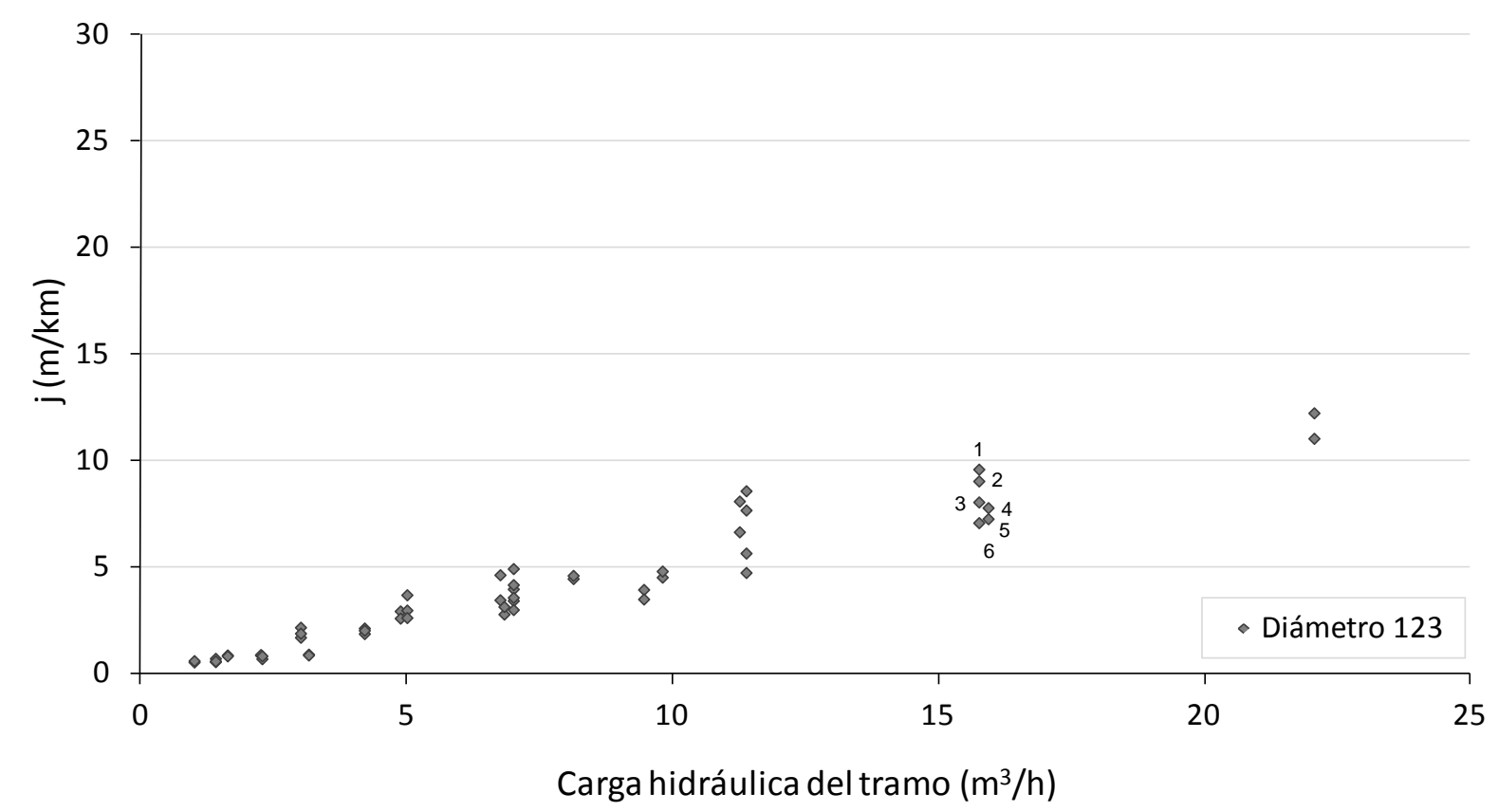

FIGURA C3-36. DeTALLE DE PÉRDIDAS UNITARIAS CON SUMINISTRO TIPO III Y DIÁMETRO 123 MM

Tal como se aprecia en la siguiente tabla el número de viviendas por nudo se muestra como uno de los parámetros críticos sobre la severidad de la respuesta del tramo, presentado las mayores pendientes hidráulicas en aquellas instalaciones que cuentan con un mayor número de viviendas por acometida. Esta influencia se debe al aumento del caudal de bombeo de los grupos tal como se comentó en el análisis del esquema Tipo II.

TABLA C3-2. TRAZABILIDAD DE LOS PUNTOS ANALIZADOS (ESQUEMA TIPO III, DIÁMETRO 123 MM)

\begin{tabular}{|c|c|c|c|c|c|c|c|c|c|c|}
\hline Serie & $\begin{array}{c}C \\
\left(m^{3} / h\right)\end{array}$ & $\begin{array}{c}\mathbf{j}_{\max } \\
(\mathrm{mca} / \mathrm{km})\end{array}$ & $\begin{array}{c}\text { jed } \\
(\mathbf{m c a} / \mathbf{k m})\end{array}$ & $\begin{array}{c}\mathbf{L} \\
(\mathrm{m})\end{array}$ & $n$ & $\begin{array}{c}d \\
(m)\end{array}$ & $\begin{array}{c}\text { viv. } \\
\text { nudo }\end{array}$ & $\begin{array}{l}\text { qmed } \\
(\mathrm{l} / \mathrm{h})\end{array}$ & $\begin{array}{c}\text { Simult. } \\
\text { Máx. }\end{array}$ & $\begin{array}{c}\text { Simult. } \\
\text { Med. }\end{array}$ \\
\hline 1 & 15,75 & 9,60 & 5,50 & 760 & 20 & 40 & 35 & 25 & 9 & 5,34 \\
\hline 2 & 15,925 & 9,05 & 5,59 & 280 & 15 & 20 & 35 & 35 & 9 & 5,365 \\
\hline 3 & 15,75 & 8,06 & 4,13 & 380 & 20 & 20 & 35 & 25 & 8 & 4,795 \\
\hline 4 & 15,925 & 7,79 & 4,31 & 560 & 15 & 40 & 35 & 35 & 5 & 4,31 \\
\hline 5 & 15,75 & 7,27 & 4,35 & 760 & 20 & 40 & 25 & 35 & 6 & 4,37 \\
\hline 6 & 15,75 & 7,09 & 3,96 & 380 & 20 & 20 & 25 & 35 & 8 & 4,62 \\
\hline
\end{tabular}

Respecto a la simultaneidad máxima, la situación de máxima pendiente coincide con un evento que mantiene en funcionamiento simultáneo varias bombas de la instalación (concretamente 9 de 18 grupos). Valor próximo al correspondiente a los análisis del esquema Tipo II, pero la pendiente hidráulica máxima en este caso pasa de $28,54 \mathrm{mca} / \mathrm{km}$ a $9,6 \mathrm{mca} / \mathrm{km}$, debido a un menor tamaño de las bombas y una mayor contribución del suministro en directo Tipo I. 
Para los resultados asociados a la serie 2 se observa una elevada proporción de grupos de presión con funcionamiento simultáneo (9 bombas de las 13 instaladas), condicionado previsiblemente a un mayor caudal medio demandado por vivienda y hora. Sin embargo, en otros eventos como la serie 4, el número máximo de bombas con funcionamiento simultáneo no toma un valor significativo frente al valor de simultaneidad media.

\subsubsection{Representación de los resultados de las simulaciones}

Si se traza una curva que incluya la parte superior de la nube de puntos asociada a cada diámetro es posible obtener una gráfica de referencia para instalaciones que cuentan con un suministro compartido entre bomba de velocidad fija y directo sin grupo de presión (en una relación 1:3).

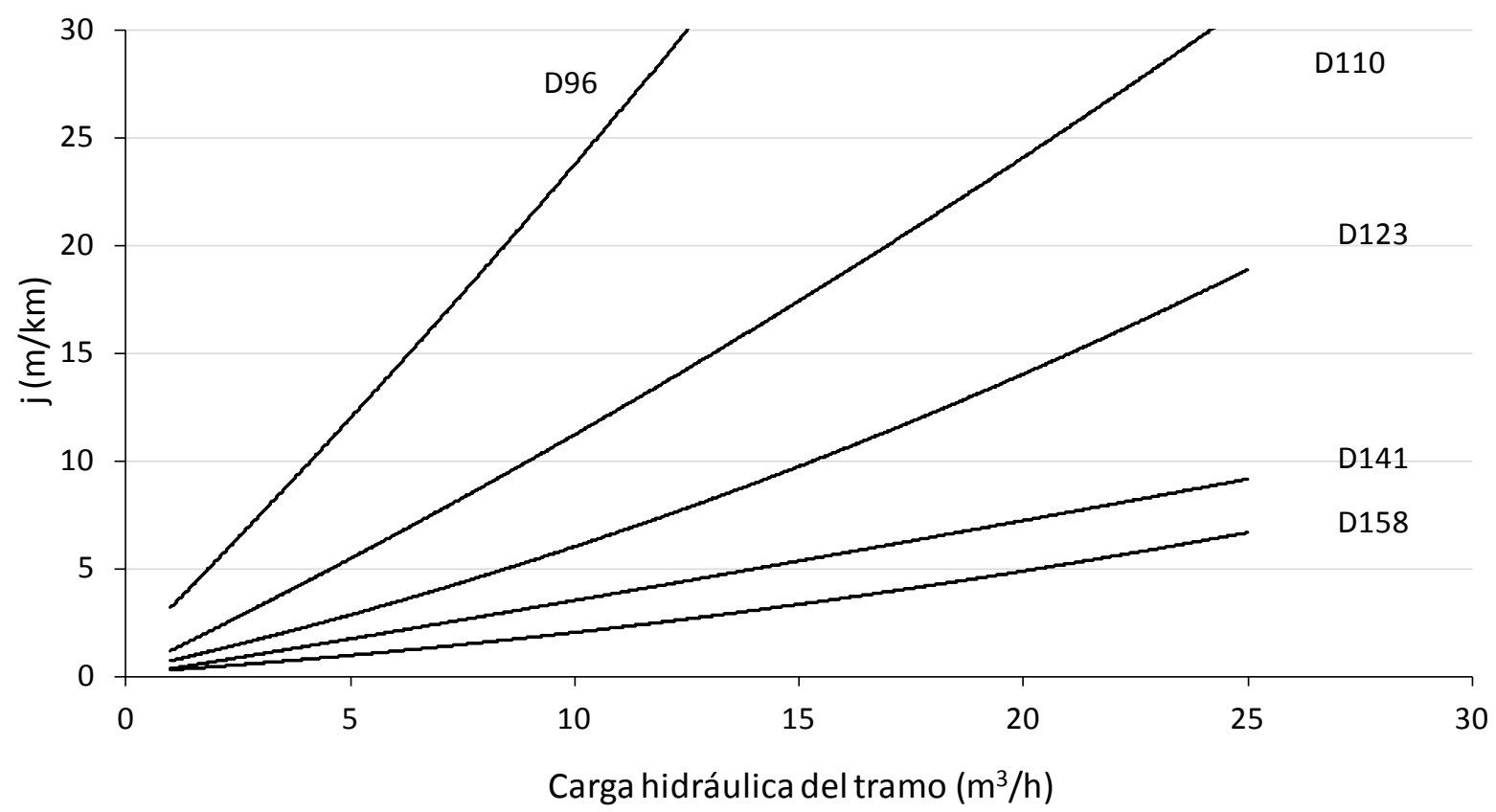

FIGURA C3-37. CURVAS DE PENDIENTES UNITARIAS MÁXIMAS (ESQUEMA TIPO III)

Si bien la obtención de la gráfica no presenta la misma rigurosidad que las curvas asociadas al esquema Tipo I (por el peor ajuste obtenido con la distribución tipo utilizada), sirva de referencia como representación de la delimitación de las pérdidas de carga máximas esperables.

En la extrapolación a otras relaciones entre viviendas con bomba y viviendas en directo diferentes a 1:3 se debe tener presente la reducción del ajuste a la distribución tipo utilizada a medida que aumenta la proporción de viviendas suministradas con bomba. Del mismo modo, las solicitaciones asociadas deberán estar limitadas inferiormente por los resultados para un esquema Tipo I, y superiormente por un esquema Tipo II en el que todas las viviendas son suministradas con grupo de presión. 


\subsection{COMPARACIÓN DE LAS RESPUESTAS DE LOS ESQUEMAS DE SUMINISTRO}

A continuación se comparan las solicitaciones máximas de los 3 escenarios presentados anteriormente para uno de los diámetros analizados.

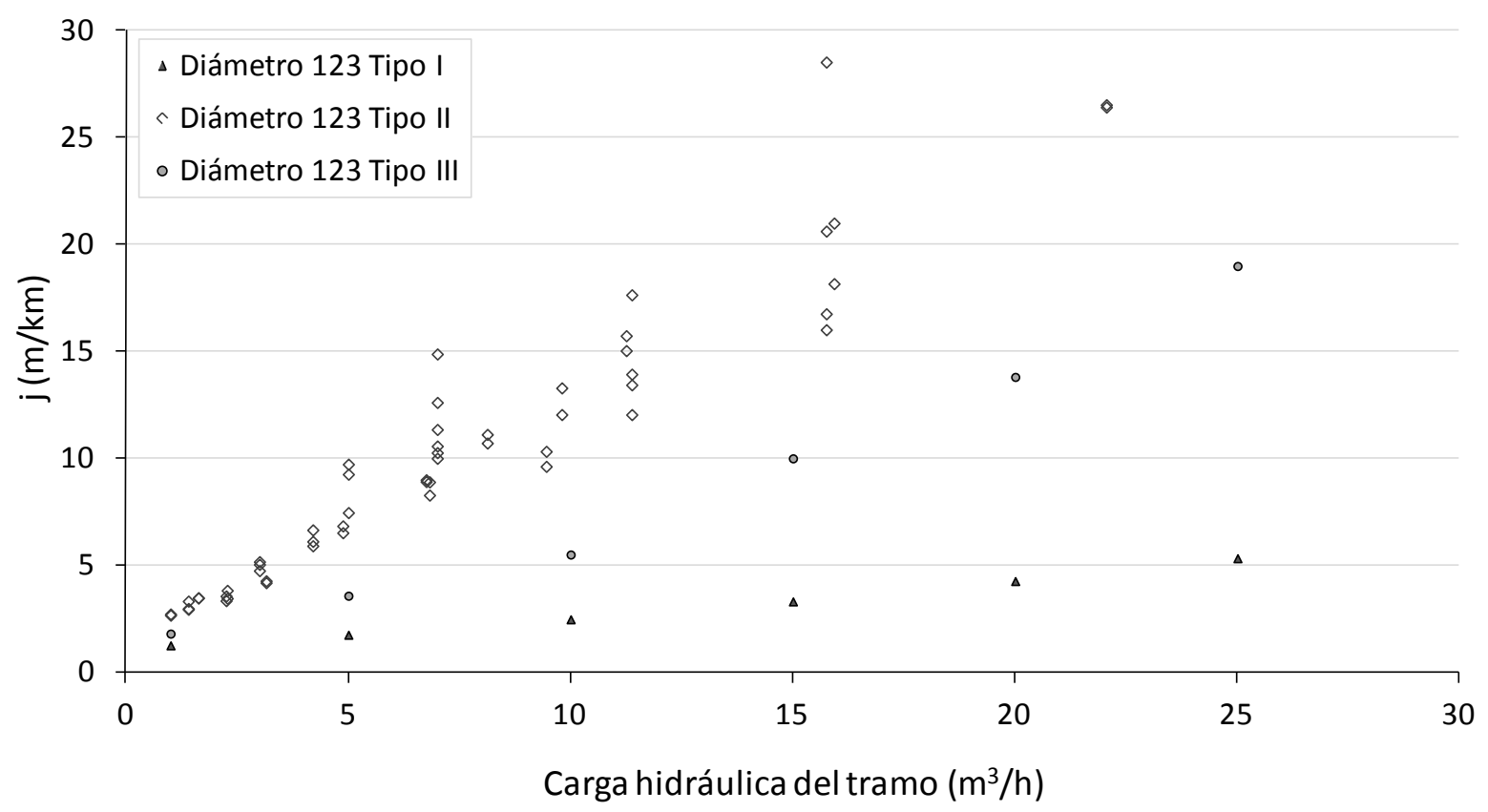

FIGURA C3-38. PÉRDIDAS UNITARIAS MÁXIMAS EN FUNCIÓN DEL ESQUEMA DE SUMINISTRO (D 123 MM)

De la gráfica anterior se pueden obtener las siguientes conclusiones:

- La dispersión de los datos para una misma carga es mayor si se instalan grupos de velocidad fija, mientras que en la situación de suministro en directo o con bombas de velocidad variable la pendiente hidráulica máxima está localizada sobre una curva bien definida. Derivado de lo anterior la influencia del valor de los parámetros del tramo ("número de nudos", "demanda media", "número de viviendas por nudo"...) genera, en el suministro con grupos de bombeo sin variador, rangos de pendientes máximas para una misma carga y no un valor único como en el caso de suministro con bombas de velocidad variable o en directo.

- El suministro con bombas de velocidad fija origina pérdidas de carga muy superiores a las ocasionadas con grupos de velocidad variable. Por ello para una carga y diámetro de red dado, la utilización de grupos de presión de velocidad variable reduce significativamente las solicitaciones.

- Las pendientes máximas originadas con el aumento de porcentaje de grupos de velocidad fija en el tramo no sigue una tendencia lineal, de forma que un aumento de este porcentaje no supone un aumento proporcional en las pérdidas en el tramo. 


\subsection{EJEMPLO DE APLICACIÓN}

A continuación se muestra un ejemplo de utilización de las gráficas obtenidas en el estudio en régimen permanente. Se trata por tanto de validar la posibilidad de eliminar los depósitos atmosféricos con los que actualmente cuentan los edificios de un sector ejemplo. Dado que de los esquemas analizados el que menor severidad presenta es el esquema Tipo I (suministro en directo sin grupos de presión), y puesto que se estima que presenta un comportamiento asimilable a los grupos de velocidad variable (esquema Tipo IV), se utilizan los resultados asociadas al esquema Tipo I para comprobar la capacidad del sector una vez desprovisto de depósitos.

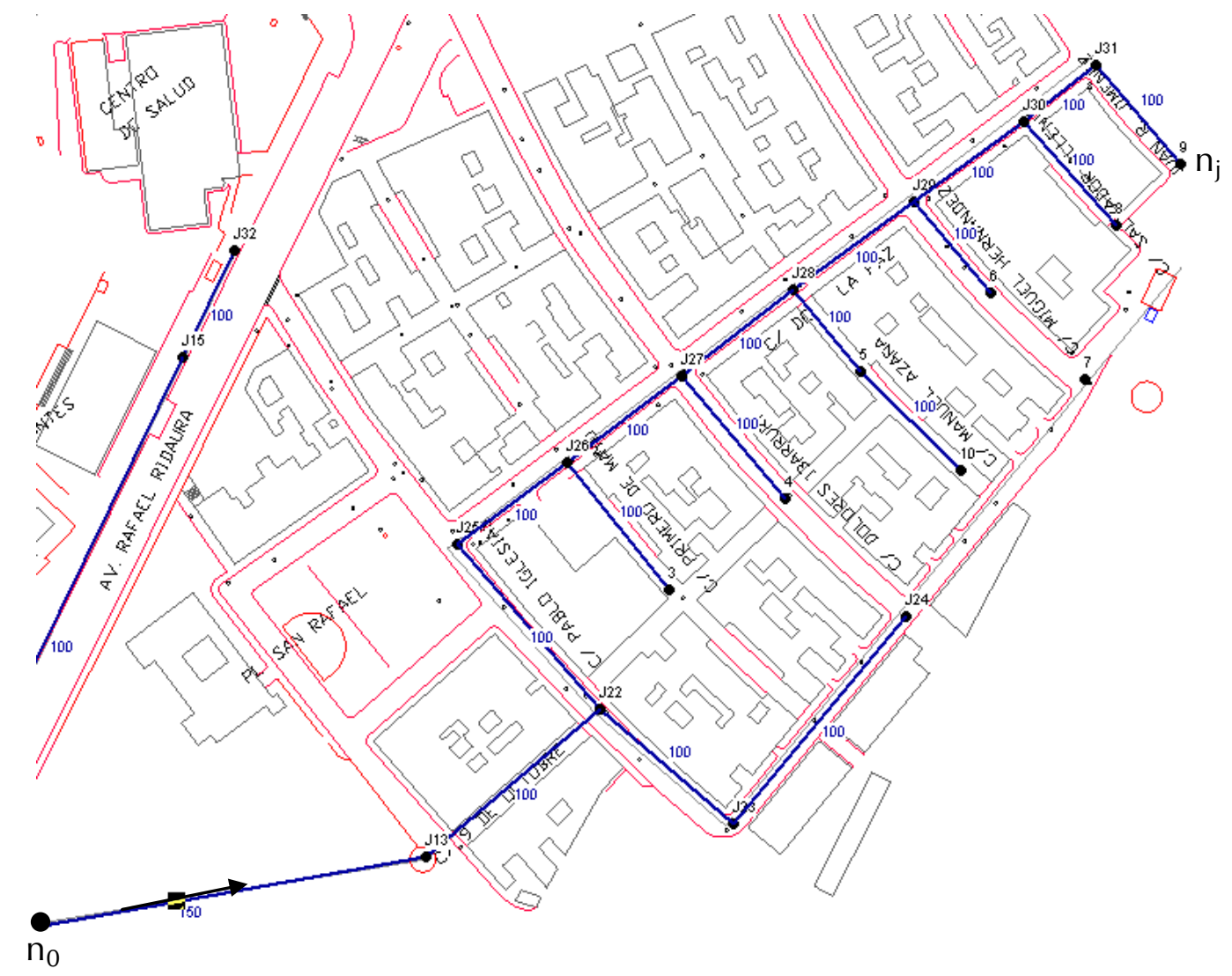

FIGURA C3-39. ESQUEMA DEL SECTOR DE RED DE EJEMPLO

El tramo en cuestión ocupa una zona terminal de red que bien podría representar una ampliación a una zona de nueva urbanización. Del sector se conocen las características físicas de los elementos que lo componen, y la dotación hidráulica instalada. Aunque la red cuenta con un mayor trazado aguas arriba del sector, se supone la disponibilidad de una presión prácticamente estable en el punto de conexión del sector y se debe controlar la presión mínima que se originaría en éste bajo un esquema de suministro con conexión directa y para las condiciones constructivas actuales. 


\subsubsection{Descripción del procedimiento}

El sector de red anterior puede ser simplificado en uno similar al mostrado en la siguiente figura, en el que todas las acometidas de los edificios se conectan sobre la conducción principal, así como las tuberías que dan servicio a las calles secundarias.

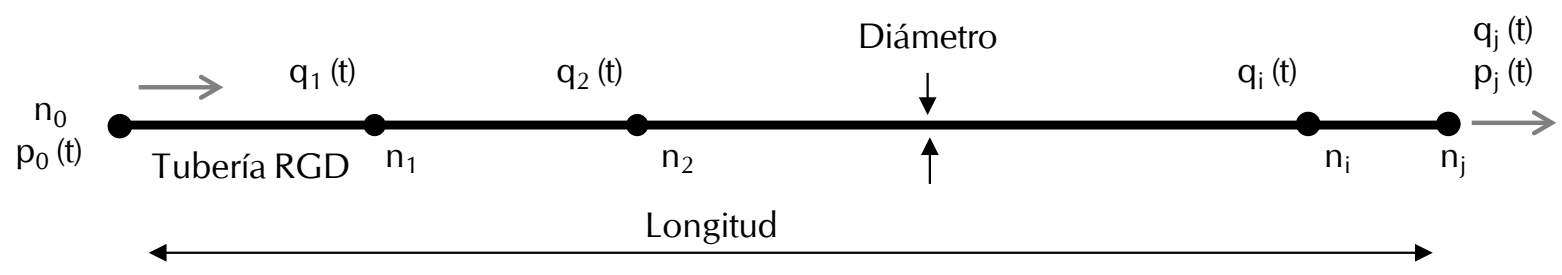

FIGURA C3-40. ESQUEMA SIMPLIFICADO DEL TRAMO

Puesto que se trata de un procedimiento estimativo, se simplifican algunas de las características del tramo, como la existencia de un ramal situado en la parte inferior del sector (las viviendas equivalentes pueden repartirse a lo largo del tramo). Los datos básicos necesarios para la caracterización son:

- Presión a la entrada (Pentrada)

- Presión mínima admisible en el punto más alejado o punto crítico $\left(n_{j}\right)$

- Diámetro interior de las conducciones $(D)$

- Distancia entre el punto de alimentación al tramo y el punto crítico $(L)$

- Diferencia de cotas entre nudo crítico y alimentación

- Número de viviendas conectadas a cada nudo (o número total de viviendas suministradas en el tramo)

- Valor del volumen suministrado en hora punta por vivienda o para la totalidad del tramo

\subsubsection{Desarrollo numérico}

Para acceder a la gráfica se debe obtener la carga hidráulica del sector. Ésta se corresponde con el volumen total que circula en una hora en el tramo asociado a las viviendas y diferentes usos, por ello se contabiliza el número de viviendas totales a abastecer y se asigna un consumo máximo por vivienda y hora. Aunque el sector cuenta con otros usos diferentes a viviendas, al mismo tiempo que no todas las viviendas son de la misma tipología, en el cálculo se debe considerar la posible equivalencia entre éstos, requiriéndose un mayor nivel de detalle en la medida que los usos puedan mostrar un comportamiento más exigente. En el ejemplo se ha asimilado algunos de los locales a viviendas dado su reducido número. 
La información referente al sector se detalla a continuación:

- Presión mínima en la entrada del tramo en condiciones normales: 26 m

- Presión mínima en acometida asegurada por el gestor: 20 m

- Diámetro de las conducciones es de 100 mm (diámetro interior)

- Viviendas equivalentes del tramo: 210

- Consumo medio en hora punta por vivienda considerado: 31 litros

- Desnivel nudo más alejado: 2 metros

- Distancia hasta punto más alejado: 650 metros

Bajo estas condiciones la carga se calcula según la siguiente expresión:

$$
C=210 \frac{\text { viviendas }}{\text { tramo }} \cdot 31 \frac{\text { litros }}{\text { vivienda } \cdot \text { hora }}=6,5 \frac{\mathrm{m}^{3}}{\text { hora } \cdot \text { tramo }}
$$

Acudimos a la gráfica para un diámetro interior de $96 \mathrm{~mm}$, que es el que más se aproxima con el diámetro instalado en el tramo, se obtiene un valor aproximado de la pendiente unitaria máxima de $3,8 \mathrm{~m} / \mathrm{km}$. En principio se considera un valor aceptable en una red de distribución.

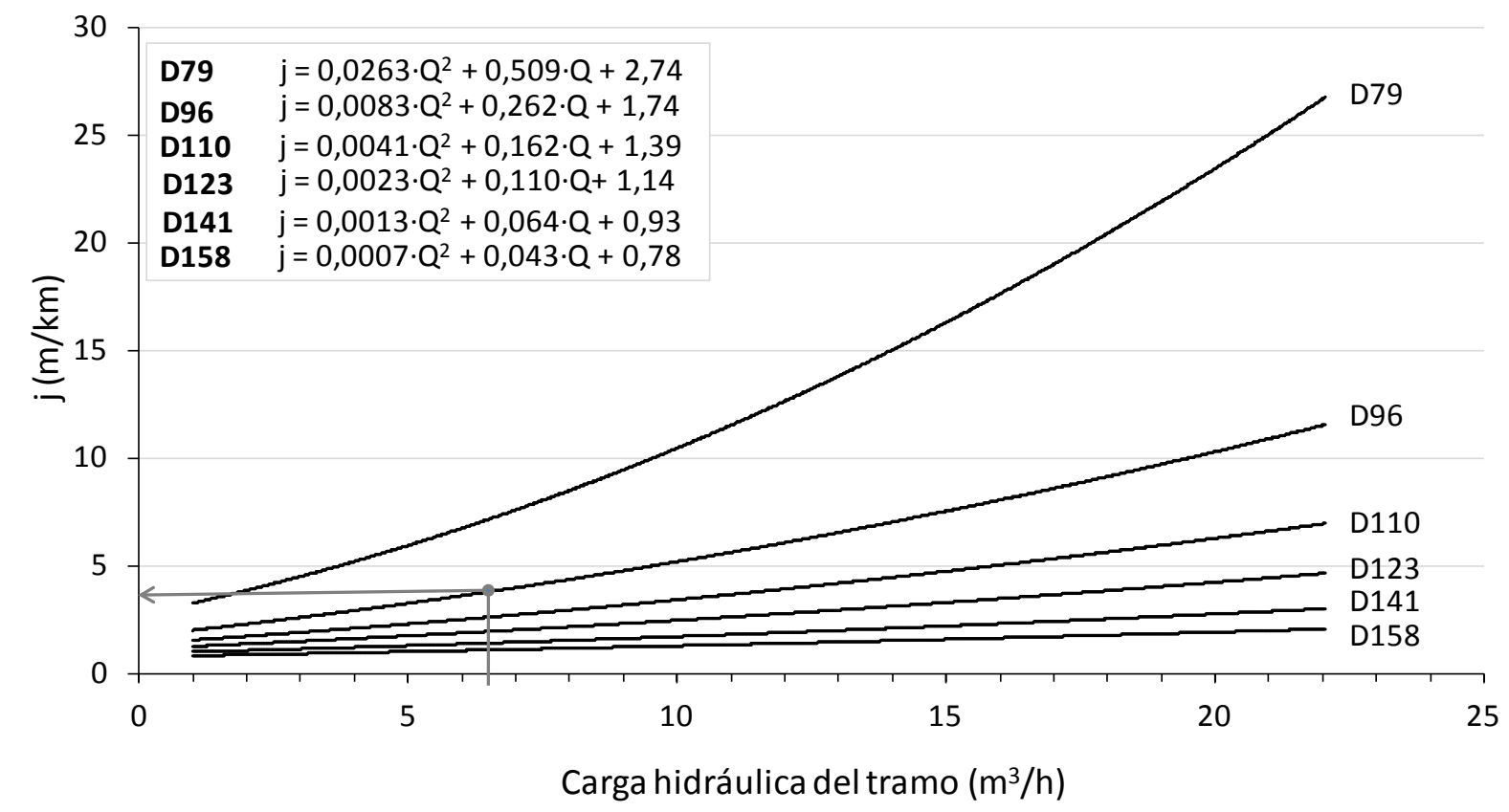

FIGURA C3-41. PENDIENTE MÁXIMA ADMISIBLE PARA EL DIÁMETRO INSTALADO 


\subsubsection{Conclusión sobre la capacidad del tramo}

Para la pendiente hidráulica dada la presión mínima que se alcanzaría en el tramo bajo un esquema de conexión directa sin grupos de presión o a partir de bombas de velocidad variable sería de:

$$
j=3.8=\frac{26 \mathrm{~m}-\left(p_{\min }-2\right) m}{0.65 \mathrm{~km}} \rightarrow p_{\min }=21,53 \mathrm{~m}
$$

Dado que la presión mínima obtenida con la curva es mayor que la presión mínima que debe asegurar el gestor a la entrada de la acometida del nudo más desfavorable, se concluye que con el diámetro instalado es posible realizar la sustitución de los depósitos domiciliarios por un suministro en directo para los edificios en los que sea posible éste, y un suministro con grupo de bombeo de velocidad variable en aquéllos en los que la presión en red sea insuficiente para asegurar una presión residual mínima en los puntos de consumo.

A la vista de la respuesta del sector de red es importante matizar sobre las limitaciones de la gráfica, ya que como se introdujo al inicio del presente capítulo en las hipótesis de partida, es preciso contemplar el sector como una parte indivisible de la red, y la capacidad obtenida tendrá validez en la medida que pueda ser asegurada la presión mínima en la entrada. Esta garantía está condicionada por la nueva carga hidráulica que soporta la red, ya que los nuevos flujos de caudal podrán reducir de forma más o menos significativa la presión en la entrada.

Respecto a los esquemas equipados con bomba de velocidad fija y dado el reducido margen disponible bajo el esquema Tipo I, es posible concluir que se debería acudir a un diámetro superior al instalado para mantener el valor mínimo de presión establecido por la empresa.

En el caso de realizar una valoración para la renovación de la conducción principal sería conveniente acudir a un diámetro mayor, y de valor mínimo $110 \mathrm{~mm}$. Por otro lado, para una ampliación del suministro a un mayor número de viviendas, con un diámetro de $123 \mathrm{~mm}$ y para la misma pendiente hidráulica será posible aumentar la capacidad del tramo hasta prácticamente $18 \mathrm{~m}^{3} / \mathrm{h}$ (equivalente aproximadamente a 600 viviendas). 
Capítulo 4

\section{Análisis de los efectos de la conexión directa en régimen transitorio}




\subsection{INTRODUCCIÓN}

En instalaciones interiores de edificios en el ámbito urbano rara vez son modelados los efectos transitorios generados. El reducido alcance del fenómeno para las conexiones más comunes, junto con la necesidad de un software y conocimientos específicos muchas veces no justifica la realización de este tipo de estudios. La modelación y análisis en régimen transitorio tiene mayor trascendencia en el estudio de instalaciones singulares, tales como grandes aducciones o sistemas en los que se trasiegan caudales considerables. En todas estas situaciones, el estudio de los efectos transitorios y en particular la correcta protección de la instalación, es más que evidente.

En realidad la dinámica introducida por algunos componentes de la instalación interior del edificio bajo un esquema de conexión directa justifica la necesidad de valorar la magnitud de los efectos transitorios. Es el caso de los grupos de presión, elemento cada vez más indispensable en los esquemas de instalaciones interiores. Sin embargo, la modelación de los diferentes componentes y condiciones de funcionamiento presenta una complejidad analítica adicional. Esto se debe principalmente a la variabilidad de las configuraciones y la dificultad en la caracterización de las condiciones de contorno asociadas.

Adicionalmente el uso de los depósitos atmosféricos no ha favorecido la necesidad de analizar este efecto, debido a la función de aislamiento entre la red pública y la instalación interior realizada por este elemento. Bajo un esquema de conexión indirecta se reducen sensiblemente los efectos transitorios, condicionados en cualquier caso por la maniobra de apertura y cierre de la válvula que controla el llenado. Pero si se pretenden eliminar los depósitos atmosféricos y reducir los inconvenientes derivados de su uso, está más que justificada la necesidad de un estudio de la protección de la instalación, y en este estudio el análisis en régimen transitorio adquiere un indudable protagonismo. 
En el presente capítulo se modela la instalación interior de un edificio equipado con grupo de presión en directo, y se analizan los efectos transitorios generados por este esquema, y los parámetros que mayor influencia ejercen sobre la magnitud del transitorio originado. La finalidad perseguida es verificar la posibilidad de realizar una conexión en directo de los grupos de presión, tanto de velocidad fija como de velocidad variable, en aras de prescindir de la instalación de depósitos auxiliares de alimentación.

\subsection{DESCRIPCIÓN DE LAS SOLICITACIONES TRANSITORIAS EN UNA INSTALACIÓN MONITORIZADA}

A modo de introducción, a continuación se muestran los efectos asociados al funcionamiento de grupos de presión es aspiración directa. Para ello la monitorización de un edificio ha permitido obtener registros de presión asociados a cada funcionamiento. Además ha sido posible configurar diferentes esquemas con conexión directa; a partir de un grupo de velocidad fija (Tipo II) y mediante un grupo equipado con variador de frecuencia (Tipo IV). Las series representadas se corresponden con las tres sondas de presión instaladas en diferentes puntos (en las proximidades de la acometida del edificio, en un punto intermedio de la instalación interior, y en la propia tubería de aspiración de la bomba).

\subsubsection{Bomba de velocidad fija conectada en directo}

Para el esquema equipado con bomba de velocidad fija (BVF) las solicitaciones en aspiración directa son considerables, ya que el arranque del grupo genera depresiones significativas, registrándose caídas de presión elevadas durante los primeros instantes del arranque de la bomba.

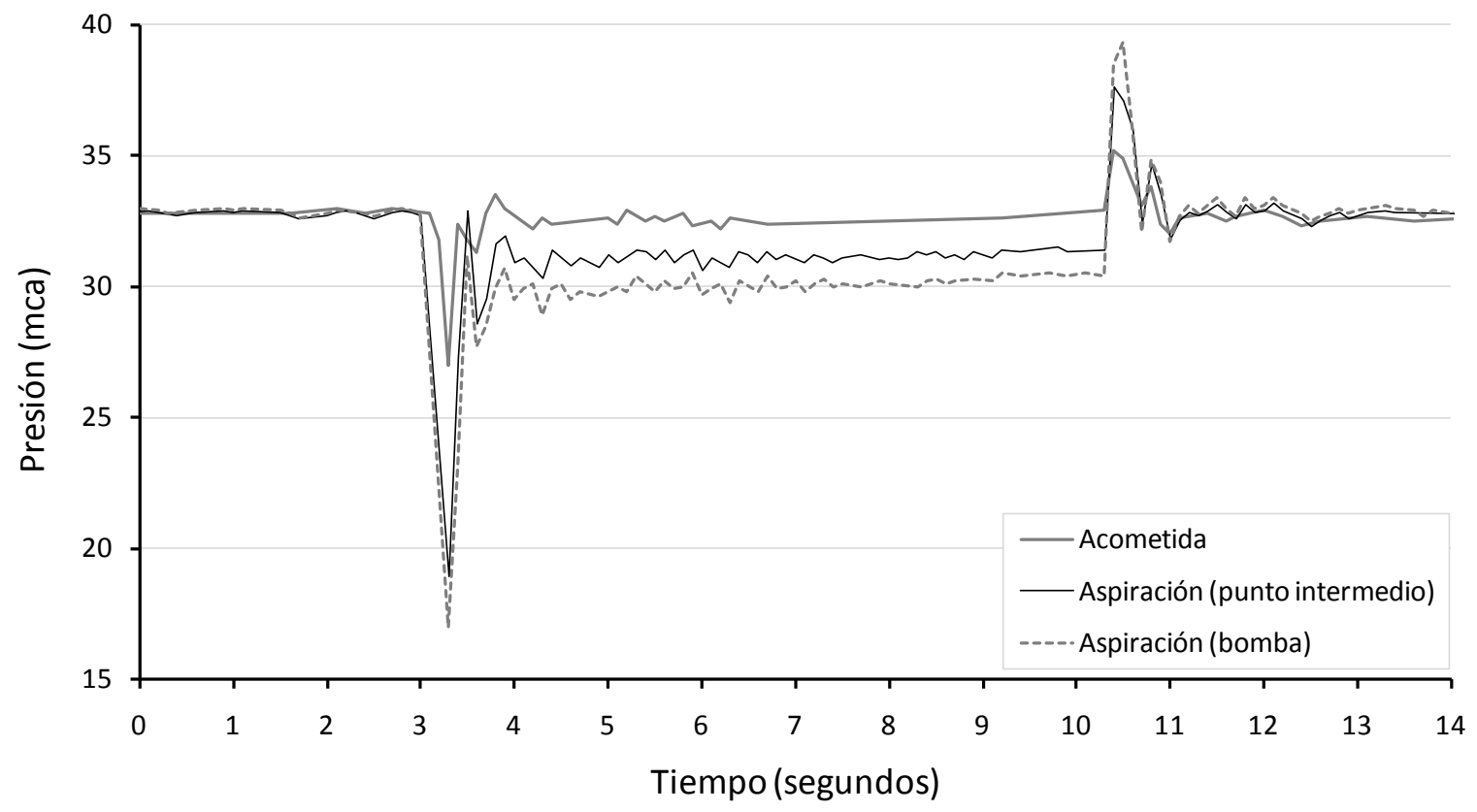

FIGURA C4-1. REGISTRO DE PRESIÓN DURANTE EL FUNCIONAMIENTO EN DIRECTO DE LA BVF 
La presión mínima alcanzada en la instalación es próxima a 16 mca. Este registro de presión tiene lugar en la aspiración de la bomba implicando una reducción puntual de la presión en este punto próxima a 17 mca (caída de presión cercana al 50\% respecto a la presión estática en ese mismo punto). Si bien el valor de la presión mínima alcanzada en este punto no es crítico, en otras instalaciones o bajo otras condiciones de operación puede suponer un riesgo para el normal suministro.

Como es de esperar las solicitaciones en la acometida del edificio son mucho más reducidas. Esto es debido principalmente al efecto de atenuación de la perturbación por la reflexión de las ondas en el entronque con la red general, y a la disipación energética que se da en el tramo. Derivado de lo anterior, este efecto puede incluso revelar caídas de presión prácticamente inapreciables en esta zona, por el contrario la depresión en la aspiración de la bomba puede alcanzar valores elevados. En este punto el valor del registro mínimo de presión es próximo a $27 \mathrm{mca}$, presentando una caída de presión cercana al $18 \%$ respecto a su presión estática.

Otro efecto a considerar es la duración del fenómeno. Como puede apreciarse ésta es reducida con tiempos próximos a 0,5 segundos y en ningún caso superior a 1 segundo. Esta peculiaridad muchas veces hace que el fenómeno sea inapreciable en algunos puntos de la instalación, principalmente para manómetros convencionales. Adicionalmente este tiempo reducido favorece la generación de menores solicitaciones transitorias en el tramo, ya que disminuye la posible simultaneidad en el arranque de varios grupos en edificios próximos, y por tanto se reduce la superposición de los efectos.

Una vez estabilizado el funcionamiento de la bomba después de su arranque la presión registrada en los diferentes puntos es la propia del régimen permanente, estando directamente relacionada con las pérdidas de carga en el tramo de aspiración (conjunto de tuberías formado por el tubo de acometida y tubo de alimentación hasta la conexión de la bomba), y las pérdidas de carga asociadas a la respuesta de la red. En esta instalación la variación de presión en la acometida es muy reducida respecto a las condiciones estáticas. En otras instalaciones si el caudal detraído de la red origina una reducción de la presión en el entronque las series de presión presentarían valores más bajos, todo ello de acuerdo a los resultados obtenidos en el capítulo anterior. Por otro lado, la respuesta de las series es ligeramente ascendente ya que a medida que se Ilena el calderín de impulsión aumenta la altura de bombeo, reduciéndose el caudal bombeado y con él las pérdidas de carga en aspiración.

Cuando el grupo alcanzada la presión de paro cesa su alimentación eléctrica, iniciándose el transitorio de parada que provoca una sobrepresión asociada a la deceleración del grupo y del flujo de caudal trasegado por éste. De forma similar al transitorio de arranque, el punto de control con mayores solicitaciones es el próximo a 
la aspiración de la bomba. Para el caso de una instalación como la monitorizada bajo el funcionamiento con una bomba de velocidad fija, el valor de esta sobrepresión es similar al derivado de la parada por fallo de alimentación eléctrica (efecto más sensible en función del caudal impulsado en cada instante).

\subsubsection{Bomba de velocidad variable conectada en directo}

Si se permuta en la instalación monitorizada el grupo de presión y se pasa a funcionar con grupo de velocidad variable los efectos originados se reducen sensiblemente. Este efecto se debe a un arranque más progresivo derivado del funcionamiento del controlador, unido a una velocidad de giro durante el arranque inferior a la nominal del grupo (condicionada por la respuesta del PID). La Figura C4-2 muestra las variaciones de presión en las sondas para dos arranques consecutivos.

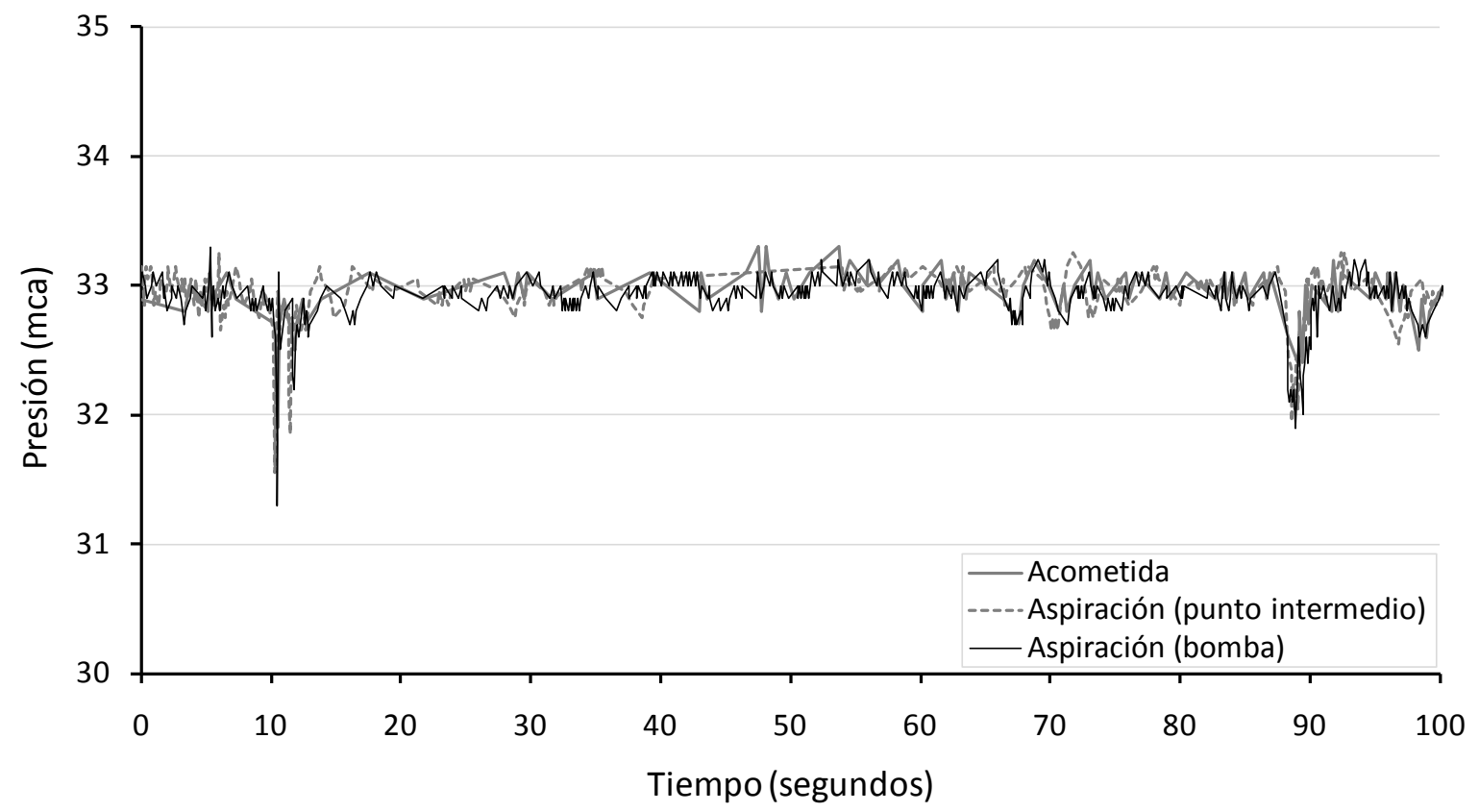

FIGURA C4-2. REGISTROS DE PRESIÓN DURANTE EL FUNCIONAMIENTO EN DIRECTO DE LA BVV

Otra de las particularidades del funcionamiento de este tipo de grupos es la reducción de los efectos correspondientes al funcionamiento en régimen permanente, ya que al reducirse la probabilidad de giro a velocidad nominal, el caudal trasegado pocas veces alcanza el caudal de diseño del grupo. Por otro lado hay que destacar que el funcionamiento del controlador muestra diferentes respuestas ante las variaciones de presión que se dan en impulsión (relacionadas con la demanda instantánea de agua), tal como se puede apreciar en la figura tanto los arranques como resto de instantes las variaciones de presión no se mantienen idénticas. En cualquier caso la magnitud de la depresión máxima no ha variado significativamente durante el periodo de monitorización. 
Respecto a la parada del grupo, el variador de frecuencia realiza una laminación significativa siendo incluso complicado fijar el instante exacto de la parada. Esta situación se vería modificada ante un fallo de alimentación eléctrica ya que el variador no realizaría un control sobre la deceleración del grupo y tan solo se atiende a la inercia de éste. El caudal con mayor probabilidad de ocurrencia está en torno al 40\%-60\% de su capacidad máxima a diferencia de lo que ocurre con el grupo de velocidad fija.

\subsubsection{Comparación de las respuestas}

Como se ha comprobado para la instalación monitorizada las solicitaciones asociadas al esquema equipado con bomba de velocidad fija son mucho más severas que las propias del grupo con variador, esto se debe a la dinámica propia del funcionamiento de cada uno de los equipos. En la Figura C4-3 se comparan las solicitaciones para el funcionamiento de la bomba de velocidad fija (BVF) y la bomba de velocidad variable (BVV), a partir de los registros obtenidos. Para cada equipo se muestran las solicitaciones en la aspiración de la bomba y en acometida, distinguiéndose entre los efectos de depresión (tanto en régimen permanente RP como en régimen transitorio RT) y sobrepresión por parada del grupo (se han seleccionado los valores máximos observados).

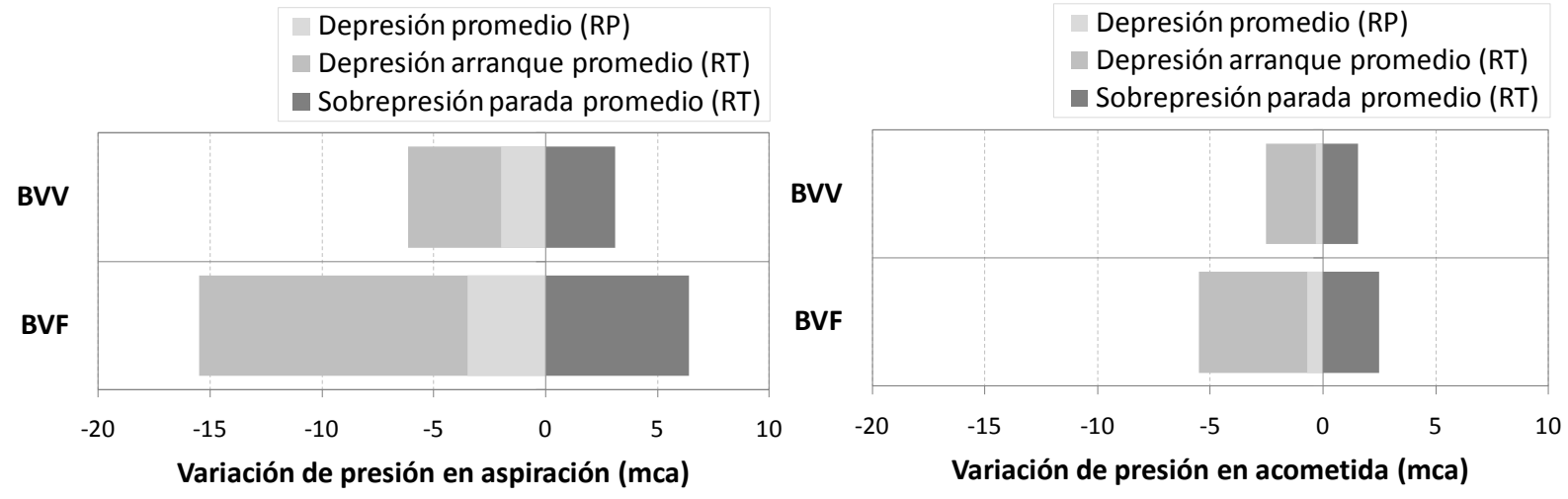

FIGURA C4-3. COMPARACIÓN ENTRE LAS SOLICITACIONES CON BVF Y BVV (INSTALACIÓN MONITORIZADA)

Durante las mediciones se ha registrado una reducción de la caída de presión promedio del $58 \%$ en la aspiración de la bomba para el funcionamiento de un grupo equipado con variador. Del mismo modo la reducción porcentual en la acometida del edificio es próxima a este valor (52\%).

La diferencia entre las solicitaciones se debe al comportamiento dispar presentado por ambos grupos de presión. El motor asociado al grupo de velocidad fija, una vez recibe alimentación eléctrica realiza un arranque directo aumentando progresivamente su velocidad de giro hasta alcanzar la velocidad de régimen (sin estar controlado por ningún dispositivo auxiliar y tan solo obedeciendo a la curva de par y resistente de la instalación, y a la dinámica propia del grupo moto-bomba). Por el 
contrario, el motor con variador dispone en todo momento del controlador PID que regula la velocidad de rotación del motor por medio del control de la frecuencia y tensión de alimentación a éste, haciendo más progresivos los cambios de estado y manteniendo en condiciones de régimen un funcionamiento asociado a la demanda real en la instalación que no coincide con su capacidad máxima.

\subsection{RESPUESTA DE LA INSTALACIÓN OBTENIDA MEDIANTE SU MODELO HIDRÁULICO}

Para completar los resultados anteriores se ha construido el modelo hidráulico correspondiente al edificio monitorizado bajo el esquema de conexión en directo siguiendo las consideraciones expuestas en el Capítulo 2. Este modelo se ha simulando utilizando el programa de transitorios hidráulicos Allievi.

En una primera instancia se ha modelado la conexión en directo de una bomba de velocidad fija con las características de la instalación monitorizada, manteniendo los resultados de este esquema como el comportamiento de referencia. Del mismo modo el principal fenómeno que se ha tratado de modelar es el correspondiente al funcionamiento del grupo de presión en su fase de arranque, ya que es el que mayores solicitaciones presenta para posibilitar la conexión en directo.

Los resultados obtenidos mediante el modelo van a permitir realizar un análisis de sensibilidad sobre la influencia de las principales variables hidráulicas constructivas, así como extrapolar los resultados a otras instalaciones tras la modificación de las características de la instalación de referencia.

\subsubsection{Evolución de los caudales en el modelo}

La simulación parte del régimen permanente en el cual el caudal bombeado por el grupo de presión es nulo. Una vez que se produce el arranque se modifica el caudal en circulación por cada conducción tal como se muestra en la siguiente tabla (valores mostrados para la estabilización de la bomba 4 segundos después de su arranque). No se dispone de información referente al caudal real por las conducciones de la RGD, pero sí del caudal por la acometida del edificio, coincidiendo con el valor indicado.

En la Figura C4-5 se muestra la evolución de caudal que se experimente en las conducciones conectadas al nudo de acometida del edificio, tuberías pertenecientes a la red general de distribución (tuberías T3 y T4, y tubo de acometida T7). La conducción T3 representa la tubería que discurre en el exterior del inmueble y que aporta el flujo a la instalación. Por ello en el instante de arranque de la bomba aumenta el caudal trasegado por esta conducción, debido a la aspiración introducida por el grupo, al mismo tiempo que se reduce la presión en el punto de entronque. 


\begin{tabular}{ccc}
\hline $\begin{array}{c}\text { Tuberí } \\
\text { a }\end{array}$ & $\begin{array}{c}\text { Bomba } \\
\text { parada }\end{array}$ & $\begin{array}{c}\text { Bomba } \\
\text { en } \\
\text { marcha }\end{array}$ \\
\hline T1 & $\mathbf{( I / s )}$ & $\mathbf{( I / s )}$ \\
\hline T2 & 32,37 & 18,70 \\
\hline T3 & 12,66 & 32,55 \\
\hline T4 & 12,66 & 13,85 \\
\hline T5 & 9,46 & 10,53 \\
\hline T6 & 22,12 & 21,71 \\
\hline T7-T9 & 0 & 2,72 \\
\hline T11 & 0,1 & 0,15 \\
\hline
\end{tabular}

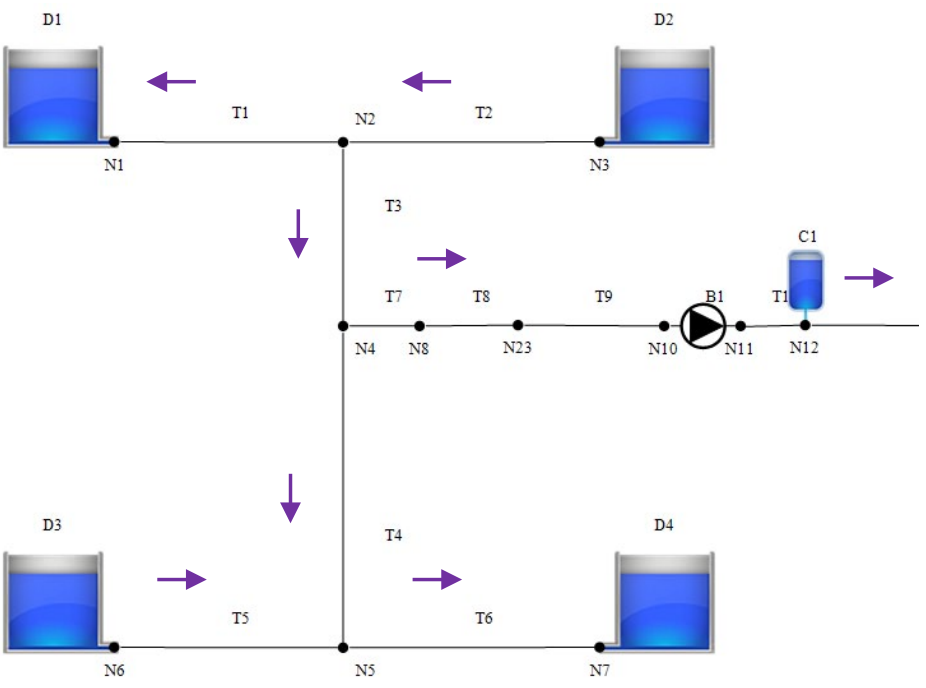

Figura C4-4. (IZQDA.) CAUDALES EN LA INSTALACIÓN. (DCHA.) DETALLE DE LOS SENTIDOS DE CIRCULACIÓN DEL AGUA EN EL MODELO DE SIMULACIÓN

Por otro lado la tubería T4 representa una prolongación de la tubería anterior, pero situada aguas abajo de la conexión de la acometida. Esta particularidad favorece que experimente una reducción del caudal trasegado durante el tiempo en el que la bomba se mantiene aspirando. Con posterioridad al paro de la bomba los caudales en la red general vuelven a estabilizarse en los valores anteriores al arranque.

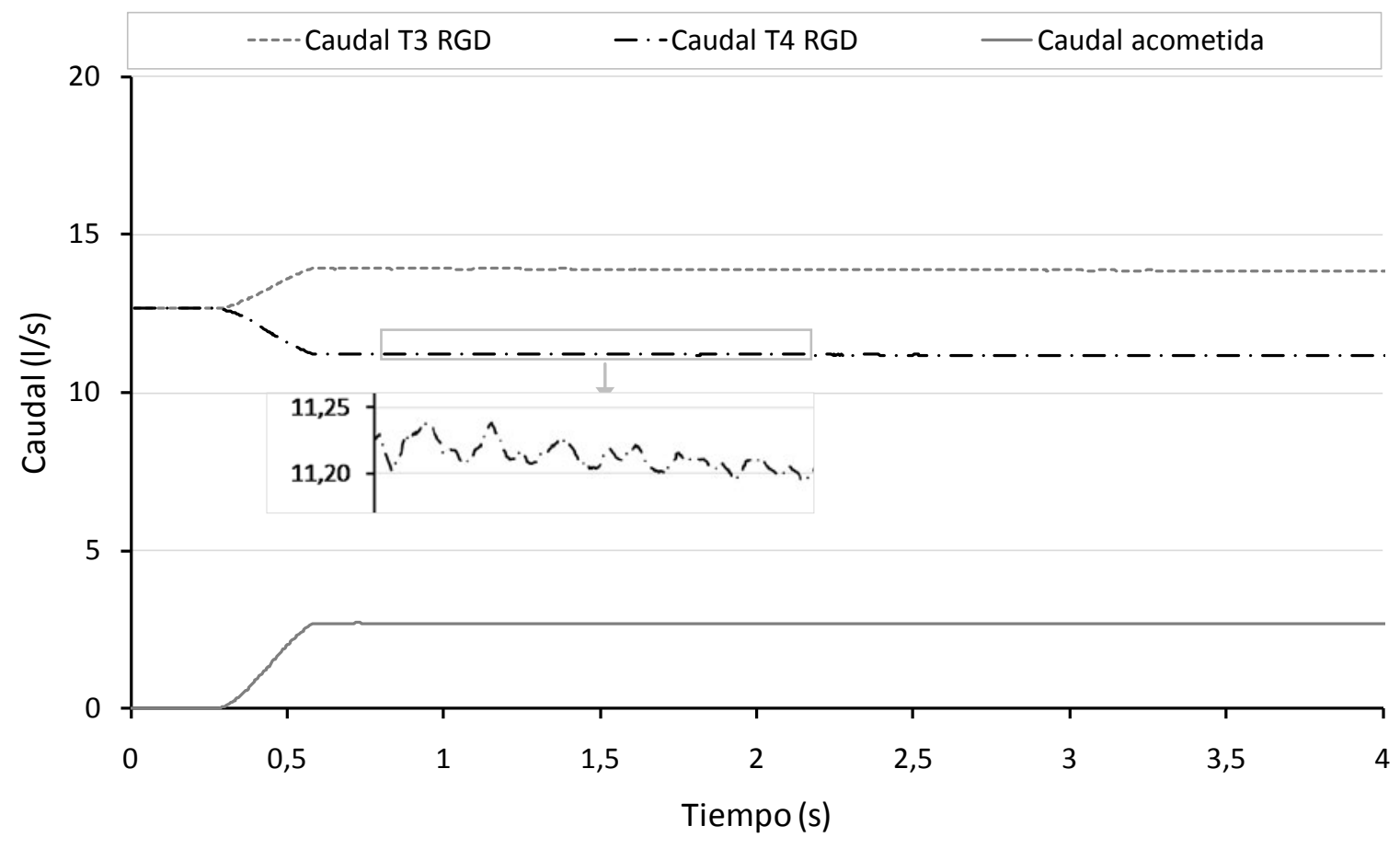

FIGURA C4-5. SimULACIÓN DE LOS CAUDALES EN LAS TUBERÍAS CONECTADAS A LA ACOMETIDA

Como puede observarse la perturbación origina una ligera oscilación del caudal que circulan por la RGD más sensible en las proximidades de la conexión. Esta 
oscilación progresivamente reduce su rizado como efecto de las variaciones de presión debidas a la dinámica transitoria. Para instantes posteriores al arranque la evolución de los caudales por las conducciones de la RGD tienden al caudal del régimen permanente asociado a la bomba parada.

\subsubsection{Evolución de la presión en los diferentes puntos del modelo}

En cuanto a la evolución de las presiones en los puntos más característicos del modelo la Figura C4-6 muestra una mayor variación de la presión durante el arranque de la bomba en los nudos próximos al grupo de presión, punto donde se genera la perturbación. El arranque para la bomba de velocidad fija se inicia para $t=0 \mathrm{~s}$ y la duración del mismo es de 0,55 s. El trasiego de caudal por parte de la bomba no se inicia hasta aproximadamente $\mathrm{t}=0,25 \mathrm{~s}$ debido al funcionamiento de la válvula de retención instalada aguas abajo de la bomba (para su apertura es necesario que la presión a la entrada de la válvula sea superior a la que existe a la salida, presión fijada en 50 mca como presión de arranque del grupo).

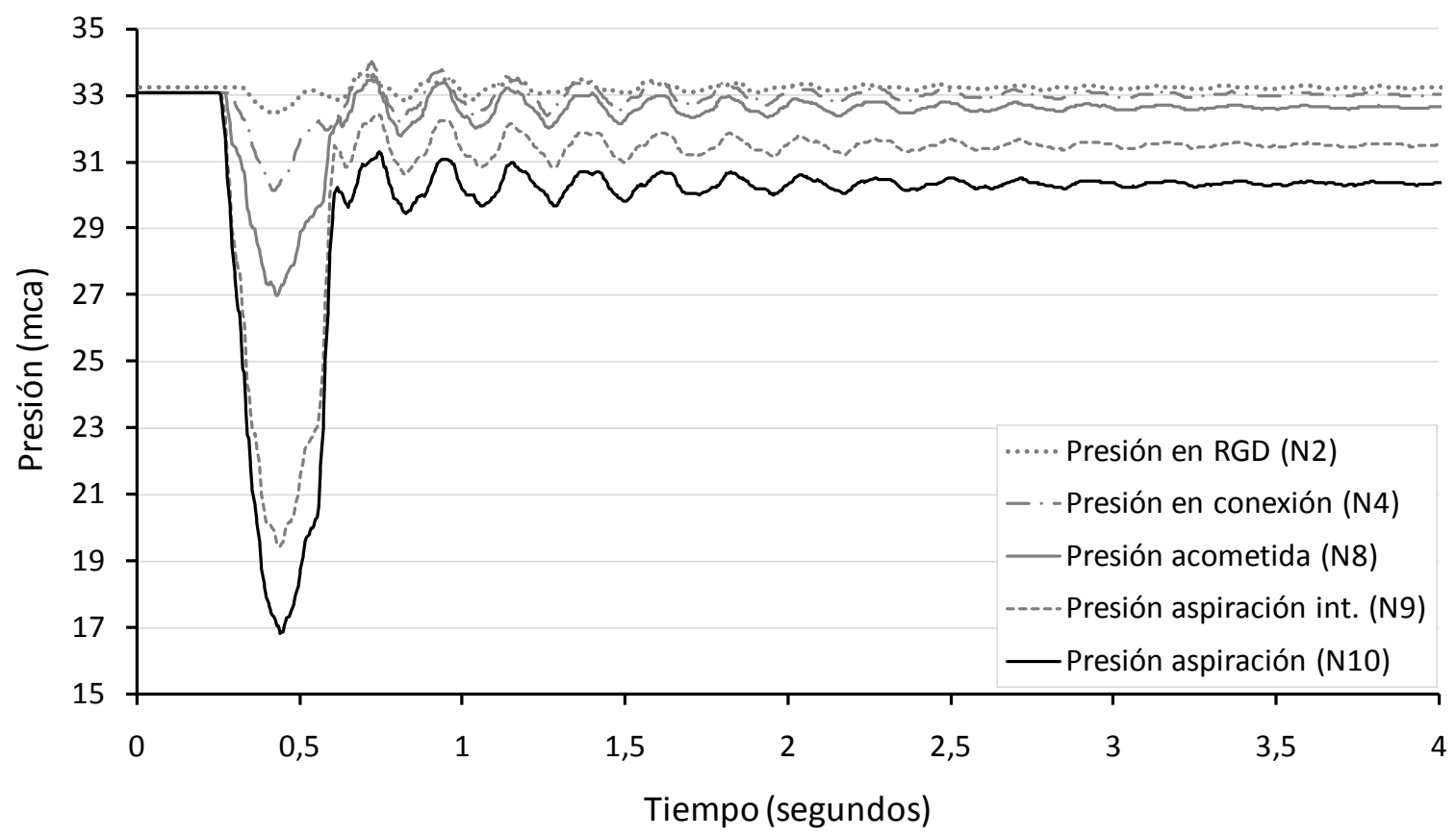

FIGURA C4-6. SiMULACIÓN DE LA EVOLUCIÓN DE LA PRESIÓN EN DIFERENTES PUNTOS DE LA INSTALACIÓN

Respecto a las variaciones de presión que se alcanzan en los diferentes nudos de la RGD (por ejemplo en el nudo N2 situado a 73 metros de la bomba), la perturbación origina una ligera variación de reducida magnitud que se atenúa rápidamente tras el arranque de la bomba. Un efecto similar se origina en los nudos de la red general más próximos a la conexión de la acometida, pero con un aumento de la magnitud de la depresión a medida que el nudo está más próximo a ésta (N4). 
Una situación más crítica se da en la instalación interior del edificio durante los primeros instantes del arranque $(\mathrm{t}=0,42 \mathrm{~s}$ desde el inicio de la alimentación eléctrica), la aspiración de la bomba localiza las solicitaciones mayores originadas en la instalación, tanto en régimen transitorio durante el arranque del grupo de presión, como en el régimen permanente alcanzado una vez que se estabiliza la respuesta de la instalación (aproximadamente a los $4 \mathrm{~s}$ del arranque).

La tabla siguiente muestra la caída de presión obtenida a partir del modelo de simulación en los diferentes nudos. Dicha caída se ha referenciado a la presión de equilibrio que se da antes del arranque de la bomba. También se muestra las variaciones para un instante en el que el funcionamiento de la bomba está estabilizado $(t=4 \mathrm{~s}$ correspondiente al funcionamiento en régimen permanente). Si bien en la acometida la caída de presión es próxima a $6 \mathrm{mca}$, en la aspiración de la bomba esta depresión toma valores cercanos a los 16 mca según el modelo de simulación.

TABLA C4-1. VARIACIÓN DE LAS PRESIONES EN DIFERENTES NUDOS DEL MODELO

\begin{tabular}{|c|c|c|c|c|c|c|c|}
\hline Nudo & $\begin{array}{c}\text { Presión } \\
\text { t=0 s }\end{array}$ & $\begin{array}{l}\text { Presión } \\
t=0,42 \mathrm{~s}\end{array}$ & $\begin{array}{c}\Delta p \\
(\Delta t=0,42 s)\end{array}$ & $\begin{array}{c}\Delta p \\
(\Delta t=0,42 s)\end{array}$ & $\begin{array}{c}\text { Presión } \\
t=4 \mathrm{~s}\end{array}$ & $\begin{array}{c}\Delta p \\
(\Delta t=4 s)\end{array}$ & $\begin{array}{c}\Delta p \\
(\Delta t=4 s)\end{array}$ \\
\hline & (mca) & (mca) & (mca) & $\%$ & (mca) & (mca) & $\%$ \\
\hline N2 & 33,25 & 32,46 & 0,79 & $2,4 \%$ & 33,23 & 0,0 & $0,1 \%$ \\
\hline N4 & 33,06 & 31,13 & 2,03 & $6,1 \%$ & 33,03 & 0,03 & $0,1 \%$ \\
\hline N5 & 32,88 & 32,41 & 0,47 & $1,4 \%$ & 32,80 & 0,08 & $0,2 \%$ \\
\hline N8 & 33,06 & 27,38 & 5,68 & $17,2 \%$ & 32,66 & 0,4 & $1,2 \%$ \\
\hline N9 & 33,06 & 19,41 & 13,65 & $41,3 \%$ & 31,52 & 1,54 & $4,7 \%$ \\
\hline N10 & 33,06 & 16,82 & 16,24 & $49,1 \%$ & 30,17 & 2,89 & $8,7 \%$ \\
\hline
\end{tabular}

Por otro lado y a la vista de la caída de presión en la acometida del edificio para el funcionamiento en régimen permanente, se observa que aun siendo reducida en este punto (próxima a 2 mca para la instalación de referencia), en la aspiración de la bomba puede alcanzar valores elevados durante el arranque de la bomba (próximos a 16 mca) presentando una caída de presión próxima al 50\% de la presión antes del arranque.

\subsubsection{Comportamiento de la bomba}

Tras la señal de arranque de la bomba aumenta progresivamente su velocidad de giro hasta alcanzar su velocidad nominal de $2900 \mathrm{rpm}$. Como se ha comentado el inicio de bombeo de caudal no tiene lugar hasta que la presión es suficiente para abrir la válvula de retención. Por otro lado, y tal como se aprecia en la Figura C4-7, la presión mínima se origina antes de que la bomba alcance la velocidad nominal de giro (instante $t=0,42 s)$. 


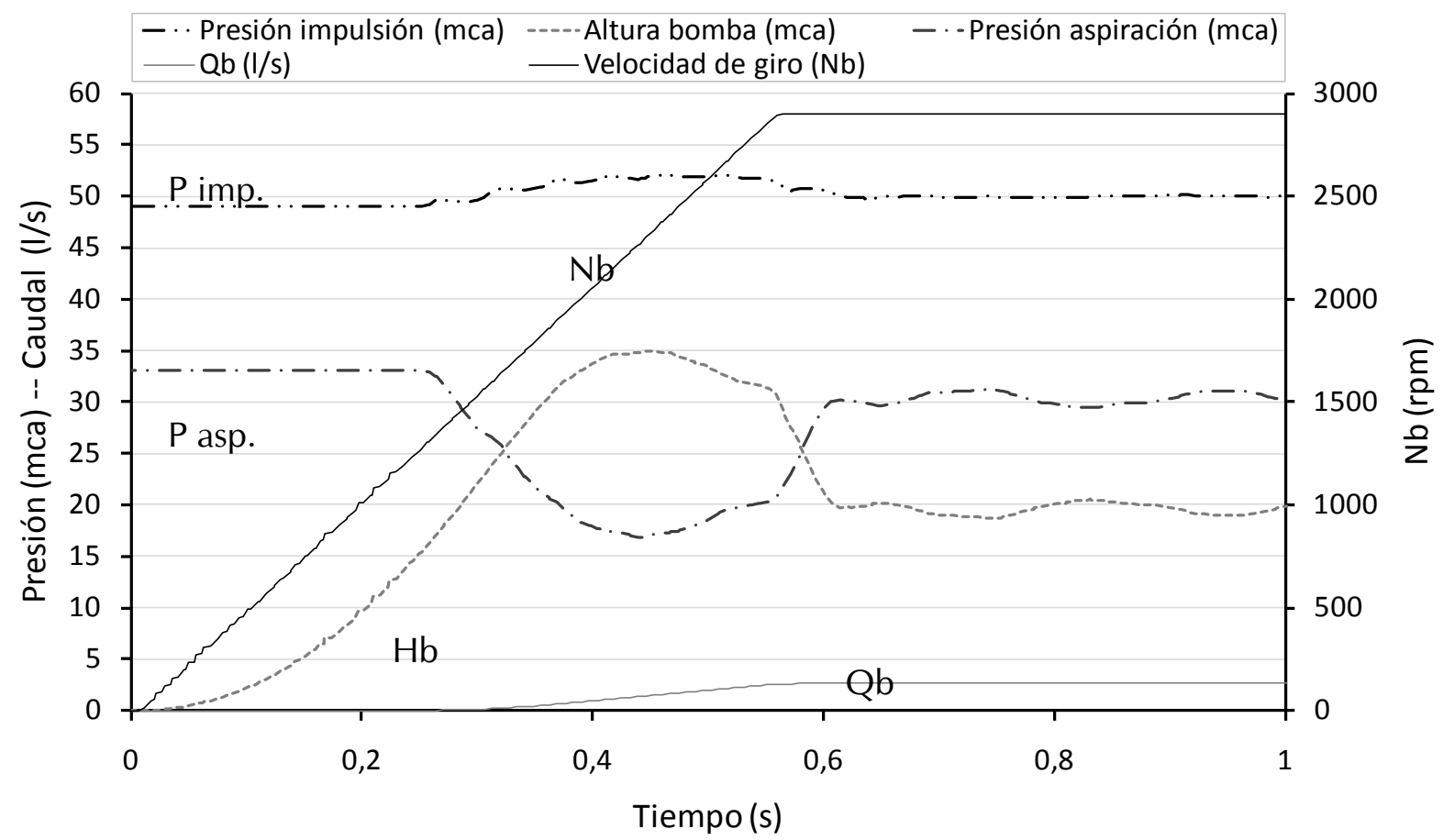

FIGURA C4-7. SIMULACIÓN DEL COMPORTAMIENTO DE LA BOMBA DEL MODELO

La presión en la aspiración de la bomba se reduce como resultado del inicio del fenómeno transitorio (originado a medida que se empieza a trasegar caudal por la conducción de aspiración). El punto de inflexión en esta serie se origina una vez que la altura de bombeo alcanza su valor máximo. En la impulsión de la bomba la presión aumenta sobre la presión de referencia mantenida por el calderín, como resultado de la suma de la altura de bombeo y la presión en aspiración.

En cuanto a la velocidad de giro de la bomba es importante destacar que la evolución seguida por Allievi es lineal, y que el comportamiento real puede diferir de éste. En cualquier caso hay que tener presente que se persigue obtener una aproximación razonable al efecto transitorio, y que la evolución mostrada puede ser suficiente para representar una aproximación al fenómeno.

\subsubsection{Consideraciones de cálculo}

Una de las decisiones tomadas para la realización de las simulaciones ha sido fijar la discretización temporal $\Delta t$ con la que se llevan a cabo las simulaciones. Este incremento de tiempo está directamente relacionado con el número de discretizaciones espaciales $\Delta x$ que se realizan en cada conducción, y por tanto entra a formar parte del error del valor de las alturas aportadas por el algoritmo de cálculo. De forma que intervalos de tiempo elevados producen errores mayores, y por el contrario intervalos de tiempo reducido precisan tiempos computacionales elevados pero proporcionan mejores aproximaciones a la respuesta real. 
Para comprobar el error originado para diferentes intervalos de cálculo, se han realizado diversas simulaciones para diferentes tiempos de arranque del grupo de presión, ya que como se mostrará éste es uno de los parámetros que mayor repercusión presenta sobre la magnitud del transitorio. Se ha programado inicialmente un intervalo de cálculo muy reducido (0,0005 segundos), considerándose la respuesta de presión mínima para este intervalo como el resultado de referencia para cada tiempo de arranque establecido.

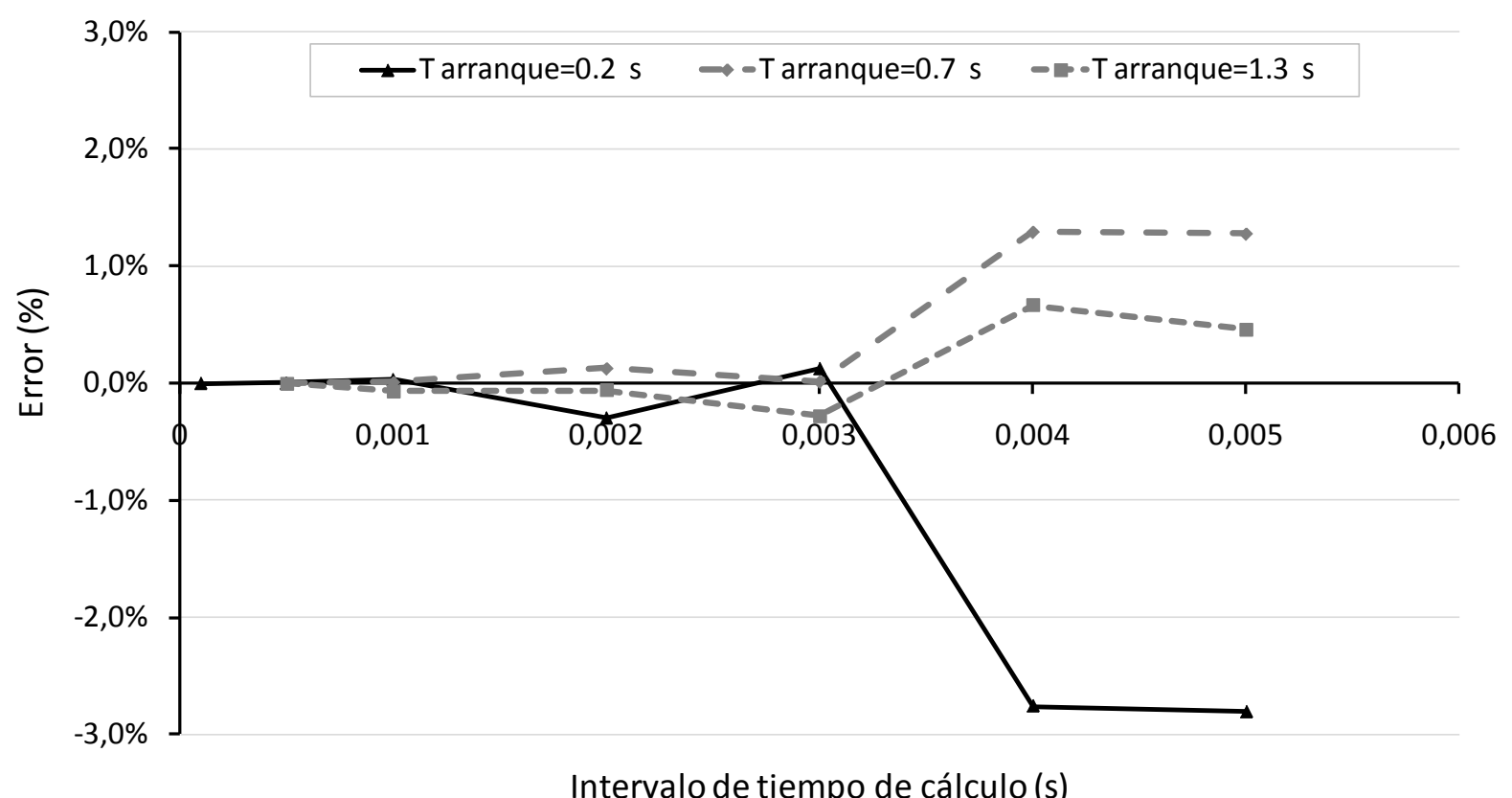

FIGURA C4-8. INFLUENCIA DEL INTERVALO DE TIEMPO DE CÁLCULO EN EL ERROR

En la figura anterior se observa que a medida que se aumenta el intervalo de cálculo el error de la presión aumenta, siendo menor de un 0,5\% para un tiempo de 0,001 segundos, intervalo fijado para la realización de las simulaciones en el presente estudio.

\subsection{VALIDACIÓN DEL MODELO HIDRÁULICO}

La validación del estudio en régimen transitorio ha consistido en comprobar la bondad de los resultados obtenidos con el programa Allievi. Para ello, ha sido de gran ayuda los registros correspondientes a la monitorización de la instalación del edificio comentada anteriormente. La comparación directa de ambas respuestas va a permitir conocer las consideraciones sobre la respuesta del software de transitorios utilizado, siempre teniendo presente las limitaciones de los registros medidos y la complejidad de la modelación de la instalación interior del edificio. Se ha analizado de forma independiente el fenómeno de arranque y parada de ambos grupos en los puntos de control correspondientes a las tres sondas de presión instaladas. 


\subsubsection{Arranque de la bomba de velocidad fija}

La Figura C4-9 muestra la comparación entre los datos registrados y los datos obtenidos de la simulación con Allievi para el instante de arranque de la bomba de velocidad fija conectada en directo. Las medidas se corresponden con la sonda de presión instalada en la acometida.

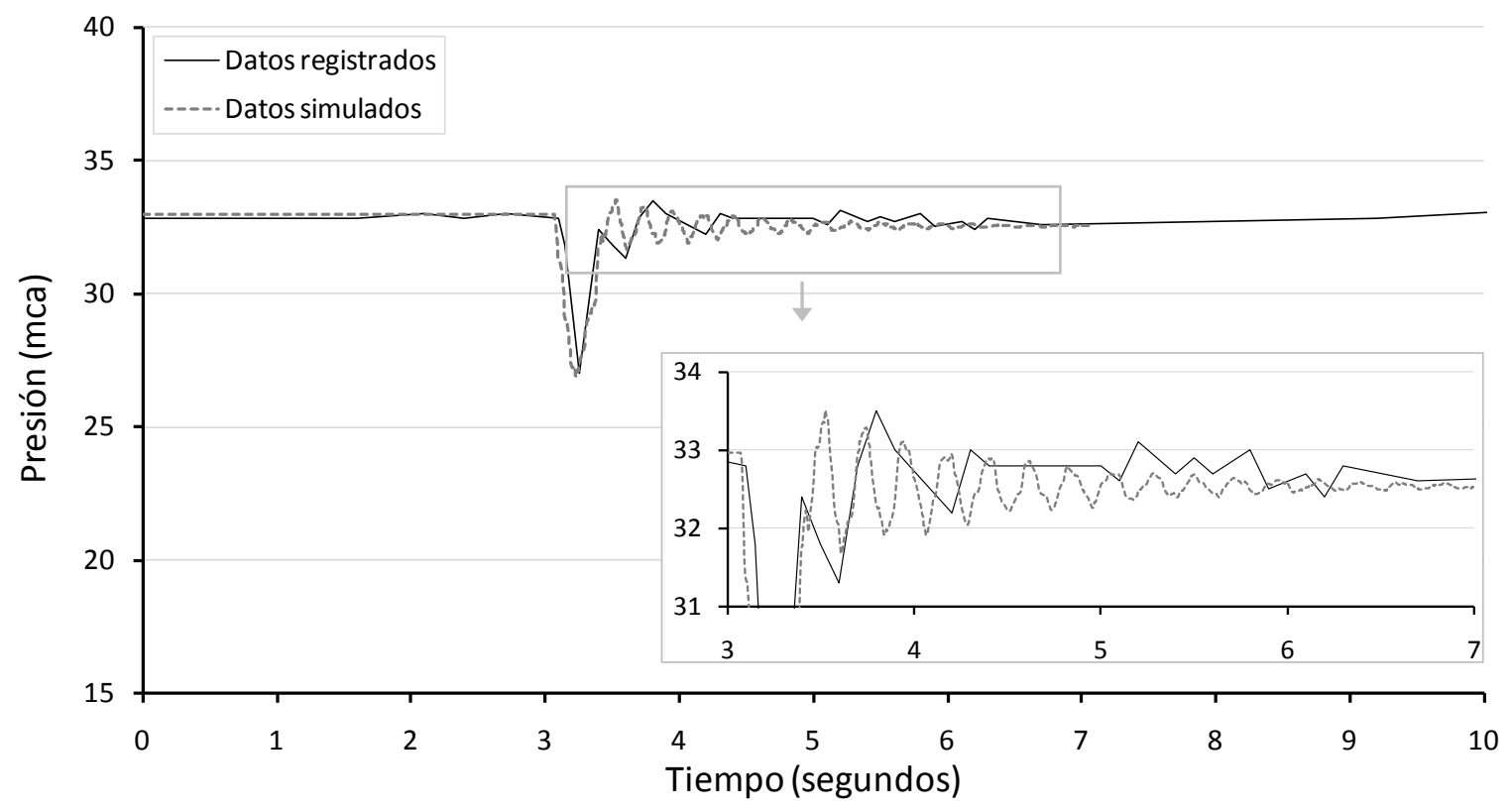

FIGURA C4-9. COMPARACIÓN DE LA PRESIÓN EN LA ACOMETIDA DURANTE EL ARRANQUE

Como puede observarse en la figura, los resultados obtenidos con el programa son muy similares a los registros de presión medidos en la instalación. En la acometida del edificio se reproduce con elevada fidelidad la evolución de la presión desde los primeros instantes de arranque de la bomba hasta que se alcanza el valor mínimo de presión. Para sucesivas variaciones de presión la simulación muestra un comportamiento más dispar entre la presión registrada y los resultados obtenidos con el modelo, observándose una mayor atenuación de la presión real y una mayor irregularidad de los sucesivos registros.

Existen varias razones que justifican esta diferencia, y principalmente se debe a la complejidad que presenta la simulación del comportamiento de instalaciones en régimen transitorio. Diferente bibliografía ha tratado de profundizar en aspectos relacionados con los parámetros que afectan a la atenuación, modificación de forma y retraso en tiempo de las variaciones de presión tras un transitorio. Entre los efectos a destacar las interacciones fluido estructura ( $\mathrm{FSI}$, fluid-structure interaction) presentan una notable influencia (Tijsseling, 1996; Vardy et al., 1996). Incluso los propios anclajes de tuberías y elementos de unión favorecen la modificación de las evoluciones de presión (Apollino et al., 2009). Por otro lado, la existencia de fugas, elementos perturbadores o bloqueantes del flujo (como filtros, contadores y elementos 
antivibratorios) también tienen una notable influencia (Bergant et al., 2008; Vítkovský, 2001). El comportamiento viscoelástico de las paredes de las conducciones afecta a las variaciones de presión transitorias por las continuas deformaciones que experimentan (Covas et al., 2004, 2005; Holmboe et al., 1967; Bergant, 2003a, 2003b). Esta deformación a su vez conlleva una disipación energética y amortiguamiento de la onda transitoria de presión.

La modelación de la fricción en régimen transitorio también presenta una complejidad adicional. En la situación real existe una dependencia de ésta con el caudal instantáneo durante el fenómeno transitorio (consideración llevada a cabo por el programa Allievi). Algunos autores han desarrollado modelos de fricción como suma de dos términos correspondientes al régimen permanente y al régimen transitorio (Bergant et al., 2001; Vítkovský, 2001; Vítkovský et al., 2006). La no consideración de la variación del perfil de velocidades en el eje radial de las conducciones, condiciona la disipación de la energía en la pared y por ello se origina un amortiguamiento más rápido en la instalación real (Abreu y Cabrera, 2011).

En la comparación realizada también se observa una discrepancia en el ajuste para el régimen permanente después del arranque. Esto se debe a la dificultad que presenta una caracterización precisa de las pérdidas en los componentes de la aspiración. Su adecuación precisaría de un análisis pormenorizado de cada elemento, junto con un mayor conocimiento de las características funcionales de la RGD, principalmente en la acometida.

Para el punto de control intermedio entre la sonda de acometida y la aspiración de la bomba se obtiene un ajuste aceptable con las mismas consideraciones que en el caso anterior tal como se muestra en la siguiente figura.

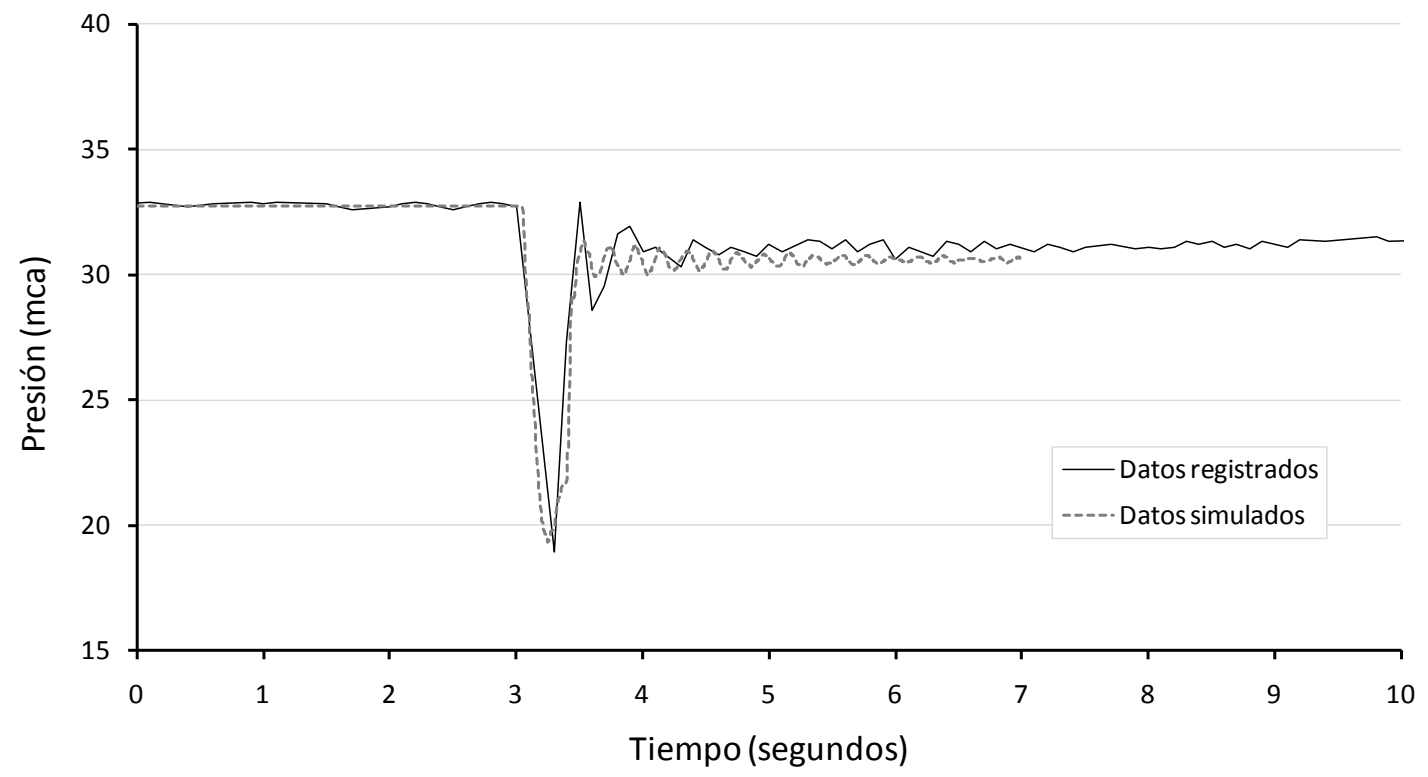

FIGURA C4-10. COMPARACIÓN DE LA PRESIÓN EN EL PUNTO INTERMEDIO DE CONTROL DURANTE EL ARRANQUE 
En cuanto al ajuste en la aspiración de la bomba se ha conseguido reproducir con suficiente exactitud la respuesta del modelo de simulación, tanto en la primera onda de perturbación como en la depresión en régimen permanente.

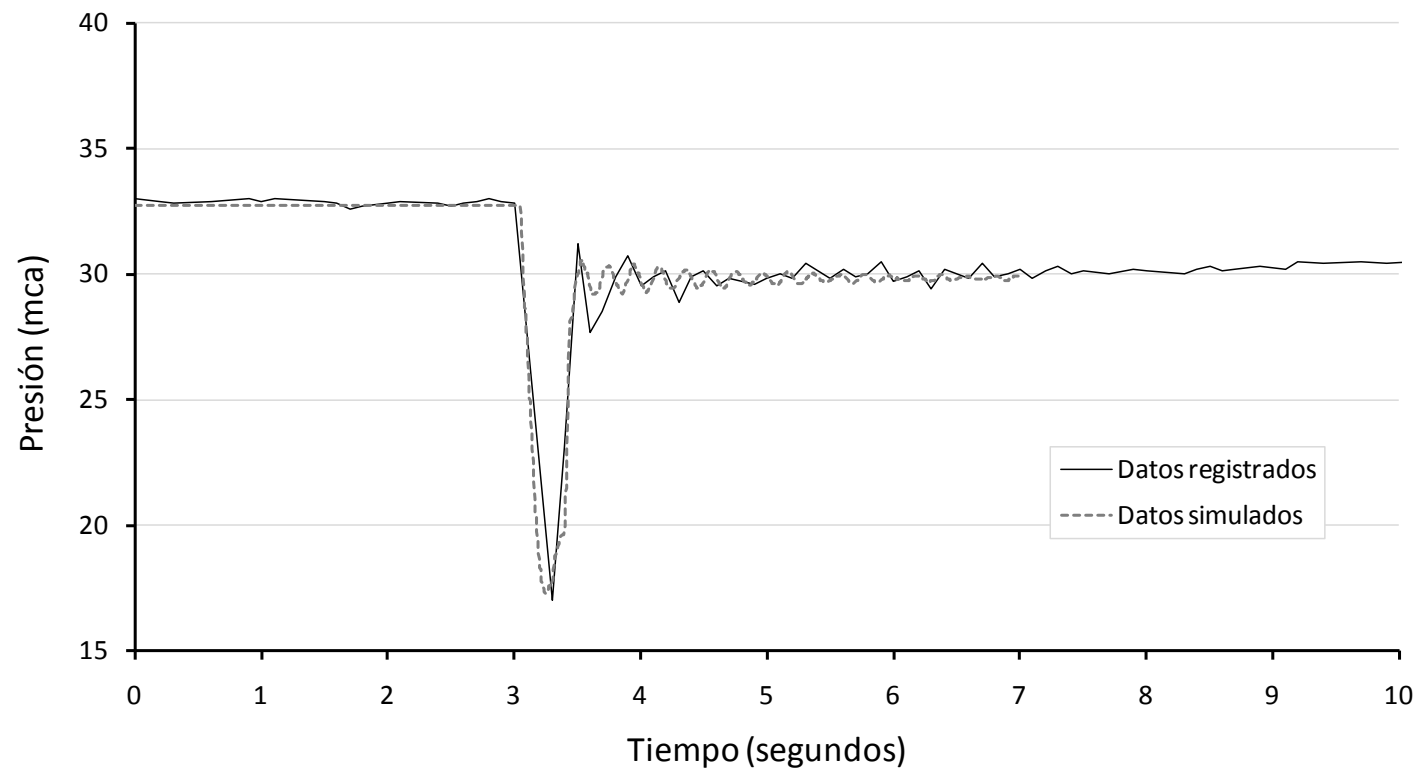

FIGURA C4-11. COMPARACIÓN DE LA PRESIÓN EN LA ASPIRACIÓN DURANTE EL ARRANQUE

\subsubsection{Parada de la bomba de velocidad fija}

En cuanto a la parada de la bomba de velocidad fija también ha sido posible ajustar su respuesta en los tres puntos de control (se grafican sólo los extremos), obteniendo respuestas similares a las registradas en la monitorización. Si bien los valores máximos de presión son similares en la tubería de aspiración de la bomba, se ha observado un comportamiento algo dispar en lo referente a la atenuación de las series simuladas (efecto más sensible a medida que nos acercamos a la propia bomba).

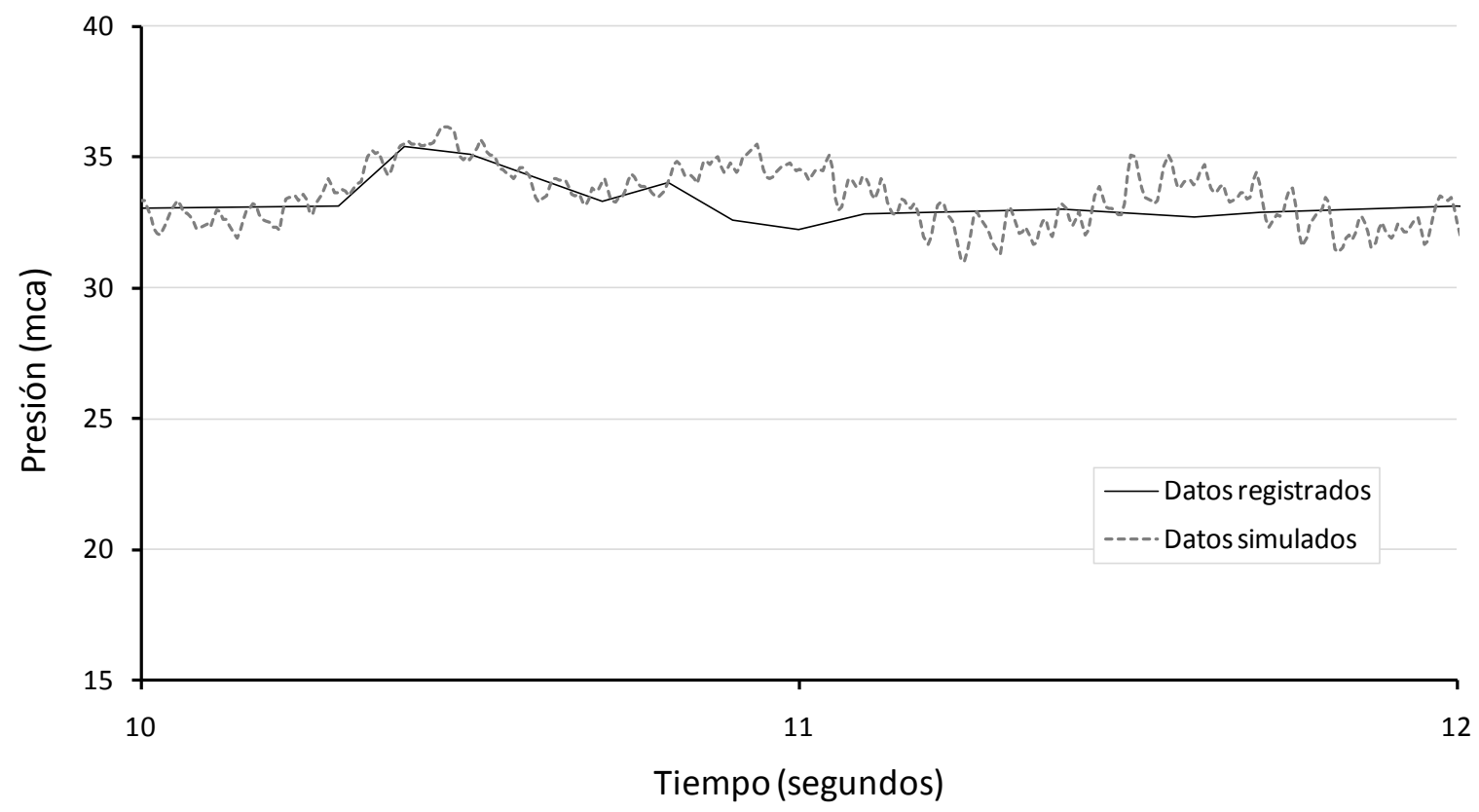

FIGURA C4-12. COMPARACIÓN DE LA PRESIÓN EN LA ACOMETIDA DURANTE LA PARADA 
En la respuesta real las oscilaciones decrecen rápidamente (tiempos en torno a 1 s), mientras que en las simulaciones se prolonga este tiempo. Las razones de esta atenuación son similares a las comentadas para el fenómeno de depresión. Del mismo modo es complejo corregir este comportamiento en el modelo sin alterar la respuesta del transitorio de arranque. Una posible solución para la modelación sería introducir un depósito presurizado en la aspiración de volumen reducido, de forma que este elemento absorbiera parte de la perturbación, como en la instalación real sucede con los elementos y accesorios.

Por otro lado, de la misma forma que sucedía durante el arranque del grupo, se observa un desfase entre la serie real y la simulada. Este desfase como se ha comentado está relacionado con las características físicas de la instalación. En cualquier caso hay que tener presente la rapidez con la que se produce el fenómeno y la dificultad que presenta el registro de estos comportamientos en entornos no controlados como pudiera ser un laboratorio.

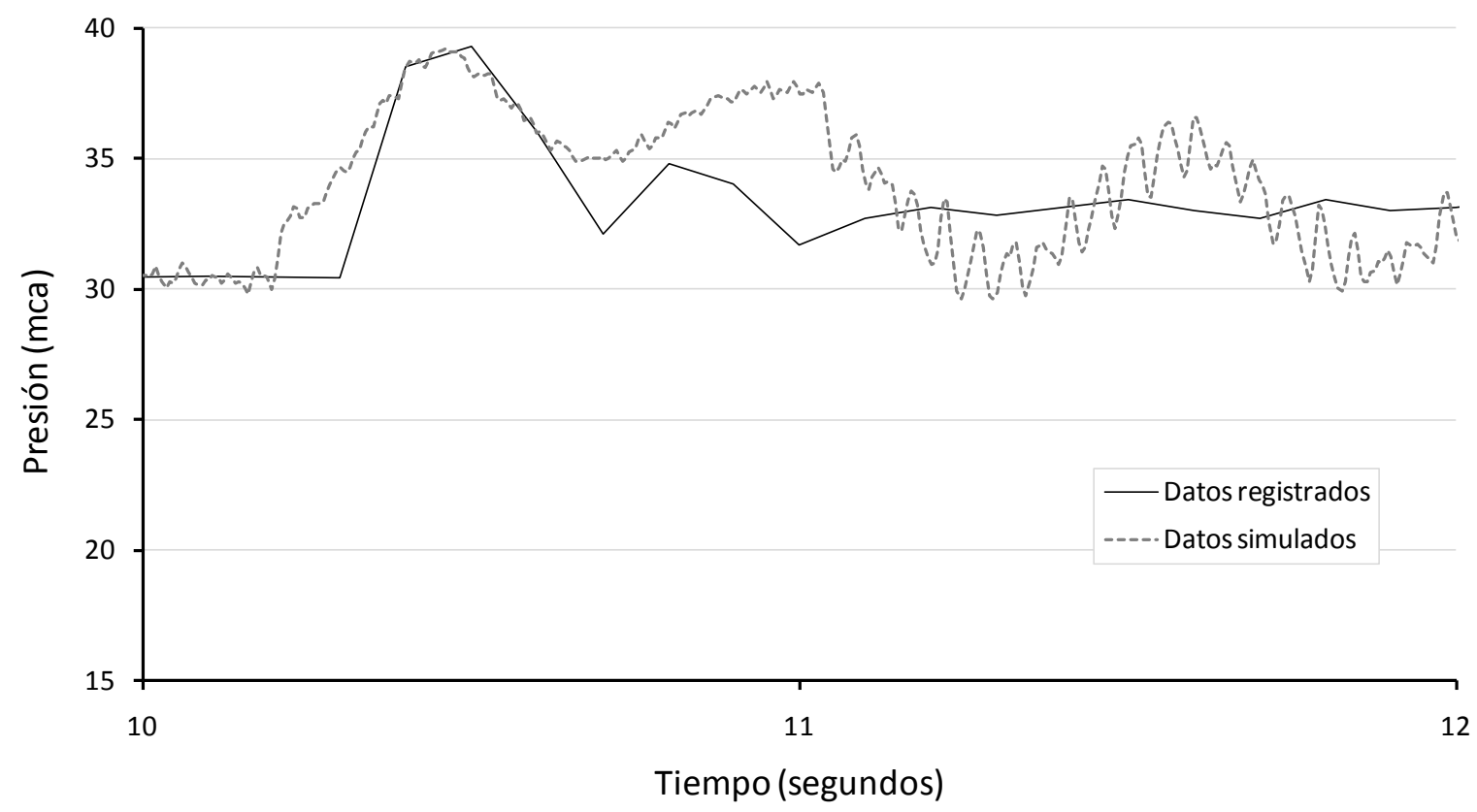

FIGURA C4-13. COMPARACIÓN DE LA PRESIÓN EN LA ASPIRACIÓN DURANTE LA PARADA

Teniendo en cuenta las limitaciones de los equipos de adquisición de datos junto con el entorno donde se han realizado las mediciones y los objetivos del estudio, se considera que se ha reproducido con una buena aproximación los fenómenos de arranque y parada de un grupo de velocidad fija conectado en directo, y principalmente en lo relacionado con las magnitudes máximas de ambos efectos en la instalación de referencia. El resto de valores de presión para instantes posteriores al arranque no precisan un ajuste tan elevado atendiendo a los propósitos del estudio. 


\subsubsection{Validación del modelo de la bomba de velocidad variable}

De forma similar a la validación realizada para la bomba de velocidad fija se ha tratado de validar la respuesta del modelo hidráulico cuando éste simula la respuesta de un grupo equipado con bomba de velocidad variable. En este caso el ajuste es considerablemente más complejo debido a la dificultad que presenta la modelación del controlador PID instalado en el equipo (este dispositivo modifica la alimentación al motor de forma instantánea en función de condicionantes como la diferencia entre la presión de salida frente a la de consigna).

Como se ha comentado con el programa de simulación utilizado esta progresión hasta las condiciones nominales de funcionamiento es lineal. Referente a la comparación entre las solicitaciones originadas por un modo de progresión u otro hacia las condiciones nominales de funcionamiento, se estima que para los primeros instantes del arranque de la bomba el comportamiento no es muy diferente, pudiendo presentar más dificultad en el ajuste para instantes posteriores a éste.

La siguiente figura muestra la comparación entre la respuesta aportada por el modelo hidráulico y la correspondiente a los datos registrados en la instalación (considérese la diferencia de escalas de presión entre el comportamiento de la bomba de velocidad variable frente a la de velocidad fija). Como puede observarse los primeros instantes del arranque (el arranque se programa para $\mathrm{t}=10 \mathrm{~s}$ ) el pico de mínima presión registrada se aproxima a los datos obtenidos con el modelo de simulación en la acometida del edificio.

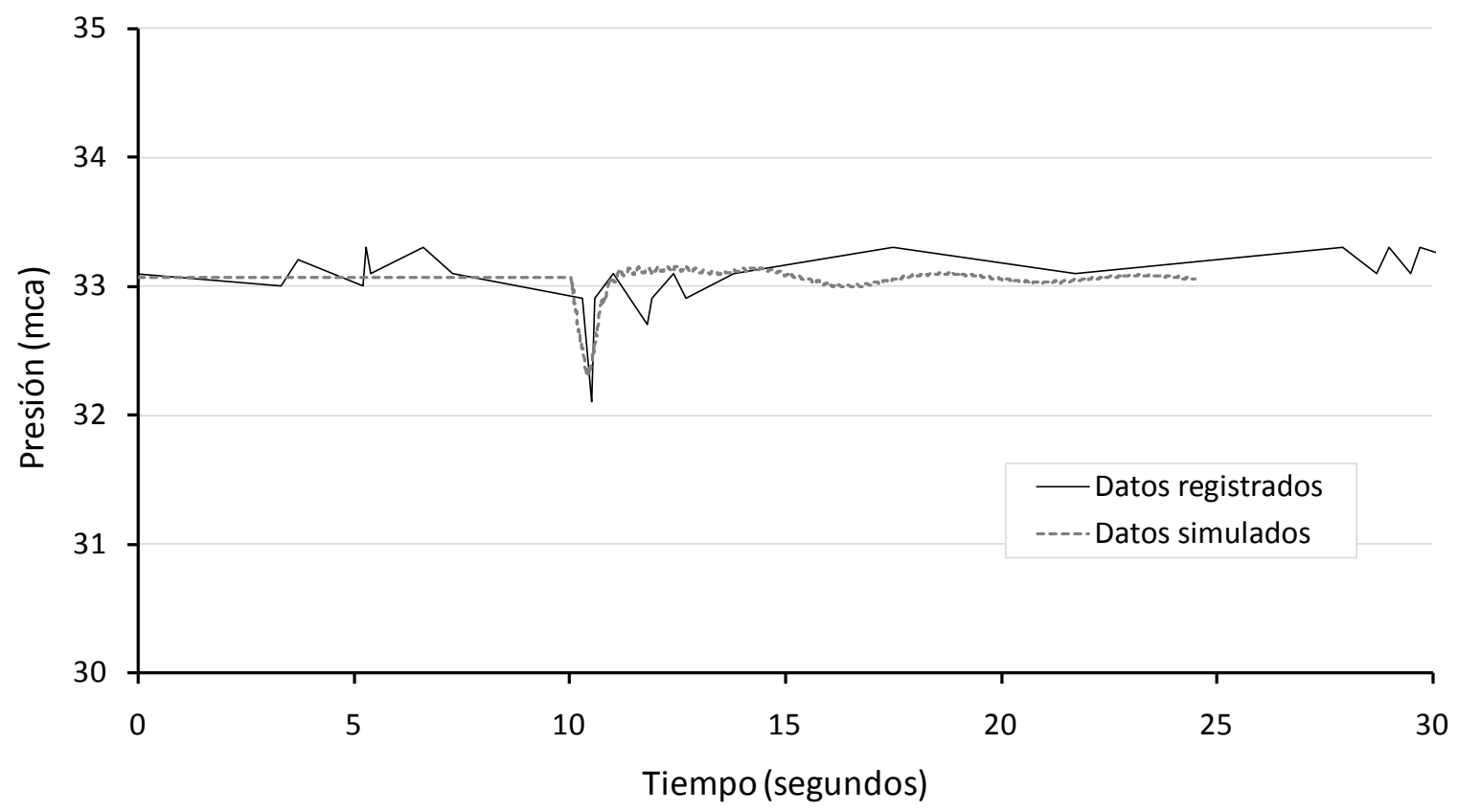

FIGURA C4-14. COMPARACIÓN DE LA PRESIÓN EN LA ACOMETIDA DURANTE EL ARRANQUE DE UNA BVV 
Algo similar ocurre en la aspiración de la bomba. La primera caída de presión tras el arranque origina un primer pico que presenta una cierta proximidad entre el modelo y los registros, si bien durante los instantes posteriores a la aparición de la presión mínima la calidad del ajuste es menor, ya que el modelo aporta una ligera sobrepresión no registrada en la monitorización. En cualquier caso es importante limitar la bondad de los datos registrados para variaciones de presión tan reducidas (inferiores a $1 \mathrm{mca}$ ), ya que el error propio de estos sensores es próximo a un 0,5\%, que para el rango de medidas de utilización puede tomar un valor máximo de 0,5 mca. Del mismo modo, la presión registrada puede estar distorsionada por las lógicas variaciones de presión transmitidas por otras instalaciones próximas (este efecto se puede apreciar en instantes anteriores al arranque del grupo en las que se encontraba la bomba parada).

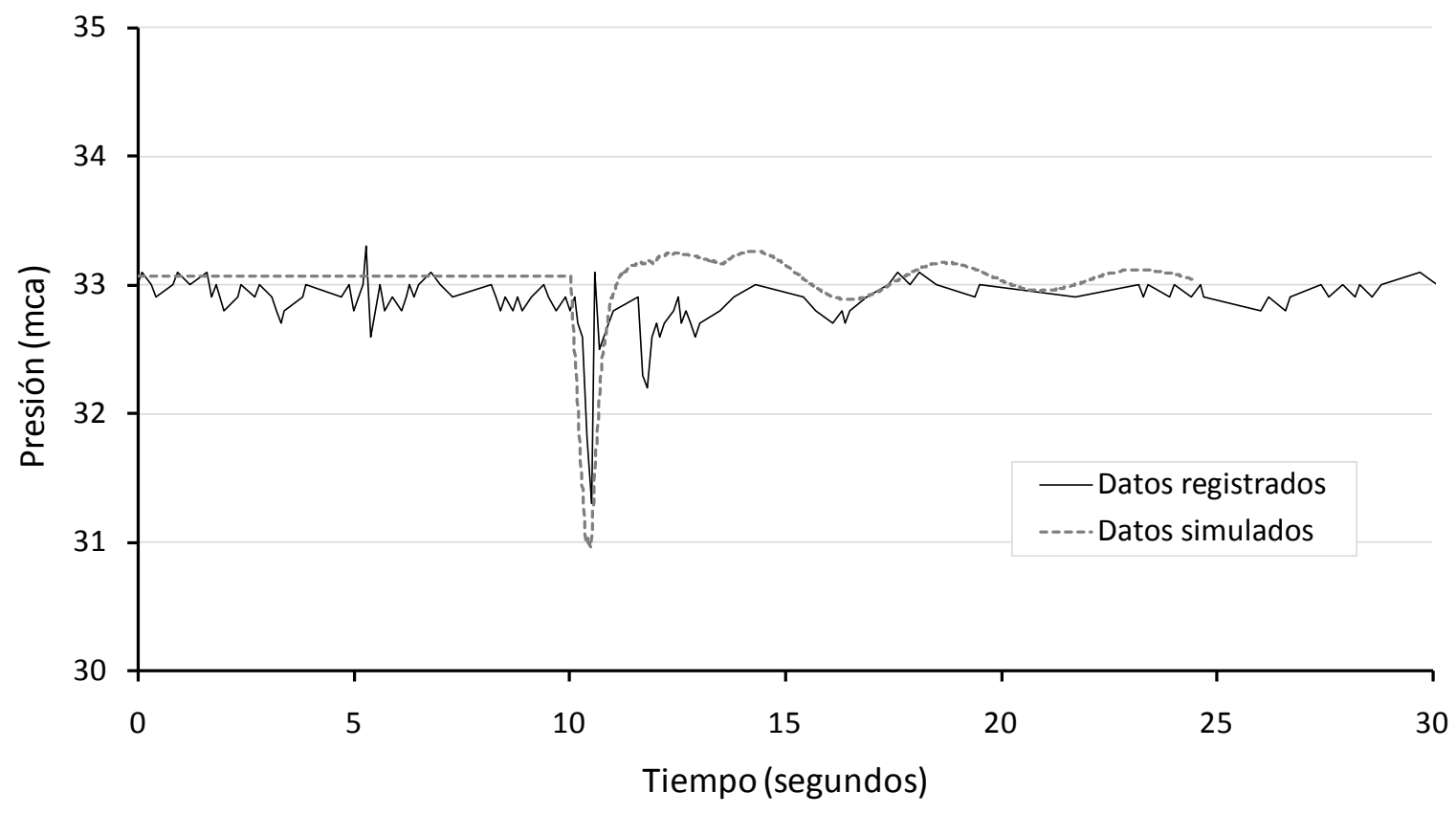

FIGURA C4-15. COMPARACIÓN DE LA PRESIÓN EN LA ASPIRACIÓN DURANTE EL ARRANQUE DE UNA BVV.

Respecto al ajuste del arranque de bomba de velocidad variable y de la misma forma que en los casos anteriores, se considera que la respuesta aportada por el modelo de simulación es suficientemente precisa para analizar la depresión originada en aspiración directa. Por otro lado y dada la dificultad en analizar el fenómeno de parada para este tipo de grupo, y su reducidas solicitaciones en condiciones normales de funcionamiento, no se analiza su ajuste (téngase en cuenta que la parada por fallo eléctrico para bombas de velocidad variable se aproxima al comportamiento de parada de una bomba de velocidad fija). 


\subsection{ANÁLISIS DE SENSIBILIDAD DE LAS CARACTERÍSTICAS DEL TRAMO}

Una vez construido el modelo de simulación, establecida la respuesta de referencia y validada la misma con los registros de la monitorización, se pretende mostrar un análisis de sensibilidad sobre la influencia de los principales parámetros que intervienen en el modelo hidráulico de la instalación. Por otro lado se ha decidido analizar la respuesta de un grupo de velocidad fija ya que es el que mayores exigencias presenta. En cualquier caso se trata de una política de simulaciones más bien conservadora prestando especial atención a la situación más desfavorable.

El análisis de sensibilidad permite conocer el grado de influencia de cada variable que define las propiedades del tramo, por ejemplo la influencia del caudal bombeado por el grupo, o las propias características de la red general de distribución, aportando en estos casos magnitudes de referencia sobre las solicitaciones asociadas a cada parámetro de la instalación. Del mismo modo aporta resultados que pueden ser extrapolables a otras instalaciones derivados de la modificación de las características constructivas del modelo. Por otro lado el conocimiento de los factores que mayor influencia ejercen sobre la magnitud del transitorio generado, servirá de base para el estudio de mecanismos de protección que reduzcan los efectos transmitidos a la acometida del edificio.

\subsubsection{Influencia de los parámetros de la RGD}

Se pretende analizar cómo afectan los principales parámetros de la red general de distribución en la caída de presión tras el arranque del grupo. Entre los parámetros analizados, se destacan los resultados sobre la influencia del caudal circulante por la RGD en las inmediaciones de la acometida y la presión de entrega en este punto, parámetros que pueden variar significativamente a lo largo del día condicionados por la demanda horaria de los usuarios y las características de la red.

\subsubsection{Caudal por la $R G D$}

Uno de los errores más comunes referidos a los efectos transitorios asocia variaciones en la magnitud de la perturbación bajo diferentes caudales por la RGD. Por ello, se han simulado diferentes escenarios en los que se ha variado la carga de caudal circulante por la RGD (y por tanto la velocidad del flujo de agua), manteniendo las características del resto de la instalación invariables (diámetro de la red general, presión de entrega en la acometida y características de la instalación interior). 
Este análisis es equivalente a comprobar cómo afecta la variación del caudal en la RGD para diferentes acometidas conectadas a un diámetro determinado de la RGD y una presión de entrega constante. Situación que se puede dar para acometidas similares situadas en diferentes tramos de la red, o incluso para una misma acometida en la que se experimenta una variación del caudal derivado de la modificación de la demanda horaria (siempre que la fluctuación de presión de entrega no sea elevada).

En la siguiente figura se muestra los resultados obtenidos para diferentes velocidades establecidas en la RGD (velocidades comprendidas dentro del rango habitual que suele darse en estas conducciones, 0,5 y 2,5 m/s). La depresión considera la caída de presión máxima originada en los puntos de control por el arranque de la bomba (obtenida como diferencia de la presión estática antes del arranque del grupo menos la presión mínima que se alcanza durante el transitorio).

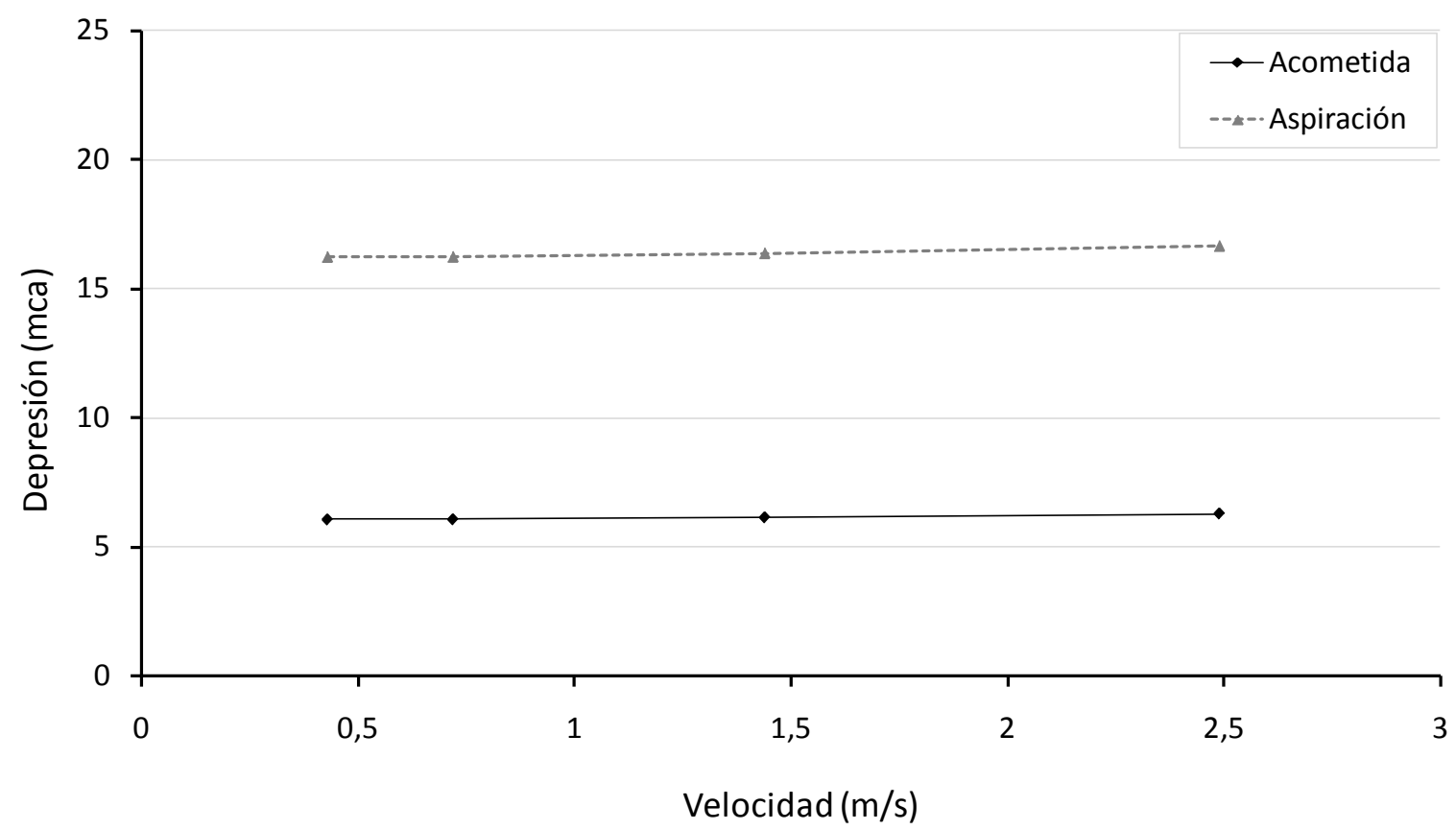

FIGURA C4-16. DEPRESIÓN EN FUNCIÓN DE LA VELOCIDAD DEL AGUA POR LA RGD. DIÁMETRO RED = 150 MM

El análisis muestra que la modificación del caudal (para un mismo diámetro y una misma presión en la acometida), no genera variaciones significativas de la caída de presión máxima durante el arranque. Por tanto, bajo estas consideraciones la variación de la demanda en la red no es un parámetro que pudiera limitar la posible conexión en directo de una instalación, siempre que la instalación garantice el suministro en régimen permanente (puede darse el caso que la red origine una caída de presión elevada para el caudal detraído durante el suministro en directo, en tal caso la limitación de conectar en directo vendría condicionada por el régimen permanente y por tanto no tiene cabida el análisis de la respuesta transitoria). 
En esta misma línea hay que tener presente que modificaciones en el caudal detraído en la acometida originará variaciones del caudal por la RGD. Esta situación puede favorecer la caída de presión en la acometida del edificio a medida que el caudal detraído genere mayores pendientes hidráulicas en la red general. Por tanto, este efecto indirecto debe ser evaluado independientemente, comprobando cómo afecta la variación de la presión de entrega en la magnitud del transitorio generado. En cualquier caso cuando la variación de la presión de entrega no sea significativa, la caída de presión máxima se mantiene prácticamente constante para un mismo diámetro.

\subsubsection{Presión en el punto de entrega}

Respecto a la presión en acometida del edificio, si bien lo ideal es disponer de un valor estable (este valor condiciona el dimensionado de los elementos de la instalación), en la práctica resulta complejo debido a las características de la red y a la variabilidad horaria de la demanda. Por tanto tal variabilidad justifica que el modelo de referencia haya sido analizado bajo diferentes presiones de entrega. Se ha analizado la respuesta del modelo en el rango más usual de variación de este parámetro (12-45 mca), mantenido fijas el resto de características del modelo.

Por otro lado se ha obtenido una serie asociada a los registros monitorizados para diferentes presiones en acometida (siendo la variación reducida por las propias características de la red general del emplazamiento), comparándose directamente los datos obtenidos con el modelo de simulación y los propios del registro.

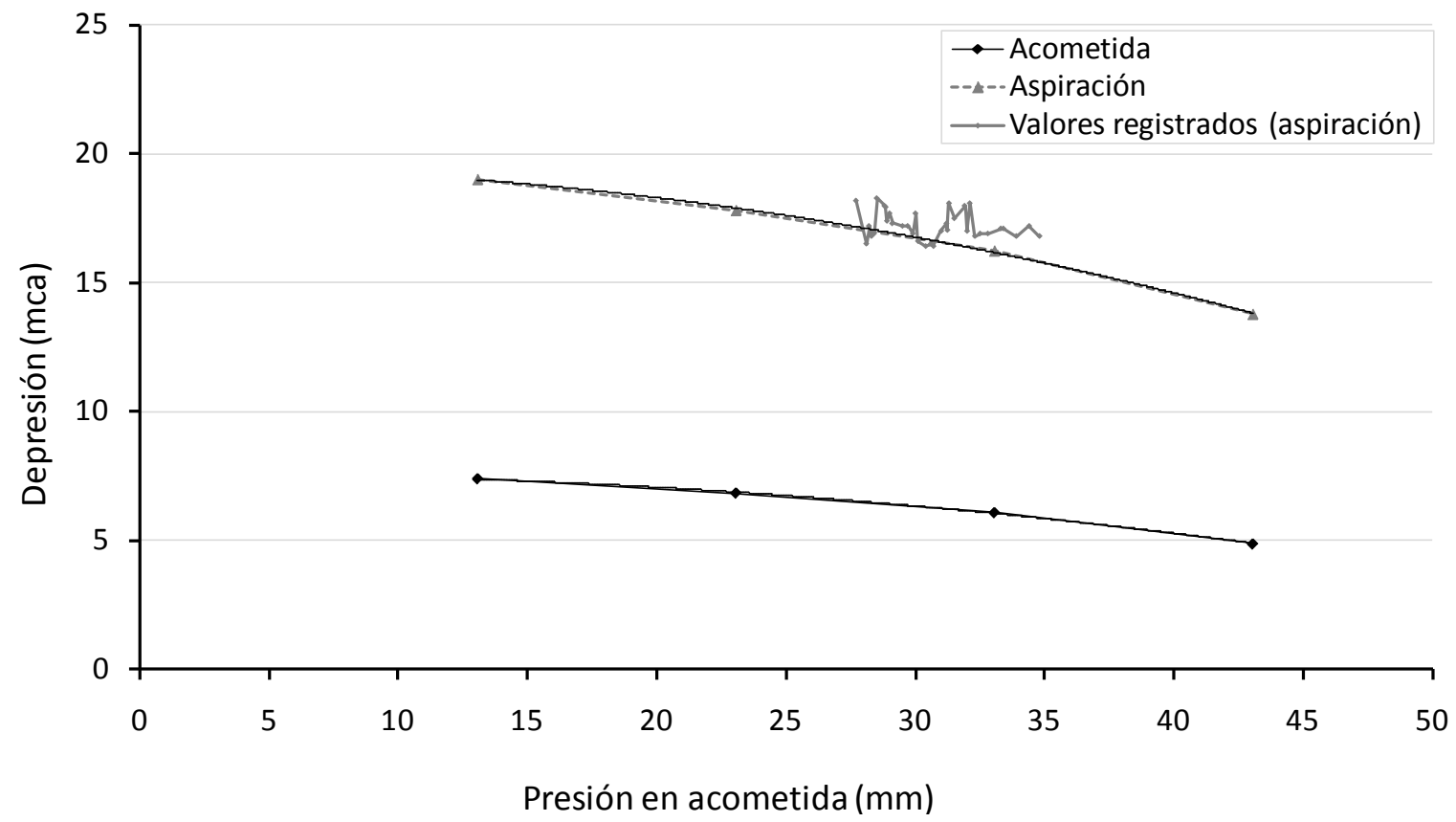

FIGURA C4-17. DEPRESIÓN EN FUNCIÓN DE LA PRESIÓN DE ENTREGA (DRED=150 MM) 
Como puede observarse a medida que aumenta la presión en la acometida, se reduce la depresión originada por el transitorio, siendo la situación más exigente cuando se dan presiones más bajas en acometida. En el caso de los datos registrados también se aprecia una ligera tendencia ante variaciones de presión en red, pero en cualquier caso no es tan significativa como la aportada por el modelo de simulación. La justificación de esta tendencia se basa en que la disminución de la presión en la aspiración conlleva un cambio en el punto de funcionamiento de la bomba con un aumento de la altura necesaria y una disminución del caudal bombeado.

Una bajada de la presión en aspiración de la bomba da lugar a un desplazamiento ascendente de la curva resistente de la instalación $\mathrm{Hr}_{2}$, respecto a la curva característica de la bomba (Figura C4-19). Esta particularidad origina un retraso en la apertura de la válvula de retención, ya que ésta se realiza cuando la bomba alcanza una mayor velocidad de giro (es necesario disponer de una presión mínima en la entrada superior a la salida para que la válvula abra). Aunque el incremento de caudal para el escenario sin bajada de presión $\Delta Q\left(H_{1}\right)$ es mayor que el incremento de caudal cuando hay una bajada, $\Delta Q\left(\mathrm{Hr}_{2}\right)$, la diferencia de tiempo desde que hay flujo hasta que se alcanza la velocidad de régimen de la bomba es en el segundo caso menor (la bomba pasa del aproximadamente el $75 \%$ de velocidad de régimen al $100 \%$, frente al cambio de aproximadamente el $50 \%$ al $100 \%$, por ello y para una duración en el arranque fija (tal como se modela en Allievi), la evolución del caudal es más rápida ante una bajada, y con ella se favorece el origen de una mayor caída de presión.

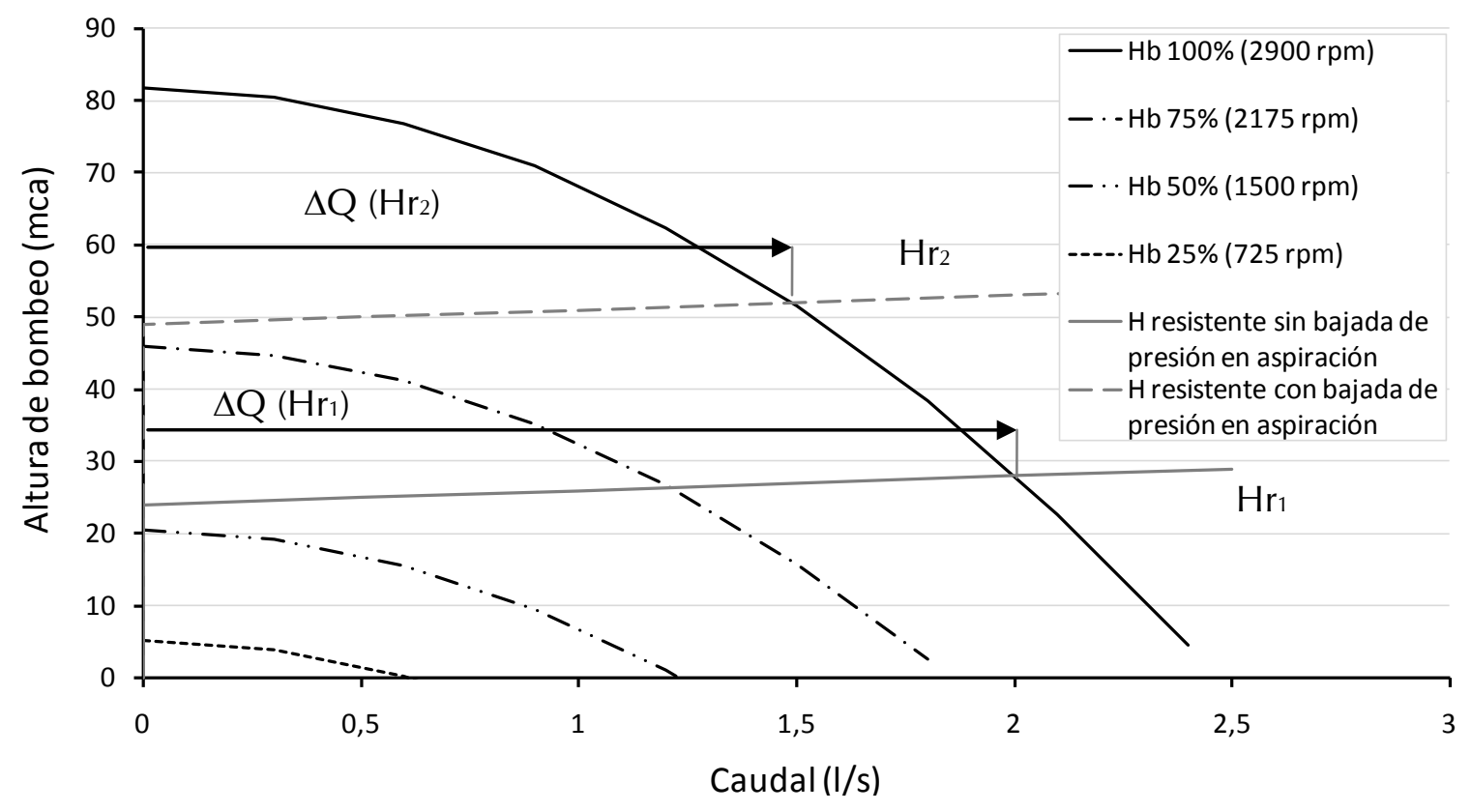

FIGURA C4-18. RESPUESTA DE LA BOMBA EN EL ARRANQUE ANTE UNA BAJADA DE PRESIÓN EN ASPIRACIÓN 
La siguiente figura muestra el comportamiento de la bomba para dos de las situaciones analizadas (presión en régimen permanente en acometida de 33 mca y de 13 mca antes del arranque del grupo). Como puede observarse para las dos presiones de entrega analizadas la bomba trabaja en todo momento en puntos de funcionamiento diferentes, prolongando el aumento de altura de bombeo en el caso de una bajada de presión en la aspiración. Tal como se ha comentado, cuando se origina una bajada de presión el inicio de aportación de caudal se retrasa por la apertura de la válvula de retención.

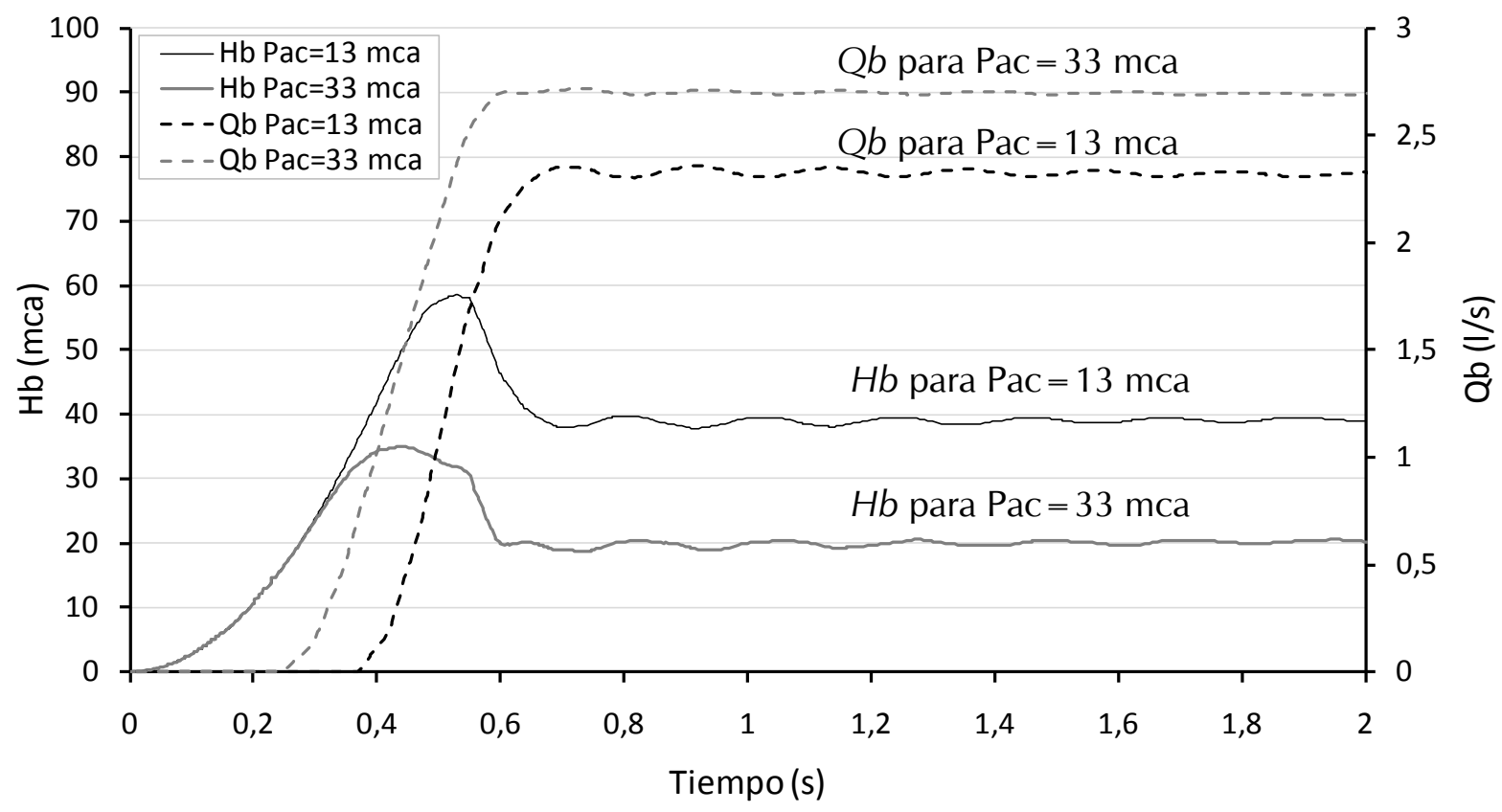

FIGURA C4-19. RESPUESTA DE LA BOMBA PARA DIFERENTES PRESIONES EN ACOMETIDA

Si se analiza la evolución de caudales que tiene lugar durante los primeros instantes de arranque del grupo (Figura C4-20) puede comprobarse lo comentado; ante una bajada de presión en la acometida, el caudal en la aspiración de la bomba experimenta una variación mayor que en el caso de disponer de mayor presión. Este incremento en la modificación del valor de la velocidad es el que justifica una mayor magnitud del transitorio. Por tanto y tal como se ha podido comprobar, la reducción de la presión en la acometida (manteniendo el resto de características de la instalación invariables), origina un ligero aumento de las solicitaciones durante el transitorio de arranque de la bomba por la modificación de los puntos de funcionamiento que sigue la bomba, hasta que ésta alcanza la velocidad nominal de giro.

Por otro lado es conveniente especificar las limitaciones presentadas por el software utilizado, ya que además de presentar una evolución lineal del aumento de la velocidad de giro de la bomba, mantiene fija la duración del arranque. Esta situación puede no ser equivalente al comportamiento que realmente se da en una instalación, 
pero dada la extrema complejidad que presenta una modelación más precisa del comportamiento, y puesto que cada grupo de presión presenta una dinámica particular función de las propiedades del motor, de las características de la bomba, y de la propia característica resistente de la instalación, se considera que la modelación realizada puede aportar información aproximada del fenómeno, quedando fuera del propósito del presente estudio un exhaustivo análisis eléctrico del fenómeno de arranque del grupo moto-bomba que detalle en mayor medida su comportamiento.

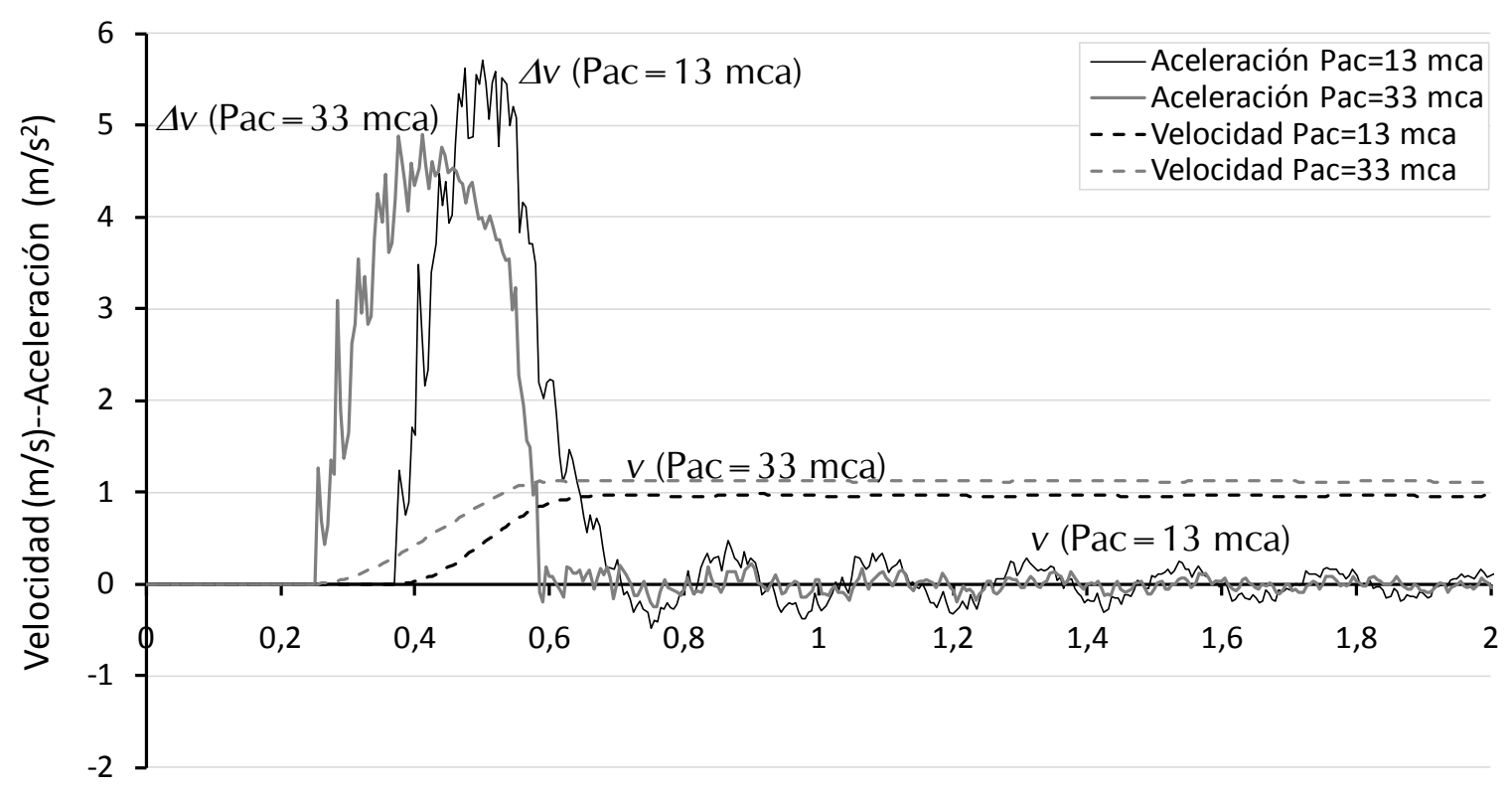

Tiempo (s)

FIGURA C4-20. EVOLUCIÓN DE LA CINÉTICA EN LAS PROXIMIDADES DE LA BOMBA

\subsubsection{Diámetro de la RGD}

Si bien el valor del caudal circulante por la RGD no supone una influencia significativa, la modificación de las características constructivas de la RGD, como pueda ser la variación del diámetro de las conducciones próximas a la acometida, sí que condiciona una variación sensible de la magnitud de la perturbación.

En las simulaciones realizadas se ha modificado el valor del diámetro interior de las conducciones T3 y T4, manteniendo invariante el modelo de la instalación interior, así como la presión de entrega en la acometida (modificando el nivel de los depósitos D1-D4). Del mismo modo, se ha comprobado que las variaciones del caudal (y velocidad) por la RDG para un mismo diámetro no alteran el valor de la presión mínima originada, tal como se observó anteriormente. Este análisis es equivalente a comprobar la influencia que presenta el hecho de que una misma instalación interior de un edificio (de características similares a las del edificio de referencia), esté conectada a una tubería de la red general de mayor o menor entidad, siempre y cuando se mantenga la presión de entrega constante y las características de la instalación interior inalterables. 
Como se aprecia en la Figura C4-21 la conexión de la instalación interior a una conducción de mayor o menor diámetro puede variar la caída de presión máxima esperada tanto en la acometida como en la propia aspiración de la bomba, reduciéndose tal influencia a medida que aumenta el diámetro de la RGD.

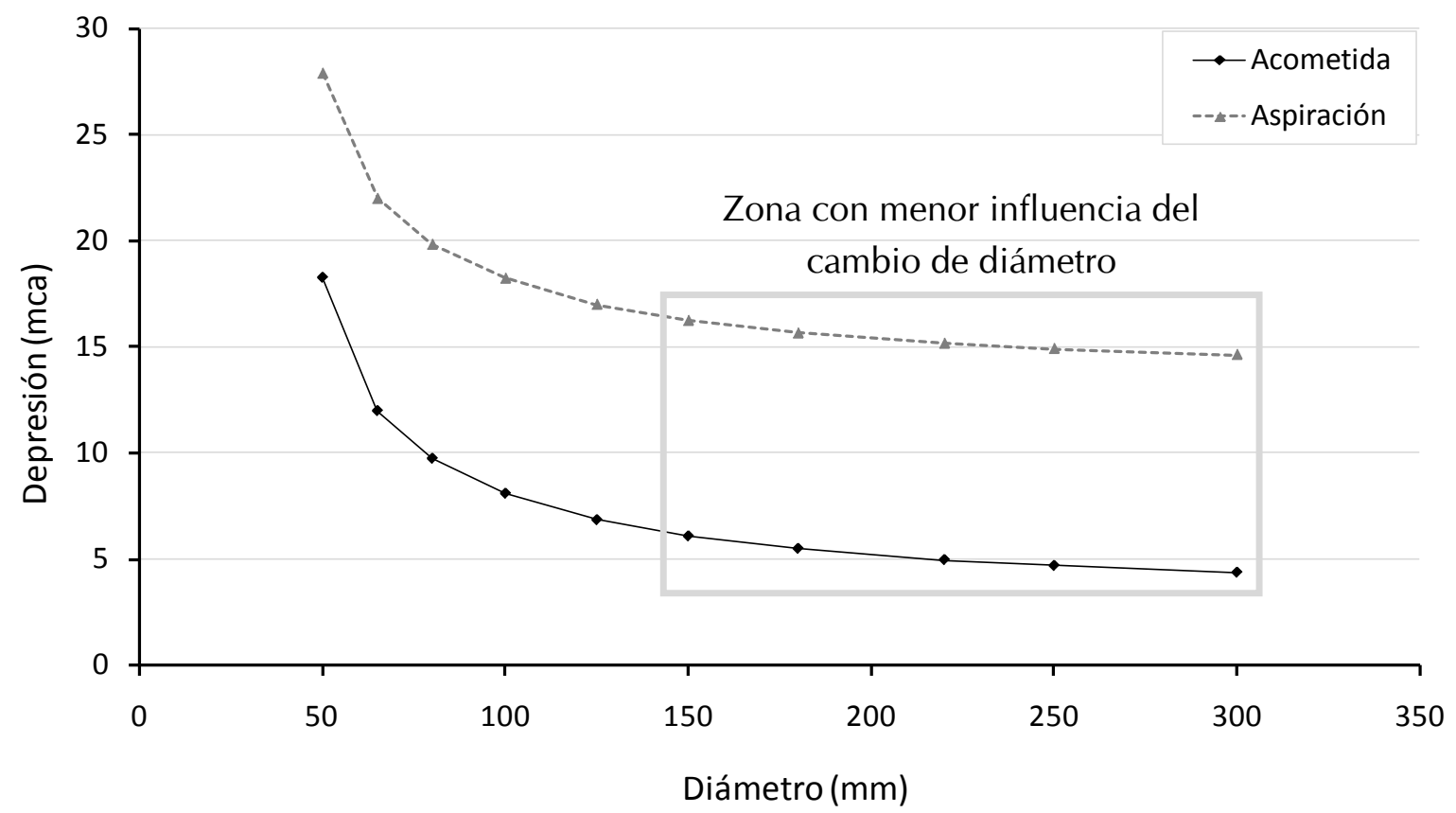

FIGURA C4-21. DEPRESIÓN EN FUNCIÓN DEL DIÁMETRO DE LA RGD

Hay que tener presente que la caída de presión originada está formada por dos componentes, por un lado un término asociado a las pérdidas en régimen permanente, función del caudal circulante por la acometida y las características físicas de la tubería aguas arriba de la bomba. Este término es constante para todas las simulaciones, y por tanto la serie de puntos asociada sería equidistante a las series representadas, del mismo modo su contribución durante los primeros instantes del arranque puede ser reducida ya que los caudales trasegados son reducidos.

La segunda componente de la depresión estaría asociada directamente a la magnitud de la perturbación en régimen transitorio (más sensible para diámetro de RGD menores). Sobre esta última componente aparece una tendencia en la depresión para diferentes diámetros de la RGD en ambas series; para diámetros pequeños un ligero aumento del diámetro de la RGD reduce significativamente la depresión originada, y para mayores diámetros este beneficio se reduce sensiblemente, no justificando el aumento del diámetro de la tubería de la RGD (a partir de un determinado diámetro el aumento del diámetro no supone una mejora apreciable en lo que respecta a las depresiones generadas). 
La explicación a esta tendencia hay que buscarla en efecto derivado de la transmisión y reflexión de la perturbación que tiene lugar en el entronque entre la RGD y la acometida. En este caso el fenómeno puede ser explicado a partir de la resolución analítica de las ecuaciones características que se dan en un volumen de control que incluiría la acometida del edificio y la intersección en las inmediaciones de éste (tramo perteneciente a la red general de distribución).
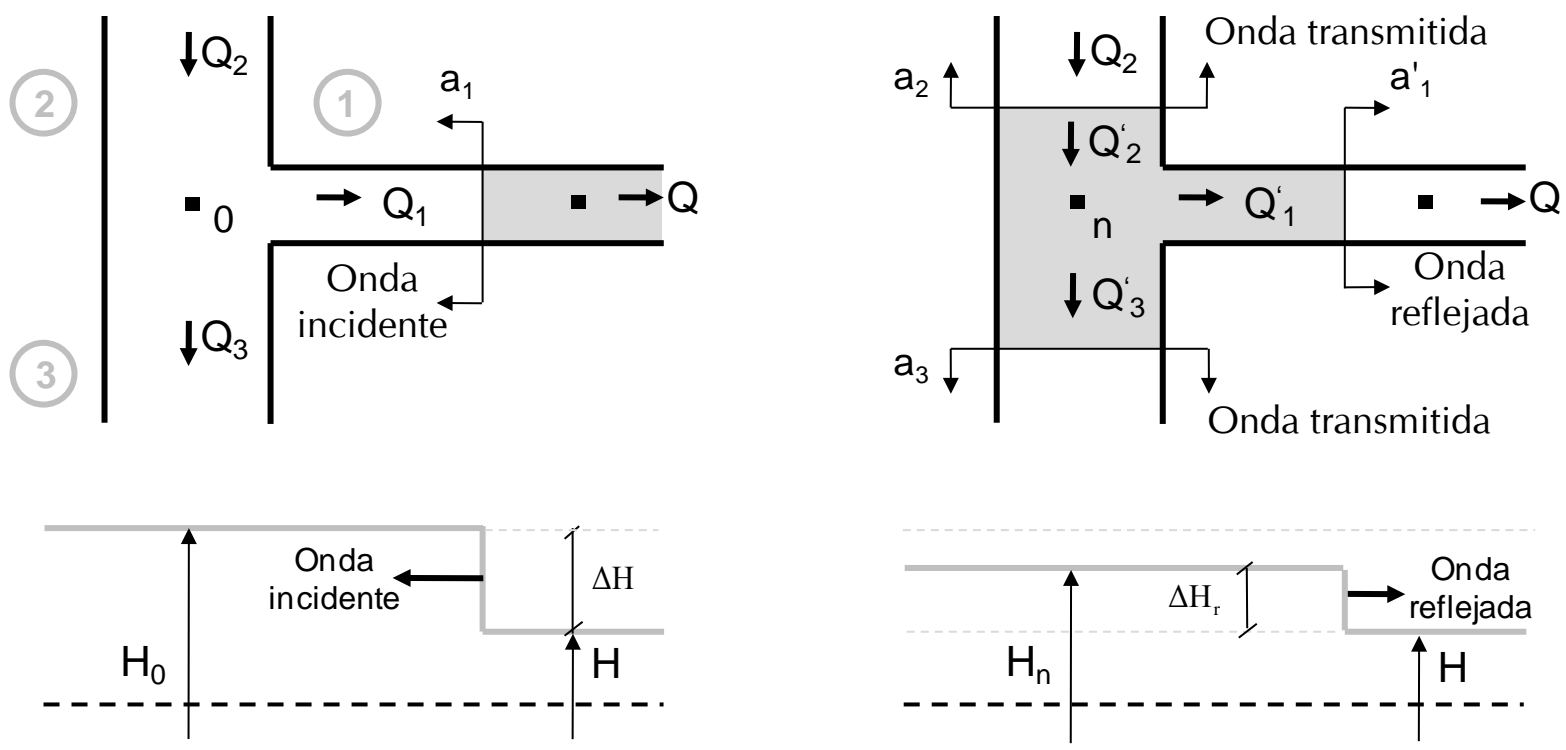

FIGURA C4-22. EVALUACIÓN DE LA INCIDENCIA DE LA PERTURBACIÓN EN EL NUDO DE CONEXIÓN DE LA RGD

Se evalúa la evolución de la perturbación para las secciones próximas al volumen de control definido, $y$ cuyos límites distan longitudes $\Delta x_{1}=a_{1} \cdot \Delta t, \Delta x_{2}=a_{2} \cdot \Delta t y$ $\Delta x_{3}=a_{3} \cdot \Delta t$ del nudo de intermedio de conexión (para los instantes de tiempo $t-\Delta t$, $t$ y $t+\Delta t$ ). Para el primero de los instantes indicados $(t-\Delta t)$, la onda de presión viaja por la conducción 1 (acometida del edificio) en sentido hacia el nudo de conexión. Para este instante las características en este punto vienen fijadas por las condiciones de altura y caudal de referencia $\left(Q_{1}, H_{1}\right)$. Para el siguiente instante de tiempo $t$, la onda ha pasado por la sección de la tubería 1, originando una variación de las condiciones anteriores, y estableciendo un caudal $Q$ y una altura $H$, suma de la altura inicial más el decremento asociado a la perturbación $\left(H=H_{1}+\Delta H\right)$. En el siguiente instante $(t+\Delta t)$ la onda ha atravesado el nudo intermedio y se ha transmitido a las conducciones de la RGD al mismo tiempo que se ha reflejado en la acometida en dirección a la bomba.

La resolución del fenómeno puede realizarse a partir de las características $\mathrm{C}^{+} \mathrm{y} \mathrm{C}^{-}$ para los instantes considerados, al mismo tiempo que debe satisfacerse la ecuación de continuidad en el nudo de confluencia al no existir almacenamiento en el mismo. Por ello, las ecuaciones características que definen el fenómeno de forma genérica para la confluencia de 3 tuberías en un mismo nudo son: 
Para la evolución de $t-\Delta t$ a $t$ :

$$
\begin{array}{cc}
C_{1}^{+}: H-H_{0}=-B_{1} \cdot\left(Q-Q_{1}\right) & \text { EC. } 13 \\
Q_{1}=Q_{2}-Q_{3} & \text { EC. } 14
\end{array}
$$

Para la evolución de $t$ a $t+\Delta t$ :

$$
\begin{array}{cc}
C_{1}^{-}: H_{n}-H=B_{1} \cdot\left(Q_{1}^{\prime}-Q\right) & \text { EC. } 15 \\
C_{2}^{+}: H_{n}-H_{0}=-B_{2} \cdot\left(Q_{2}^{\prime}-Q_{2}\right) & \text { EC. } 16 \\
C_{3}^{+}: H_{n}-H_{0}=-B_{3} \cdot\left(Q_{3}^{\prime}-Q_{3}\right) & \text { EC. } 17 \\
Q_{1}^{\prime}=Q_{2}^{\prime}-Q_{3}^{\prime} & \text { EC. } 18
\end{array}
$$

Restando Ec. 13 y Ec. 15 se tiene:

$$
\left(H-H_{0}\right)-\left(H_{n}-H\right)=\Delta H-\Delta H_{r}=-B_{1} \cdot\left(Q_{1}^{\prime}-Q_{1}\right)
$$

Y a partir de la Ec. 14 y de la Ec. 18:

$$
\left(Q_{1}^{\prime}-Q_{1}\right)=\left(Q_{2}^{\prime}-Q_{2}\right)+\left(Q_{3}^{\prime}-Q_{3}\right)
$$

Y utilizando las dos ecuaciones anteriores junto con la Ec. 16 y Ec. 17 se tiene:

$$
\Delta H-\Delta H_{r}=B_{1} \cdot\left(\frac{1}{B_{2}}+\frac{1}{B_{3}}\right) \cdot \Delta H_{t}
$$

Como $\Delta H_{r}=\Delta H_{t}-\Delta H$ se obtiene:

$$
2 \cdot \Delta H=B_{1} \cdot\left(\frac{1}{B_{1}}+\frac{1}{B_{2}}+\frac{1}{B_{3}}\right) \cdot \Delta H_{t}
$$

Por lo que el coeficiente de transmisión $s$, que tiene en cuenta la fracción de perturbación incidente que se transmite a las conducciones de la RGD resulta:

$$
S=\frac{2 \cdot \frac{A_{1}}{a_{1}}}{\frac{A_{1}}{a_{1}}+\frac{A_{2}}{a_{2}}+\frac{A_{3}}{a_{3}}}
$$

En cuanto al coeficiente de reflexión $r$, que tiene en cuenta la reflexión de la onda incidente en dirección hacia la perturbación, y aplicado el caso concreto de la 
instalación de referencia (las conducciones de la RGD mantienen las mismas propiedades), y asumiendo igualdad de celeridades $\left(a_{\text {acom }}=a_{R G D}\right)$ :

$$
r=s-1=\frac{\frac{A_{\text {acom }}}{a_{\text {acom }}}-\frac{2 A_{R G D}}{a_{R G D}}}{\frac{A_{\text {acom }}}{a_{\text {acom }}}+\frac{2 A_{R G D}}{a_{R G D}}}=\frac{A_{\text {acom }}-2 A_{R G D}}{A_{\text {acom }}+2 A_{R G D}}=\frac{D_{\text {acom }}^{2}-2 \cdot D_{R G D}^{2}}{D_{\text {acom }}^{2}+2 \cdot D_{R G D}^{2}}
$$

Como puede deducirse de la expresión anterior y a partir de la Figura C4-23, existe una relación entre el coeficiente de reflexión en la caída máxima en acometida; a medida que aumenta el diámetro de las tuberías de la RGD frente a la conducción de la acometida mayor será la atenuación de la onda incidente, y por tanto mayor la perturbación reflejada hacia la aspiración de la bomba, dando por tanto sentido a la tendencia

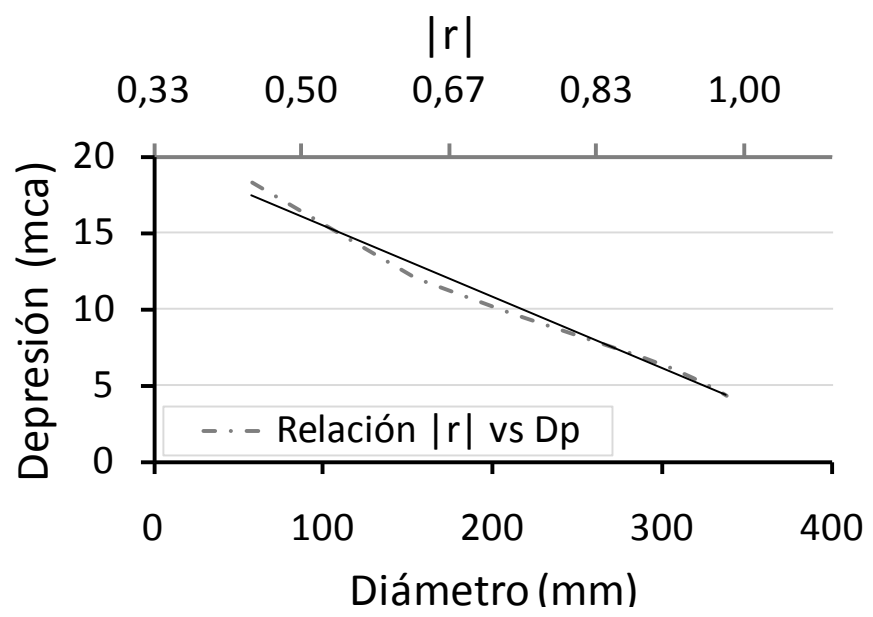

FIGURA C4-23. RELACIÓN ENTRE EL COEFICIENTE DE REFLEXIÓN Y LA DEPRESIÓN EN ACOMETIDA mostrada en la Figura C4-21.

Téngase en cuenta que la onda reflejada es de signo contrario a la onda incidente, neutralizando por tanto parte de la magnitud de la perturbación. Por otro lado la pendiente de la serie anterior es función de las características propias de la instalación interior y las de la RGD siendo dependiente de cada instalación.

\subsubsection{Influencia de los parámetros de la instalación interior}

En este punto se trata de analizar la influencia de las principales características de la instalación interior del edificio en la depresión generada por el arranque del grupo de bombeo. Como es lógico la magnitud de la depresión originada presenta una elevada dependencia de las características de esta instalación, y para una misma RGD pueden originarse perturbaciones más significativas a medida que la instalación interior presenta unas características más desfavorables.

\subsubsection{Tiempo de arranque del grupo de presión}

Uno de los parámetros que mayor influencia presenta sobre la magnitud de la depresión está relacionado con el tiempo de arranque del grupo, tiempo comprendido desde el inicio de la alimentación eléctrica hasta que éste alcanza su velocidad 
nominal. La determinación precisa de este tiempo es compleja dada la necesidad de una análisis riguroso sobre la dinámica de arranque de un grupo moto-bomba, de forma orientativa la intensidad eléctrica en el arranque presenta una relación con este valor. En el caso de la BVF la intensidad de alimentación toma valores usuales de 6 veces la intensidad nominal de funcionamiento $(I n)$, frente a los $3 \cdot \ln$ correspondiente a los motores con variador (Documentación técnica EMOTRON) para los tamaños de grupos de presión usuales en el entorno residencial (potencias en torno a los $3 \mathrm{~kW}$ ).

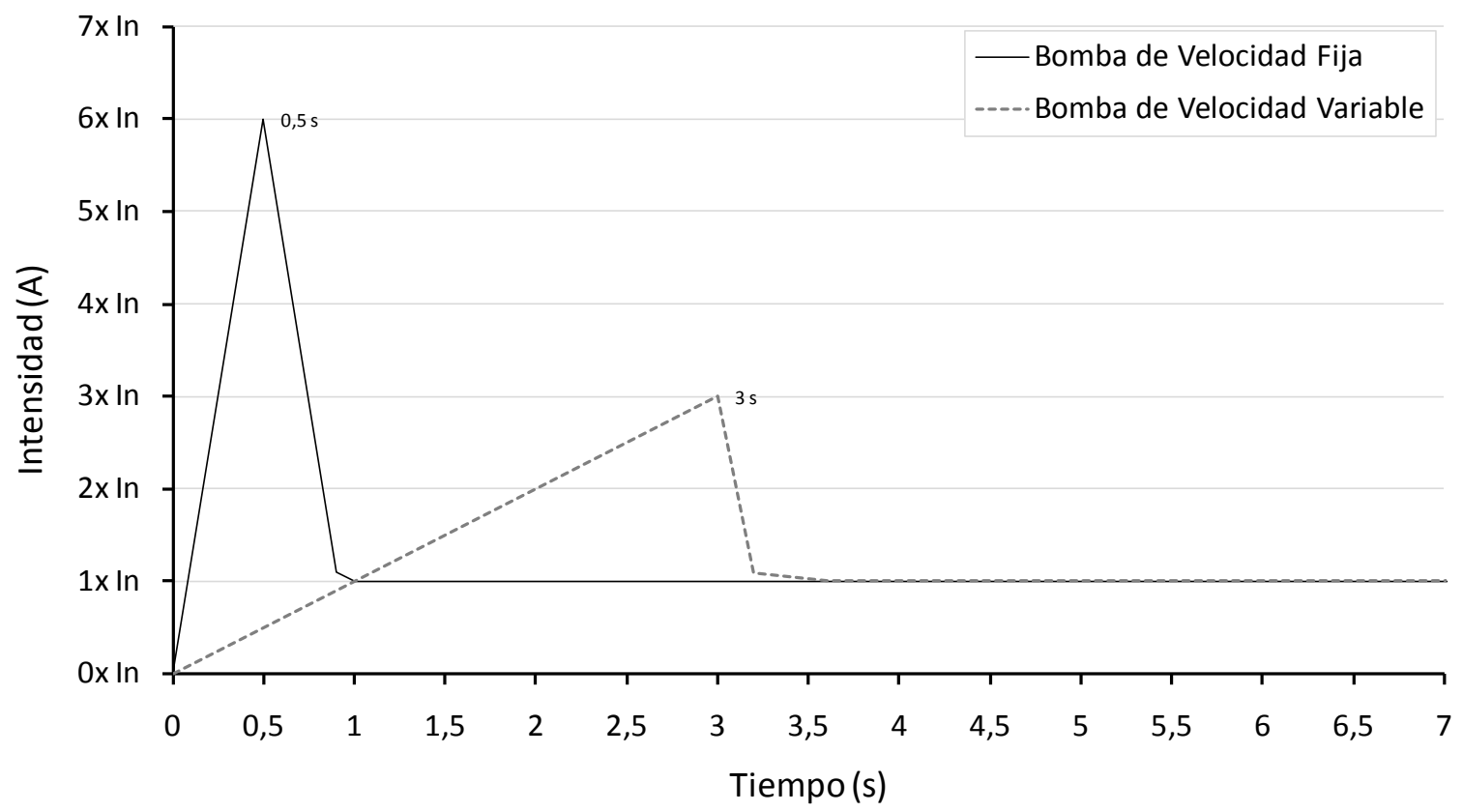

FIGURA C4-24. VARIACIÓN DE LA INTENSIDAD ELÉCTRICA CONSUMIDA EN FUNCIÓN DEL TIPO DE BOMBA

Con el objetivo de disponer de una orientación sobre la influencia de esta variable y, conocidas las limitaciones del software utilizado, se ha analizado el arranque con evolución lineal en el espectro de tiempos en los que suele variar este parámetro. En el caso de bombas de velocidad fija, este tiempo es complejo de obtener siendo principalmente función de la potencia del motor y de la carga de arrastre. Diferentes fabricantes coinciden a la hora de acotar el tiempo entre 0,4 y 0,6 segundos para este tipo de grupos en instalaciones interiores similares a la de referencia. En el caso de bombas de velocidad variable, este parámetro es ajustable a partir de la rampa de arranque programada en el PID del variador. La duración de este arranque en instalaciones interiores de edificios suele estar acotada en valores que van desde los 2 a los 5 segundos (en función de la potencia de la bomba).

Como puede observarse en la Figura C4-25 las solicitaciones se reducen sensiblemente a medida que aumenta el tiempo de arranque, originándose depresiones muy elevadas para tiempos cortos, y depresiones prácticamente despreciables en acometida para tiempos más elevados. El primero de los casos se asociaría al comportamiento de la BVF, y el segundo caso a motores equipados con variador. La 
capacidad del control del tiempo de arranque justifica en gran medida la idoneidad de estos grupos frente a los de velocidad fija. La capacidad de fijar la duración en el arranque junto con la adecuación de la respuesta del motor en función de la demanda real reduce significativamente las solicitaciones del grupo de presión, manteniendo un comportamiento menos severo y con menores solicitaciones. Aunque en algunas instalaciones se suelen mantener los valores de fábrica de los parámetros del controlador, interesa un ajuste preciso, ya que una configuración no adecuada puede llevar a respuestas inaceptables (un tiempo de respuesta prolongado puede derivar en un déficit de presión disponible perjudicando el correcto suministro en la instalación).

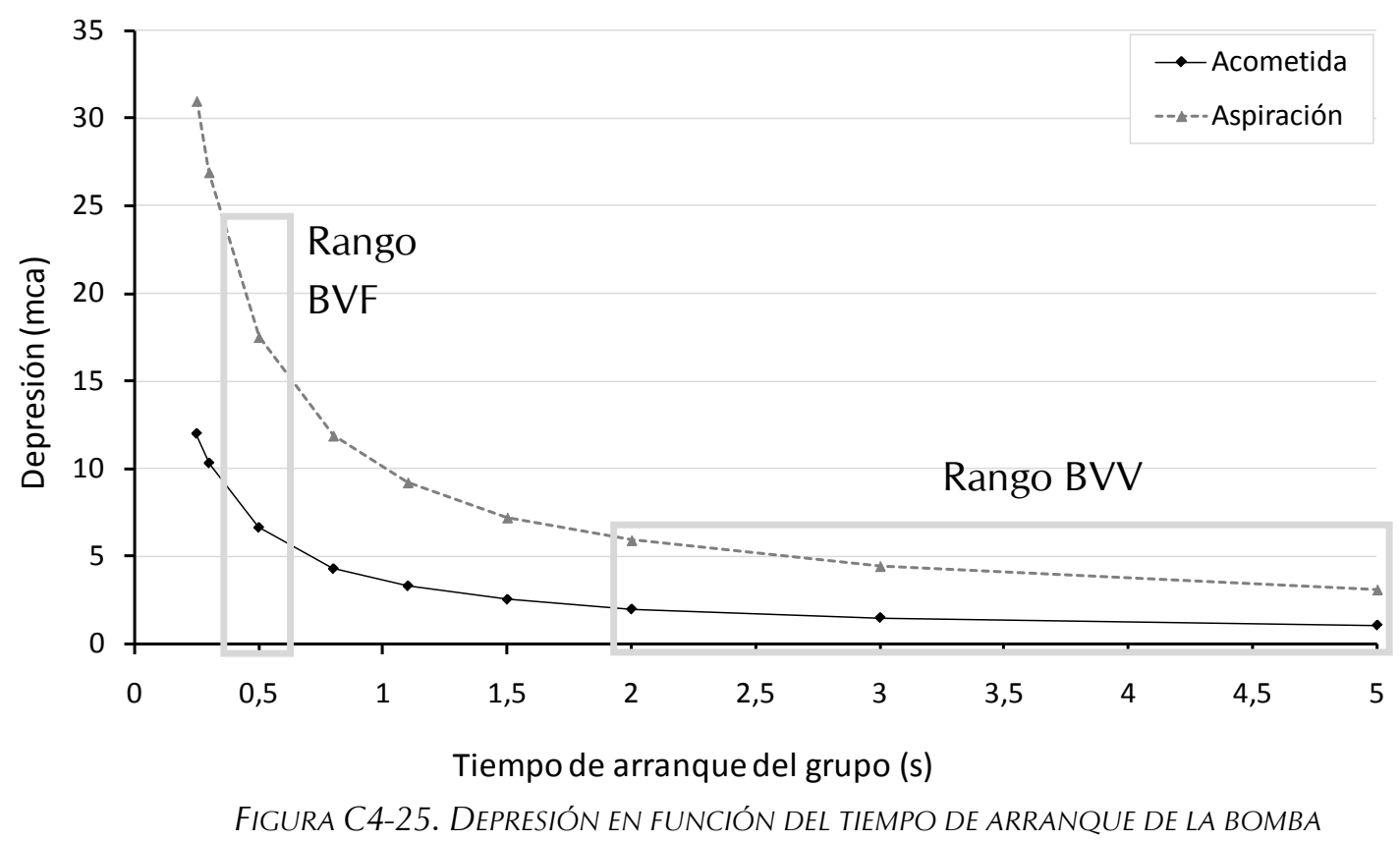

\subsubsection{Caudal de bombeo del grupo}

Otro parámetro característico que presenta gran influencia sobre la depresión originada durante el arranque es el caudal trasegado por el grupo de bombeo. En esta línea mayores caudales originan una mayor caída de presión durante el funcionamiento del grupo, tanto en régimen transitorio como en permanente.

A continuación se muestra el análisis sobre la influencia del caudal trasegado por el grupo tanto para la instalación de referencia como para instalaciones de diferente tamaño. Para ello se ha acudido a diferentes catálogos de fabricantes y se han seleccionado diversas bombas comerciales (Figura C4-26). Estas bombas están dimensionadas para el aprovechamiento de la presión en red (téngase en cuenta que una de las bomba instalada en el edificio (B3) no presenta un funcionamiento óptimo para una conexión directa, ya que el aprovechamiento de la presión de la red puede derivar en puntos de funcionamiento no considerados en su dimensionado). 


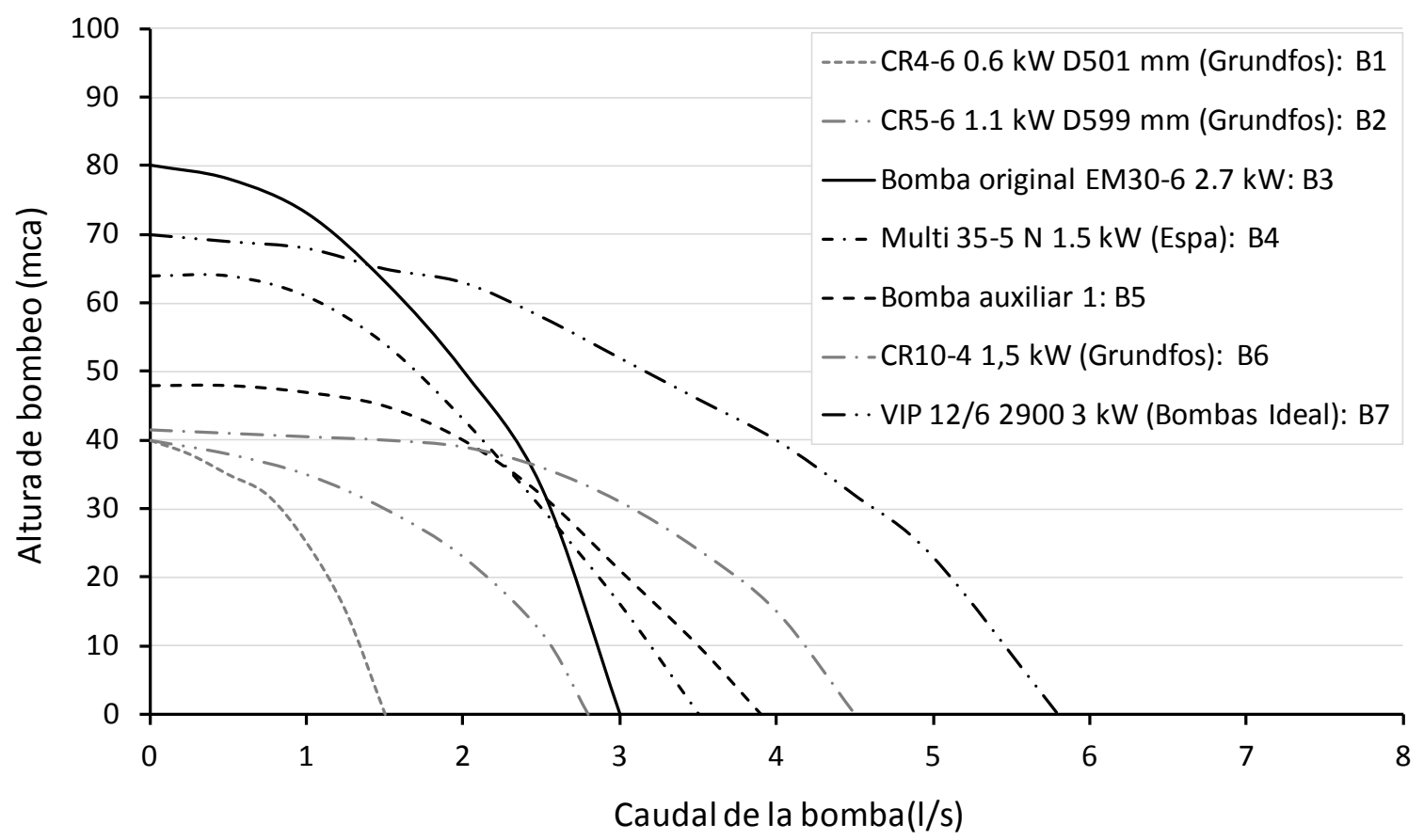

FIGURA C4-26. CURVAS DE BOMBEO PARA DIFERENTES ALTERNATIVAS DE GRUPOS DE PRESIÓN

A su vez, el número de bombas instaladas en el grupo de presión presenta una considerable implicación. En esta línea la normativa de referencia (CTE y Pr UNE 149202) establece, para los grupos de presión en el entorno residencial, la instalación de varias bombas asociadas en paralelo para cubrir todo el rango de caudales de diseño. Al mismo tiempo, las bombas principales de estos grupos de presión deben totalizar (entre ellas) el caudal de diseño de la instalación (consideración no contemplada en el CTE), por ello es fácil encontrar instalaciones con dos bombas cuyo caudal de diseño unitario coincide con el caudal de cálculo de la instalación.

La estratificación de caudales propuesta para el dimensionado en la mencionada norma se muestra en la Tabla C4-2. A la vista de la tabla se puede concluir que la propuesta de la norma se encamina en instalar mayor número de bombas de menor tamaño. Esta situación favorece en gran medida la generación de transitorios de menor magnitud tal como se comprobará más adelante.

TABLA C4-2. NúMERO DE BOMBAS EN FUNCIÓN DEL CAUDAL DE DISEÑO (PR UNE 149202)

\begin{tabular}{cc}
\hline Caudal diseño & $\begin{array}{c}\text { Número de bombas } \\
\text { (principales/reserva) }\end{array}$ \\
\hline Menor de $3 \mathrm{l} / \mathrm{s}$ & $\mathbf{2 / \mathbf { 0 } ^ { \mathbf { 1 } }}$ \\
\hline Entre $3 \mathrm{l} / \mathrm{s}$ y $10 \mathrm{l} / \mathrm{s}$ & $\mathbf{2 / 1}$ \\
Entre $10 \mathrm{l} / \mathrm{s}$ y $20 \mathrm{l} / \mathrm{s}$ & $\mathbf{3 / 1}$ \\
Mayor de $20 \mathrm{l} / \mathrm{s}$ & $\mathbf{4 / 1}$ \\
\hline
\end{tabular}

${ }^{1}$ Propuesto en el Pr UNE 149202. 
Por las implicaciones que tiene el número de bombas, se ha discretizado el análisis para caudales inferiores a $5 \mathrm{l} / \mathrm{s}$ y para caudales superiores a este valor. Esta discretización pretende analizar los dos primeros estratos de la tabla, ya que estas situaciones contemplan la mayoría de las instalaciones en el ámbito residencial. Adicionalmente y según la tabla anterior, una instalación con un caudal de diseño de 10 I/s estará equipada en la situación más desfavorable con dos bombas principales cuyo caudal unitario será la mitad del caudal de diseño indicado. Del mismo modo, y para simplificar el análisis se ha considerado que todo el caudal del edificio es suministrado por el grupo de bombeo.

\section{Instalaciones con caudal de diseño inferior a $5 \mathrm{l} / \mathrm{s}$}

Este análisis trata de comprobar los efectos originados por el arranque de una única bomba con un caudal variable pero limitado a $5 \mathrm{l} / \mathrm{s}$. Para ello se ha simulado la instalación de referencia equipada con las bombas comerciales comentadas anteriormente. Al disponer cada bomba de una curva característica diferente, durante su arranque propiciarán caudales trasegados diferentes y por tanto será posible analizar la influencia de esta variable. El estudio realizado es equivalente a analizar diferentes tamaños de edificios conectados a una misma red general (edificios con diferente número de viviendas suministradas en directo con el grupo de presión), en la medida que se mantenga el tubo de alimentación inalterable (condicionado a velocidades no excesivas).

Las bombas mostradas en la Figura C4-26 tienen cabida en la instalación ya que son capaces de aportar tanto la presión mínima (aproximadamente 18 mca para alcanzar los 50 mca considerando la presión de red) como la presión máxima de la instalación (con el margen establecido por la reglamentación de referencia). Al mismo tiempo generan velocidades máximas en el tramo acorde a los criterios usuales de dimensionado (desde $0,57 \mathrm{~m} / \mathrm{s}$ a $2,4 \mathrm{~m} / \mathrm{s}$ aproximadamente). Dentro de la variabilidad de caudales que se dan durante el funcionamiento, el estudio sólo ha considerado el caudal que se origina durante los primeros instantes de suministro, condicionado por la presión de arranque en el interior del calderín establecida en 50 mca.

Para las bombas analizadas las simulaciones indican que el aumento de caudal deriva en una mayor caída de presión durante el arranque tanto en la aspiración de la bomba como en la acometida del edificio. Esta relación se mantiene para todas las bombas modeladas, y por tanto es posible aproximar el aumento de caudal a una tendencia prácticamente lineal que relaciona ambas variables (caída de presión y caudal de la bomba). Al punto de inflexión observado (B5) se corresponde a una curva de bombeo que presenta una característica más plana, y se prestará atención a la justificación de tal comportamiento al analizar la influencia del tipo de curva de la bomba. 


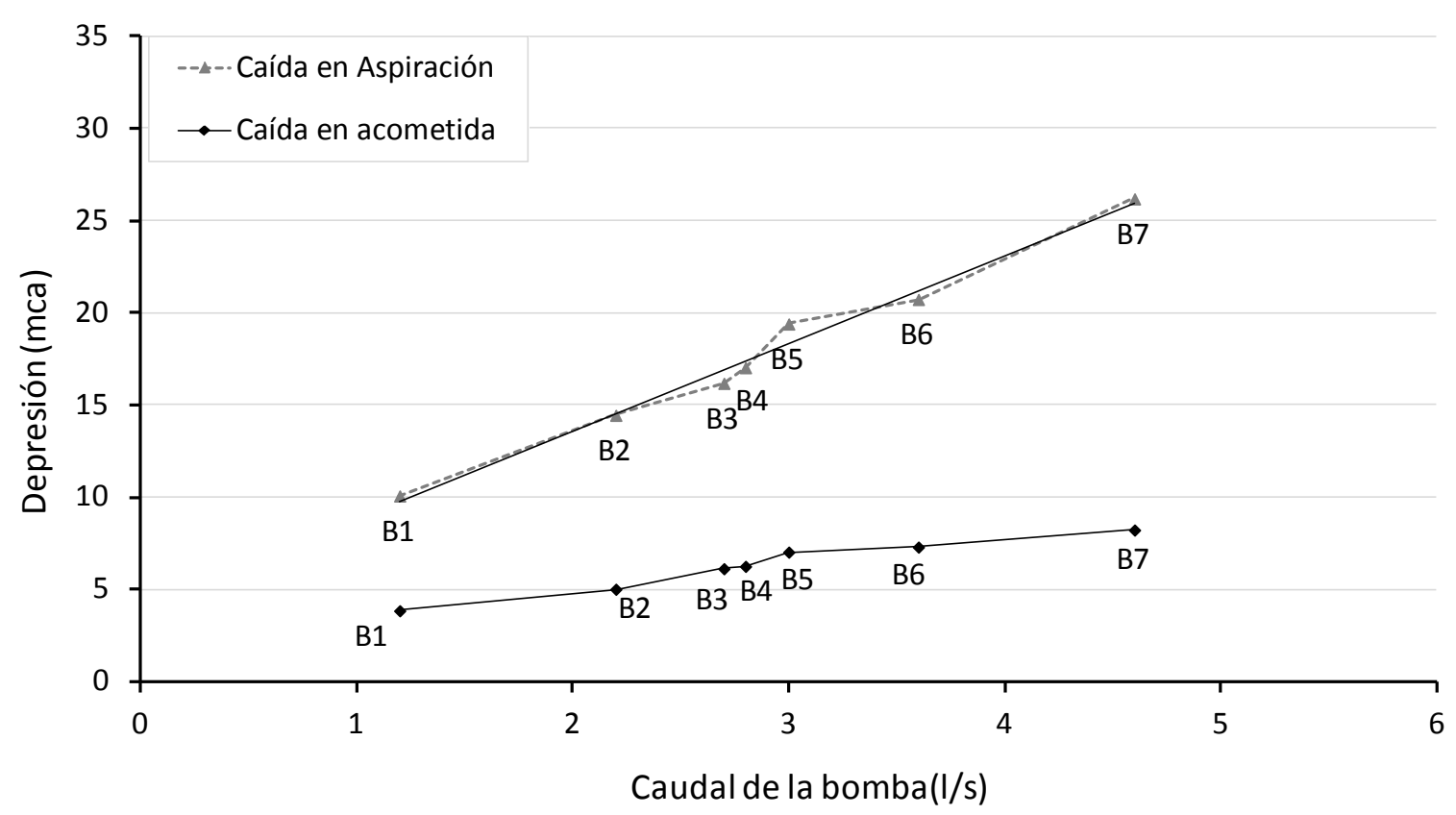

FIGURA C4-27. DEPRESIÓN EN FUNCIÓN DEL CAUDAL DE LA BOMBA PARA LA INSTALACIÓN DE REFERENCIA

La tendencia anterior se fundamenta en que para la maniobra de arranque programada mayores caudales de bombeo originan mayores incrementos de velocidad en la red (para una misma sección de conducción y un mismo tiempo de arranque), y por tanto aumenta la magnitud de la perturbación en la instalación.

Los resultados anteriores aplicarían para la instalación de referencia, sobre la que se ha variado el hipotético tamaño del edificio a partir de las características funcionales del grupo de presión, manteniendo el resto de propiedades de la instalación inalterables. El análisis realizado está limitado a los caudales que generan velocidades en la conducción de aspiración dentro de los valores razonables comentados anteriormente, si se pretende extrapolar los resultados a otras instalaciones es necesario construir el modelo para otros diámetros interiores, fijando para ello diferentes diámetros para la conducción de aspiración y caudales bombeados.

Instalaciones con caudal de diseño superior a $5 \mathrm{l} / \mathrm{s}$

Para caudales de diseño superiores a $5 \mathrm{l} / \mathrm{s}$ comúnmente se insta a la utilización de varias bombas en paralelo, si bien y tal como se ha comentado esta exigencia contemplaría cualquier instalación con bombeo.

La regulación bajo estas consideraciones generalmente se realiza de forma escalonada. Esta regulación se fundamenta en el arranque consecutivo de las bombas en función de la presión en impulsión. La primera bomba arranca cuando la presión en el calderín alcanza un determinado valor ( $P_{1}{ }_{1 B}$, presión de arranque). Si la demanda instantánea no supera el caudal asociado a la presión anterior, la bomba mantendría su funcionamiento originándose su parada cuando se reduce la demanda y se alcanza la 
presión de paro $P p_{1 в}$. Si por el contrario la demanda es superior al caudal máximo aportado por una única bomba y se alcanza $P_{2}$ se originará el arranque de la segunda bomba, con el correspondiente fenómeno transitorio asociado. De esta forma se mantiene el arranque y paro de las bombas en función de la presión a la salida del grupo, directamente relacionada con la demanda de agua instantánea.

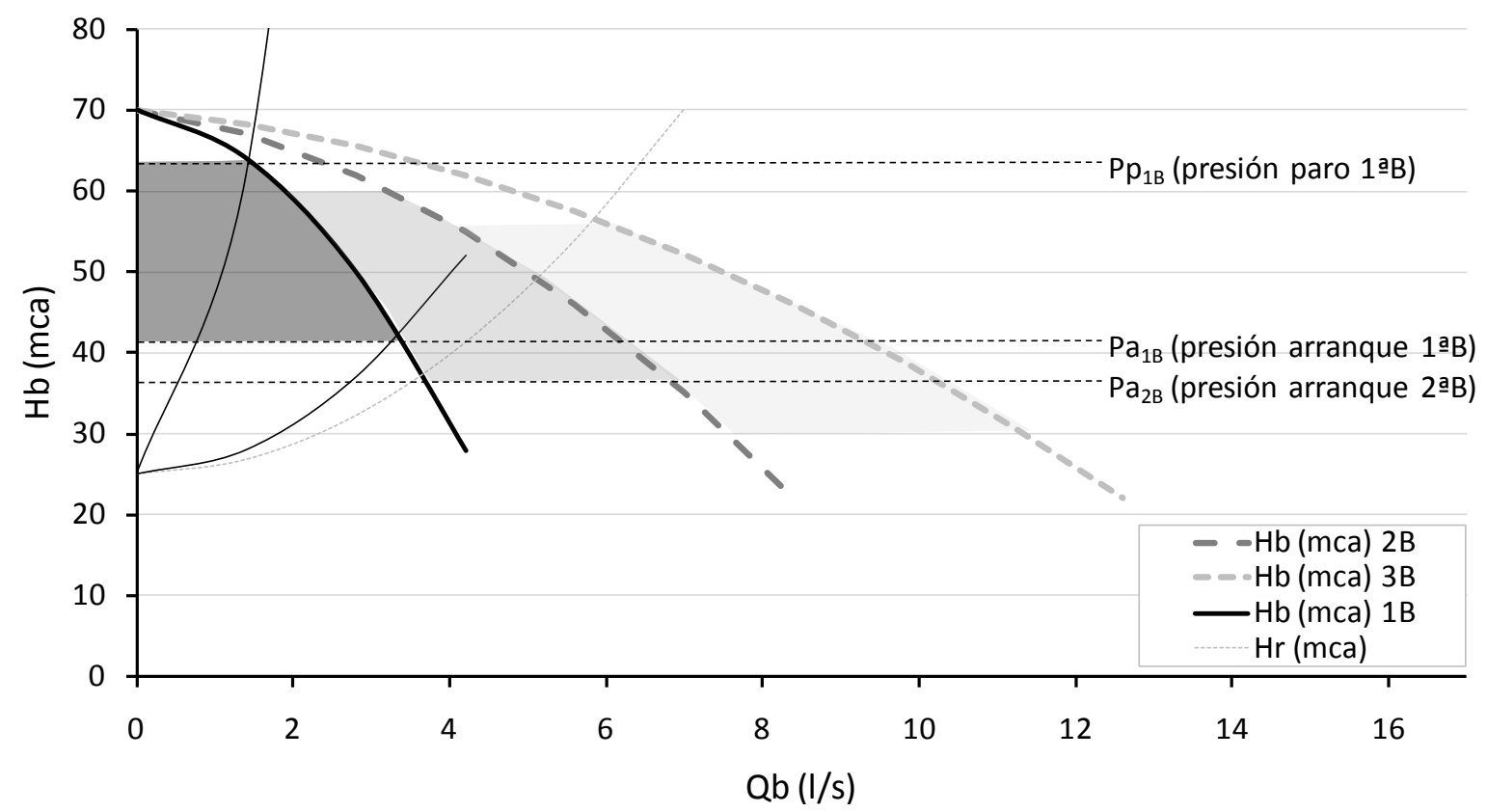

FIGURA C4-28. ARRANQUE ESCALONADO EN UNA INSTALACIÓN CON 3 BOMBAS EN PARALELO

La posibilidad de que arranquen de forma simultánea dos bombas es prácticamente nula en condiciones normales de suministro ya que la primera bomba recibirá siempre la señal de arranque con anterioridad a la segunda. En la práctica el calderín de impulsión con membrana dispone de un volumen de agua presurizada que establece un desfase en el arranque de sucesivas bombas, de la misma forma el tarado de los interruptores de presión establecido por diferentes fabricantes suele mantener una variación de presión próxima a $10 \mathrm{mca}$ y se cuenta con mecanismos electrónicos que mantienen un retardo para la entrada de la segunda bomba con valores usuales de $2 \mathrm{~s}$.

Para analizar el fenómeno se ha simulado el arranque de dos bombas asociadas en paralelo para un caudal de diseño próximo a $5 \mathrm{l} / \mathrm{s}$ (cada bomba aporta la mitad de dicho caudal, Figura C4-29). Se ha programado el arranque de la segunda bomba cuando el funcionamiento de la primera está estabilizado (desfase $=2 \mathrm{~s}$ ). Además se compara dicho comportamiento con el que originaría una bomba que totalizada dicho caudal. 


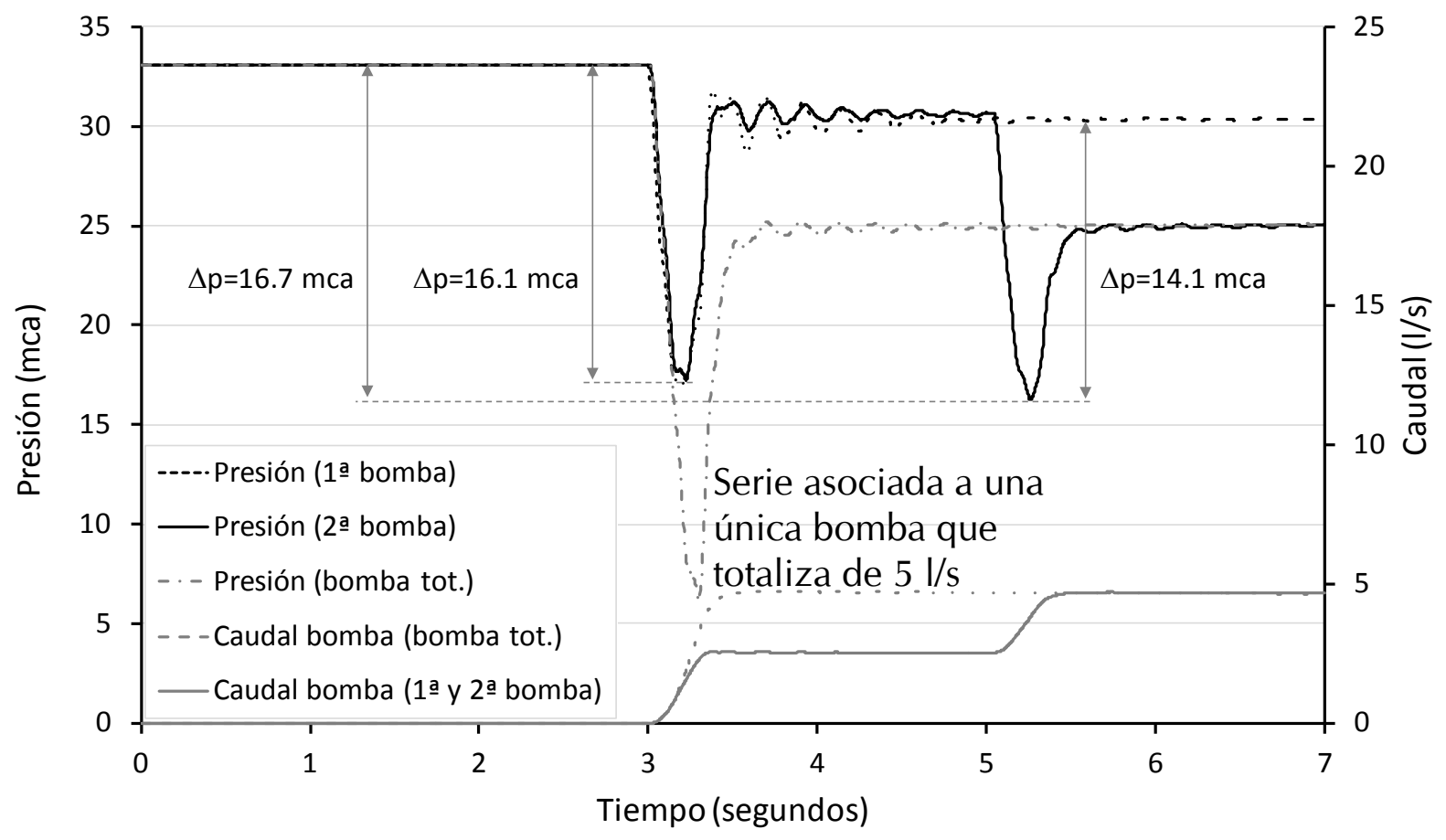

FIGURA C4-29. EFECTOS DERIVADOS DEL ARRANQUE DE DOS BOMBAS EN PARALELO (DESFASE $=2 \mathrm{~S}$ )

La caída de presión originada por dos bombas es mucho más reducida que la correspondiente al funcionamiento de una única bomba que totalice el caudal de diseño (la variación de caudal respecto al tiempo es menor con el funcionamiento de varias bombas). Por ello resulta conveniente acudir a un mayor número de bombas en la instalación, a favor de un menor tamaño unitario. Además se observa que la caída máxima de presión generada por el arranque de la segunda bomba es menor que el originado por la primera. Esto se debe a la reducción del caudal unitario trasegado por la segunda bomba (ligeramente inferior al de la primera). Otro parámetro a considerar estaría asociado con el aprovechamiento de la inercia del fluido en movimiento, a diferencia de lo que ocurre cuando no existe circulación de caudal.

Adicionalmente se destaca la respuesta en régimen permanente debida a las pérdidas de carga en tuberías y elementos. En el caso analizado, la velocidad del flujo de agua para el funcionamiento de una bomba es de $1,2 \mathrm{~m} / \mathrm{s}$, aumentando a 2,5 m/s para el funcionamiento de dos. En esta última situación las pérdidas de carga son elevadas, reduciendo por tanto la presión disponible en la aspiración de la bomba, y pudiendo suponer un riesgo para el suministro normal con este caudal.

Si se originara el arranque de la segunda bomba antes de la estabilización del arranque de la primera se superpondrán los efectos transitorios de ambas bombas. La caída de presión máxima en este caso es ligeramente superior a la originada si la primera bomba está estabilizada, pero en cualquier caso resulta sensiblemente inferior a la correspondiente a la depresión de una única bomba que totalice el caudal de diseño de la instalación (según Figura C4-31). 


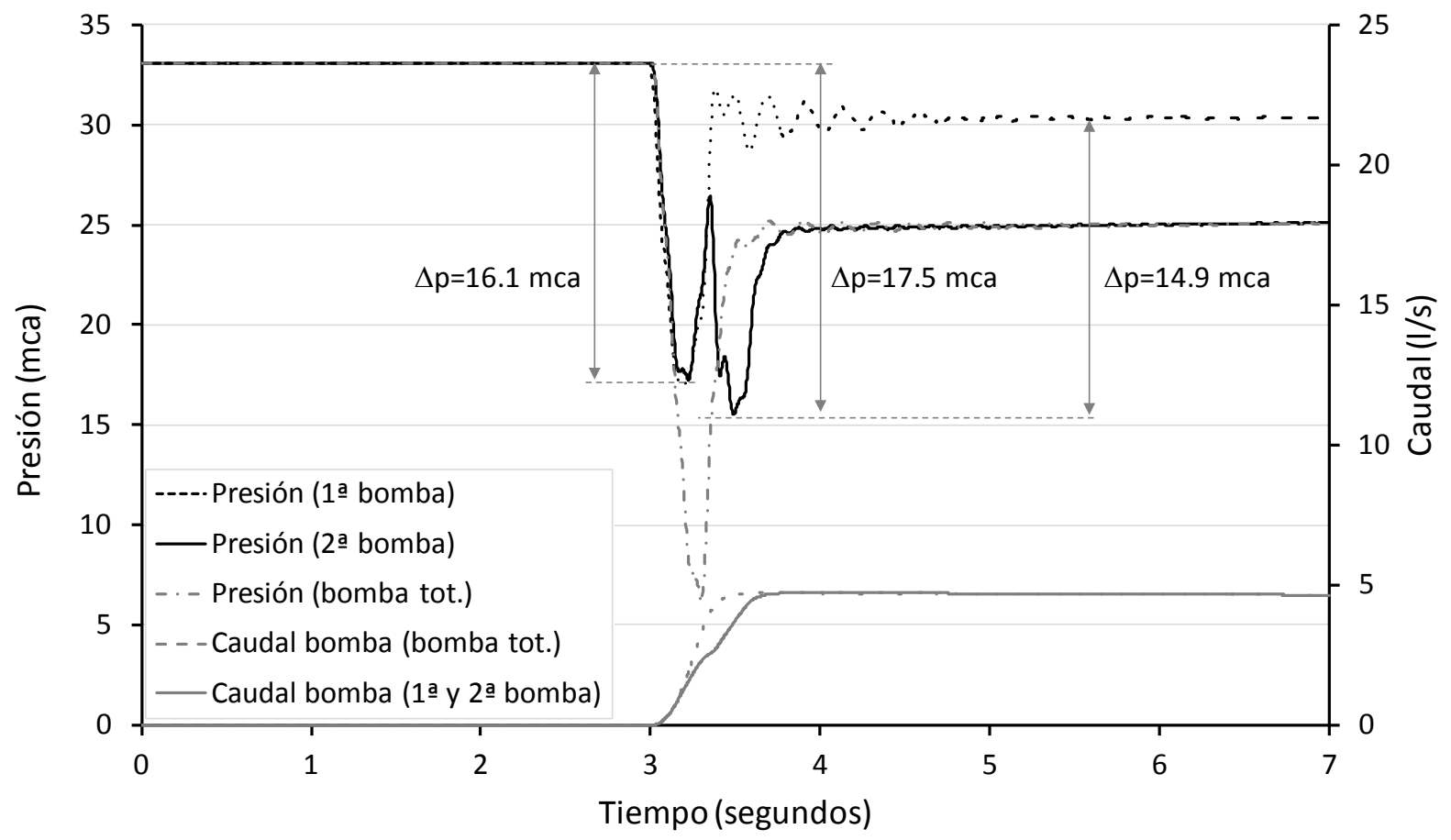

FIGURA C4-31. EFECTOS DERIVADOS DEL ARRANQUE DE DOS BOMBAS EN PARALELO (DESFASE $=0,25$ S)

La Figura C4-30 muestra que en las situaciones en las que el caudal de diseño es totalizado por varias bombas, el aumento del tiempo de desfase entre los arranques no conlleva a una disminución de los efectos transitorios (para tiempos de desfase superiores al tiempo de estabilización de la bomba).

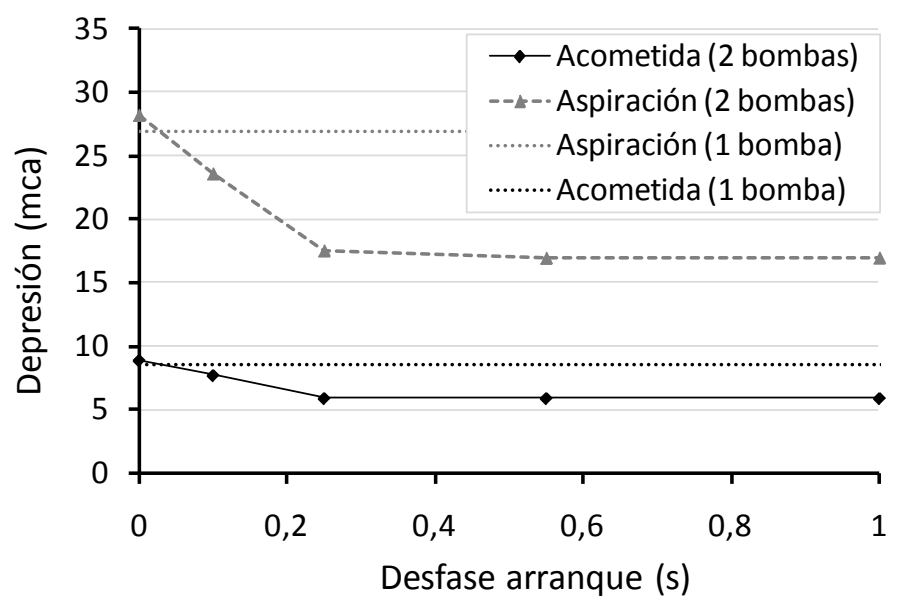

FIGURA C4-30. INFLUENCIA EN EL DESFASE ENTRE LOS ARRANQUES

Por otro lado desfases próximos a cero muestran una respuesta similar a la obtenida con el funcionamiento de una única bomba, pudiendo ser algo dispar dada la dinámica de arranque en ambas situaciones.

Como se ha comentado, la totalización del caudal de diseño por varias bombas unido a una regulación escalonada con desfases apropiados, favorece la reducción de las solicitaciones al materializarse menores variaciones de velocidad en la conducción de aspiración de la bomba. Si se analizan para una misma instalación el funcionamiento de una o varias bombas asociadas en paralelo es posible obtener una relación entre el caudal de bombeo y la caída de presión máxima para cada configuración (Figura C432), al mismo tiempo que puede analizarse el efecto de acudir a una o varias bombas. 


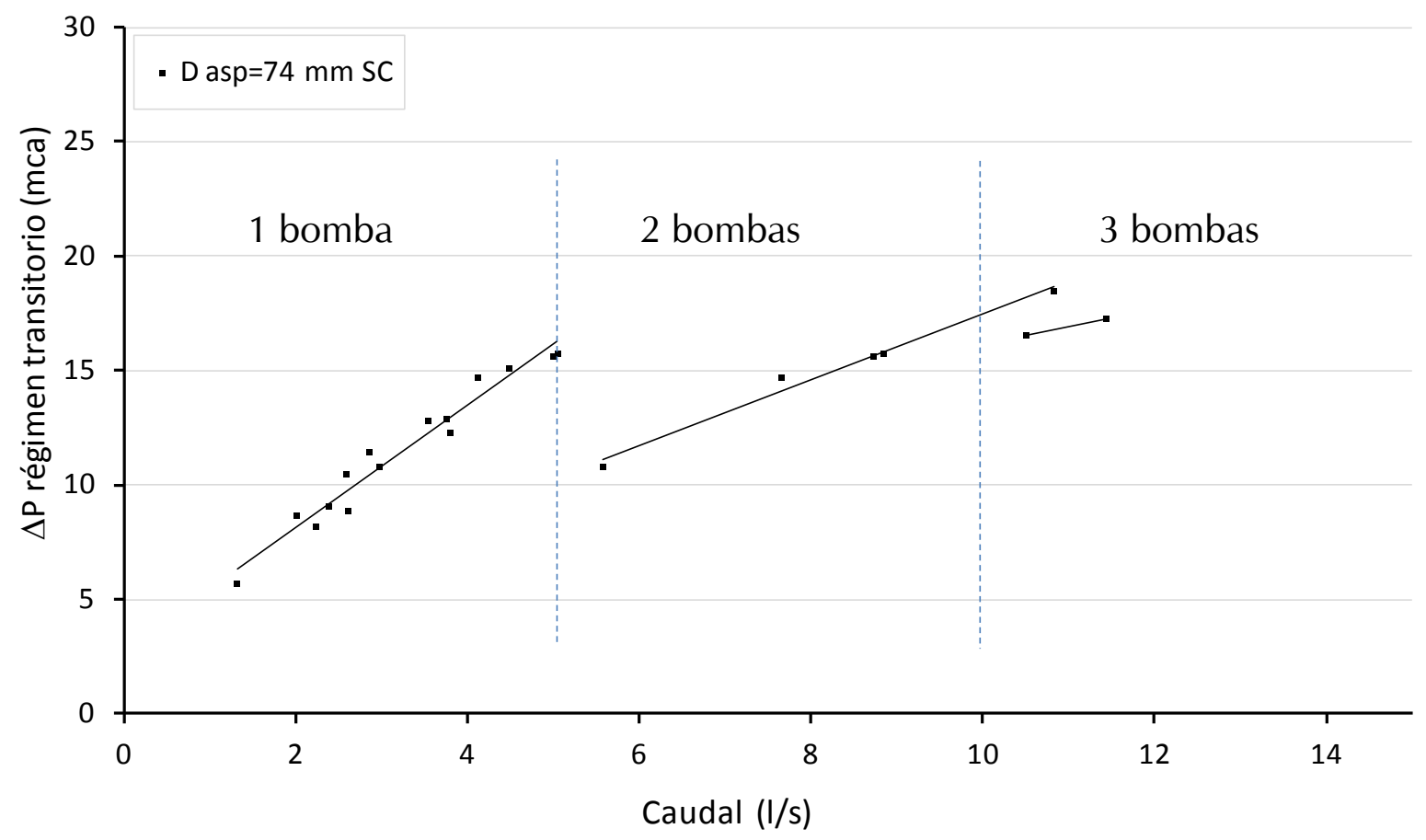

FIGURA C4-32. DEPRESIÓN PARA LA ASOCIACIÓN DE VARIAS BOMBAS EN FUNCIÓN DEL CAUDAL. D ASP. 74 MM.

Para la elaboración de las series se ha realizado un conjunto de simulaciones correspondientes al arranque aislado o combinado de varias bombas de idénticas propiedades según las curvas mostradas en la Figura C4-26. Por tanto cada punto graficado se corresponde con la caída de presión máxima en la aspiración del grupo cuando se origina la entrada en funcionamiento de una bomba. En el caso de modelos con varias bombas se han representado las depresiones originadas por los arranques de cada una de forma aislada, así como la máxima depresión del conjunto ( $\Delta p_{\max }$ en la Figura C4-29). Téngase en cuenta que para la representación se ha acudido a un modelo similar al de la instalación de referencia, pero se ha fijado una conducción de aspiración común de diámetro $74 \mathrm{~mm}$ (para poder contemplar un mayor rango de caudal sin originar valores excesivos de velocidad).

Como puede observarse la gráfica muestra una tendencia lineal que asocia el caudal bombeado con la caída de presión máxima en el arranque, de forma independiente a la curva de bombeo del grupo. Este efecto también se observa cuando se considera el funcionamiento de dos bombas (caudales entre 5 y $10 \mathrm{l} / \mathrm{s}$ ). Incluso para el funcionamiento de tres bombas el fenómeno mantiene las mismas consideraciones, obteniéndose una mayor caída de presión cuando se totaliza el caudal de diseño con un menor número de bombas. Como es lógico la limitación del caudal de operación para un determinado diámetro está condicionada por las velocidades en la conducción de aspiración (para la gráfica anterior se limita a $12 \mathrm{l} / \mathrm{s}$ al originarse velocidades superiores a $2,5 \mathrm{~m} / \mathrm{s})$. 


\subsubsection{Diámetro del tubo de alimentación}

Dada la estrecha vinculación entre el caudal trasegado por la bomba y el diámetro de la conducción de aspiración, el estudio anterior se ha extrapolado creando diferentes escenarios. En cada escenario se han modelado conducciones de aspiración de diámetro interior que van desde los $44 \mathrm{~mm}$ hasta los $135 \mathrm{~mm}$, y que establecen velocidades dentro de los rangos usuales de dimensionado $(0,5 \mathrm{~m} / \mathrm{s}$ y $3 \mathrm{~m} / \mathrm{s}$ para la velocidad mínima y máxima respectivamente). Para la construcción de los modelos se ha acudido de nuevo a las diferentes curvas de bombas definidas anteriormente.

Como puede observarse, de nuevo todos estos puntos se encuentran dentro de una misma recta. En el caso de funcionar varias bombas la caída de presión de la segunda bomba (caudales superiores a $5 \mathrm{l} / \mathrm{s}$ ), se reduce sensiblemente y se mantiene un ajuste lineal de los puntos (las líneas dibujadas tratan de unir puntos asociados a un mismo diámetro y un mismo número de bombas en funcionamiento).

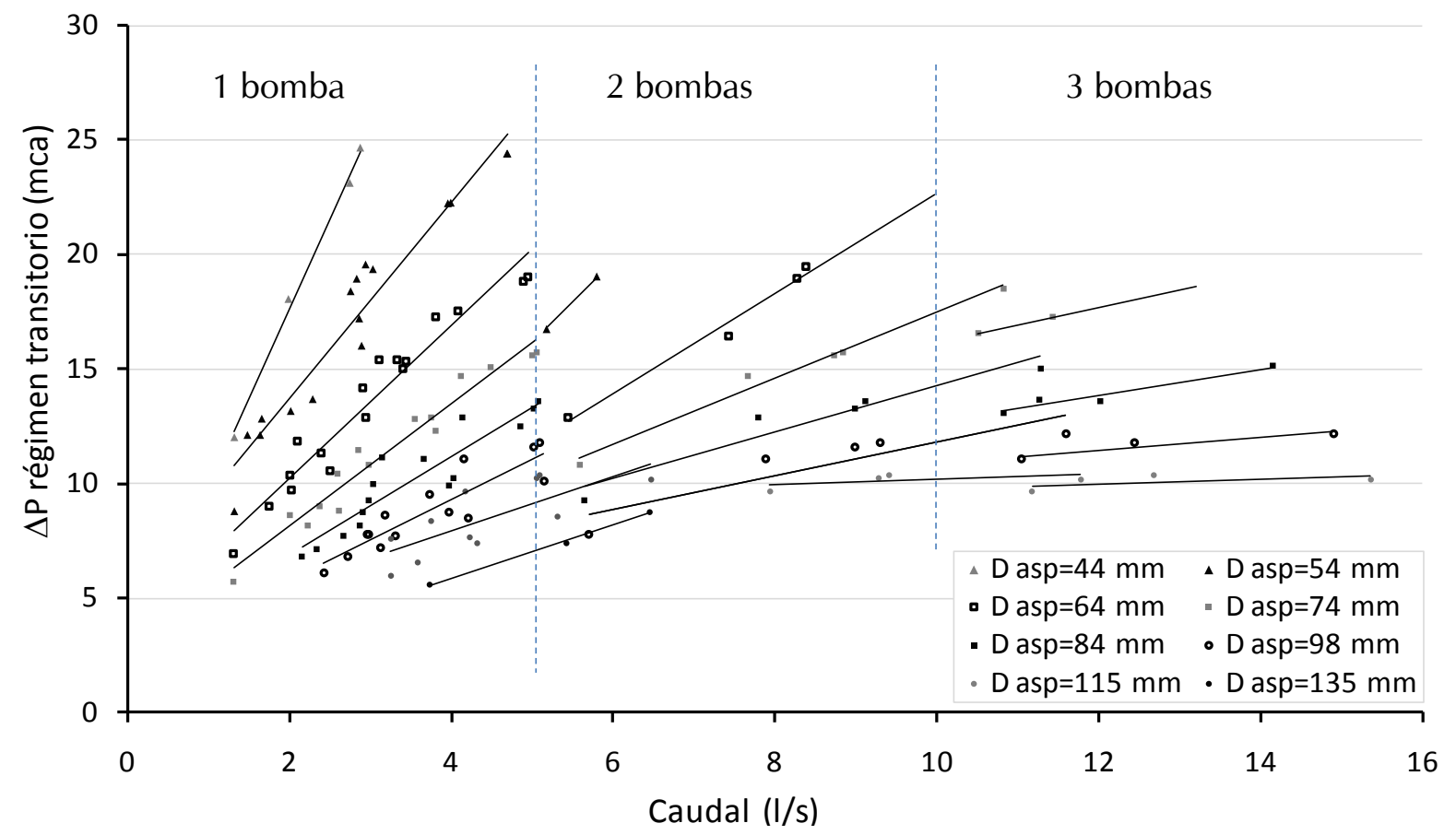

FIGURA C4-33. DEPRESIÓN EN ASPIRACIÓN EN FUNCIÓN DEL CAUDAL DE LA BOMBA EN RÉGIMEN TRANSITORIO

La gráfica anterior tiene gran utilidad ya que permite aproximar la caída de presión que se dará en una instalación (de características similares a las del edificio de referencia) en función del diámetro de la conducción de aspiración (de valor uniforme hasta la acometida), y de las características del grupo. Ésta es representativa en la medida que ha sido obtenida a partir de la modelación de diferentes grupos de presión comercial realizando el dimensionado correspondiente como si de una instalación real se tratase. El ajuste también se observa en la acometida (Figura C4-34). 


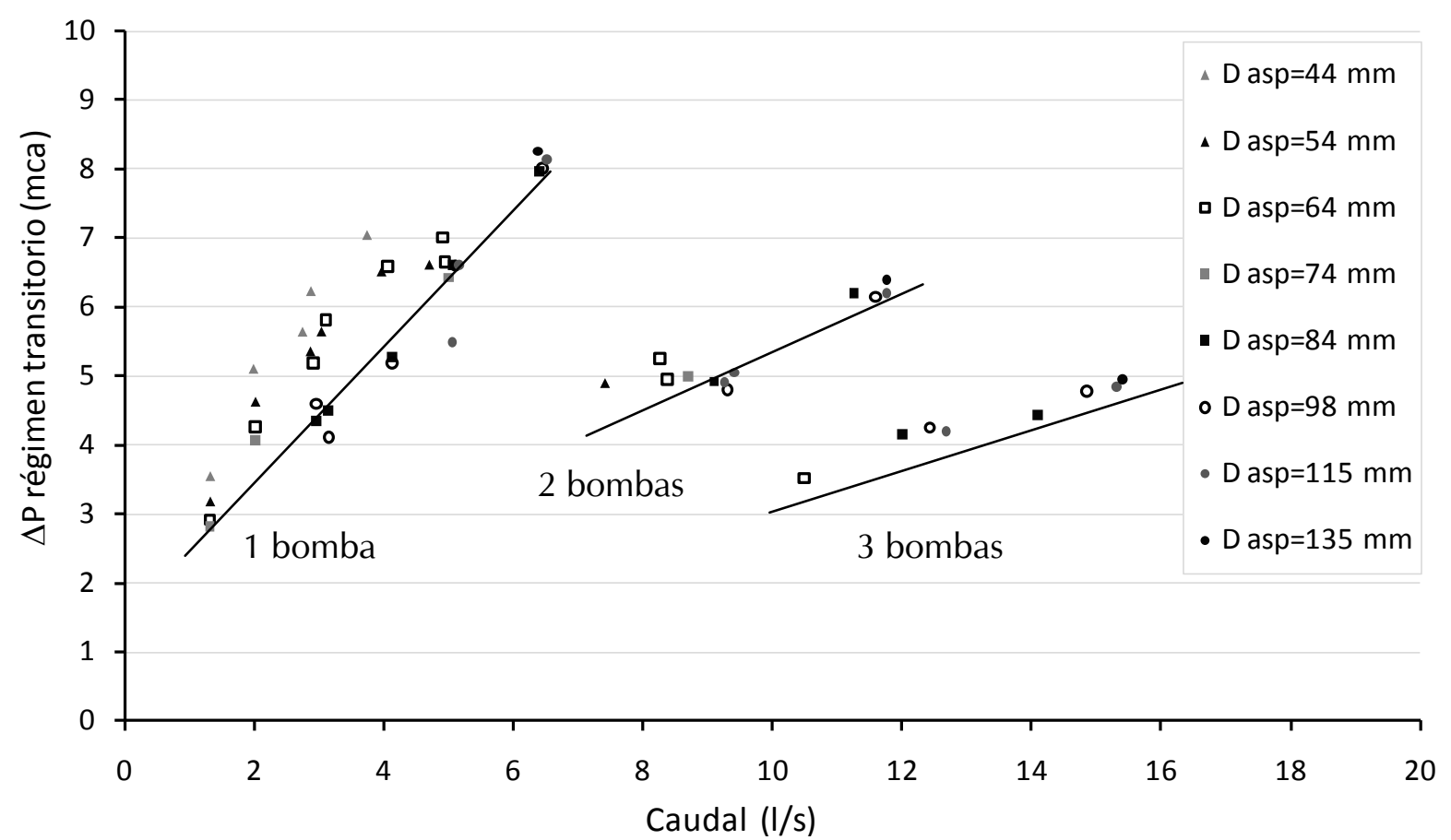

FIGURA C4-34. DEPRESIÓN EN FUNCIÓN DEL CAUDAL DE LA BOMBA EN RÉGIMEN TRANSITORIO EN ACOMETIDA

En la Figura C4-35 se representa la relación entre el cambio de velocidad que se da en la tubería de aspiración al arrancar una bomba, y la caída de presión máxima originada en el transitorio. Respecto a la primera variable se ha considerado la variación instantánea desde una velocidad inicial a una velocidad final (por ejemplo, para el funcionamiento de una única bomba la velocidad inicial es nula, y la final es la correspondiente al caudal estacionario del grupo, pero en el caso del arranque de una segunda bomba la velocidad inicial no es nula). Esta gráfica muestra una relación prácticamente lineal entre dichas variables.

Es importante tener en consideración esta gráfica ya que para un caudal dado puede aproximar la caída de presión estimada en aspiración, sin que exista una dispersión elevada para los diferentes diámetros. Por ejemplo, en el caso de la instalación monitorizada el caudal de diseño del grupo próximo a 2,7 l/s, que para el diámetro instalado resulta una velocidad cercana a $1,27 \mathrm{~m} / \mathrm{s}$, y a partir de la expresión anterior se estima una caída de presión de 17,2 mca, valor próximo al valor obtenido durante la monitorización del edificio (17 mca es el valor extremo registrado). La expresión obtenida, y especialmente su pendiente, sólo tiene cabida para la instalación de referencia (bajo diferentes diámetros y caudales), pero otros parámetros como el tiempo de arranque o la longitud del tramo pueden originar una lógica variación. 


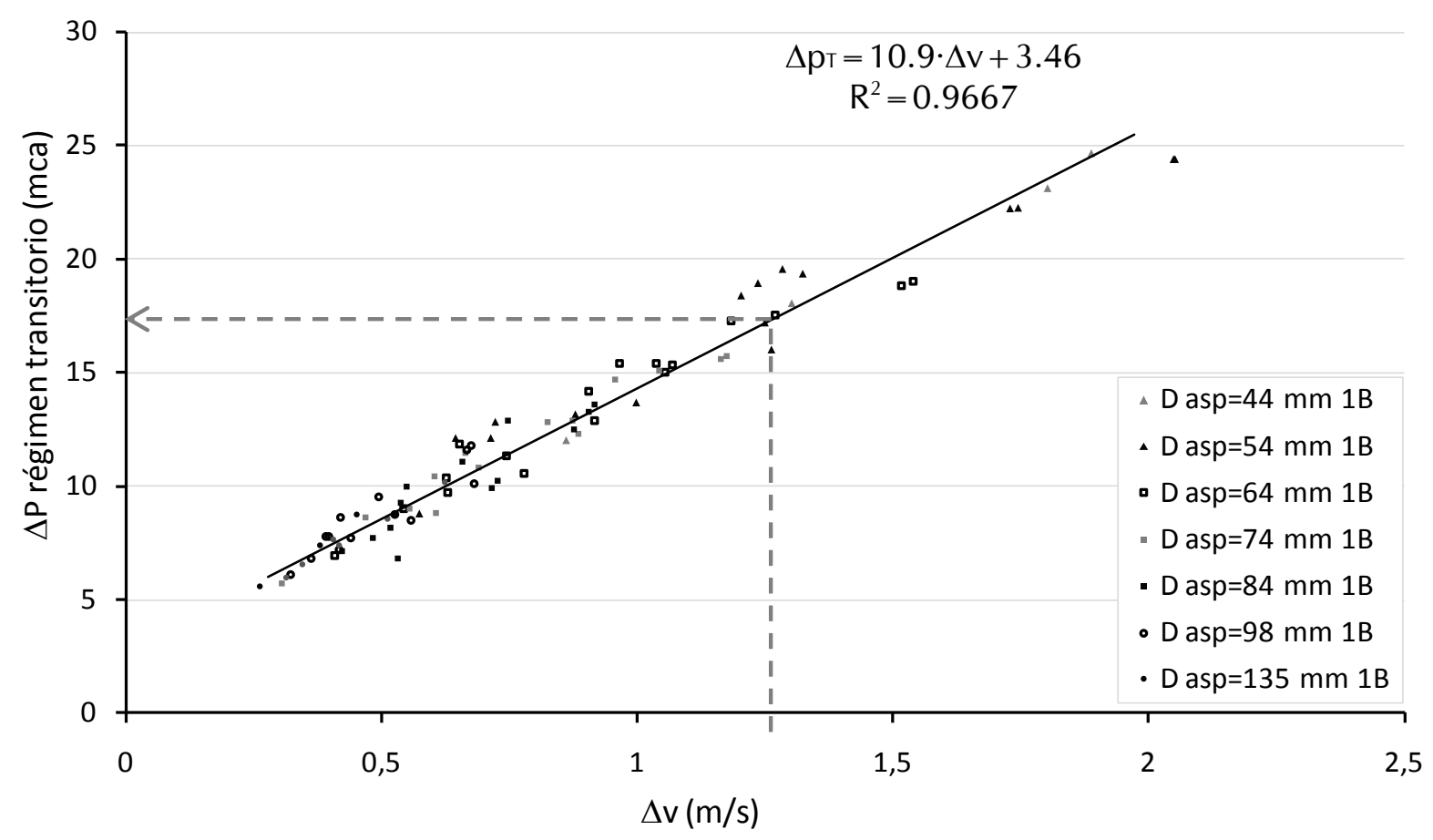

FIGURA C4-35. RELACIÓN ENTRE LA VARIACIÓN DE VELOCIDAD EN LA ASPIRACIÓN Y LA DEPRESIÓN

Por otro lado, para garantizar una variación máxima de 10 mca (valor orientativo propuesto en el presente estudio), la velocidad máxima permitida está en torno a los 0,6 $\mathrm{m} / \mathrm{s}$, valor ligeramente superior al propuesto por la norma DIN 1988 para permitir la conexión en directo sin protección adicional para el diámetro de red considerado.

De las simulaciones también se ha estudiado las respuestas en régimen permanente una vez que el funcionamiento del grupo de presión está estabilizado. Para ello, de cada uno de los escenarios se ha obtenido el valor de la caída de presión asociada al régimen permanente, tanto para las situaciones del funcionamiento de una única bomba o de varias bombas asociadas en paralelo, el resultado se muestra en la Figura C4-36. Como puede observarse, en este caso todos los puntos asociados al mismo diámetro se encuentra dentro de la misma curva.

El resultado obtenido mediante esta gráfica también tiene su importancia, ya que de forma similar a la figura anterior, es posible estimar la caída de presión máxima esperada en una instalación en función de diámetro del tramo y del caudal de la bomba (caída de presión en la aspiración de la bomba, pero que se reduce sensiblemente en la acometida del edificio). Por otro lado, la gráfica aporta indicativos para el dimensionado de este tramo de la instalación, ya que fijado un caudal de bombeo (parámetro obtenido en el dimensionado de la instalación), es posible estimar la depresión que se originaría por la conexión en directo de una instalación como la modelada. 


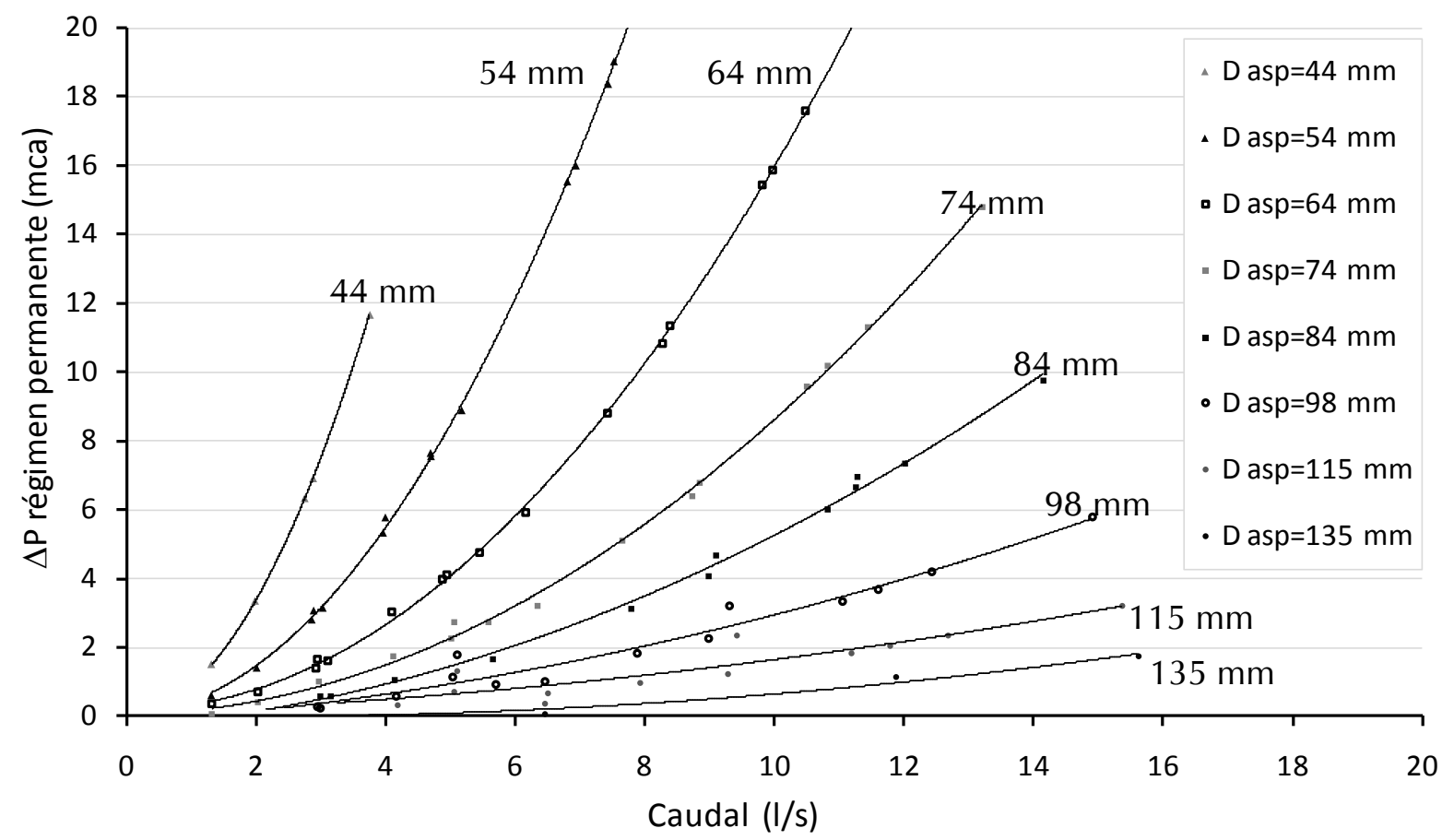

FIGURA C4-36. DEPRESIÓN EN FUNCIÓN DEL CAUDAL DE LA BOMBA EN RÉGIMEN PERMANENTE

Finalmente y relacionado con el caudal del grupo, hay que tener presente que en las instalaciones que disponen de grupo de presión dimensionado para la conexión indirecta (a partir de depósito atmosférico en aspiración), su utilización en aspiración directa no es inmediata, ya que la altura que aportarán bajo conexión directa toma valores inferiores, y los caudales trasegados durante el arranque resultan más elevados.

\subsubsection{Altura de la bomba y tipo de curva}

De las bombas analizadas en la Figura C4-27 tres de ellas mantienen un punto de funcionamiento próximo (B3, B4 y B5; Q 3 l/s, y $\mathrm{H} \sim 22 \mathrm{mca}$ ), y por tanto permiten obtener una aproximación sobre la influencia de la forma de la curva en la depresión originada. Tal como se puede observar se genera una caída de presión mayor en la bomba B5 frente a la generada en la bomba B3. En esta misma figura se puede observa además que la bomba B3 presenta unas solicitaciones ligeramente inferiores a la línea de ajuste representada.

Por lo general, curvas más planas provocan caídas de presión más significativas frente a las bombas que tienen un carácter más vertical, ya que con una curva más vertical se inicia antes el trasiego de caudal. En la Figura C4-37 se comparan dos bombas con diferente curva en una misma instalación (curva resistente $H_{r}$ fija).

Para la curva más vertical $\left(H_{B 1}\right)$ se alcanza antes la presión necesaria para abrir la válvula antirretorno $\left(N_{B 1}=0,65\right)$, mientras que para la bomba con curva más plana $\left(H_{B 2}\right)$ este mismo punto de funcionamiento tiene lugar a una velocidad de giro superior 
$\left(N_{B 2}=0,8\right)$. En este segundo caso ha transcurrido un mayor tiempo desde el inicio de arranque de la bomba, y por tanto para un tiempo fijo de arranque (bajo una evolución lineal de $N$ considerada por Allievi), se origina una variación más rápida del caudal hasta que se estabiliza el punto de funcionamiento en el arranque. Por tanto, para un mismo punto de funcionamiento, curvas más verticales originan menores caídas de presión.

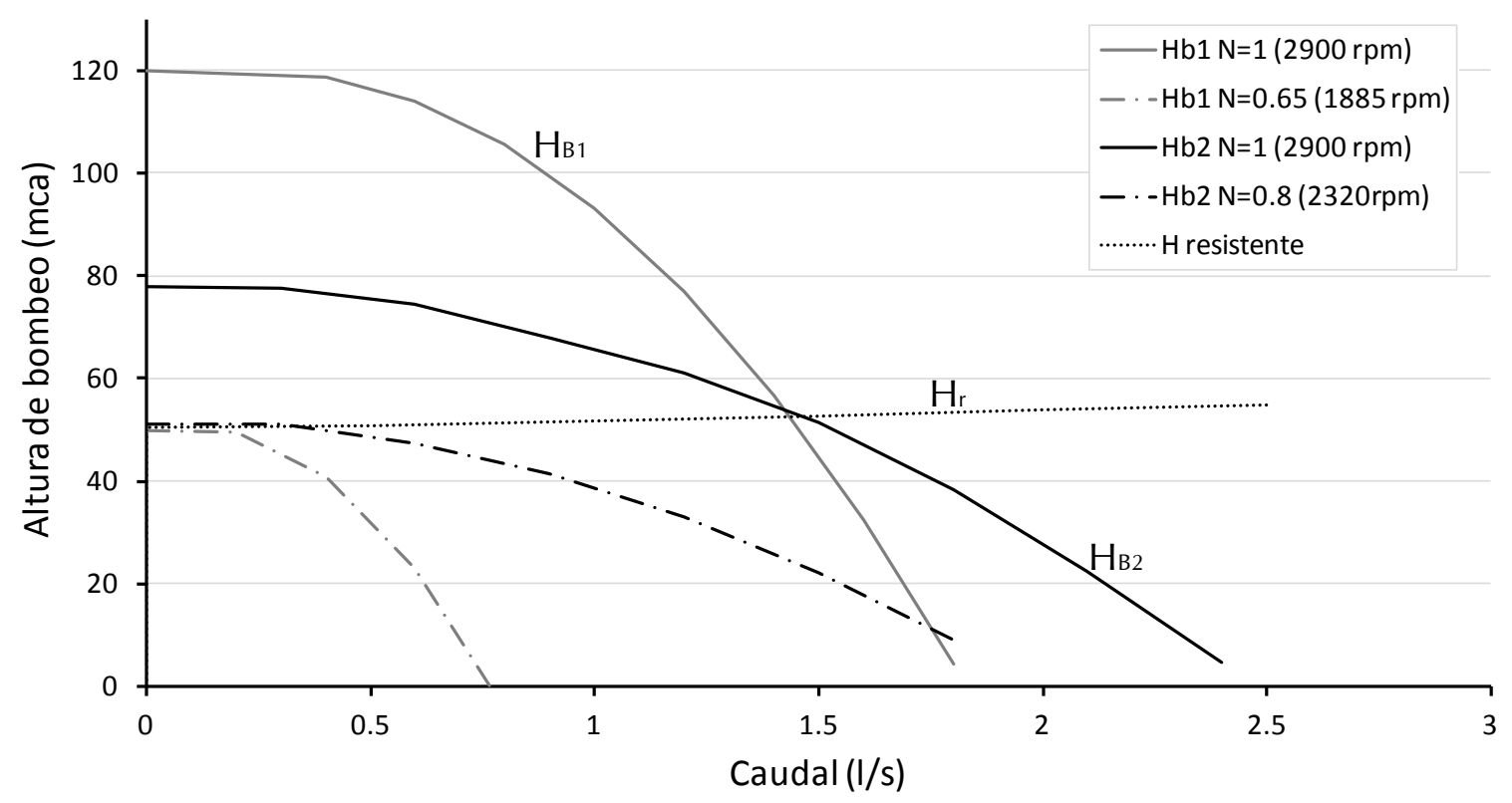

FIGURA C4-37. DIFERENCIA DE COMPORTAMIENTO ENTRE BOMBAS CON DIFERENTE TIPO DE CURVA

Regresando a la Figura C4-27 se puede comprobar que de las tres curvas la B3 tiene un carácter más vertical, por ello presenta la menor caída de presión. La bomba B5 es la más plana, por ello presenta las mayores solicitaciones, mientras que la curva B4 tiene una forma intermedia entre las curvas anteriores y por ello presenta unas solicitaciones intermedias.

\subsubsection{Características del tramo de aspiración}

Longitud del tramo de aspiración

Para la instalación de referencia se ha analizado la influencia que presenta la variación de la longitud de la tubería de aspiración (conducción comprendida desde la conexión de la acometida hasta la aspiración de la bomba), manteniendo el resto de características de la instalación fijas (Figura C4-38). Esto aproximaría el efecto de que el grupo de presión esté más o menos próximo a la RGD.

En las proximidades de la aspiración de la bomba un aumento de la longitud del tramo favorece el aumento de la magnitud de la depresión de forma considerable. Esto se debe a que al aumentar la distancia entre la aspiración de la bomba y la conexión de 
la acometida se reduce la capacidad de atenuación de la perturbación, ya que aumenta el tiempo que tardan las sucesivas ondas de sobrepresión en alcanzar el frente de avance de la perturbación. Una vez que este frente es alcanzado, la sobrepresión derivada aumentará sensiblemente la altura piezométrica en la aspiración de la bomba, y con ella, se producirá una estabilización de su funcionamiento. En tal caso, para longitudes más cortas el tiempo de viaje de la onda se reduce, y se consigue estabilizar el comportamiento de la bomba con mayor premura. Ante esta situación la bomba es capaz de generar mayores variaciones de velocidad en la tubería de aspiración (se estabiliza antes el punto de funcionamiento de la bomba).

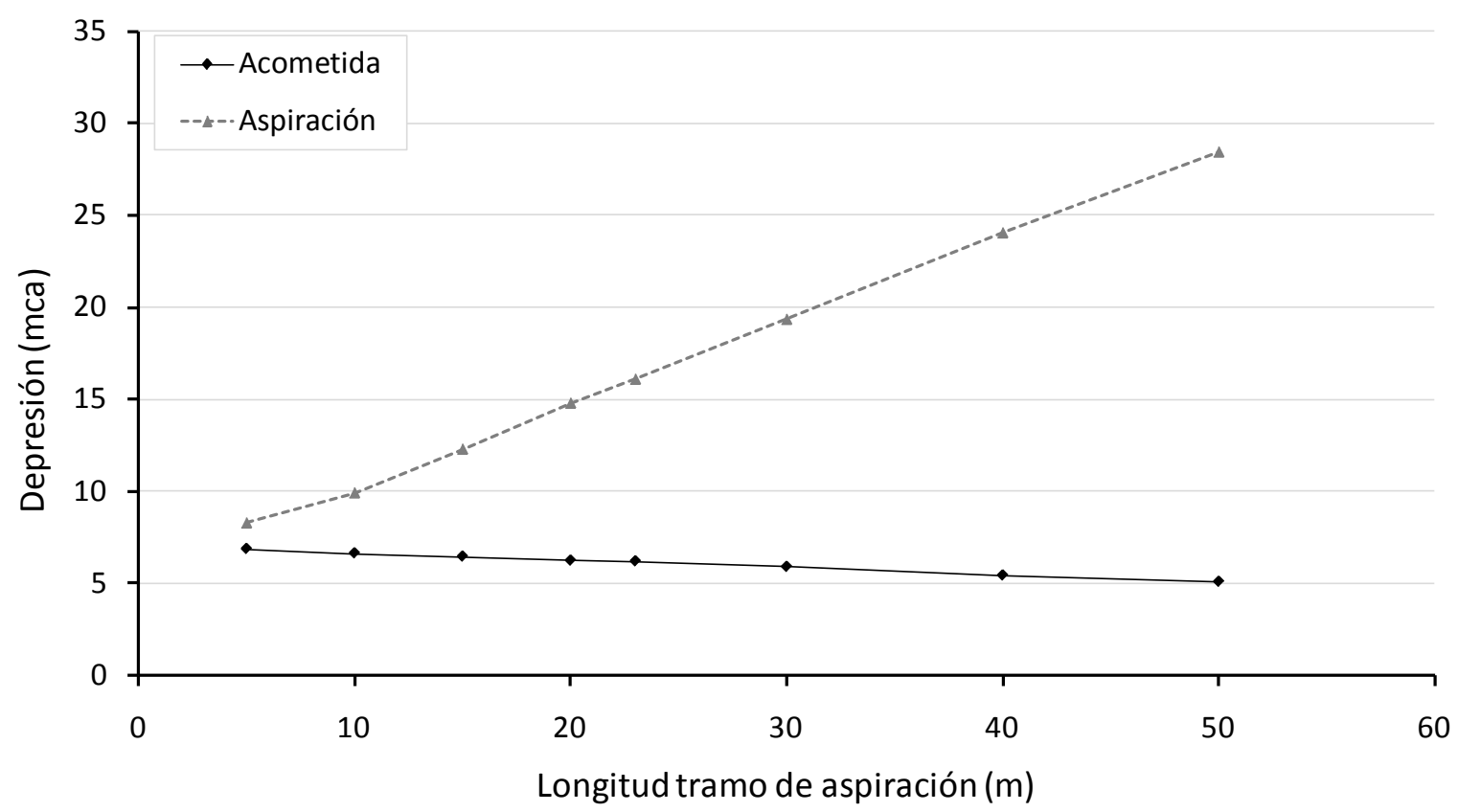

FIGURA C4-38. DEPRESIÓN EN FUNCIÓN DE LA LONGITUD DEL TRAMO DE ASPIRACIÓN

Este efecto se aprecia en la Figura C4-39 (izda.), en el que se compara la caída de presión para dos longitudes analizadas. Complementariamente, en la figura de la derecha se compara la velocidad del agua en la tubería de aspiración durante el arranque del grupo para ambos escenarios. Para un mismo instante de tiempo después del arranque la velocidad del flujo para una longitud de $40 \mathrm{~m}$ es de $1,2 \mathrm{~m} / \mathrm{s}$, mientras que para la longitud de tramo $10 \mathrm{~m}$ la velocidad es de $0,7 \mathrm{~m} / \mathrm{s}$, soportando por tanto una mayor aceleración el flujo para la tubería de mayor tamaño. 

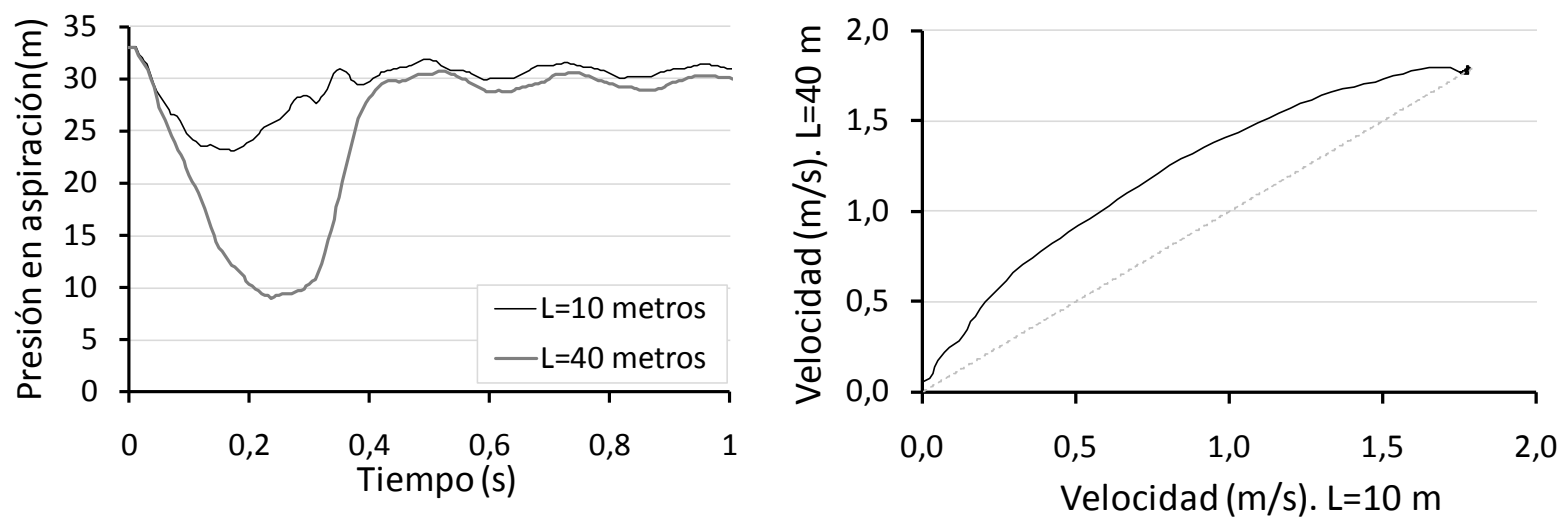

FIGURA C4-39. (IZDA.) VARIACIÓN DE LA PRESIÓN EN LA ASPIRACIÓN DE LA BOMBA. (DCHA.) COMPARACIÓN DE LA VELOCIDAD EN LA CONDUCCIÓN DE ACOMETIDA

Por otro lado y volviendo a la Figura C4-38, el alejamiento del grupo de presión de la RGD favorece una menor caída de presión registrada en la acometida del edificio. Para longitudes menores el avance del frente de perturbación alcanza rápidamente el nudo de acometida, mientras que mayores longitudes permiten atenuar en mayor medida este frente (por las sucesivas reflexiones de las ondas en el entronque con la RGD), manteniendo en el nudo en cuestión una altura piezométrica próxima a la que se da en dicho entronque.

Finalmente, hay que tener además presente que mayores tramos originan una atenuación de la presión en acometida derivada de las pérdidas de carga en el tramo, ya que a medida que la longitud del mismo aumento también lo hacen las pérdidas de carga y con ellas se origina una mayor atenuación de la onda de perturbación. Este fenómeno se manifiesta principalmente en instantes posteriores a la depresión máxima.

Pérdidas menores en el tramo de aspiración

Otro de los parámetros a considerar relacionado con la característica resistente de la instalación interior, hace referencia a las pérdidas de carga menores debidas a los diferentes accesorios y elementos perturbadores instalados en el tramo de aspiración (llaves, filtro, contador general, válvula antirretorno, etc.). Estas pérdidas se han caracterizado con el coeficiente de pérdidas adimensional $k$ tal como muestra la siguiente expresión:

$$
h_{f}=k \cdot \frac{v^{2}}{2 \cdot g}
$$




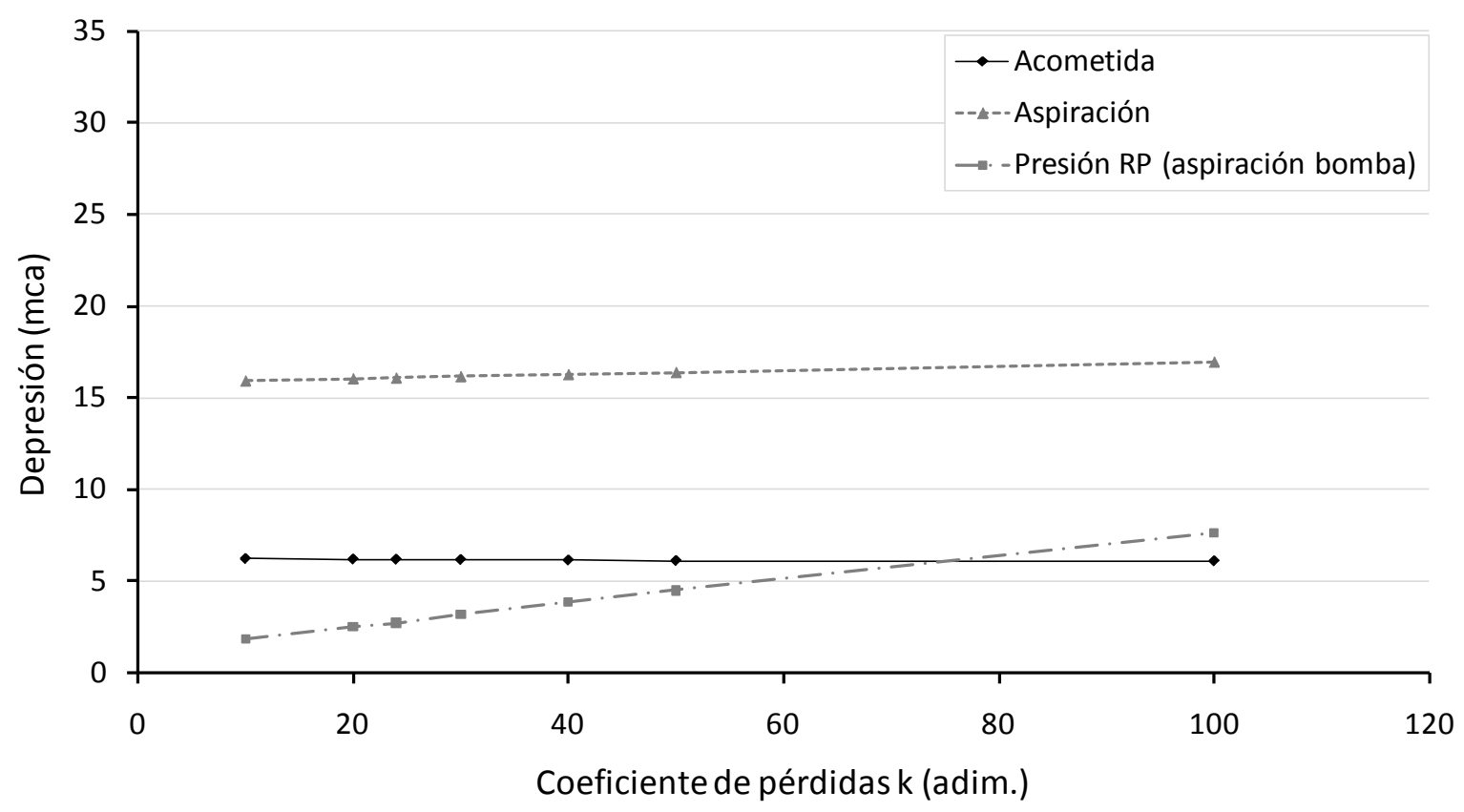

FIGURA C4-40. DEPRESIÓN EN FUNCIÓN DE LAS PÉRDIDAS MENORES EN EL TRAMO

Un aumento significativo (por ejemplo por la obturación del filtro) altera significativamente la caída de presión en la aspiración de la bomba cuando ésta estabilice su funcionamiento, situación que ocurre con posterioridad a la fase de arranque (régimen permanente). Esta situación puede originar presiones excesivamente bajas (situación especialmente desfavorable cuando la red mantenga presiones de entrega reducidas).

Material de las tuberías del tramo de aspiración

Aunque generalmente existe una coexistencia de diferentes materiales en la instalación interior del edificio para el tramo considerado, las simulaciones muestran que la celeridad de la onda (parámetro directamente relacionado al material de la tubería), no presenta una influencia significativa en la depresión, debido principalmente al

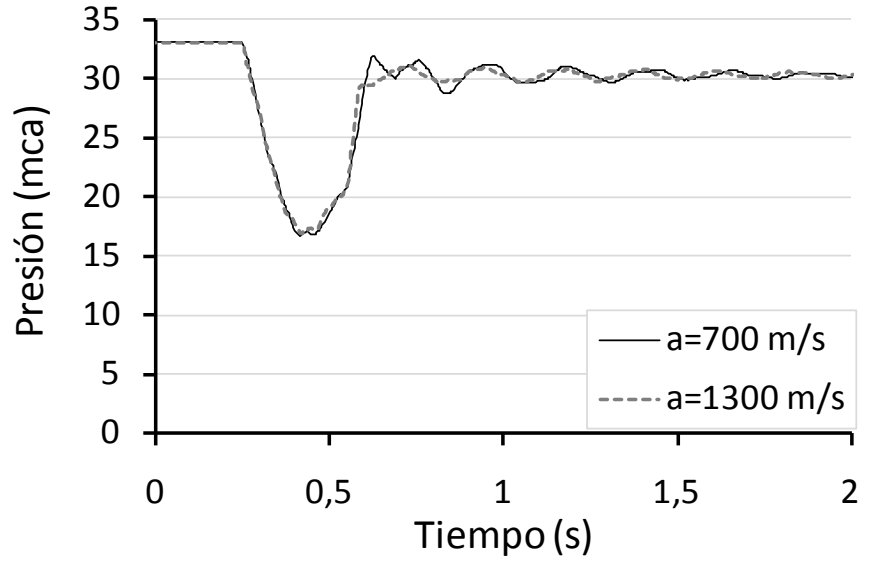

FIGURA C4-41. INFLUENCA DE LA CELERIDAD SOBRE LA PRESIÓN reducido tamaño de los tramos. 


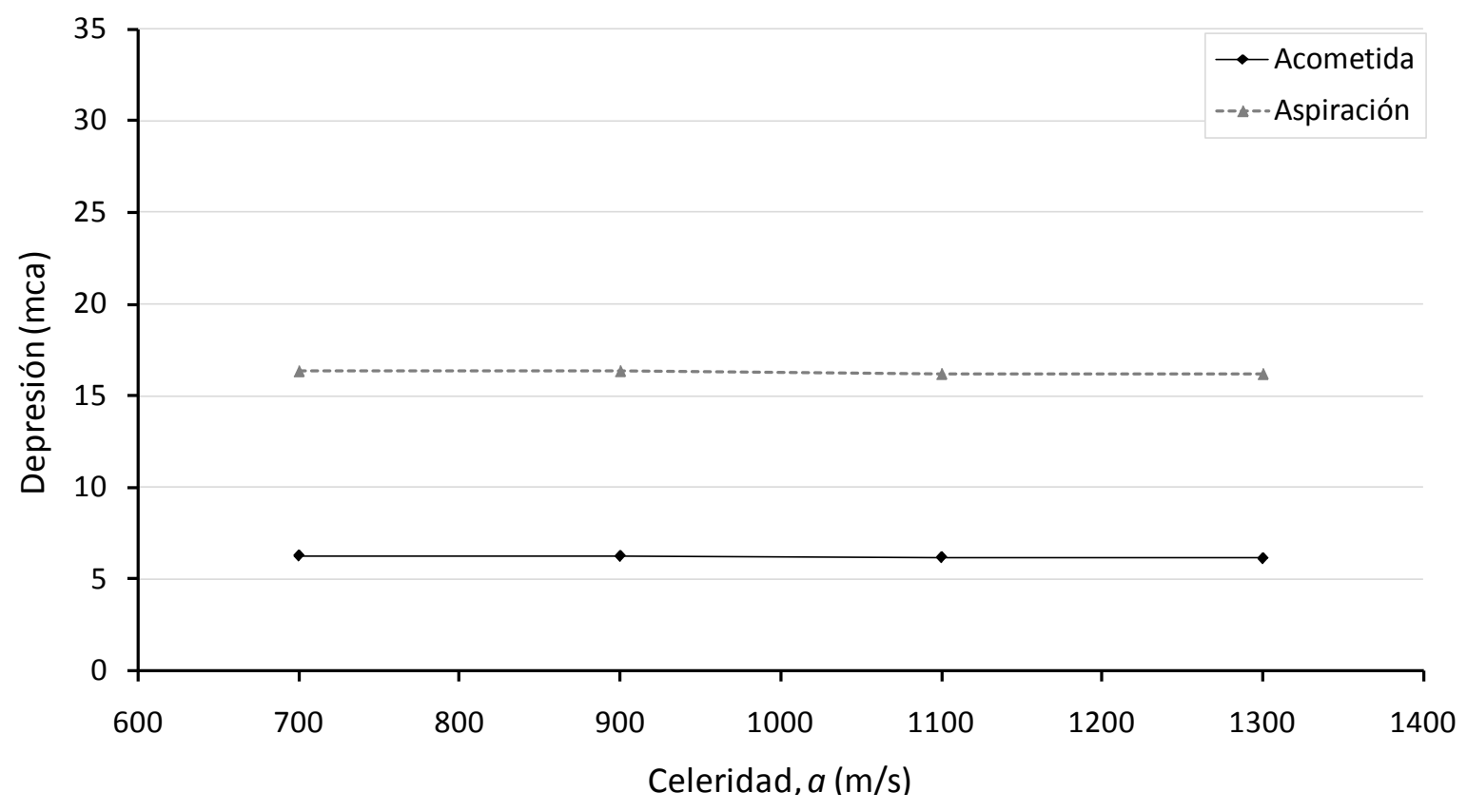

FIGURA C4-42. DEPRESIÓN EN FUNCIÓN DE LA CELERIDAD EN EL TRAMO DE ASPIRACIÓN

\subsubsection{Instalación de impulsión}

Las condiciones que se dan aguas abajo de la bomba también influyen en la magnitud de la caída de presión del transitorio. En el estudio se ha cambiado la presión de arranque de la bomba para la instalación de referencia (efecto similar al cambio de la presión de tarado del presostato que controla el arranque). Este análisis es equivalente a considerar una distribución de alturas en el edificio que precisan una mayor o menor altura de la bomba para garantizar la presión mínima de suministro.

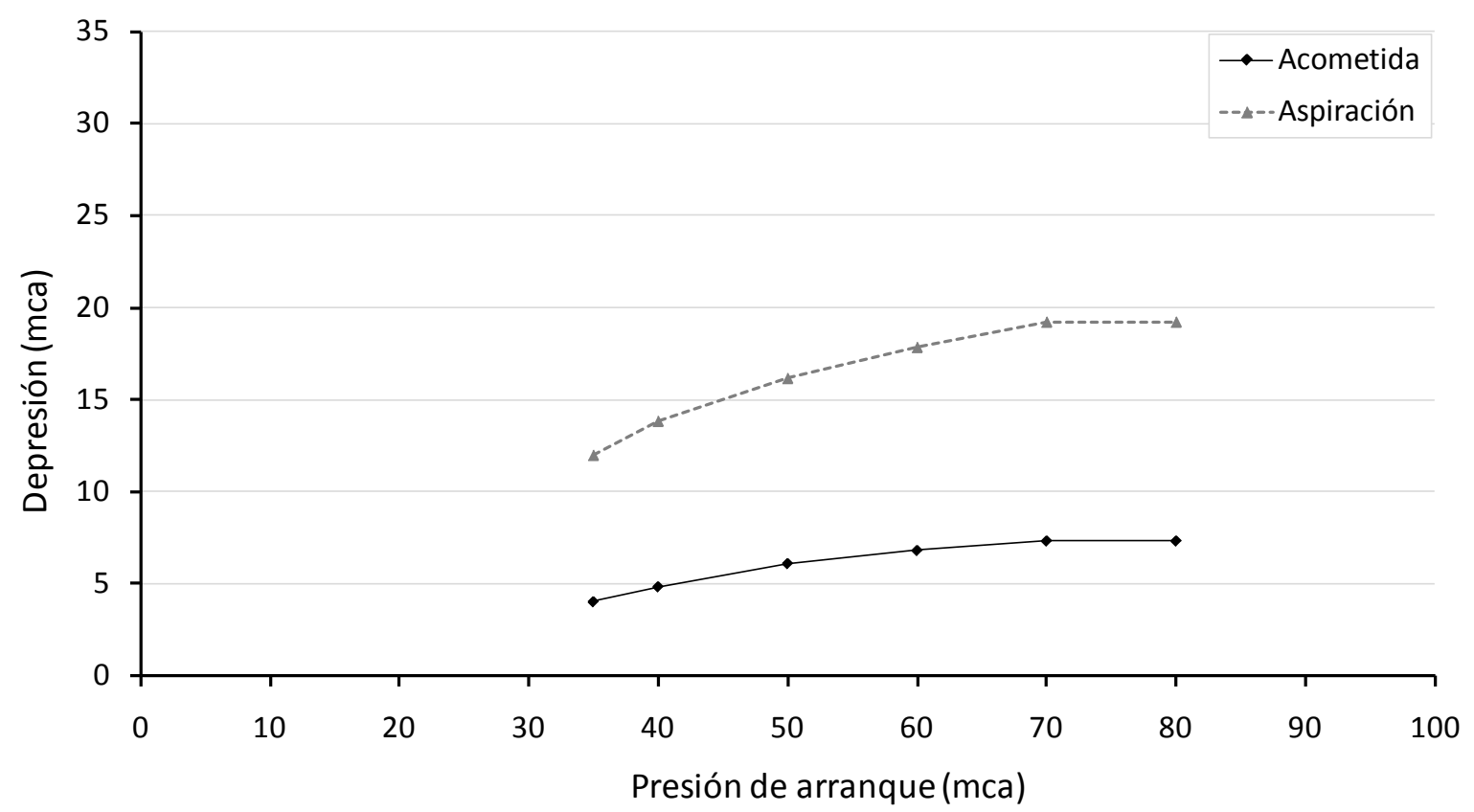

FIGURA C4-43. DEPRESIÓN EN FUNCIÓN DE LA PRESIÓN DE ARRANQUE DEL GRUPO 
Como puede observarse, a medida que aumenta la contrapresión a la salida de la bomba aumenta la caída de presión en los puntos de control. Este fenómeno está relacionado principalmente con la alteración que origina la apertura de la válvula de retención situada a la salida de la bomba, ya que a medida que aumenta la presión de arranque, la bomba debe alcanzar una presión mayor a la salida de la misma para conseguir la apertura de la válvula. Para esta situación los incrementos de caudal a diferentes velocidades de giro son mayores a medida que aumenta la presión de arranque, originando mayores aceleraciones de agua que circula por la tubería en las proximidades de la bomba tal como se puede apreciar en la Figura C4-44.

Las variaciones de velocidad (para el mismo tiempo de arranque) son mayores cuando se retrasa la apertura de la válvula, si bien hay que tener presente que la respuesta del programa de simulación utilizado puede ser más exigente que las condiciones normales que se dan en la instalación real, ya que la duración del arranque no es fija (como en el modelo se programa), al mismo tiempo que aparecen las pérdidas, inercias y maniobras complejas de modelar.

Otras variables asociadas a las condiciones que se dan en la impulsión de la bomba, tales como caudal demandado por la instalación, las propiedades del calderín de impulsión o la característica resistente de la conducción de impulsión, presentan una menor influencia en la caída de presión originada durante el arranque de la bomba. En cualquier caso aquellas medidas que favorezcan cambios más bruscos en el caudal detraído por la acometida, generarán mayores variaciones de presión.

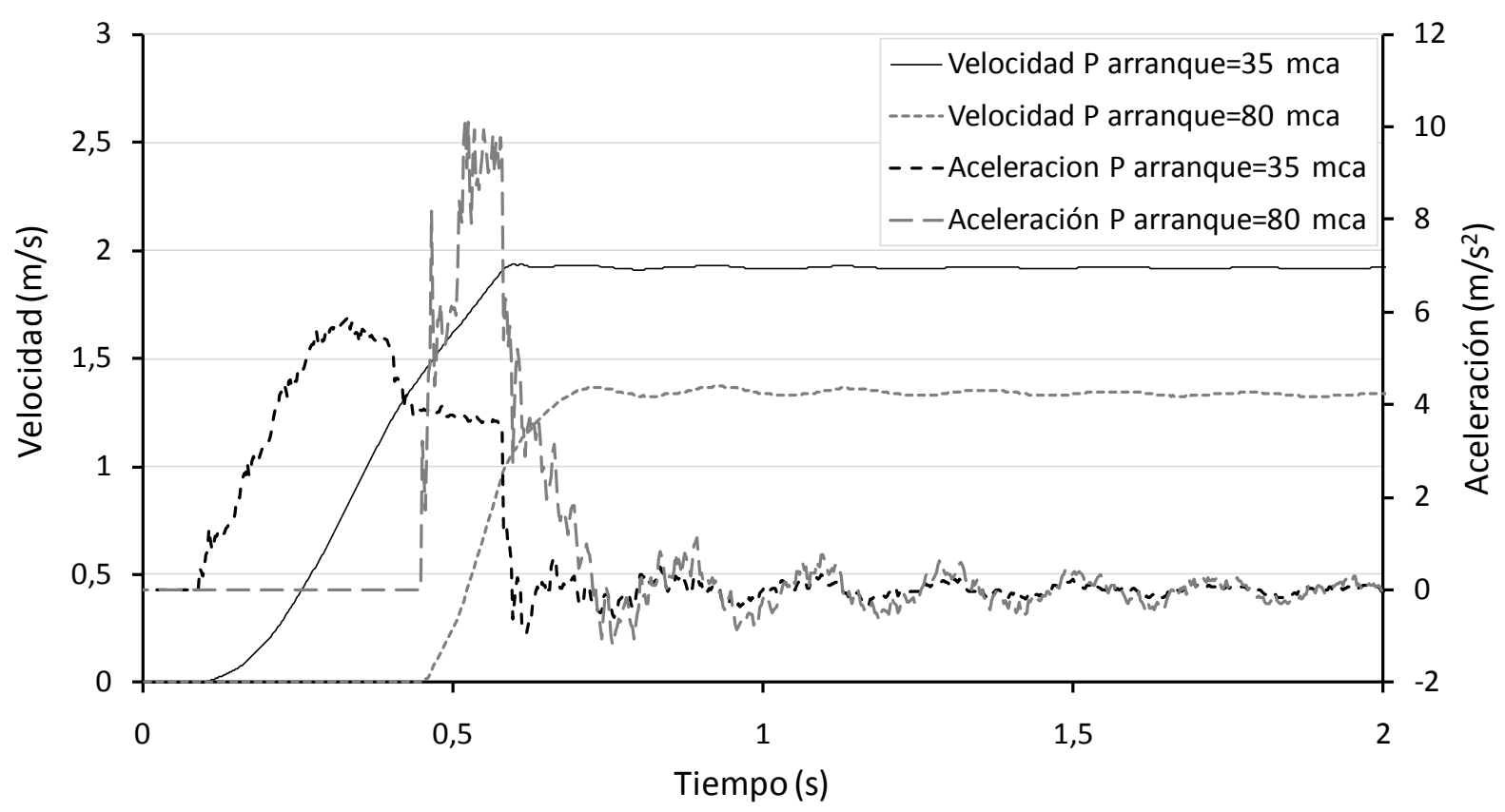

FIGURA C4-44. COMPARACIÓN DE LA VELOCIDAD Y ACELERACIÓN EN LAS PROXIMIDADES DE LA BOMBA. 


\subsubsection{Transitorio por parada del grupo}

Adicionalmente se ha modelado la parada del grupo en Allievi para comprobar los valores resultantes y su comparación con la magnitud del transitorio de arranque. Este análisis se ha realizado para la instalación de referencia sobre la que se ha alterado el caudal trasegado por el grupo de presión, a partir de la modificación del tamaño de éste (de nuevo se ha acudido a las curvas de las bombas comerciales mostradas en la Figura C4-26, y complementariamente se han incluido varias bombas con mayores caudales de bombeo). Dada la no disponibilidad de datos sobre la inercia real de las bombas (valor no aportado por el fabricante en sus catálogos comerciales), se ha acudido a la expresión propuesta por Thorley (Ec. 81).

Los resultados de sobrepresión por parada del grupo muestran valores inferiores a los correspondientes a la depresión por arranque. Esto se debe a una variación de la velocidad por la conducción de aspiración de menor magnitud en esta fase de funcionamiento de la bomba, favorecido por una parada no instantánea del flujo por la inercia de las masas móviles del conjunto moto-bomba, junto con la correspondiente al volumen de agua.

Del mismo modo aparece una tendencia lineal que relaciona la magnitud de la sobrepresión con el aumento del caudal por la conducción de aspiración. Esta tendencia a su vez mantiene una elevada similitud con la serie de depresiones tanto en acometida como en la aspiración de la bomba. También se ha comprobado que esta perturbación es menos sensible en la medida que se generan menores velocidades del agua en la conducción de aspiración (en el análisis se ha evaluado una velocidad máxima de 2,8 $\mathrm{m} / \mathrm{s}$, recomendándose limitar esta variable a valores próximos a $2 \mathrm{~m} / \mathrm{s}$ ).

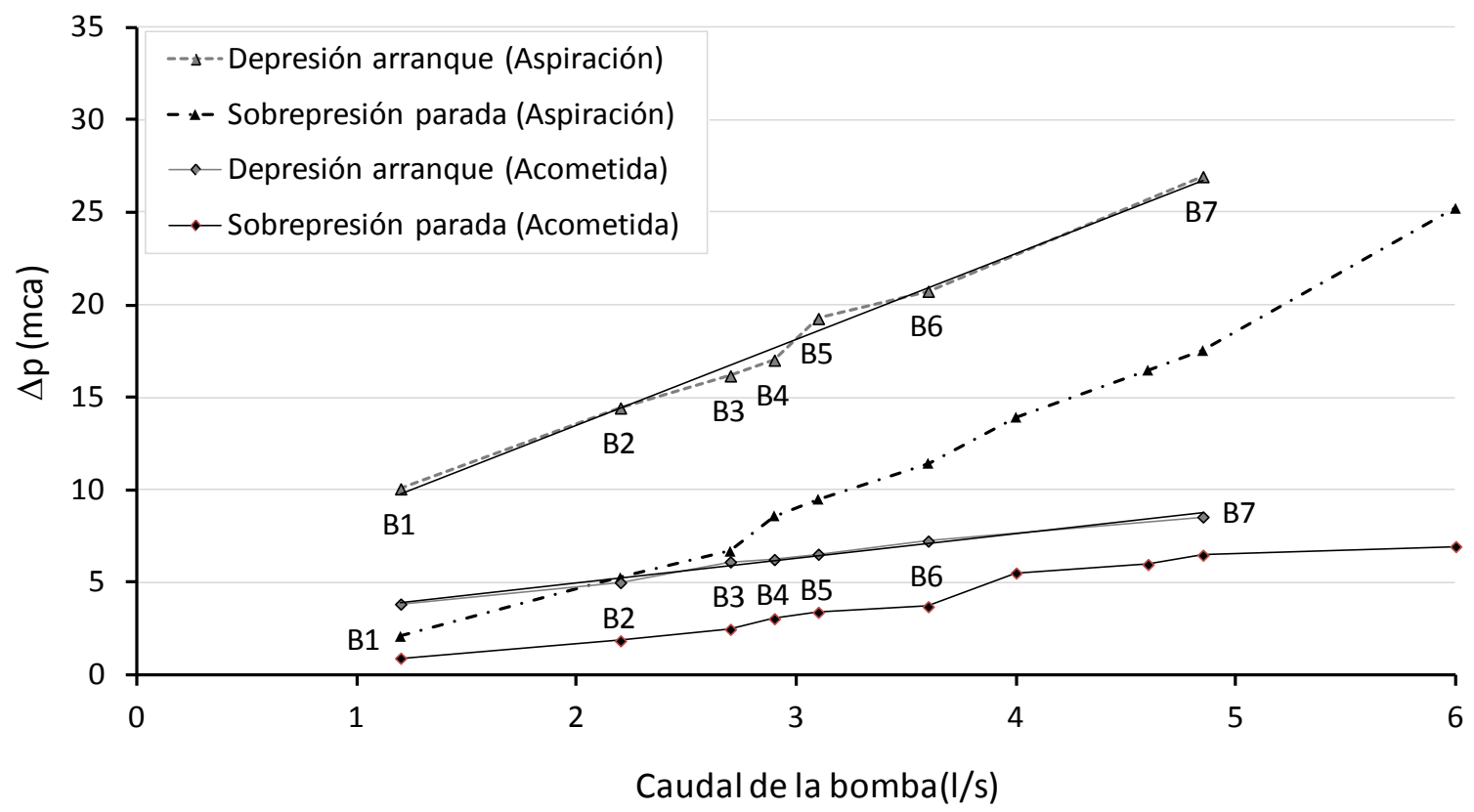

FIGURA C4-45. VARIACIÓN DE PRESIÓN POR PARADA Y ARRANQUE DE UN GRUPO (INST. REFERENCIA) 
Las magnitudes obtenidas de sobrepresión con las simulaciones son similares a las registradas en la monitorización del edificio. Para este escenario concreto la magnitud de la perturbación de parada muestra una disminución media próxima al 56\% (respecto al valor de la magnitud de la variación de presión generada en el arranque), evidenciando una mayor severidad del transitorio de arranque de la bomba. Para las simulaciones este porcentaje se reduce a medida que aumenta el caudal del grupo.

Respecto a las bombas equipadas con variador, la posibilidad de trasegar caudales menores a los nominales para la mayoría de instantes de funcionamiento favorece la aparición de menores solicitaciones en caso de parada repentina de la bomba.

Por otro lado, el funcionamiento con varias bombas en paralelo y su parada progresiva atendiendo a una regulación escalonada favorece la aparición de sobrepresiones de magnitud reducida, de forma similar a la fase de arranque. En cualquier caso es conveniente acudir a la protección de la instalación para situaciones excepcionales de parada como la originada por un fallo eléctrico de alimentación.

\subsection{CONCLUSIONeS}

La aspiración en directo puede originar variaciones de presión significativas tanto en el arranque como en la parada de la bomba. La zona más expuesta es la aspiración de ésta, pero los efectos pueden ser transmitidos a las proximidades de la acometida, siendo en este último punto menos sensible por la atenuación de la perturbación.

El valor de la magnitud del transitorio originado en la instalación está directamente relacionado con las características particulares de la red general y de la instalación interior del edificio. En la medida que estas instalaciones presenten unas propiedades más adecuadas será posible garantizar un funcionamiento correcto con conexión directa. En esta línea disponer de diámetros mayores en la red general al mismo tiempo que la presión de entrega sea suficiente favorece el origen de menores efectos transitorios. En cualquier caso no hay que perder de vista que la red debe disponer de capacidad suficiente para mantener esas condiciones de funcionamiento para el caudal de régimen extraído por el edificio.

Los parámetros que mayor dependencia presentan sobre la magnitud de la caída de presión están asociados a la instalación interior del edificio, y concretamente a las características particulares del grupo de presión. En esta línea, se destaca la influencia del tiempo de arranque del grupo, generándose mayores depresiones a medida que se reduce dicho tiempo. Mayores tiempo de arranque fundamentan la utilización de bombas equipadas con variador, en las que el funcionamiento normal generan una caída de presión de valor significativamente menor que en el caso de bombas de 
velocidad fija. Por ello en la medida de lo posible será conveniente instalar grupos de presión equipados con variador.

El caudal de diseño del grupo de presión es otro de los parámetros característicos del fenómeno, ya que un incremento de éste presenta un aumento lineal de las solicitaciones, presentando una discontinuidad en la evolución al variar el número de bombas en funcionamiento. Asociado a este parámetro, la totalización del caudal de diseño por varios grupos con regulación escalonada reduce la severidad del transitorio. Del mismo modo es importante prestar atención a las velocidades máximas que se originan en la aspiración de la bomba, tratando de limitar los valores por debajo de 2 $\mathrm{m} / \mathrm{s}$.

En cuanto a las características resistentes de la instalación, conviene tener controlada las pérdidas menores en los diferentes elementos de la instalación interior por la reducción que supone en régimen permanente sobre la presión en la aspiración de la bomba. En cuanto a la distancia entre la acometida y la aspiración de la bomba es importante limitar el tamaño de este tramo en aras de reducir la caída de presión en régimen transitorio durante el arranque de la bomba. 
Capítulo 5

Mecanismos de protección para la reducción de los efectos transitorios por la conexión directa 


\subsection{INTRODUCCIÓN}

Conocida la influencia de las diferentes variables que definen la instalación sobre la magnitud del fenómeno transitorio generado, en el presente capítulo se presenta un mecanismo de protección para reducir su valor, tanto en el interior del edificio como en sus inmediaciones. La finalidad perseguida es la de permitir la conexión directa de grupos de presión (por las ventajas que aporta este tipo de esquema en algunas instalaciones), al mismo tiempo que se garantiza un funcionamiento fiable.

En primera instancia es importante limitar las condiciones mínimas que deben dar en la acometida del edificio para que se pueda adoptar un esquema con conexión directa. La existencia de una presión mínima y de forma continuada durante el funcionamiento del grupo es una de las condiciones que se deben exigir para el normal funcionamiento de la instalación. Adicionalmente y en aras de proteger la instalación interior del edificio, se deben definir unas afecciones mínimas en la propia instalación interior en aquellos instantes en los que funciona el grupo.

Tal como se ha podido comprobar, bajo algunos escenarios es posible garantizar un funcionamiento correcto en aspiración directa, y bajo otros las solicitaciones originadas en la instalación son importantes. En ambos casos es recomendable incorporar medidas de protección para reducir la severidad operativa. Entre estas medidas la reducción de la variación temporal de caudal originada por el grupo es la más efectiva, y la utilización de variador ha mostrado una indudable bondad.

Adicionalmente la instalación de un depósito presurizado en aspiración favorece la reducción de las solicitaciones y puede ser un complemento perfecto para los grupos, incluso para aquéllos sin variador. En esta línea se aporta un dimensionado de esta protección, precedido por un análisis de sensibilidad de la influencia de las diferentes variables que intervienen en el esquema.

No todas las instalaciones podrán protegerse con los mecanismos anteriores, y por ello éstas deberán mantener una conexión indirecta. En el Anexo 5 se analizan los efectos transitorios asociados a esta conexión, y se presenta una serie de recomendaciones para reducir las afecciones en instalaciones con depósito atmosférico. 


\subsection{SOLICITACIONES MÁXIMAS RECOMENDADAS}

Para que se pueda proceder a la conexión en directo de una instalación interior se debe disponer de unas condiciones mínimas de operación en el punto de conexión de la RGD, al mismo tiempo que se deben limitar las solicitaciones máximas generadas en el edificio. En esta línea, existen pocos estudios técnicos de referencia, y quizá el documento precursor sea la normativa alemana DIN 1988-5. Este documento aboga por los esquemas con conexión directa, al mismo tiempo limita las variaciones de presión originadas durante el arranque y parada de un grupo de bombeo.

En el presente estudio se ha tomado como referencia las recomendaciones fijadas en la norma anterior, y se ha completado con algunos valores para establecer una mayor definición de las solicitaciones máximas recomendadas y de los requerimientos mínimos. En cualquier caso, resultaría conveniente centrar esfuerzos en futuros estudios para delimitar bajo criterios objetivos las máximas afecciones permitidas en el tramo, aunando criterios como la resistencia de materiales, principalmente en lo que respecta a la fatiga de componentes, con seguridad y ahorro energético.

La siguiente figura muestra las solicitaciones máximas propuestas para garantizar una protección suficiente en la instalación interior y las proximidades de ésta. Estas solicitaciones pueden aplicarse a diferentes esquemas de conexión, y aplicaría del mismo modo a aquellas instalaciones que cuentan con válvulas de control de llenado (válvulas de boya), o cualquier otro dispositivo que origine variaciones de caudal significativas. El dimensionado de la protección propuesta en este capítulo atiende a estas condiciones de operación, del mismo modo pueden servir como referencia para el análisis de protecciones de otras instalaciones con características diferentes a las aquí consideradas.

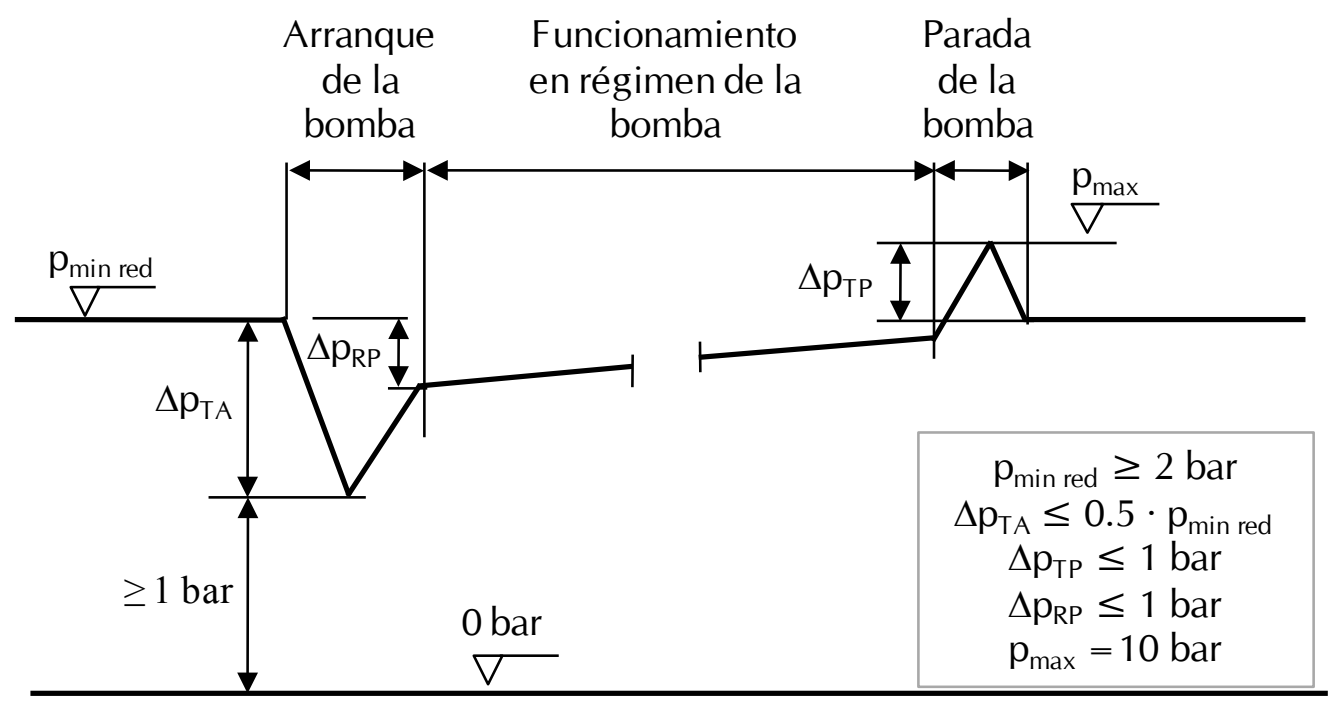

FIGURA C5-1. SOLICITACIONES MÁXIMAS PROPUESTAS PARA LA CONEXIÓN EN DIRECTO DE UN GRUPO 


\subsubsection{Presión mínima en red, pmin red}

Para permitir la conexión en directo de grupos de presión, se recomienda disponer de una presión mínima garantizada en la acometida del edificio en condiciones normales de suministro de 2 bar (en condiciones estáticas de la instalación interior), debiéndose disponer como es lógico de un suministro continuo con estas condiciones de funcionamiento. El valor establecido no parte de ningún documento técnico que establezca antecedentes, ni la mencionada norma fija ningún valor al respecto. Según el estudio realizado se considera aceptable una presión mínima en red del valor propuesto siempre que se tenga en cuenta el resto de limitaciones.

$$
p_{\text {min red(estática) }} \geq 2 b a r
$$

Junto con la presión mínima en red debe limitarse la variación de presión que se experimenta en el punto de entrega en condiciones dinámicas (bomba en funcionamiento). Esta fluctuación de presión puede originar la operación de las bombas en zonas con bajo rendimiento, o incluso imposibilitar su funcionamiento.

\subsubsection{Caída máxima asociada al transitorio de arranque o equivalente, $\Delta \mathrm{p}_{\mathrm{TA}}$}

Para condiciones normales de suministro del grupo de presión, o para el caudal detraído a través de una válvula de control de llenado, la normativa anterior establece una caída máxima de presión asociada al transitorio de arranque de la bomba con valor igual a la mitad de la presión en acometida.

$$
\Delta p_{T A}=\frac{p_{\text {min red }}}{2}
$$

Derivado del valor anterior, se recomienda limitar el valor de presión mínima registrada en el interior de la instalación a 1 bar.

$$
p_{\text {min red(dinámica) }}=1 \text { bar }
$$

Adicionalmente la instalación interior debe contar con elementos de protección que impidan el funcionamiento en seco de las bombas, o en condiciones de presión reducida. Para este propósito se puede acudir a la instalación de un presostato de mínima, un transductor de presión, o dispositivos similares. La entrada en funcionamiento de estos dispositivos protege el funcionamiento del grupo de presión y el resto de instalación, impidiendo la generación de presiones reducidas, e incluso depresiones importantes que favorecieran la contaminación del agua por intrusión patógena, la aparición del fenómeno de cavitación en el grupo, o el propio colapso de algún elemento de la instalación. 


\subsubsection{Caída de presión máxima en régimen permanente, $\Delta \mathrm{p}_{\mathrm{RP}}$}

La norma DIN y el resto de normativa de referencia en el ámbito de las instalaciones interiores (CTE y normas UNE), no establecen ningún valor asociado a la caída de presión máxima durante el funcionamiento del grupo en régimen permanente. Si atendemos a la presión mínima que se puede establecer durante el transitorio de arranque de la bomba, parece lógico mantener este mismo valor ya que bajo estas condiciones de funcionamiento no se pone en riesgo la instalación. En cualquier caso, para la mejora del rendimiento de la instalación es recomendable mantener unas pérdidas mínimas en régimen permanente, asociadas al mismo tiempo a velocidades de diseño reducidas (inferiores a $2 \mathrm{~m} / \mathrm{s}$ ), de forma que se acuda a un diámetro suficiente para mantener unas condiciones de funcionamiento razonables. En esta línea, se recomienda no generar una caída de presión en régimen permanente superior a 1 bar.

$$
\Delta p_{R P} \leq 1 b a r
$$

\subsubsection{Sobrepresión máxima asociada al transitorio de paro o equivalente}

La norma DIN establece una sobrepresión máxima de 1 bar sobre la presión de entrega en la acometida. La limitación de esta variación de presión favorece la reducción de la fatiga de los diferentes componentes instalados en la aspiración del grupo.

$$
\Delta p_{T P} \leq 1 b a r
$$

\subsubsection{Presión máxima asociada al transitorio de paro o equivalente}

Es conveniente establecer una presión máxima en la instalación asociada al funcionamiento del grupo (o por el cierre brusco de una válvula). Por ello se considera razonable fijar una presión máxima asociada a la presión de trabajo de los componentes. Por lo general, en instalaciones interiores el diseño de elementos atiende a una presión máxima de trabajo de 10 bar, por tanto no se deberá superar este valor.

$$
p_{\text {max }}=10 \text { bar }
$$

En aquellas instalaciones cuyos componentes estén diseñados para trabajar a una presión superior a la anterior, podrá superarse la presión máxima fijada anteriormente, atendiendo en todo caso a la presión nominal de estos componentes. Por otro lado es conveniente instalar válvulas limitadoras en aquellos puntos en los que se prevea la superación de esta presión. 


\subsection{UTILIZACIÓN DE DEPÓSITO HIDRONEUMÁTICO EN ASPIRACIÓN}

\subsubsection{Principio de funcionamiento}

Una de las vías de actuación para la reducción de la magnitud de la perturbación generada por el funcionamiento del grupo de presión, es la instalación de un depósito hidroneumático de membrana (calderín) en las proximidades de la aspiración del equipo de bombeo. El calderín realiza dos funciones importantes para la protección, por un lado sostiene la presión en su punto de instalación a partir de la masa de aire a presión acumulada en su interior, de forma que las ondas generadas por una perturbación atenúan su magnitud de forma similar al efecto conseguido en el entronque de acometida. Por otro lado el calderín aporta parte del volumen de agua demandado por el grupo de presión durante la fase de arranque, reduciendo la solicitación de agua a la red y con ella la depresión originada en el tramo (al reducirse las variaciones de caudal detraído se reduce la magnitud de la perturbación generada).

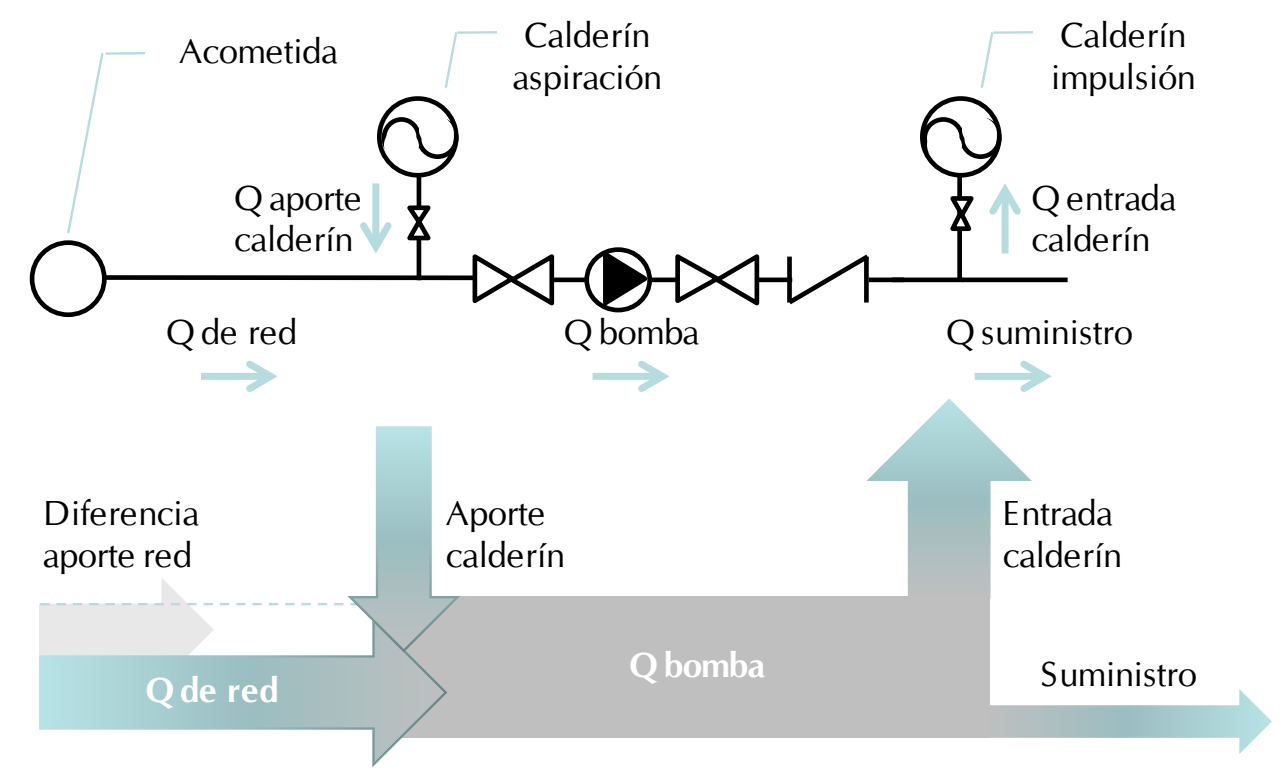

FIGURA C5-2. FLUJO DE CAUDALES EN LA FASE DE ARRANQUE DE LA BOMBA

Con posterioridad a los instantes de arranque de la bomba, ésta continúa detrayendo caudal de red, reduciéndose la aportación desde el calderín hasta que se anula (situación que propicia ciclos cortos de llenado y vaciado por efecto de la variación de presión en su interior y en su punto de conexión). Este efecto también se origina en la parada del grupo ya que en esta fase la masa de agua en las proximidades de la bomba encuentra una vía de escape para rellenar el calderín al mismo tiempo que éste absorbe parte de la energía del flujo. Cuando la bomba para la presión en la instalación recupera la presión de red, y se produce un llenado del calderín hasta que éste vuelve a alcanzar el equilibrio, manteniendo en su interior un volumen de agua auxiliar disponible para el siguiente arranque. 
Sobre este proceso de aporte auxiliar del calderín se entrará más en detalle a partir del análisis realizado sobre el modelo de simulación correspondiente, mostrándose la evolución de las variables implicadas así como la alteración de la respuesta de otros elementos de la instalación.

\subsubsection{Esquema de instalación}

El esquema propuesto localiza el calderín en la tubería de aspiración del equipo de presión, próximo a la alimentación de las bombas (Figura C5-3), de forma similar al calderín instalado en impulsión.

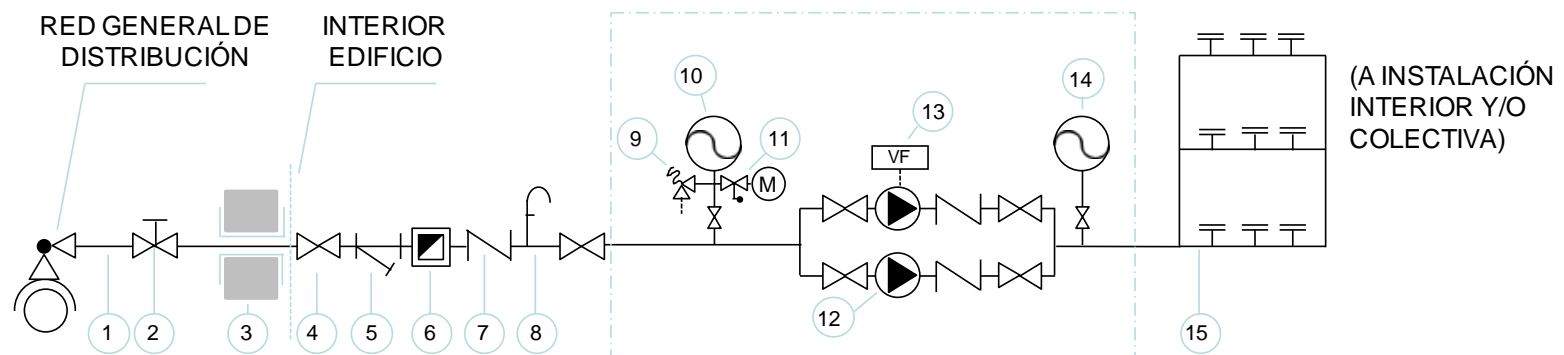

\begin{tabular}{l|ll}
\multicolumn{1}{|l}{ ACOMETIDA } & \multicolumn{1}{|c}{ INSTALACIÓN INTERIOR GENERAL } \\
\hline 1. Tubo de acometida & 6. Contador general & 11. Llave de paso con grifo de vaciado \\
2. Válvula de aislamiento (registro) & 7. Válvula antirretorno & 12. Bomba \\
3. Pasamuros & 8. Toma auxiliar & 13. Variador de frecuencia \\
4. Llave de paso & 9. Válvula de alivio & 14. Depósito hidroneumático (impulsión) \\
5. Filtro general & 10.Depósito/s hidroneumático/s (aspiración) & 15. Batería de contadores (distribuidor)
\end{tabular}

FIGURA C5-3. INSTALACIÓN CON CONEXIÓN DIRECTA CON CALDERÍN EN ASPIRACIÓN

\subsubsection{Monitorización del comportamiento de un calderín en aspiración}

En la instalación interior del edificio monitorizado se realizaron las modificaciones oportunas para permitir la instalación de un calderín en aspiración (bajo los dos esquemas de conexión directa). Estas medidas han permitido comprobar la eficacia de la protección propuesta, y adicionalmente la validación del modelo de simulación para analizar con el programa Allievi la protección.

El calderín instalado es de tipo membrada, con un volumen total de 25 litros y una presión de hinchado de 20 mca. El ramal de conexión es de 1 metro de longitud con diámetro interior de $20 \mathrm{~mm}$. El calderín se colocó a una distancia aproximada de 4 metros respecto a la aspiración de la bomba (en tramo de tubería). El criterio seguido para la selección del volumen total del calderín y la presión de hinchado se basó en mantener un volumen de agua útil en su interior suficiente para alimentar a la bomba durante los primeros instantes del arranque (conocido su caudal máximo y la duración del arranque). En estas condiciones y para la presión en red próxima a 30 mca, es posible garantizar una reserva de agua en su interior próxima a los 7 litros (frente a los 2 litros de aporte esperados). 
La Figura C5-4 muestra los datos correspondientes al registro de presión de las tres sondas con el esquema de funcionamiento con bomba de velocidad fija equipado con calderín en aspiración (conexión directa con protección). Como puede observarse las series de presiones siguen una evolución similar a la observada en el grupo sin protección (Figura C4-1), y claramente se evidencian los instantes de arranque y paro del grupo.

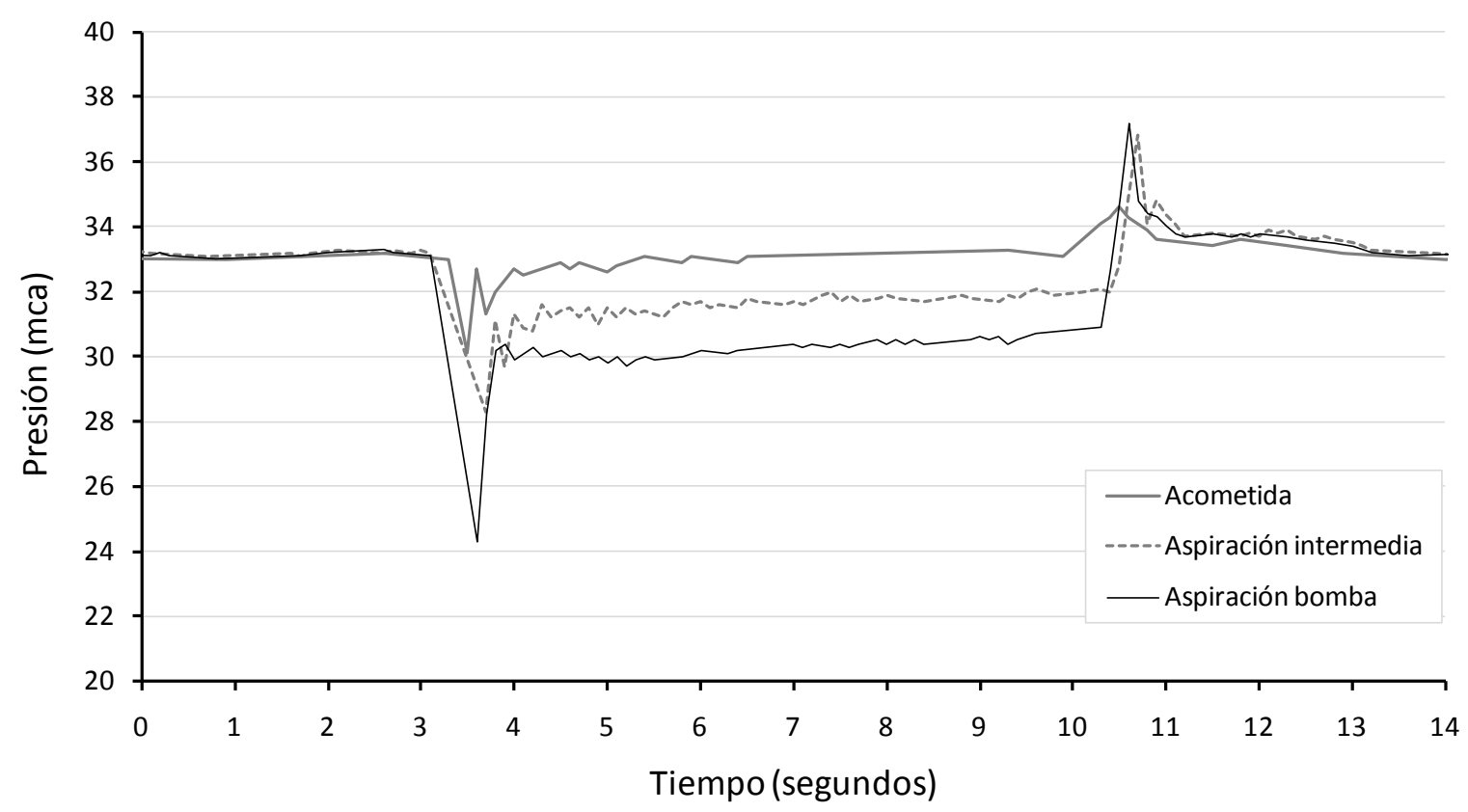

FIGURA C5-4. REGISTRO DE PRESIONES PARA LA BVF EQUIPADA CON CALDERÍN EN ASPIRACIÓN

\subsubsection{Mejoras obtenidas en la instalación de referencia con calderín de aspiración}

La Figura C5-5 muestra una de las conclusiones iniciales sobre la implicación de instalar un calderín en la aspiración. Existe una reducción significativa de las solicitaciones durante el arranque del grupo (depresión) y en la parada (sobrepresión). En la figura se muestra el valor promedio de los registros y los valores extremos medidos para ambos fenómenos (líneas en los laterales).

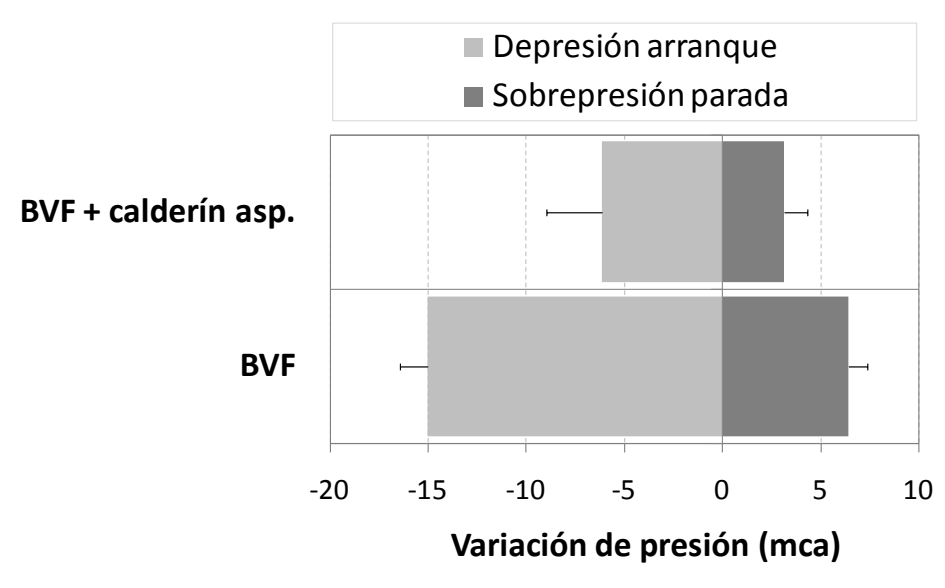

FIGURA C5-5. COMPARACIÓN DE LAS SOLICITACIONES DE UNA BVF (CON Y SIN CALDERÍN) EN ASPIRACIÓN DE LA BOMBA. 
Por tanto en las proximidades de la aspiración de la bomba se registró una reducción promedio de las solicitaciones en torno a un 55\% (tanto en el transitorio de parada como en el de arranque).

En el caso de la acometida del edificio las reducciones son también significativas y con valores próximos a los indicados anteriormente. Esto supone una reducción considerable de la magnitud de la perturbación generada en la conducción de aspiración del edificio, y por tanto una reducción de la perturbación transmitida al exterior de éste.

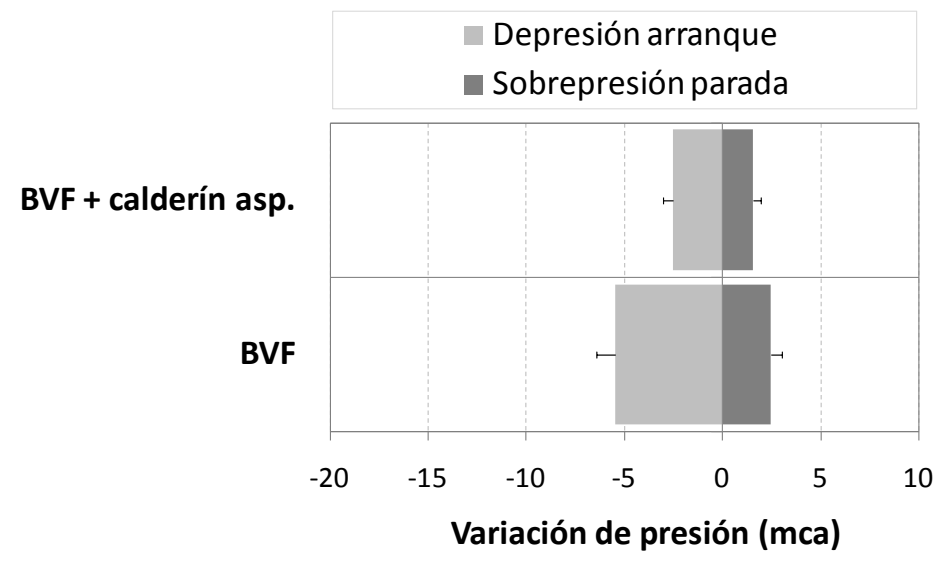

FIGURA C5-6. COMPARACIÓN DE LAS SOLICITACIONES DE UNA BVF (CON Y SIN CALDERÍN) EN LA ACOMETIDA.

Como puede observarse en las figuras anteriores, en todos los registros realizados la magnitud del transitorio de arranque es superior al de parada, siendo la diferencia de la magnitud de ambos transitorios próxima a un 50\%. Respecto al régimen permanente para instantes posteriores al arranque no se ha apreciado una influencia del calderín de aspiración, salvo ligeras fluctuaciones iniciales de presión como efecto de las oscilaciones en masa del agua en la instalación y de la masa de aire en el interior de éste.

\subsubsection{Modelo de simulación del tramo}

Para

analizar

el

funcionamiento del calderín en aspiración y poder proponer reglas de dimensionado de la protección, se ha modelado dicho elemento en el programa Allievi. Para ello se ha modificado el modelo hidráulico de la instalación de referencia incorporando el depósito hidroneumático junto con un ramal de conexión (atendiendo en ambos casos a las características constructivas del edificio monitorizado).

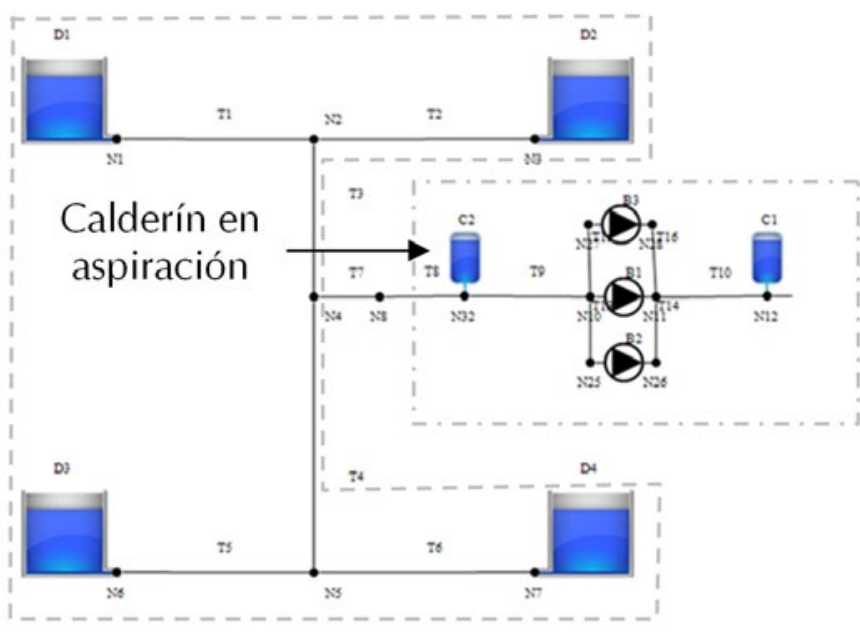

FIGURA C5-7. MODELO DE SIMULACIÓN EN ALLIEVI CON CALDERÍN EN ASPIRACIÓN (C2) 
Al mismo tiempo se ha comparado la respuesta del modelo a partir de los registros medidos, destacándose que la respuesta de éste se ajusta en gran medida a la registrada (Figura C5-8). La caída de presión máxima aportada por el modelo presenta una magnitud similar a la respuesta monitorizada (tanto en acometida como en aspiración), y se observa una mayor laminación durante los instantes posteriores al valor mínimo.

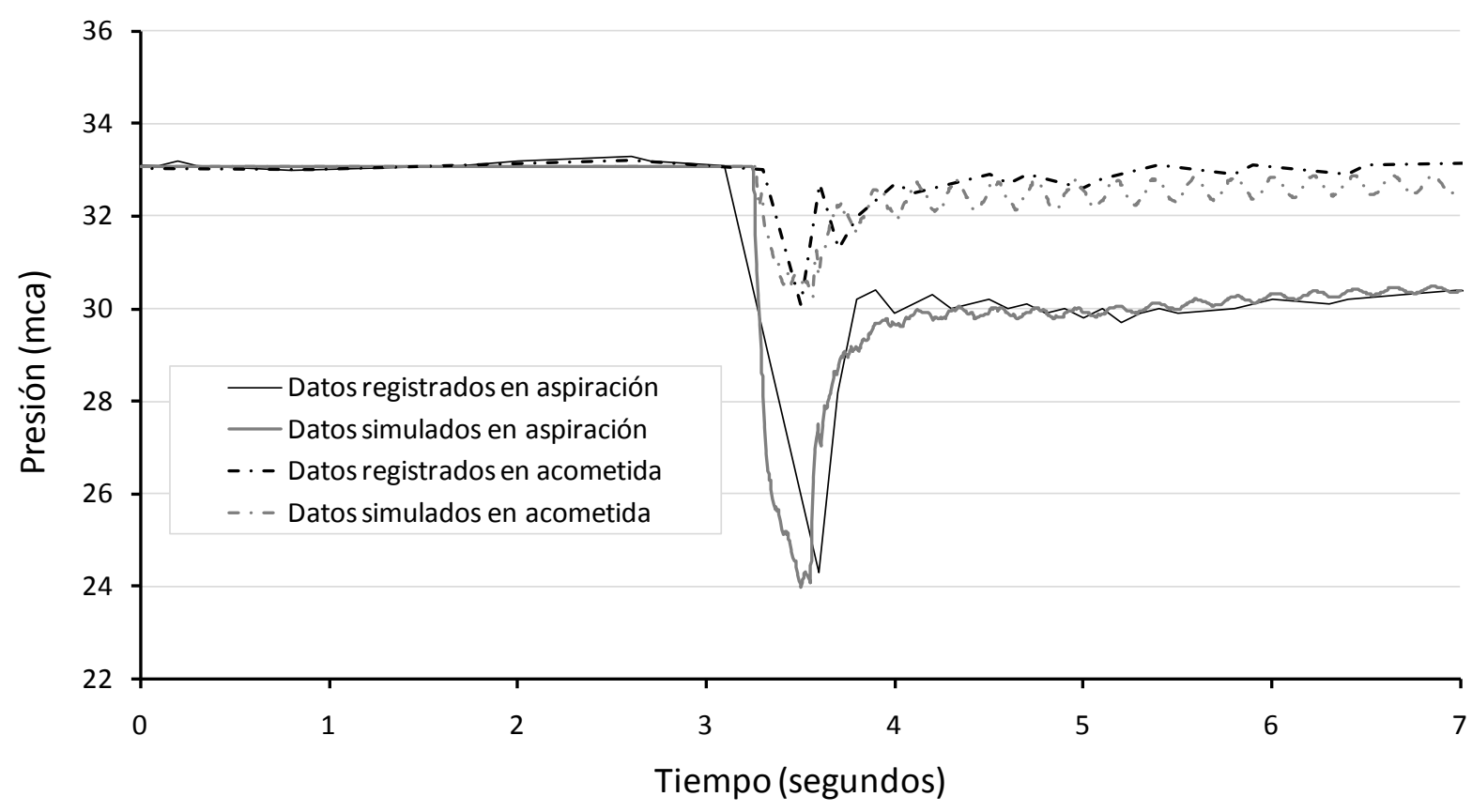

FIGURA C5-8. COMPARACIÓN DE LA RESPUESTA DEL MODELO Y LA REGISTRADA

\subsubsection{Análisis del comportamiento de la instalación equipada con calderín}

A continuación se muestra el análisis sobre el funcionamiento de la instalación de referencia equipada con calderín obtenida a partir del modelo de simulación. Para comprender en mayor medida las implicaciones asociadas a la utilización del calderín se realiza una comparación entre el esquema que cuenta con calderín (CC) frente al esquema desprovisto de éste (SC). Para simplificar el estudio se ha supuesto que todo el caudal del edificio pasa por la bomba.

\subsubsection{Comparación de caudales por la acometida}

La Figura C5-9 se muestra la evolución de caudales en las proximidades del calderín. La variación de caudal más significativa tiene lugar en la conducción de acometida (caudal referido como $Q$ red por su procedencia de la red de distribución). Se puede observar que la evolución de este caudal se modifica sensiblemente con la instalación del calderín ya que en los primeros instantes del arranque éste aporta mayor parte del volumen solicitado por el grupo, hasta $t=3,2$ segundos (de forma similar a cómo resultaría si no se dispusiera de calderín). El aporte de caudal auxiliar del calderín 
alcanza su máximo valor en $\mathrm{t}=3,3 \mathrm{~s}$, momento a partir del cual empieza a reducirse hasta anularse. El valor es próximo a un $68 \%$ del caudal nominal de la bomba $(1,83 \mathrm{l} / \mathrm{s}$ frente a los 2,71 l/s de la bomba) y el volumen total de agua aportado es de aproximadamente 1,3 litros.

A modo general en la medida que se consiga un aporte suficiente por parte del calderín durante los instantes de arranque del grupo de presión será posible reducir las solicitaciones originadas por el arranque de la bomba. Para ello, se deberá disponer de un volumen útil mínimo a la presión de régimen (antes del arranque de la bomba).

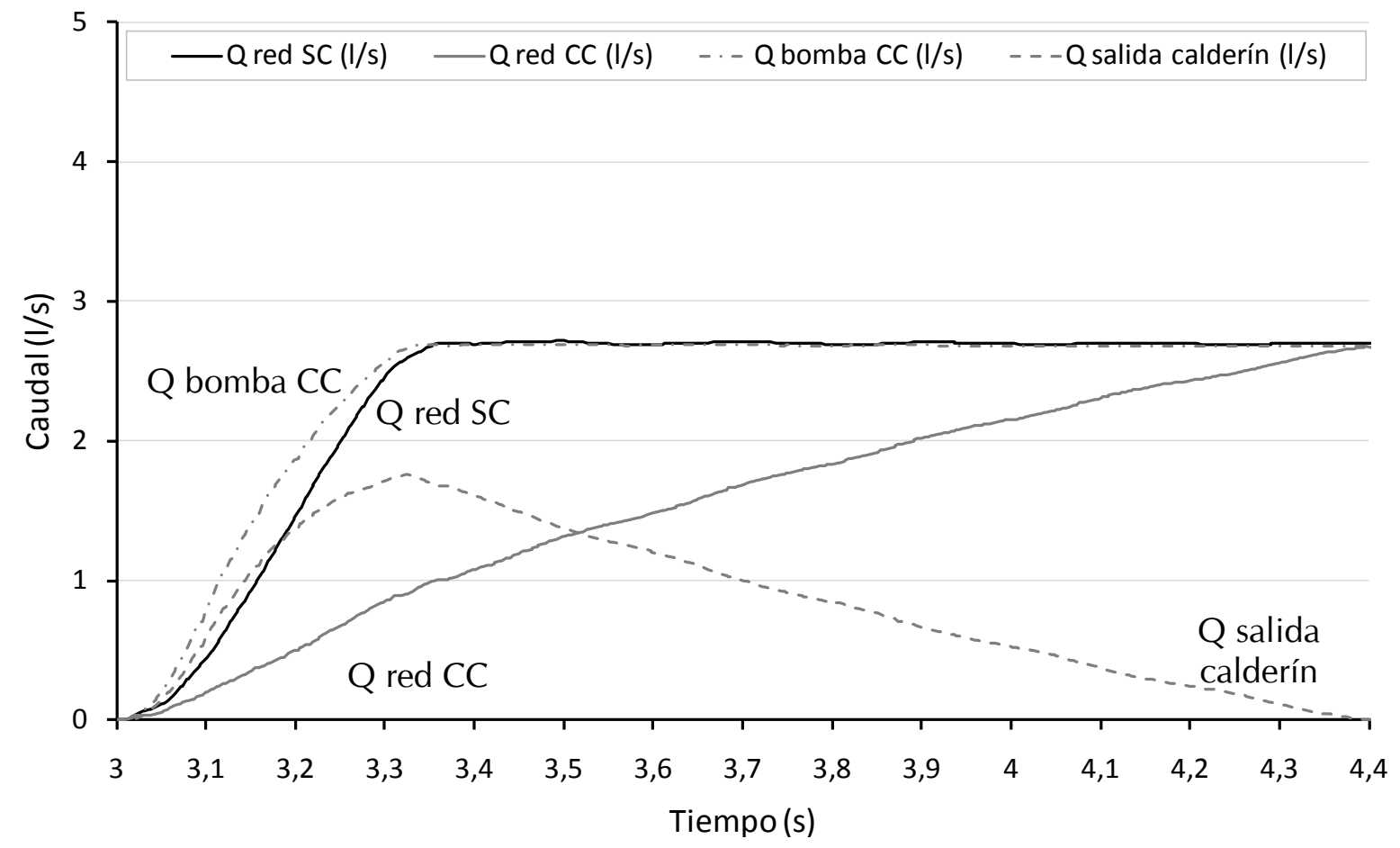

FIGURA C5-9. CAUDALES EN LOS DIFERENTES TRAMOS DE LA INSTALACIÓN PARA LOS ESQUEMAS CC Y SC

Como puede observarse en la figura anterior el balance de volúmenes que entran en juego para los dos esquemas presenta una elevada similitud; por un lado la suma del volumen aportado por el calderín (área encerrada bajo la serie correspondiente) y el volumen de agua detraído de red para el esquema con calderín, es similar al volumen total detraído cuando la instalación no cuenta con calderín.

Por otro lado el caudal trasegado por la bomba se modifica ligeramente en ambas situaciones (para la instalación sin calderín el caudal de la bomba coindice con el caudal de red), esto se debe a la variación de la presión en la aspiración del grupo. Para el esquema sin calderín se origina una mayor caída de presión en este punto, y por tanto la bomba modifica su punto de funcionamiento (similar al efecto analizado en el Capítulo 4 por un descenso de presión en red). Por esta razón la bomba genera un mismo incremento de caudal en menor tiempo. 
Respecto a los caudales en régimen permanente para instantes posteriores al transitorio de arranque de la bomba, ambos esquemas tienden al mismo caudal de bombeo, si bien el modelo de simulación presenta unas ligeras fluctuaciones hasta la estabilización completa de ésta. Estas fluctuaciones se atenuarán con mayor rapidez en la instalación real, de forma similar al comportamiento observado en los registros.

\subsubsection{Comportamiento del calderín}

El comportamiento del calderín en aspiración es función de la evolución de la presión en su punto de conexión. En condiciones iniciales y para el estado de la bomba parada, la presión prácticamente constante en la conexión establece un volumen de gas de acuerdo a una evolución politrópica tal como establece la siguiente expresión:

$$
p_{h}^{*} \cdot V_{c}^{\gamma}=p_{\text {reg }}^{*} \cdot V_{\text {gas }}^{\gamma} \longrightarrow V_{\text {gas }}^{\gamma}=\frac{p_{h}^{*} \cdot V_{c}^{\gamma}}{p_{\text {reg }}^{*}}
$$

Siendo:

- $p_{h}^{*}$ la presión de hinchado del calderín en términos absolutos (próxima a 2 bar)

- $V_{c}$ el volumen total del calderín (25 litros para el calderín del modelo)

- $p_{\text {reg }}^{*}$ la presión de régimen antes del arranque del grupo en términos absolutos

- $V_{\text {gas }}$ el volumen de aire para la presión de régimen (aproximadamente 18 litros)

- $\gamma$ el coeficiente politrópico de la evolución (considerado con valor de 1,2)

En la Figura C5-10 se muestra el comportamiento del calderín.

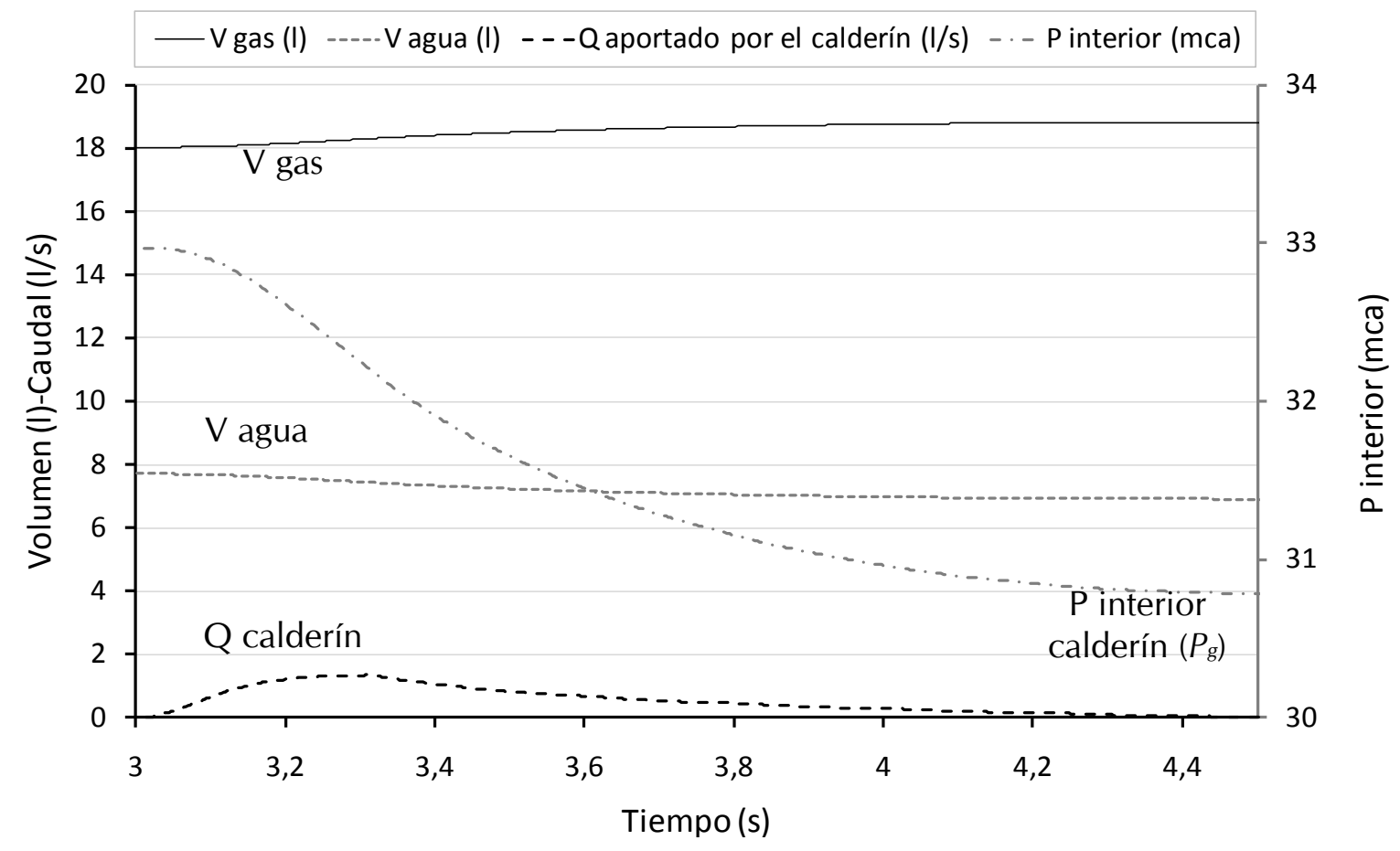

FIGURA C5-10. COMPORTAMIENTO DEL CALDERÍN EN ASPIRACIÓN DURANTE EL ARRANQUE DEL GRUPO 
Durante el arranque de la bomba comienza el aporte de agua por parte del calderín. Por ello se reduce ligeramente la presión en su interior (siguiendo la depresión originada por la succión de la bomba). Al mismo tiempo se reduce el volumen de agua ( $V$ agua) con la correspondiente expansión del gas en el interior de la vejiga ( $V$ gas).

En la Figura C5-11 se representa la evolución de la presión en las proximidades del calderín. Se comprueba que la presión en su interior $\left(P_{g}\right)$ no desciende de forma tan significativa como en la aspiración de la bomba (aun siendo puntos próximos). Esto se debe al comportamiento del gas cuya evolución es más lenta que la derivada de la propagación de las ondas del transitorio y a la inercia

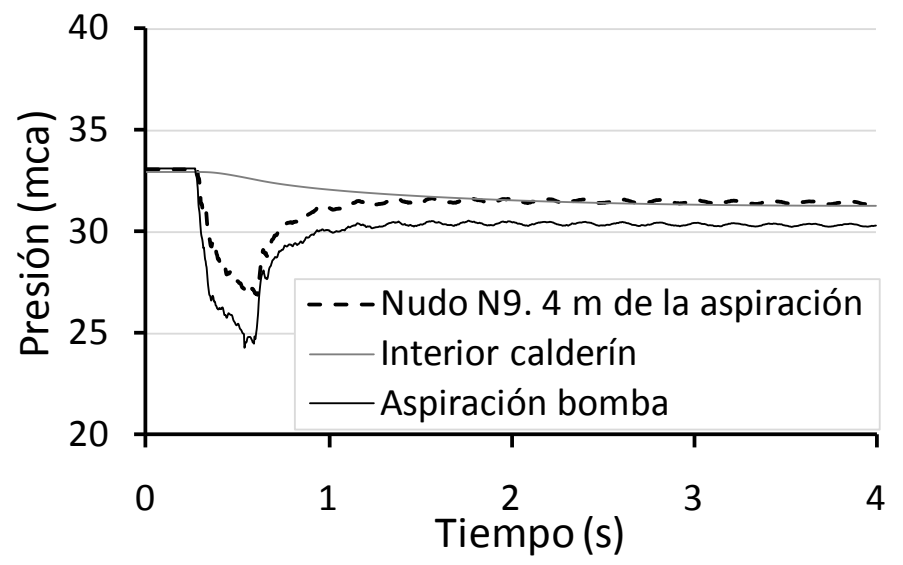

FIGURA C5-11. VARIACIÓN DE PRESIONES EN LAS PROXIMIDADES DE LA BOMBA Y EN EL CALDERÍN de la masa de agua en movimiento.

Este fenómeno asociado a la ligera variación de presión en el interior del calderín es el que propicia un mayor sustento de la presión en el ramal de conexión, limitando la caída de presión que se daría en este punto de no existir éste. Además de un aporte de agua, el calderín mantiene la presión en su punto de conexión (similar al fenómeno que tiene lugar en un entronque con un depósito), favoreciendo el establecimiento del valor de la presión en el punto de conexión, por ello la evolución de la presión en el interior del calderín sostiene la presión en la conexión (efecto similar a cómo reacciona un resorte ante variaciones de su posición de equilibrio), tanto en los primeros instantes del arranque como en las posteriores fluctuaciones hasta la estabilización.

Una vez la bomba para, y se alcanza la presión estática en la aspiración ( $\mathrm{t}=10$ en la Figura C512), el calderín absorbe las variaciones de presión que se dan en su punto de conexión. Posteriormente, éste acumula en su interior un nuevo volumen de agua que permita de nuevo el aporte auxiliar durante el siguiente ciclo de arranque del grupo.

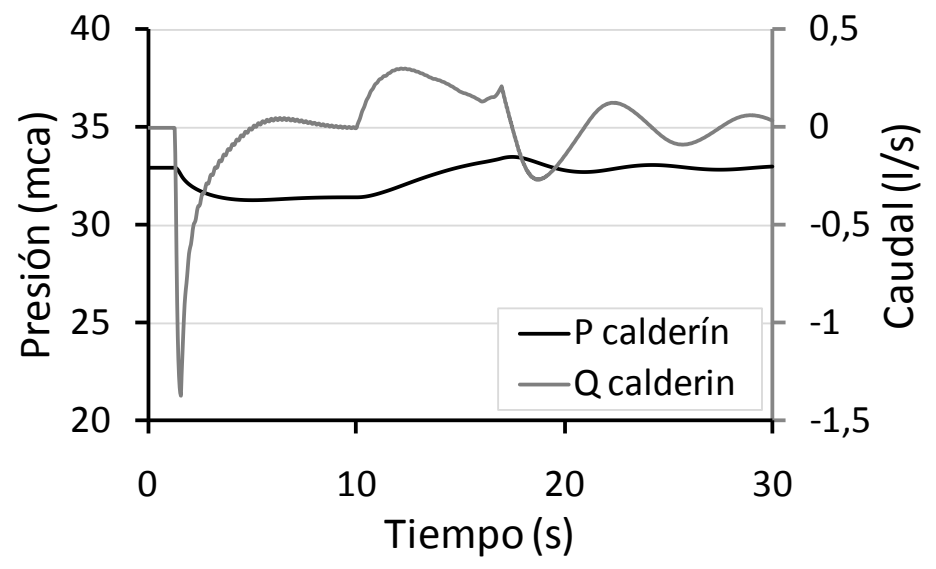

FIGURA C5-12. EVOLUCIÓN DEL CAUDAL Y LA PRESIÓN EN EL CALDERÍN EN UN CICLO DE FUNCIONAMIENTO 


\subsubsection{Comportamiento de la bomba}

La siguiente figura compara el comportamiento de la bomba para ambos esquemas de funcionamiento (CC y SC), durante su arranque.

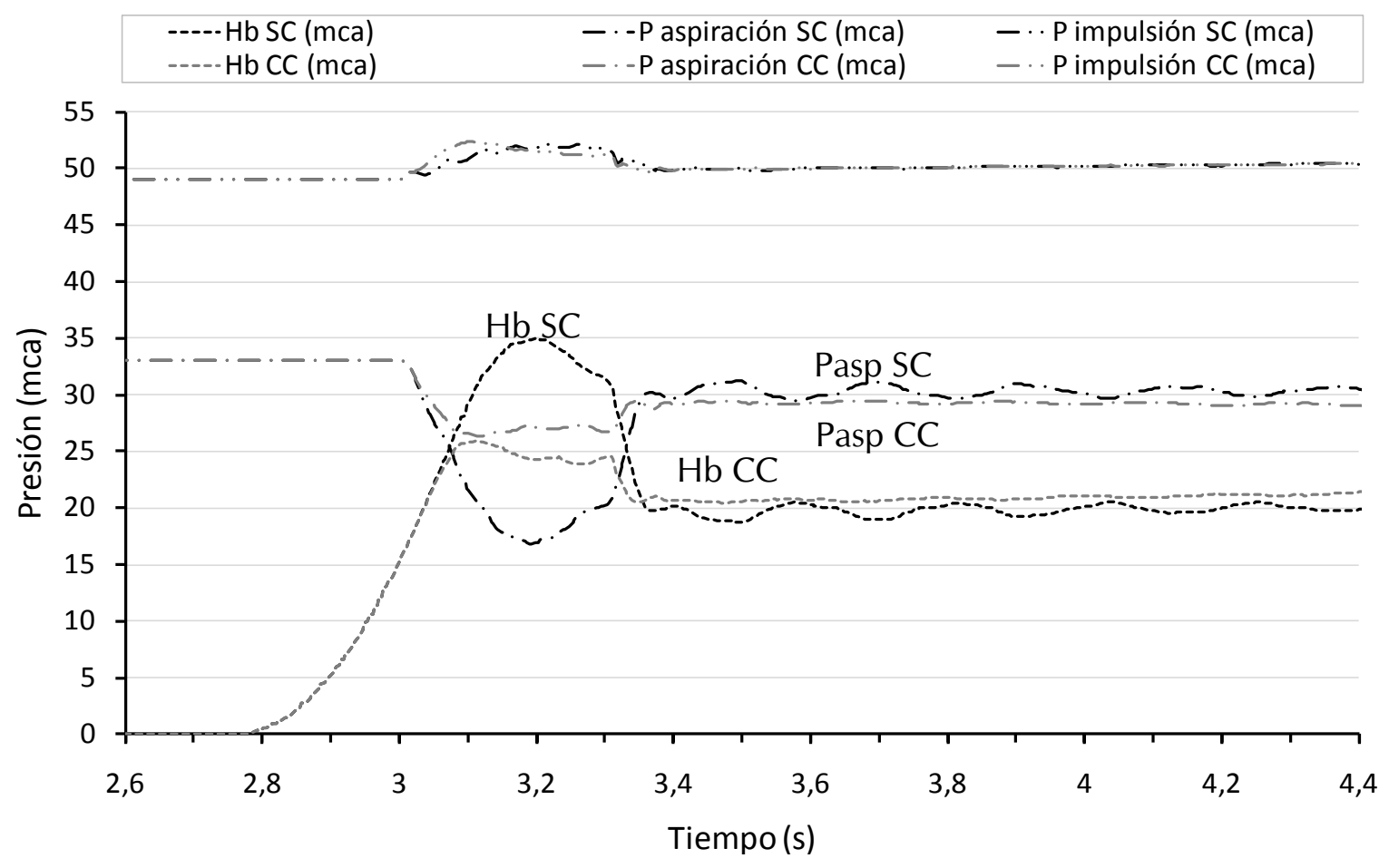

FIGURA C5-13. COMPORTAMIENTO DE LA BOMBA DURANTE EL INSTANTE DE ARRANQUE

La principal implicación al incorporar el calderín es la reducción tanto de la altura de bombeo como de la caída de presión en la aspiración de la bomba durante el transitorio. Esta reducción está asociada con el aporte del calderín, y la contención de la presión en el punto de conexión tal como se ha comentado.

Respecto al caudal del grupo, y tal como se observó en la Figura C5-9, aparece una ligera diferencia durante los primeros instantes del bombeo asociada al cambio de puntos de funcionamiento por la variación de la presión en la aspiración de la bomba.

\subsubsection{Influencia de las principales variables constructivas}

Comprobada la modificación en el comportamiento en la instalación de referencia al incorporar un calderín en aspiración, se ha desarrollado un análisis de sensibilidad para determinar la influencia de las variables del tramo asociado al calderín. Los resultados servirán para establecer los criterios de dimensionado y de las recomendaciones sobre el diseño de la protección. 


\subsubsection{Volumen del calderín de aspiración}

Un primer parámetro a considerar está relacionado con el volumen útil del calderín de aspiración. En una primera instancia y para simplificar se analiza volumen total del mismo. Para ello se ha equipado la instalación de referencia con diferentes volúmenes de depósito y se ha simulado con Allievi (Figura C5-14).

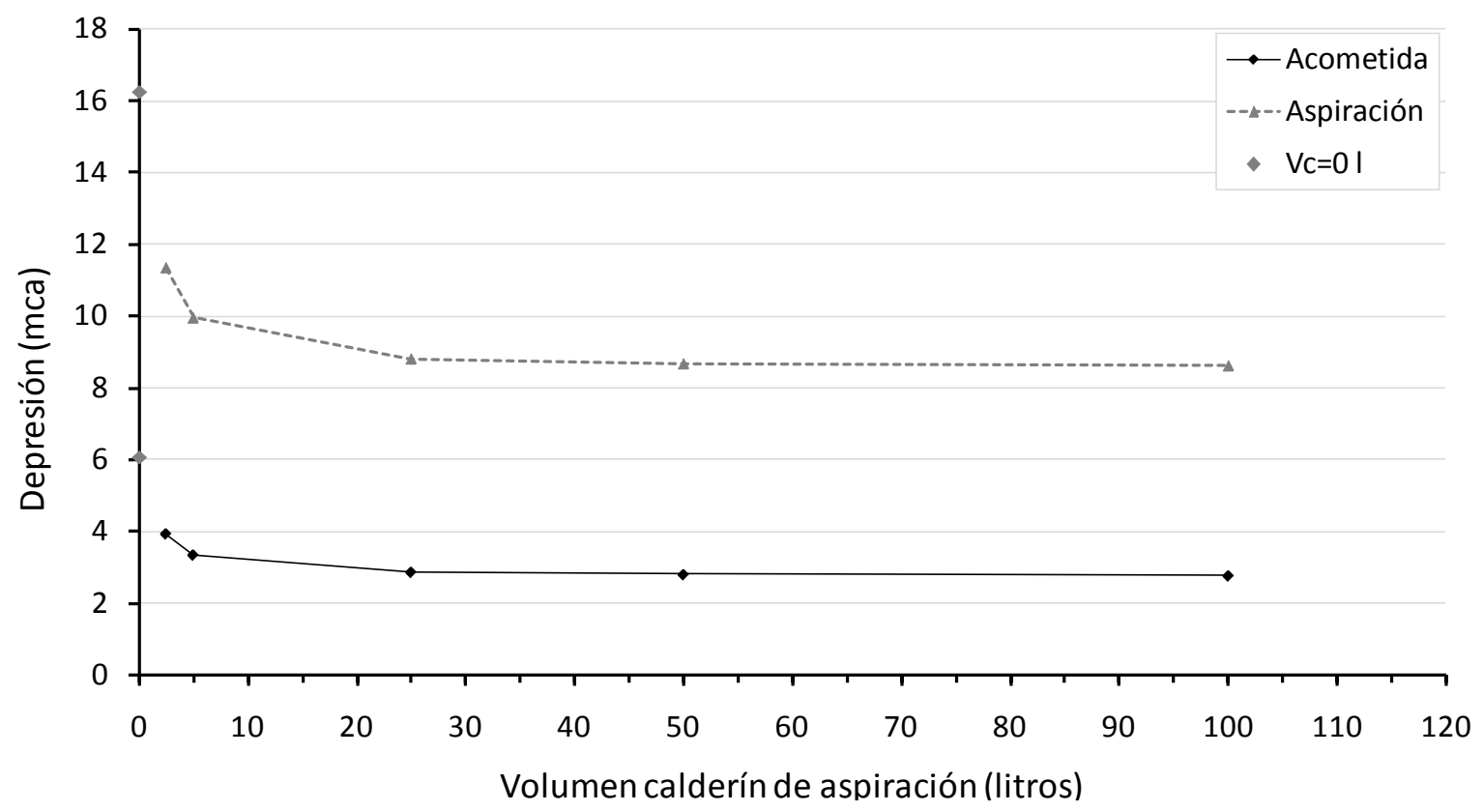

FIGURA C5-14. INFLUENCIA DEL VOLUMEN DEL CALDERÍN DE ASPIRACIÓN EN LA INSTALACIÓN DE REFERENCIA

En este caso, si se mantienen fijas sus características y tan sólo se modifica el volumen total del calderín, la reducción del volumen origina mayores caídas de presión. Por otro lado, un aumento del volumen no origina una reducción equivalente de las solicitaciones, presentando una estabilización de la magnitud de la depresión generada independientemente del volumen total del calderín. Este efecto está relacionado con las pérdidas en el ramal del calderín, junto con las correspondientes al tramo comprendido entre el calderín y la bomba, parámetros que se analizan más adelante. Como consideración general, a medida que se facilite la salida de agua del calderín mayor contribución del mismo en la protección y menores caídas de presión.

Como se comprobará más adelante, el volumen total por sí solo no garantiza una correcta protección, ya que no asegura un volumen útil de agua suficiente para el aporte auxiliar a la bomba, ni una energía en forma de presión almacenada para favorecer el soporte de presión durante los primeros instantes del arranque. Por ello, y aunque el volumen de agua aportado por el calderín durante el instante de arranque es reducido (el calderín de 25 litros aporta aproximadamente 1,3 litros, apenas un 18\% del volumen útil de agua disponible a la presión de régimen), es necesario disponer de un valor mínimo que asegure un correcto aporte durante el instante de arranque. 
En la Figura C5-15 se muestra el comportamiento de tres calderines; de 2, 25 y 50 litros de volumen total.

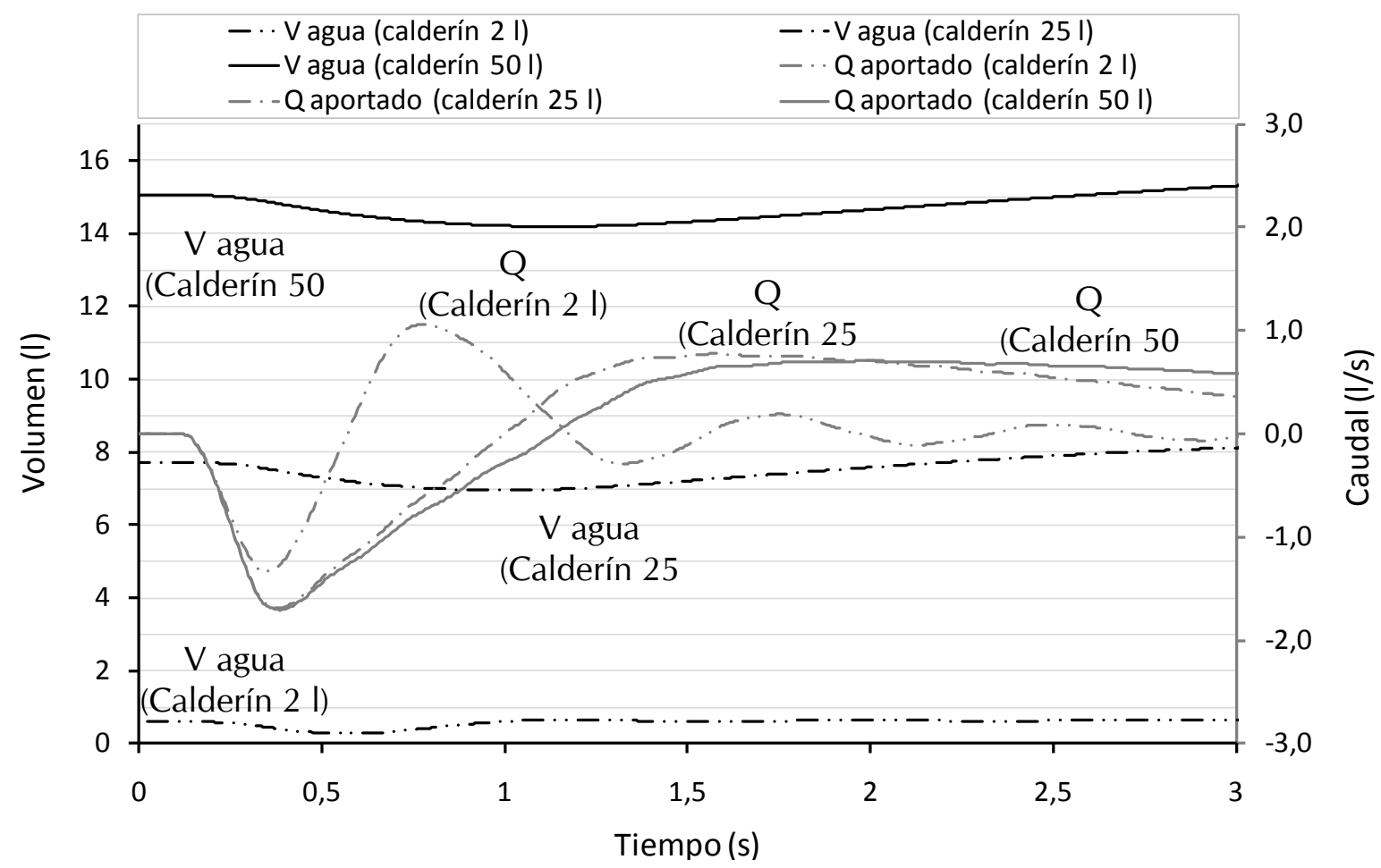

FIGURA C5-15. COMPARACIÓN DEL COMPORTAMIENTO DEL CALDERÍN PARA DIFERENTES VOLÚMENES

Como puede apreciarse, dos de los calderines disponen de un volumen útil suficiente (para las características particulares de la instalación de referencia), mientras que el de menor capacidad proporciona una protección limitada. El caudal máximo de agua aportado es similar para aquellos calderines con volumen útil suficiente (25 y 50 litros), originándose en el mismo instante y con evoluciones similares el máximo caudal detraído, razón por la que la depresión originada en ambos casos es próxima.

El efecto anterior justifica la tendencia observada en la Figura C5-14, en la que un aumento del volumen útil de agua disponible en el calderín (prácticamente el doble en el ejemplo mostrado), no reduce depresión en la instalación (Figura C5-16), no estando por tanto justificada la instalación de volúmenes elevados de almacenamiento.

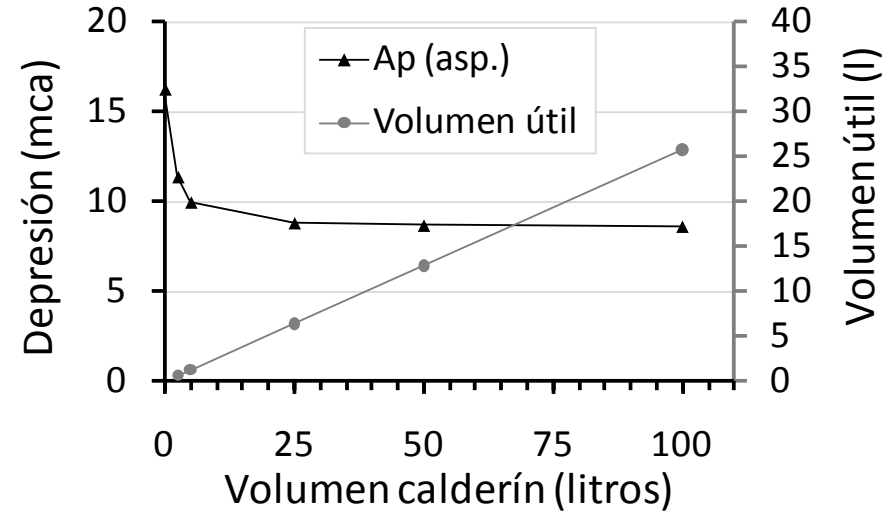

FIGURA C5-16. INFLUENCIA DEL VOLUMEN ÚTIL DE AGUA 
Por otro lado, no todos los calderines analizados mantienen un volumen útil de agua suficiente, por ello las solicitaciones originadas para el calderín más pequeño aumentan tendiendo al valor de la depresión cuando la instalación está desprovista de protección mediante un calderín en aspiración, Figura C5-14. Esta situación ocurre por ejemplo para el calderín de 2 litros. Bajo estas condiciones de funcionamiento, el volumen aportado por el calderín es muy bajo (aproximadamente 0,4 litros), y por ello aumentan las oscilaciones de presión en el sistema derivado de una más rápida despresurización (se origina un menor sustento de la presión en la conexión al alterarse de forma más sensible la presión en el interior del calderín). Para mayores volúmenes la despresurización es menor, consiguiéndose mantener la presión más estabilizada durante el funcionamiento del grupo (menor rizado). Por esta razón y dada la relación directa entre el volumen de agua útil del calderín y la presión de hinchado, es necesario analizar con detalle este segundo parámetro.

\subsubsection{Presión de hinchado del calderín de aspiración}

Otro concepto importante por su influencia directa con el volumen útil de agua en el calderín, así como con el proceso de descarga es la presión de hinchado. Esta presión se corresponde con la presión del aire cuando el calderín está vacío de agua, y el aire ocupa todo el volumen del calderín y comprime la vejiga que no contiene agua. La precarga usual del fabricante es próxima a 2 bar, pero dicho valor puede variar sensiblemente de un fabricante a otro.

En la Figura C5-17 se modela un calderín que cuenta con un volumen útil de agua suficiente, pero existe un volumen muy reducido de aire presurizado en su interior (presión de hinchado baja). En esta situación, aun disponiendo de un volumen útil de agua suficiente (25 litros), el arranque de la bomba generaría caídas de presión elevadas con valores similares a los que se dan cuando no existe calderín en aspiración.

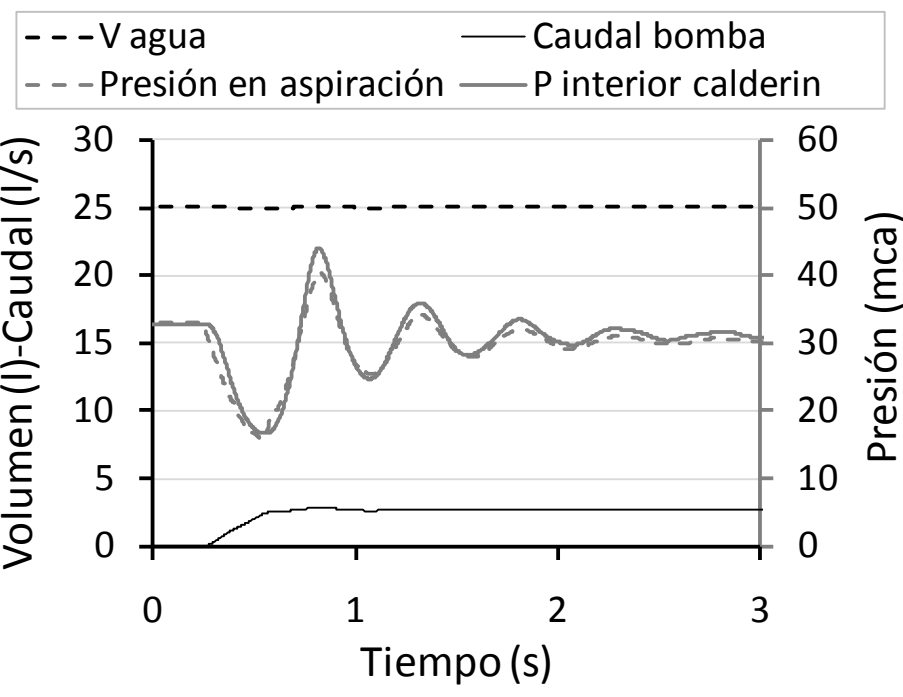

FIGURA C5-17. RESPUESTA DE UN CALDERÍN DE 25 L CON UNA MASA DE AIRE PRÁCTICAMENTE NULA 
Por tanto la existencia de una mínima masa de aire a presión en el interior del calderín antes del instante de arranque de la bomba, permite el aporte auxiliar de agua a la bomba, ya que como se ha comentado, el carácter compresible de esta masa junto con la evolución propia del gas introduce una dinámica en el sistema que favorece el sustento de la presión en la aspiración, con una atenuación del frente de depresión originado por la reflexión de sucesivas ondas transitorias que alcanzan el depósito, al mismo tiempo que posibilita el aporte de agua a la bomba. Puesto que el caudal aportado es función de la diferencia de presión que se da en el interior del calderín y en el punto de conexión del mismo, en la medida que se mantenga una presión suficiente y volumen de agua, se garantizará un aporte auxiliar.

La presión de hinchado del calderín debe ser función de la presión mínima que se puede dar en la conexión de éste antes del arranque del grupo. En un caso extremo, una presión de hinchado excesiva (por ejemplo de valor similar a la presión en la conexión en régimen antes del arranque del grupo), limitaría el volumen de agua útil en su interior, pudiendo no garantizar un aporte suficiente. En el otro extremo, una presión de hinchado insuficiente, aun favoreciendo la acumulación de agua en su interior, limitaría el sustento de presión originándose una despresurización rápida y una protección ineficiente. Por ello, tal como se indicará en el dimensionado de la protección, es necesario establecer un valor que considere las situaciones anteriores y las propias características del grupo de presión. En el caso concreto de la instalación de referencia, la Figura C5-18 muestra el efecto de esta variable para diferentes volúmenes totales de calderín (5, 10 y 25 litros), en función de la diferencia entre la presión estática de régimen (para la bomba parada), y la presión de hinchado.

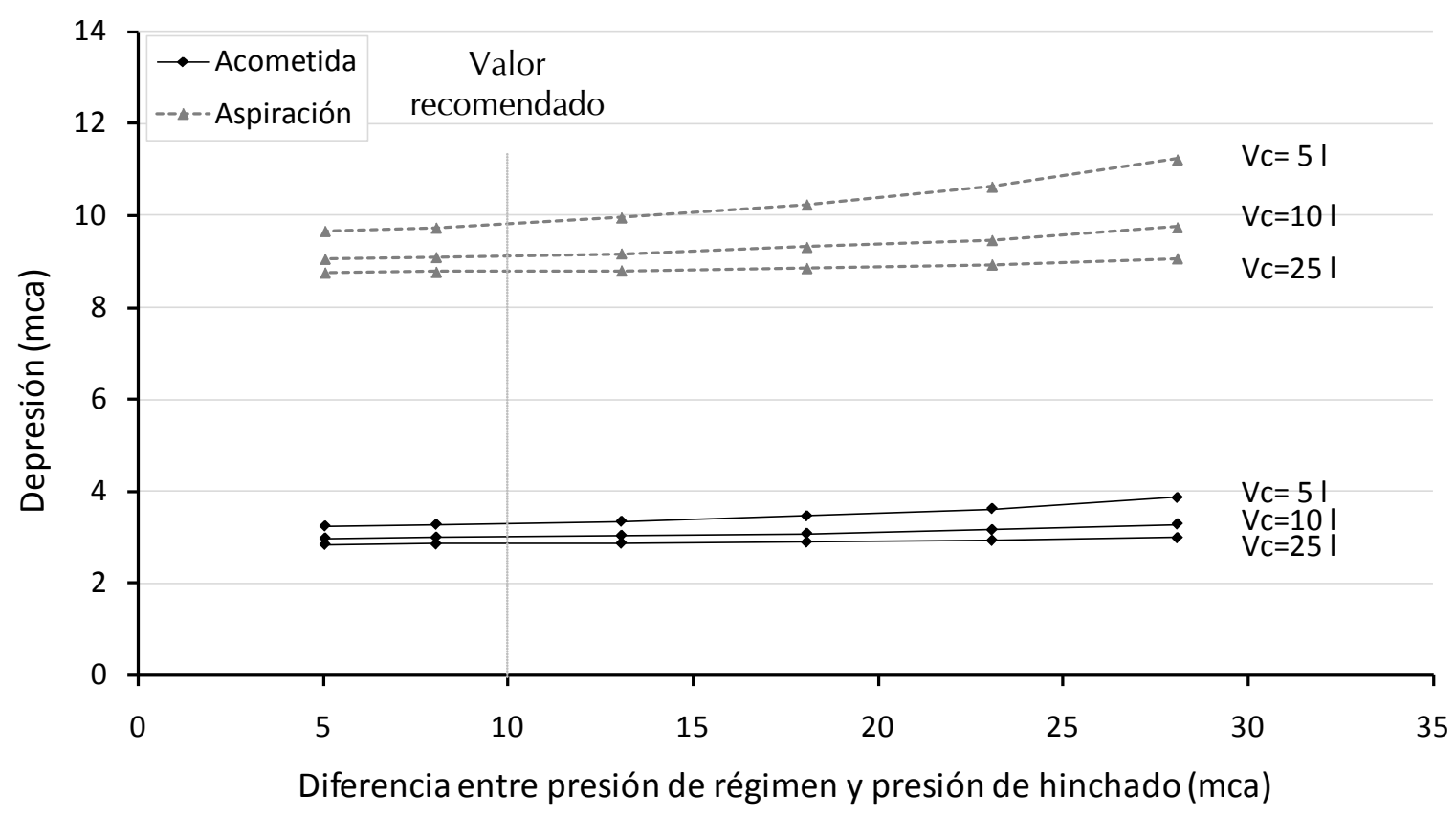

FIGURA C5-18. INFLUENCIA DE LA PRESIÓN DE HINCHADO Y EL VOLUMEN DEL CALDERÍN 
Para presiones de hinchado bajas, el modelo muestra un aumento de la magnitud de la perturbación frente aquellas situaciones en las que hay menos diferencia entre el valor de la presión de régimen y la presión de hinchado. Al mismo tiempo, el aumento del volumen del calderín favorece un aumento del volumen de agua en su interior para una misma relación de presiones, mostrando una caída de presión ligeramente inferior.

Para una presión de hinchado próxima a la presión en red las solicitaciones se aproximan a la magnitud originada cuando no se instala calderín en aspiración. En esta situación además hay que tener presente la posibilidad del que el calderín se vacíe completamente. Aunque el modelo de simulación aporta valores excesivamente exigentes bajo esta situación, se debe impedir el vaciado completo de éste.

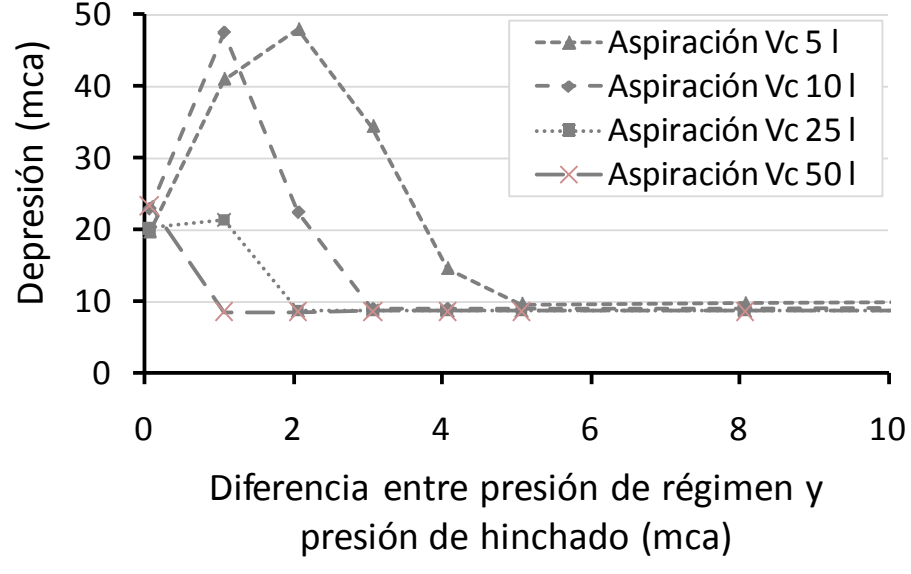

FIGURA C5-19. RESPUESTA ANTE VALORES REDUCIDOS DE PRESIÓN DE HINCHADO DEL CALDERÍN

\subsubsection{Pérdidas de carga en la descarga del calderín}

En el estudio se ha comprobado que las pérdidas de carga durante la descarga auxiliar de agua del calderín influyen en la protección. De esta forma, a medida que se facilite la aportación de caudal por parte de este elemento, más eficiente será la protección. Para comprobar la influencia, se ha analizado con Allievi cómo afectan los principales términos de pérdidas sobre la protección en una instalación de características similares a la de la instalación modelada, pero equipada con una conducción de aspiración de diámetro interior uniforme de $44 \mathrm{~mm}$, y coeficiente de pérdidas constante en todas las conducciones que forman dicho tramo.

Distancia entre la bomba y la conexión del calderín

Un parámetro determinante en la protección mediante calderín de aspiración es la distancia existente entre la conexión del calderín y el punto de aspiración de la bomba. Para comprobar la importancia de este factor se ha analizado la respuesta del modelo alterando el punto en el que se conecta el calderín respecto a la posición de la bomba (Figura C5-20).

A medida que aumenta la distancia entre la conexión del calderín y la aspiración de la bomba, aumenta la depresión por el arranque del grupo. Esto se debe a que el frente de depresión tarda más tiempo en recibir la influencia de las ondas de presión 
reflejadas en el punto de conexión del calderín, y por tanto reduce la atenuación de la perturbación. Por otro lado, mayores distancias favorecen mayores inercias de la masa de agua que se encuentra en la aspiración de la bomba, siendo más desfavorable su movilización. Por todo ello la distancia del calderín al punto de aspiración de la bomba presenta una influencia nada despreciable, siendo recomendable por tanto acudir a tramos cortos e instalar el calderín lo más próximo al grupo de bombeo.

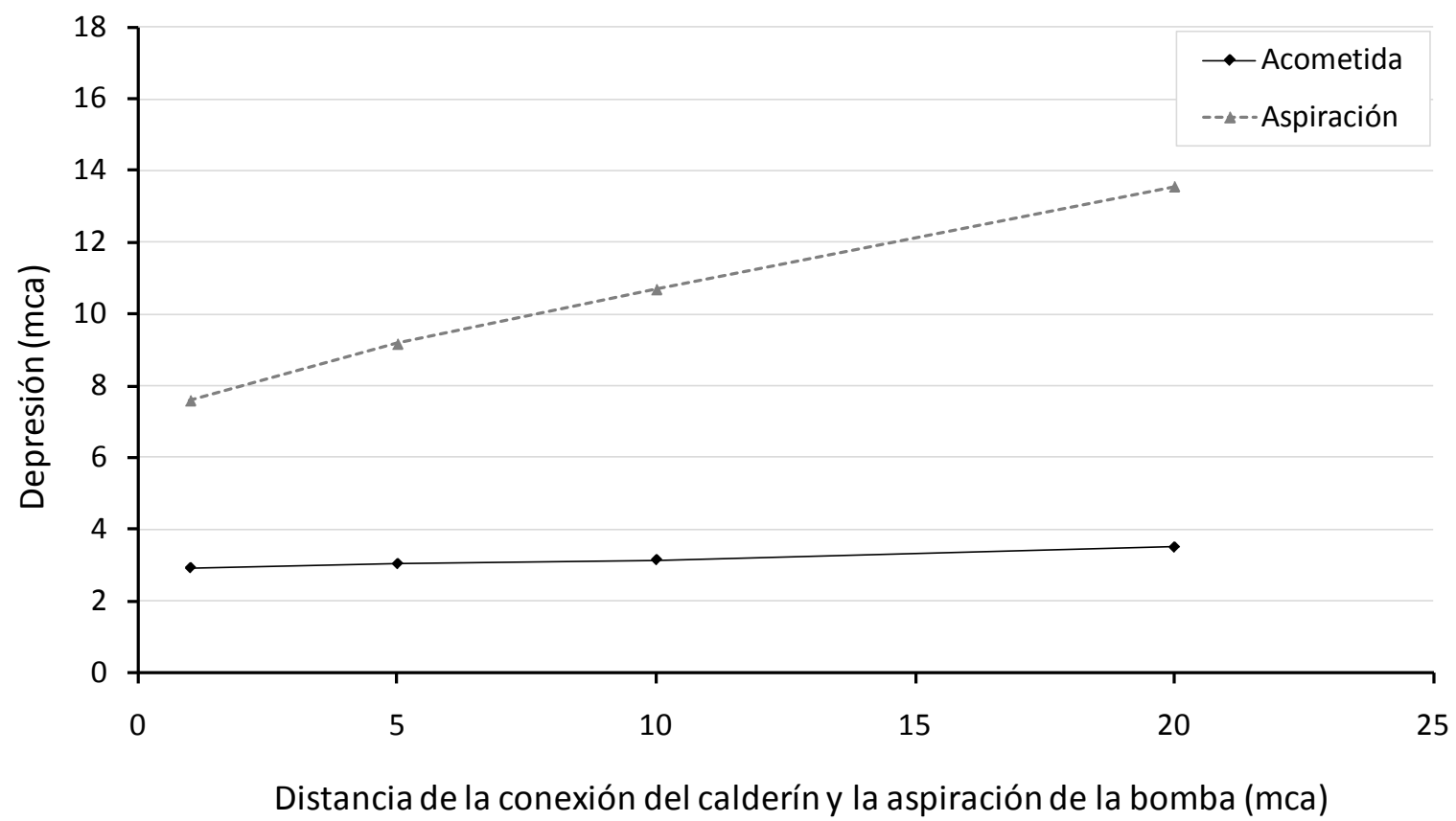

FIGURA C5-20. INFLUENCIA DE LA DISTANCIA DEL CALDERÍN A LA ASPIRACIÓN DE LA BOMBA (VC=25 L)

Longitud del ramal a calderín

Las características constructivas de la instalación muchas veces exigirán la incorporación de un ramal en derivación que conecte el calderín a la propia conducción de aspiración de la bomba (por ejemplo en instalaciones en las que no se cuente con espacio suficiente). Del mismo modo, sobre esta conducción será necesario incorporar diferentes elementos para realizar las tareas de mantenimiento y conexión, favoreciendo en todo caso el aumento de la característica resistente del tramo, y reduciendo la eficiencia de la protección.

Si se simula el comportamiento de la instalación de referencia para diferentes longitudes del ramal de conexión se puede apreciar un aumento de la caída de presión para mayores longitudes del ramal (una mayor longitud del ramal también se asocia a un aumento de las pérdidas menores, si bien no contribuyen al aumento de la inercia de la masa de agua). La magnitud de la depresión tiende al valor que se origina cuando la instalación no cuenta con protección (Figura C5-21). 


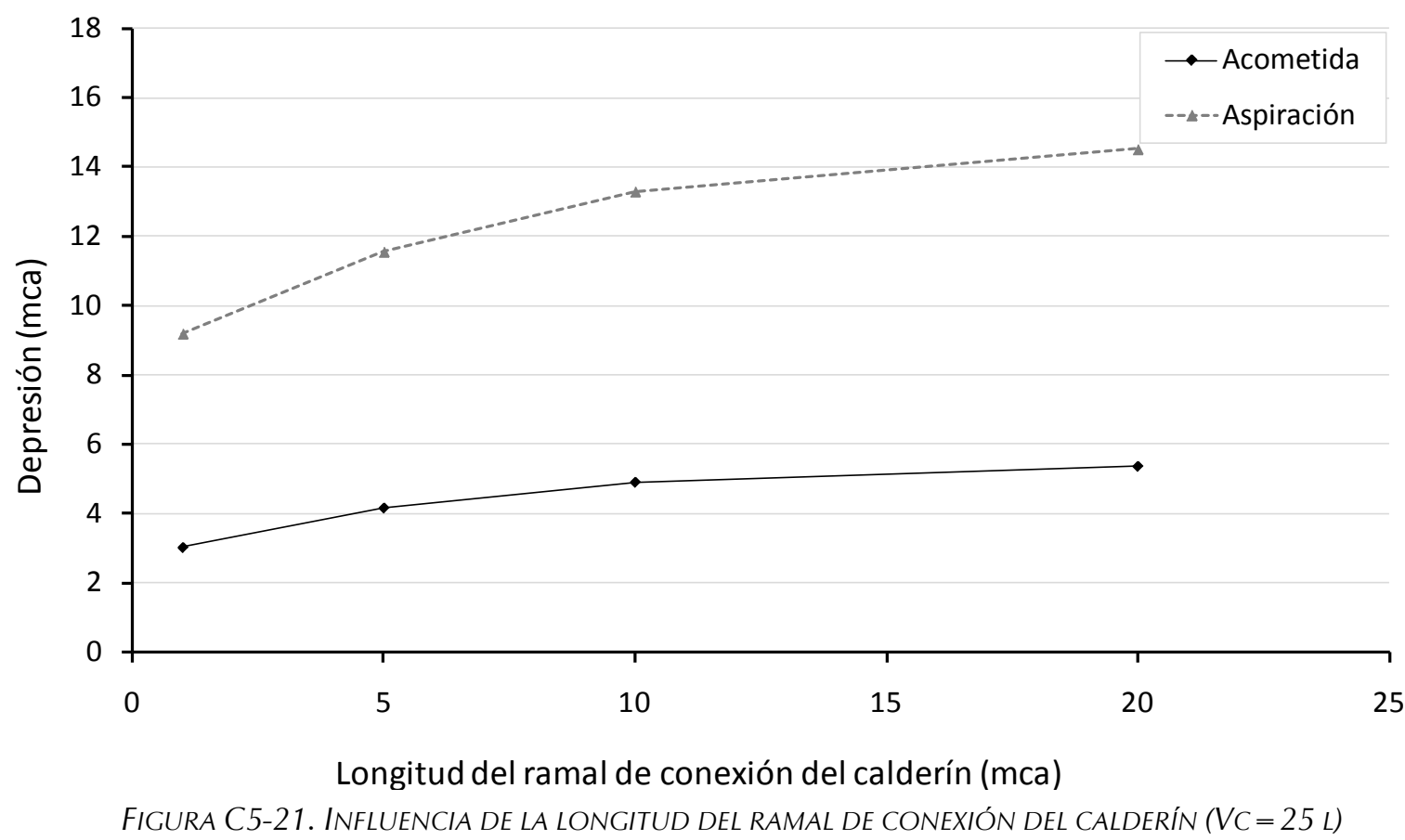

Varias consideraciones justifican una mayor caída de presión para longitudes de ramal mayores. El aumento del tiempo de viaje de las ondas hasta que se reflejan en el interior del calderín, aumenta la magnitud de la perturbación al retrasarse su atenuación. Además, el aumento de pérdidas de carga del tramo dificulta la descarga. También influye la inercia asociada a las masas de agua, ya que a medida que aumenta el volumen retenido en el ramal, mayor dificultad presenta su movilización.

\section{Diámetro del ramal a calderín}

Otro parámetro que también favorecerá la descarga del calderín es el diámetro interior del ramal de conexión. Tal como se puede observar en la Figura C5-22, y de forma similar al efecto introducido por el aumento de la longitud del ramal que conecta al calderín, una disminución del diámetro de esta conducción empeora la capacidad de descarga del calderín, aumentando las solicitaciones en la instalación y tendiendo de nuevo a valores correspondientes a la aspiración en directo sin protección.

Resulta por ello interesante la instalación de ramales de corta o nula longitud (entronque directo a un collarín o conexión directa a " $\mathrm{T}$ " interponiendo una válvula de aislamiento), de forma que el calderín esté lo más próximo posible al grupo de presión (la utilización del ramal de conexión muchas veces se hace necesaria por las características constructivas de la instalación, y especialmente en aquéllas en las que sus condiciones iniciales de diseño no incorporaba este elemento como medida de protección). Respecto al diámetro de éste, comentar que debe ser suficiente para facilitar el aporte y el soporte de la presión acudiendo preferiblemente a conexiones de similar sección a la tubería de aspiración. 


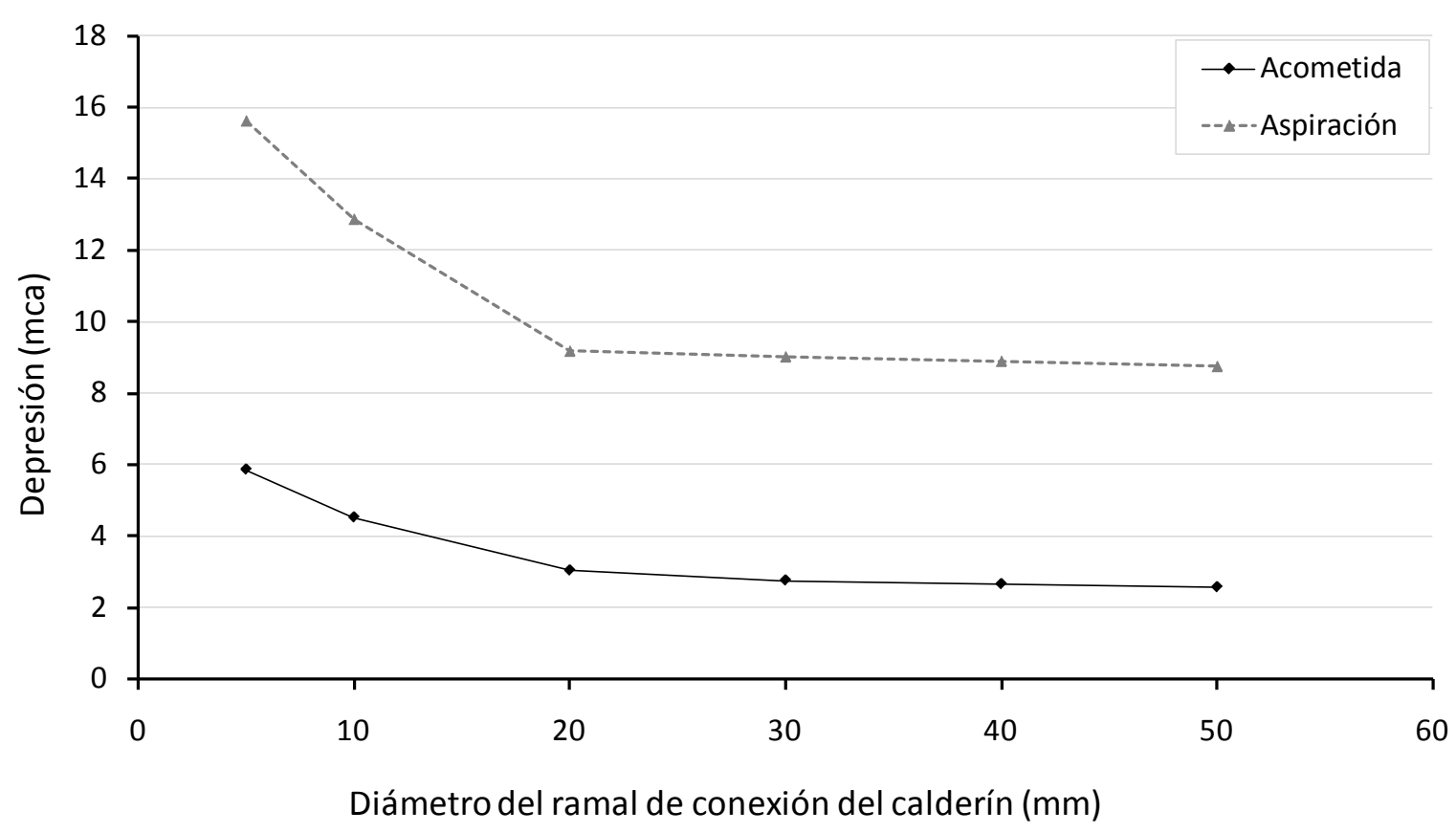

FIGURA C5-22. INFLUENCIA DEL DIÁMETRO INTERIOR DEL RAMAL DE CONEXIÓN DEL CALDERÍN (VC $=25$ L)

Por otro lado, a partir de un determinado diámetro de conexión el aumento del diámetro del ramal no supone una reducción de las solicitaciones. Esto se debe a la influencia más significativa de otra variable, concretamente del coeficiente de pérdidas asociado a la descarga del calderín, parámetro que se analizará más adelante.

Pérdidas menores en el entronque del calderín

Como se ha comentado, en el vaciado del calderín durante la fase depresiva del sistema las pérdidas deben ser mínimas, de forma que se favorezca su descarga. En esta línea, un parámetro que presenta una influencia a considerar es el coeficiente de pérdidas de la conexión. Estas pérdidas tienen en cuenta no sólo el estrechamiento que sufre el paso del agua durante la descarga (y las pérdidas en la conexión), también la contracción y reducción del área efectiva de paso del agua, de forma similar al fenómeno de descarga de un orificio, así como las pérdidas introducidas por la vejiga, la fricción en la pared del calderín, o las asociadas a la rejilla que aísla la vejiga en algunos calderines.

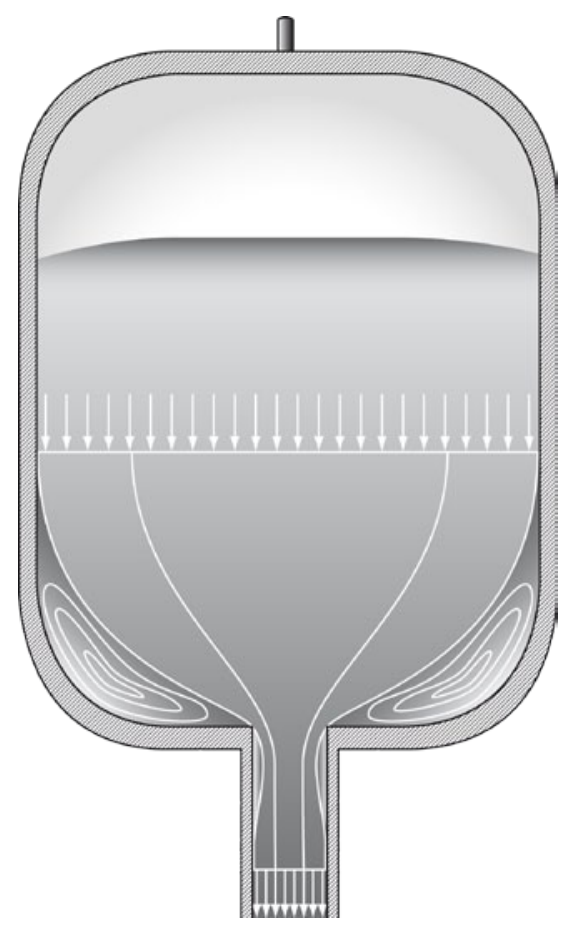

FIGURA C5-23. SECCIÓN DE UN CALDERÍN 
Es por tanto necesario establecer una relación entre las pérdidas de carga entre el calderín y la tubería (o viceversa) en función del caudal de entrada o salida del dispositivo (los coeficientes para el proceso de llenado y vaciado suelen ser diferentes). La forma usual de expresar las pérdidas localizadas, tanto para la entrada como la salida del agua, es a través de las siguientes expresiones:

$$
\begin{aligned}
& h_{l e}=K_{e} \cdot Q^{2}=k_{e} \cdot \frac{v^{2}}{2 \cdot g} \\
& h_{l s}=K_{s} \cdot Q^{2}=k_{s} \cdot \frac{v^{2}}{2 \cdot g}
\end{aligned}
$$

En ellas, el caudal se expresa en $\mathrm{m}^{3} / \mathrm{s}$ y la pérdida de carga en mca.

La relación entre el coeficiente adimensional $\mathrm{k}$ y el coeficiente $\mathrm{K}\left(\mathrm{mca} /\left(\mathrm{m}^{3} / \mathrm{s}\right)\right)$, en función del diámetro de éste (indirectamente considerado a partir de su sección $A$ en $\left.\mathrm{m}^{2}\right)$, es:

$$
K=\frac{k}{2 \cdot g \cdot A^{2}}
$$

La obtención de estos coeficientes no es sencilla, ya que los catálogos comerciales no suelen disponer de esta información para diámetros de conexión inferiores a DN $100\left(4^{\prime \prime}\right)$, al mismo tiempo que los fabricantes no suelen facilitar este dato por razones puramente comerciales. En la Tabla C5-1 se muestran los coeficientes de pérdidas aportados por un fabricante, tanto para el vaciado como para el Ilenado del calderín. Como puede observarse los datos disponibles están limitados a conexiones superiores a las consideradas en el estudio (estos datos servirán para el estudio de la

\begin{tabular}{|c|c|c|c|c|}
\hline $\begin{array}{l}\text { Diámetro } \\
\text { conexión }\end{array}$ & $\begin{array}{c}\text { Ke } \\
\text { Entrada } \\
\text { calderín }\end{array}$ & $\begin{array}{c}\text { Ks } \\
\text { Salida } \\
\text { calderín }\end{array}$ & $\begin{array}{c}\text { ke } \\
\text { Entrada } \\
\text { calderín }\end{array}$ & $\begin{array}{c}\text { ks } \\
\text { Salida } \\
\text { calderín }\end{array}$ \\
\hline $\mathrm{DN}(\mathrm{mm})$ & $\mathrm{mca} /\left(\mathrm{m}^{3} / \mathrm{s}\right)^{2}$ & $\mathrm{mca} /\left(\mathrm{m}^{3} / \mathrm{s}\right)^{2}$ & - & - \\
\hline 100 & 7064,2 & 6014,3 & 8,55 & 7,28 \\
\hline 150 & 713,6 & 509,7 & 4,37 & 3,12 \\
\hline 200 & 168,2 & 105,0 & 3,26 & 2,03 \\
\hline 250 & 69,0 & 43,1 & 3,26 & 2,04 \\
\hline 300 & 33,2 & 20,8 & 3,26 & 2,04 \\
\hline
\end{tabular}
protección de instalaciones singulares).

TABLA C5-1. COEFICIENTES DE PÉRDIDAS PARA DIFERENTES DIÁMETROS DE CONEXIÓN (OLAER) 
Si se realiza una extrapolación de los valores disponibles según la tabla anterior para estimar los coeficientes de pérdidas para diámetros de conexión inferiores a DN100, se llega a unos valores de $k_{s}$ comprendidos entre $\mathrm{k}=7$ hasta valores próximos a $\mathrm{k}=16(\mathrm{DN}$ 20). El valor superior se considera elevado, ya que para el ajuste del modelo de simulación que representa la instalación monitorizada se acudió a un $k_{s}$

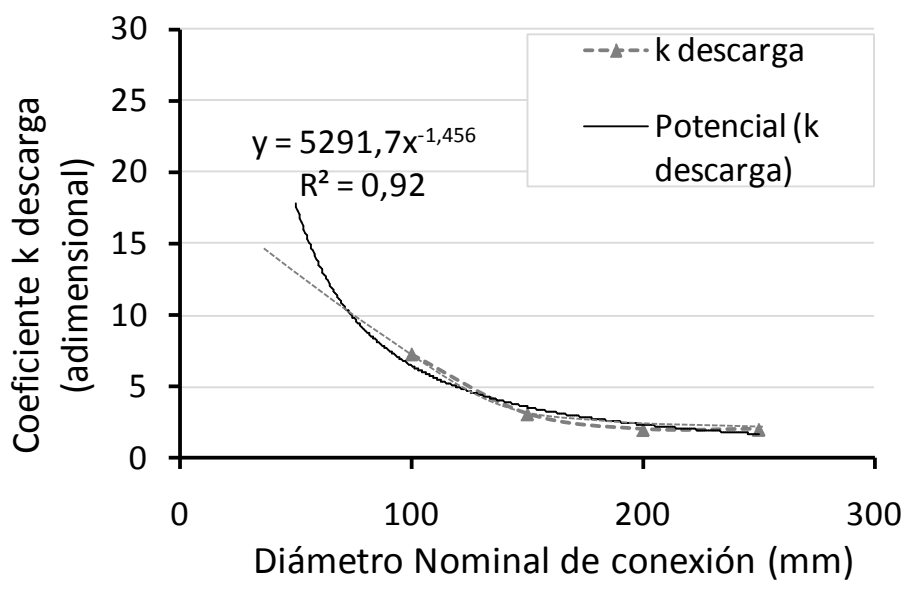

FIGURA C5-24. COEFICIENTE DE PÉRDIAS KS EN FUNCIÓN DEL DIÁMETRO NOMINAL DE LA CONEXIÓN próximo a 7.

De la misma forma, acudiendo a las expresiones usuales para el cálculo del coeficiente de pérdidas que se da en estrechamientos brusco, en función de las secciones del interior del calderín y de la conexión, los valores obtenidos son muy inferiores a los valores estimados, y en cualquier caso inferiores a 5 (Crane, 1987).

Dada la relación del diámetro de la conexión con el coeficiente de descarga $k_{s}$, se ha analizado la magnitud de la perturbación manteniendo el diámetro de la conexión constante $(20 \quad \mathrm{~mm}) \quad \mathrm{y}$ modificando el coeficiente en el rango de valores comentado anteriormente. De manera general, a medida que aumenta el coeficiente de pérdidas en la descarga, aumenta la magnitud de la perturbación y se reduce

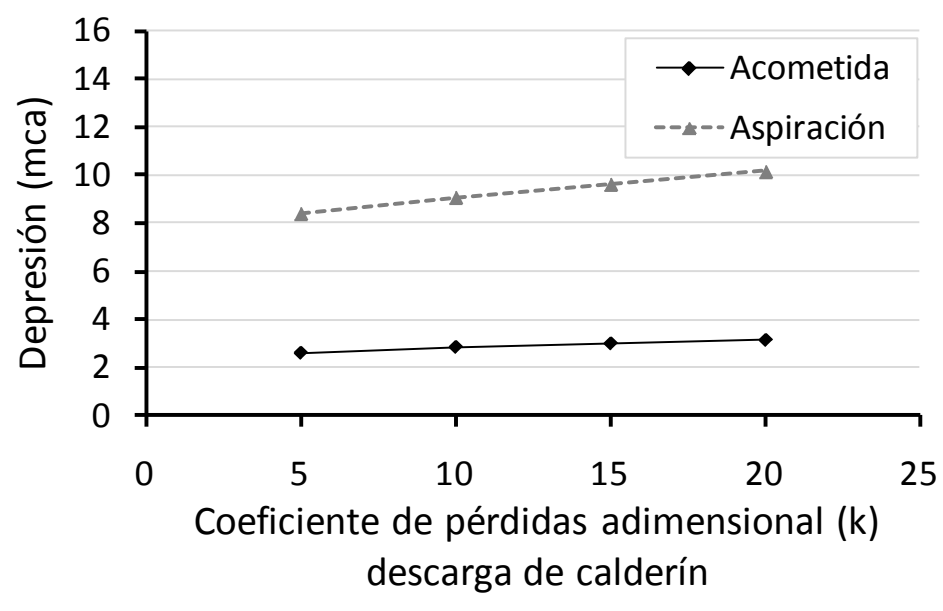

FIGURA C5-25. INFLUENCIA DEL COEFICIENTE DE PÉRDIDAS EN LA DESCARGA DEL CALDERÍN $(\mathrm{VC}=25 \mathrm{~L})$ el aporte del calderín.

Respecto a los valores del coeficiente utilizados en el presente estudio, y tal como se ha comentado, para el ajuste del modelo, se ha acudido a una conexión de $20 \mathrm{~mm}\left(3 / 4^{\prime \prime}\right)$ de diámetro con un valor de $k_{s}$ próximo a 7 . Esta misma configuración se ha utilizado para realizar el análisis sobre la influencia de los parámetros que 
intervienen en el modelo. En cuanto a la fase de dimensionado de la protección, el coeficiente de pérdidas en la descarga se ha aumentado ligeramente, y se programa un coeficiente $k_{s}$ próximo a 12 (valor superior al valor real estimado, y que en cualquier caso estará en el lado de la seguridad al no disponerse de datos reales sobre el comportamiento).

Por otro lado, y dada la influencia del coeficiente de descarga en la magnitud de la depresión, conviene acudir a conexiones del mayor diámetro posible ya que proporcionan menores coeficientes de pérdidas en la descarga. En esta línea, para los volúmenes de calderín considerados (de valor máximo 50 litros), además de los calderines con conexión de $3 / 4 "$ (principalmente diseñados para su instalación en la impulsión de la bomba), comercialmente se dispone de calderines con diámetros de conexión superiores, por ejemplo 1". Del mismo modo, algunos fabricantes disponen de calderines antieariete especialmente indicados para la protección de instalaciones frente a los fenómenos transitorios. Se trata de depósitos de similares características a los calderines de membrana convencionales, pero con una conexión de mayor diámetro (generalmente 3 " frente a los de $3 / 4^{\prime \prime}$ ) y mayores presiones de timbrado. En la medida de lo posible será conveniente acudir a este tipo de elementos para realizar la protección.

\section{Número de calderines en aspiración}

Una vía para reducir las solicitaciones, modificando la capacidad resistente de la protección, se consigue mediante la instalación de varias unidades de calderines (a modo de batería) que tengan un aporte mayor que el conseguido con un único calderín que totalice el mismo volumen. Para analizar este comportamiento se ha simulado con Allievi la descarga que se da en la instalación de referencia con la incorporación de un único calderín de 50 litros (1C), y su comparación con el comportamiento de dos vasos de expansión que totalicen dicho volumen (2C), manteniendo en todo caso condiciones análogas de conexión (en el caso de instalar dos vasos, estos se conectan a un único ramal que funciona a modo de colector).

Analizando el balance de caudales que se genera durante los primeros instantes del arranque de la bomba (Figura C5-26) se puede observar que la evolución del caudal detraído de la red varía sensiblemente al instalar un segundo vaso, retrasándose su solicitación e incluso detrayendo un caudal mayor que con un único calderín. Este retraso en la detracción de caudal de red está justificado por el mayor aporte de agua desde los dos calderines (el caudal máximo aportado es superior al contar con varios vasos). Esto puede atribuirse a la mejora de la descarga ya que es posible reducir las pérdidas al aumentar la sección útil de paso y por tanto aportar un mayor caudal. El retraso en la extracción de caudal de red junto con la evolución más lenta en el proceso favorece la aparición de menores depresiones durante el arranque del grupo. 


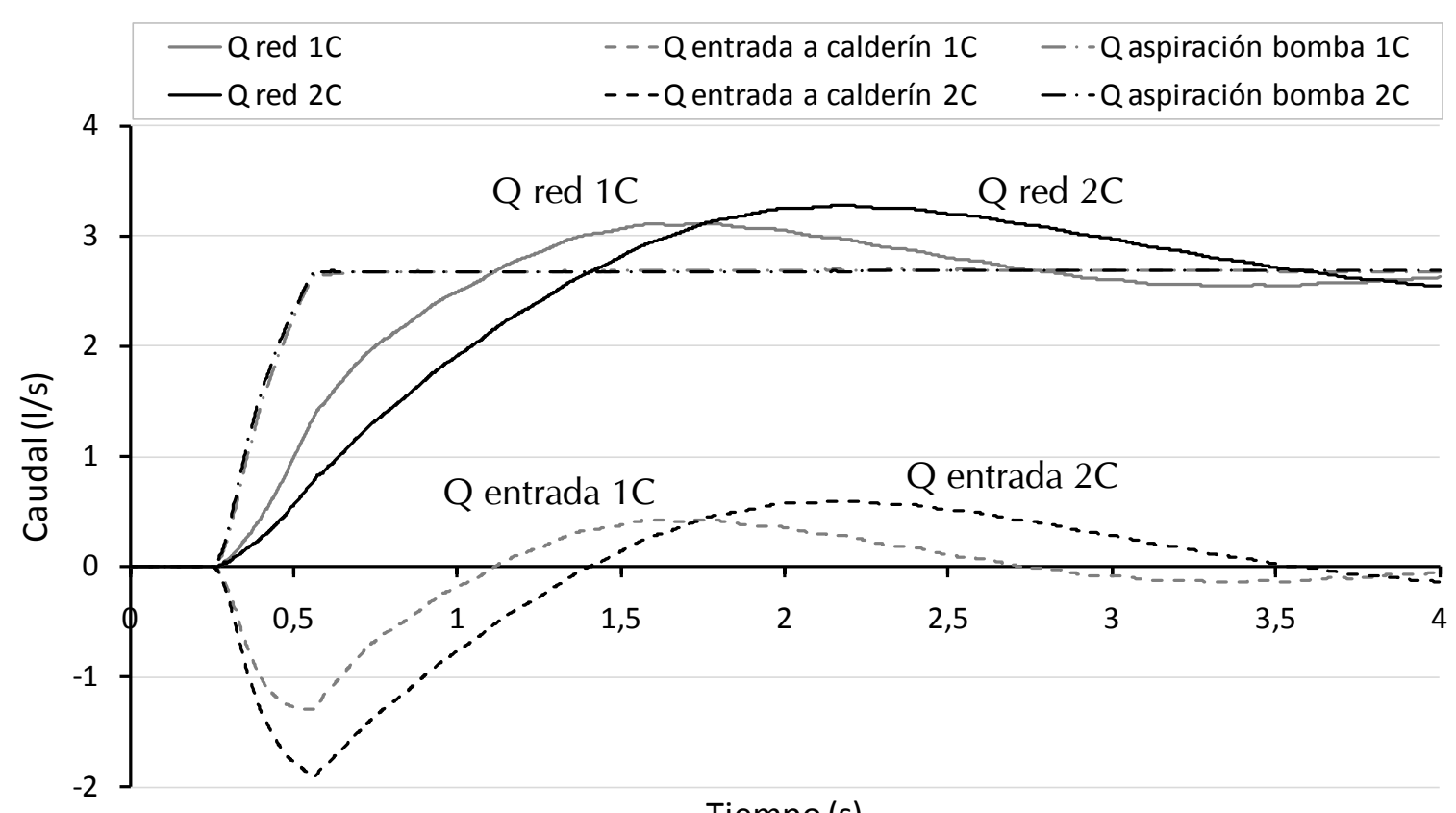

Tiempo (s)

FIGURA C5-26. COMPARACIÓN ENTRE EL COMPORTAMIENTO DE UNO O DOS VASOS DE EXPANSIÓN

Por otro lado, si se analiza la influencia de instalar varios vasos de expansión (con el correspondiente aumento del volumen útil de agua disponible), se puede apreciar una reducción de las solicitaciones, consiguiéndose una mayor protección que con la instalación de un único calderín de volumen equivalente (Figura C5-27). Para el caso estudiado, esta reducción es más significativa al aumentar de uno a dos vasos que en sucesivos

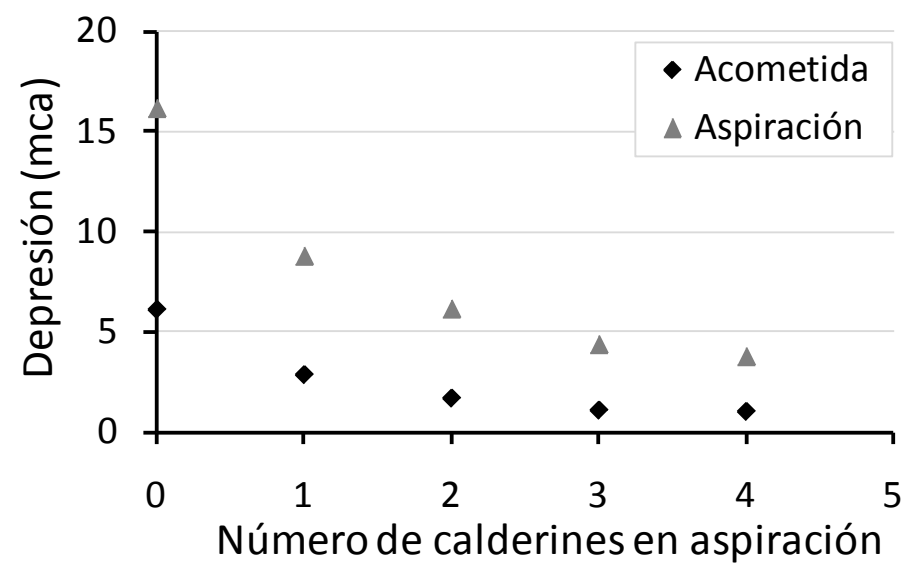

FIGURA C5-27. INFLUENCIA DEL NÚMERO DE CALDERINES EN LA ASPIRACIÓN ( $V=25$ LITROS) aumentos.

En el caso extremo, la disponibilidad de multitud de calderines con volumen útil suficiente y correctamente hinchados, reducirían la caída de presión máxima a valores estrechos (tendiendo a valores próximos a la caída de presión en régimen permanente por las pérdidas de fricción). En esta situación el aporte de caudal a la bomba durante los primeros instantes de arranque se asociaría principalmente a la batería de calderines, laminando y retrasando la solicitación de caudal de red. 
En la Figura C5-28 se muestra la evolución del caudal y presión cuando se instalan 4 calderines en aspiración. La presión en el interior del calderín (superior en todo momento a la presión en su punto de conexión) sustenta la presión en las proximidades de su punto de instalación, impidiendo la caída excesiva de su valor y tendiendo a presiones similares a las del régimen permanente. Por ello sólo se observa una caída de presión inicial que rápidamente se recupera.

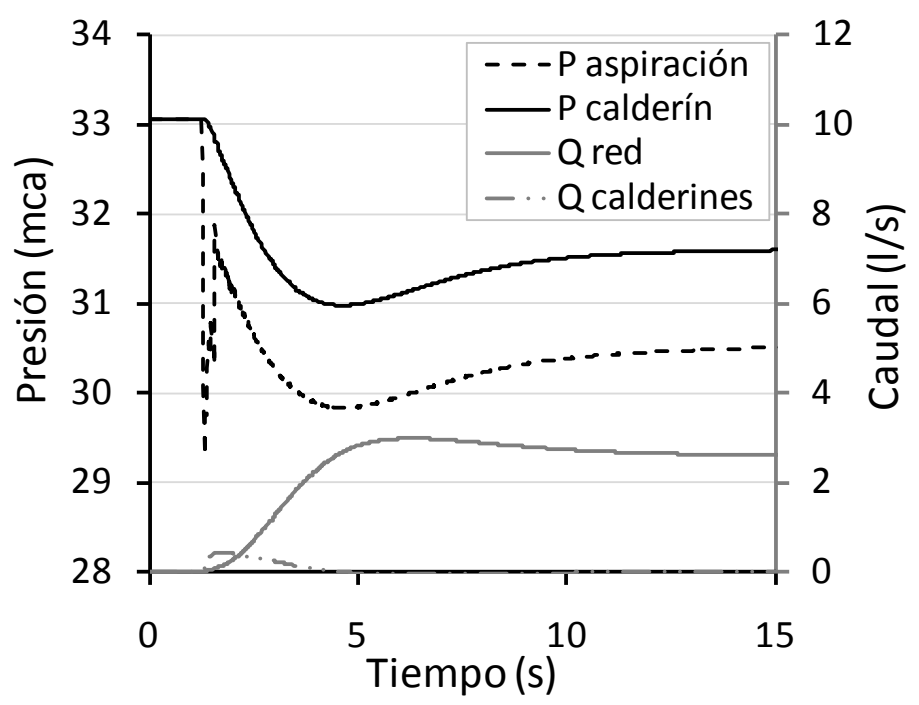

FIGURA C5-28. SIMULACIÓN DE LA RESPUESTA DE LA INSTALACIÓN CON UNA BATERÍA DE 4 CALDERINES DE 25 L

\subsubsection{Proceso de expansión del aire en la descarga}

Para la instalación modelo se han programado diferentes procesos termodinámicos de evolución del aire atrapado en el interior de la vejiga durante su expansión cuando tiene lugar la descarga del calderín (Figura C5-29).

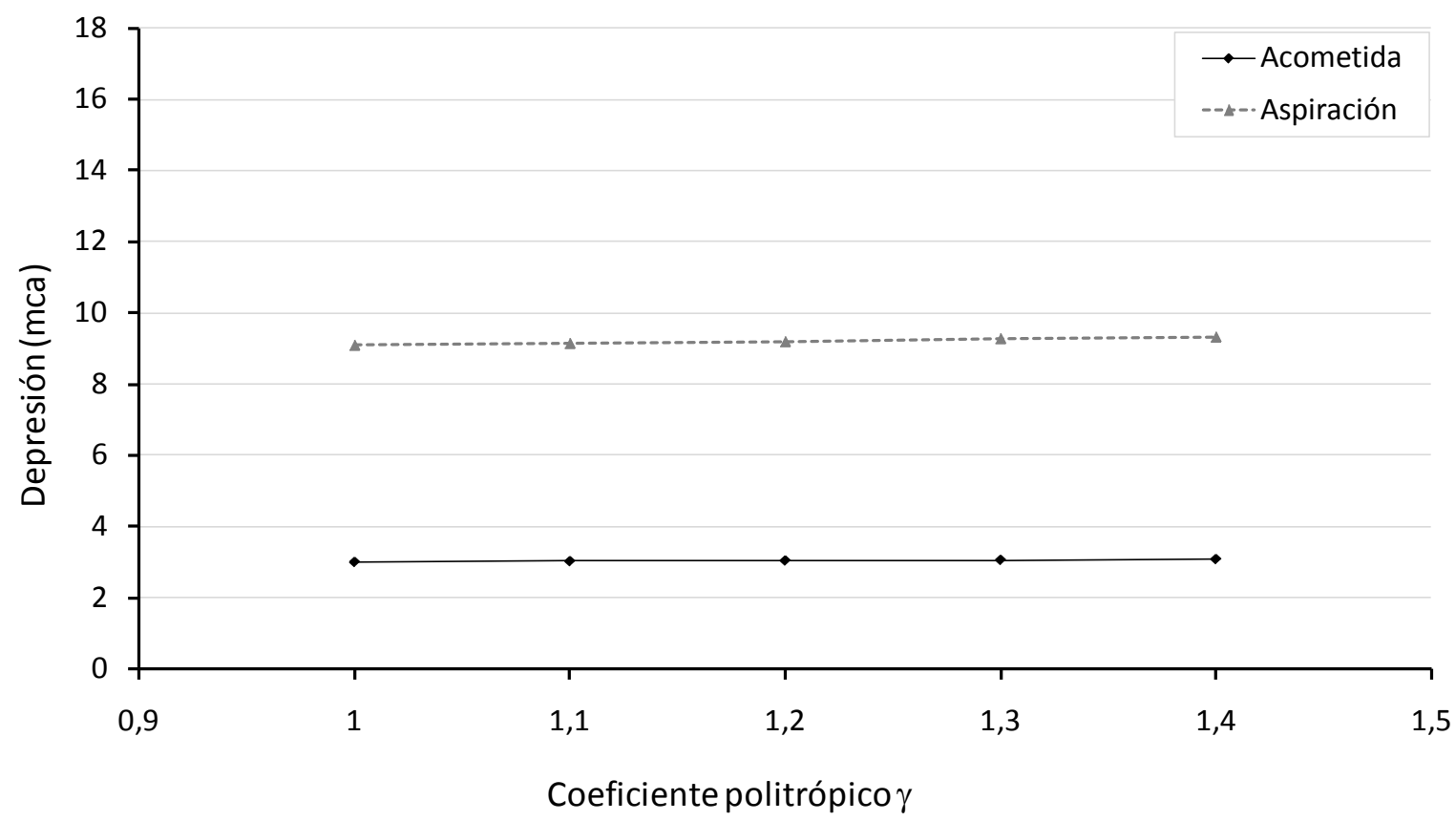

FIGURA C5-29.INFLUENCIA DEL COEFICIENTE POLITRÓPICO DE EXPANSIÓN DEL GAS (V=25 LITROS)

Se han programado valores correspondientes al proceso adiabático, caracterizado por un valor del coeficiente politrópico de 1,4. Este valor ajusta el comportamiento para dinámicas rápidas de expansión sin intercambio de calor, tal como se estima que tiene 
lugar la descarga del calderín (el aporte del agua para los volúmenes de calderín analizados, puede tener duraciones inferiores a un segundo). Por otro lado y, en el otro extremo se ha programado un proceso isotermo, caracterizado por una expansión de mayor lentitud, permitiendo el intercambio de calor con el exterior. El valor del coeficiente politrópico para este caso es de 1.

Para ambas evoluciones el modelo muestra magnitudes de las solicitaciones próximas, por tanto se considera que no se trata de un parámetro que pueda influir significativamente en instalaciones que cuenten con calderines de características similares a las analizadas. La baja influencia de este parámetro está asociada a la rapidez con la que se origina el fenómeno (el principal aporte tiene una duración inferior a 1 segundo), junto con el reducido volumen de aire que entra en juego en la expansión. Para instalaciones protegidas con este elemento, pero que cuentan con volúmenes muchos mayores es posible que la influencia de este parámetro sea mayor.

\subsubsection{Influencia del caudal del grupo de presión}

Aun siendo reducido el volumen de agua aportado por el calderín, a medida que aumenta el caudal del grupo la solicitación de volumen de agua aumenta, siendo por tanto necesario un mayor aporte para limitar la caída de presión. Como se ha comprobado el aumento del caudal del grupo conduce a la necesidad de instalar volúmenes de calderín mayores, o a la instalación de varios vasos de expansión que favorezcan el aporte auxiliar al grupo.

\section{Instalaciones con caudal de diseño inferior a $5 \mathrm{l} / \mathrm{s}$}

Tal como se muestra en la Figura C5-30, para la instalación de referencia se ha modelado diferentes grupos de presión cuyas curvas características están definidas en el capítulo anterior, analizado la mejora conseguida con la instalación de un calderín en aspiración de 25 litros, con una conexión de 3/4" (asumiendo un coeficiente de pérdidas $\mathrm{k}_{\mathrm{s}}=12$, valor ligeramente superior al obtenido en la validación del modelo).

El calderín modelado consigue una reducción similar de la caída de presión para los caudales analizados (para el rango de caudales existe un volumen útil suficiente). En lo que respecta a la protección de la instalación, si se atiende al valor máximo recomendado según la Figura C5-1, los escenario con menor caudal de diseño podrían mantener una conexión en directo con bombas de velocidad fija; por un lado, el grupo B1 (con caudal de diseño de1,2 l/s) no necesitaría protección, y por otro lado, el grupo B2 (con caudal de 2,3 l/s) precisa la instalación de un calderín en aspiración con volumen de 25 litros (también protege correctamente con un volumen de 10 litros). 
Para el resto de grupos de presión la protección analizada resultaría insuficiente ya que se genera una caída de presión superior al valor máximo recomendado, por ello para estas situaciones sería necesario analizar otra protección que asegure unos niveles mínimos de presión suficientes en la aspiración de la bomba.

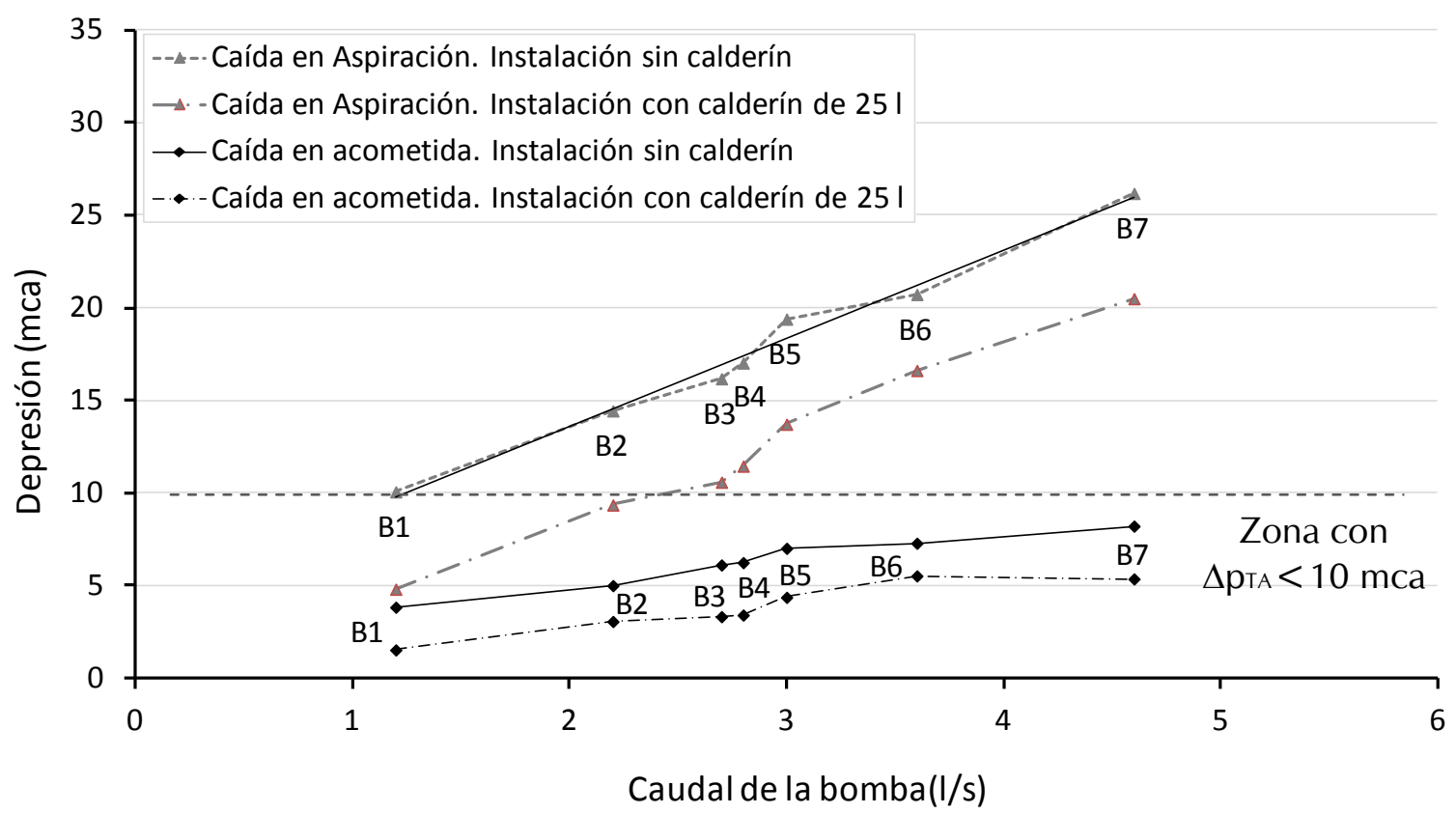

FIGURA C5-30. INFLUENCIA DEL CAUDAL DE LA BOMBA EN LA PROTECCIÓN CON UN CALDERÍN DE 25 L

Adicionalmente se han realizado diferentes simulaciones para los mismos grupos de presión pero variando las características constructivas de la protección. Entre las soluciones adoptadas se ha variado el volumen total del calderín de aspiración, el número de vasos de expansión instalados en batería o incluso la modificación de las características constructivas de la protección para favorecer el aporte de agua del calderín. El resultado obtenido es similar al mostrado en la Figura C5-31. En esta figura se muestra la reducción en la caída de presión para algunas de las soluciones constructivas analizadas en la aspiración del grupo.

Como puede apreciarse, seleccionando convenientemente el volumen y número de calderines es posible conseguir la protección para los diferentes grupos de bombeo, y mantener la caída máxima recomendada durante el arranque del grupo dentro del valor máximo establecido al inicio de este capítulo. Concretamente, la protección conseguida con la instalación de dos calderines de 25 litros cubriría caudales de diseño de hasta $3 \mathrm{l} / \mathrm{s}$, siendo necesario acudir a un tercer vaso para caudales próximos a $4 \mathrm{l} / \mathrm{s}$, e incluso a dos de 50 litros (con una conexión mínima de $35 \mathrm{~mm}$ ) para caudales de hasta $5 \mathrm{l} / \mathrm{s}$. 


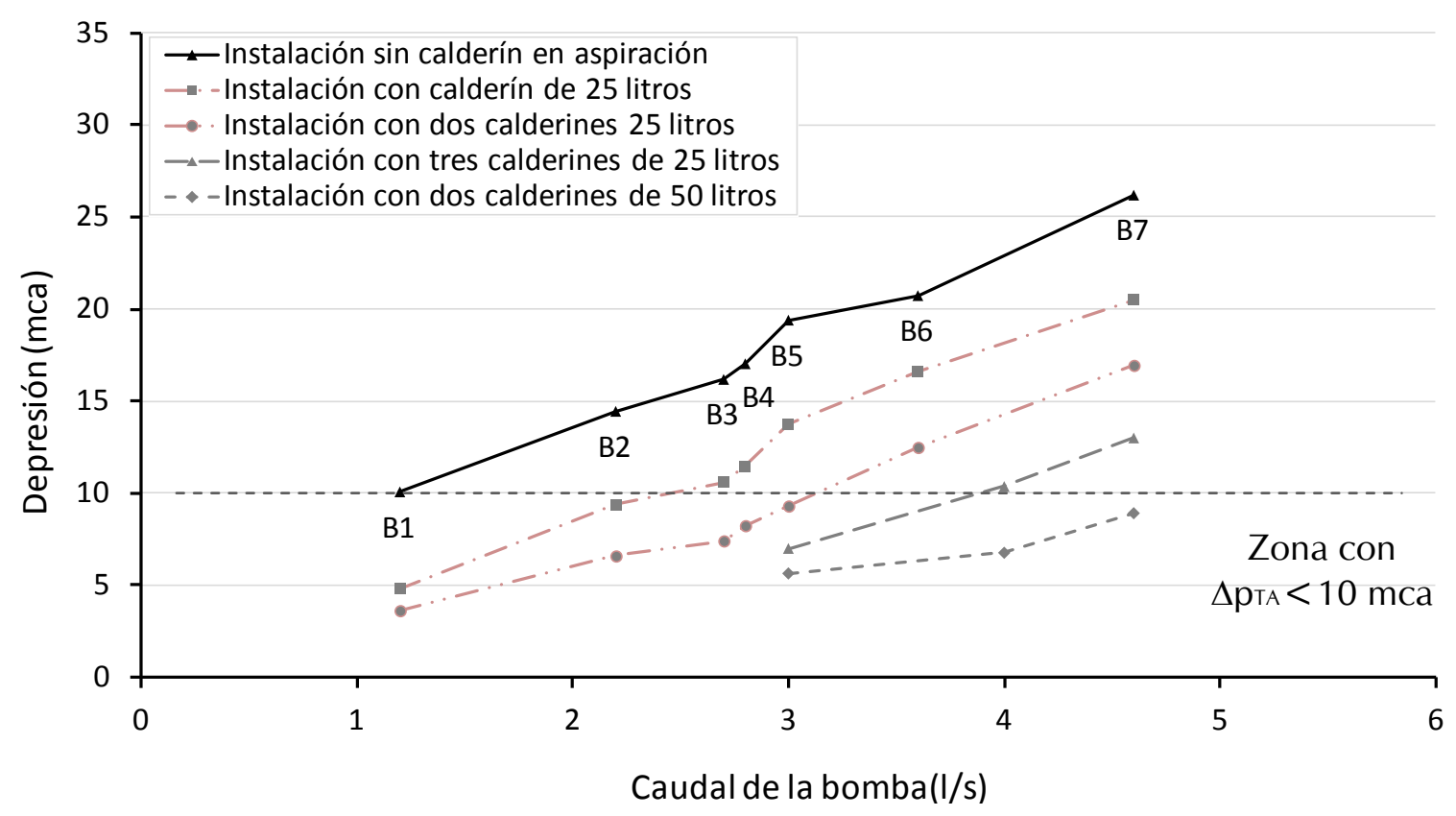

FIGURA C5-31. INFLUENCIA DEL CAUDAL DE LA BOMBA PARA DIFERENTES PROTECCIONES EN ASPIRACIÓN

Instalaciones con caudal de diseño superior a $5 \mathrm{l} / \mathrm{s}$

Tal como se comprobó en el capítulo anterior, las instalaciones con un caudal de diseño superior a $5 \mathrm{l} / \mathrm{s}$ precisan la incorporación de varias bombas que totalicen el caudal de diseño. En tal caso, y para desfases en el arranque de bombas sucesivas con una duración normal (superiores a 2 segundos), las solicitaciones son inferiores a las originadas por un único grupo que totalice dicho caudal. Una consideración necesaria respecto al desfase en el arranque de una segunda bomba parte por cumplir con unas condiciones mínimas de la protección; debe disponer de un volumen mínimo de agua para arranques consecutivos y una masa presurizada de aire que asegure el sustento de la presión. Estas consideraciones son más críticas a medida que se dispone de mayor número de bombas en paralelo, o los tiempos de desfase entre arranques consecutivos se reducen.

La Figura C5-32 muestra la influencia de instalar un calderín de 25 I en aspiración para la instalación de referencia cuando ésta está equipa con dos bombas que totalizan un caudal próximo a $5 \mathrm{l} / \mathrm{s}$. Como puede observarse, para el desfase programado de 2 segundos se mantiene la reducción de las solicitaciones con el calderín modelado (CC), si bien el porcentaje de protección en el arranque de la segunda bomba es ligeramente inferior a la reducción que se da en el arranque de la primera $(41,6 \%$ frente al $31,6 \%$ del segundo arranque). La razón del comportamiento anterior hay que buscarla en la evolución en el interior del calderín y principalmente en lo correspondiente a la presión del aire y su relación con el caudal aportado. Con posterioridad al primer arranque, la presión en la aspiración desciende igual que sucede con la presión en el interior del calderín. Antes del arranque de la segunda bomba 
(próximo a $t=4 \mathrm{~s}$ ), la presión en el calderín comienza a recuperarse, disminuyendo el caudal de salida del calderín hasta la anulación o posterior recarga. En este instante $(t=5 \mathrm{~s})$ comienza el aporte para el arranque de la segunda bomba, originándose una despresurización mucho mayor que en el caso anterior y consecuentemente una caída de presión más notable.

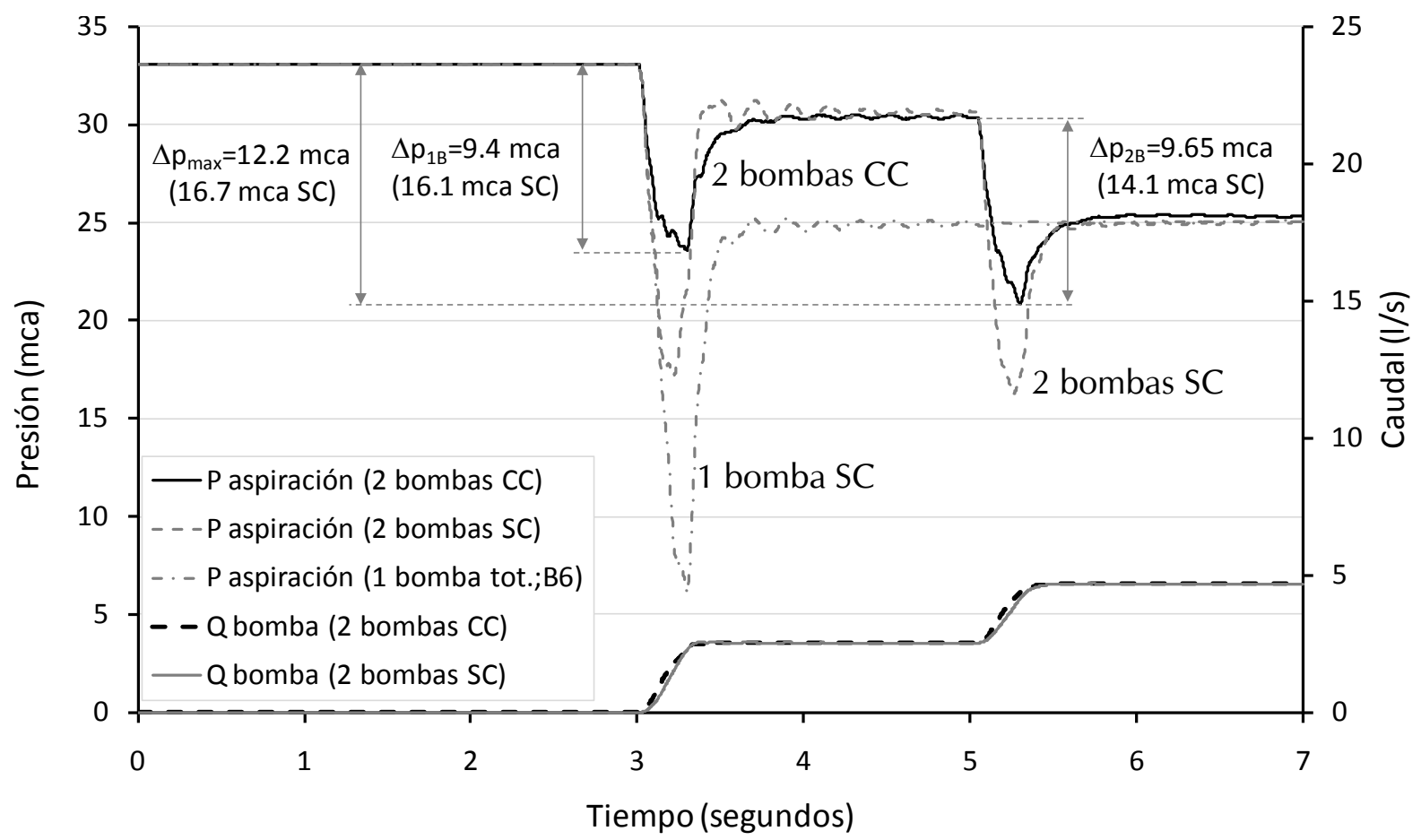

FIGURA C5-32. EFECTOS DERIVADOS DEL ARRANQUE DE DOS BOMBAS EN PARALELO (DESFASE $=2$ S)

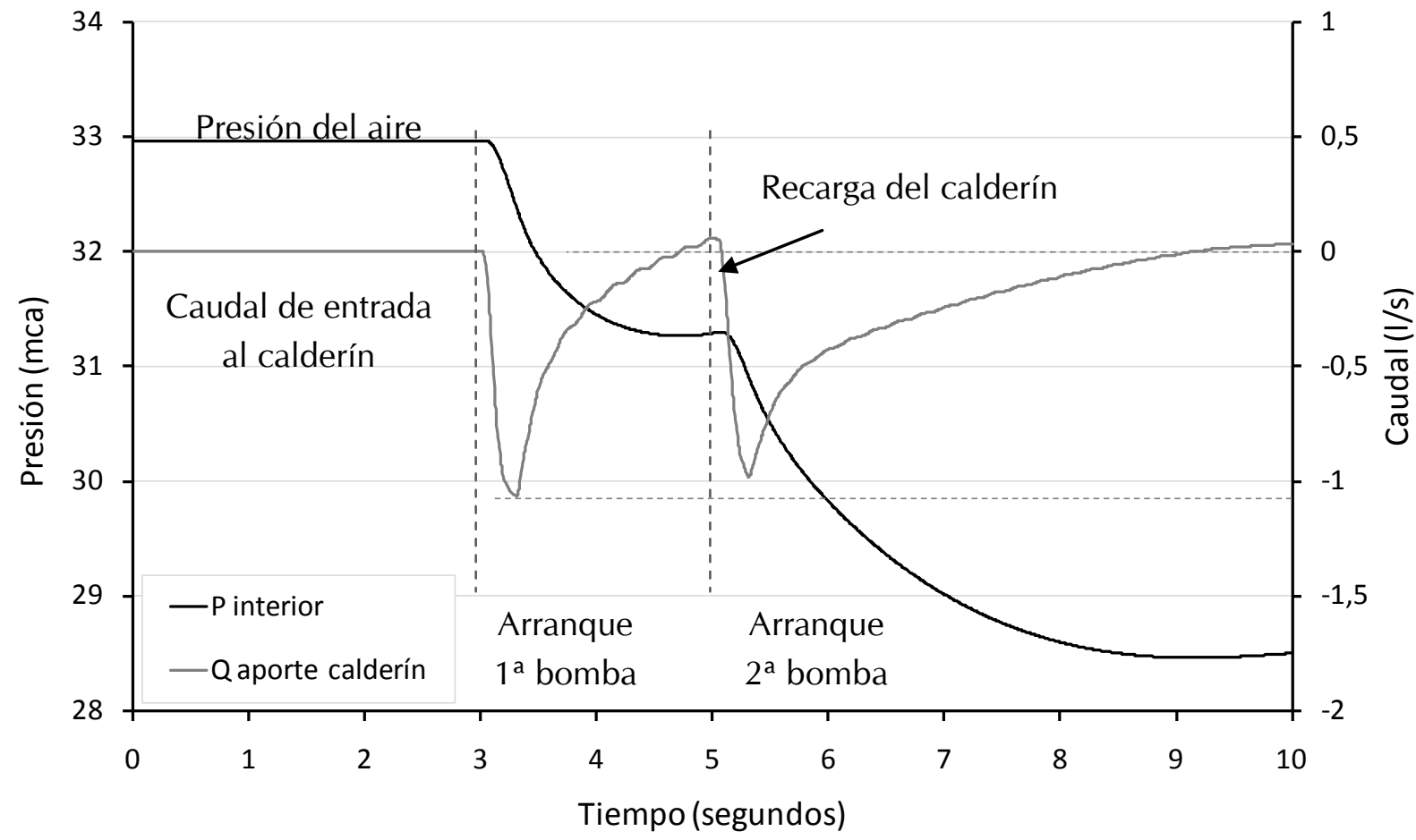

FIGURA C5-33. EFECTOS DERIVADOS DEL ARRANQUE DE DOS BOMBAS EN PARALELO (DESFASE = 2 S), CC 
Respecto al caudal aportado, se puede apreciar que en el segundo arranque hay una ligera reducción del valor máximo, si bien ambas variaciones son similares. Un efecto a considerar es el cambio de sentido del flujo de entrada al calderín una vez arranca la segunda bomba. Un adelantamiento del arranque (antes de la recarga) no mejora la protección, aportando un mismo caudal máximo (próximo a 1 l/s).

En cuanto a la evolución del volumen útil de agua en el calderín, éste mantiene un valor suficiente durante el arranque de ambas bombas, observándose una reducción a medida que se origina el aporte auxiliar. Dado que la presión de hinchado es inferior a la presión de régimen, es posible rellenar el volumen de agua del calderín, efecto más sensible para el funcionamiento de la primera

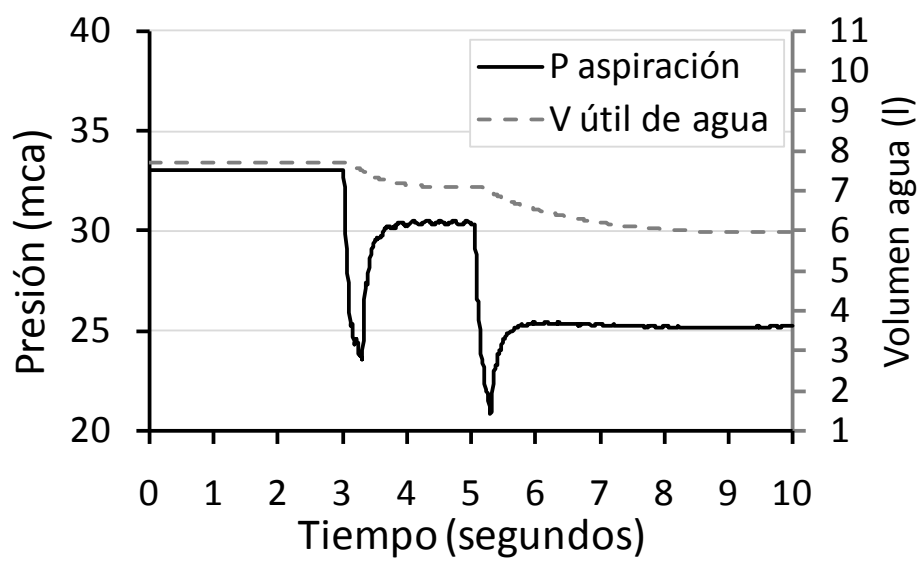
bomba en régimen.

FiGuRa C5-34. EVOLUCIÓN DEL VOLUMEN DE AGUA EN EL CALDERÍN Y DE LA PRESIÓN EN LA ASPIRACIÓN

Si el desfase entre dos arranques consecutivos se reduce de forma excesiva (por ejemplo $0,25 \mathrm{~s}$ ), la perturbación originada por la segunda bomba aumenta reduciéndose por tanto la protección del calderín tal como se aprecia en la Figura C5-33.

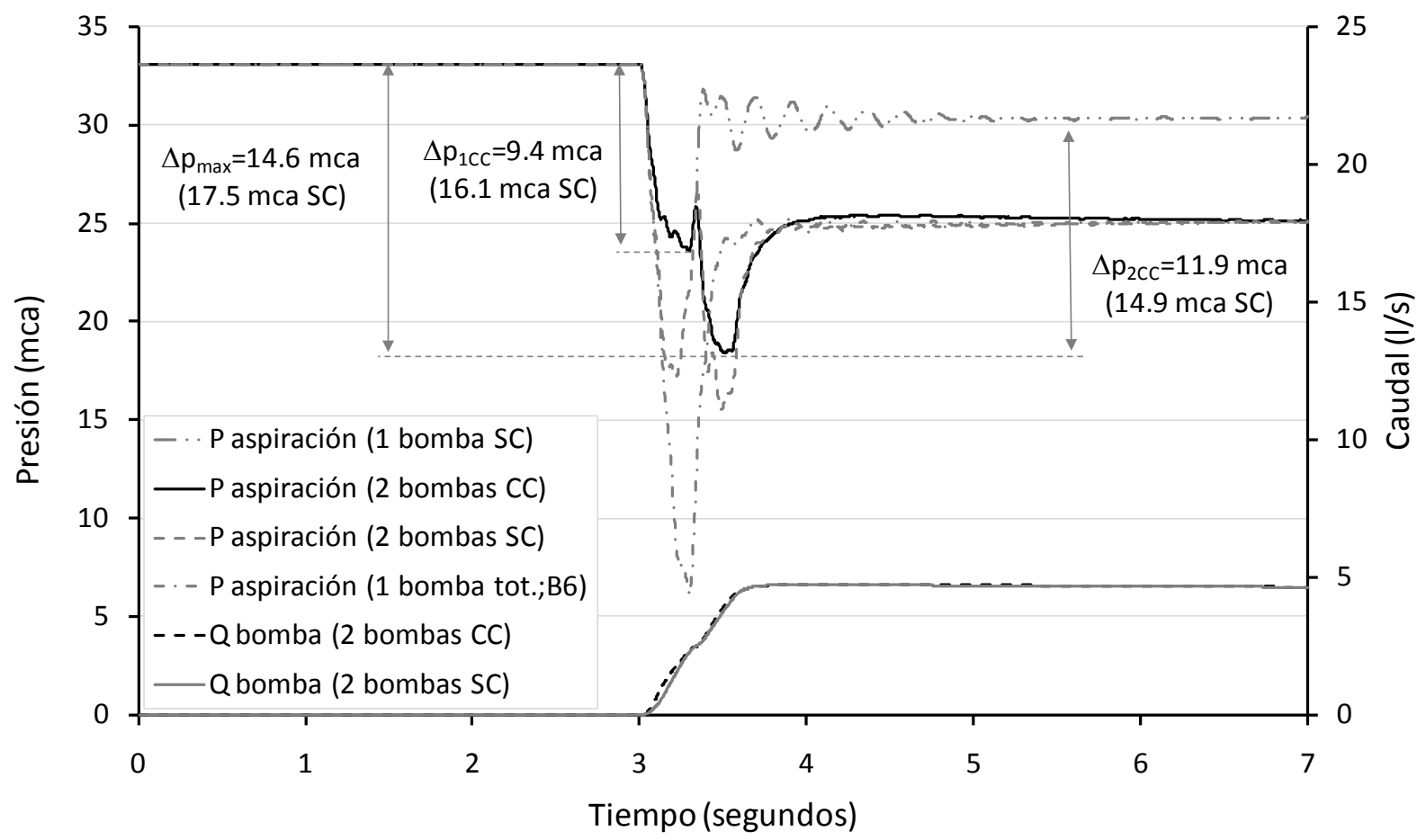

FIGURA C5-35. EFECTOS DERIVADOS DEL ARRANQUE DE DOS BOMBAS EN PARALELO (DESFASE =0,25 S) 
En cualquier caso para tiempos razonables de desfase entre bombas se estima una reducción en las solicitaciones por el arranque de las bombas con la instalación del calderín en aspiración. Se tomará para futuros análisis un desfase mínimo de 2 s.

De forma similar a la mostrada en la Figura C4- 39, en la que se relacionada para diferentes diámetros de tubería de aspiración y diferente número de bombas, las solicitaciones en función del caudal del grupo de bombeo, la Figura C5-36 muestra las solicitaciones para una instalación equipada con diferentes grupos de presión (para simplificar se presenta sólo la respuesta para un único diámetro de la conducción de aspiración de $74 \mathrm{~mm}$ ). En la figura se comparan las solicitaciones para la instalación protegida con calderín de 50 litros (CC) frente a la instalación con aspiración en directo y sin calderín en aspiración (SC).

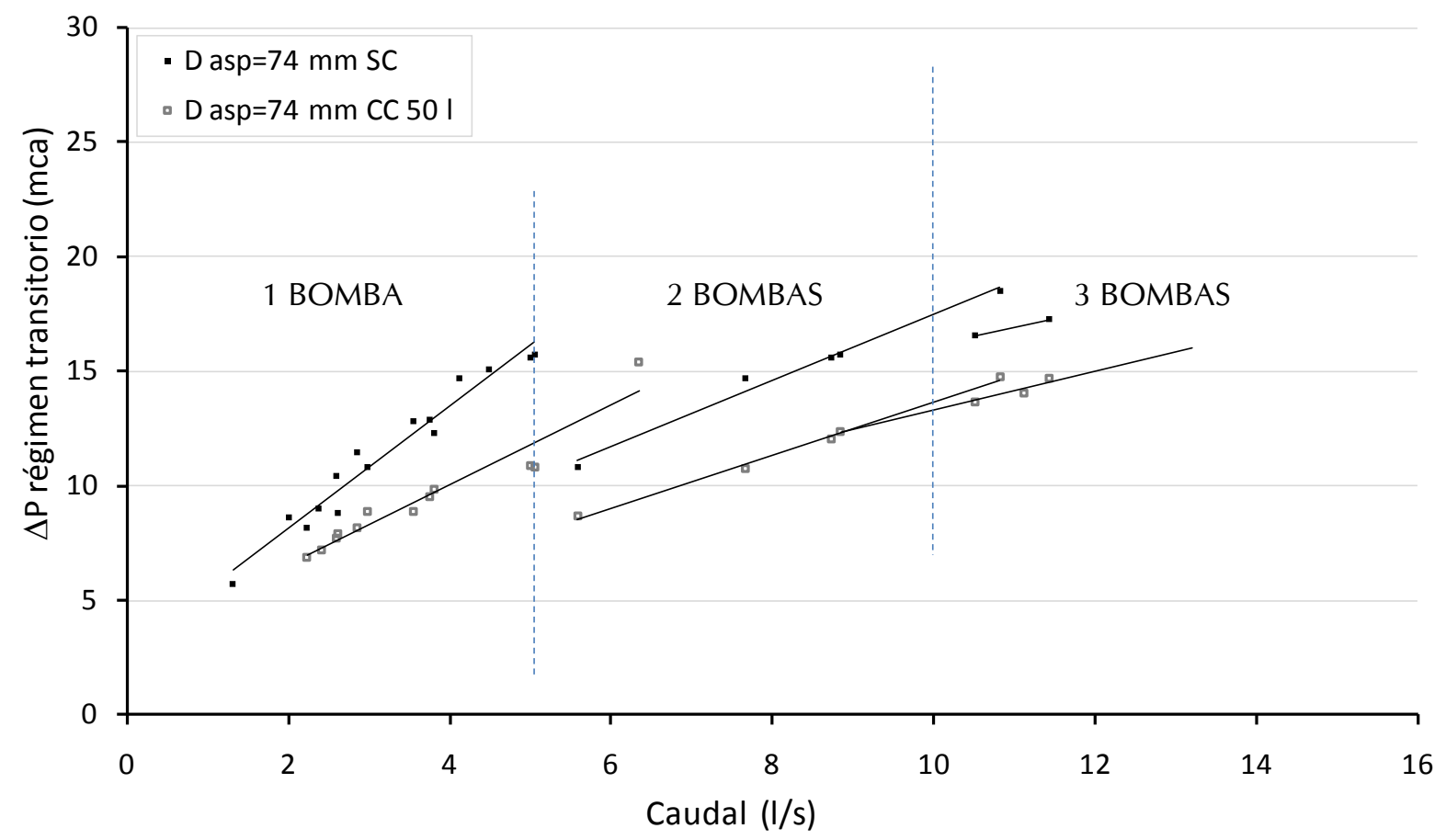

FIGURA C5-36. INFLUENCIA DEL CAUDAL Y NÚMERO DE BOMBAS PARA LA PROTECCIÓN CON CALDERÍN DE 50 L

La protección de la instalación con un calderín en aspiración reduce las solicitaciones tal como sucede en la instalación de referencia. Del mismo modo, se obtiene de nuevo una evolución lineal de las series asociadas a diferente número de bombas. Los caudales analizados para este diámetro originan velocidades desde $0,4 \mathrm{~m} / \mathrm{s}$ hasta velocidades próximas a $3 \mathrm{~m} / \mathrm{s}$, si bien es conveniente limitar la velocidad en la conducción de aspiración a valores máximos de $2 \mathrm{~m} / \mathrm{s}$ o inferiores.

Bajo esta configuración es posible mantener una conexión en directo en la que se limite la caída al valor recomendado de10 mca, por ejemplo para caudales menores a 4 l/s, previa instalación de un calderín en aspiración de volumen mínimo de 50 litros. Para caudales superiores a éste sería necesaria una mayor protección, por ello, se ha 
analizado el grado de protección a partir de la instalación de diferente número de vasos de expansión o a partir de la modificación de la conexión del calderín (tal como se muestra en la Figura C5-37). Para un caudal de hasta $5 \mathrm{l} / \mathrm{s}$ y una única bomba, sería posible proteger la instalación a partir de dos calderines de 50 litros, o bien a partir de la instalación de un calderín cuyo ramal y diámetro de conexión fuera como mínimo de $50 \mathrm{~mm}\left(2^{\prime \prime}\right)$.

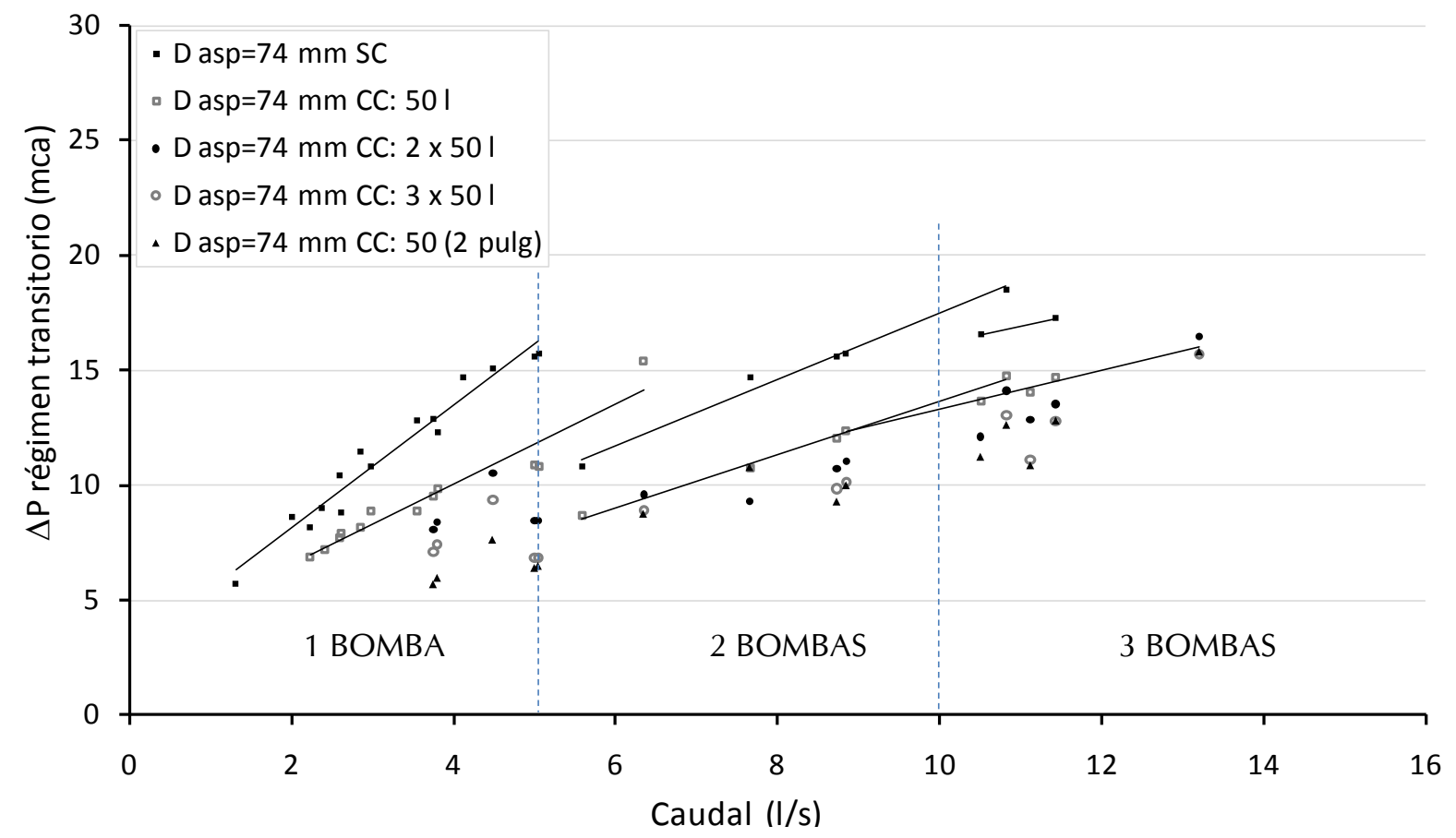

FIGURA C5-37. INFLUENCIA DEL CAUDAL Y NÚMERO DE BOMBAS PARA DIFERENTES ESQUEMAS DE PROTECCIÓN

Del mismo modo sería posible mantener la protección para un caudal máximo de $9 \mathrm{l} / \mathrm{s}$. A partir de este valor, se supera la velocidad de $2 \mathrm{~m} / \mathrm{s}$ en la conducción de aspiración al mismo tiempo que aumentan de forma notable las pérdidas en régimen permanente tal como se puede apreciar en la Figura C5-38, que deriva del análisis realizado en el capítulo anterior.

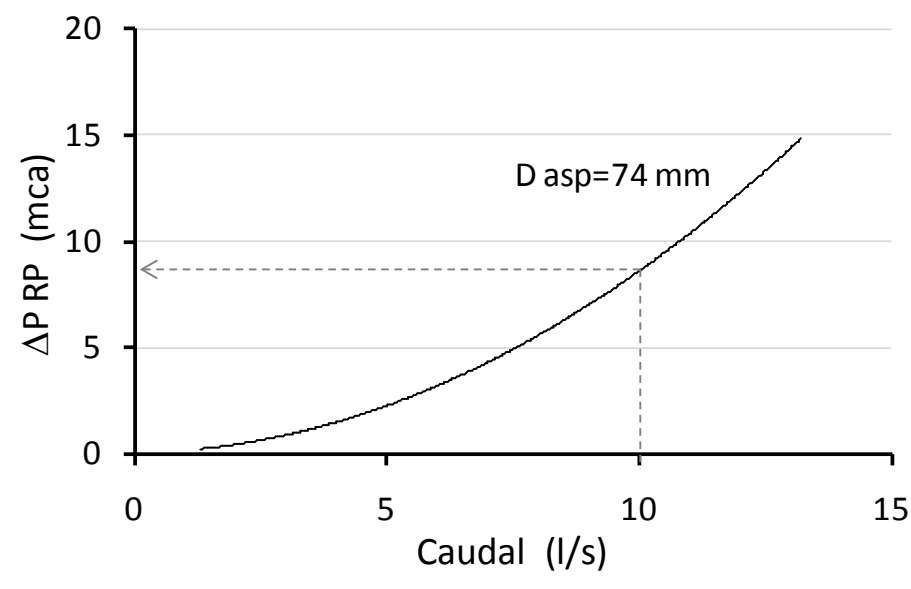

FIGURA C5-38. CAÍDA DE PRESIÓN EN RÉGIMEN PERMANENTE PARA UN DIÁMETRO DE $74 \mathrm{MM}$

El mismo análisis puede ser desarrollado para diferentes diámetros, siendo el procedimiento mostrado la base para la protección de la instalación teniendo en cuenta la caída máxima establecida, así como el comportamiento aceptable en régimen permanente y la limitación de la velocidad máxima en la conducción. 


\subsection{Dimensionado de la PROTECCIÓN}

El análisis y dimensionado de la protección necesaria se ha realizado para una instalación de características similares a las mostradas por la instalación de referencia del estudio, si bien se destaca la gran similitud que presenta la mayor parte de instalaciones interiores en el entorno residencial, los resultados obtenidos pueden orientar sobre el comportamiento asociado a otro tipo de instalaciones (para escenarios no asimilables al de referencia debe realizarse el estudio de protección de forma particularizada de acuerdo a las recomendaciones fijadas en la Figura C5-1). Las características básicas de la instalación de referencia se detallan en la siguiente tabla:

TABLA C5-2. CONSIDERACIONES SOBRE LA CAPACIDAD DE PROTECCIÓN

\begin{tabular}{lc}
\hline Característica constructiva & Valor mínimo \\
\hline Diámetro red general & $150 \mathrm{~mm}$ \\
\hline Longitud tubería de aspiración $^{2}$ & $20 \mathrm{~m}$ \\
\hline Distancia conexión calderín-bomba & $4 \mathrm{~m}$ \\
\hline Longitud ramal de conexión del calderín & $1 \mathrm{~m}$ \\
\hline Diámetro del ramal de conexión & Conexión del calderín \\
\hline
\end{tabular}

Respecto al tipo de grupo de presión analizado se ha mantenido el comportamiento asociado a un grupo de velocidad fija, con un tiempo de arranque de 0,55 segundos. Para grupos de velocidad variable, y aunque estos presentan una menor severidad en su comportamiento, no se ha acudido a una protección inferior. Esta decisión está sujeta a las consideraciones establecidas en la reglamentación vigente para grupos de velocidad variable, ya que ante una avería del variador el grupo de presión debe poder garantizar el suministro (funcionamiento como grupo de velocidad fija).

Realizado el análisis se destaca que, existiendo una presión de hinchado y un volumen de agua útil suficiente en el calderín, los parámetros que mayor influencia presentan son la proximidad del calderín a la bomba y capacidad de aporte de caudal a la instalación. En esta línea las características del calderín modelado disponen de volúmenes de 25 y 50 litros, y conexión de $20 \mathrm{~mm}\left(3 / 4^{\prime \prime}\right)$, ya que se trata del valor comercial más usual en este tipo de instalaciones. También se ha diseñado protecciones equipadas con conexión de $50 \mathrm{~mm}\left(2^{\prime \prime}\right)$, que aunque no es una conexión comercialmente distribuida presenta un comportamiento más indicado para este tipo de protección. Por ello, se hace hincapié en la necesidad de desarrollar comercialmente esta línea de protección, ofreciendo para este propósito volúmenes de calderín reducidos con conexiones de más de $3 / 4 "$, por ejemplo $2 "$.

\footnotetext{
${ }^{2}$ Considerada desde la conexión de la acometida hasta el grupo de presión con valor uniforme
} 
Adicionalmente, se deben tener presentes las siguientes consideraciones sobre la protección de la instalación:

- Para un mismo caudal, el aumento del número de bombas reduce las solicitaciones, y por tanto la depresión generada por el arranque del grupo de bombeo.

- Mayores conexiones de calderín favorecen la protección de la instalación.

- Acudir a volúmenes de calderín mayores no es una solución que mejore notablemente la protección (si ambos disponen de suficiente volumen de agua).

- El volumen útil de agua puede estimarse a partir del caudal del grupo y el tiempo previsto de arranque.

- Mayor número de calderines reduce las solicitaciones al mejorar el aporte de agua, si bien constructivamente puede que no sea una solución atractiva.

- La presión de hinchado debe ser suficiente para garantizar el aporte auxiliar de agua, al mismo tiempo que debe permitir el relleno del calderín con posterioridad al arranque.

- Se debe garantizar el desfase entre arranques para instalaciones con varias bombas en paralelo, de forma que no se superpongan los efectos transitorios asociados a cada una.

\subsubsection{Criterio de dimensionado de la protección}

\subsubsection{Volumen mínimo necesario y número de calderines}

A partir de los resultados obtenidos para la protección en instalaciones de diferentes características, se elabora una tabla con la protección mínima necesaria para mantener una caída de presión durante el transitorio de arranque de la bomba, y de la caída máxima en régimen permanente limitada según la Figura C5-1.

La protección establecida mantiene dos volúmenes de calderín; 25 y 50 litros, con dos conexiones posibles; $20 \mathrm{~mm}$ y $50 \mathrm{~mm}$. A modo general, las instalaciones con caudal de diseño inferior al valor analizado (15 l/s), pueden ser protegidas siempre que la caída de presión en régimen permanente sea inferior a 1 bar, ya que mediante la instalación de calderines en aspiración, es posible reducir el caudal detraído de red y con éste la caída de presión transitoria derivada. Para instalaciones con caudales de diseño superiores a $15 \mathrm{l} / \mathrm{s}$ se recomienda realizar el estudio particularizado de la protección más conveniente. 
TABLA C5-3. PROTECCIÓN NECESARIA EN FUNCIÓN DEL CAUDAL DE LA BOMBAY DIÁMETRO DE ASPIRACIÓN

\begin{tabular}{|c|c|c|c|c|c|c|}
\hline $\begin{array}{l}\text { Diámetro } \\
\text { de } \\
\text { aspiración }\end{array}$ & $\begin{array}{c}\text { Velocidad } \\
\text { agua }\end{array}$ & $\begin{array}{c}\text { Caudal de } \\
\text { diseño } \\
\text { del grupo }\end{array}$ & $\begin{array}{c}\text { Número } \\
\text { de } \\
\text { bombas }\end{array}$ & $\begin{array}{c}\text { Número } \\
\text { de } \\
\text { calderines }\end{array}$ & $\begin{array}{l}\text { Volumen } \\
\text { unitario } \\
\text { calderín }\end{array}$ & $\begin{array}{l}\text { Diámetro } \\
\text { conexión }\end{array}$ \\
\hline$(\mathrm{mm})$ & $(\mathrm{m} / \mathrm{s})$ & $(\mathrm{l} / \mathrm{s})$ & & & (l) & $(\mathrm{mm} / ")$ \\
\hline \multirow{4}{*}{$40-50$} & 0,5 & 0,76 & 1 & 1 & 25 & $25 / 1$ \\
\hline & 1 & 1,52 & 1 & 1 & 25 & $25 / 1$ \\
\hline & 1,5 & 2,28 & 1 & 1 & 25 & $25 / 1$ \\
\hline & 2 & 3,04 & 1 & 2 & 25 & $25 / 1$ \\
\hline \multirow{4}{*}{$50-60$} & 0,5 & 1,15 & 1 & 1 & 25 & $25 / 1$ \\
\hline & 1 & 2,29 & 1 & 1 & 25 & $25 / 1$ \\
\hline & 1,5 & 3,44 & 1 & 1 & 25 & $50 / 2$ \\
\hline & 2 & 4,58 & 1 & 2 & 25 & $50 / 2$ \\
\hline \multirow{4}{*}{$60-70$} & 0,5 & 1,61 & 1 & 1 & 25 & $25 / 1$ \\
\hline & 1 & 3,22 & 1 & 2 & 25 & $25 / 1$ \\
\hline & 1,5 & 4,83 & 1 & 1 & 25 & $50 / 2$ \\
\hline & 2 & 6,43 & 2 & 2 & 25 & $50 / 2$ \\
\hline \multirow{4}{*}{$70-80$} & 0,5 & 2,15 & 1 & 1 & 50 & $25 / 1$ \\
\hline & 1 & 4,30 & 1 & 2 & 50 & $25 / 1$ \\
\hline & 1,5 & 6,45 & 2 & 1 & 50 & $25 / 1$ \\
\hline & 2 & 8,60 & 2 & 2 & 50 & $50 / 2$ \\
\hline \multirow{4}{*}{$80-90$} & 0,5 & 2,77 & 1 & 1 & 50 & $25 / 1$ \\
\hline & 1 & 5,54 & 2 & 2 & 50 & $25 / 1$ \\
\hline & 1,5 & 8,31 & 2 & 1 & 50 & $50 / 2$ \\
\hline & 2 & 11,08 & 3 & 2 & 50 & $50 / 2$ \\
\hline \multirow{4}{*}{$90-110$} & 0,5 & 3,77 & 1 & 1 & 50 & $25 / 1$ \\
\hline & 1 & 7,54 & 2 & 2 & 50 & $25 / 1$ \\
\hline & 1,5 & 11,31 & 3 & 1 & 50 & $50 / 2$ \\
\hline & 2 & 15,09 & 3 & 2 & 50 & $75 / 3$ \\
\hline \multirow{3}{*}{$110-120$} & 0,5 & 5,19 & 2 & 1 & 50 & $75 / 3$ \\
\hline & 1 & 10,39 & 3 & 1 & 50 & $75 / 3$ \\
\hline & 1,5 & 15,58 & 3 & 2 & 50 & $75 / 3$ \\
\hline
\end{tabular}

\subsubsection{Presión de hinchado}

La presión de hinchado debe ser inferior a la presión estática que se origine en la conexión del calderín, de forma que pueda almacenar un volumen útil de agua suficiente al mismo tiempo que disponga de una mínima masa de aire que aporte la energía en forma de presión necesaria para mantener limitada la caída de presión. La presión de hinchado debe ser de 1 bar por debajo de la presión mínima estática garantizada. A modo general se limita a 1 bar el valor mínimo de esta presión. Se deberá tener presente que la presión de prehinchado inicial servida desde fábrica.

$$
p_{h}=p_{\text {minred }}-1 \text { bar }
$$




\subsection{CONSIDERACIONES SOBRE EL DISEÑO DE LA INSTALACIÓN}

\subsubsection{Consideraciones generales}

Aunque el análisis de la protección se ha realizado el funcionamiento de una bomba de velocidad fija, se aconseja que la protección propuesta vaya acompañada de un grupo con variador por su bondad operativa. El calderín debe estar lo más próximo a la aspiración de la bomba, y en derivación respecto a esta conducción, recomendándose su instalación directa sin la interposición de ningún ramal de conexión. También es recomendable acudir a depósitos con entrada y salida independiente.

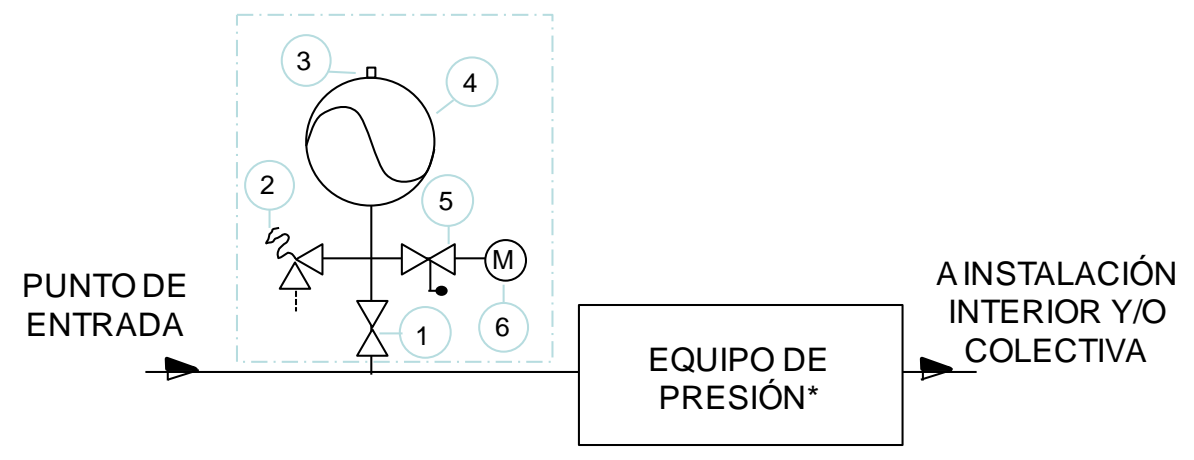
1. Válvula de aislamiento
5. Llave con grifo de vaciado
2. Válvula de alivio
6. Manómetro
3. Válvula de hinchado
*. Con variador de frecuencia
4. Depósito/s hidroneumático/s

FIGURA C5-39. INSTALACIÓN EQUIPADA CON CONEXIÓN DIRECTA Y PROTEGIDA CON CALDERÍN EN ASPIRACIÓN

El calderín puede instalarse en derivación de la tubería de aspiración a partir de un ramal de conexión, o bien directamente insertado sobre esta conducción. En el caso de utilizar un ramal de conexión éste debe incorporar una llave que permita aislar el depósito, y una derivación para la realización de las operaciones de mantenimiento. Para instalaciones que precisen la incorporación de más de un calderín en aspiración se deberá favorecer el Ilenado y vaciado de los diferentes depósitos. También deberá disponer de una válvula de alivio que limite el valor máximo de presión en la aspiración.

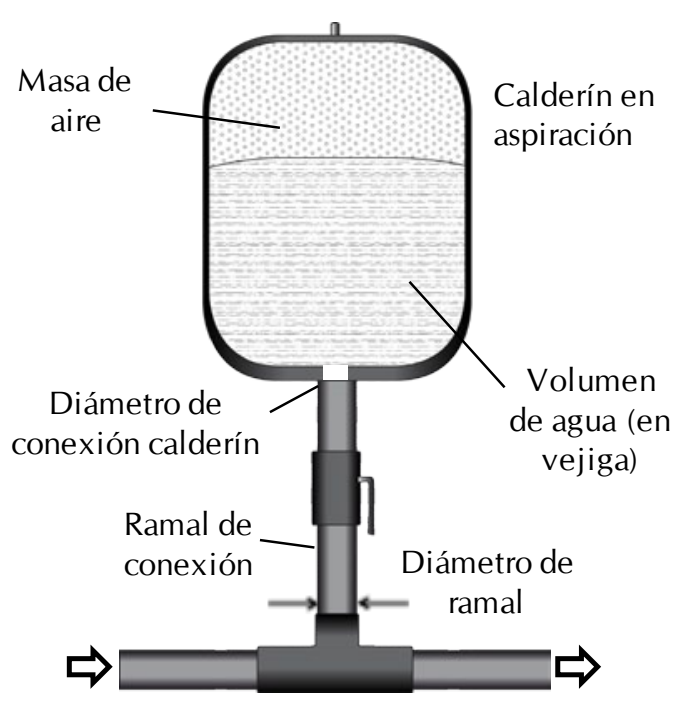

Tubería de aspiración FIGURA C5-40. SECCIÓN DE UN CALDERÍN 


\subsubsection{Diámetro de la conexión del calderín}

El diámetro de la conexión debe ser lo mayor posible para aumentar la capacidad de aporte. Comercialmente este valor, para los volúmenes de calderín analizados de 25 y 50 litros es de $3 / 4^{\prime \prime}$ y 1 ", pero es posible solicitar diámetros de conexión superiores.

\subsubsection{Ramal de conexión}

En el caso de recurrir a un ramal de conexión (requerido por las propias características constructivas de la instalación), y en aras de optimizar su funcionamiento, es recomendable que se acuda a ramales lo más cortos posibles. Se seleccionará un diámetro de ramal próximo al diámetro de la tubería de aspiración de la bomba, y nunca de valor inferior al diámetro de conexión del calderín. En el caso de acudir a reducciones para la adaptación del diámetro del ramal al diámetro de la conducción de aspiración, ésta se situará lo más próximo a dicha conexión, y deberá ser lo más progresiva posible.

El ramal debe incorporar una llave para aislar el calderín, así como un racor o grifo de vaciado que permita adecuar la presión de hinchado del depósito durante las operaciones de mantenimiento y sustitución. Así mismo es conveniente contar con la instalación de un manómetro que permita la comprobación de la presión estática, y la presión de hinchado del calderín.

\subsubsection{Anclaje del calderín}

El calderín debe estar sujeto a alguna estructura (bien a un cerramiento o a la propia solera del local donde esté instalado), de forma que disponga de rigidez suficiente para no desconectarse y transmita convenientemente las vibraciones generadas debido a las vibraciones generadas durante el funcionamiento del grupo.

\subsubsection{Batería de calderines}

En instalaciones en las que se deba acudir a la instalación de más de un vaso de expansión se recomienda establecer distribuciones que faciliten la descarga de los calderines, siendo recomendable la conexión directa de los vasos en la propia tubería de aspiración de forma equidistante y lo más próximos a las bombas.

\subsubsection{Sistemas de arranque de las bombas}

Las bombas de la instalación deberán mantener un sistema de arranque progresivo a partir de la incorporación de un variador de frecuencia. Se recomienda fijar una rampa de arranque de al menos 2 segundos de duración. En instalaciones con varias bombas en paralelo, se incorporará un dispositivo que impida el arranque simultáneo de varias bombas, existiendo un decalaje mínimo de 2 segundos entre arranques consecutivos. 


\subsection{CONSIDERACIONES SOBRE EL MANTENIMIENTO DE LA INSTALACIÓN}

Antes de proceder a la instalación del calderín deberá adecuarse la presión de hinchado de acuerdo a la presión mínima estática que pueda darse en su punto de conexión. Para su instalación, deberá comprobarse que el calderín dispone en su interior de un volumen de agua útil para suministrar al grupo de presión. Los pasos necesarios para la instalación de este equipo son:

- Comprobar la correcta instalación de la unión entre la conducción y el calderín, y cerrar la válvula del ramal de conexión (8).

- Vaciar por completo de agua el calderín (9).

- Efectuar el Ilenado de aire del calderín por la válvula instalada en el depósito para tal fin en el propio cuerpo de éste.

- Abrir la válvula que aísla el calderín de la instalación (8). En ese momento, si el resto de la instalación está ya con agua, se produce el llenado del calderín.

- Abrir todas las llaves del equipo y poner en marcha la bomba, dejando a la conducción en régimen continuo.

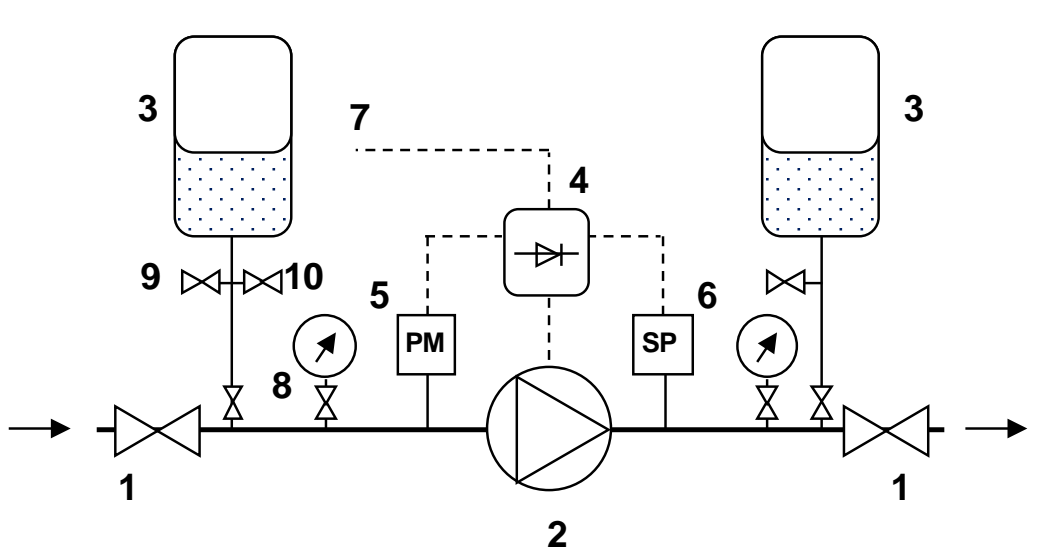

(1) Válvula de aislamiento

(2) Bomba hidráulica

(3) Depósito hidroneumático

(4) Variador de frecuencia

(5) Presostato de mínima

(6) Sensor de presión (transductor)

(7) Conexión eléctrica

(8) Manómetro

(9) Toma en derivación

(10) Válvula de alivio

FIGURA C5-41. ESQUEMA DE CONEXIÓN DEL CALDERÍN EN ASPIRACIÓN AL GRUPO DE BOMBEO

Del mismo modo, es conveniente comprobar cada 6 meses la presión en el interior del calderín, y el correcto funcionamiento del variador. Los pasos necesarios para la comprobación de la presión de hinchado del calderín son:

- Aislar el calderín con la válvula de seccionamiento (8).

- Vaciar el agua contenida en el calderín por la derivación (9).

- Comprobar la presión en el interior del calderín (presión de hinchado) en (10). 
Capítulo 6

\section{Conclusiones y desarrollos futuros}




\subsection{INTRODUCCIÓN}

La instalación interior de un edificio mantiene un estrecho vínculo con la red general de distribución de un abastecimiento en la medida que ésta debe ser considerada como una extensión de la red, ya que forma parte del fin último de la distribución: el aprovisionamiento de un recurso a los diferentes puntos de consumo atendiendo a un umbral mínimo de calidad de servicio (principalmente basada en una garantía de caudal con una mínima presión, y unas condiciones de salubridad que hagan apto su consumo).

Esta vinculación no siempre está convenientemente aprovechada. La limitación de responsabilidades entre los elementos de la red pública y la instalación interior, establece en muchas situaciones una frontera que aleja el suministro de un objetivo tan básico como la mejora de la eficiencia global del sistema. El desarrollo de estudios que involucren ambos elementos como un único puede mejorar el conocimiento sobre su interacción, y posibilitar mejoras en su funcionamiento como conjunto. En esta línea, la presente Tesis Doctoral ha perseguido conocer en mayor medida la vinculación entre estas dos instalaciones, y para conocer las posibilidades que ofrece una conexión directa entre ambas, dada la problemática asociada a la utilización de elementos de aislamiento como el depósito atmosférico, en el esquema de conexión conocido como alimentación indirecta.

Un desconocimiento de las posibilidades que ofrece este esquema, de las capacidades de la red general, o incluso de los requerimientos asociados a su funcionamiento, son algunos de los rigurosos obstáculos a los que hoy en día se enfrenta esta conexión. Al mismo tiempo, la reglamentación actual en los diferentes niveles no favorece su adopción principalmente debido a la dificultad de aportar garantías de fiabilidad por la considerable casuística a contemplar. En su lugar, una incorporación generalizada de depósitos atmosféricos, al mismo tiempo que reduce las solicitaciones de la red, puede repercutir en una merma en la salubridad del agua entregada, y de la eficiencia del servicio prestado. 


\subsubsection{Problemática asociada a la aspiración indirecta}

En el Capítulo 1 de la presente Tesis se han indicado las principales ventajas vinculadas a cada esquema de suministro adoptado en el interior de un edificio. A modo general, un esquema de aspiración directa, caracterizado por la eliminación de los depósitos atmosféricos, puede presentar una mejora de la calidad de servicio prestado así como un aumento del rendimiento global de la red.

El uso de depósitos favorece mayores tiempos de permanencia del agua hasta que es consumida (al tiempo de viaje del agua en las conducciones de la red general, se le añade el tiempo que el agua permanece en el interior de los depósitos). Si a la situación anterior se le une la reducción de la concentración del desinfectante con mayores edades del agua, es evidente una mayor posibilidad de contaminación del recurso en aquellas instalaciones con esquema de aspiración indirecta. Este efecto es mucho más notable en instalaciones con elevados volúmenes almacenados, o aquéllas que cuentan con una mayor estacionalidad.

De forma análoga, un depósito atmosférico es un punto abierto en la red que posibilita la entrada de contaminantes. $\mathrm{Si}$ bien en condiciones normales un mantenimiento activo de este elemento reduce la posibilidad de contaminación, la práctica ha demostrado que no siempre se realizan las labores necesarias para mantener unas condiciones mínimas de salubridad, ya que el depósito puede pasar a convertirse en un hábitat inmejorable para la proliferación de algunos microorganismos.

Por todo ello, desde el punto de vista de calidad la aspiración directa de red se presenta como un privilegio al que no todas las instalaciones interiores pueden optar. $Y$ es que la reducción de la posible contaminación del recurso en aquellas instalaciones sin depósito, debe estar vinculada a una mayor calidad de servicio ofrecida por el gestor. Prueba de ello, las motivaciones de los principales agentes involucrados en el suministro (entre ellos empresas de abastecimiento y comités de normalización), para posibilitar un mayor conocimiento sobre las posibilidades para la eliminación de depósitos domiciliarios.

Energéticamente conectar la red interior directamente a la tubería de llegada permite el aprovechamiento de la presurización de esta última, y por tanto no se desperdicia la presión disponible en la red. En una conexión indirecta se debe presurizar de nuevo el agua aspirada del depósito previa despresurización durante el llenado del depósito. Lógicamente una conexión directa debe ir acompañada de una garantía de servicio por parte de la compañía, y por tanto deben aunarse esfuerzos para favorecer este tipo de conexión. 
Otros de los inconvenientes asociados al uso de depósitos están relacionados con el rendimiento hidráulico de la red y con la preservación del recurso. Ya que en muchas situaciones este elemento facilita la extracción de agua sin contabilizar, bien por errores de contador (derivados por ejemplo del subcontaje en la apertura de las válvulas de Ilenado o por rebose) o por la inexistencia de éstos.

Finalmente, la utilización de depósitos puede derivar en un encarecimiento de la instalación interior, tanto a nivel constructivo como operacional. Al coste asociado a varios depósitos se le debe añadir mayores tamaños de grupos de presión, así como unas tareas de mantenimiento adicional para mantener unas condiciones mínimas de salubridad.

\subsubsection{Problemática asociada a la aspiración directa}

Por el contrario, y tal como se ha venido indicando a lo largo de la Tesis, la aspiración directa presenta una serie de inconvenientes que deben tenerse presentes. Entre ellos, la capacidad de laminación introducida por el depósito junto con las solicitaciones en régimen transitorio provocadas por la aspiración directa son las que mayor limitación presentan.

En el primero de los casos, y tal como puede entenderse, el depósito permite almacenar un recurso que no tiene porqué ser consumido de forma inmediata. Al mismo tiempo, el llenado de éste presenta un desfase frente a la demanda, favoreciendo la laminación del caudal extraído de la red, y con ello reduciendo las solicitaciones en periodos pico de demanda. La disminución de esta componente de laminación con la eliminación generalizada de depósitos puede alterar en mayor o menor medida el funcionamiento de la red, dependiendo en cualquier caso de sus características constructivas.

Por otro lado, el depósito atmosférico sirve de elemento de aislamiento de forma que el grupo de presión no aspira directamente agua de la tubería de Ilegada. Esto favorece a la generación de menores solicitaciones por fenómenos transitorios en la instalación interior, y por tanto, menores efectos transmitidos al exterior del edificio (con conexión indirecta estos efectos están principalmente condicionados al mecanismo de control de llenado del depósito). En aquellas instalaciones desprovistas de depósito, las fases transitorias del funcionamiento del grupo (arranque y parada) pueden presentar alteraciones significativas en la presión aguas arriba de la bomba. En el caso concreto de la fase de arranque, la variación del caudal experimentada en la conducción de aspiración genera una depresión que puede reducir peligrosamente la presión en este punto. Por el contrario, la parada de la bomba origina una sobrepresión asociada a la brusca deceleración que experimenta el agua. 


\subsubsection{Necesidades de un modelo de simulación}

El conocimiento de las características operativas de una red de abastecimiento de agua precisa la elaboración de modelos de simulación. En el caso concreto de analizar las implicaciones de una conexión directa entre la red general y las instalaciones interiores de edificios servidos, los modelos adquieren una complejidad adicional dada la considerable casuística inherente a ambas instalaciones, y la necesidad de acudir a intervalos de tiempo de cálculo reducidos para contemplar los efectos transitorios asociados a esta conexión. A las peculiaridades anteriores, se une la necesidad de obtener respuestas generalizadas para los diferentes esquemas y situaciones operación. En este escenario, la simplificación de los modelos, y el análisis particularizado del funcionamiento en régimen permanente y en régimen transitorio de la instalación, es una buena alternativa para permitir un mejor conocimiento de las implicaciones asociadas a esta conexión.

En el caso de aproximar la respuesta de la red bajo una conexión directa de las diferentes instalaciones interiores, ha sido necesario acudir a una simulación en régimen permanente. Al mismo tiempo, se ha acudido a un modelo simplificado asociado a un sector de suministro que vincula tanto la red como las instalaciones interiores de suministro. El método propuesto elabora los modelos de simulación de diferentes escenarios, éstos integran por un lado la información relativa a la estructura del tramo, junto con la información propia de la instalación general de los edificios conectados, y por otro lado las pautas de consumo características en viviendas residenciales.

De estos modelos pueden variarse las características constructivas y funcionales, adquiriendo la flexibilidad necesaria para evaluar la influencia de diferentes variables. Respecto a la carga hidráulica del modelo simplificado, la disponibilidad de datos de consumo reales con elevada discretización, junto con la correlación entre la demanda instantánea y su asignación al modelo en función del esquema de suministro, propicia una metodología de simulación que mantiene una elevada aproximación a las condiciones reales de suministro, favorecida por la elevada resolución de los datos de consumos utilizados (volúmenes consumidos cada 10 segundos), y su vinculación directa con datos reales de viviendas en el entorno residencial.

Para la atención a los efectos transitorios asociados a la aspiración directa ha sido preciso acudir a una mínima discretización temporal de cálculo que contemple las variaciones puntuales que se generan durante el funcionamiento de un equipo de presión. A su vez, el origen de la perturbación en el interior de las instalaciones interiores (zona donde las magnitudes adquieren los valores máximos), ha sido necesario simplificar un modelo que contemple la instalación interior de un edificio junto con las inmediaciones de éste. 
La consideración de forma conjunta de los resultados asociados a los dos análisis comentados (régimen permanente en la red y régimen transitorio en la instalación interior), puede orientar en gran medida sobre los requerimientos para adoptar estos esquemas, o sobre las implicaciones asociadas a su funcionamiento.

\subsubsection{Capacidad de la red general}

Uno de los principales inconvenientes asociado a la adopción de la alimentación directa es el conocimiento de la capacidad de la red en régimen permanente, es decir en los instantes en los que las instalaciones interiores mantienen su suministro. De lo que no hay ninguna duda, es que el continuo crecimiento que ha experimentado una red, favorecido por su flexible adaptación a los cambios, mantiene una incertidumbre sobre su respuesta ante una conexión directa.

En esta línea, y como se ha comprobado en el Capítulo 3, en algunas situaciones es posible acudir a esquemas con conexión directa, ya que la caída de presión originada en un tramo con conexión directa favorece la garantía de una presión mínima en todas las acometidas de los edificios. Esta garantía está directamente relacionada con las características constructivas del sector de la red, en la medida que se acuda a diámetros de red mayores, o que muestre una capacidad suficiente a la carga actual, se favorece la adopción de esquemas con conexión directa.

Por otro lado, en tantos otros sectores las características particulares de la red o las de la instalación interior de los edificios imposibilitarán esta conexión, siendo necesario acudir a esquemas que interponga un depósito atmosférico. Por ello, es importante conocer las solicitaciones asociadas a cada uno de los esquemas adoptados en las instalaciones interiores de los edificios, y aquellas situaciones en las que es posible aprovechar las ventajas ofrecidas por los esquemas de conexión directa.

En cuanto a las instalaciones generales de los edificios, se han modelado las tipologías más comunes, con la finalidad de obtener para cada una de ellas el grado de afección en el valor de las presiones alcanzadas en el tramo de red. Se ha conseguido además obtener la respuesta de cada una de ellas para un mismo escenario hidráulico, y una misma asignación de datos de consumo. Esta consideración puede orientar sobre la necesidad de modificar algunos esquemas de instalaciones generales, en el caso de que no sea posible garantizar condiciones mínimas de servicio debido a las perturbaciones introducidas por algún diseño, o bien validar la posibilidad de introducir nuevos esquemas, como el derivado de la eliminación de depósitos atmosféricos de aspiración. En esta línea, la comprobación de la capacidad de transporte de un tramo a partir de los resultados de las simulaciones, puede advertir al gestor del servicio de la posibilidad de instalar grupos de bombeo conectados directamente en aspiración, evitando los problemas derivados de los depósitos auxiliares de alimentación. 


\subsubsection{Esquemas de conexión directa con menores solicitaciones}

De entre los posibles esquemas de conexión directa, el que menores solicitaciones origina a la red de abastecimiento es aquél que no se sirve de grupo de presión (esquema de suministro Tipo I). Esta situación, si bien puede presentar unos beneficios desde el punto de vista energético y los lógicos desde el punto de vista de salubridad, sólo tiene cabida si las características operacionales de la red son capaces de garantizar una presión mínima en los diferentes puntos de consumo de los diferentes usos.

Adoptando un esquema de suministro Tipo I el caudal detraído de la acometida de un edificio sólo atiende a la demanda instantánea de los usuarios. Bajo esta situación las variaciones de caudal presentan cambios significativos en diferentes periodos horarios, condicionado por los hábitos de consumo de los usuarios, pero las variaciones dentro de un mismo periodo no son tan significativas favorecida por una simultaneidad de la demanda para un conjunto de usuarios. Esta reducida variabilidad instantánea del caudal servido a su vez favorece que las variaciones de presión que se experimentan en la red también adquieran una magnitud reducida.

La adopción de este esquemas de forma generalizada pueden ser una alternativa interesante en algunas redes, principalmente en aquéllas con un reducido tamaño y una homogeneidad de los diferentes edificios conectados, si bien el estudio para su implementación tiene que contemplar otros aspectos como el relacionado con las implicaciones energéticas y al tiempo que se debe realizar una gestión rigurosa de la presión, adaptándola a las necesidades reales de cada instante, y no favorecer un aumento del nivel de fugas.

Inevitablemente, la dificultad de disponer de forma continua de una presión suficiente en red para garantizar el correcto suministro bajo el esquema Tipo I, hace necesario acudir a esquemas de conexión directa equipados con grupos de presión. Entre los grupos más comunes, el que cuenta con variación de frecuencia (esquema Tipo IV) presenta unas solicitaciones reducidas ya que el variador mantiene un punto de funcionamiento próximo al equivalente de la demanda instantánea. Estas solicitaciones pueden ser asimilables a las del esquema anterior en la medida que el controlador del variador es adecuadamente programado. No obstante la asimilación al esquema Tipo I, además de precisar una adecuada programación del controlador hace necesario el dimensionado conveniente del grupo, de forma que éste no se vea forzado a operar en puntos de funcionamiento con un rendimiento reducido.

De forma práctica, si se pretende estimar la respuesta de un tramo del que se eliminan los depósitos atmosféricos, la alternativa más favorable es la conexión directa sin grupos de presión o mediante grupos equipados con variador de frecuencia. 
En esta línea, los resultados obtenidos de los diferentes escenarios simulados, caracterizados a partir de la gráfica de la Figura C3-22 pueden orientar a un técnico sobre la capacidad de un tramo, y concretamente sobre la viabilidad de esta solución en función de sus características particulares. Entre los resultados derivados del análisis del funcionamiento de la red bajo los esquemas Tipo I y Tipo IV se destaca:

- Las variables que mayor influencia presentan sobre la capacidad de un tramo son el diámetro interior de la conducción principal de éste y la carga hidráulica conectada (asociada principalmente al consumo total de los usos conectados).

- Para un mismo diámetro existe una relación directa entre la pendiente hidráulica y la carga de consumo total en el tramo. El aumento de la pendiente hidráulica frente a la carga de consumo es aproximadamente cuadrático, de forma que, para un mismo diámetro un aumento en la carga del tramo origina un incremento mayor al proporcional en la pendiente hidráulica.

- Para las diferentes cargas hidráulicas analizadas existen varios puntos superpuestos que representan varios escenarios, por ello el parámetro carga hidráulica presenta una elevada dependencia frente a otras variables del tramo (entre ellos el número de viviendas o el tamaño de los edificios).

- La dispersión del valor de la caída de presión media de una simulación aumenta con la carga y disminuye con el aumento de diámetro, al disponer el tramo de una mayor capacidad hidráulica.

- Fijadas unas pautas de consumo de un sector y una simultaneidad en la demanda en función del número de viviendas servidas, los resultados son extrapolables a otros sectores.

- Con la limitación de una pendiente hidráulica máxima es posible conocer aquellos escenarios más favorables para adoptar una aspiración directa.

Adicionalmente la grafica obtenida puede servir en tareas de dimensionado de una red, piénsese en una renovación de conducciones o incluso en una ampliación del área servida. Conocida una carga hidráulica de un sector y fijadas una presión mínima de entrega, es posible determinar el diámetro interior de la conducción de la red que posibilita la conexión directa de los edificios, sirviendo como una herramienta adicional para contrastar los procedimientos usuales de dimensionado. 


\subsubsection{Esquemas de conexión directa con grupos de velocidad fija}

Tal como se ha podido comprobar, el esquema que mantiene una mayor solicitación de la red es aquél que dispone de un esquema equipado con grupo de presión de velocidad fija conectado en directo para la totalidad de viviendas servidas. La severidad con la que opera este tipo de grupos, caracterizado por el aporte de forma fija del caudal total de cálculo de la instalación, aumenta de forma sensible el flujo de caudal extraído de una acometida. Si a este efecto se une la posible simultaneidad en la demanda de edificios contiguos, se evidencia una mayor sobrecarga en la red que aumenta sensiblemente a medida que la densidad del número de viviendas suministradas con grupo es más elevada.

Por otro lado, y tal como augura la existencia de redes de abastecimiento que permiten una conexión directa de grupos de velocidad fija, es posible mantener este esquema de conexión parcialmente sin que la situación ponga en riesgo el normal suministro de la totalidad de usuarios. Como es lógico, esta situación precisa que la red reúna unas características mínimas para que las variaciones de caudal originadas en la instalación interior no provoquen caídas de presión excesivas.

En esta línea los resultados obtenidos con las simulaciones de diferentes escenarios, caracterizados a partir de las gráficas de la Figura C3-31 y la Figura C3-37 pueden orientar a un técnico sobre los efectos esperados en un sector de red equipado en su totalidad o de forma parcial con bombas de velocidad fija (esquema Tipo II y Tipo III respectivamente). Entre los resultados derivados del análisis del funcionamiento de la red bajo los esquemas Tipo II y Tipo III se destaca:

- Para un mismo caudal demandado por un conjunto de usuarios, y unas mismas características del sector, las solicitaciones que presentan estos esquemas frente a los esquemas sin grupo son sensiblemente mayores, debido principalmente a unos mayores caudales detraídos.

- Para una determinada carga hidráulica demandada por el sector, a medida que disminuye el diámetro de la conducción del tramo aumentan las solicitaciones, mostrando además una elevada dispersión de los valores para diámetros más pequeños. Este efecto es más sensible a media que aumenta la proporción de viviendas suministradas con grupo de presión.

- La influencia sobre la localización de viviendas con demanda favorece el origen de mayores caídas de presión, ya que el funcionamiento simultáneo de grupos situados en la zona final del tramo origina las mayores solicitaciones. 
- El número de viviendas de un edificio presenta una influencia notable sobre las solicitaciones del tramo. En la medida que éste cuente con grupos de presión de mayor tamaño, los caudales detraídos por estos grupos serán mayores, y por tanto aumentarán las caídas de presión en el tramo.

- Este efecto también se ve favorecido por mayores caudales horarios demandados, ya que esta situación puede provocar una mayor probabilidad del funcionamiento simultáneo de varios grupos.

- Las solicitaciones asociadas a diferentes proporciones entre viviendas suministradas en directo y con bomba de velocidad fija presentan comportamientos intermedios.

- Indirectamente la gráfica (de forma similar a la asociada a la conexión directa) puede aportar una orientación sobre la carga hidráulica en situación punta demandada en un sector; conocido el diámetro instalado, la longitud del mismo y la diferencia de presión entre dos puntos extremos para la hora de máxima demanda, es posible acceder a las gráficas y aproximar dicha carga (en cualquier caso no se debe perder de vista la pertenencia del sector a una red de mayor tamaño).

Con todo ello, los resultados de las simulaciones y la materialización en las gráficas indicadas, puede servir de orientación para un mejor conocimiento sobre la capacidad de la red a funcionar bajo un esquema de suministro de conexión directa, y sobre la capacidad de funcionar sin la interposición de depósitos atmosféricos.

Por otro lado, y si se atiende al actual uso extendido de grupos de velocidad fija en conexión indirecta (el conocido como grupo convencional), una eliminación de los depósitos cuestiona en primera instancia el posible uso del equipo instalado (bomba de velocidad fija). Dadas las elevadas solicitaciones de este tipo de grupos frente a los grupos equipados con variador, se debe favorecer el uso de este segundo tipo de grupo de presión, acudiendo sólo al uso de la bomba de velocidad fija en aspiración directa en aquellas situaciones que se estime que las solicitaciones no son elevadas. Por ejemplo, en algunas instalaciones integradas por un elevado número de viviendas, la detracción del caudal de cálculo por varias bombas en funcionamiento simultáneo, puede conllevar caídas de presión elevadas en la red en instantes en los que la demanda es elevada. 


\subsubsection{Solicitaciones transitorias asociadas a la conexión directa}

La aspiración directa favorece la generación de perturbaciones en los instantes en los que se origina el arranque o parada de las bombas del grupo presión, debidas a las variaciones de caudal en la tubería de aspiración. De estas dos maniobras la depresión provocada por el arranque suele mostrar una mayor severidad que el transitorio generado por la parada del grupo.

Las solicitaciones adquieren su magnitud máxima en las propias instalaciones interiores, transmitiéndose su efecto aguas arriba del punto de instalación del grupo, y por tanto pudiendo alcanzar los tramos más inmediatos a la acometida del edificio. El punto más expuesto a presiones extremas es el ubicado en las inmediaciones de la aspiración de la bomba. Por el contrario la acometida presenta solicitaciones más reducidas, debidos principalmente a la atenuación de la onda de presión. Por ello, si se limitan las afecciones máximas en la instalación interior (la Figura C5-1 expone las limitaciones propuestas), es posible garantizar una afección limitada a la red general.

Dentro de las variables que influyen en la severidad del fenómeno, el tiempo de arranque del grupo entendido éste como el tiempo desde que se procede a su alimentación hasta que alcanza su velocidad de régimen, presenta una elevada contribución sobre la magnitud de la perturbación. La utilización de grupos equipados con variador de frecuencia, y la adecuada programación de rampas de aceleración para el arranque inducen depresiones de magnitud muy reducida. Por el contrario, la utilización de bombas de velocidad fija además de presentar una elevada complejidad en la determinación del tiempo de arranque, origina caídas de presión considerables.

Otra de las variables asociadas a la instalación que presentan una notable influencia es el propio caudal de bombeo. Equipos con mayores caudales propician mayores variaciones del flujo en la conducción de aspiración, y por tanto originan mayores perturbaciones. En esta línea, la normativa actual que exige la totalización del caudal de cálculo a partir de varias bombas, favorece menores variaciones de caudal y por tanto solicitaciones más reducidas en los arranques de las diferentes bombas (atendiendo a tiempos de desfase entre arranques suficientes).

La cercanía entre el entronque de la acometida y la instalación interior del edificio favorece una menor caída de presión. Por ello, aquellas instalaciones más alejadas de la red general presentarán mayores depresiones en el arranque para unas mismas características operativas. La atenuación de la perturbación se debe a la reflexión de la onda de depresión en el entronque de acometida y la inversión de su sentido de circulación y signo. Una reducción de la distancia también favorece menores tiempos de viaje de las ondas de reflexión y por tanto una mayor atenuación. 
Respecto a la influencia de las variables principales asociadas a la red general, el cambio en el caudal que circula por la red no presenta una elevada influencia, debido a que la perturbación se genera en la propia instalación interior. Por el contrario es conveniente que la red a la que se conecta la acometida mantenga un elevado diámetro interior, a medida que este diámetro toma mayores valores se ve favorecido el coeficiente de reflexión, y por tanto aumenta la capacidad de atenuación. La presión disponible en el punto de entrega de la acometida también presenta una influencia considerable respecto a la caída de presión experimentada en el interior de la instalación. Menores presiones favorecen una menor atenuación de la perturbación y por tanto mayores efectos transitorios.

\subsubsection{Alternativas para la protección de instalaciones para la conexión directa}

Como se ha podido comprobar, las líneas de actuación para la reducción de los efectos transitorios generados en la instalación interior parten principalmente de la reducción de las variaciones de caudal que experimenta la tubería de aspiración, y de una mayor atenuación de la perturbación. En la primera de las alternativas, el control del tiempo de arranque del grupo es una solución que favorece variaciones más lentas de caudal. Un control del arranque del grupo como el realizado a partir del variador de frecuencia reduce significativamente las solicitaciones en la red tanto en la parada del grupo como en el arranque. En esta línea, comercialmente se dispone de multitud de soluciones que incorporan este elemento en grupos compactos. Al mismo tiempo, la posibilidad que ofrece la programación del controlador permite ajustar las variaciones funcionales del grupo y su adecuación a las propias características de la instalación.

Por otro lado, y para instalaciones que cuentan con esquema de suministro convencional, en aquellas situaciones que se estime una reducida incidencia es posible proceder a la eliminación del depósito atmosférico (previa comprobación de la capacidad de red), y acudir a la conexión directa junto con la incorporación de variadores externos especialmente concebidos para este fin. En cualquier caso se debe comprobar la idoneidad del grupo para el nuevo esquema de aspiración directa.

La segunda de las líneas de actuación se encamina a facilitar la atenuación de la perturbación. Para ello, las posibilidades que ofrece la incorporación de un depósito presurizado en la aspiración de la bomba pueden resultar suficientes para permitir una correcta protección de la instalación. De forma similar al efecto de reflexión de la onda en el entronque de la acometida, la proximidad de un depósito con una masa mínima de aire presurizado, realiza la función de soporte de presión en la aspiración y reduce la posibilidad de aparición de depresiones elevadas. Al mismo tiempo, el volumen de agua almacenado en el depósito permite un aporte auxiliar al grupo, de forma que se reduce el caudal total extraído de la red, y por tanto las variaciones de esta variable. 
De los resultados obtenidos a partir del análisis de sensibilidad realizado para la protección se destaca la influencia de la distancia entre el calderín y la aspiración de la bomba, ya que un alejamiento deriva en una menor atenuación de la perturbación. Por ello es interesante que la instalación del calderín sea lo más próxima a la aspiración, y preferiblemente directamente conectado sobre su tubería de aspiración. Puesto que esta solución constructiva no siempre es posible, en el caso de incorporar ramales de derivación se recomienda que la longitud de este ramal y sus pérdidas asociadas sean lo más reducidas posible.

Otra de las medidas a las que se le debe prestar atención es a la capacidad de descarga del calderín. El aumento de las pérdidas en la descarga para conexiones de calderines menores (boca de calderín), reduce sensiblemente la eficiencia de la protección, por ello el aporte de caudal debe verse favorecido en la medida de lo posible. Esta limitación debe considerarse del mismo modo en el ramal de conexión, e incluso en los accesorios incluidos es éste, manteniendo diámetros suficientes para facilitar la descarga. Estos elementos deberán presentar en su conjunto un coeficiente de pérdidas bajo para el flujo de salida de la estructura, y un coeficiente de pérdidas alto para el flujo de entrada. De esta manera se facilita el flujo de salida desde la estructura hacia la tubería principal, con lo que se reducen las depresiones en esta última tubería y la posibilidad de aparición de presiones negativas. Además, en el flujo de entrada desde la tubería principal hacia la estructura de protección se crean pérdidas importantes en la tubería de entronque, las cuales van disipando la energía del agua y frenando el desarrollo del transitorio, favoreciendo por tanto la atenuación del transitorio por parada de la bomba.

Esta solución también presenta una buena respuesta desde el punto de vista de la calidad, ya que el almacenamiento de menores volúmenes de agua favorece su renovación. Aunque los volúmenes de protección propuestos son reducidos, otra solución constructiva que disminuye el tiempo de permanencia del agua en el interior del depósito es la utilización de calderines con entrada y salida independiente. Del mismo modo, el calderín instalado debe ser de tipo membrana para que impida el contacto aire agua, al mismo tiempo que imposibilite la pérdida de masa de aire por aspiración o disolución (la reducción de la masa de aire disminuye la capacidad de atenuación de la perturbación al originar un menor sustento de la presión en el entronque, junto con una menor capacidad de aporte de agua).

La instalación del calderín en aspiración también reduce la magnitud de la perturbación por parada de bomba, especialmente indicado en caso de fallo de alimentación del grupo. Para esta situación extrema también se recomienda la instalación de una válvula de alivio que permita la descarga de agua en caso de sobrepresión excesiva. 
Además de la influencia de los parámetros comentados anteriormente, la correcta protección es función de las características particulares de la instalación interior. Tabla C5-3 resume la configuración recomendada para la protección de una instalación con aspiración directa mediante la incorporación de depósitos presurizados, en función de las características de la tubería de aspiración y de la acometida domiciliaria, y del caudal de diseño del grupo. Para cada una de las configuraciones en la tabla anterior se establecen las características que debe tener la protección:

- número de depósitos presurizados necesarios

- volumen de los depósitos

- diámetro de conexión

Para escenarios no contemplados en la tabla anterior, o adicionalmente para validar la protección propuesta, es conveniente analizar de forma particularizada el fenómeno transitorio. En esta línea las solicitaciones mostradas en la Figura C5-1 pueden servir para limitar los efectos durante el funcionamiento del grupo.

Respecto al número de depósitos necesarios, los resultados obtenidos en las simulaciones muestran la conveniencia de acudir a un mayor número de depósitos de presión en aquellas instalaciones que presenten una mayor severidad de funcionamiento. Disponer de varios depósitos facilita el aporte de caudal, para un mismo volumen de protección acudir a varios vasos que totalicen este volumen presenta un comportamiento más favorable que acudir a uno de mayores dimensiones.

Por otro lado, se ha comprobado que el aporte auxiliar de las bombas no requiere un volumen de agua elevado. Es posible llegar a esta conclusión si se atiende a los reducidos tiempos de arranque característicos de los grupos y a la magnitud de los caudales aspirados antes de alcanzar la velocidad de régimen. Del mismo modo, en las simulaciones se ha comprobado que a partir de un volumen mínimo el aumento del volumen útil no presenta una mejora que justifique su instalación. En cualquier caso, el volumen total de protección debe ser acorde al tamaño del grupo. Respecto a la conexión del calderín, y dada la conveniencia de favorecer la descarga durante los instantes de arranque tal como se ha comentado, se limita su valor mínimo al mismo tiempo que se recomienda acudir a diámetros de conexión elevados.

Finalmente se destaca la importancia de disponer de una correcta presión de hinchado; si bien el aumento de la presión de hinchado (respecto a la presión estática en su punto de instalación) mejora la protección por una mayor atenuación de la perturbación, una presión excesiva puede limitar el volumen de agua almacenada y por tanto reducir la protección. En el lado opuesto, una presión muy reducida si bien garantiza la acumulación un elevado volumen de agua en su interior dificulta la protección, debido a la menor atenuación de la onda de depresión. 
Por todo ello se recomienda mantener una presión mínima en el interior del depósito de 1 bar, y en aquellas instalaciones en las que se tenga controlada la presión mínima garantizada en red en condiciones normales de suministro, se establece una presión ligeramente inferior a este valor. Adicionalmente y aunque las solicitaciones que experimenta este depósito son inferiores a las que experimenta un calderín en impulsión, se debe mantener un control de la presión en su interior a partir de la realización de revisiones periódicas de su funcionamiento.

\subsection{Resultados DiRECTOS DE LA TESIS}

Entre los logros alcanzados con la presente Tesis se destaca la propuesta de una metodología para la simulación de redes a partir de la carga directa de datos reales de consumo con elevada discretización (10 segundos). En la medida que se disponga de datos particularizados de un conjunto de usuarios de un sector concreto, será posible adecuar la respuesta de éste con una aproximación superior a la conseguida con los procedimientos usuales, los cuales basan la carga hidráulica del modelo a partir de datos estadísticos con una menor discretización temporal (generalmente una hora).

Derivado de los resultados del análisis en régimen permanente, se han presentado unas gráficas que aproximan las solicitaciones de un determinado sector en el que se adopta de forma generalizada una alimentación directa de las instalaciones interiores que lo integran. El sector está caracterizado por su carga de demanda y sus características constructivas (entre ellas, el diámetro interior de la conducción principal del tramo, el esquema de suministro adoptado en las instalaciones y longitud del tramo). A su vez estos gráficos pueden ser utilizados como una herramienta complementaria en tareas de dimensionado. Fijado un valor mínimo de presión en las acometidas de los abonados, es posible obtener la pendiente hidráulica máxima posible y el diámetro más indicado para su carga de consumos, o bien, obtener el margen de presión disponible según el diámetro instalado. Este margen puede orientar al equipo gestor sobre la posibilidad de prescindir de depósitos auxiliares de aspiración, o bien exigir la instalación de los mismos tal como se especifica en el CTE.

A su vez se destaca la aportación de una expresión que permite aproximar el caudal punta demandado por un conjunto de viviendas. Además se han comparado los procedimientos comúnmente utilizados para el cálculo del caudal simultáneo asociado a un conjunto de viviendas.

Finalmente se destaca la aportación de una tabla para la determinación de la protección necesaria en función de las características de la instalación. Esta tabla puede ser útil para un técnico a la hora de dimensionar la protección por su sencillez de utilización. 


\subsection{Desarrollos futuros}

Como se ha podido comprobar, el arranque y parada del grupo de presión puede alterar significativamente la magnitud del transitorio generado en una instalación. Si bien la importancia de este efecto en grupos con variador no es tan crítica por la intervención del controlador en la maniobra de arranque y parada, en grupos de velocidad fija la dinámica transitoria adquiere una complejidad adicional. En lo que respecta al arranque, es interesante acudir a un análisis sobre el comportamiento del conjunto moto-bomba, condicionado notablemente por las características del motor y por la carga asociada a la instalación. En el primero de los casos, la tipología y tamaño del motor establece el par aplicado al rotor del motor eléctrico y su evolución en el tiempo (par motor de origen eléctrico), al mismo tiempo el par resistente en el eje (carga) también presenta una variación temporal que condiciona la dinámica de aceleración del motor, y por tanto el valor de la depresión generada en la aspiración de la bomba. Por ello, un mejor conocimiento sobre el proceso de arranque en grupos de velocidad fija puede facilitar la adaptación de instalaciones con equipos de esta naturaleza en aspiración directa.

Del mismo modo, un estudio sobre las diferentes alternativas de arrancadores (arrancador estrella-triángulo, arrancador con autotransformador o arrancadores suaves) puede agilizar la progresiva adaptación de instalaciones que cuenten con motor de arranque directo. Paralelamente, el desarrollo comercial de variadores externos independientes, y la bondad aportada por su controlador puede ser aprovechado con este mismo propósito, y principalmente encaminado en reducir la severidad con la que opera este grupo.

En esta misma dirección, y con objeto favorecer una adecuada programación del controlador integrado en el variador de frecuencia, y aproximar en mayor medida los comportamientos de los esquemas Tipo I y Tipo IV, es conveniente analizar el efecto introducido con la modificación de cada uno de los parámetros característicos del PID (a saber la componente proporcional $K_{p}$, la integral $K_{i}$ y la derivativa $K_{d}$ ). Como extensión, sería conveniente aportar un protocolo que sirva al instalador como guía durante la programación de estos equipos. Tal como se ha podido comprobar durante el desarrollo de la Tesis, la instalación directa del equipo con valores de fábrica, unida a la reducida formación técnica en esta área, frecuentemente conlleva una ineficiencia operativa alejada del comportamiento óptimo de la bomba. En su lugar, la programación particular de cada dispositivo, y la adecuación in situ de las variables características, favorece una reducción de las solicitaciones de la instalación interior, y una menor sobrecarga de la red de abastecimiento. 
Por otro lado, y dado el carácter progresivo de la adaptación de instalaciones para la aspiración directa, sería conveniente realizar un seguimiento de la nueva respuesta en los diferentes sectores de red. Esta medida permitirá conocer cómo responde la red a los diferentes cambios introducidos, y además orientará sobre su capacidad a la hora de adaptar un mayor número de instalaciones. Del mismo modo, el conocimiento práctico de aquellas situaciones que favorecen el aumento de las solicitaciones puede ser aprovechado para mejorar la ejecución de instalaciones, pudiendo resultar interesante la elaboración de un manual técnico de buenas prácticas promovido por el propio abastecimiento.

Además de controlar la evolución funcional de la respuesta de la red, el control de otras implicaciones como ahora la energética, asociadas al aprovechamiento de la presión en las instalaciones interiores, o incluso la posible variación del rendimiento hidráulico de la red (téngase en cuenta que una mayor control de la presión en las instalaciones puede favorecer una reducción del caudal consumido), puede ser un indicativo que favorezca la modificación de instalaciones. En contraposición, la detección anticipada de problemas asociados a la reducción en la laminación de la demanda, puede precisar una modificación de las características operacionales de la red en aquellas situaciones que sea posible, o imposibilitar la conexión directa favoreciendo la investigación de medidas alternativas.

De cara a una mayor generalización de los resultados, principalmente en el análisis en régimen transitorio, es interesante establecer expresiones que relacionen las diferentes variables de la instalación, y del propio equipo de presión. En esta línea, la utilización de variables adimensionales puede favorecer la extrapolación de resultados a diferentes situaciones. De forma similar, a partir de los resultados gráficos obtenidos con el procedimiento de análisis en régimen permanente, podría ampliarse el número de simulaciones y la casuística que define los diferentes escenarios, de esta forma se podría realizar una caracterización estadística de la probabilidad de ocurrencia de una determinada presión en función de la carga hidráulica del tramo.

En esta misma línea, la consideración de unas pautas de demanda propias de cada sector, o incluso los desarrollos para la inclusión de otros tipos de usos diferentes al doméstico, puede permitir una adecuación de los resultados a una determinada localización. Adicionalmente, la utilización de series sintéticas de demanda convenientemente caracterizadas, permitiría extrapolar los resultados de forma más sencilla a partir de los datos singulares de cada abastecimiento. Actualmente, estas medidas están favorecidas por una mayor facilidad en la obtención de datos reales de consumo, esto se debe a los desarrollos en el campo de la telelectura, junto con un esfuerzo por parte de los abastecimientos en la incorporación de esta tecnología. 
Del mismo modo, y unido a los esfuerzos recientes en el campo de la monitorización de abastecimientos (Sarrió, 2011), como una evolución a las herramientas de información geográfica, la eliminación del aislamiento introducido por los depósitos atmosféricos, unido a la capacidad de adquirir información en tiempo real (de los diferentes usos y de otras variables hidráulicas características), pueden resultar interesantes los desarrollos encaminados a la monitorización global de un abastecimiento. Entre las posibles líneas de actuación, un mayor conocimiento del flujo de caudales en las diferentes zonas puede ser una valiosa herramienta para la mejora del rendimiento hidráulico del abastecimiento, para optimaciones operativas de la red, o incluso para un mayor conocimiento de los caudales evacuados de la instalación dada su vinculación directa y los reducidos desarrollos al respecto. 
ANEXOS 


\section{Anexo 1}

\section{Descripción de los elementos que forman parte de una instalación interior de suministro de agua}




\subsection{INTRODUCCIÓN}

El estudio asociado a la conexión directa entre la red general de distribución y la propia instalación interior del edificio, hace necesario describir convenientemente cada uno de las partes en las que se divide la instalación interior, así como la parte de la red que se localiza en las inmediaciones del inmueble. Un conocimiento de las diferentes partes permitirá elaborar el modelo de simulación, tanto para régimen transitorio como para régimen permanente, atendiendo a aquellos elementos que pudieran presentar una mayor influencia.

Con el presente anexo se persigue describir cada uno de los tramos de la red general de distribución, y principalmente en lo que respecta a la acometida que sirve de enlace al edificio, y así como los elementos que forman parte del esquema hidráulico de este último. Los principales tramos en los que se divide una instalación son:

- Red general de distribución (RGD)

- Tramo de acometida

- Tramo de instalación general

- Tramo de instalación particular o de derivaciones colectivas

\subsection{ReD GeNERAL DE DISTRIBUCIÓN (RGD)}

\subsubsection{Consideraciones sobre la RGD}

Se conoce como red general de distribución al conjunto de elementos de titularidad pública o privada que permiten el suministro de agua en un abastecimiento, dando servicio a través de las diferentes acometidas domiciliarias a los edificios conectados. A continuación se detallan las propiedades de los diferentes elementos que forman esta instalación en las inmediaciones del edificio.

\subsubsection{Tuberías de la RGD}

Las instalaciones en redes de suministro en el entorno residencial cuentan con una serie de conducciones de mayor o menor entidad que forman el trazado de la red 
de distribución. Usualmente se acude al término de red arterial de distribución para las conducciones de mayor entidad por el caudal que trasiegan y que dan servicio a diferentes sectores, y a tuberías de distribución (o tuberías principales y secundarias), para el resto de conducciones a las que están conectadas las propias acometidas.

Generalmente el dimensionado de las conducciones es acorde a los caudales de diseño trasegados por cada tramo de red, y de las pendientes hidráulicas derivadas. Es usual además limitar el valor mínimo a instalar en un tramo, por ejemplo $100 \mathrm{~mm}$ (ARPEMSA, Aguas del Puerto). Para diámetros grandes, es usual desdoblar en varias conducciones de diámetros inferiores, atendiendo en todo caso a la fiabilidad en el suministro y costes. Respecto a su instalación, estas conducciones suelen disponerse enterradas mayoritariamente, $\mathrm{y}$ asentadas en zanjas en camas de arena prensada.

En cuanto a los materiales utilizados frecuentemente se acude a conducciones de fundición nodular y a materiales termoplásticos como el polietileno de alta densidad. En cualquier caso, existe gran variabilidad de materiales instalados en los diferentes abastecimientos.

Respecto al trazado, los esquemas suelen acudir a trazados ramificados, mallados, o a una combinación de ambos en los conocidos como esquemas mixtos. La tendencia general es acudir a disposiciones en forma de malla por las ventajas que presenta frente al trazado ramificado.

\subsubsection{Válvulas y elementos de control RGD}

La RGD cuenta con una serie de elementos que permiten controlar el flujo de agua en diferentes puntos. Comercialmente existen diferentes tipologías y características operativas que adecuan el funcionamiento de la red a las necesidades del suministro.

La tipología de válvulas más frecuente es la válvula de seccionamiento. Esta válvula permite aislar diferentes tramos para tareas de manteniendo u otros propósitos. Generalmente permanecen completamente abierta, por tanto en condiciones normales de funcionamiento introducen unas pérdidas de carga prácticamente despreciables, comportándose como si de un tramo de tubería se tratase.

Otro tipo de válvula comúnmente utilizada es la válvula automática de control de variables, como es el caso de la válvula reductora de presión. En condiciones normales de funcionamiento, estos elementos operan introduciendo pérdidas localizadas que modifican el funcionamiento normal de la red en esos puntos. Respecto a la incidencia sobre la perturbación generada en una instalación interior, este tipo de válvulas puede presentar fluctuaciones cuando están pilotadas, si bien la magnitud de la perturbación que recibe no suele ser considerable. 


\subsubsection{Tramo de acometida}

\subsubsection{Descripción}

La acometida es el tramo que conecta la tubería de la red general de distribución (o tubería de suministro) con la instalación interior del edificio (tubería de alimentación del edificio). Generalmente cada edificio está provisto de una única acometida, la cual trasiega el total del caudal consumido por las viviendas y resto de locales. En residenciales de gran tamaño es posible encontrar más de una acometida.

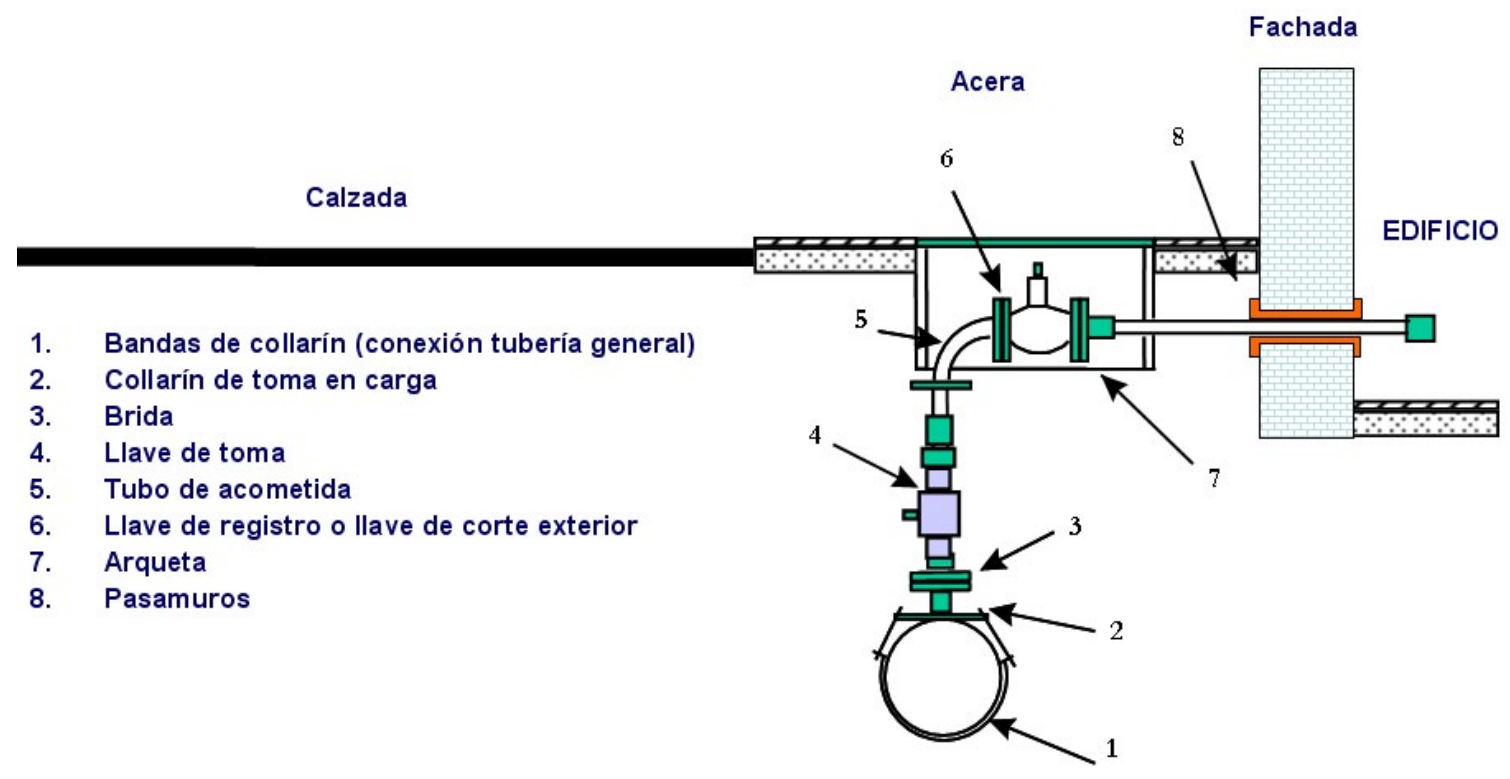

FIGURA A1-1. ESQUEMA DE ACOMETIDA Y ELEMENTOS.

La acometida comprende desde el collarín conectado a la tubería de suministro hasta la llave de registro situada en el exterior del edificio. En algunas ocasiones se añade además el tramo que une con la llave de paso del interior del edificio (acometida interior), dependerá en todo caso de cómo se define el tramo en la reglamentación DEL servicio. En el entorno residencial esta conducción es propiedad de la compañía suministradora, y sus dimensiones y características están fijadas por ésta, generalmente condicionadas por las propias características de la red interior a la que sirve.

Los elementos con los que tiene que contar la acometida son:

- llave de toma o un collarín de toma en carga

- tubo de acometida que enlace la llave de toma con la llave de corte general

- Ilave de corte en el exterior de la propiedad (Ilave de registro)

La finalidad de las válvulas instaladas en la acometida (llave de toma y llave de registro), es aislar los diferentes tramos para proceder al mantenimiento de la instalación. Funcionalmente introducen pérdidas de carga como si se tratasen de tramos 
de tubería, y por lo general se encuentran abiertas y presentan una mínima repercusión en el caudal trasegado (suelen ser válvulas de tipo bola o compuerta cuya incidencia es mínima frente otro tipo de válvulas).

\subsubsection{Collarín de toma}

Se trata de un elemento que se conecta a la tubería general y del que parte la tubería de acometida que suministra al edificio.

\subsubsection{Llave de toma}

Se encuentra colocada sobre la tubería de la red de distribución y abre el paso a la acometida. En ocasiones la acometida se ejecuta directamente y esta llave no se coloca. Esta llave la maniobra exclusivamente la entidad suministradora o persona autorizada, sin que los abonados, propietarios ni terceras personas puedan manipularla.

Es útil si hay mucha distancia entre el collarín y la llave de registro, de forma que no sería necesario cortar el suministro al resto de los abonados de la red si se debe realizar alguna operación en el tubo de acometida. En otros casos, resulta interesante su instalación por su bajo coste y por las ventajas que puede aportar en situaciones puntuales a la empresa suministradora.

\subsubsection{Tubo de acometida}

Es la tubería que enlaza la red de distribución pública con la tubería de la instalación general interior del edificio. La tendencia es la utilización de materiales plásticos, principalmente el polietileno de media densidad (PE-80 y PE-100, de color negro con bandas azules), por las ventajas que presenta frente a otros materiales (maneabililidad, resistencia, coste, entre otras). Para grandes diámetros suele también utilizarse fundición dúctil. Este tubo generalmente se encuentra enterrado en zanja, y su longitud suele ser reducida. La longitud va a influir en las pérdidas de carga originadas, reduciendo la presión disponible en el punto de entrega. El trazado suele ser perpendicular a la fachada del edificio.

En cuanto al diámetro de esta tubería y dado que este tramo generalmente trasiega solamente el caudal simultáneo del edificio, suele adoptar valores reducidos con respecto a otras conducciones de la red general de distribución. El valor mínimo de este diámetro también suele estar impuesto por la compañía (Tabla A1-1, en función del caudal del edificio), de forma que las velocidades que se originan (para el caudal de diseño de la instalación) tomen valores aceptables. Por tanto, sus características serán próximas a las del tubo de alimentación al que se conecta, pudiendo incluso modelarse como una prolongación de éste. 
TABLA A1-1. DiÁMETROS DE ACOMETIDA (CANAL DE ISABEL II)

\begin{tabular}{ccc}
\hline $\begin{array}{c}\mathbf{Q} \\
\text { máximo }\end{array}$ & $\begin{array}{c}\mathbf{D} \\
\text { acometida }\end{array}$ & $\begin{array}{c}\mathbf{v} \\
\text { máxima }\end{array}$ \\
\hline $\mathbf{( I / s})$ & $\mathbf{( m m )}$ & $\mathbf{( \mathbf { m } / \mathbf { s } )}$ \\
$\mathbf{0 , 7 5}$ & 20 & 2,39 \\
$\mathbf{2}$ & 30 & 2,83 \\
$\mathbf{3 , 5}$ & 40 & 2,79 \\
$\mathbf{6}$ & 50 & 3,06 \\
$\mathbf{8 , 5}$ & 65 & 2,56 \\
$\mathbf{1 1}$ & 80 & 2,19 \\
$\mathbf{1 5}$ & 100 & 1,91 \\
$\mathbf{5 8 , 3 3}$ & 150 & 3,30 \\
\hline
\end{tabular}

\subsubsection{Llave de corte general de la propiedad (Ilave de registro)}

La Ilave de registro está situada sobre la acometida en la vía pública, junto a la edificación a abastecer. Se instalará en el interior de una arqueta construida para tal efecto. La maniobra exclusivamente la entidad suministradora o persona autorizada, sin que los abonados, propietarios ni terceras personas puedan manipularla.

\subsection{INSTALACIÓN GENERAL DEL EDIFICIO}

Se trata del tramo conectado a la acometida del edificio y abastece a las diferentes unidades individuales de consumo; instalaciones particulares (viviendas individuales o locales), o instalaciones colectivas (cuarto de limpieza del edificio, piscina, riego de jardines o agrupaciones de instalaciones particulares).

Esta instalación empieza a la salida de la llave de registro situada en el exterior de la propiedad o, en función de la definición de acometida, en la llave de paso del interior del edificio. Discurre por el edificio por zonas comunes de éste hasta llegar a la llave de paso instalada en el interior de cada unidad individual de consumo.

Algunos de los elementos con los que cuenta la instalación general son:

- Llave de paso o de corte general (situada en el interior del edificio)

- Filtro general de la instalación

- Armario o arqueta con contador general (si existe)

- Tubo de alimentación

- Equipo de presión (si existe)

- Distribuidor o batería de contadores

- Contadores divisionarios (individuales), si existen. 
- Ascendentes o montantes (discurren por zonas comunes).

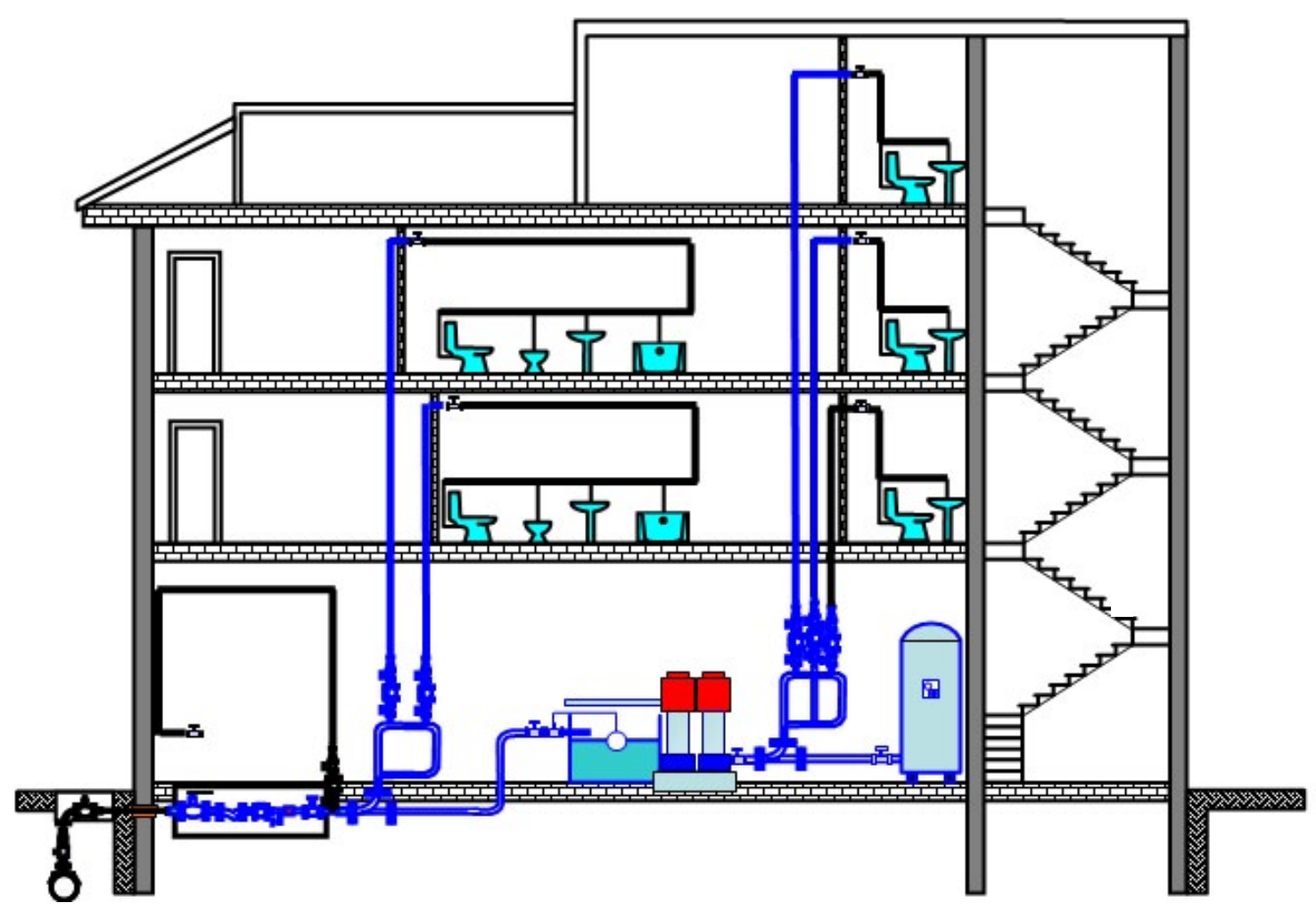

FIGURA A1-2. INSTALACIÓN INTERIOR GENERAL DE UN EDIFICIO

\subsubsection{Llave de paso o de corte general (situada en el interior del edificio)}

Se trata del principal elemento de maniobra del edificio, permite abrir o cerrar el suministro al interior de toda la instalación. Debe estar situada en el interior de la propiedad, en un lugar accesible, y estar señalada para su identificación. Esta Ilave es la que se tiene que manipular si se desea realizar alguna operación de mantenimiento en el interior del edificio que precise del corte total del suministro.

\subsubsection{Filtro general de la instalación}

Se trata del primer elemento instalado después de la llave general. Su finalidad es evitar el paso partículas e impurezas sólidas para proteger los equipos más sensibles de la instalación y reducir el efecto de corrosión en tuberías y depósitos. Según el CTE debe ser de tipo $\mathrm{Y}$ con un umbral de filtrado entre 25 y $50 \mu \mathrm{m}$, con malla de acero inoxidable y con baño de plata para reducir la posible acumulación de bacterias.

La obligatoriedad de instalación de un filtro da lugar a la necesidad de realizar operaciones de mantenimiento frecuentes. De no realizarlas, la colmatación del filtro incrementará muy notablemente las pérdidas de carga en la instalación, con una merma importante en los caudales y presiones suministradas. Se acepta comúnmente una pérdida de carga máxima en los filtros de $5 \mathrm{mca}$, valor que puede incrementarse notablemente a medida que acumula más suciedad. 


\subsubsection{Contador general}

Elemento que contabiliza el total del volumen consumido en la instalación, y no es obligatorio a no ser que así se indique en el reglamento de servicio. Debe estar correctamente dimensionado (en función del caudal nominal y máximo de la instalación). En algunos abastecimientos el calibre lo fija la propia empresa suministradora. En cualquier caso se debe atender a las pérdidas de carga originadas (la normativa actual fija 1 bar a caudal máximo).

\subsubsection{Llave, grifo o racor de prueba}

Permite comprobar el correcto funcionamiento del contador y del dispositivo antirretorno, así como el cumplimiento de las exigencias de suministro, sirviendo también para la toma de muestras que permiten analizar la calidad del agua en el interior.

\subsubsection{Válvula de retención (dispositivo antirretorno)}

Evita los retornos de agua a la red general de suministro (impide que el agua que ha estado dentro de la instalación ingrese de nuevo a la red pública). Este antirretorno independiza la instalación general pública de la instalación general del edificio en cuanto a posibles reflujos de agua contaminada en la instalación.

\subsubsection{Llave de salida de arqueta}

Junto con la llave de la entrada de la arqueta, realiza el cierre para el aislamiento de los elementos de la misma, permitiendo el mantenimiento de éstos sin necesidad de vaciar la instalación o manipular la llave de registro de la acometida (especialmente en lo referente a la sustitución del contador general).

\subsubsection{Tubo de alimentación}

Tubo de la instalación general por el que circula la totalidad de caudal que se consume en el interior del edificio. También incluye el conjunto de tramos de tuberías principales que llevan el agua hasta los distribuidores del edificio. Si existen derivaciones (particulares o colectivas) este tubo termina justo a la entrada de la batería de contadores domiciliarios.

\subsubsection{Distribuidor o batería de contadores}

Elemento que distribuye el agua de forma independiente a cada una de las instalaciones de un edificio. Puede tratarse de una simple conducción a la que se conectan en derivación tuberías de suministro (distribuidor), o bien una batería de contadores donde van directamente conectados los contadores de diferentes unidades de uso. La Figura A1-3 muestra los elementos que usualmente incorpora la batería. 


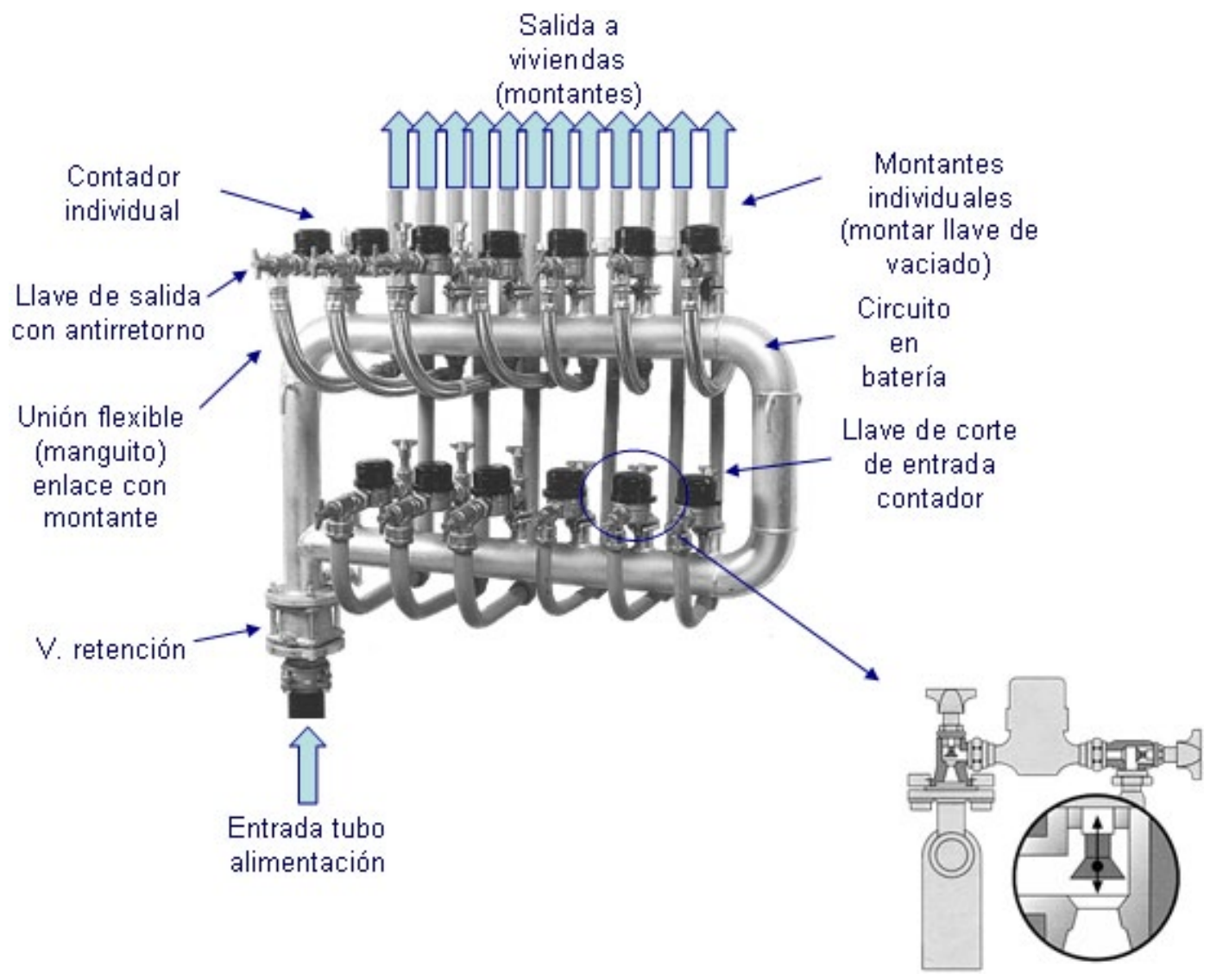

FIGURA A1-3. ELEMENTOS DE UNA BATERÍA DE CONTADORES

Es distribuidor es más común en instalaciones con contador general, tales como hoteles, colegios, industrias, etc. Cada derivación conectaría con un área diferente de consumo del edificio o parcela. También es común en instalaciones de viviendas dotadas de contadores divisionarios en rellano, en esta situación desde el distribuidor parten los montantes comunes a varias viviendas.

\subsubsection{Contadores divisionarios}

Dispositivo de medida que contabiliza la totalidad de volumen consumido por una unidad de consumo del edificio. Generalmente están conectados en baterías de contadores o en arquetas individuales (edificio de vivienda unifamiliar). Se debe atender a las pérdidas menores originadas, limitadas de forma similar a las del contador general.

\subsubsection{Ascendentes o montantes}

Conducciones principalmente verticales que enlazan el distribuidor principal con las instalaciones individuales (con montante individual por vivienda o colectivo que distribuye a varias viviendas) o derivaciones colectivas. En instalaciones con contador general único o en instalaciones con contadores aislados en cada planta o por rellanos, es posible que cada una de estas conducciones alimente a varias viviendas (Figura A1$4)$. 


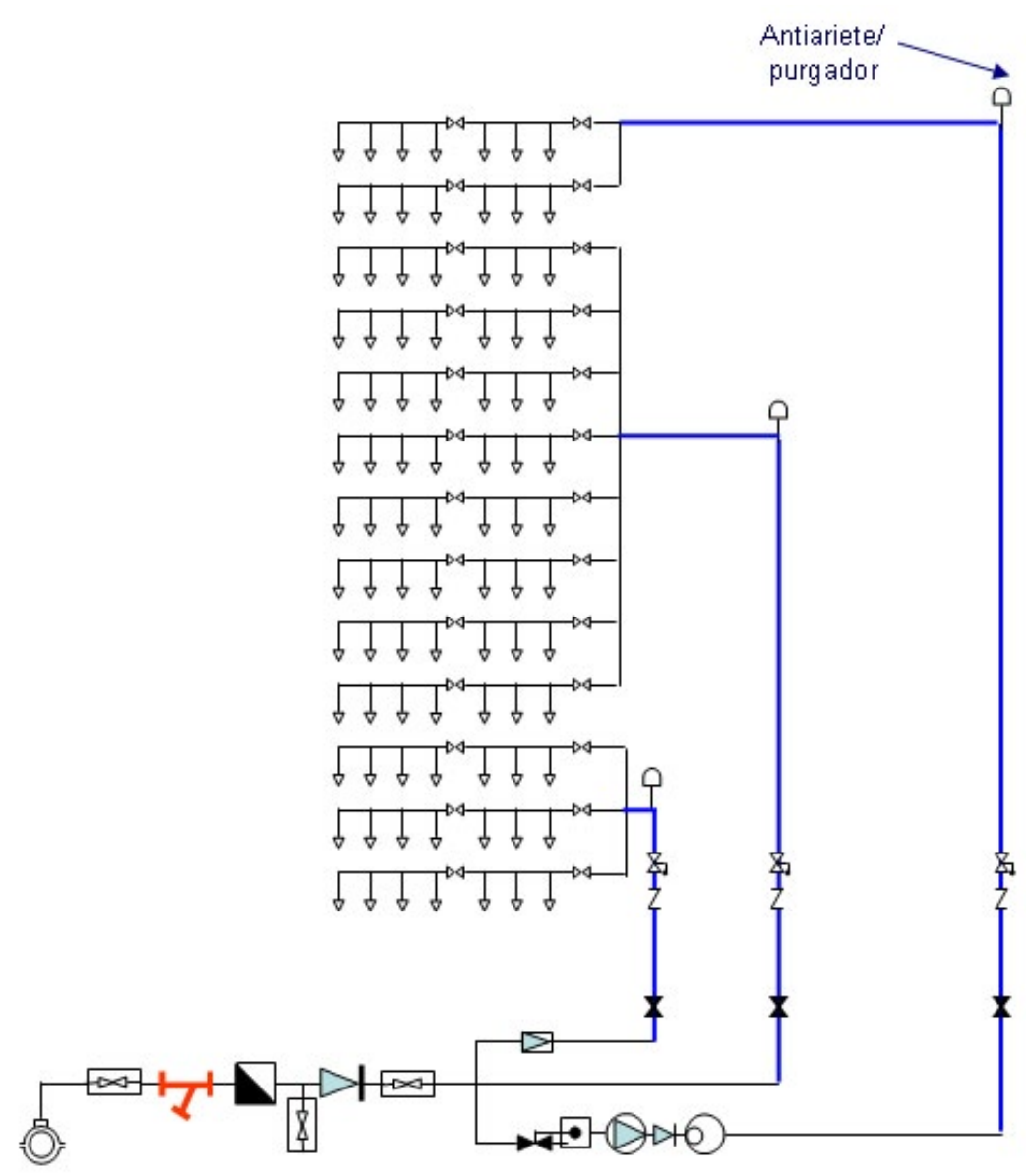

FIGURA A1-4. ESQUEMA DE INSTALACIÓN CON MONTANTES COLECTIVOS

En la parte superior del montante es conveniente instalar un elemento que reduzca el efecto de los golpes de ariete en la instalación, absorbiendo los cambios bruscos y alternativos de presión. No es usual instalarlo en montantes individuales, pero sí en montantes que suministran a más de una vivienda (instalaciones más expuestas a variaciones bruscas de caudal). Con este elemento se absorben las variaciones de presión del agua bien a partir de un muelle que se comprime o expande, o mediante un depósito con aire que varía su volumen (similar a un calderín de pequeño tamaño, ver Figura A1-5).

\subsection{INSTALACIÓN PARTICULAR Y DERIVACIONES COLECTIVAS}

La instalación general del edificio puede suministrar a dos tipos diferentes instalaciones, instalación particular y derivaciones colectivas. Generalmente, los edificios de viviendas cuentan con ambas instalaciones, mientas que instalaciones como las de un colegio sólo tienen derivaciones colectivas. 


\subsubsection{Instalación particular}

Tramo de la instalación que une la instalación general del edificio con los puntos de consumo de la vivienda (grifos y conexión de aparatos). Esta instalación empieza en la llave de paso de la vivienda y discurre por el interior de la vivienda (zonas privadas del edificio). Las conducciones de la instalación particular tienen un trazado oculto, estando en algunos casos las conducciones empotradas y en otros, discurriendo por falsos techos o alojamientos similares

Los elementos de la instalación particular son los siguientes:

- Llave de paso del abonado (situada en el interior de la vivienda)

- Ramal general

- Derivaciones particulares a cuartos húmedos o ramales de enlace

- Puntos finales o de consumo (Ilaves de corte o de escuadra)

\subsubsection{Derivaciones colectivas}

Se trata del conjunto de instalaciones de un edificio destinadas al suministro de locales diferentes a viviendas. Suelen tener un uso común para la comunidad de propietarios, tal como la instalación de un grifo en un garaje, instalación completa de un cuarto de limpieza, instalación de una zona deportiva, etc. También suele comprender la a agrupación de instalaciones particulares (viviendas, locales, etc.)

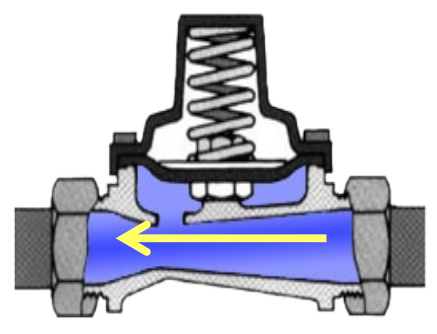

Funcionamiento en régimen permanente

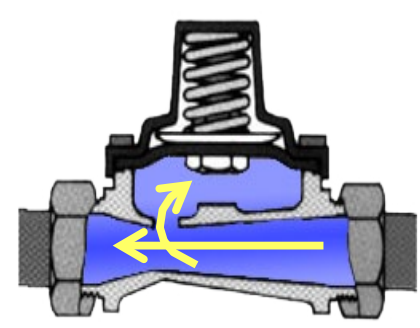

Funcionamiento en régimen transitorio

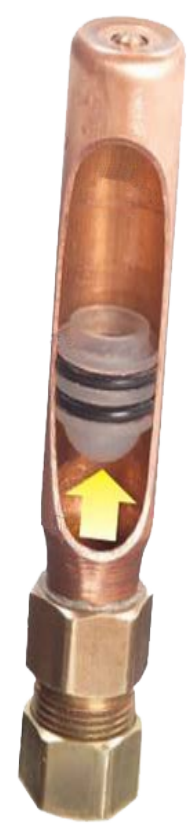

Sección antiariete

FIGURA A1-5. ESQUEMA DE FUNCIONAMIENTO DE UN ANTIARIETE 
Anexo 2

Esquemas de suministro adoptados en las instalaciones interiores 


\subsection{INTRODUCCIÓN}

La instalación interior de suministro de agua de un edificio puede adoptar diferentes esquemas de suministro en función de la configuración y elementos integrantes. Por ello a continuación se describen las disposiciones más usuales, al mismo tiempo que se indican las consideraciones más importantes asociadas a su funcionamiento. Los esquemas contemplados en el presente anexo son:

- Suministro en directo sin grupo de presión (Tipo I)

- Suministro en directo con bomba de velocidad fija (Tipo II)

- Suministro en directo y con grupo de velocidad fija (Tipo III)

- Suministro con grupo de velocidad variable (Tipo IV)

- Suministro con grupo de velocidad fija y depósito atmosférico (convencional)

- Suministro con depósito en la parte superior del edificio

Si bien existen esquemas adicionales, no se ha considerado su incorporación ya que en muchos casos derivan de los anteriores o tienen poca incidencia.

\subsection{SUMINISTRO EN DIRECTO SIN GRUPO DE PRESIÓN (TIPO I)}

En instalaciones con suministro en directo sin grupo de presión el agua entra en la instalación a través de la acometida domiciliaria y recorre las conducciones hasta los puntos de consumo del abonado sin la interposición de elementos de almacenamiento ni grupos de bombeo (ver Figura A2-1). Este esquema de suministro ha sido designado como Tipo I a lo largo de la presente Tesis para facilitar su identificación.

Desde el punto de vista energético, es la tipología de instalación óptima, ya que aprovecha la presión disponible en la red pública para vencer las pérdidas de carga en la instalación y el desnivel geométrico, manteniendo en los puntos de consumo condiciones de suministro suficientes para la correcta alimentación de los aparatos, a saber, la reglamentación vigente fija una presión mínima $\left(P_{\min }\right)$ en los puntos de consumo de 10 mca para grifos comunes y 15 mca para fluxores y calentadores (CTE HS4). 
Por otro lado, desde el punto de vista de la calidad del agua suministrada, la alteración de las características de salubridad es reducida, ya que el esquema cerrado limita la entrada de agentes externos a la instalación (UNE 806-2). En cuanto a la conservación de los agentes desinfectantes, para tiempos de permanencia reducidos, mantiene la concentración de éstos en niveles similares a los existentes a la entrada del edificio.

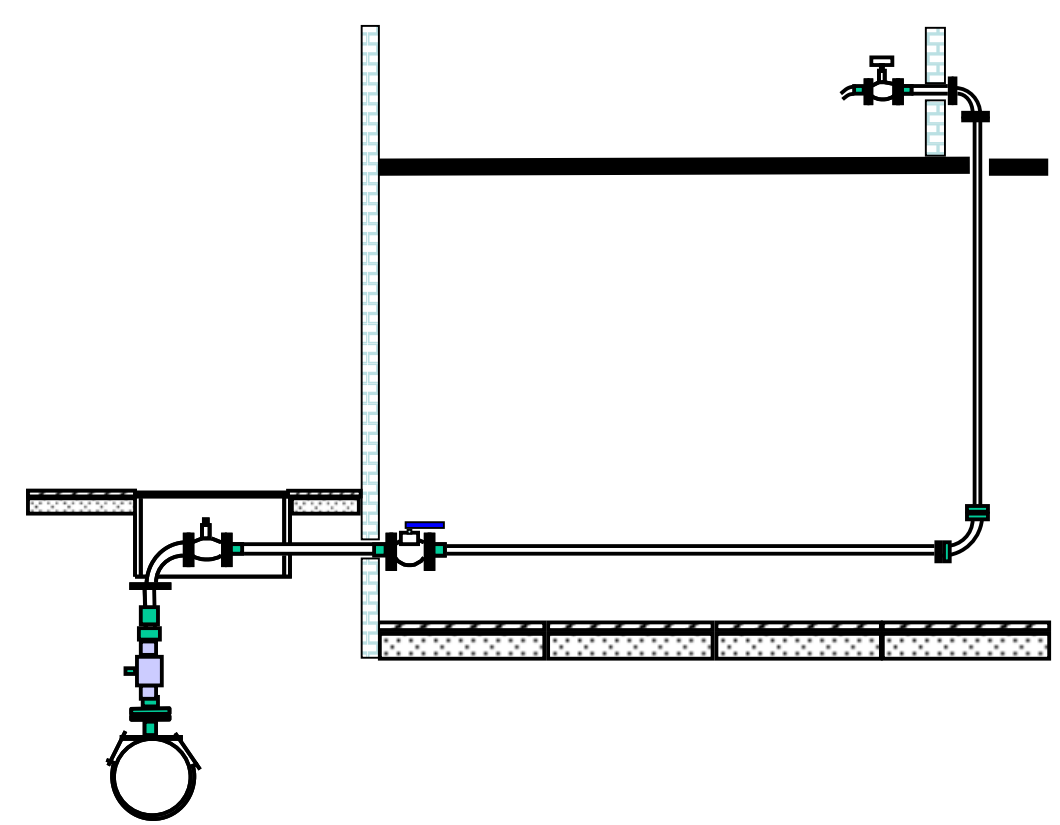

FIGURA A2-1. ESQUEMA DE UNA INSTALACIÓN CON SUMINISTRO EN DIRECTO SIN GRUPO DE PRESIÓN

Este esquema está condicionado a la existencia de presión suficiente y de forma continua en la red pública para garantizar el suministro, presentando problemas en redes que experimentan variaciones de presión considerables en la acometida, ya que ante descensos de presión la instalación experimentaría fluctuaciones pudiendo incluso imposibilitar el suministro correcto a los aparatos. Del mismo modo, la reducción de la presión disponible a medida que aumenta la altura del inmueble, o derivada de las pérdidas de carga, puede limitar la adopción de este esquema de forma total o parcial en el edificio.

Por todo ello este esquema se puede adoptar en instalaciones en las que la red pública de abastecimiento opera con niveles de presión estabilizados y de valor medio suficiente para garantizar las condiciones mínimas indicadas anteriormente. Y por tanto, será necesario acudir al Reglamento de Servicio del abastecimiento, o directamente a la compañía gestora del servicio, para conocer la presión mínima disponible en las acometidas, y determinar la posibilidad de adoptar dicho esquema. 


\subsection{SUMINISTRO EN DIRECTO CON BOMBA DE VELOCIDAD FIJA (TIPO II)}

La instalación de grupos de bombeo está justificada ante la imposibilidad de garantizar las condiciones mínimas exigidas mediante la presión disponible en red. Por ello en muchas instalaciones resulta necesaria la instalación de un equipo de bombeo que compense la insuficiencia de presión. En la Figura A2-2 se muestra un grupo de presión de velocidad fija conectado directamente a la conducción de alimentación (sin la interposición de ningún depósito). Adicionalmente el equipo de presión debe estar equipado con otros elementos como un calderín o acumulador de presión, cuya finalidad es reducir el tiempo durante el cual el grupo está en marcha.

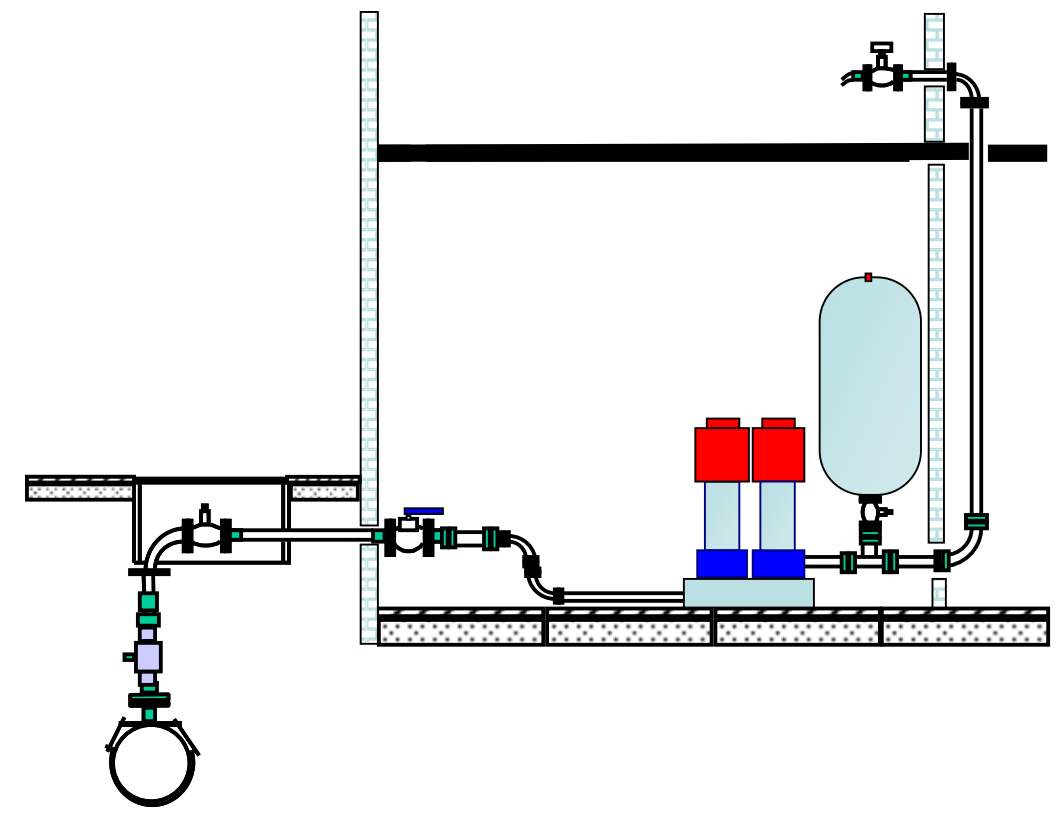

FIGURA A2-2. ESQUEMA DE UNA INSTALACIÓN CON SUMINISTRO CON BVF EN DIRECTO

La existencia de un grupo de bombeo aumenta las exigencias de la red, siendo este efecto más notable cuando se utiliza un grupo de velocidad fija, por esta razón el CTE insta a la empresa instaladora a disponer de un depósito auxiliar (atmosférico) que reduzca el efecto introducido por la aspiración de este tipo de grupos de bombeo, y reduzca las solicitaciones a la red. Entre las solicitaciones asociadas al funcionamiento bajo este esquema, se debe atender al régimen permanente (bomba a velocidad nominal) y a su funcionamiento transitorio durante los instantes de arranque y parada.

En el comportamiento en régimen permanente, el caudal detraído por el grupo suele resultar superior al demandado de forma instantánea por los usuarios, consecuentemente y tal como se ha comprobado en el Capítulo 3, el funcionamiento del grupo puede originar descensos de presión en la acometida considerables por un aumento de las pérdidas de carga en la instalación, y de forma más sensible en la medida que es posible el solapamiento de varios grupos con funcionamiento simultáneo. 
El funcionamiento transitorio debido al arranque y parada del grupo origina fluctuaciones de presión en la instalación interior más o menos sensibles, al mismo tiempo que pueden ser transmitidas al exterior de éste (fenómeno descrito en el Capítulo 4). El arranque provoca una caída de presión, mientras que la parada genera un aumento localizado de la presión en las proximidades de la bomba.

De forma similar al esquema anterior, la adopción del esquema Tipo II precisa de una mínima estabilidad de la presión en red, ya que una fluctuación de ésta puede alterar el punto de funcionamiento del grupo, y por tanto trabajar alejado del punto óptimo. La consideración de este efecto es importante con regulación escalonada mediante presostados. Adicionalmente se debe comprobar que las solicitaciones originadas por el funcionamiento del grupo son asumibles por la red general y por la instalación interior del edificio.

\subsection{SUMINISTRO EN DIRECTO Y CON GRUPO DE VELOCIDAD FIJA (TIPO III)}

Se trata de una combinación de los dos esquemas anteriores (Figura A2-3); una zona del edificio se suministra directamente con la presión de red con garantía de presiones mínimas en los aparatos (coincidiendo ésta con las alturas más bajas del edificio), y la parte superior se abastece a partir de un grupo de bombeo. La proporción de viviendas servidas con un esquema u otro es función de la presión en red y de las características del inmueble. Este esquema aprovecha la presión disponible en red al mismo tiempo que reduce el número de viviendas servidas con el grupo, por ello acude a tamaños de grupo más pequeños reduciendo por tanto las solicitaciones respecto al esquema anterior (para un mismo número de viviendas servidas).

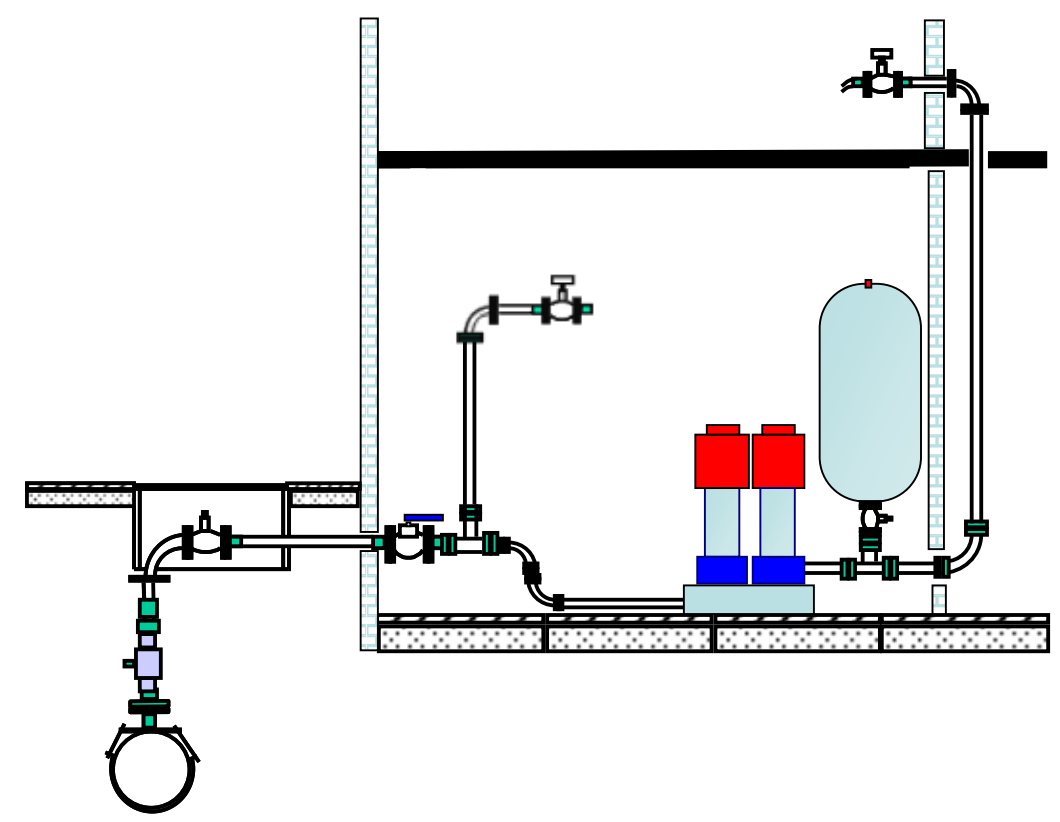

FIGURA A2-3. ESQUEMA DE UNA INSTALACIÓN CON SUMINISTRO DIRECTO Y BOMBAS DE VELOCIDAD FIJA 
Esta disposición exige mantener una presión estabilizada en la acometida del inmueble, y de valor mínimo para garantizar el correcto suministro de las instalaciones conectadas en directo sin grupo de presión. La configuración de esquemas presenta una reducida flexibilidad, no siendo inmediata la permutación de viviendas de un esquema a otro, y por ello puede presentar problemas a la hora de adaptar la instalación ante variaciones del comportamiento de la red.

\subsection{SUMINISTRO CON GRUPO DE VELOCIDAD VARIABLE (TIPO IV)}

Derivado del esquema Tipo II, el esquema Tipo IV dota al equipo de un variador de frecuencia (Figura A2-4) capaz de modificar la velocidad de giro del motor y, en función de las necesidades de la instalación, variar el caudal y la altura aportada por el grupo, manteniendo una presión prácticamente constante en los puntos de consumo de los usuarios (presión de consigna, PC).

Respecto a la calidad del agua suministrada y, de forma similar a lo que ocurre en los esquemas anteriores, al tratarse de un sistema cerrado no se alteran sensiblemente las propiedades del agua suministrada ni la de los agentes desinfectantes, pero debe prestar atención al volumen de agua almacenada en el depósito (de menor capacidad que en el esquema Tipo II).

A diferencia del esquema Tipo II y tal como se comprueba en el Capítulo 4, el funcionamiento del grupo con variador es más moderado, reduciéndose de forma significativa las fluctuaciones de presión originadas en los transitorios de arranque y parada del grupo. En régimen permanente también se reducen las solicitaciones a la red ya que el grupo atiende a la demanda instantánea de los usuarios, y por tanto favorece la aparición de caudales inferiores a los del esquema Tipo II.

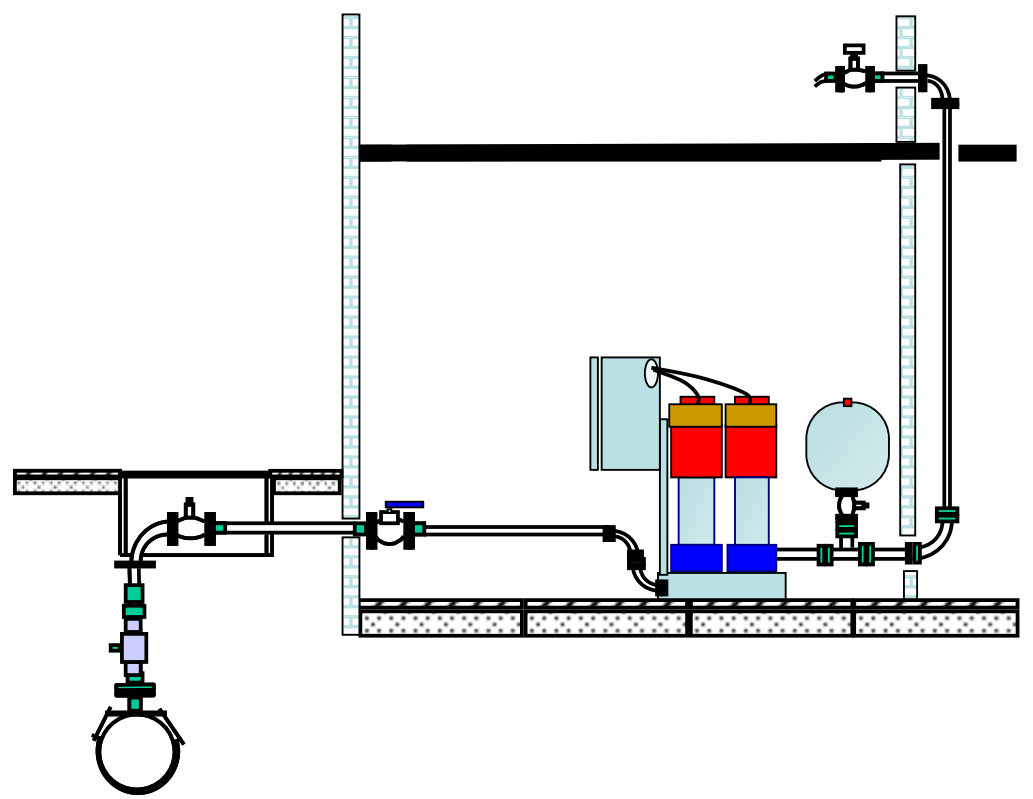

FIGURA A2-4. ESQUEMA DE UNA INSTALACIÓN CON SUMINISTRO CON BOMBAS DE VELOCIDAD VARIABLE 
Respecto a la calidad en el suministro, entendida ésta como la capacidad de mantener estables los valores de presión en los puntos de consumo, este esquema consigue mantener constante la consigna de presión programada, de forma que el abonado no experimenta variaciones de presión considerables, reduciendo por tanto, la fatiga de los elementos y aumentando la durabilidad de los mismos. Los ruidos generados durante el funcionamiento de este tipo de grupos se reducen respecto al grupo de velocidad fija, debido a la reducción de la velocidad de giro de la bomba.

Este esquema está contemplado en el CTE (definido como grupo de accionamiento regulable o de caudal variable), y puede ser instalado sin necesidad de disponer de depósito atmosférico. Este esquema también contempla disposiciones que combinan BVF y BVV (las BVF cubren los escalones de regulación y la BVV realiza el ajuste fino de presión). Es importante adecuar la configuración del controlador PID del variador de frecuencia del equipo para reducir los efectos transitorios, y evitar el funcionamiento con rendimientos bajos (limitando la velocidad mínima de giro del motor).

Respecto a las posibilidades de adoptar este esquema, se precisa una presión estabilizada en red de forma similar a las disposiciones con BVF. En cualquier caso, una bajada significativa de la presión podría reducir la capacidad de aporte de caudal de grupo.

\subsection{SUMINISTRO CON GRUPO DE VELOCIDAD FIJA Y DEPÓSITO ATMOSFÉRICO (CONVENCIONAL)}

Suministro Ilamado también "conexión indirecta" según la norma UNE 806-2, y definido como: "conexión indirecta del dispositivo elevador de la presión a través de una cisterna que está permanentemente abierta a la atmósfera". Tal como se describen en el Capítulo 1, los problemas más destacados de este sistema de suministro están relacionados con la dificultad de garantizar la calidad del agua suministrada, y la reducción de la eficiencia del bombeo por la ruptura de presión realizada en el depósito, ya que la despresurización suele ir acompañada de un bombeo posterior.

Este tipo de instalación está muy extendido en la mayoría de abastecimientos, ya que la presurización de la red no es suficiente para mantener un correcto suministro a las instalaciones más elevadas de un inmueble, y además presenta una importante de labor de laminación de las solicitaciones sobre la red. Por otro lado, su instalación ha estado favorecida por el elevado coste que inicialmente presentaba la incorporación del variador de frecuencia en el grupo, si bien este coste ha descendido significativamente.

Adicionalmente, este esquema se caracteriza por presentar unas reducidas solicitaciones en régimen transitorio, tanto en la instalación interior (condicionado por diámetros suficientes y distancias entre depósito y la bomba no muy elevadas) y en la 
instalación general. En este último caso debe considerarse el comportamiento de las válvulas de control de llenado tal como se describe en el Anexo 5, ya que un dimensionado inadecuado favorece un mayor caudal detraído, y una respuesta rápida que contribuye a la generación de transitorios peligrosos.

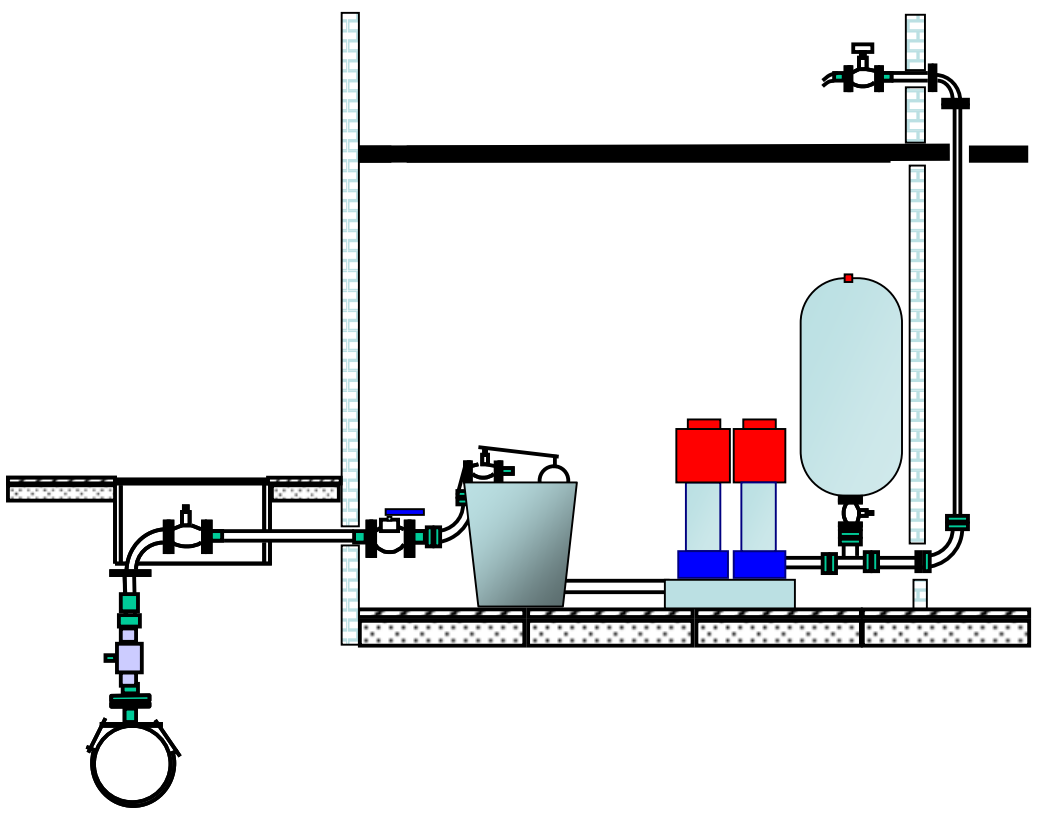

FIGURA A2-5. ESQUEMA DE UNA INSTALACIÓN CON BOMBA DE VELOCIDAD FIJA Y DEPÓSITO AUXILIAR

Esta disposición a diferencia de las anteriores puede garantizar el correcto suministro tanto con fluctuaciones de presión en acometida, como con valores bajos (incluso con cortes de suministro de reducida duración). Por tanto puede adoptarse en aquellas redes con capacidad insuficiente, o para aquellos usos que pudieran poner en riesgo el normal suministro en la red (por ejemplo grandes consumidores).

\subsection{SUMINISTRO CON DEPÓSITO EN LA PARTE SUPERIOR DEL EDIFICIO}

Esta disposición conecta el tubo de alimentación del edificio con un depósito atmosférico situado en la parte superior del inmueble, aprovechando los instantes en los que la red dispone de presión suficiente para proceder el relleno. En otras circunstancias es posible acudir a un grupo de presión situado en la parte baja del edificio (conectado aguas arriba del depósito), para realizar el llenado de éste en función del nivel de agua en su interior. Esta situación sería similar a la originada por el Esquema Tipo II, pero presenta una serie de ventajas principalmente asociadas a menores caudales de bombeo (función del dimensionado del depósito).

La presión de suministro en los aparatos es función de la altura a la que se encuentra la vivienda y del nivel de agua. Esto origina diferencias de presión sensibles en las diferentes alturas del inmueble, por un lado los abonados situados en viviendas 
más alejadas del depósito disponen de presión elevada, y las viviendas situadas más próximas disponen de presiones muy reducidas.

Los problemas característicos de esta tipología de suministro son similares a los que experimenta el esquema con suministro indirecto, además la instalación de estos elementos en el exterior del edificio, compromete en mayor medida la salubridad del agua almacenada, ya que posibilita temperaturas más elevadas y mayor facilidad para la admisión de agentes contaminantes. Este tipo de instalación tiende a reemplazarse por suministros que incorporar grupos de bombeo ya que reducen sensiblemente los problemas derivados de este esquema.

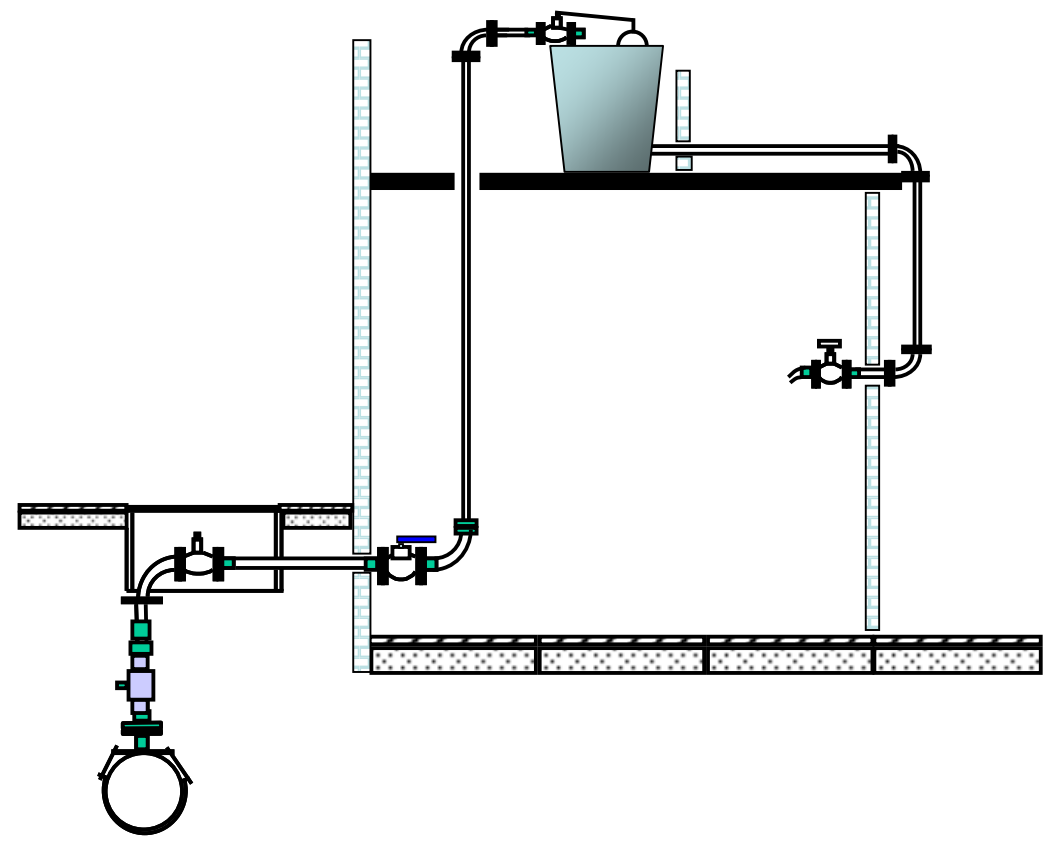

FIGURA A2-6. ESQUEMA DE UNA INSTALACIÓN CON DEPÓSITO SUPERIOR

Adicionalmente, la utilización de depósitos situados en la parte superior del edificio se realiza en abastecimientos o zonas de éste, donde no se puede garantizar el suministro con niveles de presión mínima, de forma que con la presión disponible en red es posible rellenar los depósitos durante el día o en horas de mínima demanda, o bien requieren de un volumen de almacenamiento de emergencia útil en situaciones de corte de suministro. Esto sucede por ejemplo en algunos abastecimientos por gravedad, en zonas próximas a los depósitos, en los que la presión disponible es insuficiente para permitir el correcto funcionamiento de los aparatos durante el día (horas de mayor demanda), y se recurre al suministro a partir del depósito que ha sido previamente llenado en horas de menor demanda. 
Anexo 3

Estimación de la demanda de agua en viviendas en el entorno residencial 


\subsection{INTRODUCCIÓN}

En el dimensionado de las instalaciones de suministro de agua, el procedimiento para la determinación de las características de las conducciones y del resto de elementos parte de la obtención del caudal de cálculo, también conocido como caudal simultáneo. Este caudal aproxima el valor real del caudal que de forma simultánea puede circular por un determinado tramo de la instalación.

Como puede entenderse, la determinación de la demanda simultánea de agua para un conjunto de usos presenta una complejidad nada despreciable. Si bien factores socioeconómicos, hábitos higiénicos e incluso la climatología son algunos de los aspectos que pueden alterar sensiblemente las pautas de consumo en una instalación, rara vez son contemplados en los modelos de cálculo empleados. La necesidad de procedimientos sencillos y que al mismo tiempo aporten una respuesta generalizada limita la incorporación de estos factores en las diferentes metodologías.

El propósito del estudio realizado en el presente anexo no pretende incurrir sobre factores condicionantes de la demanda de agua, en su lugar y dada la disponibilidad de datos reales de demanda con una resolución suficientemente elevada, trata de comparar las metodologías de cálculo más usuales con los registros obtenidos en diferentes campañas de mediciones. El estudio particulariza el análisis para instalaciones de viviendas en el ámbito urbano, ya que se trata del usuario mayoritario en redes de abastecimiento de agua. El ajuste del caudal de simultaneidad a las condiciones reales de funcionamiento, permite optimizar el dimensionado algunos elementos de la instalación. Por ejemplo, la adecuación de los diámetros de las conducciones o tamaños de grupos de presión, puede incurrir en un ahorro energético y económico al mismo tiempo que garantiza la calidad del suministro. En esta línea, se propone una expresión para la determinación del caudal de cálculo de una instalación, obtenida a partir de simulaciones con datos reales de consumo.

Finalmente, los resultados obtenidos permitirán conocer en mayor medida las pautas de consumo asociadas a un conjunto de usuarios de un edificio, y principalmente en lo que respecta al uso simultáneo del recurso. 


\subsection{Metodologías Para el Cálculo del CaUdal Simultáneo en un tramo}

Para el análisis de la simultaneidad se ha trabajado con la base de datos de consumos elaborada en el desarrollo de la Tesis. Los consumos se corresponden con datos de viviendas en el entorno residencial que pueden ser asimiladas en su mayoría a viviendas Tipo D según la NIA. Dado que las pautas y volúmenes consumidos pueden variar en función de aspectos sociales, económicos, regionales, etc. debe tenerse en cuenta que los resultados obtenidos no pueden generalizarse, pero en cualquier caso pueden servir de referencia para instalaciones que mantengan un consumo similar al de las viviendas de la base de datos.

Son muchos los procedimientos comúnmente utilizados en el dimensionado de instalaciones. Todos ellos tratan de relacionar directa o indirectamente el caudal total instalado con el caudal máximo probable de utilización (caudal de cálculo). Para ello suelen acudir a expresiones empíricas para el cálculo directo del caudal simultáneo, o bien parten de la obtención de diferentes coeficientes de simultaneidad que tienen en cuenta la posible confluencia en el uso de aparatos o viviendas de la instalación. Los procedimientos más usuales para el dimensionado de instalaciones de viviendas son:

- Procedimiento según la NIA

- Procedimiento según las Normas Francesas (NF P 41-204)

- Método Racional (método español)

- Procedimiento según las Normas Españolas (UNE 149201)

\subsubsection{Procedimiento establecido en la NIA}

Uno de los procedimientos más utilizados en el dimensionado de instalaciones se realiza a partir de la derogada NIA, documento que mantiene su carácter consultivo dada su simplicidad para el dimensionado y por los hábitos adquiridos por los técnicos. La NIA no propone calcular directamente el caudal de cálculo de una conducción, en su lugar parte de la definición del caudal mínimo de cada aparato (caudal instantáneo Qinst), a partir del cual se puede obtener el caudal total instalado en una vivienda, para posteriormente clasificarla según cinco Tipos de vivienda).

TABLA A3-1. DESCRIPCIÓN DE LOS TIPOS DE VIVIENDA DEFINIDOS POR LA NIA

\begin{tabular}{|c|c|c|}
\hline Vivienda & $Q_{\text {inst }}(\mathrm{I} / \mathrm{s})$ & Descripción \\
\hline Tipo A & $0<Q_{\text {inst }}<0,6$ & Locales con cocina, lavadero y sanitario \\
\hline Tipo B & $0,6 \leq Q_{\text {inst }}<1,0$ & Locales con cocina, lavadero y cuarto de baño completo \\
\hline Tipo C & $1,0 \leq Q_{\text {inst }}<1,5$ & Locales con cocina, lavadero y cuarto de baño completo \\
\hline Tipo D & $1,5 \leq Q_{\text {inst }}<2,0$ & $\begin{array}{l}\text { Locales con cocina, office, lavadero y cuarto de baño y/o } \\
\text { aseo }\end{array}$ \\
\hline Tipo E & $2,0 \leq Q_{\text {inst }}<3,0$ & $\begin{array}{l}\text { Locales dotados de cocina, office, lavadero y dos baños y } \\
\text { aseo }\end{array}$ \\
\hline
\end{tabular}


Una vez obtenido el tipo de vivienda se dimensiona el tramo según las tablas de cálculo propuestas por el documento. La siguiente figura muestra la tabla del NIA para el dimensionado del tubo de alimentación de un edificio (el documento establece tablas similares para el dimensionado de otros tramos).

TABLA A3-2. TABLA PARA EL DIMENSIONADO DEL TUBO DE ALIMENTACIÓN DE UN EDIFICIO SEGÚN LA NIA

\begin{tabular}{ccccccc}
\hline D tubería & D tubería & \multicolumn{5}{c}{ Número máximo de suministros } \\
\cline { 3 - 7 } rugosas $(\mathbf{m m})$ & lisas $(\mathbf{m m})$ & Tipo A & Tipo B & Tipo C & Tipo D & Tipo E \\
$\mathbf{3 1 , 7 5}$ & $\mathbf{3 0}$ & 2 & 1 & 1 & - & - \\
$\mathbf{3 8 , 1}$ & $\mathbf{4 0}$ & 5 & 3 & 2 & 2 & 1 \\
$\mathbf{5 0 , 5}$ & $\mathbf{5 0}$ & 25 & 16 & 14 & 10 & 6 \\
$\mathbf{6 3 , 5}$ & $\mathbf{6 0}$ & 75 & 50 & 45 & 40 & 30 \\
$\mathbf{7 6 , 2}$ & $\mathbf{8 0}$ & 120 & 90 & 80 & 70 & 60 \\
$\mathbf{8 8 , 9}$ & $\mathbf{1 0 0}$ & 200 & 150 & 130 & 110 & 90 \\
\hline
\end{tabular}

Como puede observarse, el procedimiento propuesto no calcula los caudales simultáneos de los tramos, y el dimensionado sólo es función del número y tipo de vivienda, y las características de las tuberías.

Con la finalidad de comparar diferentes metodologías, se va a tratar de obtener a partir de la tabla anterior, y para diferentes tamaños de edificio, la relación existente entre el caudal total instalado Qт у el caudal de cálculo derivado Qc. Las expresiones que relacionan las variables anteriores son:

$$
Q_{C}=\frac{\pi}{4} \cdot v \cdot D_{\min }^{2} \leftrightarrow Q_{T}=N_{v i v} \cdot Q_{i n s t}^{v i v}
$$

Por un lado, la relación existente entre el diámetro de la tubería (considerando los dos tipos de tubería especificados) y la velocidad de diseño, es posible obtener el caudal de cálculo correspondiente. En condiciones normales, los valores de velocidad máxima en la fase de diseño pueden alcanzar valores comprendidos entre 2 y $3 \mathrm{~m} / \mathrm{s}$ (según se trate de tuberías metálicas o termo plásticas respectivamente, si bien el valor máximo fijado por el CTE para tuberías termoplásticas es ligeramente superior). En el estudio se han considerado los caudales de cálculo asociados a estas velocidades, y a una velocidad de diseño de $1 \mathrm{~m} / \mathrm{s}$.

Por otro lado, a partir del número máximo de suministros (Tabla A3-2) y los rangos de variación de caudal instalado establecidos en la Tabla A3-1, es posible determinar el valor del caudal total instalado en el edificio (considerando que todas las viviendas son idénticas). Para el caso concreto estudiado, se han analizado las viviendas Tipo D, ya que se trata de una de las tipologías más extendida a nivel nacional, al mismo tiempo que representan la vivienda característica de la base de datos de consumo. 
Al mismo tiempo, se han definido dos subtipos de viviendas derivados de la vivienda Tipo D; vivienda Tipo D1 y vivienda Tipo D2, dependiendo del número de aparatos instalados y del caudal instalado de éstos. Esta discretización permite fijar los límites característicos de la vivienda Tipo D.

TABLA A3-3. DEFINICIÓN DE SUBTIPOS DE VIVIENDA

\begin{tabular}{|c|c|c|c|c|}
\hline Vivienda & $\begin{array}{c}\text { Cuarto } \\
\text { húmedo }\end{array}$ & Aparatos & $\begin{array}{l}\text { Qinst } \\
(\mathrm{I} / \mathrm{s})\end{array}$ & $\begin{array}{l}Q_{t \text { inst }} \\
(\mathrm{l} / \mathrm{s})\end{array}$ \\
\hline \multirow{3}{*}{ Tipo D1 } & Cocina & Lavadora, fregadero dom., lavavajillas dom. & 0,55 & \multirow{3}{*}{1,55} \\
\hline & Baño & Inodoro cisterna, lavabo, bidé, bañera ( $>1,4$ m) & 0,6 & \\
\hline & Aseo & Inodoro cisterna, lavabo, ducha & 0,4 & \\
\hline \multirow{3}{*}{ Tipo D2 } & Cocina & Lavadora, fregadero dom., lavavaj. dom., lavadero & 0,75 & \multirow{3}{*}{1,95} \\
\hline & Baño & Inodoro cisterna, lavabo, bidé, bañera ( $>1,4$ m) & 0,6 & \\
\hline & Baño & Inodoro cisterna, lavabo, bidé, bañera (>1,4 m) & 0,6 & \\
\hline
\end{tabular}

Para diferentes tamaños de edificio, el caudal total instalado en este será la suma de los caudales instalados en la totalidad de viviendas de éste, según la siguiente expresión:

$$
Q_{T}^{\text {edif }}=\sum_{i=1}^{N v i v} Q_{t \text { inst }}^{v i v} \quad(Q \text { en } / / s)
$$

A partir de las consideraciones anteriores es posible obtener la relación entre el caudal total instalado en un edificio, y el caudal de cálculo correspondiente, en función del número del tamaño del edificio.

TABLA A3-4. RELACIÓN ENTRE EL CAUDAL INSTALADO Y CAUDAL DE CÁlCULO PARA DIFERENTES TAMAÑO DE EDIFICIO

\begin{tabular}{|c|c|c|c|c|c|c|c|c|}
\hline \multirow{2}{*}{$\begin{array}{c}\mathrm{N}^{\mathbf{o}} \\
\text { viviendas } \\
\text { Tipo D }\end{array}$} & \multicolumn{2}{|c|}{$\begin{array}{c}Q_{T} \\
(\mathbf{l} / \mathbf{s})\end{array}$} & \multicolumn{2}{|c|}{$\begin{array}{c}Q c(1 / \mathrm{s}) \\
(V \text { diseño }=1 \mathrm{~m} / \mathrm{s})\end{array}$} & \multicolumn{2}{|c|}{$\begin{array}{c}Q c(I / s) \\
(V \text { diseño }=2 \mathrm{~m} / \mathrm{s})\end{array}$} & \multicolumn{2}{|c|}{$\begin{array}{c}Q_{c}(\mathrm{l} / \mathrm{s}) \\
(\mathrm{V} \text { diseño }=3 \mathrm{~m} / \mathrm{s})\end{array}$} \\
\hline & $\begin{array}{c}\text { Subtipo } \\
\text { D1 }\end{array}$ & $\begin{array}{l}\text { Subtipo } \\
\text { D2 }\end{array}$ & $\begin{array}{l}\text { Tubería } \\
\text { rugosa }\end{array}$ & $\begin{array}{c}\text { Tubería } \\
\text { lisa }\end{array}$ & $\begin{array}{l}\text { Tubería } \\
\text { rugosa }\end{array}$ & $\begin{array}{l}\text { Tubería } \\
\text { lisa }\end{array}$ & $\begin{array}{l}\text { Tubería } \\
\text { rugosa }\end{array}$ & $\begin{array}{l}\text { Tubería } \\
\text { lisa }\end{array}$ \\
\hline 2 & 3,1 & 3,9 & 1,14 & 1,26 & 2,28 & 2,51 & 3,42 & 3,77 \\
\hline 10 & 15,5 & 19,5 & 2,00 & 1,96 & 4,01 & 3,93 & 6,01 & 5,89 \\
\hline 40 & 62 & 78 & 3,17 & 2,83 & 6,33 & 5,65 & 9,50 & 8,48 \\
\hline 70 & 108,5 & 136,5 & 4,56 & 5,03 & 9,12 & 10,05 & 13,68 & 15,08 \\
\hline 110 & 170,5 & 214,5 & 6,21 & 7,85 & 12,41 & 15,71 & 18,62 & 23,56 \\
\hline
\end{tabular}

La siguiente figura permite obtener el caudal de cálculo en función del caudal total instalado en el edificio y las velocidades consideradas para el dimensionado $(1,2$ y $3 \mathrm{~m} / \mathrm{s}$ ). A partir de esta gráfica la determinación del caudal de cálculo de un edificio parte de conocer el caudal total instalado en éste (o el número de viviendas 
equivalentes), establecer el área correspondiente en función de la velocidad de diseño fijada, y dependiendo del material del tubo obtener el caudal de cálculo.

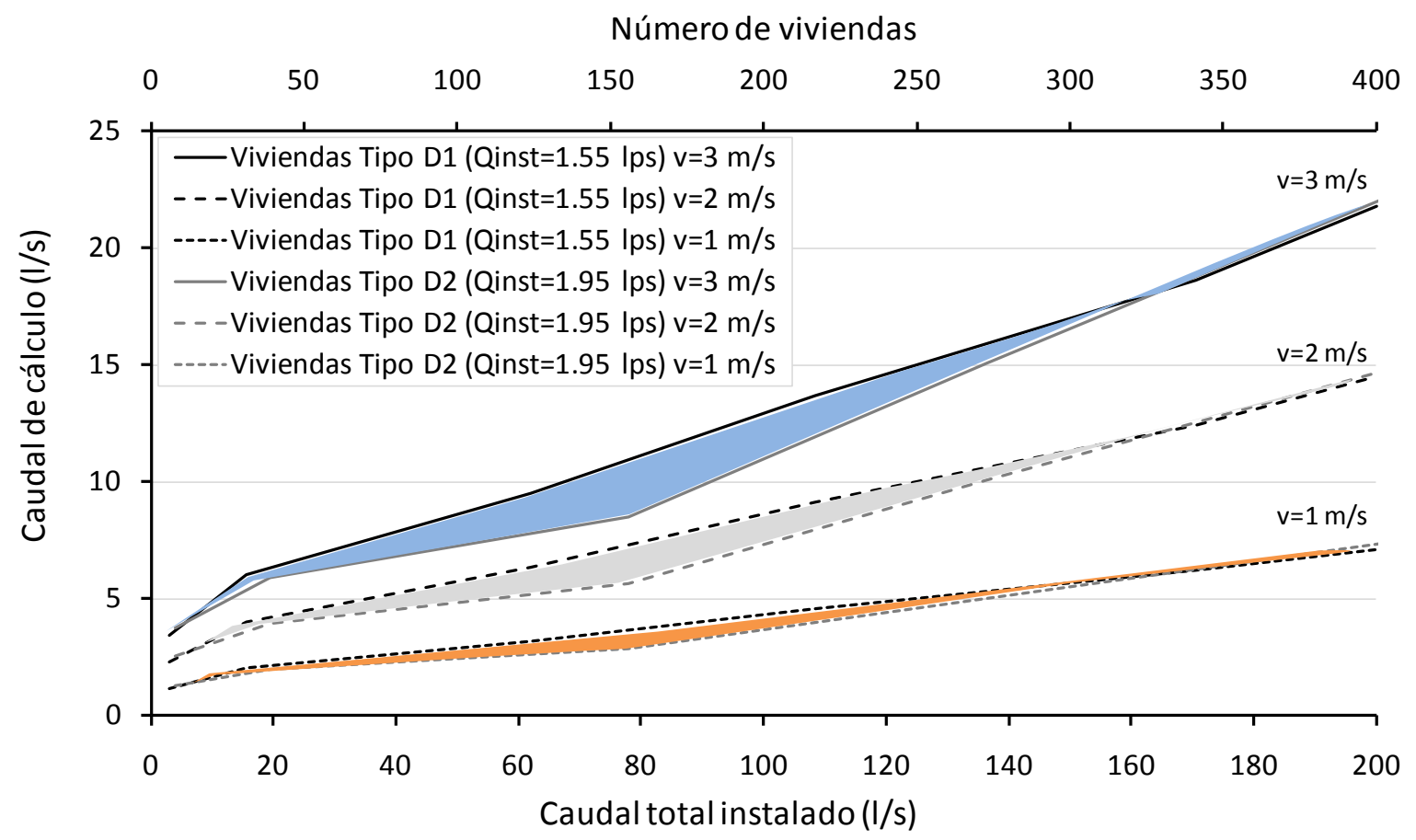

Figura A3-1. RELACIÓN ENTRE EL CAUDAL SIMULTÁNEO Y CAUDAL TOTAL DE CÁLCULO DERIVADA DE LA NIA

Si bien las velocidades mostradas pueden ser válidas para el dimensionado de diferentes tramos (según los valores establecidos por el CTE HS4), es importante considerar el material de la conducción, ya que la naturaleza de éste condiciona tanto su característica resistiva como su rigidez, pudiendo derivar en una mayor o menor nivel de ruido en condiciones normales de funcionamiento. En cualquier caso, se estima una velocidad máxima aceptable si ésta no supera los $2 \mathrm{~m} / \mathrm{s}$.

Respecto a la velocidad mínima de diseño, fijar una velocidad muy reducida puede originar problemas de deposiciones, y un aumento del tiempo de residencia del agua en la red, al mismo tiempo que supone un sobrecoste de la instalación. Por ello, se estima un valor mínimo de la velocidad en condiciones de diseño de $1 \mathrm{~m} / \mathrm{s}$.

\subsubsection{Procedimiento establecido por las Normas Francesas (NF P 41-204)}

El procedimiento propuesto por las Normas Francesas para el cálculo del caudal total de una instalación $Q_{c}$, parte del cálculo del caudal total instalado $Q_{T}$, junto con un coeficiente de simultaneidad de uso $K_{1}$ (determinado éste en función del número total de aparatos conectados aguas abajo del tramo que está siendo dimensionado).

$$
Q_{C}=K_{1} \cdot Q_{T}
$$




\subsubsection{Caudal total instalado, $Q_{T}$}

El caudal total instalado se obtiene por la suma de los caudales instantáneos de los aparatos conectados en función del número de aparatos $n$ :

$$
Q_{T}=\sum_{i=1}^{n} Q_{\text {inst }}
$$

Los valores de los caudales instantáneos, Qinst de cada aparato puede obtenerse a partir de diferentes tablas asociadas a la normativa local o estudios de referencia. En el caso concreto de España, el CTE establece unos caudales mínimos instantáneos en los diferentes aparatos según la Tabla A3-6.

\subsubsection{Coeficiente de simultaneidad, $K_{1}$}

El coeficiente de simultaneidad de aparatos $K_{1}$, tiene en cuenta que la demanda de agua no se hace de forma simultánea en la totalidad de aparatos de la instalación, y que a mayor número de aparatos instalados es lógico que se penalice el caudal de cálculo. La expresión propuesta por la norma es:

$$
K_{1}=\frac{1}{\sqrt{n-1}}
$$

Esta expresión no tiene en cuenta los diferentes tipos de grifos, ni el caudal instantáneo de cada uno de ellos. Tampoco atiende al tipo de instalación que se está dimensionando, más bien estima indirectamente la probabilidad de que en una instalación puedan estar en uso un determina número de aparatos, $n$.

En algunos docuementos, para que el caudal de cálculo no se vea excesivamente penalizado, se limitó el valor mínimo del coeficiente a 0,2 , correspondiéndose con instalaciones con más de 26 aparatos (Figura A3-2). De forma similar, en actualizaciones de la normativa se redujo el valor del numerador a 0,8 en aras de conseguir un mejor ajuste a la demanda real, reduciendo el valor del caudal resultante. 
La siguiente gráfica representa el factor de simultaneidad $K_{1}$ en función de $n$.

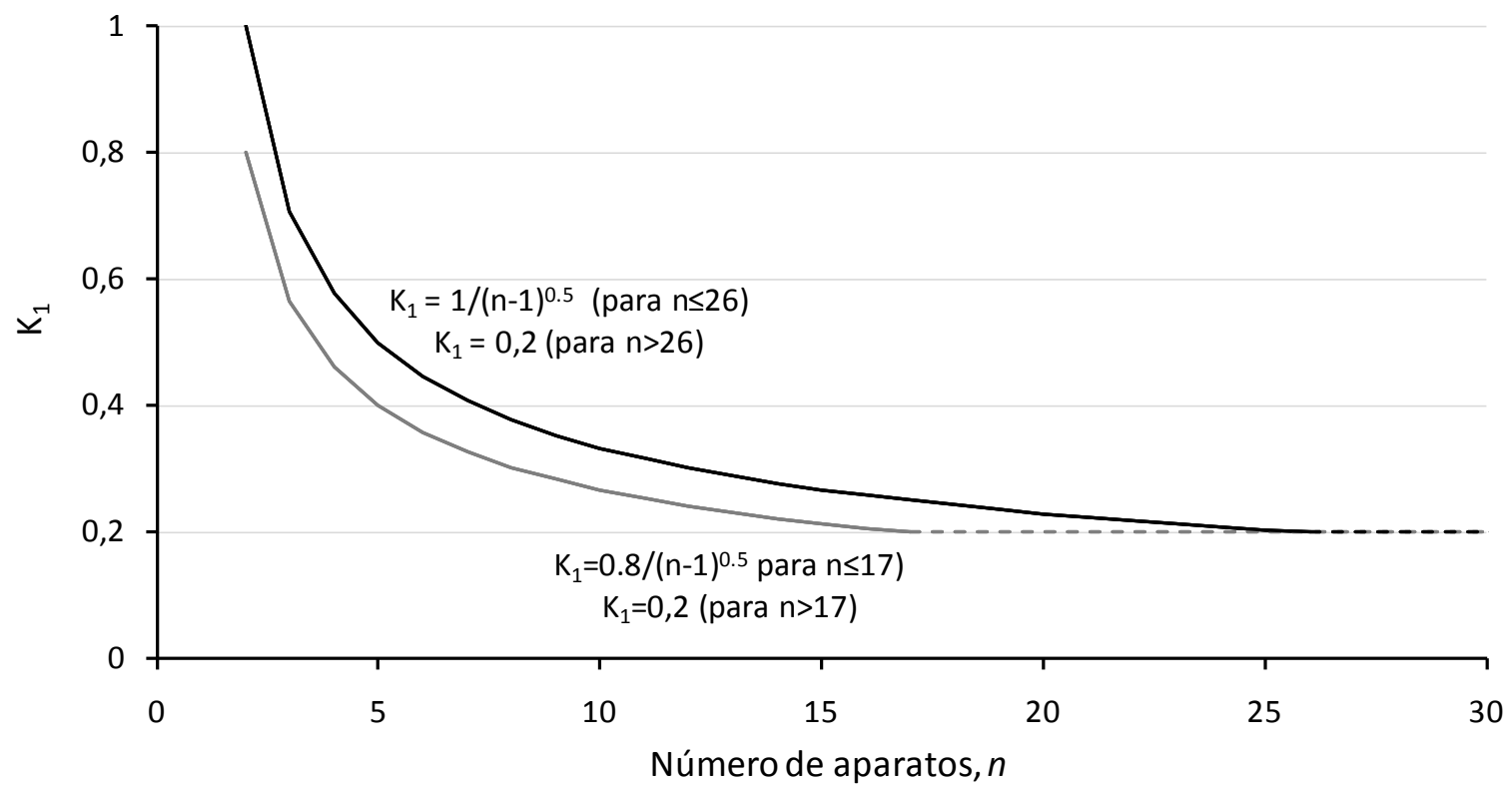

FIGURA A3-2. COEFICIENTE DE SIMULTANEIDAD EN FUNCIÓN DEL NÚMERO DE APARATOS

Existen otras expresiones y curvas de cálculo para diferentes tipos de uso. En esta línea, la siguiente figura (Arizmendi, 1985) muestra la variación del coeficiente en función del tipo de suministro:

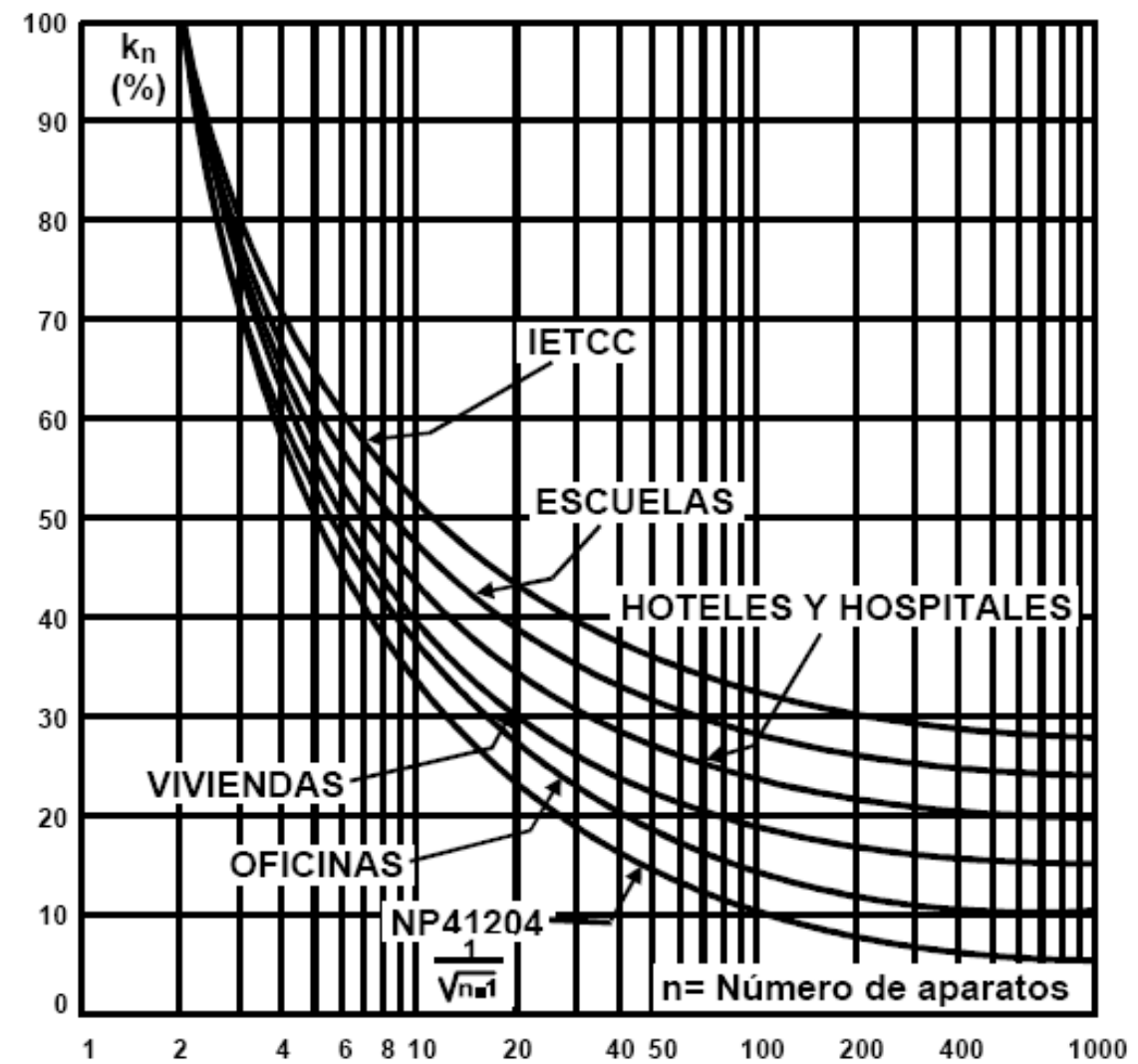

FIGURA A3-3. CuRVAS PARA EL COEFICIENTE DE SIMULTANEIDAD DEL USO DE APARATOS 
Otros autores introducen un factor $F$ para adaptar la expresión anterior a diferentes tipos de usos.

$$
K_{1}=F \cdot \frac{0.8}{\sqrt{n-1}}
$$

TABLA A3-5. AJUSTE DEL COEFICIENTE DE SIMULTANEIDAD DE APARATOS

\begin{tabular}{cc}
\hline Instalación & $\boldsymbol{F}$ \\
\hline Estándar & 1 \\
Hotel & 1,25 \\
Restaurante & 1,5 \\
\hline
\end{tabular}

Si se analiza el caudal de cálculo de diferentes edificios hipotéticos formados por viviendas con 9 y 11 aparatos para los mismos caudales instalados por vivienda definidos en el procedimiento anterior $(1,55 \mathrm{l} / \mathrm{s}$ y $1,95 \mathrm{l} / \mathrm{s})$, se obtiene la siguiente relación respecto al caudal total instalado correspondiente (se han representado las series correspondientes a las dos expresiones de cálculo comentadas, con y sin limitación del valor mínimo del coeficiente $K_{1}$ a 0,2 ).

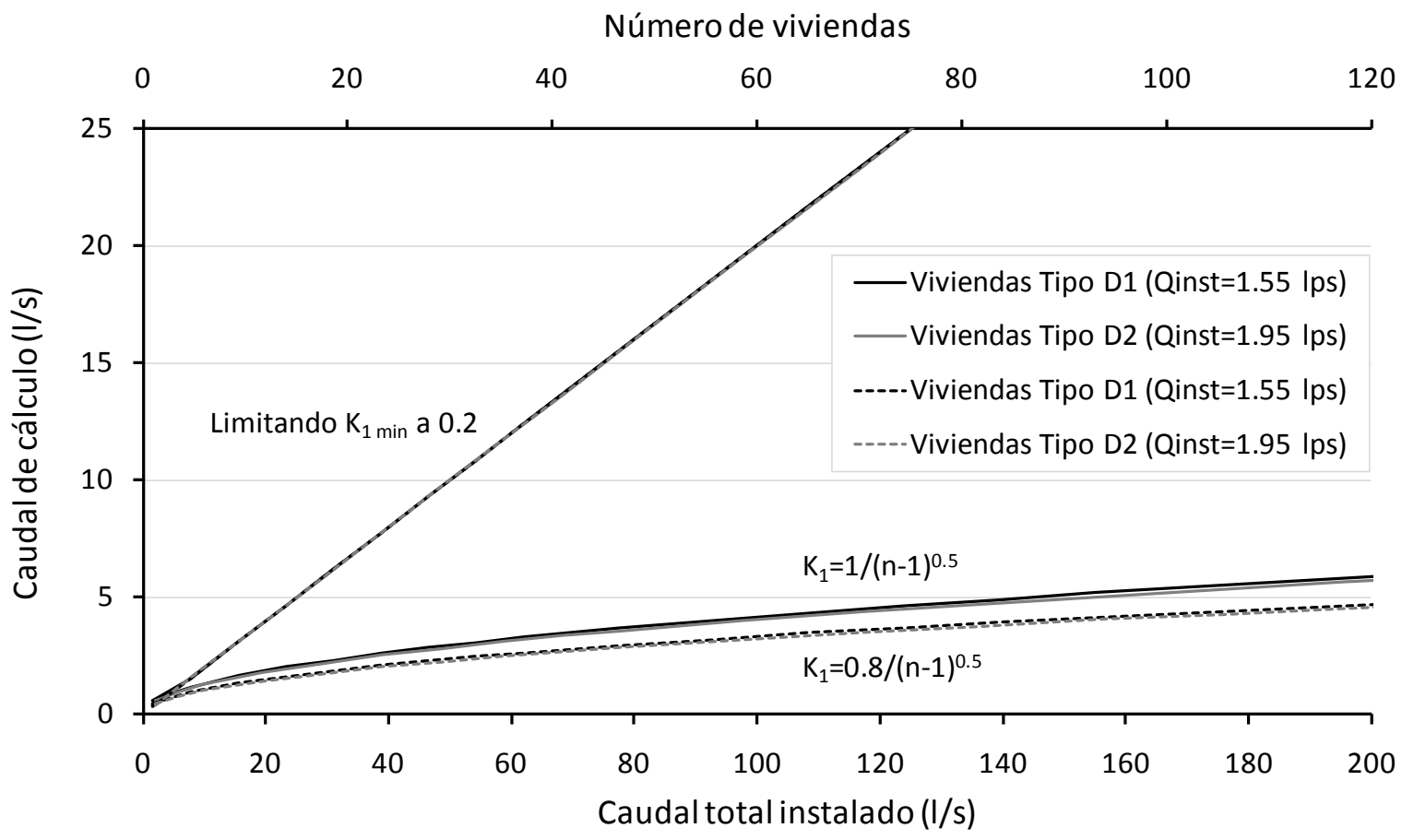

FIGURA A3-4. RELACIÓN ENTRE EL CAUDAL SIMULTÁNEO Y CAUDAL TOTAL DE CÁLCULO SEGÚN NF 41-204

Como puede observarse, la limitación del valor mínimo del coeficiente aumenta sensiblemente los caudales de cálculo, teniendo sólo sentido la expresión para el cálculo de la simultaneidad para edificios con un reducido número de aparatos, o para usos diferentes a viviendas. Al mismo tiempo la variación del numerador del coeficiente (de 1 a 0,8$)$ no altera de forma significativa la expresión para el caso analizado. 


\subsubsection{Procedimiento racional (método español)}

Una variación del procedimiento anterior es el conocido como el procedimiento racional o método español. Éste propone el cálculo de un segundo coeficiente de simultaneidad asociado al número de viviendas de la instalación, $N$.

El coeficiente de simultaneidad de viviendas, $K_{2}$ tiene en cuenta que no todas las viviendas de la instalación están consumiendo agua de forma simultánea, y que debe aumentar la penalización del caudal de cálculo a medida que aumenta el tamaño de la instalación.

$$
K_{2}=\frac{19+\mathrm{N}_{v i v}}{10\left(\mathrm{~N}_{v i v}+1\right)}
$$

A partir de estos dos coeficientes es posible tener en cuenta por un lado el tamaño del edificio, y por otro lado la capacidad de los aparatos instalados en éste. El caudal de simultaneidad o caudal de cálculo que circula por un tramo se obtiene a partir de la siguiente expresión:

$$
Q_{C}=N_{v i v} \cdot K_{1} \cdot K_{2} \cdot Q_{t i n s t}=K_{1} \cdot K_{2} \cdot Q_{T}
$$

En este caso, el coeficiente $K_{1}$ sólo tiene en cuenta los aparatos de una vivienda tipo, y no el de la totalidad de aparatos del edificio como en el caso anterior. Y también se aconseja su limitación a un valor mínimo de 0,2 (la limitación persigue evitar la excesiva penalización del caudal de cálculo para edificios que cuentan con un elevado número de viviendas).

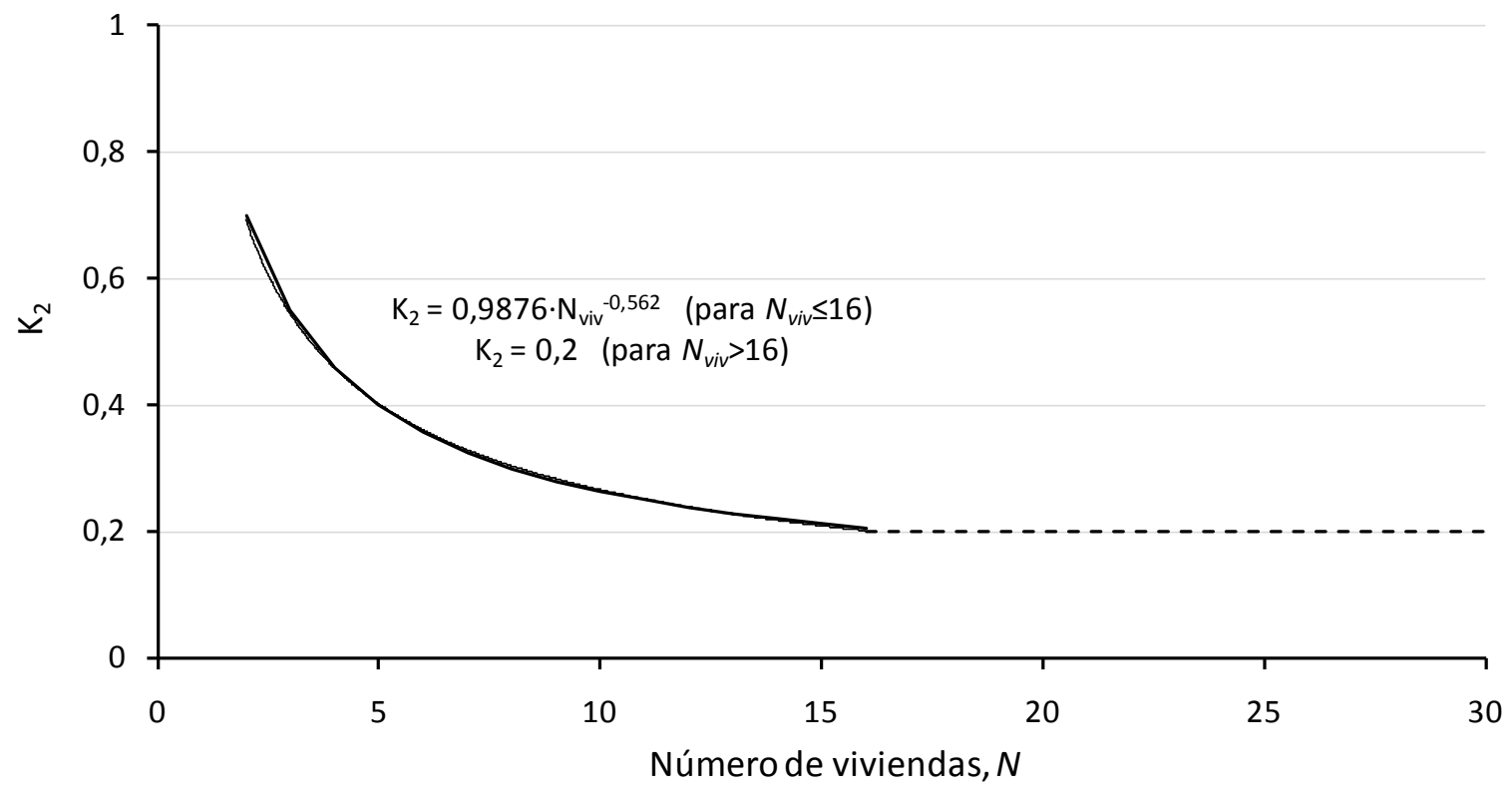

FIGURA A3-5. COEFICIENTE DE SIMULTANEIDAD DEL CONSUMO EN VIVIENDAS 
Si de forma similar a los procedimientos anteriores se relaciona el caudal instalado en el edificio con el caudal de cálculo considerando de nuevo los tipos de vivienda definidos anteriormente, se obtiene la siguiente figura.

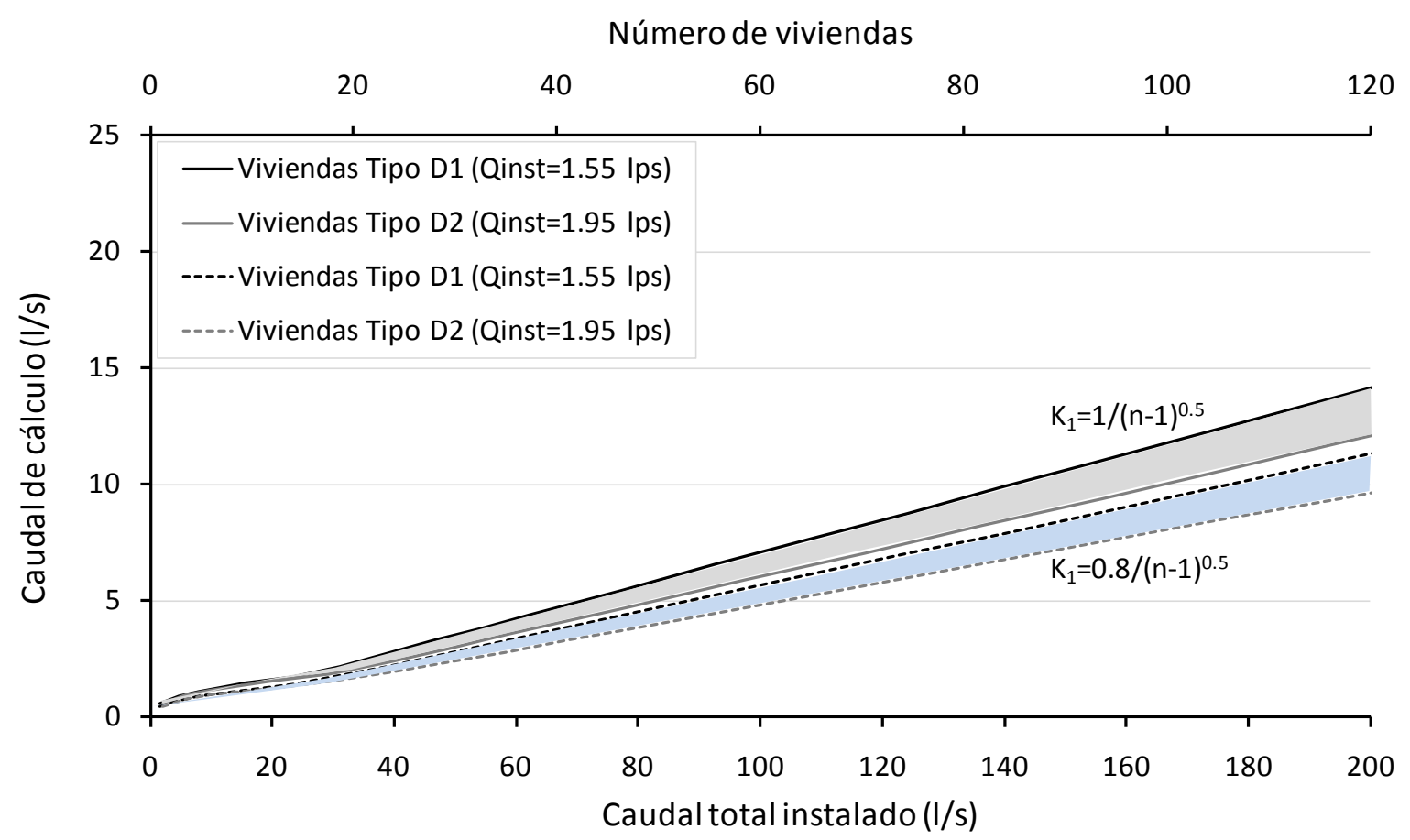

FIGURA A3-6. RELACIÓN ENTRE EL CAUDAL SIMULTÁNEO Y CAUDAL TOTAL SEGÚN EL PROC. RACIONAL

\subsubsection{Procedimiento establecido en el Código Técnico de la Edificación}

El Código Técnico de la Edificación es desde el año 2006, el documento normativo de referencia en el ámbito de las instalaciones interiores, siendo el Documento Básico de Salubridad HS-4, el correspondiente a las instalaciones interiores de suministro de agua.

El carácter prestacional del CTE evita en muchos casos incurrir en expresiones o procedimientos para la determinación de las exigencias establecidas en el documento, éste es el caso del caudal de cálculo asociado a un tramo. Si bien se establecen los caudales mínimos que se deben garantizar en cada aparato (Tabla A3-6), no se fija ninguna expresión para su obtención, dejando en manos del instalador la libertad de realizar los cálculos necesarios, atendiendo en todo caso a criterios que consideren la lógica simultaneidad en el uso.

Bajo esta reglamentación los diferentes técnicos en España mantienen por un lado el procedimiento conocido como método racional, o bien se acude a normas tecnológicas complementarias (principalmente la norma española UNE 149201). 
TABLA A3-6. CAUDALES MÍNIMOS INSTANTÁNEOS DE DIFERENTES APARATOS SEGÚN EL CTE (AGUA FRÍA)

\begin{tabular}{|cc|}
\hline $\begin{array}{c}\text { Tipo de } \\
\text { aparato }\end{array}$ & $\begin{array}{c}\text { Qinst } \\
\text { (I/s) }\end{array}$ \\
Lavamanos & 0,05 \\
Lavabo & 0,1 \\
\hline Ducha & 0,2 \\
\hline Bañera $(\geq 1,4 \mathrm{~m})$ & 0,3 \\
\hline Bañera $(<1,4 \mathrm{~m})$ & 0,2 \\
\hline Bidé & 0,1 \\
\hline Inodoro (cisterna) & 0,1 \\
\hline Inodoro (fluxor) & 1,25 \\
\hline Urinarios (temporizados) & 0,15 \\
\hline Urinarios (cisterna) & 0,04 \\
\hline Fregadero doméstico & 0,2 \\
\hline Fregadero no doméstico & 0,3 \\
\hline Lavavajillas doméstico & 0,15 \\
\hline Lavavajillas industrial (20 servicios) & 0,25 \\
\hline Lavadero & 0,2 \\
\hline Lavadora doméstica & 0,2 \\
\hline Lavadora industrial (8 kg) & 0,6 \\
\hline Grifo aislado & 0,15 \\
\hline Grifo garaje & 0,2 \\
\hline Vertedero & 0,2 \\
\hline
\end{tabular}

\subsubsection{Procedimiento establecido por las Normas Españolas (UNE 149201)}

La Norma Española UNE 149201 deriva de la norma alemana DIN 1988, en su parte $\mathrm{n}^{\circ} 3$, desarrollada por la Sociedad Alemana de Ingenieros de Instalaciones de Gas y Agua, DVGW. En el documento se establecen diferentes procedimientos para la estimación del caudal de cálculo en función de la tipología de la edificación.

En el caso concreto de edificios de viviendas se establecen las siguientes expresiones en función del caudal total instalado, Qт:

- $\quad$ Para $Q t>20 \mathrm{l} / \mathrm{s}$

$$
Q_{C}=1.7 \cdot Q_{T}^{0.21}-0.7 \quad(Q \text { en } \mathrm{l} / \mathrm{s})
$$

- $\quad$ Para $Q_{t}<20$ l/s $\quad$ (dependiendo de los caudales instantáneos de los aparatos)

$$
\text { Si todo } Q_{\text {inst }}<0,5 \mathrm{I} / \mathrm{s}
$$

$$
Q_{C}=0.682 \cdot Q_{T}^{0.45}-0.14 \quad(Q \text { en } / / s)
$$


Si todo $Q_{\text {inst }} \geq 0,5 \mathrm{I} / \mathrm{s}$

$$
\left\{\begin{array}{llc}
Q_{T} \leq 1 / / s & \Rightarrow & Q_{C}=Q_{T} \\
Q_{T}>1 / / s & \Rightarrow & Q_{C}=1.7 \cdot Q_{T}{ }^{0.21}-0.7
\end{array}\right.
$$

La particularidad que presenta este tipo de expresiones es que para el cálculo no interviene directamente el número de aparatos ni el número de viviendas, y tan sólo interviene el caudal total instalado y el caudal instantáneo mínimo de los aparatos.

Como observación, respecto a los caudales instantáneos iguales o superiores a $0,5 \mathrm{l} / \mathrm{s}$, sólo afectaría a aquellas instalaciones de viviendas equipadas con inodoro provisto de fluxor o lavadora industrial (mayor de $8 \mathrm{Kg}$ ).

La muestra la relación entre el caudal total instalado y el caudal de cálculo en función del tipo de edificio. Para el caso concreto de un edificio destinado a viviendas con caudales instantáneos de todos los aparatos inferiores a 0,5 l/s, las curvas asociadas son la B (para $Q_{T}>20 \mathrm{l} / \mathrm{s}$ ) y la A (para $Q_{T} \geq 20 \mathrm{l} / \mathrm{s}$ ).

Si se representa la relación entre el caudal de total instalado y el caudal de cálculo para diferentes tamaños de edificio considerando que se trata de viviendas Tipo D, de forma similar al procedimiento realizado para las otras metodologías, se obtiene la siguiente representación.

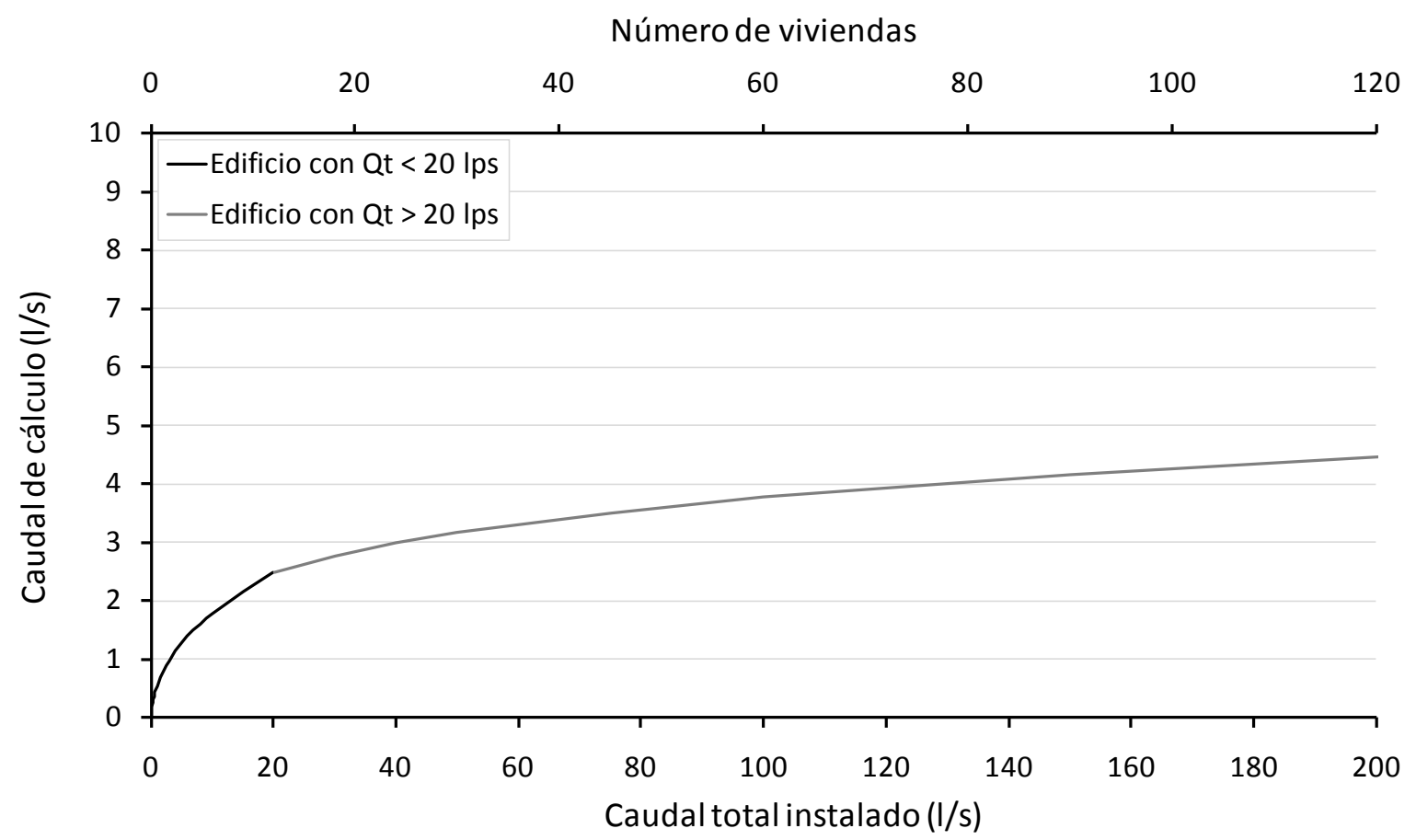

FIGURA A3-7. RELACIÓN ENTRE EL CAUDAL SIMULTÁNEO Y CAUDAL TOTAL SEGÚN LA NORMA UNE 149201 
Tal como se puede apreciar, bajo el criterio de cálculo establecido en la norma UNE 149201 y para el tipo de vivienda considerado, no existen zonas de variación para las diferentes consideraciones asociadas al dimensionado, como pueda ser el caudal instalado, la velocidad de diseño de la instalación, etc.

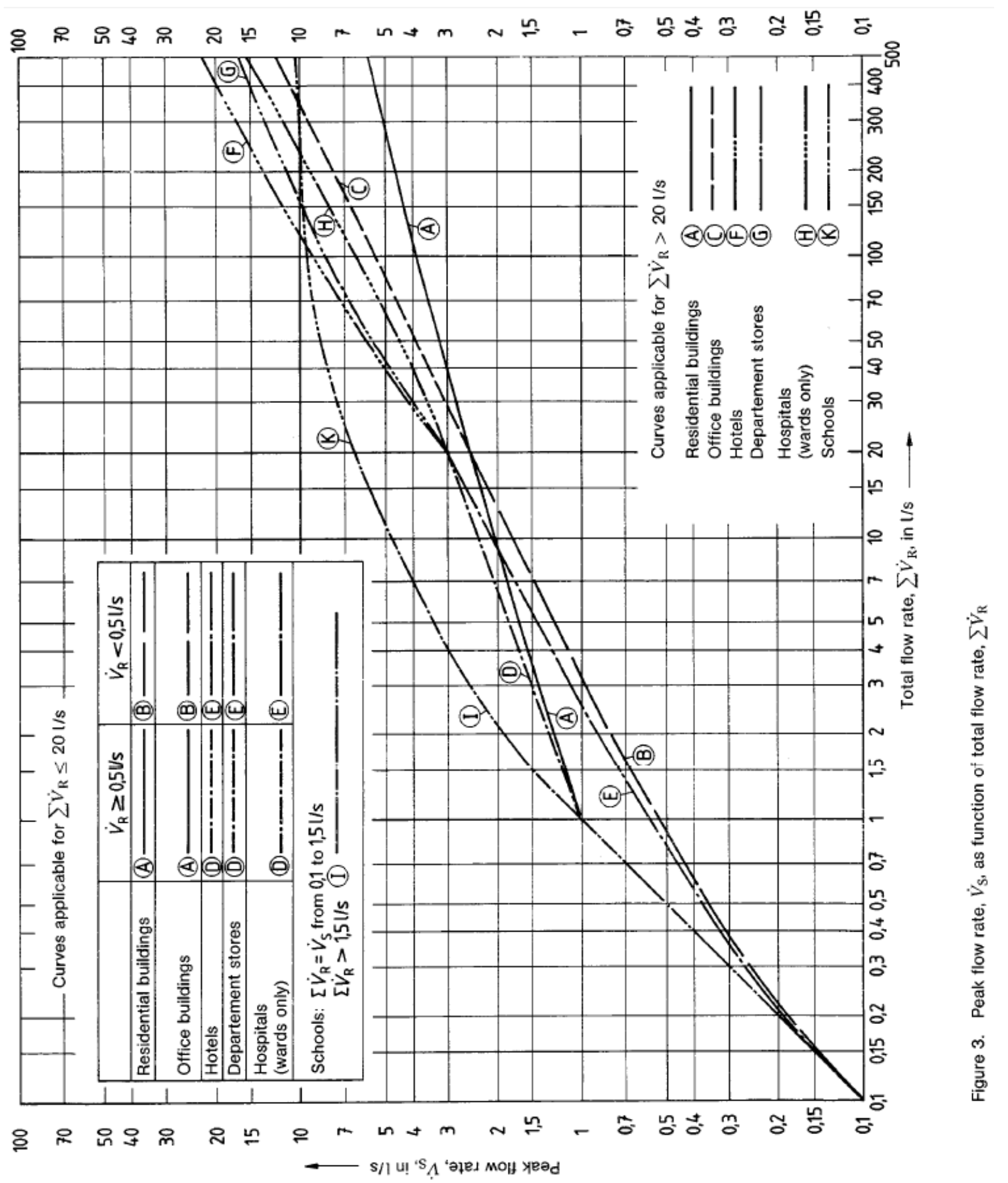

FIGURA A3-8. RELACIÓN ENTRE EL CAUDAL SIMULTÁNEO Y CAUDAL TOTAL DE CÁLCULO DE LA INSTALACIÓN (DIN 1988-5, Figure 3. PEAK FLOW RATE, aS FUNCTION OF TOTAL FLOW RATE) 


\subsection{Resultados obTenidos a PARTIR DE LA bASE DE DATOS DE CONSUMOS}

Comentadas las metodologías de dimensionado más usuales, se pretende comparar sus respuestas respecto a hipotéticos edificios formados por viviendas de la base de datos de consumos. A partir de los módulos de simulación programados en el trabajo de investigación, es posible simular cómo se combina la demanda de varias viviendas para analizar la simultaneidad en su consumo.

En cada simulación el modelo construye un edificio, éste estará formado por los datos reales de consumo de $n$ viviendas con registros asociados a días y horas aleatorios. En total se han realizado 1000 simulaciones para cada tamaño de edificio. Los edificios construidos cuentan con un tamaño que va desde 1 única vivienda a un máximo de 200 viviendas. Las características de la base de datos de consumo se establecen en (Soriano, 2008).

Cada simulación recoge datos de consumo de una hora de consumo real, en la que los registros tienen un desfase temporal de 5 segundos. La única restricción fijada es que esta hora esté dentro de horas en las que normalmente se realizan consumos intencionados, periodo incluido desde las 7 hasta las 24 horas. De cada simulación se obtiene el caudal máximo simultáneo del edificio en una hora, el número de viviendas con consumo simultáneo para ese caudal (no tiene porqué coincidir con el número máximo de viviendas con consumo simultáneo de esa hora), e información sobre su distribución estadística. A modo de ejemplo se muestra un extracto de los resultados obtenidos para un edificio de 10 viviendas.

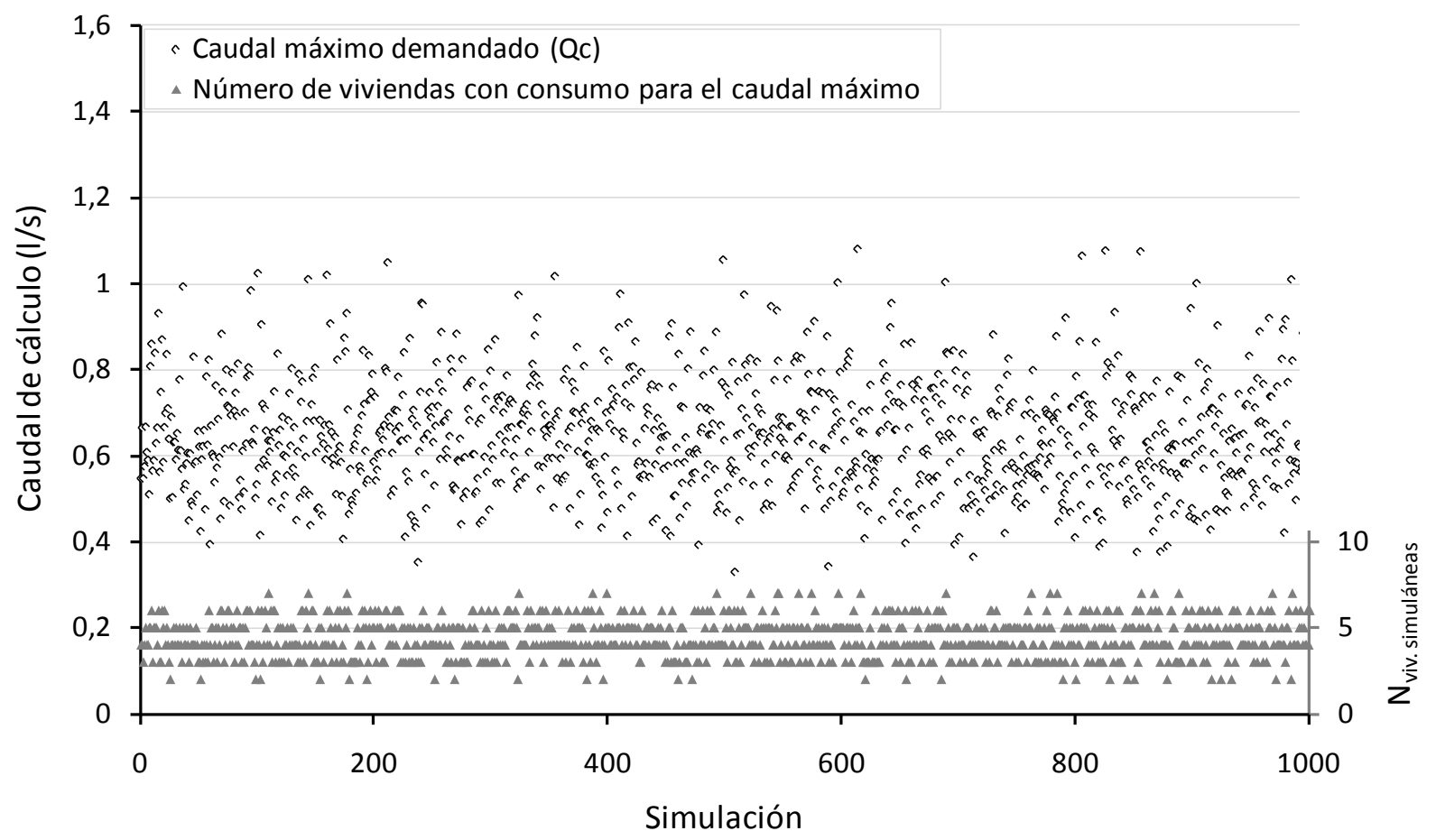

FIGURA A3-9. SIMULTANEIDAD EN LA DEMANDA PARA UN EDIFICIO DE 10 VIVIENDAS 
Al simular durante una hora con una discretización de 5 segundos, se dispone de un total de 720 instantes de demandas por hora de simulación. El ajuste de la serie aleatoria de caudales máximos se obtiene mediante una distribución lognormal. Para la simulación de edificios de 10 viviendas los parámetros característicos de la distribución son: media $=0,647 \mathrm{l} / \mathrm{s}$ y desviación típica $=0,13 \mathrm{l} / \mathrm{s}$.

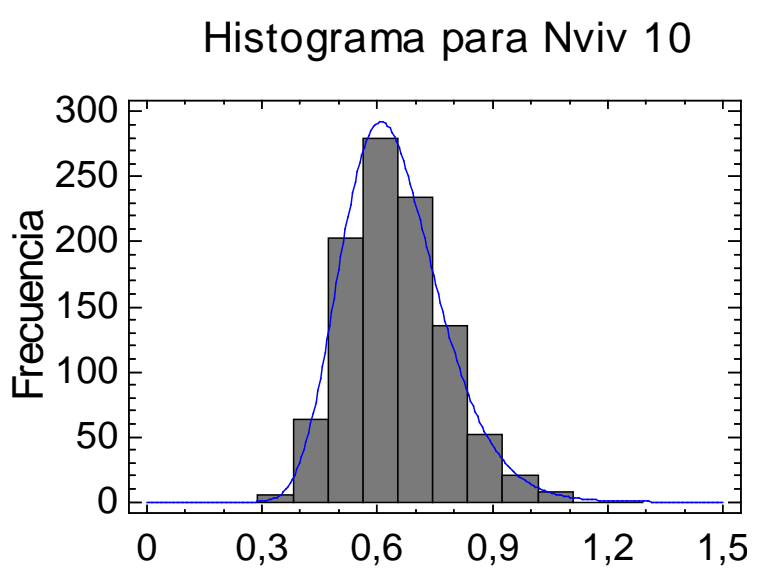

Simulación Oc (l/s) (ed. 10 viv.

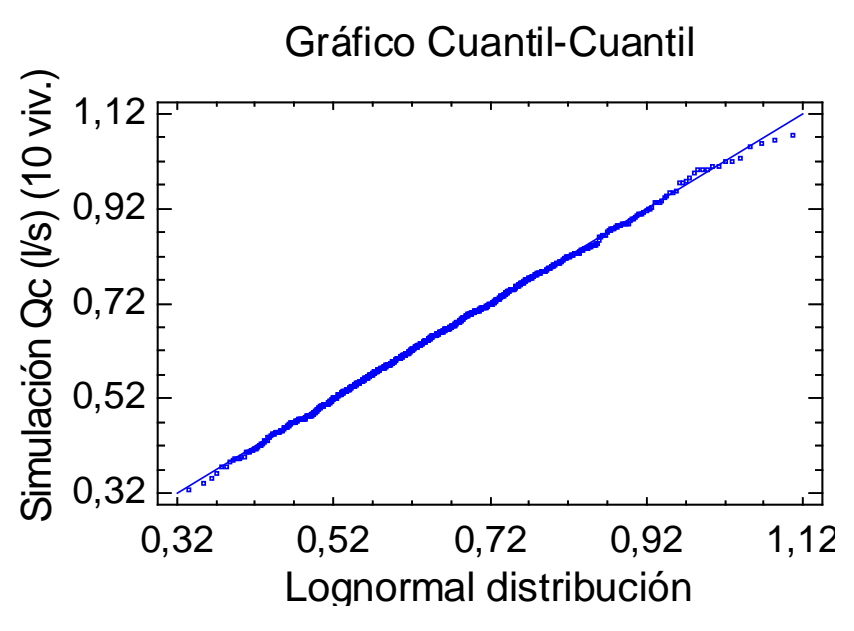

Gráfico Cuantil-Cuantil

FIGURA A3-10. SIMULTANEIDAD EN LA DEMANDA PARA UN EDIFICIO DE 10 VIVIENDAS

La siguiente tabla resume los valores característicos de la simulación en cuestión. El caudal máximo simultáneo obtenido para el edificio en cuestión es de 1,08 l/s, coincidiendo en el uso 5 viviendas de forma simultánea (el número máximo de viviendas en uso para otra simulación es de 7 viviendas). También se muestra la variabilidad del caudal promedio consumido para el conjunto de simulaciones, y de la desviación estándar del caudal total demandado por la instalación.

TABLA A3-7. VALORES CARACTERÍSTICOS PARA LA SIMULACIÓN DEL EDIFICIO DE 10 VIVIENDAS

\begin{tabular}{ccccc}
\hline & $\boldsymbol{Q}_{c}$ & $\begin{array}{c}\boldsymbol{N}_{\text {viv }} \\
(\mathbf{I} / \mathbf{s})\end{array}$ & $\begin{array}{c}\overline{\boldsymbol{Q}} \\
\text { simultáneas }\end{array}$ & $\begin{array}{c}\boldsymbol{\sigma} \\
(\mathbf{I} / \mathbf{s})\end{array}$ \\
\hline Máximo & $\mathbf{1 , 0 8}$ & 7 & 0,384 & 0,247 \\
Promedio & 0,647 & 4,383 & 0,184 & 0,128 \\
Mínimo & 0,329 & 2 & 0,076 & 0,075 \\
\hline
\end{tabular}

De forma simular, la caracterización de cada tamaño de edificio se realiza a partir del caudal máximo de cálculo obtenido en las 1000 simulaciones, correspondientes a 1000 horas de suministro en la instalación. Por otro lado y puesto que las viviendas de la base de datos utilizadas son de Tipo D según la NIA, y considerando un caudal instalado por vivienda promedio de 1,75 l/s, es posible obtener la relación entre el caudal total instalado, y el caudal de cálculo equivalente. 
En la siguiente figura, la serie superior representa el caudal de cálculo para cada tamaño de edificio (cada valor se corresponde con la demanda máxima originada en el conjunto de simulaciones), y aporta información relativa a las solicitaciones máximas que se pueden dar para cada tamaño de edificio.

La serie inferior representa el valor medio del caudal simultáneo demandado para cada tamaño de edificio. Este valor representa el valor medio del caudal que demanda el conjunto de viviendas de un edificio durante una hora de demanda exigente.

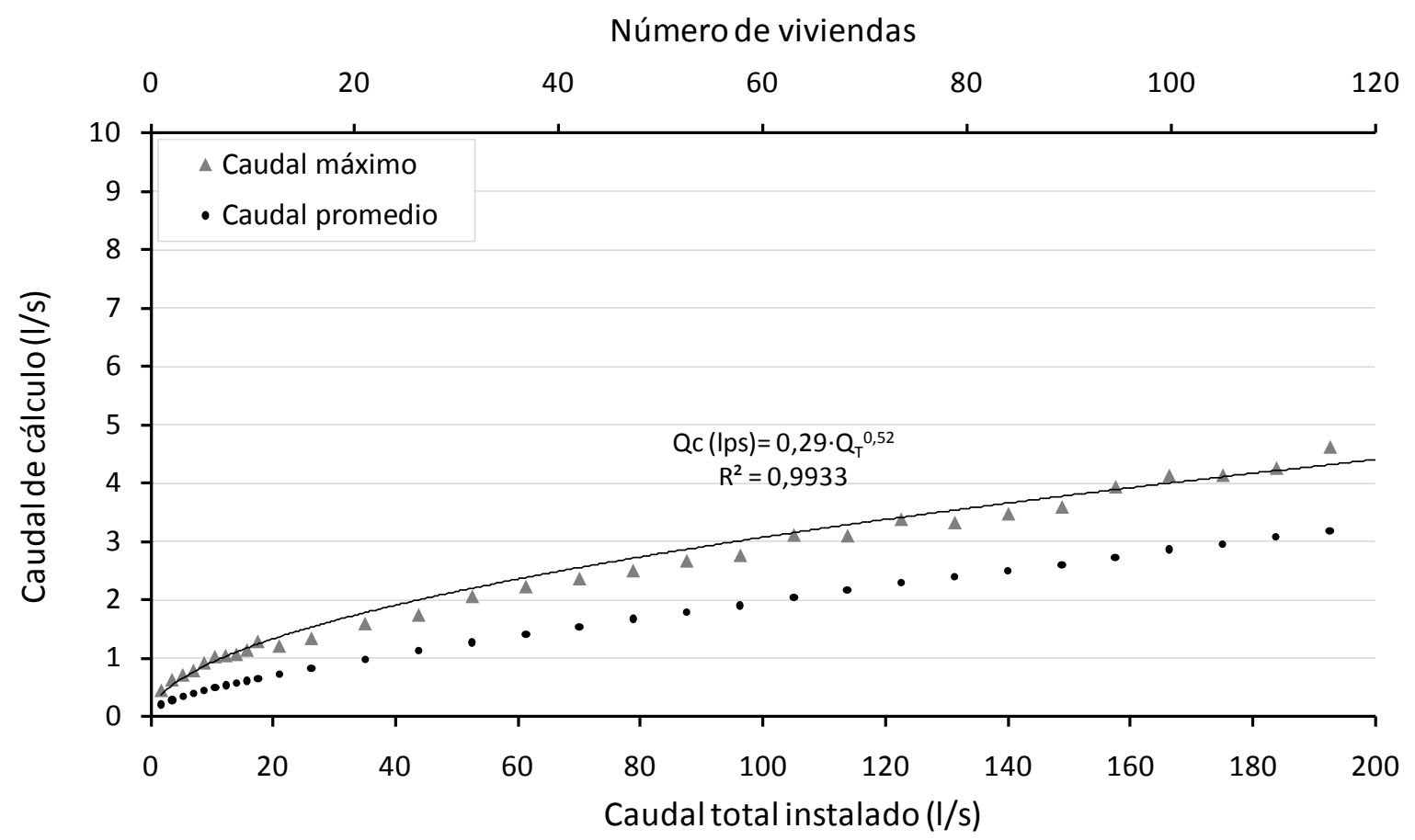

FIGURA A3-11. RELACIÓN ENTRE EL CAUDAL SIMULTÁNEO Y CAUDAL TOTAL DE SEGÚN EL RESULTADO DE LAS SIMULACIONES

Derivado de los resultados obtenidos con las simulaciones, se propone una expresión para el dimensionado de instalaciones en el entorno residencial, cuando la vivienda predominante y con mayores exigencias sea de Tipo $D$, en función del número total de viviendas del edificio o del caudal total instalado en éste.

$$
\begin{array}{lll}
Q_{C}=0.3 \cdot Q_{T}^{0.52} & (\mathrm{Q} \text { en } / / \mathrm{s}) & \text { EC. } 48 \\
Q_{C}=0.38 \cdot N_{\text {viv }}^{0.52} & (\mathrm{Q} \text { en } / / \mathrm{s}) & \text { EC. } 49
\end{array}
$$


Un procedimiento similar fue propuesto para el dimensionado de edificios con un número de viviendas máximo de 50 (Tipo D), utilizando del mismo modo consultas de otra base de datos de menor tamaño, en tal caso se llegó a la siguiente expresión (Soriano, 2008).

$$
Q_{C}=1+\frac{\text { Nviv }}{0.25} \quad(\text { Nviv } \leq 50, Q \text { en } / / s)
$$

Tal como se observa en la siguiente figura, la expresión tiene un ajuste aceptable para edificios de tamaño inferior a 60 viviendas, pero a partir de este valor el caudal de cálculo resulta superior que los valores obtenidos en las simulaciones.

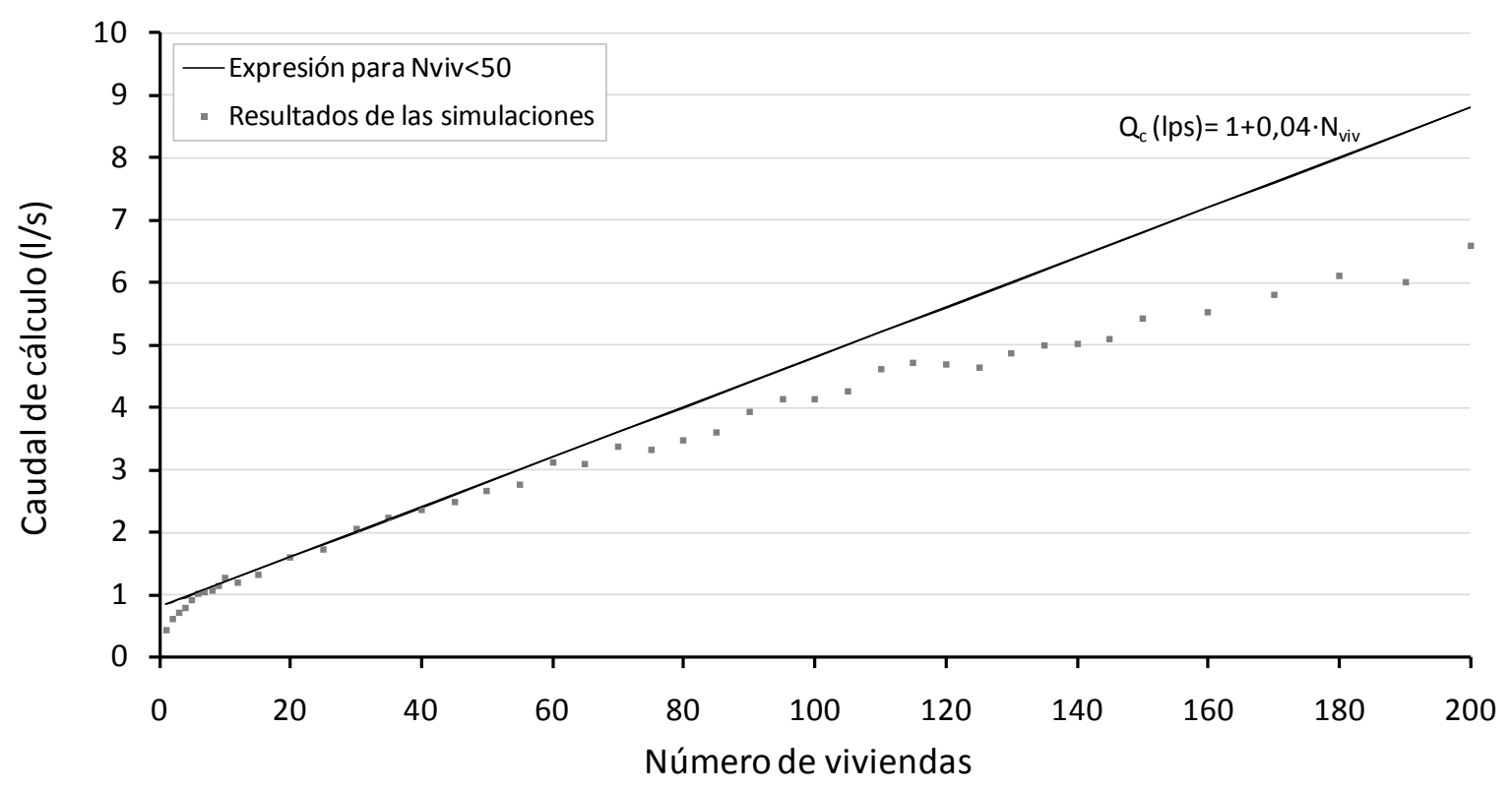

FIGURA A3-12. COMPARACIÓN DE LOS RESULTADOS DE LAS SIMULACIONES Y LA EC. 50

\subsection{COMPARACIÓN CON LAS SIMULACIONES DE LOS CONSUMOS DE LA BASE DE DATOS}

A continuación se comparan los diferentes procedimientos descritos con los resultados obtenidos de las simulaciones. Esta comparación mostrará la aproximación de cada una de las metodologías y aportará un orden de magnitud sobre las implicaciones de utilizar un procedimiento y otro en el dimensionado de una instalación. 


\subsubsection{Comparación con la metodología derivada de la NIA}

La siguiente gráfica compara los resultados asociados a la metodología de dimensionado derivada de la NIA respecto a los resultados obtenidos con las simulaciones. Como puede observarse, para todas las velocidades máximas de dimensionado consideradas, el procedimiento de la NIA obtiene un caudal de cálculo superior al real (según las simulaciones), siendo el procedimiento que más se aproxima el que considera una velocidad de dimensionado menor $(\mathrm{v}=1 \mathrm{~m} / \mathrm{s})$.

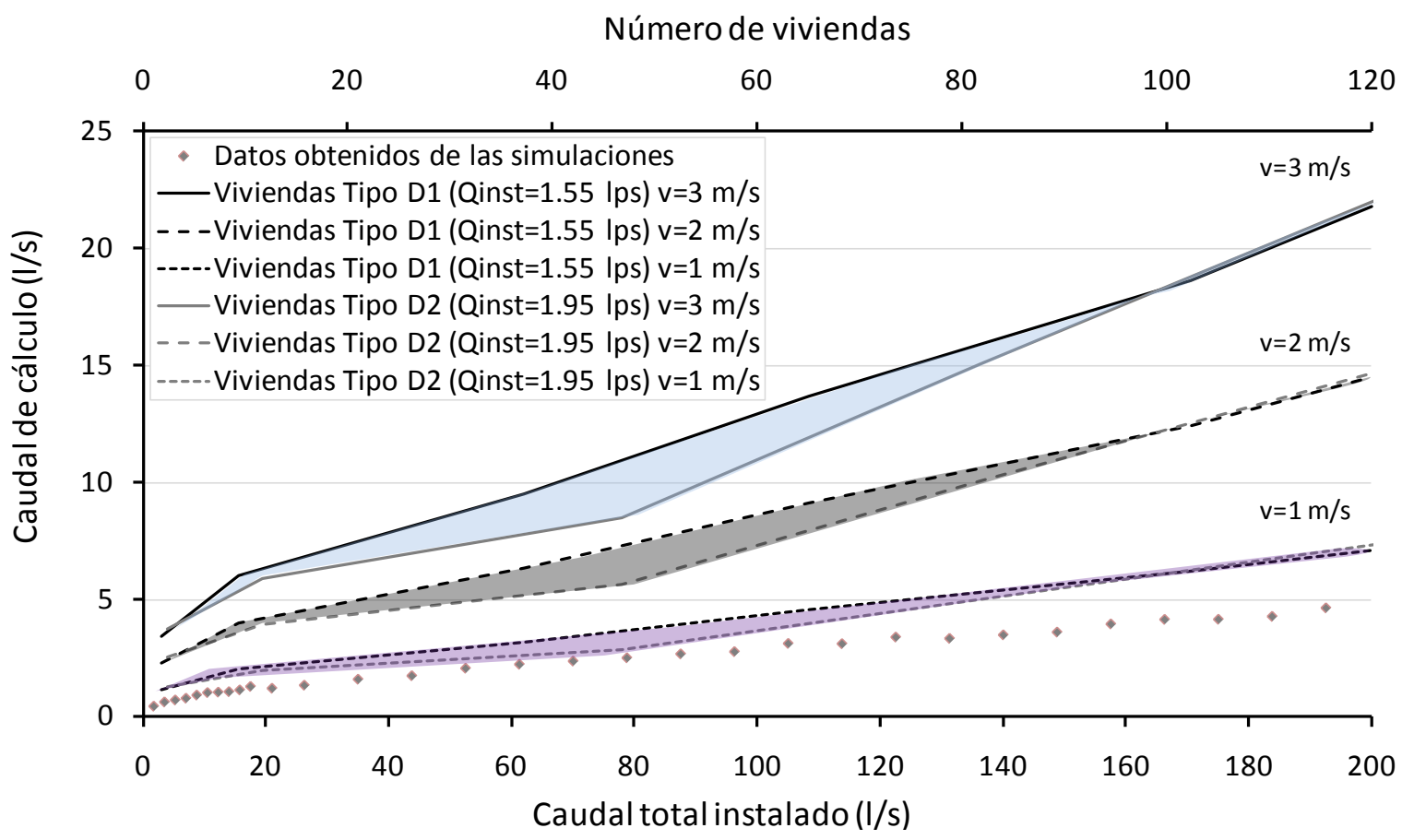

FIGURA A3-13. COMPARACIÓN DE LOS RESULTADOS DE LAS SIMULACIONES Y EL PROCEDIMIENTO DE LA NIA

El resultado de sobredimensionar las conducciones puede originar velocidades muy bajas en condiciones normales de suministro (nótese que los datos obtenidos de las simulaciones hacen referencia al caudal máximo originado para cada tamaño de edificio), al mismo tiempo que supone un coste superior de la instalación. Respecto a la velocidad máxima de dimensionado, conviene fijar valores máximos de $2 \mathrm{~m} / \mathrm{s}$ para el caudal de cálculo. 


\subsubsection{Comparación con la metodología establecida en la NF P 41-204}

En el caso del procedimiento propuesto por la Norma Francesa NF P 41-204 la aproximación es elevada, principalmente para el coeficiente de simultaneidad con numerador 0,8 , por tanto, parece lógica la modificación establecida por la norma francesa al reducir el numerador de la unidad al valor mencionado.

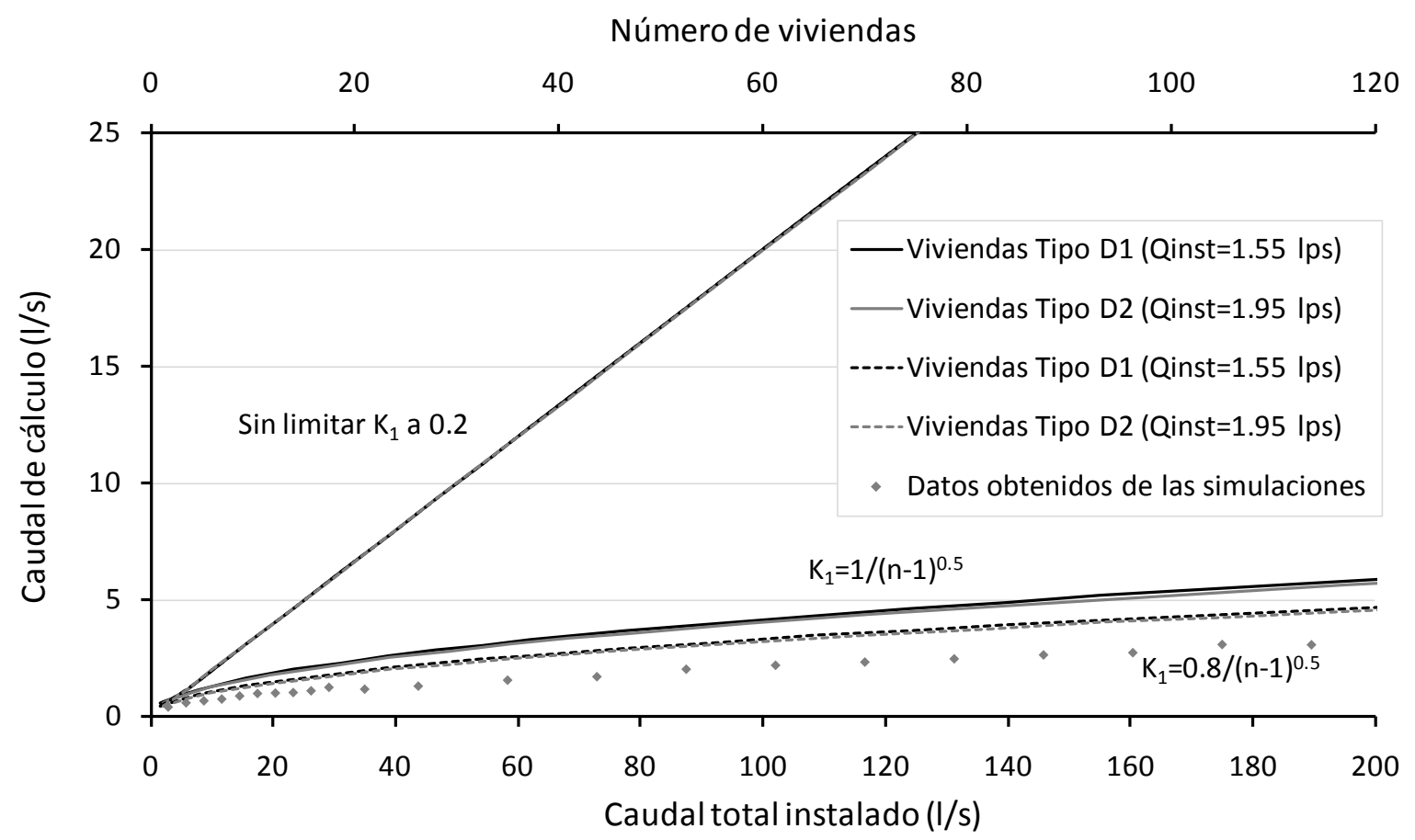

FIGURA A3-14. COMPARACIÓN DE LOS RESULTADOS DE LAS SIMULACIONES Y DE LA NF P 41-204

Por otro lado, el procedimiento que limita el valor mínimo del coeficiente $K_{1}$ a 0,2 sobreestima en gran medida el caudal de cálculo de la instalación. La disparidad en los resultados asociados hace suponer que la limitación tiene por objeto considerar un segundo coeficiente que a su vez limite los valores para instalaciones formadas por varias viviendas, tal como en el Método Racional se realiza. O bien puede ser adecuado en locales en las que se dé una mayor simultaneidad en los usos (hoteles, gimnasios, cines, etc.)

En cualquier caso, de los métodos analizados éste es el que mayor aproximación presenta, y sólo tienen en cuenta el número de aparatos totales de la instalación y el caudal total instalado en ésta, sin atender directamente al tipo de suministro o el número de viviendas del edificio. 


\subsection{COMParación CON El MÉtodo RaCiOnal}

Con el Método Racional se obtiene unos caudales de cálculo superiores a los resultados obtenidos con las simulaciones, e incluso una peor ajuste que el conseguido con la Norma Francesa (aun utilizando una expresión más compleja de cálculo, puesto considera un segundo coeficiente de simultaneidad).

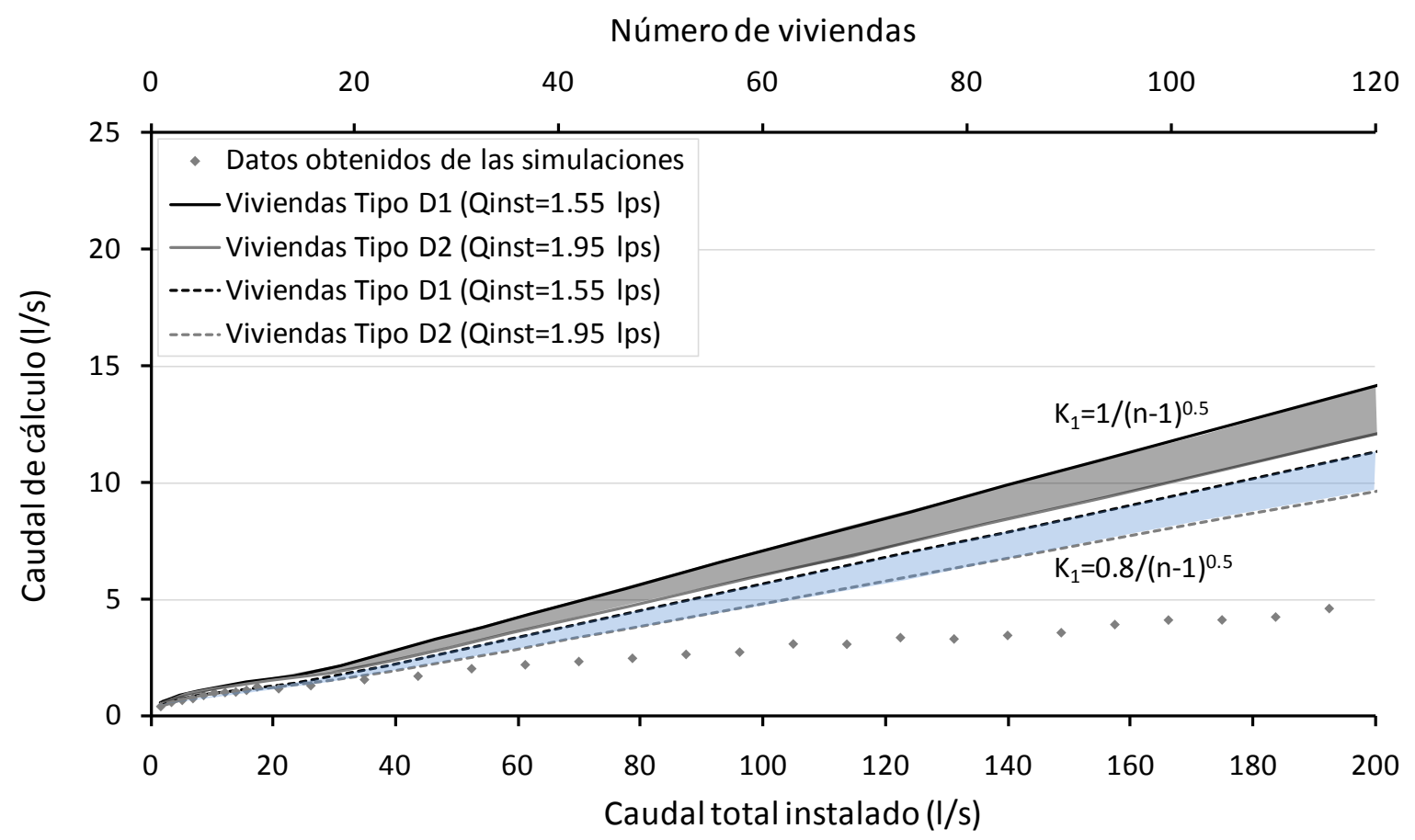

Figura A3-15. COMPARACIÓN DE LOS RESUltadOS DE LAS SiMULACIONES Y EL MÉTODO RACIONAL

De forma similar al caso anterior, la reducción del numerador del coeficiente $K_{1}$ reduce la diferencia entre ambas series.

El ajuste para edificios con un caudal total instalado inferior a $50 \mathrm{l} / \mathrm{s}$ (edificios de aproximadamente 30 viviendas) mantiene valores próximos. Para tamaños superiores se realiza una sobrestimación del caudal de cálculo. 


\subsubsection{Comparación con la metodología establecida en la UNE 149201}

Para la obtención del caudal de cálculo según la reciente norma UNE 149201, la aproximación es buena, pero se destaca que para edificios con caudal total instalado inferior a $20 \mathrm{l} / \mathrm{s}$ (edificios de aproximadamente 10 viviendas Tipo D), el caudal obtenido mediante la expresión propuesta por la norma presenta su mayor discrepancia frente a los resultado obtenidos en las simulaciones.

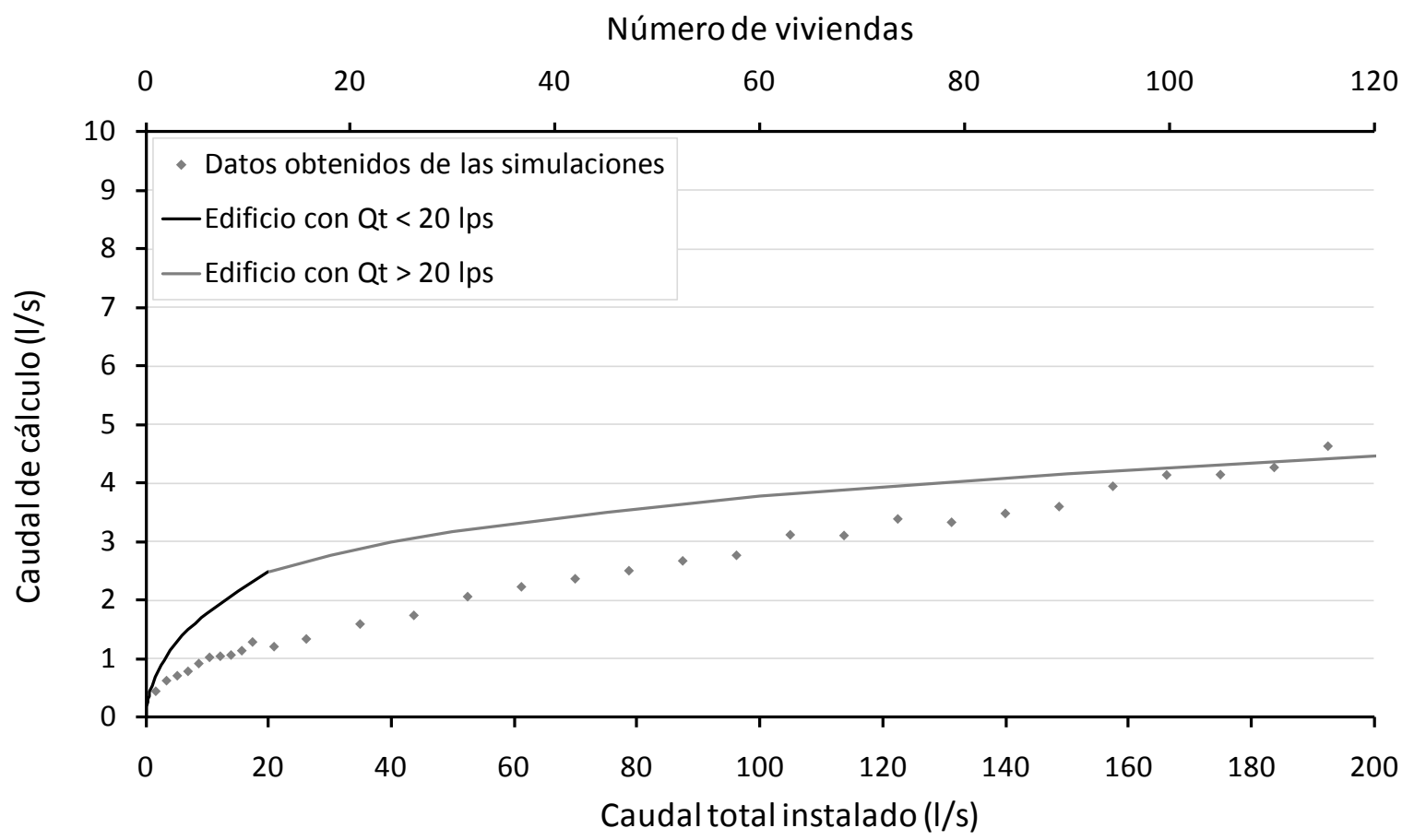

FIGURA A3-16. COMPARACIÓN DE LOS RESULTADOS DE LAS SIMULACIONES Y EL PROCEDIMIENTO DE LA UNE 149201

Para mayores tamaños de edificio la serie asociada a la norma reduce la diferencia, hasta el punto de superar el caudal de cálculo simulado al caudal obtenido con la fórmula $\left(Q_{\text {T int }}=200 \mathrm{l} / \mathrm{s}\right)$, discrepancia que se mantiene para caudales superiores al indicado. Esto supondría una posible infravaloración del caudal demandado en la instalación

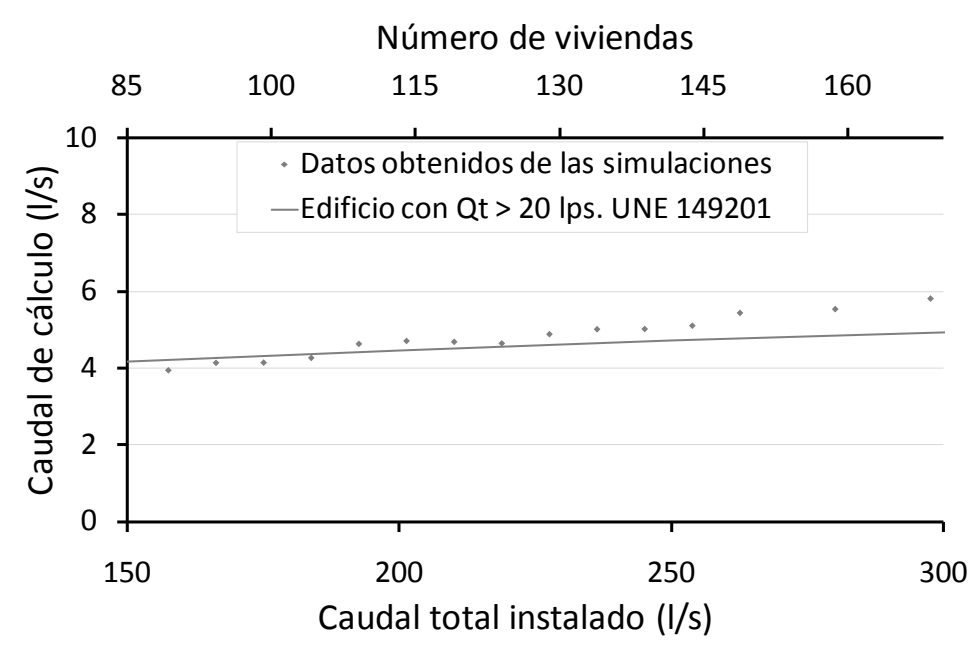

FIGURA A3-17. DETALLE DE CAUDALES SUPERIORES A $150 \mathrm{~L} / \mathrm{S}$ para edificios de más de 100 viviendas. 


\subsection{CONCLUSIONES}

Las principales conclusiones que se pueden obtener en referencia a la estimación de caudales de cálculo para edificios de viviendas Tipo D (según la NIA), y teniendo en cuenta las hipótesis de partica establecidas, son las siguientes:

- A medida que aumenta el caudal total instalado en el edificio no se origina un aumento proporcional respecto al caudal simultáneo, es por ello que una serie potencial puede aproximar en gran medida las condiciones de simultaneidad. En esta línea se propone una expresión para su determinación (Ec. 50).

- El dimensionado derivado de la NIA mayora notablemente el caudal de cálculo de una instalación, siendo por tanto necesario acudir a mayores diámetros de conducción y grupos de bombeo (el dimensionado con una velocidad de diseño máxima de $1 \mathrm{~m} / \mathrm{s}$ puede originar velocidades muy reducidas para condiciones normales de suministro).

- El mejor ajuste del caudal de simultáneo se obtiene a partir de la expresión propuesta por la Norma Francesa NF P 42-204, y en mayor medida si se reduce el numerador del coeficiente de simultaneidad de aparatos $K_{1}$ a 0,8.

- El Método Racional mayora ligeramente el caudal de cálculo, principalmente para edificios con caudal total instalado superior a $50 \mathrm{l} / \mathrm{s}$ (28 viviendas). Para caudales inferiores el ajuste es bastante aproximado.

- Las expresiones propuestas por la norma UNE 149201 originan una sobrestimación del caudal de cálculo para caudales instalados inferiores a $160 \mathrm{l} / \mathrm{s}$, mientras que para caudales superiores a $200 \mathrm{l} / \mathrm{s}$ es posible que la estimación sea insuficiente. 
Anexo 4

\author{
Monitorización de \\ un edificio para registrar los \\ efectos transitorios generados en \\ conexión directa
}




\subsection{INTRODUCCIÓN}

En el estudio realizado se ha monitorizado la instalación general de un edificio en el entorno residencial. La monitorización ha consistido en el registro de datos de presión y caudal en diferentes puntos de la instalación. La monitorización se ha prolongado durante un año. Durante este periodo, se han instalado diferentes equipos de medición y adquisición de datos, procediendo a su descarga y programación de forma periódica. Al final de cada campaña se ha obtenido una cuantiosa cantidad de datos de consumo de los diferentes usuarios, con una elevada resolución que permite el conocimiento asociados a las pautas de uso de consumidores en el entorno residencial.

De la misma forma, se ha procedido a modificar el esquema de suministro del edificio, posibilitando la aspiración en directo del grupo de presión original, a partir del correspondiente by-pass del depósito atmosférico. De esta forma se obtiene una medida directa de las perturbaciones originadas con un equipo de bombeo de velocidad fija en conexión directa. Al mismo tiempo, se ha instalado un segundo grupo equipado con variador de frecuencia. La alternancia en el funcionamiento de ambos grupos va a permitir comparar directamente sus solicitaciones.

Como complemento de los análisis anteriores, ha sido posible incorporar un calderín en la aspiración para comprobar la protección conseguida con este elemento, al mismo tiempo que ha sido posible modificar la programación del variador para optimizar su funcionamiento.

\subsection{OBJETIVOS PERSEGUIDOS}

Entre los objetivos perseguidos se destacan:

- Describir la instalación hidráulica del edificio de referencia.

- Conocer las solicitaciones generadas en un edificio con conexión directa, pudiendo analizar las exigencias de diferentes esquemas de suministro.

- Conocer la protección conseguida con la instalación de un calderín en la aspiración del grupo de presión. 
- Disponer de datos reales de funcionamiento, para validar los resultados obtenidos con modelos de simulación bajo las condiciones de contorno propias del edificio de referencia.

\subsection{DESCRIPCIÓN DE LA INSTALACIÓN MONITORIZADA}

\subsubsection{Descripción de la red general de distribución}

El estudio se ha realizado en un edificio abastecido por la empresa EMASESA (Empresa Metropolitana de Abastecimiento y Saneamiento de Aguas de Sevilla). El edificio está situado en el Complejo Residencial Puerta Sevilla, inmueble ubicado en la calle San Juan Bosco nº 61 (Portal 4).

Respecto a las características de la red general, se destaca que la acometida del edificio está conectada a una conducción de diámetro $150 \mathrm{~mm}$ en fundición (valor del diámetro interior de la conducción). Dicha conducción forma una malla que rodea la manzana del edificio y las contiguas, abasteciendo a otros edificios colindantes. La tubería discurre por la misma acera que rodea el inmueble, y conecta con la instalación interior del edificio a través de una tramo de acometida de aproximadamente 5 metros y de 63 mm de diámetro en PE-100 (PN 10), de diámetro interior 55,4 mm.

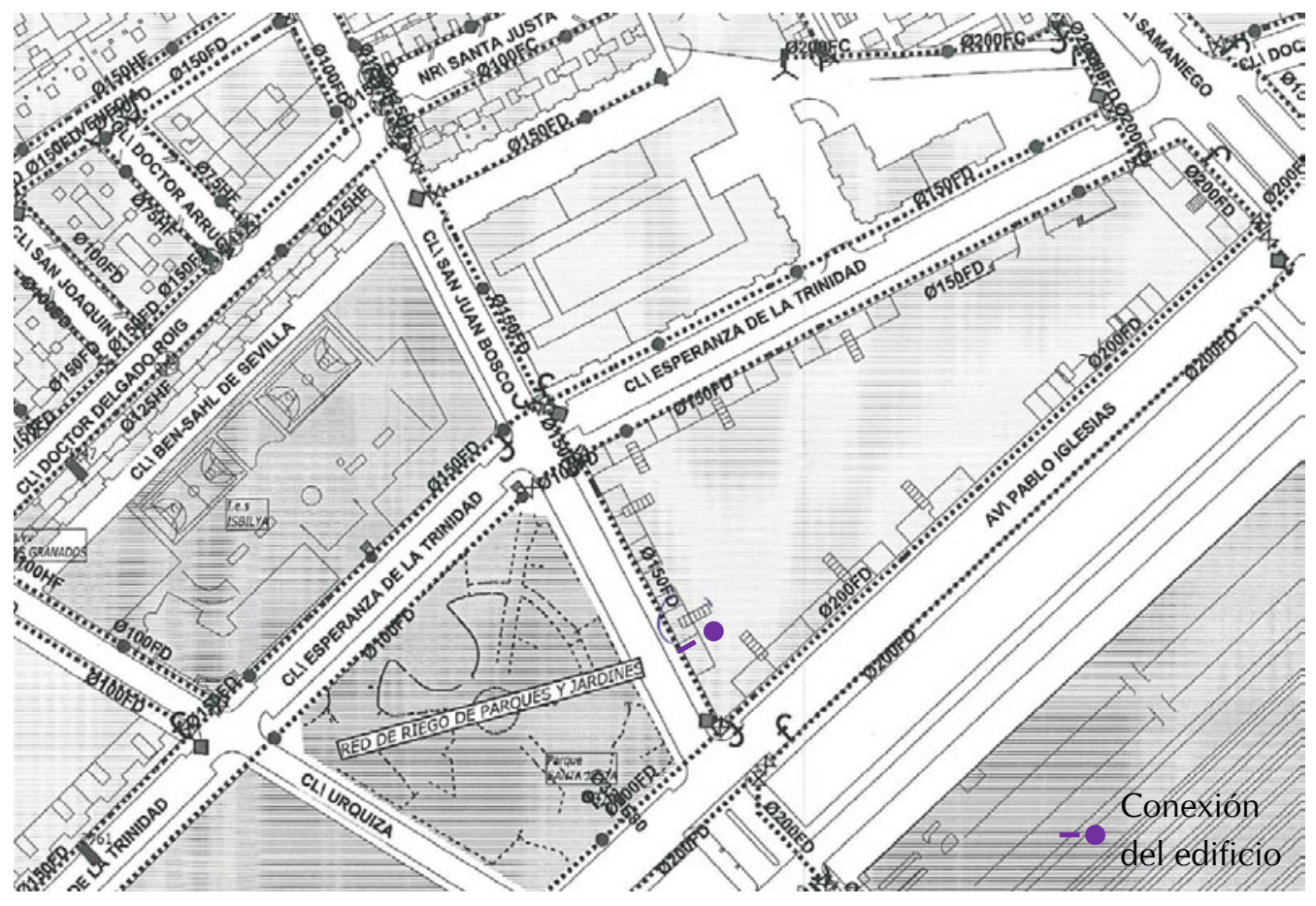

FIGURA A4-1. DETALLE RED GENERAL DE DISTRIBUCIÓN Y CONEXIÓN DEL EDIFICIO MONITORIZADO 
La presión garantizada por la compañía en la zona es próxima a los 33 mca, mostrando las lógicas variaciones correspondientes a la fluctuación horaria del caudal demandado por los usuarios. En cualquier caso, durante el periodo de registro de presión en la acometida, el valor de las presión ha mantenido valores próximos al comentado anteriormente, salvo situaciones puntuales en las que se ha realizado alguna actuación para el control de fugas en la red u operaciones de mantenimiento.

\subsubsection{Instalación general del edificio}

El edificio cuenta con un total de 18 suministros de tipo residencial, 17 de los cuales disponen de suministro contratado en el periodo de realización del estudio. El número de alturas del inmueble es de 6 plantas (aproximadamente 22 metros de desnivel desde el nivel de la acometida hasta punto de consumo más desfavorable).

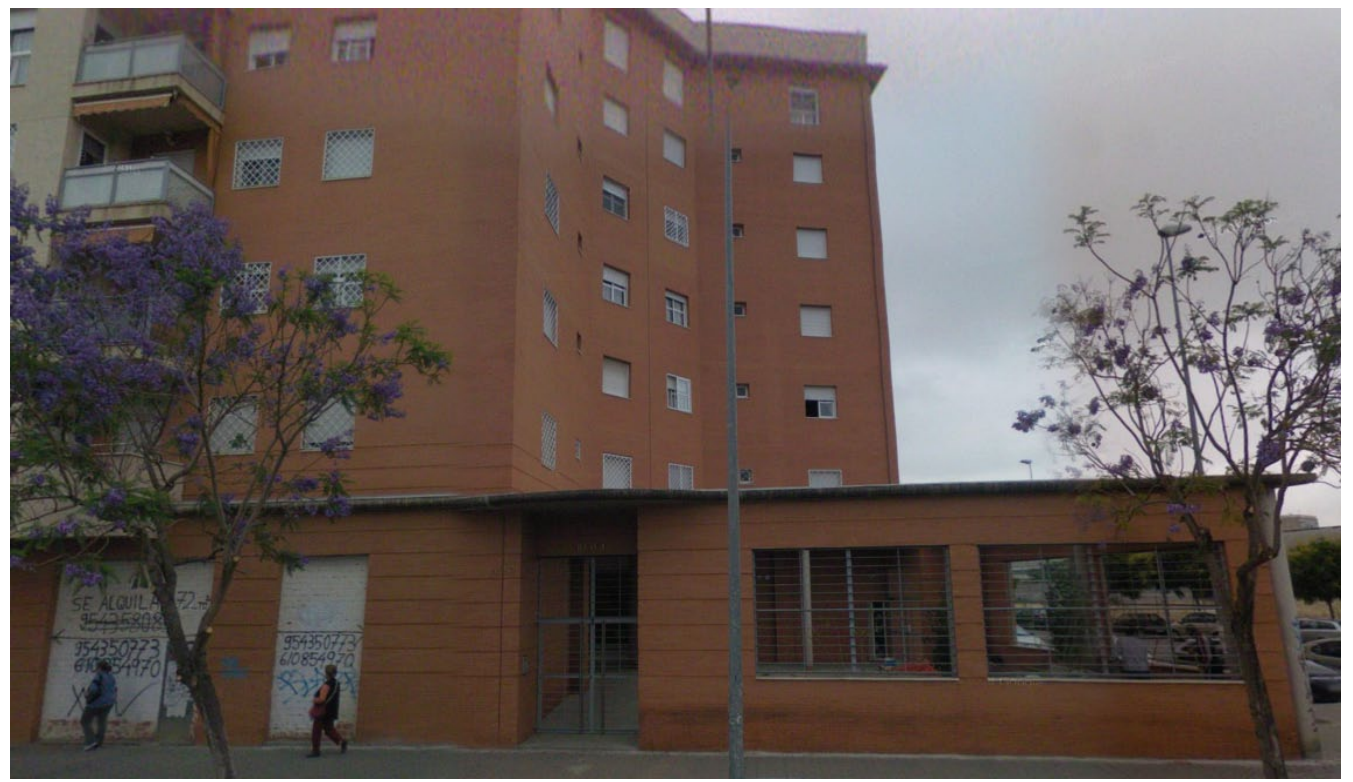

FIGURA A4-2. EDIFICIO MONITORIZADO EN EL ESTUDIO

El edificio cuenta con tres viviendas por planta, y varios locales comerciales ubicados en la planta baja del inmueble. Algunos de los locales estaban en uso, si bien todas las instalaciones correspondientes están conectadas a la acometida general del edificio. Respecto a las instalaciones colectivas del edificio (destinadas a cuarto de limpieza, aseos colectivos, etc.) están ubicadas en el complejo residencial sin que exista ninguna toma de agua para este fin en la acometida principal del inmueble (los usos comunes están conectados a la acometida de otros inmuebles del complejo).

En el año 2001 el edificio obtiene la licencia para el suministro de agua, y a partir de este instante todas las viviendas cuentan con este servicio. 


\subsubsection{Esquema de la instalación general}

En el momento de realizar el estudio todo el suministro se realizaba a través de un grupo de presión de velocidad fija conectado de forma indirecta a través de un depósito atmosférico (grupo de presión convencional según el CTE).

Aunque la presión de entrega en acometida dispone de valor suficiente para abastecer en directo y sin grupo de presión a las viviendas situadas en las plantas más bajas del inmueble, todas las viviendas se suministran a través del grupo de presión.

La siguiente imagen muestra el esquema de la instalación general del edificio con la configuración originaria.

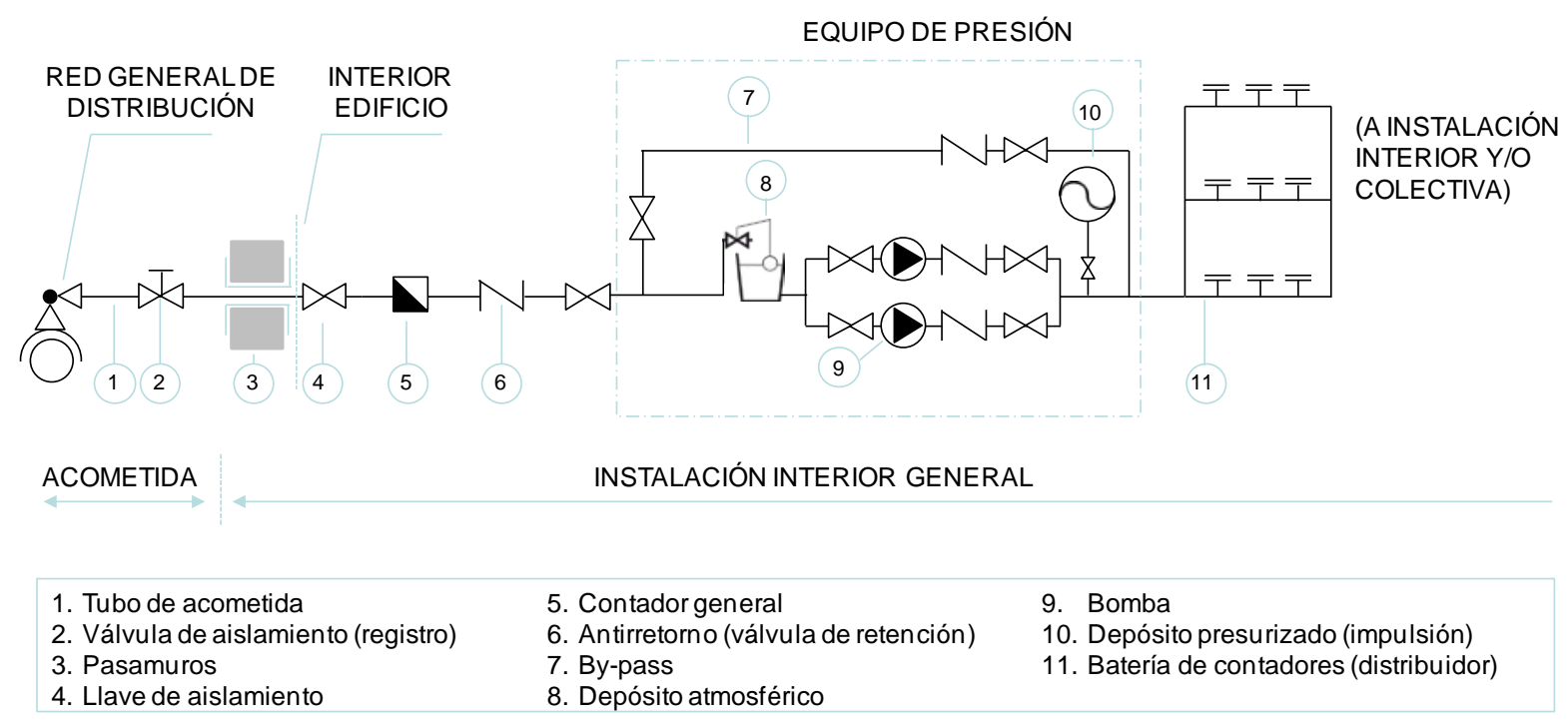

FIGURA A4-3. ESQUEMA DE LA INSTALACIÓN GENERAL DEL EDIFICIO

Como se observará más adelante, sobre este esquema se realizaron una serie de modificaciones que permitieron alternar entre diferentes esquemas de funcionamiento. Actualmente el edificio se suministra en directo a través de una bomba de velocidad variable protegido con un calderín en aspiración.

Respecto al funcionamiento del by-pass de la instalación, mediante la regulación actual del grupo no se consigue en suministro directo aun disponiendo de presión suficiente, ya que el arranque de las bombas se origina a una presión superior a la presión máxima que se suele dar en la acometida.

La conexión de los locales del inmueble se realiza en derivación, no estando conectados al grupo de presión. Actualmente los volúmenes consumidos por los locales son muy reducidos. 


\subsubsection{Características del equipo de presión}

El equipo de presión está formado por dos bombas de velocidad fija conectadas en paralelo de idénticas características. Para el funcionamiento normal, una de las bombas tiene consideración de bomba principal, mientras que la segunda es una bomba de reserva (se mantiene inoperativa efectuándose un funcionamiento alternativo entre ambas para un determinado número de horas, o ante una avería de la bomba principal).

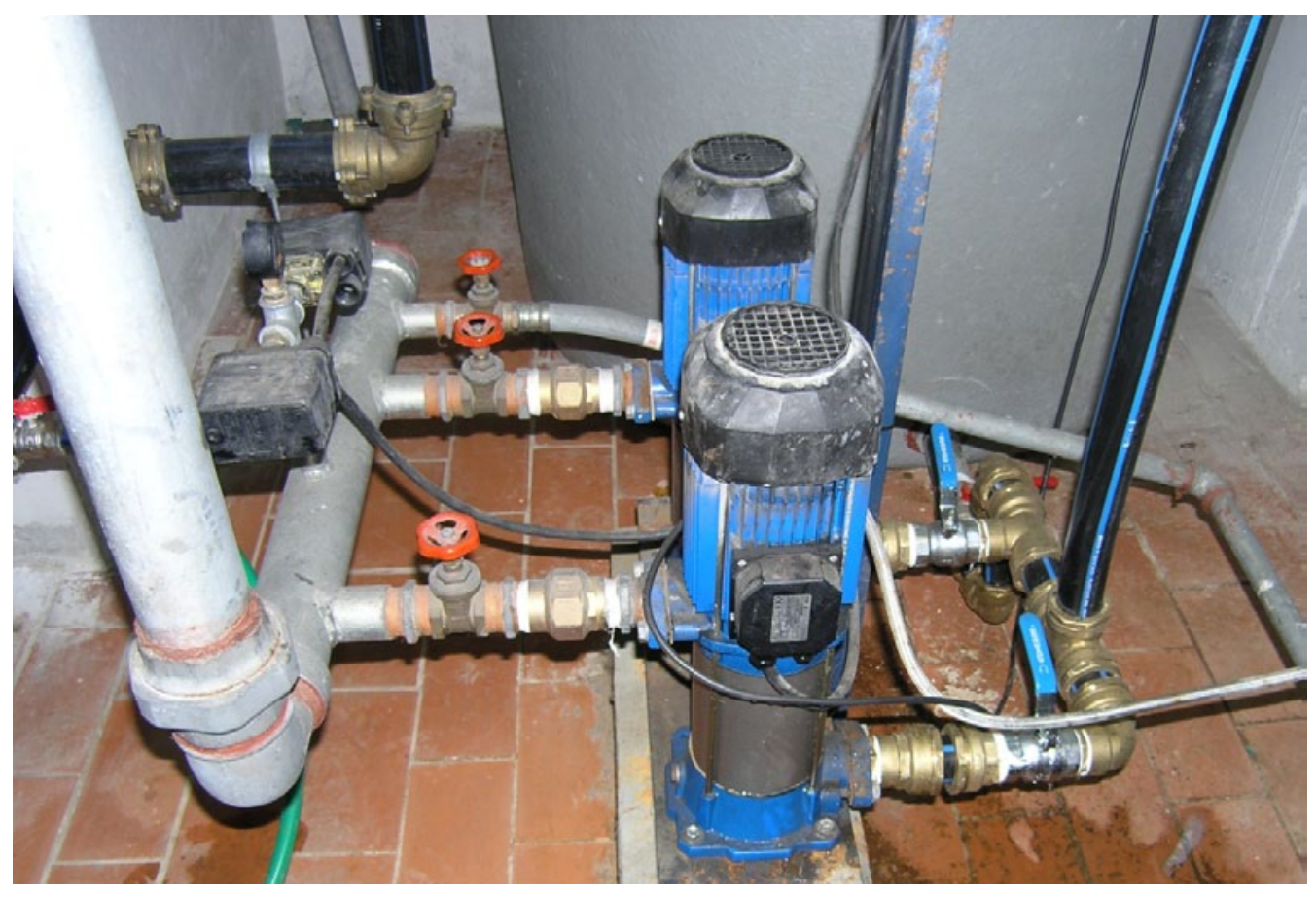

FIGURA A4-4. GRUPO MOTO-BOMBAS ORIGINAL DEL EDIFICIO

Las características técnicas leídas sobre la placa de identificación de las bombas son las siguientes:

- Ref.: EM30-6

- $\mathrm{Q}(\mathrm{I} / \mathrm{min}): 50-155$;

- $\quad H(m): 75-30$;

- P: 2,7 KW 
La curva característica de la bomba es la que se muestra a continuación (no se dispone de información de otras curvas de funcionamiento):

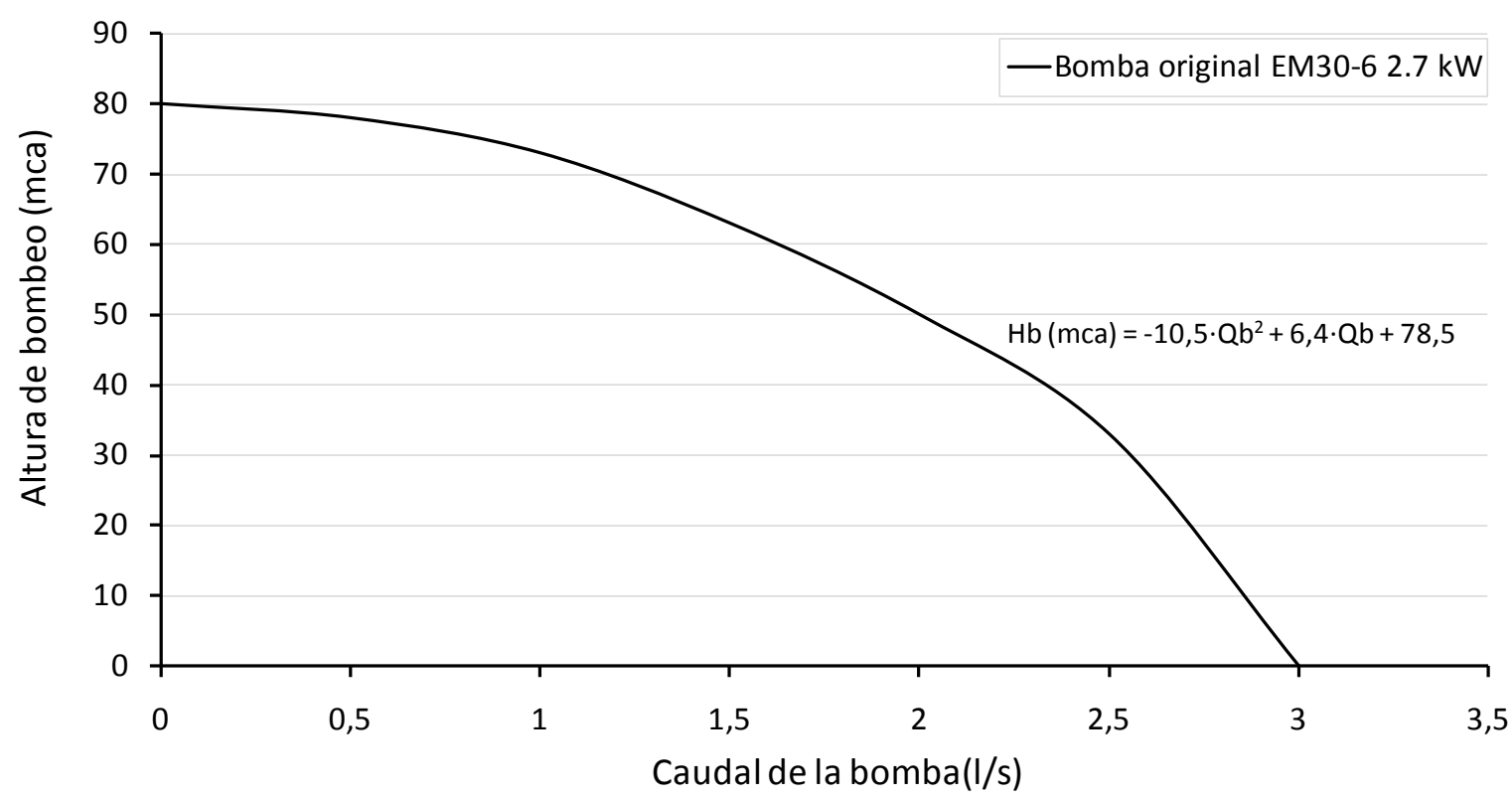

FIGURA A4-5. CURVA CARACTERÍSTICA DE LAS BOMBAS ORIGINALES

Las bombas están conectadas a la red general a través de un depósito atmosférico de aproximadamente $1 \mathrm{~m}^{3}$ de volumen útil. El control de llenado se realiza mediante una válvula automática tipo boya proporcional.

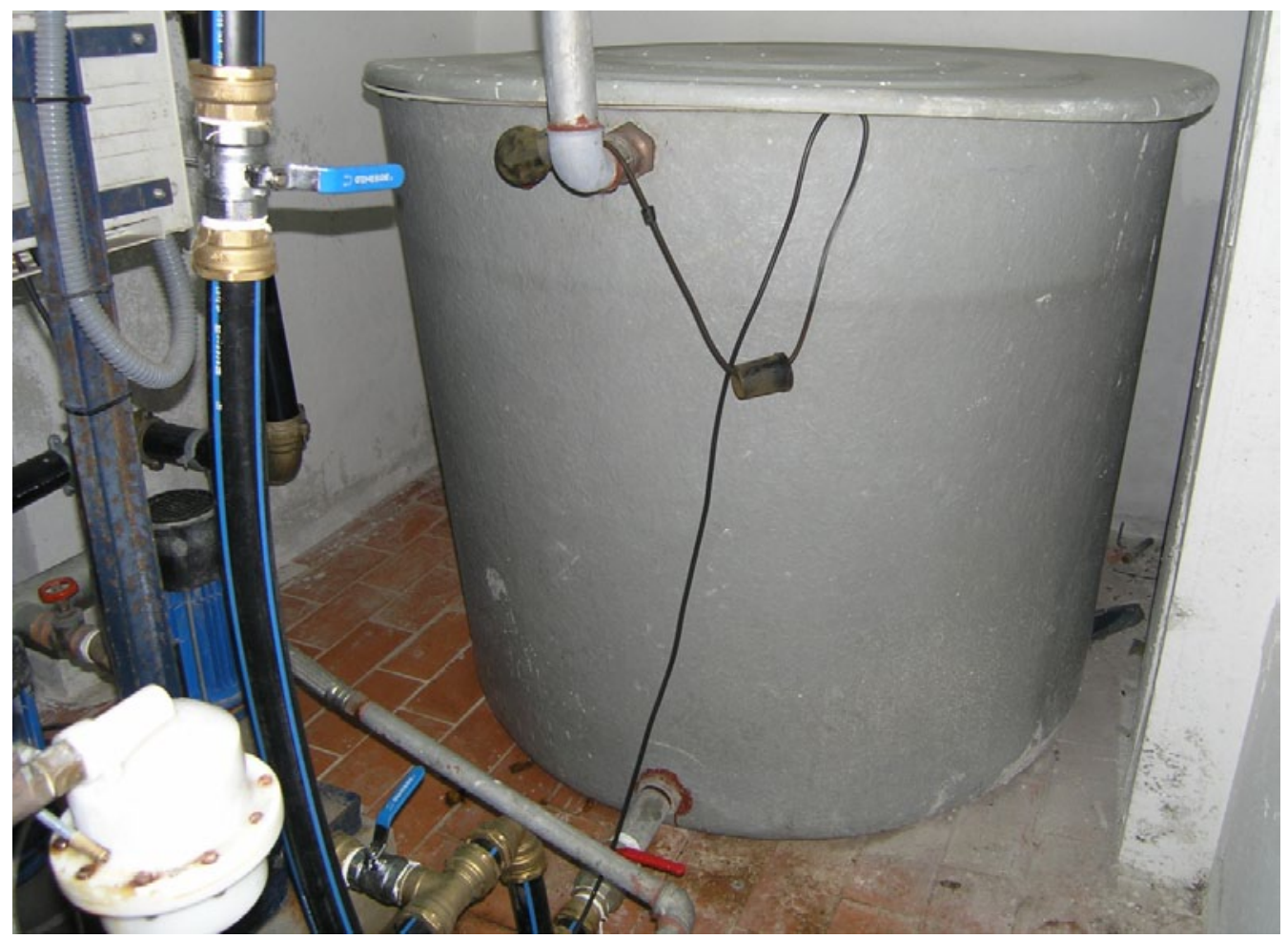

FIGURA A4-6. CONEXIÓN DEL GRUPO DE BOMBEO AL DEPÓSITO ATMOSFÉRICO 
El grupo de presión cuenta con un depósito presurizado en la impulsión (calderín). Dicho depósito es de contacto aire agua (sin vejiga interior). Su volumen total es de 500 litros y su presión de timbrado es de $8 \mathrm{Kg} / \mathrm{cm}^{2}$.

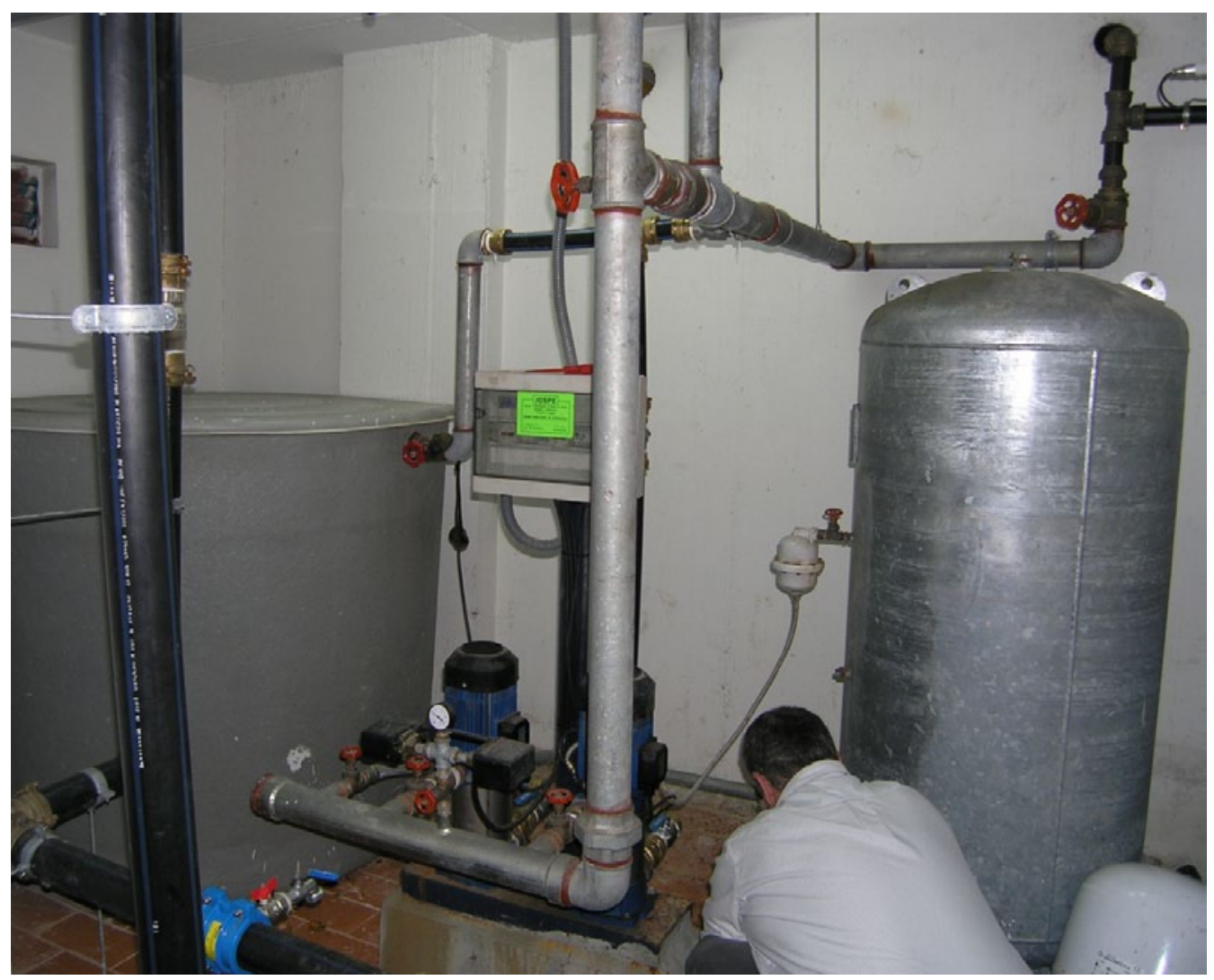

FIGURA A4-7. EQUIPO DE PRESIÓN ORIGINAL

La renovación del aire del interior del calderín se realiza mediante un inyector de conectado a la impulsión de la bomba, si bien desde un primer momento se comprobó un funcionamiento defectuoso de este dispositivo. Para la situación original, se observo un número de arranques consecutivos elevado del grupo debido a una reducida masa de aire almacenado en el interior del depósito. Actualmente la normativa de referencia prohíbe la instalación de calderines sin vejiga (CTE, 2006), debido por un lado a los problemas de calidad derivados del contacto con la masa metálica del depósito, y por otro a la facilidad con la que se pierde la masa de aire por su disolución con el volumen de agua. 


\subsubsection{Descripción de las instalaciones individuales}

Los usuarios suministrados a partir del grupo de presión son en su totalidad de tipo residencial, con un número medio de ocupantes de 2,6 habitantes por vivienda. Las viviendas disponen de una superficie catastral promedio de $124 \mathrm{~m}^{2}$ (aproximadamente $90 \mathrm{~m}^{2}$ útiles).

Cada vivienda cuenta con cuatro cuartos húmedos con los aparatos que se indican:

- cocina (equipada con fregadero, lavadora y lavavajillas),

- baño completo (equipado con bañera, inodoro, bidé y lavabo),

- aseo (equipado con inodoro, ducha y lavabo).

En total, cada vivienda cuenta de forma promedio con 10 aparatos. El caudal instalado por vivienda es de aproximadamente $1,55 \mathrm{l} / \mathrm{s}$ según las expresiones comúnmente utilizadas para el dimensionado, correspondiéndose con una vivienda Tipo C según la NIA (NIA, 1975).

Respecto a las derivaciones individuales de las viviendas, parten de una batería de contadores situada en la fachada del edificio. A la salida de cada derivación están conectadas las correspondientes llaves de contador de 3/4" de tipo esfera, con dispositivo antirretorno incorporado en la propia llave de salida. El contador instalado por la compañía suministradora es electrónico, de la marca CONTAZARA CZ2000 y de diámetro nominal DN15 (con caudal nominal de $1,5 \mathrm{~m}^{3} / \mathrm{h}$ ).

Las tuberías montantes son de cobre de $22 \mathrm{~mm}$ de diámetro exterior, y de $1 \mathrm{~mm}$ de espesor. Discurren paralelas a la fachada del inmueble, por un patinillo interior hasta la conexión en la instalación individual de cada usuario.

La instalación no cuenta con derivaciones de uso colectivo, y dispone tan sólo de una instalaciones particulares destinadas a los locales comerciales (el resto están inactivas a la hora de realizar el estudio). La conexión de las instalaciones particulares destinadas a locales se realiza en una batería de contadores paralela a la batería principal del edificio (sin pasar por el equipo de presión). 


\subsection{MONITORIZACIÓN DEL FUNCIONAMIENTO DEL EDIFICIO}

\subsubsection{Registro de datos de caudal}

\subsubsection{Caudal en derivaciones individuales}

En el edificio se instalaron contadores individuales para el registro de los volúmenes de cada una de las viviendas. Los contadores utilizados fueron de la marca ACTARIS, modelo AQUADIS con una metrología Clase D, y de $20 \mathrm{~mm}$ de diámetro nominal (caudal nominal, $\mathrm{Qn}=1,5 \mathrm{~m}^{3} / \mathrm{h}$ ). Estos contadores presentan una mayor sensibilidad que los contadores originales ya que disponen de un caudal mínimo, $q_{\min }$ y de transición más reducidos, $q_{t}\left(q_{\min }=15 \mathrm{l} / \mathrm{h}\right.$ frente a $25 \mathrm{l} / \mathrm{h}$ del Contazara CZ200-5M, y $q_{t}=22,5 \mathrm{l} / \mathrm{h}$ frente a $37,5 \mathrm{l} / \mathrm{h}$ ). Para no interferir en la facturación, se instalaron ambos contadores en serie tal como se puede apreciar en la siguiente figura.

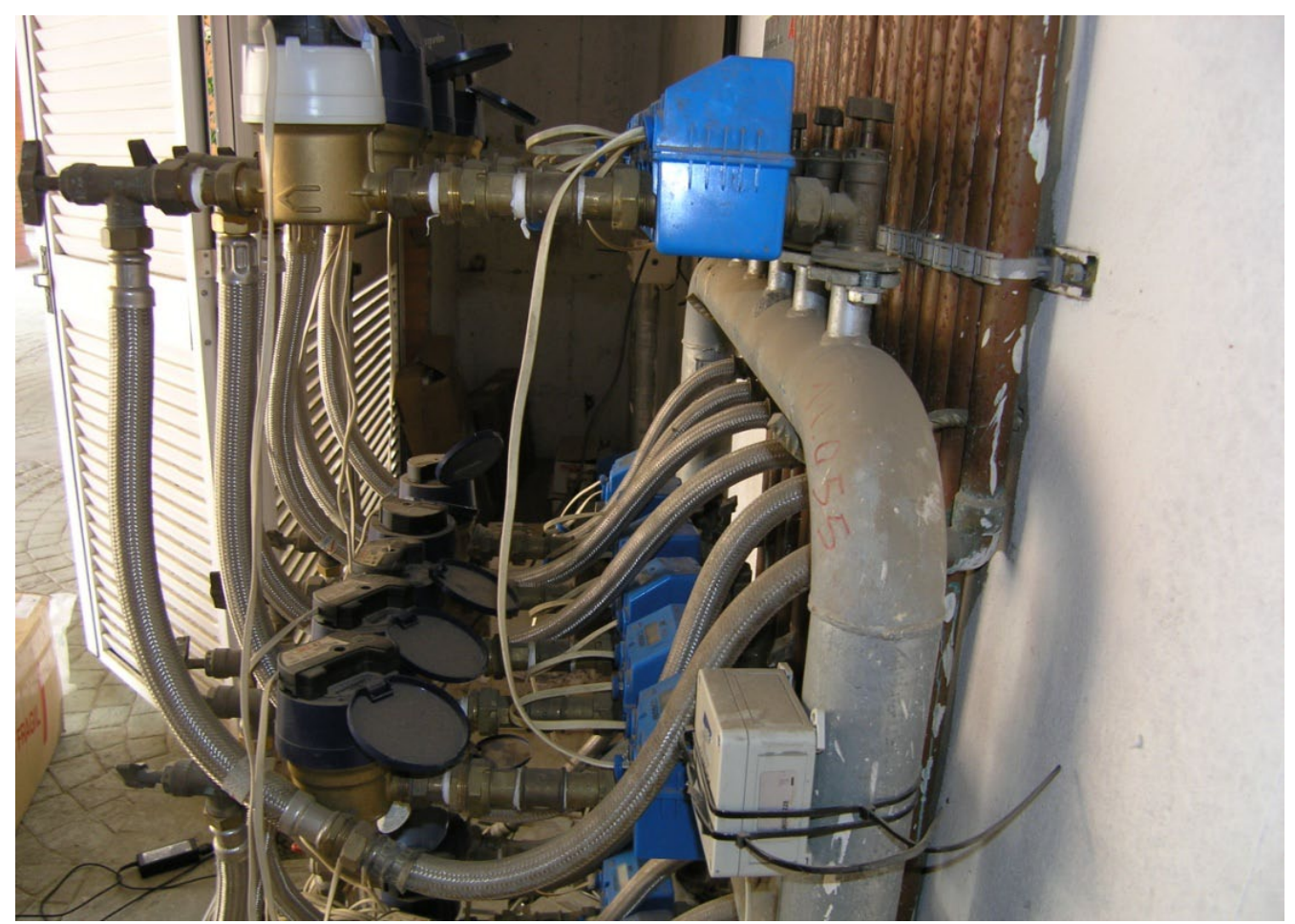

FIGURA A4-8. CONTADORES INDIVIDUALES CON SISTEMA DE CONTABILIZACIÓN DE PULSOS

Para almacenar los registros se incorporó en cada uno de los medidores un emisor de impulso (CYBLE SENSOR V2), junto con un equipo de almacenamiento de datos data logger (SENSUS CDL 4U). Se programó el registro de cada instante de tiempo en el que se origina un caudal trasegado de 0,1 litros (se trata de una sensibilidad suficiente para detectar cualquier uso intencionado o caudal de fuga estándar en una vivienda). 


\subsubsection{Caudal en la instalación general del edificio}

Además de los contadores individuales, se incorporó en la instalación un contador general ubicado en la aspiración de la bomba (Figura A4-9). El contador es de la marca ACTARIS modelo AQUADIS, de diámetro nominal DN 40, clase metrológica C y caudal nominal $10 \mathrm{~m}^{3} / \mathrm{h}$.

Este contador también se ha equipado con los elementos de registro y almacenamiento como en los contadores individuales. Para este contador se programa el registro de cada pulso asociado a 1 litro de volumen trasegado. Esta medida permite controlar los caudales bombeados por el grupo, ya que estos no son directamente equivalentes a las suma de cada uno de los contadores individuales por la existencia de un depósito presurizado en la instalación.

\subsubsection{Registro de datos de presión}

\subsubsection{Ubicación de las sondas}

Como complemento a la medida de los caudales circulantes por los diferentes tramos de la instalación, se incorporaron tres sondas de presión de alta sensibilidad con los correspondientes equipos de almacenamiento.

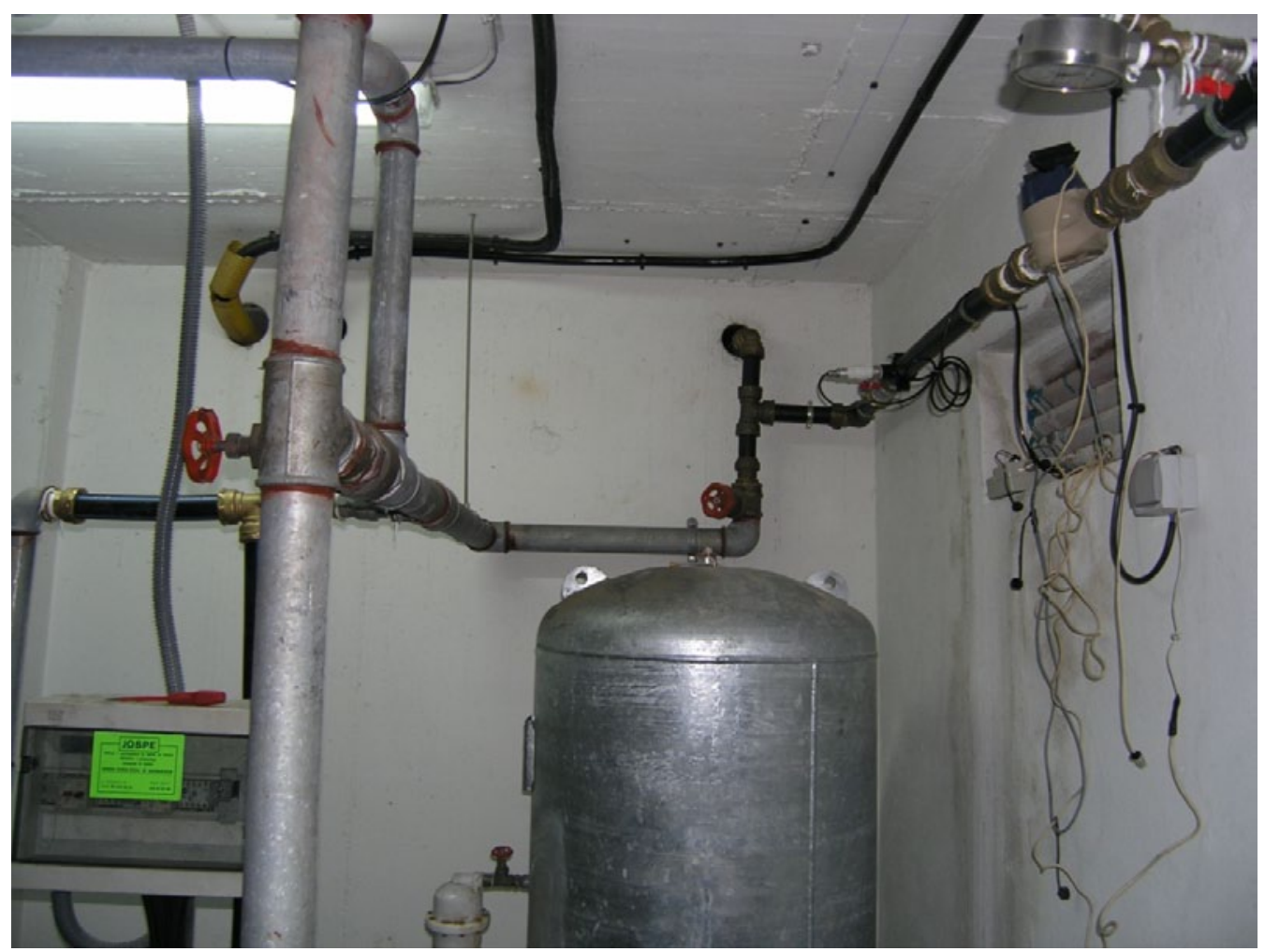

FIGURA A4-9. DETALLE CONTADOR GENERAL Y SONDA DE PRESIÓN CON DATA LOGGER 
Dos de las sondas se instalaron en el interior del edificio, justo en el tramo de aspiración de la bomba. Estas sondas aportan información de las solicitaciones máximas generadas por el funcionamiento del grupo. Por otro lado, se instaló una tercera sonda de presión en la conducción general situada en el exterior del edificio. La monitorización de esta sonda permite captar las fluctuaciones de presión transmitidas al exterior del edificio. Las fluctuaciones son ocasionadas por el arranque y paro del grupo de presión, y esta última sonda aporta una aproximación real de los efectos transmitidos a los edificios contiguos. Las características de la acometida no permitían la instalación de la sonda sobre la propia conducción, por ello se instaló en un hidrante contra incendios próximo a la acometida del inmueble.

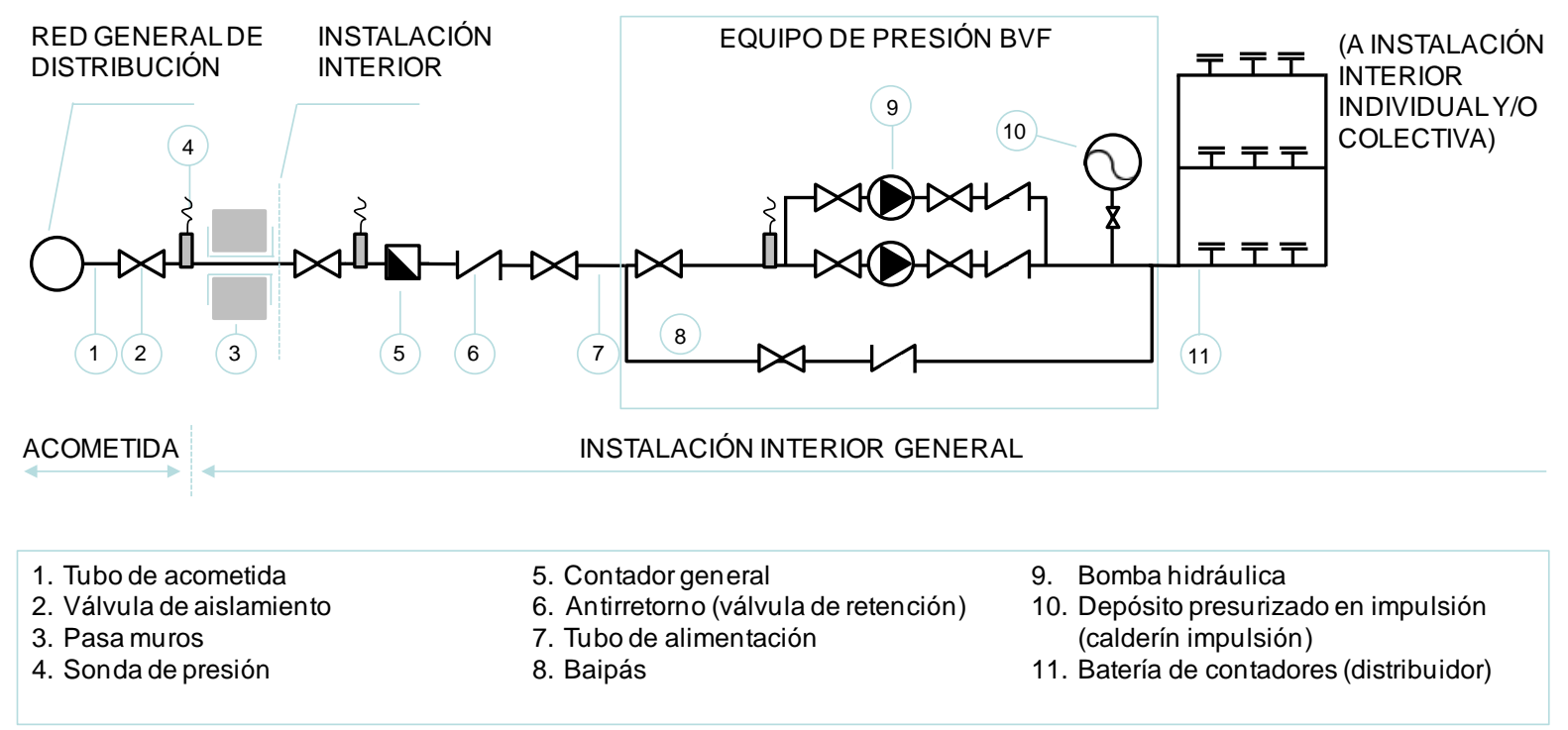

FIGURA A4-10. ESQUEMA CON LA ZONA APROXIMADA DE INSTALACIÓN DE LAS SONDAS DE PRESIÓN

\subsubsection{Características de las sondas de presión}

Las sondas instaladas son de tipo inserción con conexión de 1/4", de la marca SENSUS modelo CDL-DS, con las siguientes características:

- Rango de medida: 0-10 bar

- Error promedio: $\pm 0,5 \%$ sobre el fondo de escala

- Tiempo de reacción: $1 \mathrm{~ms}$

Se programó el registro de presión con una sensibilidad de 0,1 mca, almacenando un registro cada segundo para periodos prolongados, y cada $0,1 \mathrm{~s}$ durante el análisis transitorio (el almacenamiento con tan elevada resolución completa la memoria de los dispositivos en cortos periodos). 


\subsubsection{Alternancia del esquema de suministro}

Al mismo tiempo, la empresa EMASESA y, previa solicitación de los permisos correspondientes a la comunidad de vecinos, instala un grupo de presión equipado con variador de frecuencia (grupo de bombeo de velocidad variable, BVV). Este grupo se sitúa en el mismo cuarto de bombas que la instalación original, y se realiza su conexión directa a la tubería de entrada del agua al edificio.

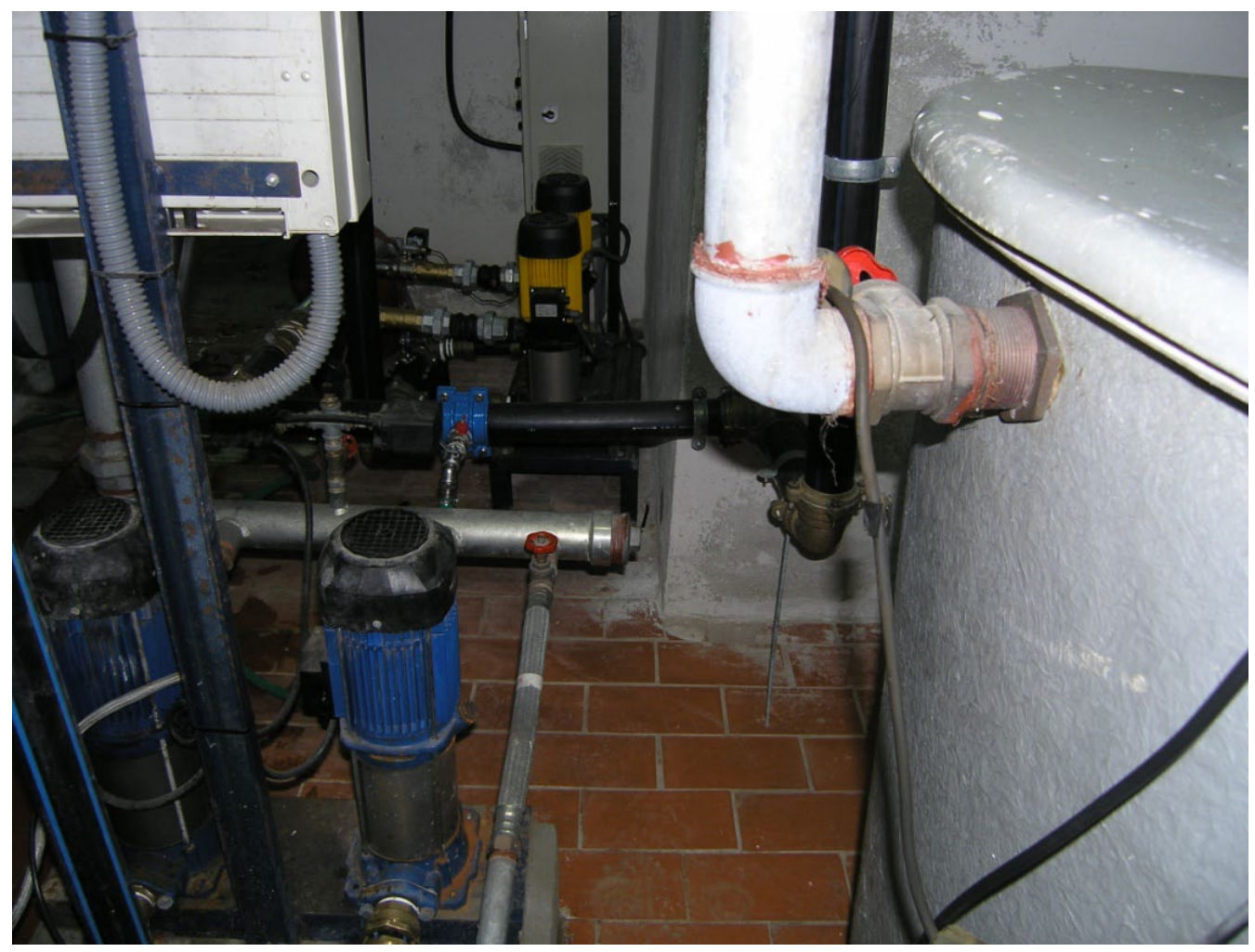

FIGURA A4-11. GRUPO DE PRESIÓN CON VARIADOR E INSTALACIÓN ORIGINAL (BOMBAS AZULES)

Además, se realizan las modificaciones necesarias en la instalación para permitir la entrada en funcionamiento de diferentes esquemas de suministro, en aras de conocer los efectos generados por cada uno de ellos (ver Anexo 2).

Los esquemas de suministro que se pueden adoptar en la instalación general son:

- Suministro con bomba de velocidad fija y depósito de aspiración (Convencional)

- Suministro con bomba de velocidad fija en directo (sin depósito). Tipo II.

- Suministro con grupo de bombeo equipado con variador de frecuencia conectado en directo (sin depósito de aspiración). Tipo IV. 


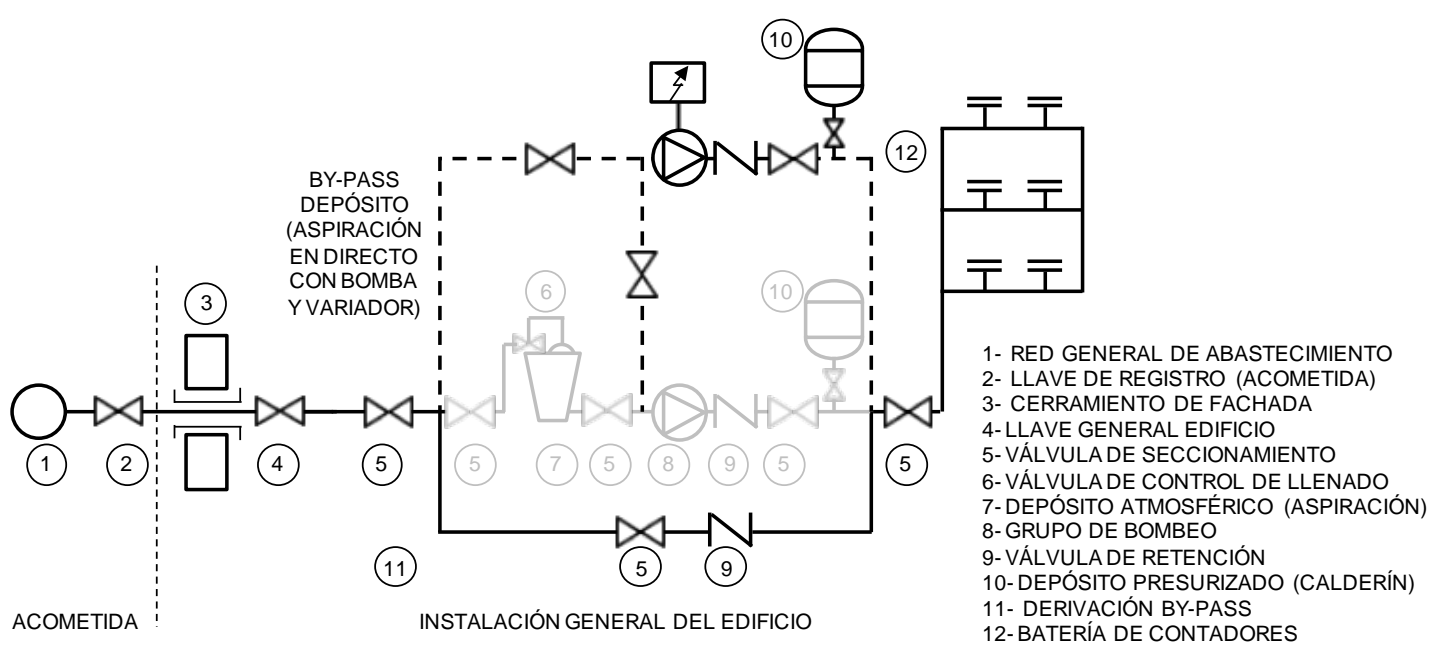

FIGURA A4-12. DETALLE DE CONEXIONES PARA LA MODIFICACIÓN DEL ESQUEMA DE SUMINISTRO

\subsubsection{Características del equipo de presión}

El equipo de presión instalado es un grupo compacto de la marca ESPA, modelo MULTI 35-5. Formado por dos bombas conectadas en paralelo y con aspiración directa. El grupo cuenta con un único variador de frecuencia con funcionamiento alternativo sobre las bombas. El calderín en impulsión está instalado sobre el colector de impulsión de las bombas, tiene un volumen de 50 litros y es de tipo membrana.

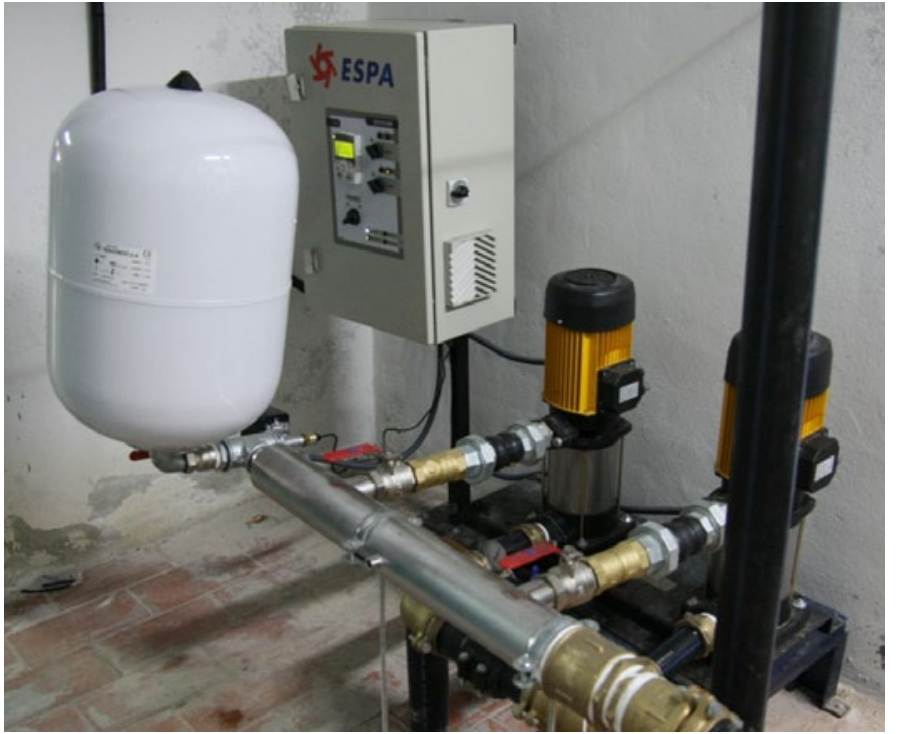

FIGURA A4-13. GRUPO MOTO-BOMBAS ORIGINAL DEL EDIFICIO

El grupo instalado se

dimensiona siguiendo los criterios usuales para este tipo de elementos, acudiendo a la normativa y recomendaciones existentes. El caudal de diseño considerado es de 1,8 l/s (según el número de viviendas y características según se ha comentado), y la altura de bombeo máxima necesaria para el caudal de diseño es de $45 \mathrm{mca}$ (valor inferior a la del grupo original, ya que sólo se contempla su conexión directa con el correspondiente aprovechamiento de la presión de red).

Los parámetros de regulación del controlador mantienen una presión de consigna de 6 bar, con una ganancia de 1 y tiempo de integración de $3 \mathrm{~s}$. 
Las curvas características de la bomba son las que se muestra a continuación:

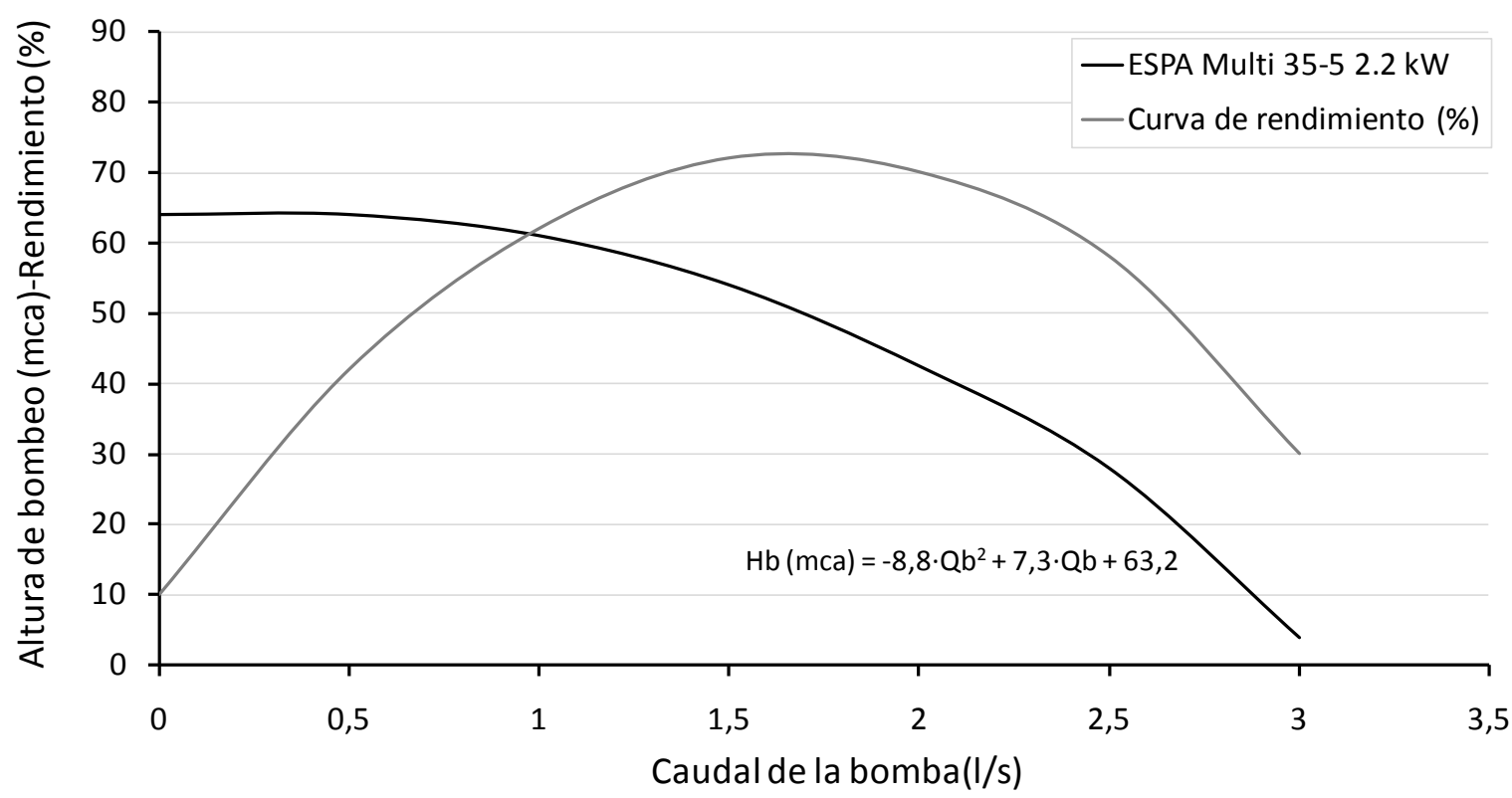

FIGURA A4-14. CURVA CARACTERÍSTICA Y DE RENDIMIENTO DE LAS BOMBAS

\subsection{DURACIÓN DE LAS MEDICIONES}

La monitorización se inicio en mayo de 2009, tras la instalación de los diferentes dispositivos de lectura y registro. Las mediciones de las diferentes variables se ha mantenido aproximadamente 20 meses (caudal en viviendas, caudal total aspirado por el grupo, presión en la aspiración de la bomba y presión en un edificio próximo), y se terminaron a finales de 2010. En dicho periodo se realizaron varias campañas de medición que permitieron descargar y reprogramar los datos almacenados.

Respecto a las medidas de presión, se ha mantenido un registro continuo durante el año 2010 en las diferentes sondas, principalmente bajo el esquema de suministro de grupo de velocidad variable con conexión directa, manteniendo periodos más reducidos de medición para la aspiración en directo con bombas de velocidad fija (dada la mayor severidad de funcionamiento de este tipo de grupo).

De la misma forma, y durante el último trimestre del 2010 se ha incorporado un calderín en aspiración para analizar la reducción de las solicitaciones conseguida con esta protección, al mismo tiempo que se han modificado los parámetros de regulación del variador de frecuencia para ajustar su funcionamiento. 


\subsection{Resultados De LA MONITORIZACIÓN DEL EDIFICIO}

Las sondas de presión instaladas, tanto en la aspiración de la bomba como en el exterior del edificio, han permitido obtener valores de presión para diferentes condiciones de funcionamiento. Por un lado, se ha monitorizado el funcionamiento de la bomba de velocidad fija conectada en directo, midiendo las depresiones y sobrepresiones que se generan tanto en la aspiración de la bomba como en el exterior del edificio. Las solicitaciones bajo este esquema son las máximas que se han registrado en la instalación.

Conocido el efecto introducido por el grupo de velocidad fija se ha analizado las posibles vías para proteger la instalación. Para ello, se ha acudido a un grupo de presión equipado con variador de frecuencia. Las solicitaciones bajo este esquema se han reducido sensiblemente debido principalmente al arranque más progresivo de este tipo de equipo (la rampa usual de arranque tiene una duración aproximada de $3 \mathrm{~s}$ ).

Otra de las vías analizadas es la instalación de un calderín en aspiración. La finalidad perseguida es que la bomba no aspire de la red la totalidad de agua durante el arranque, sirviéndose del calderín como apoyo durante este instante de funcionamiento. Para los esquemas analizados se ha conseguido una reducción sensible de las solicitaciones originadas en la instalación.

\subsubsection{Registros del grupo de velocidad fija conectado en directo}

La siguiente figura muestra la presión registrada en diferentes ciclos de funcionamiento para la bomba de velocidad fija conectada en directo sin protección.

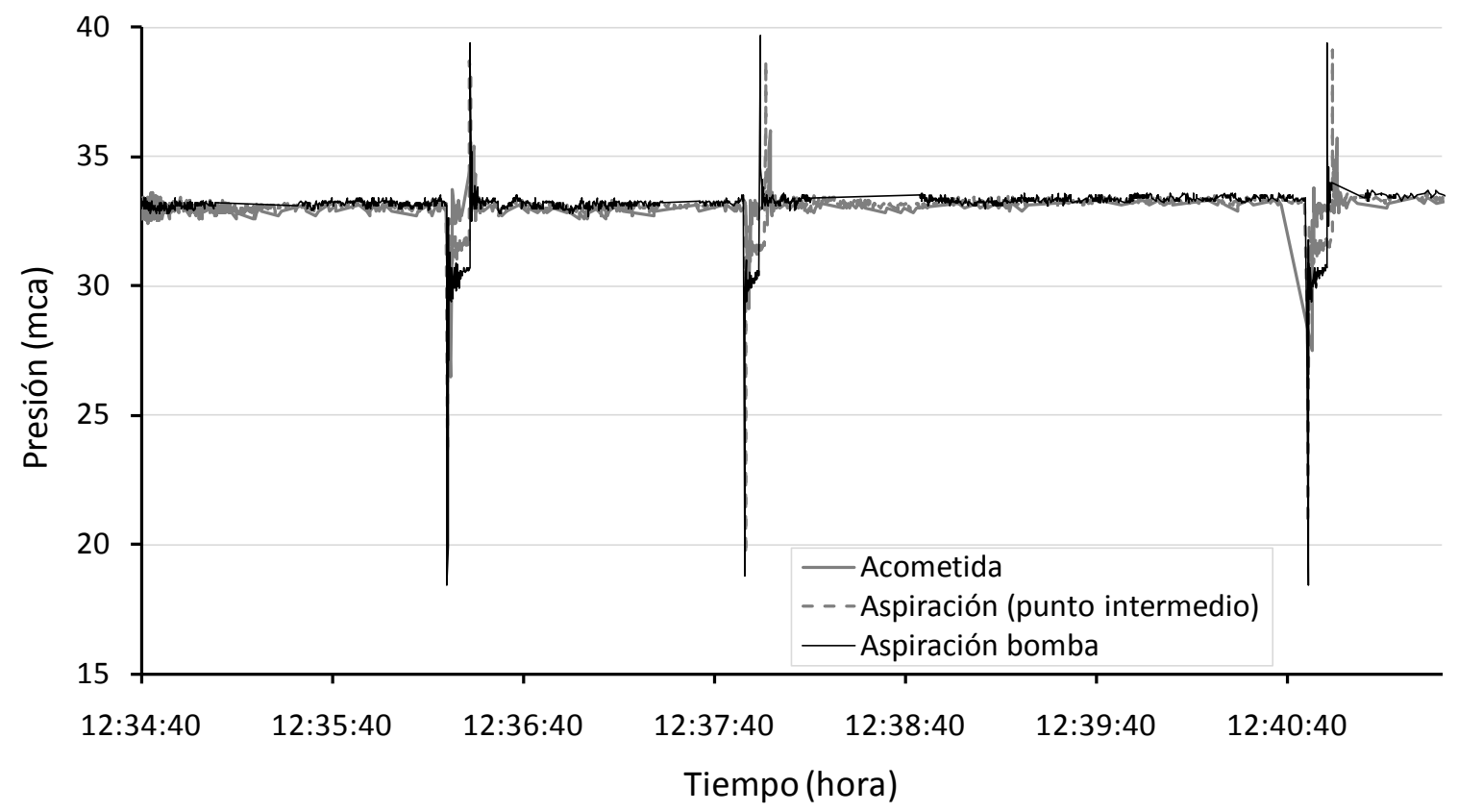

FIGURA A4-15. CiClOS DE FUNCIONAMIENTO DE LA BVF CONECTADA EN DIRECTO 
Las series graficadas se corresponden con las sondas instaladas en la aspiración del grupo y la sonda situada en la calle (próxima a la conducción de fundición de 150 $\mathrm{mm}$ ). Como puede observarse, los arranques consecutivos muestran un comportamiento similar. Para este tipo de grupos, las perturbaciones generadas en régimen transitorio para consecutivos arranques muestran valores similares. La única fase de funcionamiento que puede presentar diferencias es el régimen permanente (cuando la bomba se encuentra en marcha), ya que dependiendo de la demanda instantánea de los usuarios el tiempo de funcionamiento puede verse prolongado a mayores demandas.

Otro de los detalles que puede observarse del funcionamiento del grupo es el elevado número de arranques por hora, y la corta duración de los mismos. Este funcionamiento es indicativo de un reducido volumen de aire en el calderín.

Si se aísla uno de los ciclos es posible comprobar con detalle las variaciones de presión que se registran en cada uno de los puntos de medida. La primera variación de la presión es debida al arranque de la bomba (fenómeno transitorio). Como se puede observar, la depresión origina un descenso de aproximadamente 15 mca en aspiración y 7 mca en la acometida. La duración de dicho descenso es inferior a 1 segundo. Posteriormente la depresión se estabiliza hasta que se origina la parada de la bomba. Dicha parada genera una sobrepresión, hasta estabilizarse de nuevo la presión (régimen permanente correspondiente a la bomba parada). Se destaca que, a diferencia de la depresión la sobrepresión no supone en principio un riesgo al suministro, aunque reduce la vida útil de los componentes de la instalación por fatiga.

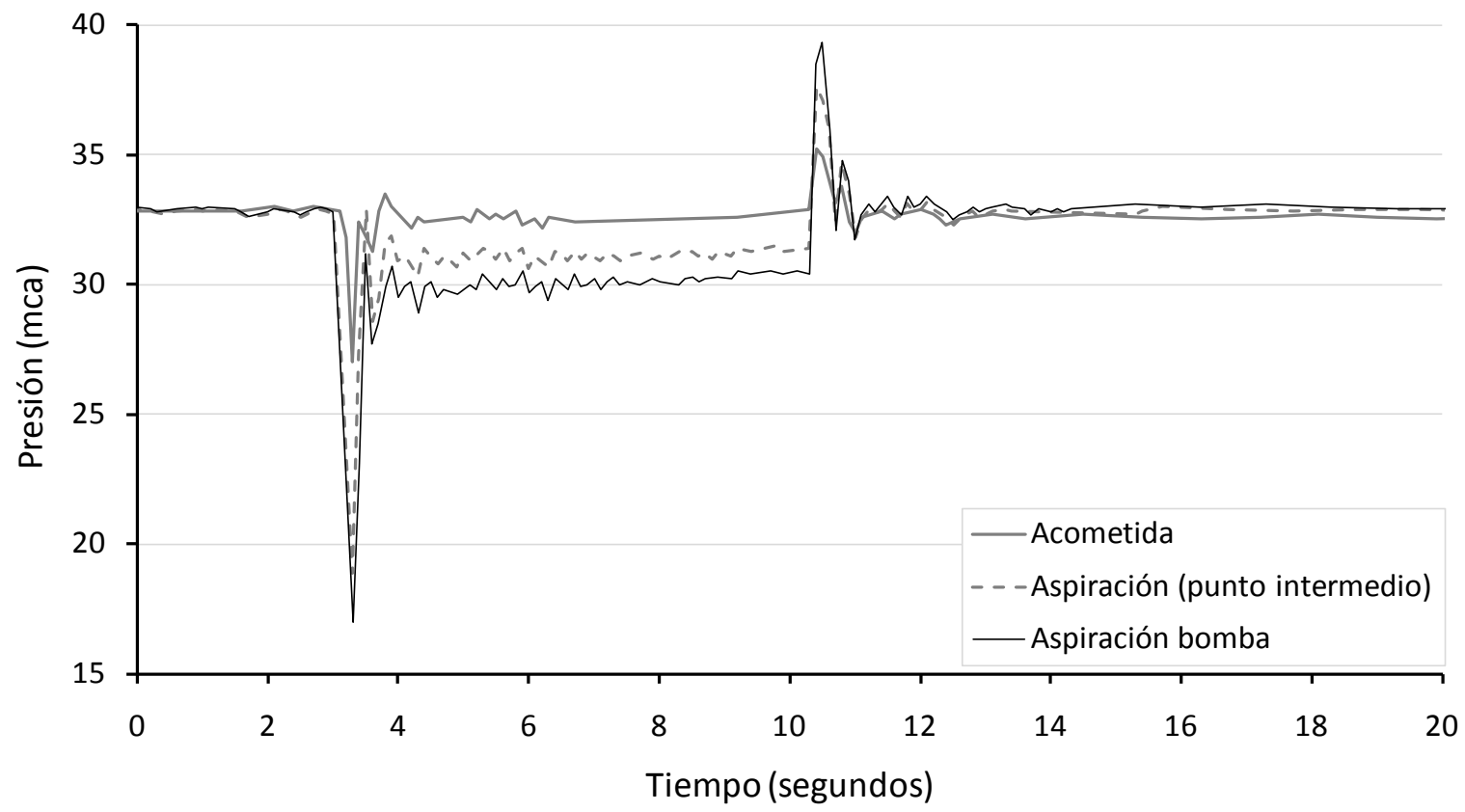

FIGURA A4-16. DetALLE DEL FUNCIONAMIENTO DEL GRUPO DE PRESIÓN DE VELOCIDAD FIJA CONECTADO EN DIRECTO 


\subsubsection{Registros del grupo de velocidad variable conectado en directo}

La siguiente figura muestra el efecto originado por el funcionamiento de la bomba de velocidad variable conectada en directo.

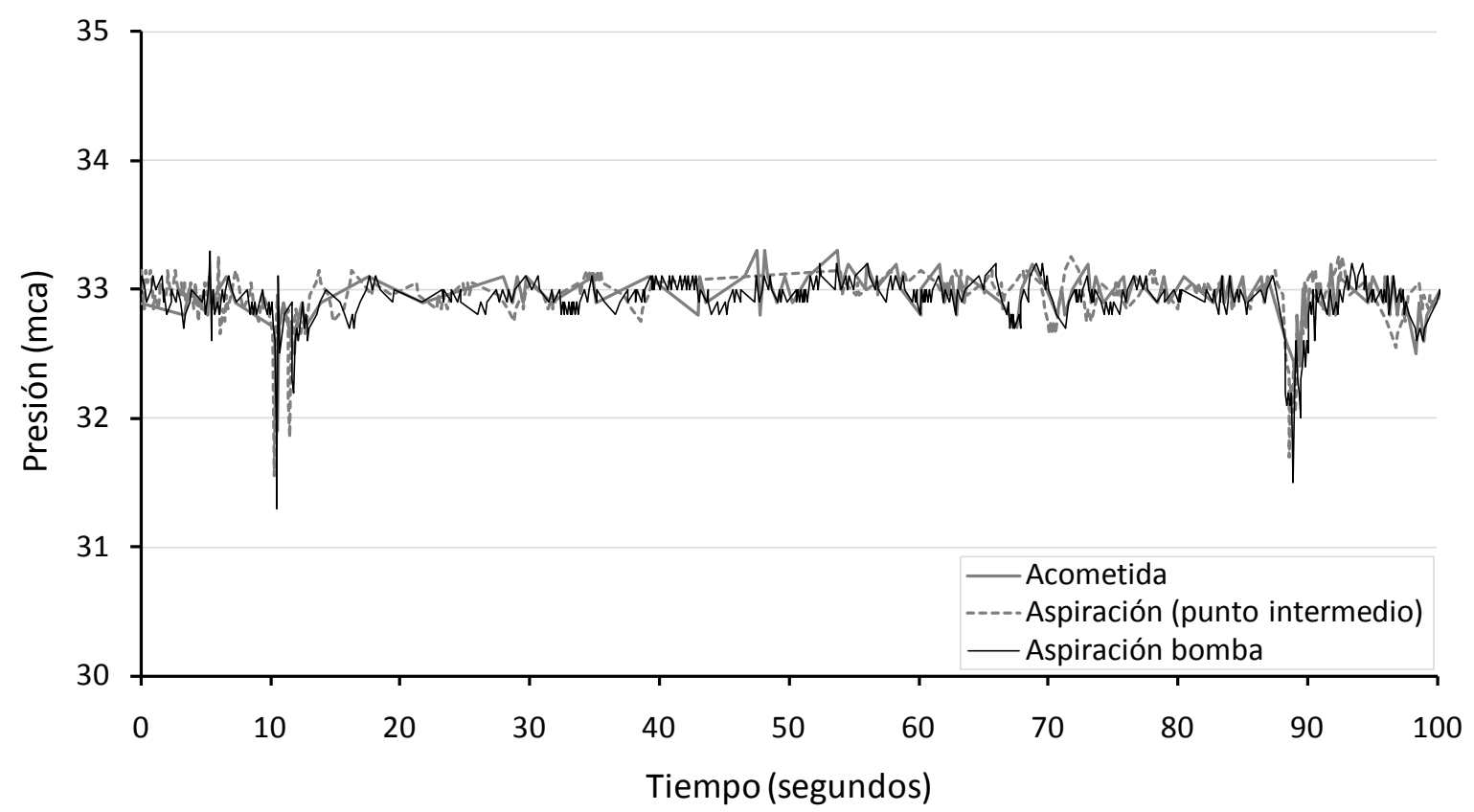

FIGURA A4-17. FUNCIONAMIENTO DEL GRUPO DE PRESIÓN CON VARIADOR CONECTADO EN DIRECTO

Como se puede observar, se mantiene las depresiones durante el arranque de la bomba de velocidad variable, pero en este caso la depresión máxima se reduce sensiblemente (téngase en cuenta la variación de la escala del eje ordenadas respecto las figuras correspondientes a la BVF). En el caso de la depresión en aspiración, la caída aproximada es de 1,5 mca (frente a los 15 mca para la BVF), mientras que la depresión en acometida es de 0,8 mca (frente a los 7 mca de la BVF).

Por otro lado, no se debe dejar de prestar atención al régimen permanente cuando la bomba está en funcionamiento. Para la BVV, la depresión es muy reducida, inferiores a 0,5 mca (la bomba gira a menos del 100\% de su régimen nominal). Mientras que para la BVF, en régimen permanente, origina una depresión en aspiración de 2,5 mca, incluso mayor que la correspondiente al arranque de la BVV. La razón hay que buscarla en la velocidad de giro de la BVV durante el arranque, que suele ser próxima al $70 \%$ de su velocidad nominal.

Respecto a la similitud de los ciclos de funcionamiento, se destaca que durante los registros realizados bajo este esquema no ha habido una variación significativa, ya que el controlador mantiene rampas de arranque de similares características. Del mismo modo, las variaciones de velocidad durante el funcionamiento tampoco han generado variaciones significativas. 


\subsubsection{Respuesta ante medidas de protección}

4.6.3.1 Registros del grupo de velocidad fija con calderín en aspiración

Para la bomba de velocidad fija la reducción en el arranque es próxima al 50\%, pasándose de una caída de presión de 16 mca a valores cercanos a 8 mca.

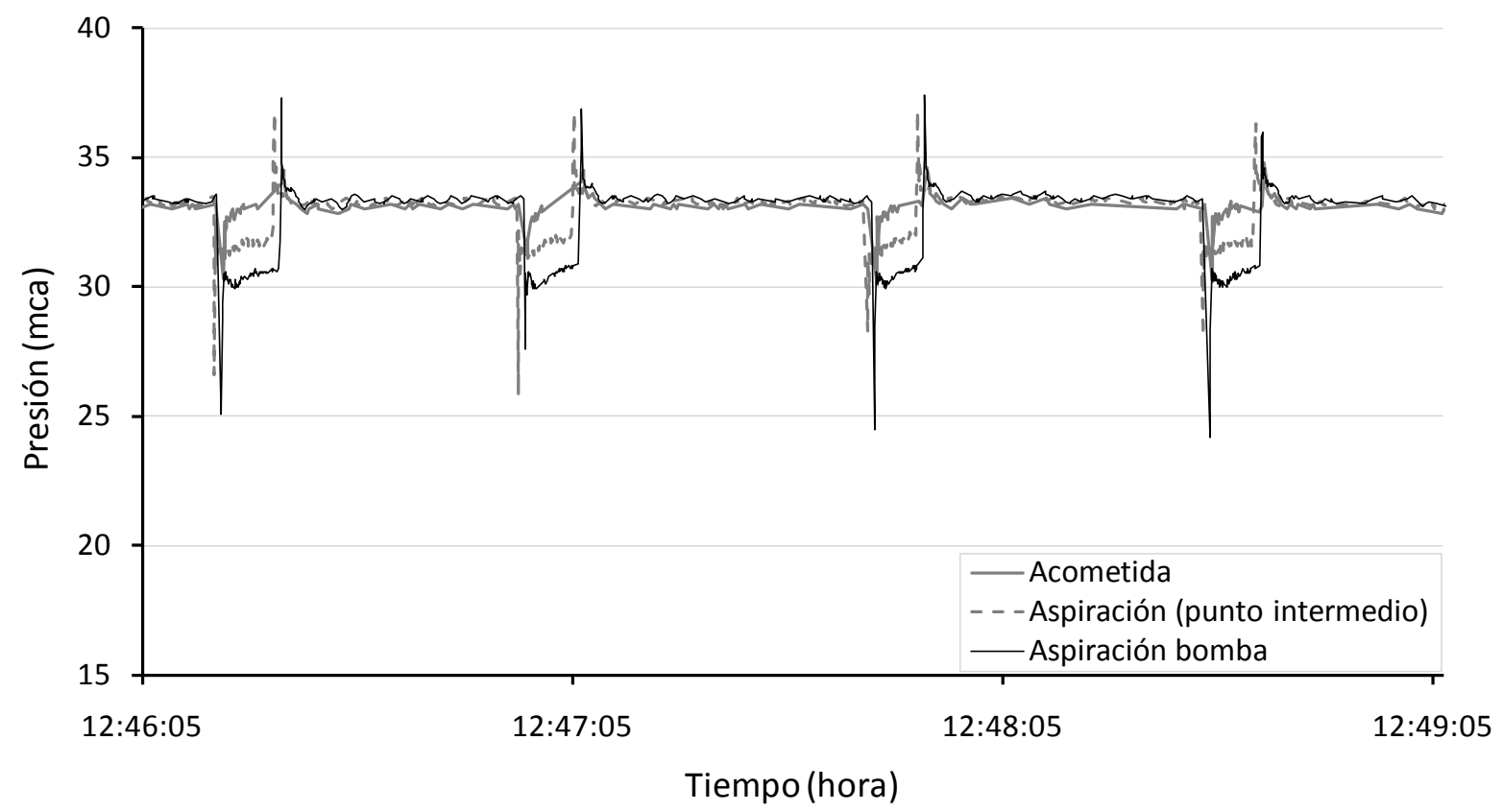

FIGURA A4-18. FUNCIONAMIENTO DE LA BVF CONECTADA EN DIRECTO CON CALDERÍN EN ASPIRACIÓN

\subsubsection{Registros del grupo de velocidad variable con calderín en aspiración}

En el caso de la bomba de velocidad variable la reducción es menor.

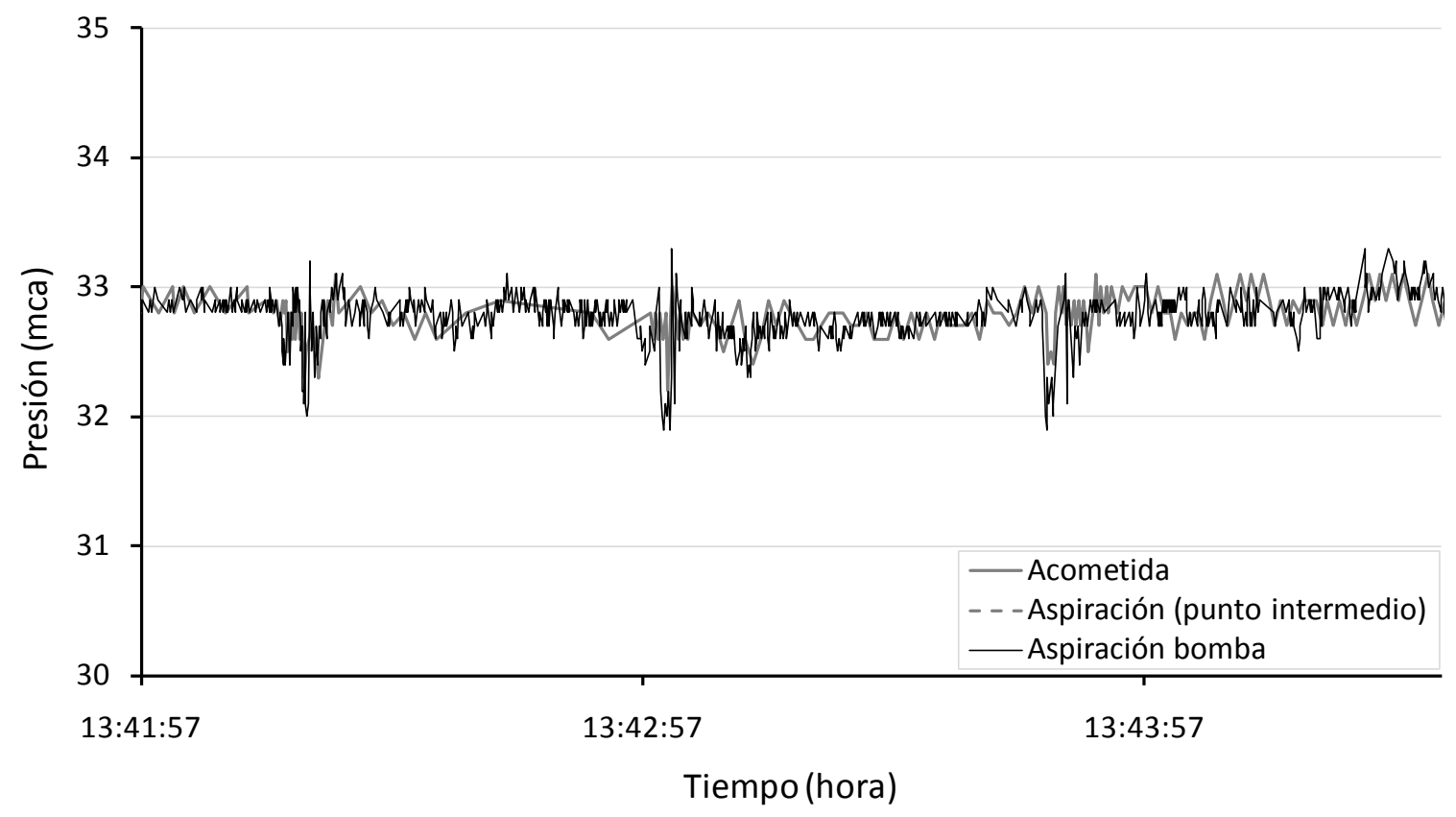

FIGURA A4-19. FUNCIONAMIENTO DE LA BVV CONECTADA EN DIRECTO CON CALDERÍN EN ASPIRACIÓN 


\subsubsection{Comparación de solicitaciones}

La siguiente gráfica muestra la comparación entre las solicitaciones de cada esquema de funcionamiento, para una conexión en directo (sin depósito atmosférico de aspiración).

- Esquema 1. Bomba de velocidad fija

- Esquema 2. Bomba de velocidad fija con calderín en aspiración

- Esquema 3. Bomba de velocidad variable

- Esquema 4. Bomba de velocidad variable con calderín en aspiración

4.6.4.1 Solicitaciones en aspiración del grupo de presión

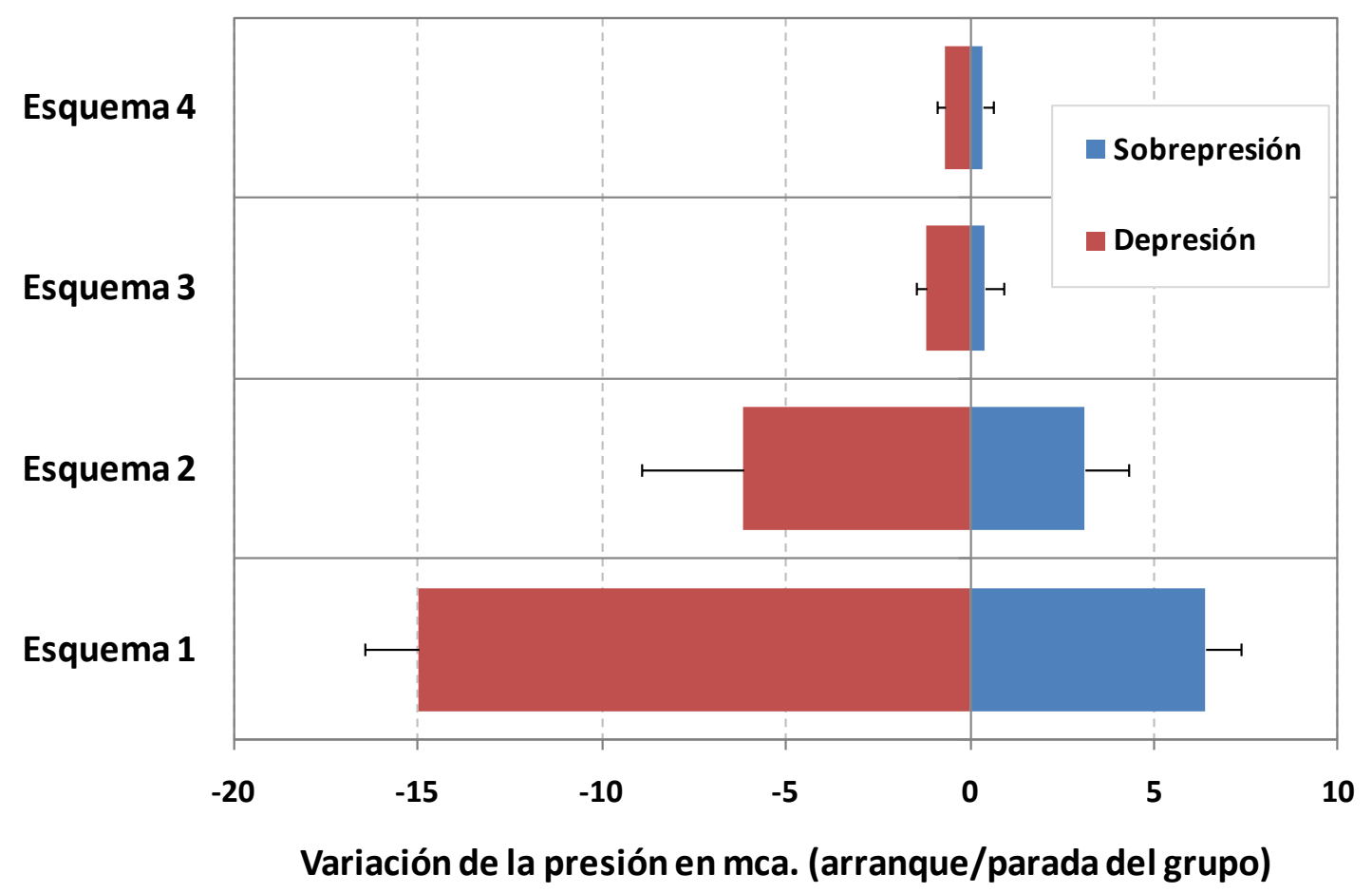

FIGURA A4-20. COMPARACIÓN DE LAS SOLICITACIONES EN ASPIRACIÓN PARA DIFERENTES ESQUEMA

En la gráfica anterior se muestra, para cada esquema de funcionamiento, las solicitaciones originadas por el funcionamiento de la bomba en el interior del edificio. Por un lado se representa la depresión derivada del arranque del grupo (color rojo), y por otro lado, las sobrepresiones originadas por el paro de la bomba (color azul). En ambos casos se representan los valores máximos y promedios observados durante el periodo de monitorización. 
En el caso de instalar bomba de velocidad fija (esquema 1), la depresión máxima en la aspiración de la bomba es de $17 \mathrm{mca}$, reduciéndose a 8,5 mca si además si instala calderín en la aspiración de la bomba (esquema 2). En el caso de la BVV (esquema 3), la depresión máxima es de 1,5 mca, reduciéndose a 0,8 mca cuando la instalación se protege con el calderín en aspiración (esquema 4).

\subsubsection{Solicitaciones en la acometida del edificio}

Por otro lado, las solicitaciones vistas en el exterior del edificio y, por tanto, las transmitidas a la red de distribución, vienen representadas por la siguiente gráfica:

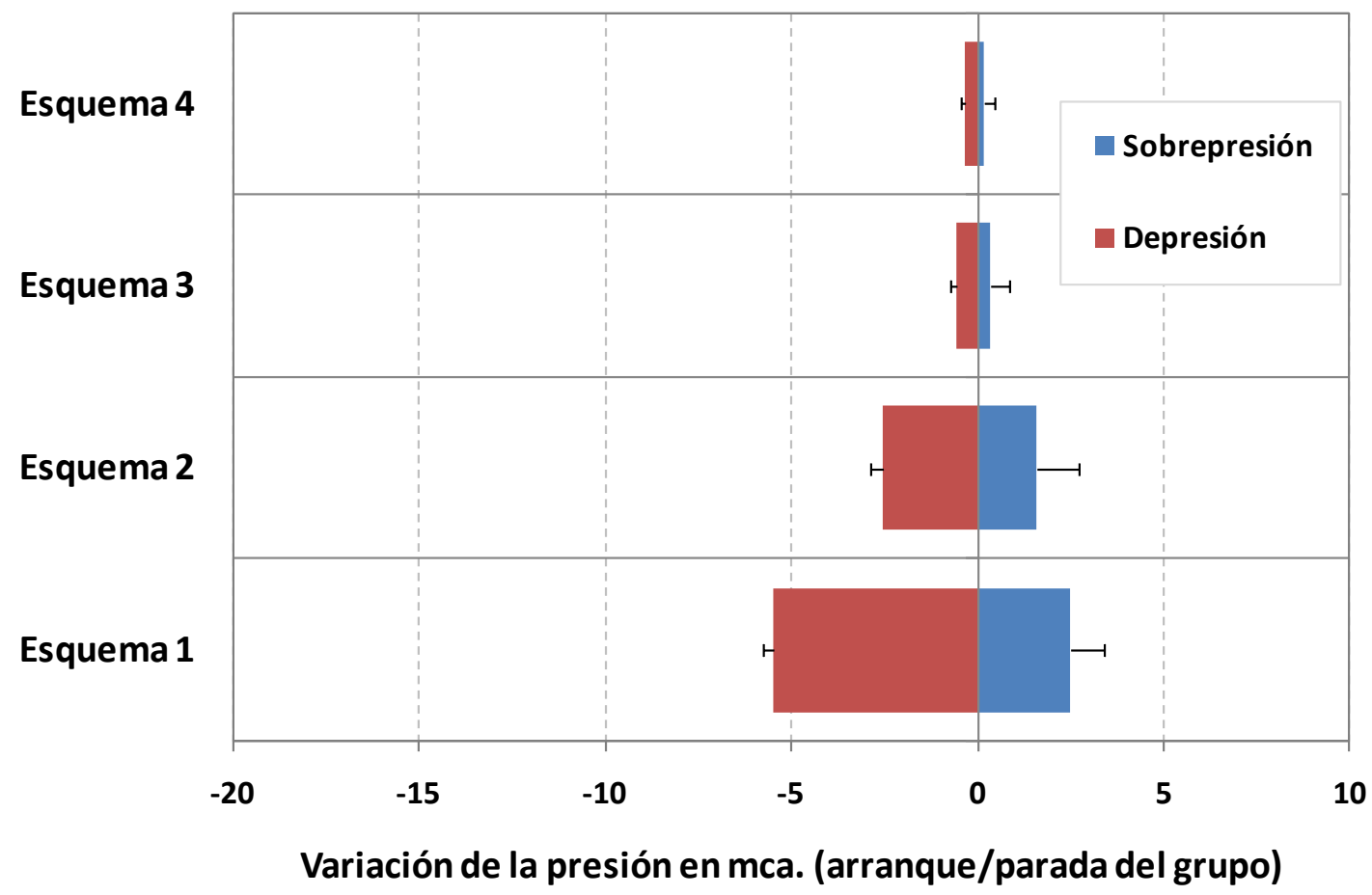

FIGURA A4-21. COMPARACIÓN DE LAS SOLICITACIONES EN ACOMETIDA PARA DIFERENTES ESQUEMAS

Respecto a los efectos transmitidos al exterior del edificio (registrados con la sonda en acometida), para la bomba de velocidad fija (esquema 1), la depresión máxima es de $6 \mathrm{mca}$, reduciéndose a los 3 mca si además si instala calderín en la aspiración de la bomba (esquema 2). En el caso de la BVV (esquema 3), la depresión máxima es de 0,8 mca (frente a los 1,5 mca en aspiración), reduciéndose a 0,6 mca (frente a los 0,8 mca en aspiración), cuando la instalación se protege con el calderín (esquema 4).

El efecto de las depresiones debe considerarse tanto en la acometida del edificio, como en la propia aspiración del grupo, ya que una depresión significativa, puede poner en riesgo el correcto funcionamiento del grupo. 


\subsection{Conclusiones}

Analizados los datos obtenidos de la monitorización se puede concluir:

- El momento crítico es el instante de arranque de la bomba por las alteraciones en la presión que se producen.

- La duración y magnitud de la depresión en este instante está acotada y puede ser obtenida con mediciones directas.

- El variador de frecuencia minimiza la depresión en el arranque, haciéndola prácticamente inapreciable durante el funcionamiento.

- La reducción en la depresión es próxima al 50\% si se cuenta con un calderín en aspiración convenientemente dimensionado.

- Con la bomba arrancada la depresión transmitida a la red pública es prácticamente inapreciable, y da una idea sobre si la red está suficientemente dimensionada, o por el contrario, la red es insuficiente para mantener dicho funcionamiento.

- Las oscilaciones durante la parada de la bomba no suelen poner en riesgo el correcto funcionamiento de la instalación. 
Anexo 5

\section{Consideraciones sobre la conexión indirecta con depósito atmosférico}




\subsection{INTRODUCCIÓN}

Como se ha comprobado en determinadas circunstancias será necesario mantener una conexión indirecta, bien por la magnitud de las solicitaciones transitorias generadas por el grupo o por la incapacidad de la red de distribución. En estas situaciones el depósito atmosférico permite aislar la instalación interior del edificio de la red general de distribución y laminar en gran medida el caudal detraído de la red.

El elemento que condiciona las alteraciones sobre la red general de suministro es la válvula de control del Ilenado del depósito. La caída de presión originada por el funcionamiento de la válvula suele ser inferior a la originada por la aspiración directa del grupo, pero un mal dimensionado o selección de la válvula puede poner en riesgo el normal suministro en la instalación.

En régimen permanente la caída de presión máxima está relacionada con el máximo grado de apertura de la válvula. En esta situación el caudal trasegado por la instalación puede ser elevado, del mismo modo que las pérdidas por fricción tanto en tuberías como en elementos de la instalación. Al mismo tiempo la extracción de caudales elevados en la instalación interior conlleva un mayor flujo por la red, favoreciendo las pérdidas y el aumento de la carga de ésta.

Por todo ello, a continuación se analiza el fenómeno asociado al funcionamiento del depósito atmosférico y se indican aquellas situaciones que conviene recurrir a su uso. Del mismo modo se establecen una serie de recomendaciones sobre el diseño y dimensionado de la instalación. 


\subsection{ESQUEMA DE INSTALACIÓN}

La instalación con depósito atmosférico realiza una conexión indirecta del grupo de presión; la alimentación del depósito se conecta a la conducción procedente de la red general de distribución y el grupo se conecta directamente aguas debajo de éste tal como se muestra en la Figura A5-1.

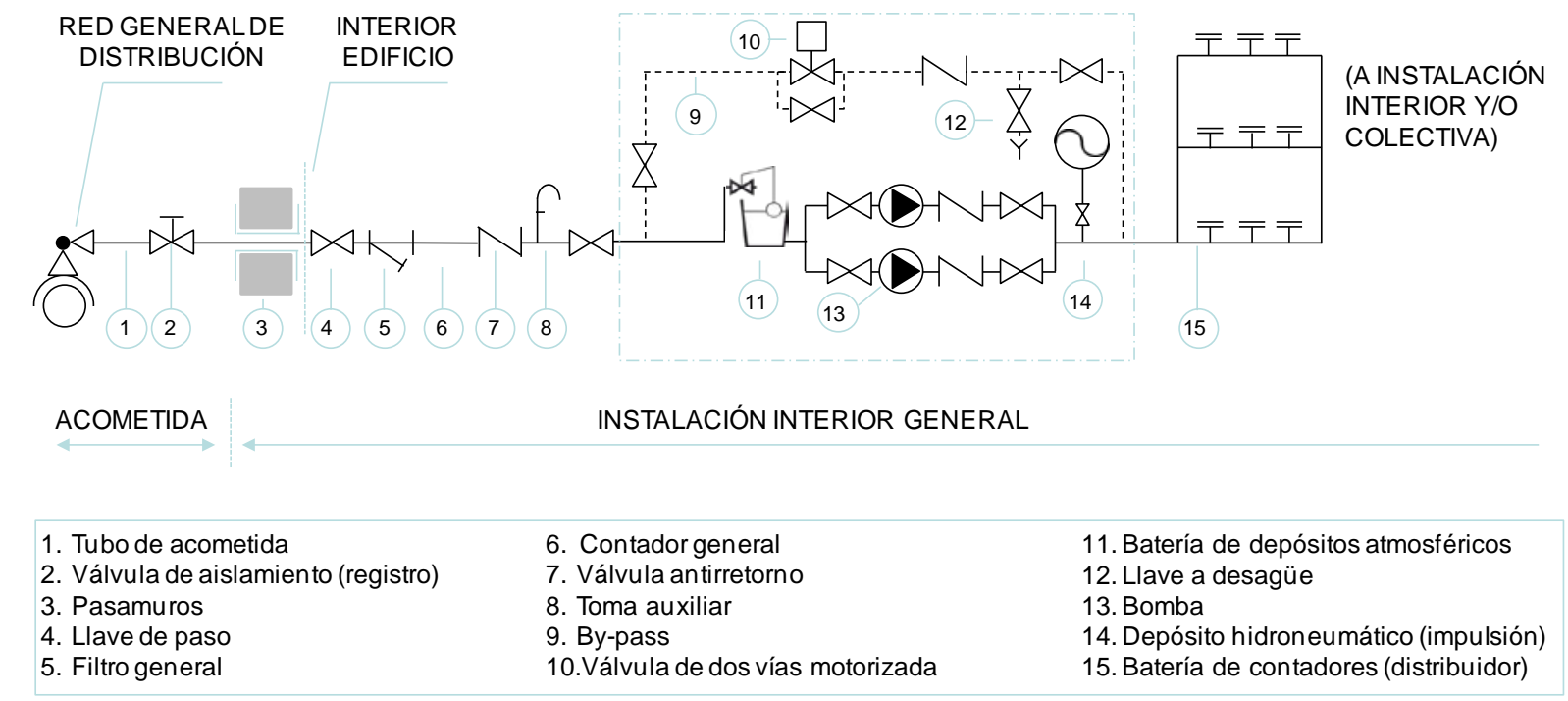

FIGURA A5-1. INSTALACIÓN INDIRECTA CON DEPÓSITO ATMOSFÉRICO DE ALIMENTACIÓN

\subsubsection{Solicitaciones asociadas al llenado del depósito atmosférico}

Las solicitaciones asociadas al funcionamiento de la válvula están condicionadas al propio mecanismo de control de llenado del depósito. Generalmente se encuentran dos mecanismos diferenciados para las válvulas de control de nivel; por un lado las válvulas de Ilenado de tipo proporcional y por otro, la válvulas tipo todo/nada. EI primero de los casos (válvula proporcional) origina un caudal variable en función del grado de apertura (condicionado por el nivel de agua en el depósito), mostrando por tanto un comportamiento más progresivo de la maniobra, y con éste unas variaciones de caudal más lentas. Por otro lado las válvulas de llenado tipo todo/nada presentan un funcionamiento más brusco, ya que de la posición cerrada pasan a un caudal constante elevado (a partir de un determinado nivel de apertura, $t=2 \mathrm{~s}$ en la Figura A5-2), originándose posteriormente el cierre completo a partir de un segundo nivel (nivel de cierre para el instante $\mathrm{t}=35 \mathrm{~s}$ ).

Las maniobras de la válvula todo/nada son más críticas que las de una válvula proporcional para condiciones de funcionamiento similares, ya que el cambio de estado si bien no es instantáneo por la histéresis del mecanismo, presenta una brusca variación de caudal tanto en la apertura como en el cierre, pudiendo originar transitorios de magnitud nada despreciable. 
La Figura A5-2 compara el comportamiento de las dos válvulas, y concretamente la evolución del caudal para una maniobra completa de apertura y cierre.

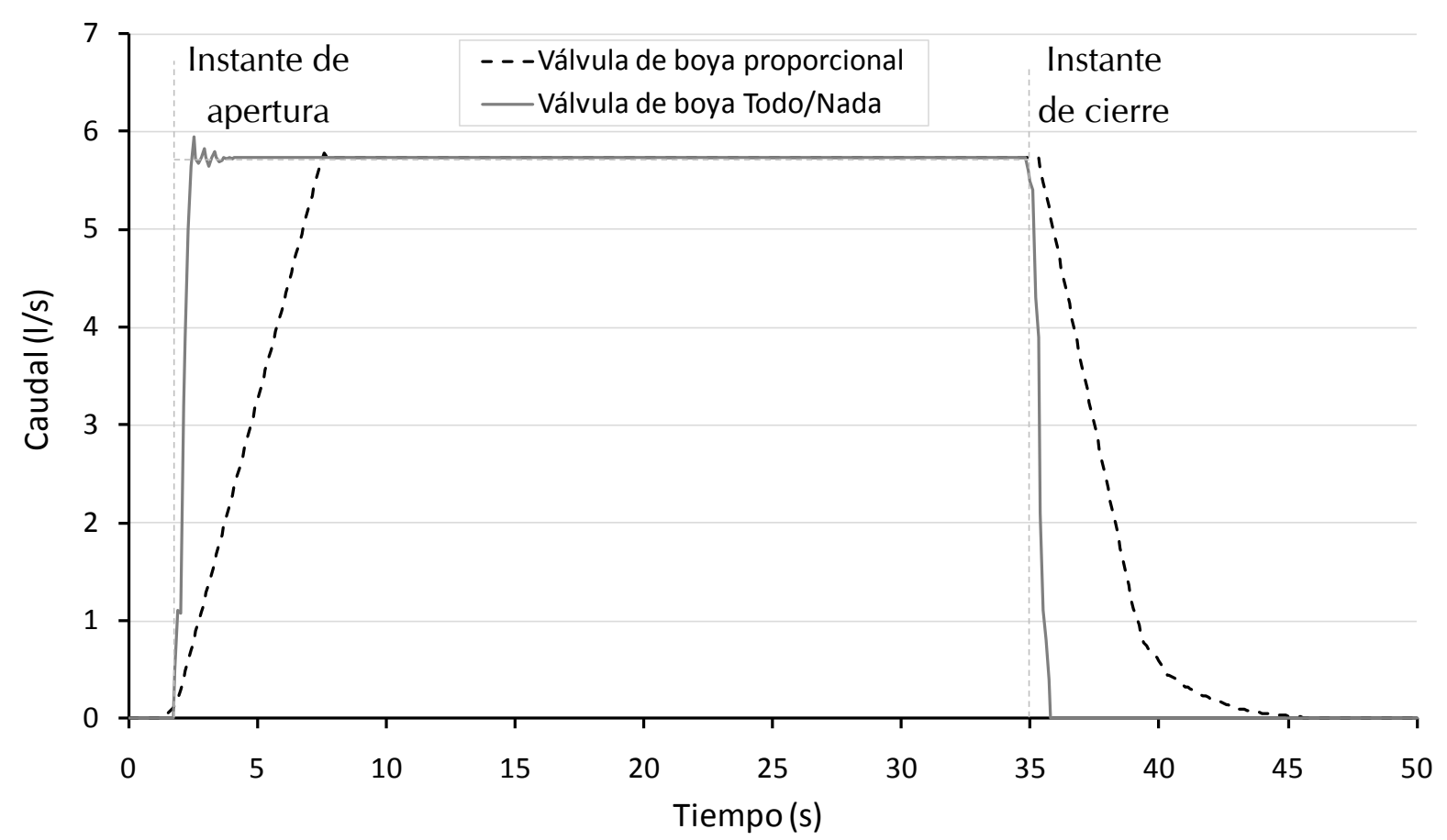

FIGURA A5-2. COMPARACIÓN DE LAS MANIOBRAS DE UNA VÁLVULA TODO/NADA Y DE UNA PROPORCIONAL

La Figura A5-3 muestra un comportamiento típico de una válvula proporcional, indicándose las alteraciones de presión originadas en la entrada en función del caudal detraído de la red.

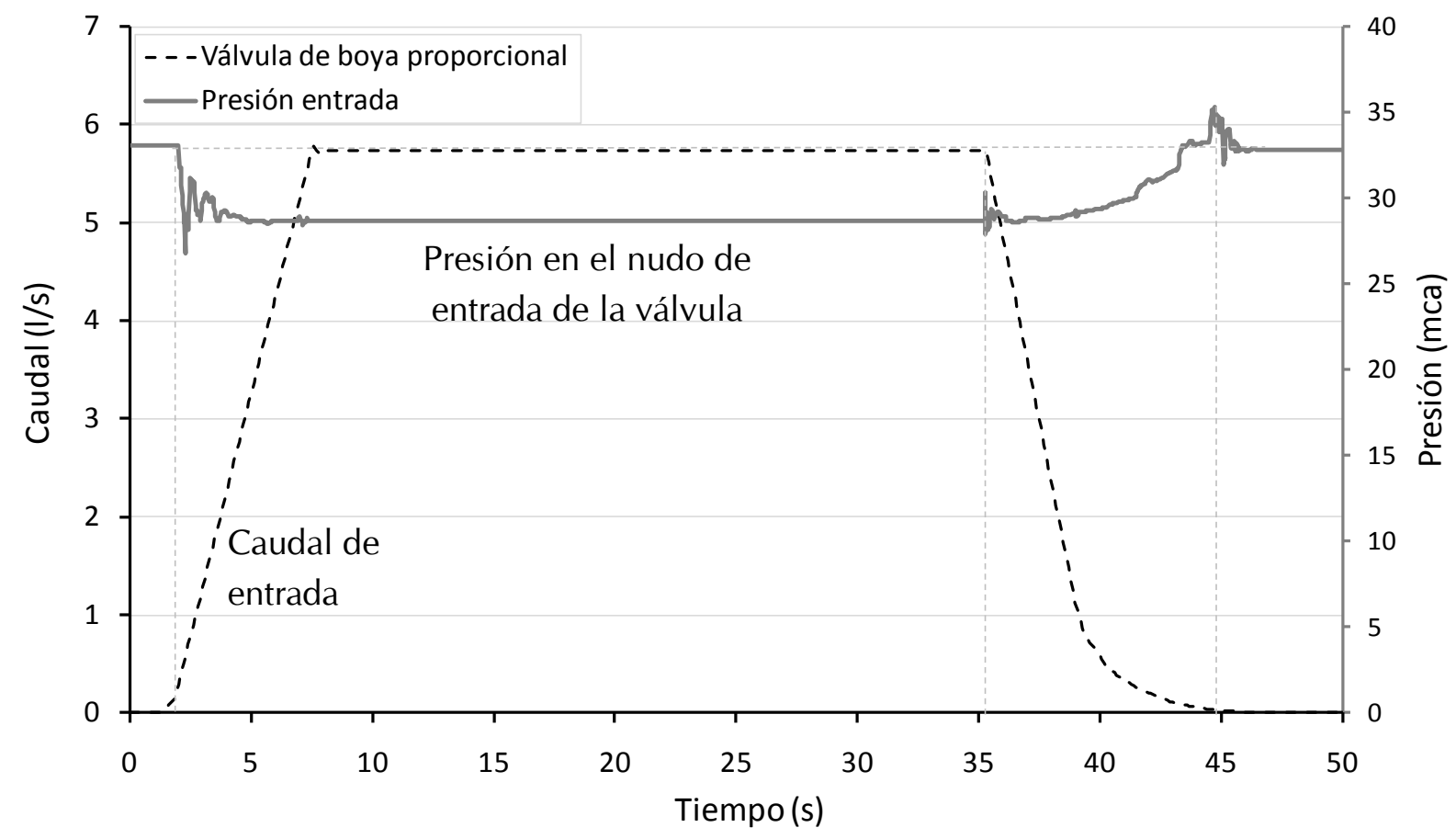

FIGURA A5-3. VARIACIÓN DE PRESIÓN EN LA ENTRADA DE LA VÁLVULA PROPORCIONAL 
Para un nivel de apertura prefijado la válvula proporcional comienza su maniobra de apertura permitiendo la entrada progresiva de agua al interior del depósito. Esta primera apertura genera una leve oscilación de presión al modificarse las condiciones normales de régimen en la tubería de alimentación al depósito. Para una maniobra de apertura lineal, las oscilaciones se atenúan rápidamente hasta alcanzar la posición de válvula completamente abierta. En esta situación es posible observar una ligera variación asociada al establecimiento de un caudal de entrada prácticamente constante para la apertura total de la válvula. Con posterioridad a la maniobra de arranque la variación de la presión puede ser constante como en la figura, o pueden aparecer oscilaciones de presión si varía la posición de la boya, originándose del mismo modo fluctuaciones del caudal de entrada.

Durante la maniobra de cierre se observa una primera variación de la presión por la modificación del grado de apertura de la válvula. En la carrera de cierre de la válvula se reduce progresivamente el caudal de entrada al depósito, aumentando así la presión en la entrada de la válvula (por la reducción de las pérdidas de carga en el tramo). Esta situación se prolonga hasta el cierre completo de la válvula, momento en el que se aprecia una nueva oscilación de presión derivada de la anulación del caudal de entrada. Al mismo tiempo, las olas en el depósito o la histéresis de la válvula pueden generar ligeras fluctuaciones de presión y variaciones del caudal de entrada al depósito, así como la variación del nivel en su interior por el arranque del grupo.

\subsubsection{Ejemplo de alteraciones de presión de una válvula todo/nada}

En el caso de la válvula todo/nada las solicitaciones suelen ser más bruscas, ya que las variaciones de caudal en la red aumentan considerablemente, principalmente durante las maniobras de apertura y cierre. Para una situación similar a la observada para la válvula proporcional, la magnitud del transitorio de apertura de la válvula todo/nada alcanza una caída de presión considerable (en el caso simulado para un tiempo total de apertura de aproximadamente 1 segundo, se originada una caída de presión de $17 \mathrm{mca}$ ). La magnitud de esta caída de presión es función del tiempo de apertura, pudiéndose alcanzar mayores caídas para tiempos de maniobra más reducidos.

Una vez la válvula alcanza el nivel de cierre fijado se anula el caudal de entrada al depósito a partir de una maniobra brusca similar a la originada en el inicio de la alimentación. Esta situación está acompañada de una sobrepresión que se atenúa hasta estabilizarse por completo. La magnitud de esta sobrepresión es también función del tiempo de maniobra de cierre, alcanzándose mayores presiones para tiempos más reducidos. 


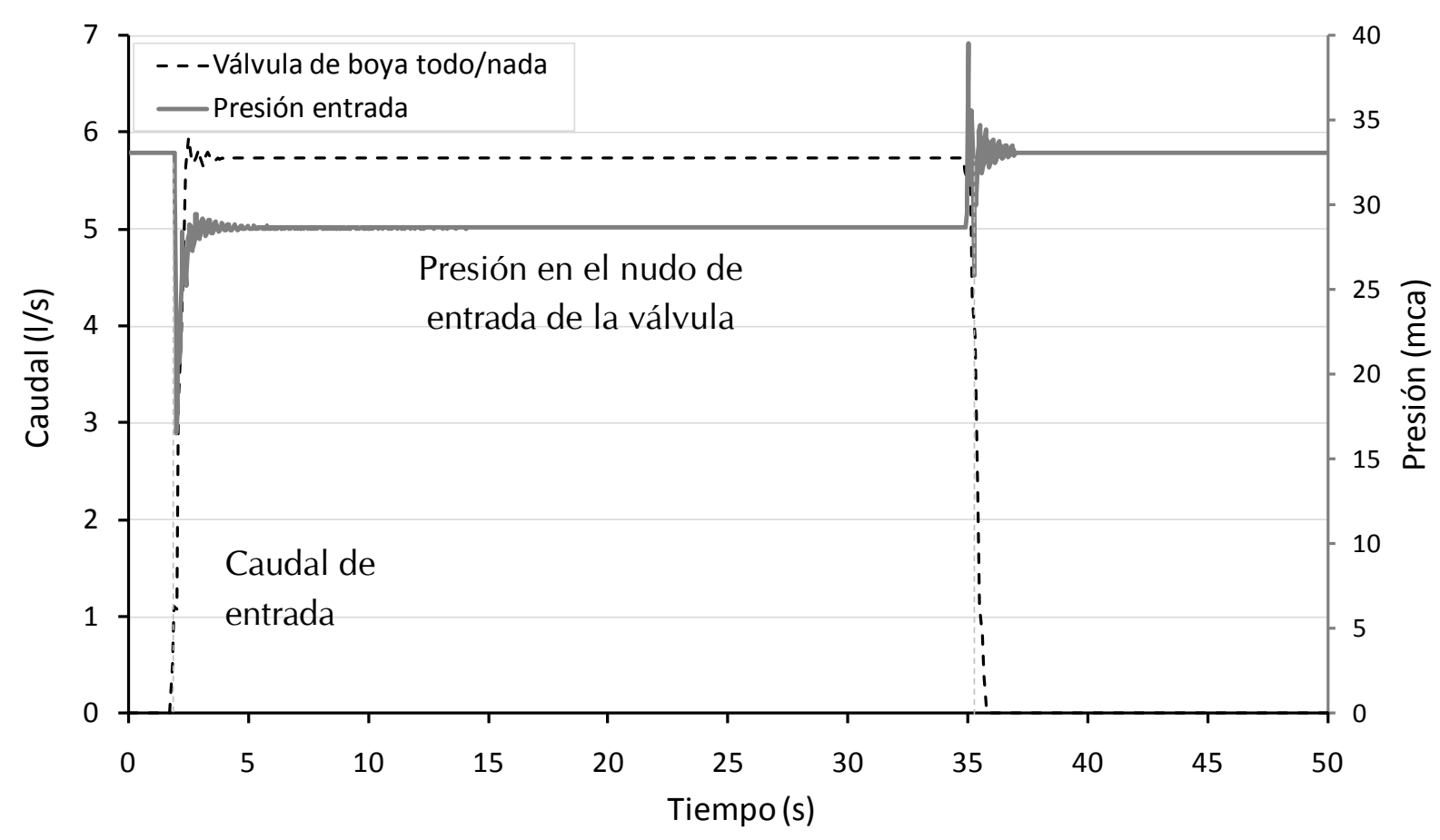

FIGURA A5-4. VARIACIÓN DE PRESIÓN EN LA ENTRADA DE LA VÁLVULA TODO/NADA

\subsection{Simulación de las SOlicitaciones de UNA VÁlvULA de CONTROL DE LLENADO}

Como se ha podido comprobar, las solicitaciones originadas por una válvula de control de llenado pueden ser incluso similares a las originadas por un grupo de presión conectado en directo (válvula todo/nada), por ello es necesario tener presente tanto las alteraciones originadas durante su funcionamiento en régimen transitorio (situación que tiene lugar durante las maniobras de apertura y cierre), como en el funcionamiento en régimen permanente (cuando se estabiliza el caudal trasegado por la válvula). Por ello, para una determinada instalación se deberá tener en cuenta tanto la selección y dimensionado de la válvula, caracterizada por el establecimiento de un determinado caudal para válvula completamente abierta, como su regulación, caracterizada por su maniobra en instantes de apertura y cierre.

Con el programa de cálculo de transitorios Allievi se ha modelado una instalación similar a la monitorizada, con un esquema de conexión indirecta a partir de la interposición de un depósito auxiliar de alimentación (Figura A5-5). En el modelo se edita sólo el comportamiento de una válvula programando diferentes tiempos de apertura, sin incidir en el tipo de válvula. Complementariamente, para simplificar el estudio no se considera la influencia del nivel en el depósito, ni se modifican las características constructivas de la instalación. Tampoco ha sido posible validar la respuesta del modelo al no disponer de datos reales registrados. 


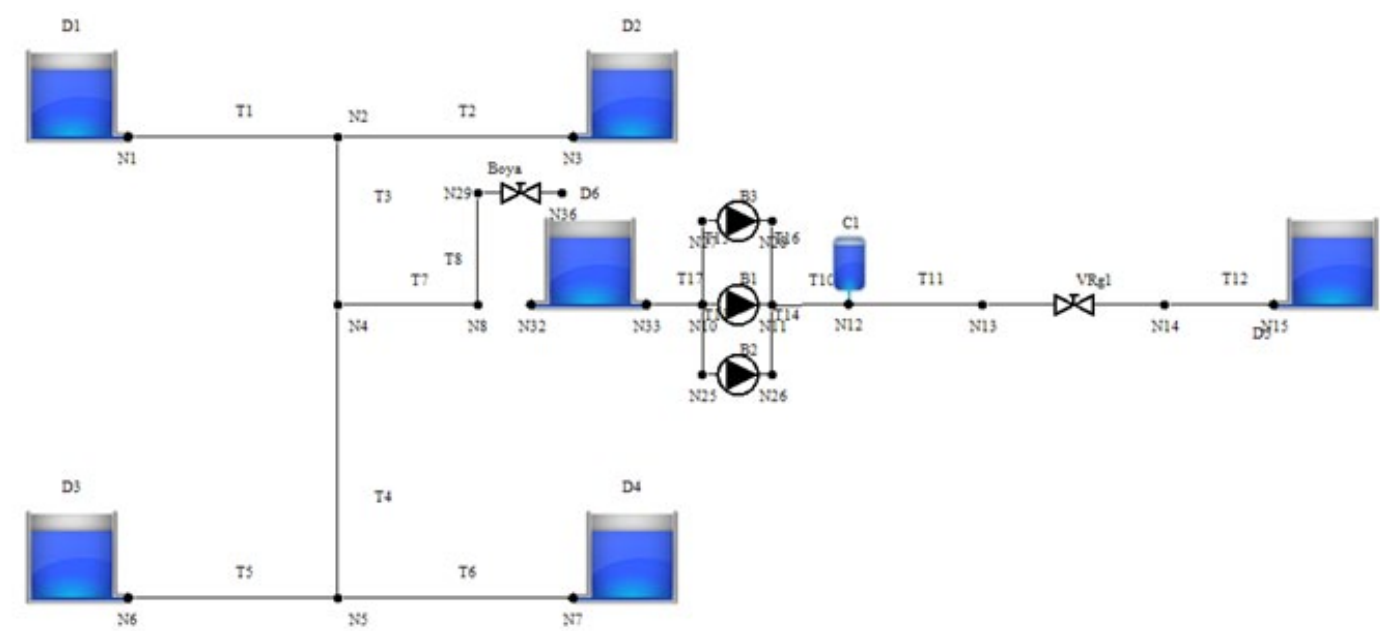

FIGURA A5-5. MODELO DE SIMULACIÓN DE LA INST. DE REFERENCIA CON CONEXIÓN INDIRECTA EN ALLIEVI

\subsubsection{Maniobras en régimen transitorio de la válvula}

Si se analiza la caída de presión para válvulas de diferentes diámetros nominales, en función del tiempo de apertura de la válvula (considerando una maniobra lineal), se observa que mayores tiempos de maniobra reducen significativamente las variaciones de presión que se dan aguas arriba de la válvula (Figura A5-6). La caída de presión se ha considerado como diferencia entre la presión de régimen y la mínima presión originada en el transitorio. Respecto a la evolución de la apertura considerada, es posible que la dinámica real presente evoluciones diferentes, pero para el propósito del presente anexo puede aportar una aproximación suficiente.

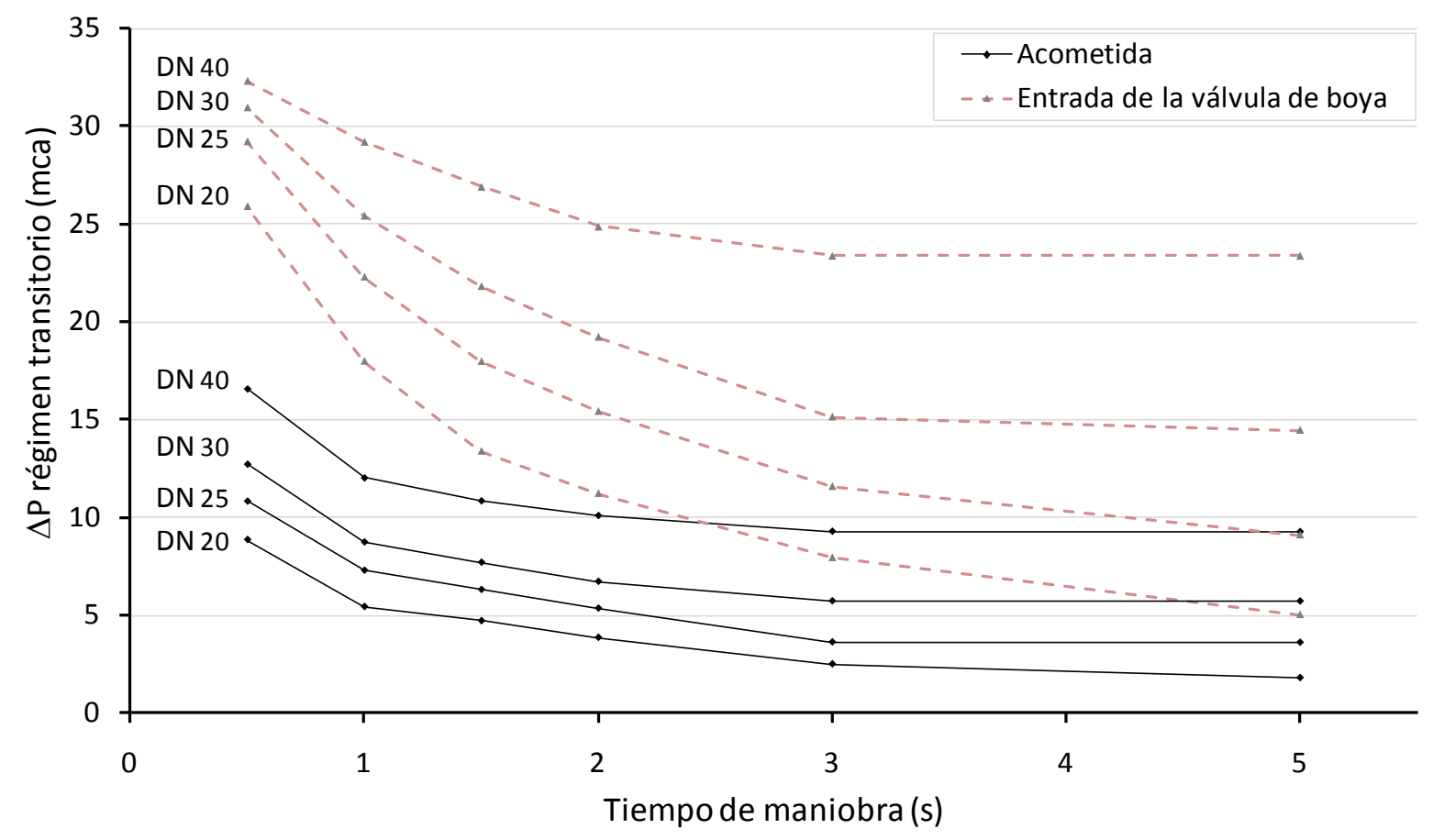

FIGURA A5-6. VARIACIÓN DE PRESIÓN ORIGINADA POR LA MANIOBRA DE UNA VÁLVULA DE LLENADO 
Por otro lado y como puede observarse, a medida que se reduce el diámetro de la válvula también se reducen las solicitaciones de ésta, ya que aumentan las pérdidas de carga en el tramo y con estas se reduce tanto el caudal que circula por el tramo como las variaciones de éste (para un comportamiento lineal como el simulado).

\subsubsection{Régimen permanente}

Una válvula completamente abierta o para determinados grados de apertura (tanto para el tipo proporcional como la todo/nada) puede originar caudales excesivos detraídos a través de la acometida del edificio. Estos caudales además de originar elevadas pérdidas de carga en el tramo, pueden reducir la presión disponible en la acometida, o incluso en la red en zonas próximas al edificio. Esta situación ha Ilevado a algunas instalaciones, principalmente en lo que respecta a grandes consumidores, a interponer elementos que aumenten la pérdida de carga en el tramo, o incluso a instalar elementos de diámetro interior inferior al empleado en otras zonas de la alimentación.

Estas prácticas pueden ser evitadas con una correcta selección del tipo de válvula a instalar, junto con un conveniente dimensionado. Respecto al caudal máximo que aporta la válvula, éste tiene que ser tal que respecte las velocidades normales de dimensionado $(0,5 \mathrm{~m} / \mathrm{s}$ a $2,5 \mathrm{~m} / \mathrm{s}$ para tuberías metálicas), para ello debe prestarse atención al coeficiente de caudal $K_{v o}$ para la válvula completamente abierta.

Para las válvulas proporcionales el caudal máximo puede pasar desapercibido ya que el balance de caudales en el depósito puede impedir el llenado con determinados grados de apertura (si el caudal detraído del depósito se iguala o supera el caudal de entrada). También es importante considerar las variaciones del grado de apertura de la válvula, ya que para un determinado volumen, depósitos más estrechos generarán mayores variaciones de nivel, y por tanto experimentarán mayores recorridos de la boya. Depósitos con mayor superficie por lo general generarán recorridos más lentos.

\subsection{Dimensionado De lOS ELEMENTOS DE LA INSTALACIÓN}

\subsubsection{Depósito auxiliar de alimentación}

El dimensionado de este depósito se puede realizar a partir de la normativa vigente, o a partir de diferentes reglamentaciones en el ámbito local. En esta línea tanto el CTE como la norma UNE 149202 mantienen el mismo criterio de selección en función del caudal de diseño del grupo según:

$$
V_{T}=Q \cdot t \cdot 60
$$

siendo:

$-V_{T}$ el volumen total del recipiente en litros 
-Q es caudal de diseño de la bomba en litros por segundo

- $t$ tiempo en minutos comprendido entre 15 y 20

Es importante remarcar que el criterio utilizado para la determinación de este volumen no se basa en ningún criterio hidráulico, más bien a un criterio práctico a partir del cual se reserva un volumen de agua suficiente que permita el suministro durante la realización de determinadas operaciones de mantenimiento en la instalación, pudiendo por tanto disponer de una garantía adicional de suministro con una duración mínima $t$. Por otro lado, la Comunidad de Madrid dispone de una expresión para el dimensionado de este tipo de elementos en función del número de viviendas $\left(N_{\text {viv }}\right)$ :

$$
V_{T}=100+(N-1) \cdot 50
$$

\subsubsection{Válvula de control de llenado}

Respecto a la selección y dimensionado del elemento control de nivel debe ser tal que garantice variaciones de caudal que no generen perturbaciones significativas, al mismo tiempo que el caudal máximo no produzca una caída de presión elevada en régimen permanente.

Como norma general no es conveniente acudir a una válvula cuyo diámetro nominal coincida con el diámetro nominal de la conducción a la que se conecta, por los elevados caudales que se generarían cuando la válvula estuviese completamente abierta.

\subsection{SituaCiOnES ACONSEjADAS de USO COMO ELEMENTO DE PROTECCIÓN}

Si bien es interesante evitar la conexión indirecta en la instalación interior por los inconvenientes que genera (principalmente en lo relacionado con la calidad de suministro y a la reducción de la eficiencia energética), en algunas instalaciones conviene acudir a este esquema. Las situaciones que inevitablemente conducen al uso de este tipo de conexión son las que se indican a continuación.

- Presión insuficiente en el punto de entrega. Esta situación aplicaría tanto a instalaciones o tramos de la instalación en los que existe una fluctuación importante de la presión para condiciones normales de consumo (influida por ejemplo por la variación horaria de la demanda) o bien en redes que presenten discontinuidad en el suministro (cortes usuales en el suministro). A modo de recomendación se establece una presión mínima de 2 bar en la acometida del edificio para redes con suministro continuo. 
- Excesiva caída de presión en régimen permanente. Como se ha comprobado en el análisis la circulación de caudal por la instalación interior genera pérdidas de carga asociadas a las conducciones y elementos instalados en este tramo. Por ello, una presión reducida en acometida puede verse sensiblemente disminuida en la aspiración de la bomba, favoreciendo la aparición de fenómenos perjudiciales como la cavitación. A modo de recomendación se establece una caída de presión máxima de 1 bar.

- Excesiva caída de presión en régimen transitorio. Es posible que para las características de la instalación y la red general de distribución la caída asociada al arranque de la bomba origine depresiones puntuales durante el funcionamiento de la bomba que puedan conducir a un valor de presión mínima excesivamente bajo en la aspiración del grupo.

- Excesiva sobrepresión en régimen transitorio. La parada del grupo también puede generar una sobrepresión que ponga en riesgo los diferentes elementos de la instalación, principalmente en el caso de fallo eléctrico para caudales elevados. La instalación del depósito reduciría sensiblemente la longitud del tramo expuesto a valores excesivos de presión al mismo tiempo que favorecería la atenuación de la perturbación a partir de las sucesivas ondas reflejadas en la conexión de éste.

\subsection{RECOMENDACIONES DE INSTALACIÓN DEL DEPÓSITO ATMOSFÉRICO}

A continuación se muestra una serie de recomendaciones referidas al depósito atmosférico, algunas de ellas están contempladas en el Pr UNE 149202:

- Se recomienda la instalación de varios vasos que totalicen el volumen de diseño del depósito, de forma que sea posible realizar las labores de mantenimiento sin la necesidad de cortar el suministro a la instalación.

- En el diseño y la selección de los materiales que componen el depósito auxiliar de alimentación se deben tener en consideración las condiciones de servicio y la calidad del agua.

- El espacio en el que estén ubicados los depósitos debe disponer de un drenaje adecuado conectado o no a la red de saneamiento interior del edificio, pero siempre mediante un sifón que asegure el cierre hidráulico, y debe disponer, a su alrededor del espacio suficiente para permitir las operaciones de mantenimiento y conservación que requieran los depósitos auxiliares de alimentación.

- La ubicación de los depósitos auxiliares de alimentación debe ser lo más próxima posible a las bombas teniendo en cuenta en todo momento las 
limitaciones derivadas del NPSHr. Se recomienda la instalación en carga en lugar de la instalación en aspiración negativa.

- El depósito auxiliar de alimentación debe tener un sistema que permita vaciar completamente el mismo a fin de evitar la acumulación de sedimentos, agua estancada y facilitar su vaciado siempre que sea requerido. El sistema de vaciado se hará por la parte inferior del depósito auxiliar.

- Se debe disponer de las válvulas de corte necesarias para aislar el depósito del resto de la instalación, y de las condiciones necesarias para poder proceder a su sustitución

- Los depósitos auxiliares de alimentación deben contar con al menos una boca de hombre de diámetro mínimo $400 \mathrm{~mm}$ para facilitar el acceso y las labores de limpieza y mantenimiento. Contará en cualquier caso con tapa hermética asegurada contra el deslizamiento.

- Estos depósitos incorporarán un rebosadero equipado con un dispositivo que impida la entrada de animales. La descarga del rebosadero deberá ser visible y no podrá estar conectado directamente con la red de saneamiento, pero deberá verter sobre el desagüe con sifón del recinto, el cual deberá estar conectado a la red de saneamiento.

- Los depósitos dispondrán de sistemas de aireación de forma que se permita la ventilación de los mismos. Debe contar con un dispositivo que impida la entrada de cuerpos extraños o animales. Se recomienda también que cuente con dispositivos tranquilizadores con el fin de evitar la agitación del agua almacenada.

- Los depósitos auxiliares de alimentación deberán ser opacos para evitar el crecimiento de algas y deberán ser estancos e impermeables.

- La entrada del agua y la toma de las bombas deben estar en lados opuestos, para procurar la circulación y renovación del agua dentro de los depósitos, acción que se puede potenciar mediante tabiques-guía que hagan serpentear el agua, evitando caminos preferentes.

- Las esquinas verticales y horizontales estarán redondeadas, para facilitar el movimiento del agua, facilitar la limpieza y evitar zonas de sedimentación y acumulación de residuos.

- Las zonas de succión de las bombas deben estar separadas de forma que se eviten los efectos de interacción de los remolinos de una bomba con la otra. Deben tener una distancia mínima de $100 \mathrm{~mm}$ a la base del depósito de manera que se evite la entrada de sedimentos al equipo de presión y para mejorar las condiciones de aspiración. 
Anexo 6

Fundamentos del cálculo transitorio de ALLIEVI 


\subsection{INTRODUCCIÓN}

Para la simulación y análisis de los efectos transitorios generados con esquemas de aspiración directa en las instalaciones interiores de los edificios, se ha acudido al programa de simulación de transitorios hidráulicos Allievi. Este paquete informático ha sido desarrollado por el Grupo de Ingeniería y Tecnología del Agua (Universitat Politècnica de València). A continuación se añade una idea básica sobre el fenómeno transitorio, al mismo tiempo que se especifican las consideraciones más importantes del programa Allievi, particularizando éstas al modelo de simulación realizado.

\subsection{Fundamentos del CÁlCulo transitorio de AllieVI}

\subsubsection{Ecuaciones fundamentales del modelo elástico}

En un conducto a presión, el transitorio hidráulico se modela según las ecuaciones de conservación de masa y de cantidad de movimiento, aplicadas a un volumen de control que incluye la onda de presión que se mueve a lo largo de la conducción. De aquí se obtiene un sistema de dos ecuaciones diferenciales no lineales con dos incógnitas, siendo éstas la altura piezométrica $H=H(x, t)$ y la velocidad $V=V(x, t)$, para los diferentes instantes de tiempo y posiciones dentro de la conducción. La forma de este sistema de ecuaciones es la siguiente:

$$
\begin{gathered}
\frac{\partial H}{\partial t}+V \frac{\partial H}{\partial x}+\frac{a^{2}}{g} \frac{\partial V}{\partial x}=0 \\
\frac{\partial V}{\partial t}+V \frac{\partial V}{\partial x}+g \frac{\partial H}{\partial x}+f \frac{V|V|}{2 D}=0
\end{gathered}
$$

donde $f$ representa el factor de fricción de Darcy-Weisbach, g la aceleración de la gravedad, y a la celeridad de la onda de presión. Se trata pues de las ecuaciones generales que forman parte del modelo completo que gobierna el transitorio hidráulico. 
Estableciendo como hipótesis simplificativas del modelo completo el valor constante de la celeridad, las reducidas variaciones de densidad y de sección de tubería (dada la limitada compresibilidad de los líquidos, así como la elasticidad de las tuberías), y refiriéndola al caudal $Q$, en lugar de la velocidad $V$, puesto que esta primera variable es una de las incógnitas del problema, es posible formular las clásicas ecuaciones del golpe de ariete, conocido como modelo simplificado, según:

$$
\begin{gathered}
\frac{\partial H}{\partial t}+\frac{a^{2}}{g \cdot A} \frac{\partial Q}{\partial x}=0 \\
\frac{\partial Q}{\partial t}+g \cdot A \cdot \frac{\partial H}{\partial x}+f \frac{Q|Q|}{2 \cdot D \cdot A}=0
\end{gathered}
$$

Para el cálculo del régimen transitorio en tuberías a presión el programa Allievi aplica el Método de las Características. Como el sistema de ecuaciones anterior no tiene solución analítica, para su integración el procedimiento habitual es admitir que la solución se obtendrá en instantes de tiempo determinados (separados entre sí un $\Delta t$ ) y en puntos concretos sobre la conducción (separados entre sí un $\Delta x$ ), cumpliéndose:

$$
\frac{\Delta x}{\Delta t}=a
$$

Del mismo modo se define el número de tramos Ntr en los que divide la conducción según:

$$
N \operatorname{tr}=\frac{L}{\Delta x}=\frac{L}{a \cdot \Delta t}
$$

Las ecuaciones diferenciales anteriores se transforman en un sistema de dos ecuaciones algebraicas, lineales, con dos incógnitas, de la forma:

$$
\begin{aligned}
& H_{i}^{n+1}-H_{i-1}^{n}+\frac{a}{g \cdot A}\left(Q_{i}^{n+1}-Q_{i-1}^{n}\right)+\frac{f_{i-1}^{n} \Delta x}{2 \cdot g \cdot D \cdot A^{2}} Q_{i-1}^{n}\left|Q_{i-1}^{n}\right|=0 \\
& H_{i}^{n+1}-H_{i+1}^{n}-\frac{a}{g \cdot A}\left(Q_{i}^{n+1}-Q_{i+1}^{n}\right)-\frac{f_{i+1}^{n} \Delta x}{2 \cdot g \cdot D \cdot A^{2}} Q_{i+1}^{n}\left|Q_{i+1}^{n}\right|=0
\end{aligned}
$$

con las que se puede calcular la altura piezométrica $H$ y el caudal $Q$ en el punto $i$ de la tubería y en el instante de cálculo $n+1$, a partir de los valores de $H$ y $Q$ de los puntos $i$ 1 e $i+1$ en el instante $n$, y así resolver el sistema. 
Al mismo tiempo, y para simplificar las ecuaciones anteriores, es posible realizar el siguiente cambio de variable:

$$
\begin{gathered}
C_{a}=\frac{a}{g \cdot A} \\
C_{i-1}^{n}=H_{i-1}^{n}+\frac{a}{g \cdot A} \cdot Q_{i-1}^{n}-\frac{f_{i-1}^{n} \Delta x}{2 \cdot g \cdot D \cdot A^{2}} Q_{i-1}^{n}\left|Q_{i-1}^{n}\right| \\
C_{i+1}^{n}=H_{i+1}^{n}-\frac{a}{g \cdot A} \cdot Q_{i+1}^{n}+\frac{f_{i+1}^{n} \cdot \Delta x}{2 \cdot g \cdot D \cdot A^{2}} Q_{i+1}^{n}\left|Q_{i+1}^{n}\right|
\end{gathered}
$$

Con todo ello, el sistema de ecuaciones anterior resultaría:

$$
\begin{aligned}
& H_{i}^{n+1}+C_{a} \cdot Q_{i}^{n+1}=C_{i-1}^{n} \\
& H_{i}^{n+1}-C_{a} \cdot Q_{i}^{n}=C_{i+1}^{n}
\end{aligned}
$$

\subsection{MODELACIÓN DE LAS CONDICIONES DE CONTORNO}

El sistema de ecuaciones anterior se puede resolver para todos los puntos de cálculo de cualquier conducto excepto en sus extremos. En dichos extremos, donde se supone que la tubería se conecta con algún elemento del sistema, la ecuación que falta se sustituye por la ecuación, o conjunto de ecuaciones, que representan el comportamiento de dicho elemento, y que se denominan condiciones de contorno.

En Allievi el sistema hidráulico a simular está constituido por elementos, los cuales se interconectan entre sí a través de sus nudos. En general, cada elemento dispone de dos nudos, uno inicial o de entrada y otro final o de salida, de manera que el sentido positivo del caudal en cada elemento se establece cuando circula desde el nudo inicial hasta el nudo final. De modo general, los tipos de elementos considerados por el programa son los siguientes:

- Depósitos

- Tuberías

- Estaciones de bombeo

- Turbinas

- Estructuras de protección

- Estructuras de control de caudal

- Conductos en lámina libre

- Leyes de caudal $(\mathrm{Q})$ o de altura $(\mathrm{H})$ 
Para la descripción de las condiciones de contorno se acude a la siguiente ecuación de nudo (Betâmio de Almeida y Koelle, 1992):

$$
\mathrm{Q}_{N d}^{n+1}+B_{N d} \cdot H_{N d}^{n+1}=E_{N d}^{n}
$$

en la que se ha hecho el siguiente cambio de variable a modo general para un nudo en el que confluyen varias tuberías (según Figura A6-1):

$$
\begin{gathered}
E_{N d}^{n}=\frac{C_{N t r A-1}^{n}}{C_{A}}+\frac{C_{N t r B-1}^{n}}{C_{B}}+\ldots+\frac{C_{1 C}^{n}}{C_{C}}+\frac{C_{1 D}^{n}}{C_{D}}+\ldots \\
B_{N d}=\frac{1}{C_{A}}+\frac{1}{C_{B}}+\frac{1}{C_{C}}+\frac{1}{C_{D}}+\ldots
\end{gathered}
$$

Como se observa en la figura, algunas de estas conducciones están conectadas aguas arriba según el sentido de circulación del flujo (A y B) y otras conectadas aguas abajo (C y D), aspecto a tener en cuenta según la designación en la Ec. 67.

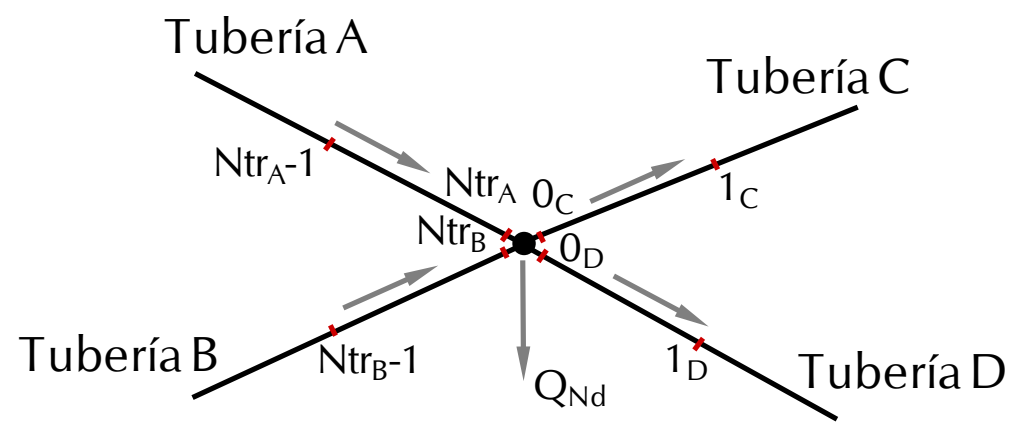

FIGURA A6-1. REPRESENTACIÓN DE UN NUDO EN EL QUE CONFLUYEN 4 TUBERÍAS

A continuación se describirán las propiedades asociadas a los nudos y elementos editables en el programa, particularizando sólo para aquellos que han sido implementados en el modelo del edificio monitorizado.

\subsection{Nudos}

La característica de cada nudo se reduce a su cota, expresada ésta a partir de un nivel de referencia determinado (el resto de coordenadas se fijan indirectamente cuando se editan los elementos conectados a éste). 


\subsection{DePÓsıtos}

Los depósitos son elementos del sistema donde se almacena agua a presión atmosférica. Los tipos de depósitos incluidos en el programa son:

- Depósitos de grandes dimensiones o de nivel constante (GD)

- Depósitos de pequeñas dimensiones (PD)

- Depósitos de sección variable

- Depósitos con división y vertedero

De los depósitos indicados el de grandes dimensiones es el único utilizado en el desarrollo de la presente Tesis. Este depósito mantiene su nivel inalterable durante la simulación independientemente de los caudales de entrada y de salida que se establezcan (valor fijado en el programa para editar su comportamiento). Del mismo modo se utiliza este valor para calcular el régimen permanente.

Se puede considerar un depósito de nivel constante cuando la línea de altura piezométrica $H_{\text {dep }}$ puede asumirse constante durante el tiempo de duración del transitorio. Bajo esta suposición las ecuaciones que se dan en los nudos de dicho elemento son (siendo $n$ el instante de tiempo y ent y sal los puntos $i$ extremos):

NUDO DE ENTRADA:

$$
Q_{\text {ent }}^{n+1}=E_{\text {ent }}^{n}-B_{\text {ent }} \cdot H_{\text {dep }}
$$

NUDO DE SALIDA:

$$
Q_{s a l}^{n+1}=-E_{s a l}^{n}+B_{\text {sal }} \cdot H_{\text {dep }}
$$

\subsection{TUBERÍAS}

Las características que definen las tuberías en el programa Allievi son su longitud, diámetro, rugosidad absoluta (calculadas las pérdidas en los modelos a partir de la ecuación de Darcy, estimando el factor de fricción mediante la fórmula de Colebrook), el coeficiente de pérdidas menores $k$ adimensional, y su celeridad. Respecto a esta última para algunas conducciones se ha calculado en función de sus características particulares, y para otras se ha fijado valores usuales.

La celeridad se ha calculado a partir del diámetro interior de la tubería, del espesor de pared y de las características propias del material, según la expresión (Korteweg, 1878):

$$
a=\frac{\sqrt{\frac{K}{\rho}}}{\sqrt{1+\frac{K}{E} \frac{D}{e}}}
$$


En el caso concreto del agua $\left(K=2,2 \cdot 10^{9} \mathrm{~N} / \mathrm{m}^{2}\right.$ y $\left.\rho=1000 \mathrm{Kg} / \mathrm{m}^{3}\right)$, la expresión para el cálculo de la celeridad queda función de las características propias de la conducción (espesor e, diámetro $D$ y módulo elástico $E$ ):

$$
a=\frac{1440}{\sqrt{1+\frac{2.2 \cdot 10^{9}}{E} \frac{D}{e}}}
$$

\subsection{VÁLVULAS}

Las estructuras de control de caudal están constituidas básicamente por válvulas u otros componentes que intervienen en el caudal que circula por las conducciones. Los elementos que se consideran estructuras de control de caudal son los siguientes:

- Válvulas de regulación

- Válvulas de retención

- Válvulas de alivio

- Válvulas de sobrevelocidad

- Pérdidas de carga localizadas

- Inyector

- Válvulas compuestas

- Válvulas automáticas

En el modelo elaborado sólo se ha utilizado aisladamente la válvula de regulación. No obstante también se describe la válvula de retención aunque ésta se ha asociado a la propia estación de bombeo.

\subsubsection{Válvula de regulación}

La válvula de regulación permite modificar el caudal circulante por la instalación. Sus características principales son: cota, diámetro nominal, coeficiente de pérdidas $k$ del ramal (coeficiente de pérdidas adimensional del ramal donde está conectada la válvula), tipo de válvula (el programa distingue entre varias tipologías) y maniobra.

Sobre esta última propiedad, es posible efectuar maniobras de cierre y/o apertura durante la simulación del transitorio. Estas maniobras pueden editarse de forma tabulada o mediante expresiones sinusoidales. A partir de una maniobra tabulada es posible definir evoluciones lineales, parabólicas u otras, si bien hay que tener presente que el programa realiza una interpolación lineal entre cada dos posiciones tabuladas.

En el modelo creado se ha acudido a la primera de las posibilidades fijando una apertura determinada para garantizar el caudal deseado. En el caso de analizar una apertura de válvula se ha seguido una evolución lineal entre dos posiciones. 
Las ecuaciones de contorno en los nudos extremos de la válvula son:

NUDO DE ENTRADA:

NUDO DE SALIDA:

$$
Q_{v a l}^{n+1}=E_{\mathrm{ent}}^{n}-B_{\mathrm{ent}} \cdot H_{\mathrm{ent}}^{n+1}
$$

$$
Q_{v a l}^{n+1}=-E_{s a l}^{n}+B_{\text {sal }} \cdot H_{\text {sal }}^{n+1}
$$

Por otro lado, la ecuación de pérdidas en la válvula (función del coeficiente de pérdidas $K$ que a su vez depende del grado de apertura $\tau$ ), resulta:

$$
H_{\mathrm{ent}}^{n+1}-H_{\mathrm{sal}}^{n+1}=K\left(\tau_{\mathrm{val}}^{n+1}\right) \cdot Q_{\mathrm{val}}^{n+1} \cdot\left|Q_{\mathrm{val}}^{n+1}\right|
$$

\subsubsection{Válvula de retención}

La válvula de retención impide el flujo inverso en una conducción, de forma que si la altura piezométrica a su entrada es superior a la altura piezométrica aguas abajo de ésta, $H_{\text {ent }}>H_{\text {sal }}$, su comportamiento es similar al de una válvula de regulación con un coeficiente $K$ de pérdidas (seguiría por tanto las ecuaciones. 73, 74 y 75).

Si por el contrario, la altura piezométrica a la entrada es inferior, $H_{\text {ent }}<H_{\text {sal }}$, la válvula en este caso permanecerá cerrada, siendo el caudal por el interior de la misma nulo, $Q_{v a l}^{n+1}=0$. En tal caso las ecuaciones de contorno en los nudos extremos de la válvula serían:

NUDO DE ENTRADA:

$$
H_{\mathrm{ent}}^{n+1}=\frac{E_{\mathrm{ent}}^{n}}{B_{\mathrm{ent}}}
$$

NUDO DE SALIDA:

$$
H_{\text {sal }}^{n+1}=\frac{E_{s a l}^{n}}{B_{s a l}}
$$

\subsection{ESTACIONES DE BOMBEO}

\subsubsection{Bombas}

El programa permite introducir las características de las bombas a partir de su curva de altura $H_{b}=H_{b}\left(Q_{b}\right)$ y de su curva de potencia de accionamiento $P_{\text {acc }}=P_{a c c}\left(Q_{b}\right)$. Estas curvas se editan de forma tabulada y el programa realiza una interpolación lineal entre cada dos posiciones tabuladas. Adicionalmente el programa permite trabajar con curvas Universales tal como se verá más adelante.

En los diferentes modelos desarrollos en la Tesis se ha acudido a valores de catálogos comerciales, ya que además de disponer de las curvas comerciales, en el 
funcionamiento normal de éstas no llegan a operar con valores negativos de caudal, altura o velocidad de rotación (fuera del primer cuadrante).

En cualquier otro caso, si se opta por trabajar con curvas universales, el programa Allievi acude a las curvas de Marchal, Flesch y Suter para un total de 14 valores de la velocidad específica (estas curvas permiten caracterizar el comportamiento de las bombas en cualesquiera condiciones de funcionamiento). Para tal caso, se definen los parámetros adimensionales siguientes (Abreu et al., 2012):

$$
h=\frac{H_{b}}{H_{b 0}} ; \quad q=\frac{Q_{b}}{Q_{b 0}} ; \quad \alpha=\frac{N}{N_{0}} ; \quad \beta=\frac{M_{b}}{M_{b 0}}
$$

donde $H_{b}$ es la altura que crea la bomba, $Q_{b}$ el caudal bombeado, $N$ la velocidad de rotación y $\mathrm{Mb}$ el par en el eje de accionamiento de la bomba. Con el subíndice 0 se indican los valores en el punto óptimo de la bomba, o punto de máximo rendimiento. La relación entre estos parámetros adimensionales se representa según:

$$
\frac{h}{\alpha^{2}+q^{2}}=f_{h}\left[\operatorname{arctg}\left(\frac{\alpha}{q}\right)\right] \quad ; \quad \frac{\beta}{\alpha^{2}+q^{2}}=f_{\beta}\left[\operatorname{arctg}\left(\frac{\alpha}{q}\right)\right]
$$

donde $f_{h}$ y $f_{\beta}$ son funciones tabuladas para 14 valores de la velocidad específica dada por la relación (siendo $\omega$ es la velocidad de rotación de la bomba en rad/s):

$$
N_{s}=\frac{\omega \sqrt{Q_{b 0}}}{\left(g H_{b 0}\right)^{3 / 4}}
$$

Los datos necesarios para caracterizar la bomba corresponden al punto óptimo de funcionamiento (o punto de rendimiento máximo) a la velocidad de rotación nominal (Qbo, $\mathrm{H}_{\mathrm{b} 0}$ y $\left.\mathrm{P}_{\mathrm{acc}}\right)$.

Respecto a la inercia de cada grupo (momento de inercia de las masas rodantes que incluye el rodete, el eje y el rotor del motor de accionamiento), es posible fijar el valor real si éste es conocido o bien el programa proporciona una estimación utilizando la fórmula de Thorley (para los análisis se ha acudido a esta segunda opción).

$$
I=0^{\prime} 03768 \cdot\left(\frac{P}{N^{3}}\right)^{0^{\prime} 9556}+0^{\prime} 0043 \cdot\left(\frac{P}{N}\right)^{\prime \prime 48}
$$

donde $I$ es el momento de inercia del grupo en $\mathrm{Kg} \cdot \mathrm{m}^{2}, P$ la potencia nominal de la bomba en $\mathrm{Kw}$, y $\mathrm{N}$ la velocidad de rotación nominal en miles de rpm (en la expresión anterior el primer término del segundo miembro representa el momento de inercia de rodete y eje, y el segundo término del segundo miembro el momento de inercia del rotor del motor eléctrico de accionamiento). 


\subsubsection{Válvulas del grupo}

Del mismo modo, el programa permite asociar diferentes tipos de válvulas a la estación de bombeo (regulación, by-pass y retención). De entre ellas, la única modelada es la válvula de retención, cuyas características se han descrito anteriormente. En cualquier caso, se debe tener presente que en Allievi los grupos de bombeo con curvas ajustadas han de disponer en todos los casos de válvula de retención, y los grupos con curvas universales pueden disponer o no de esta válvula.

\subsection{ESTRUCTURAS DE PROTECCIÓN}

Las estructuras de protección se utilizan para reducir las oscilaciones de presión una vez se ha generado el transitorio. En general almacenan un determinado volumen de agua, y funcionan aportando caudal a la conducción principal en el momento en que se reduce el caudal circulante. Posteriormente al cambiar el sentido del caudal, éste se va introduciendo dentro de la estructura de protección con lo que su frenado es más lento. De esta manera los cambios de caudal en la tubería principal se ralentizan, reduciéndose con ello las oscilaciones de presión. Los tipos de estructuras de protección incluidos en el programa son:

- Chimenea de equilibrio

- Tanque unidireccional

- Depósito hidroneumático o calderín

- Chimenea diferencial

- Chimenea de sección variable

El fundamento de protección presentado en la Tesis acude a la incorporación de uno o varios calderines en la aspiración de la bomba, así como el calderín en la impulsión del grupo.

\subsubsection{Depósito hidroneumático o calderín}

Para la definición de esta estructura de protección en el programa Allievi se definen las siguientes propiedades: número de calderines (vasos que forman la protección, todos ellos de iguales propiedades y con conexión paralela), dimensiones (a partir del diámetro interior y longitud), rugosidad interior, presión de hinchado, cota de la base, posición (se distingue entre posición vertical y horizontal) y tipo de calderín (con o sin vejiga).

Respecto a esta última propiedad en los modelos se ha acudido a calderín con vejiga (en lugar de calderín con contacto aire-agua), ya que la normativa actual exige esta disposición por la mejora asociada a la calidad del agua. En principio el comportamiento de ambos calderines es el mismo mientras no se vacíen de agua 
durante el funcionamiento en régimen transitorio. Para el caso de vaciado, si el calderín es con vejiga en el momento del vaciado dicha vejiga cierra el orificio de conexión del calderín con la tubería de entronque. En este momento se interrumpe bruscamente la alimentación de la tubería principal desde el calderín, creándose con ello una onda de depresión que puede someter a dicha tubería a presiones negativas. Posteriormente, en la fase sobrepresiva del transitorio el agua puede volver a entrar al calderín y repetirse el ciclo según cómo evolucione el transitorio.

La presión de hinchado (en caso de calderín con vejiga) es la presión a la que hay que hinchar la vejiga antes de la puesta en obra de dicho calderín. Para el calderín sin vejiga, el hinchado se realizará cerrando una válvula en la boca de conexión del calderín (posteriormente, esta válvula se abrirá una vez esté la instalación en marcha y las bombas funcionando a régimen). Para el cálculo de la presión de hinchado el programa acude a la Ec. 32 mostrada en el Capítulo 5.

\subsubsection{Datos del ramal de unión}

Los datos del ramal de unión entre la tubería principal y la estructura de protección son su longitud, diámetro interior, rugosidad absoluta de las paredes interiores del ramal de unión y los coeficientes de pérdidas de entrada y salida del calderín, siguiendo las ecuaciones 33 y 34.

\subsubsection{Condiciones de contorno del calderín}

Las condiciones de contorno que utiliza Allievi son (siendo $N_{d}$ el nudo de conexión de la estructura a la tubería, $h_{c}$ el nivel del agua desde el eje de la conducción, $Z_{N d}$ la cota del nudo $N_{d}$ y $P_{g}$ la presión del gas):

$$
\text { NUDO DE CONEXIÓN: } \quad Q_{C}^{n+1}=E_{N d}^{n}-B_{N d} \cdot H_{N d}^{n+1}
$$

Por otro lado, la ecuación de pérdidas en el calderín es:

$$
H_{N d}^{n+1}=Z_{N d}+h_{C}^{n+1}+\frac{P_{g}^{n+1}}{\gamma}+K \cdot Q_{C}^{n+1} \cdot\left|Q_{C}^{n+1}\right|
$$

El valor del coeficiente de pérdidas $K$ depende del ciclo de operación, distinguiéndose:

LLENADO:

$$
K=K_{\mathrm{e}} \quad \text { si } \mathrm{Q}_{\mathrm{C}}^{n+1}>0\left(\mathrm{Q}_{\mathrm{e}}>0\right)
$$

VACIADO:

$$
K=K_{s} \quad \text { si } Q_{C}^{n+1}<0 \quad\left(Q_{s}>0\right)
$$


Adicionalmente el programa considera la evolución del gas en el interior del calderín, según la siguiente expresión:

$$
\left(\frac{P_{g}^{n+1}}{\gamma}+\frac{P_{a t m}}{\gamma}\right)\left(\forall_{g}^{n+1}\right)^{\gamma}=\left(\frac{P_{g 0}}{\gamma}+\frac{P_{a t m}}{\gamma}\right)\left(\forall_{g 0}\right)^{\gamma}
$$

siendo $P_{\text {atm }}$ la presión atmosférica, $\forall_{g}$ el volumen del gas en el interior del calderín y $\gamma$ el coeficiente que tiene en cuenta el tipo de evolución ( $\gamma=1$ para evolución isoterma, 1,4 para una evolución adiabática, y 1,2 para evolución politrópica).

Finalmente, la ecuación para completar el modelo del calderín asociada a las condiciones de continuidad en el nudo de conexión es:

$$
\frac{Q_{c}^{n}+Q_{c}^{n+1}}{2} \Delta t=A_{c}\left(h_{c}^{n+1}-h_{c}^{n}\right) ; \quad \forall_{g}^{n+1}=\forall_{c a l d}-A_{c}\left(h_{c}^{n+1}-h_{b}\right)
$$

siendo $h_{b}$ la diferencia de cotas entre la base del calderín y el punto de entronque en la tubería tal como se detalla en la Figura A6-2.

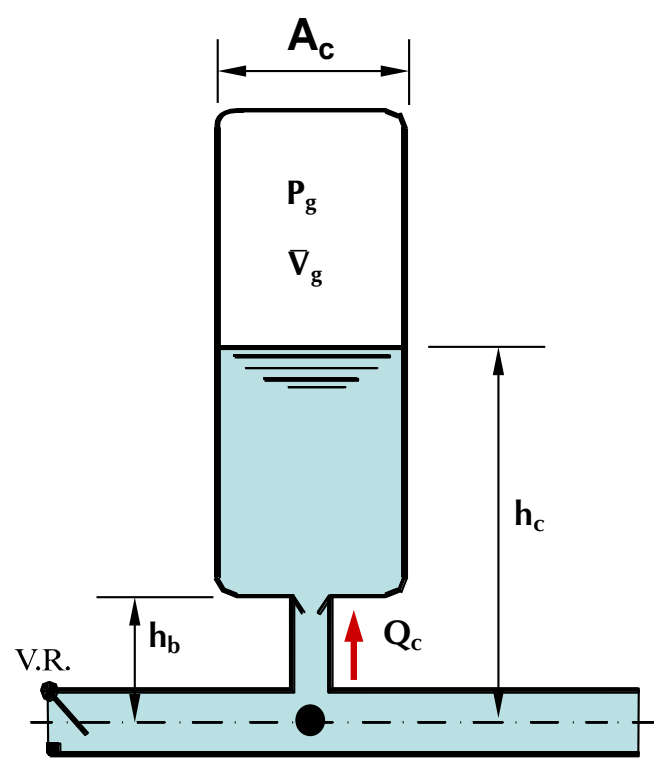

Nudo Nd

FIGURA A6-2. SECCIÓN DE UN CALDERÍN

\subsection{CÁlCULO DEL RÉGIMEN PERMANENTE}

En un sistema hidráulico, el régimen transitorio se inicia a partir del régimen permanente cuando se produce una maniobra en alguno de los elementos del sistema. En el programa Allievi, el régimen permanente se obtiene procesando el cálculo del régimen transitorio a partir de unas condiciones de funcionamiento cualesquiera, con los elementos del sistema en las posiciones iniciales y sin efectuar maniobras. Cuando en este cálculo se obtiene unas condiciones de funcionamiento que no varían en el 
tiempo, estas condiciones se adoptan como valores de partida para iniciar el cálculo del régimen transitorio. 
Anexo 7

\author{
Notación, \\ definiciones y simbología
}




\subsection{Notación}

a. Celeridad.

A. Área.

BVF. Bomba de velocidad fija.

BVV. Bomba de velocidad variable (bomba equipada con variador de frecuencia).

$\mathrm{C}^{-} \quad$ Característica negativa.

$\mathrm{C}^{+} \quad$ Característica positiva.

D Diámetro.

DN Diámetro nominal.

$\Delta p . \quad$ Caída de presión. Variación de presión.

$\Delta t . \quad$ Incremento en el tiempo.

$\Delta x . \quad$ Incremento en el espacio.

E. Módulo de Young.

$\varepsilon$. Espesor de la conducción.

f. Factor de fricción.

g. Aceleración gravitatoria.

$\gamma$. Coeficiente politrópico (dinámica de un gas)

H. Altura piezométrica.

$H_{b}$. Altura de bombeo aportada por una bomba.

$h_{f}$ Pérdidas de carga por fricción.

Hr. Altura resistente en una instalación. 
In. Intensidad nominal.

j. $\quad$ Pendiente hidráulica (pérdidas de carga unitarias).

k. $\quad$ Coeficiente de pérdidas menores.

Ka. $\quad$ Coeficiente de simultaneidad en función del número de aparatos (también $K_{1}$ ).

$K_{v}$. Coeficiente de simultaneidad en función del número de viviendas (también $\left.K_{2}\right)$.

K. $\quad$ Coeficiente de pérdidas de una válvula

k. $\quad$ Coeficiente de pérdidas de una válvula (adimensional)

L. Longitud.

nap. Número de aparatos de una instalación.

Nb. Velocidad de giro de una bomba.

Nviv. Número de viviendas de una instalación.

P. Potencia.

PID. Controlador Proporcional Integral Derivativo (asociado al variador de frecuencia).

$P$ asp. Presión en la aspiración de una bomba.

P imp. Presión en la impulsión de una bomba.

$P_{\text {ser. }} \quad$ Presión de servicio (presión de entrega en acometida).

Q. Caudal.

Qb. Caudal de una bomba.

$\bar{q}$. Demanda base (caudal promedio consumido por un usuario en un determinado periodo de tiempo.

s. $\quad$ Coeficiente de trasmisión.

$\rho . \quad$ Densidad.

RGD. Red General de Distribución.

r. Coeficiente de reflexión.

t. Tiempo.

$\forall$. Volumen

v. Velocidad.

VB. Visual Basic 


\subsection{DefiniCiOneS}

Acometida. Tubería que enlaza la red general de distribución con la instalación interior del edificio. Pertenece a la red de distribución.

Alimentación directa. Conexión directa entre la red pública de abastecimiento y la instalación particular del abonado (no hay interposición de ningún elemento como depósito atmosférico o calderín).

Ascendente o montante. Tubería que une verticalmente el distribuidor principal con las instalaciones interiores particulares o derivaciones colectivas, en edificios de propiedad múltiple.

Bomba de velocidad fija (BVF). Grupo de sobreelevación que permite disponer de una presión mayor que la proporciona por la red de distribución a partir del acople directo de un motor eléctrico y una bomba hidráulica.

Bomba de velocidad variable $(B V V)$. Grupo motobomba equipado con variador de frecuencia que permite una regulación de la velocidad de giro del motor. Definido en el CTE como grupo de accionamiento regulable o caudal variable.

By-pass. Desvío hecho en un circuito. Principalmente hace referencia al desvío hecho al grupo de presión para el aprovechamiento de la presión en red.

Calderín. Depósito a presión hidroneumático, cuya finalidad es evitar el arranque continuado del equipo de bombeo, o la protección contra efectos transitorios cuanto se instala en la aspiración del grupo.

Caudal de cálculo o caudal simultáneo (Qc). Caudal que se produce por el funcionamiento lógico y calculado simultáneo de aparatos de consumo o unidades de suministro. Caudal máximo probable de utilización por un conjunto de usos. 
Caudal instantáneo (Qinst). Volumen de agua suministrada por unidad de tiempo por un determinado aparato o tramo de la instalación.

Caudal total instalado ( $Q_{T}$ ). Caudal correspondiente a la suma de los caudales instantáneos de todos los aparatos conectados aguas abajo del tramo considerado. En el caso de un edificio es el caudal total instalado en éste.

Cavitación. Fenómeno físico por el que se produce la vaporización espontánea del agua como consecuencia del descenso local de la presión hasta alcanzar la tensión de vapor. Cuando se recupera la presión, se produce una condensación brusca, que llega a causar daños importantes en los equipos.

Coeficiente de simultaneidad de aparatos $\left(K_{\mathrm{a}}\right)$. Factor que tiene en cuenta la simultaneidad en el uso en función del número de aparatos instalados en un tramo.

Coeficiente de simultaneidad de viviendas $\left(K_{v}\right)$. Factor que tiene en cuenta la simultaneidad en el uso en función del número de viviendas servidas por un tramo.

Curva de modulación de la demanda. Conjunto de factores que tienen en cuenta el carácter variable de la demanda. La demanda resultante para un periodo es el producto de la demanda media por el factor correspondiente de la curva de modulación.

Demanda base o demanda media. Volumen de agua promedio consumida durante un determinado tiempo.

Depósito atmosférico o auxiliar. Depósito instalado en la alimentación de los grupos de bombeo, donde se realiza la succión de agua por las bombas sin hacerlo directamente de la red exterior. También llamado comúnmente aljibe.

Depósito auxiliar presurizable (condensador hidráulico). Es un depósito destinado a contener agua a presión o de forma atmosférica, sin membrana, para ser instalado en la aspiración de un equipo de presión. Cuando la presión en la acometida se reduce puede función como depósito auxiliar.

Derivación colectiva. Tubería que enlaza el montante con varias derivaciones particulares.

Derivación particular. Tubería que enlaza el montante o una derivación colectiva con las derivaciones de aparato, directamente o a través de una ramificación. 
Diámetro nominal. Número convencional que sirve de referencia y forma parte de la identificación de los diversos elementos que se acoplan entre sí en una instalación. Viene especificado en las normas correspondientes a cada tipo de tubería o elemento.

Equipo de presión. Equipo que permite disponer de una presión mayor que la que proporciona la red de distribución.

Fichero INP. Fichero propio de trabajo del programa hidráulico Epanet.

Grupo convencional. Grupo de bombeo definido en el CTE, equipado con una bomba de velocidad fija, calderín y un depósito en la aspiración de la bomba que evita los descensos de presión y perturbaciones en la red general del tramo que alimenta.

Instalación general. Instalación interior del edificio. Conecta el tramo de acometida con la instalación particular del abonado. Es el punto de la instalación donde se conecta el grupo de bombeo si se precisa.

Instalación particular del abonado. Instalación situada en el interior de la propiedad de cada abonado, empezaría en la llave de corte situada en el interior de la vivienda.

Número de aparatos (nap). Número de aparatos instalados aguas abajo de un tramo. En el caso de una vivienda, se corresponde con el número de aparatos instalados en ésta.

Número de arranque por hora máximo (n). Es el máximo número de arranques recomendado que se le debe permitir a una bomba para un adecuado funcionamiento.

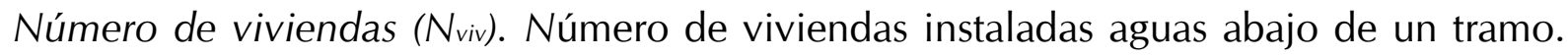
En el caso de un edificio, se corresponde con el número de viviendas de éste.

Pendiente hidráulica (j) (pérdidas de carga unitarias). Pérdida total que se origina por unidad de longitud. Está relacionada con el caudal circulante por el tramo y el diámetro de conducción en el mismo.

PID (Proporcional Integral Derivativo). Mecanismo de control por realimentación que calcula la desviación o error entre un valor medido y el valor que se quiere obtener, para aplicar una acción correctora que ajuste el proceso. El algoritmo de cálculo del control PID se da en tres parámetros distintos: el proporcional $\left(K_{p}\right)$, el integral $\left(K_{i}\right)$, y el derivativo $\left(K_{d}\right)$. 
Presión de consigna $\left(P_{C}\right)$. Presión requerida a la salida del equipo de presión de en caso de velocidad variable para garantizar la presión mínima de funcionamiento en los puntos de consumo.

Presión de paro (Pp). Presión manométrica a la que se dispone el paro completo del equipo de presión. Se trata de la presión máxima aportada por la bomba.

Presión de servicio $\left(P_{\text {ser }}\right)$. Presión manométrica disponible en la llave de registro del suministro de agua a la instalación en régimen estacionario. Presión al final de la acometida y que asegura la compañía suministradora a petición del proyectista.

Presión mínima de funcionamiento de un aparato $\left(P_{\min }\right)$. Es la presión mínima necesaria para el funcionamiento de un aparato.

Presión nominal $(P N)$. Número convencional que coincide con la presión máxima de trabajo a $20^{\circ} \mathrm{C}$.

Punto de entrega. Punto del sistema de abastecimiento que coincide con la llave de registro y es el principio de la instalación del edificio.

Red general de abastecimiento/distribución (RGD). Tramo de la red general de distribución de un municipio al que están conectados los diferentes edificios mediante la correspondiente acometida domiciliaria.

Tipo de Vivienda. Clasificación de los locales con uso de agua en función del caudal instalado. Esta clasificación fue establecida por la NIA, Normas Básicas para las Instalaciones Interiores de Suministro de Agua (NIA, 1978).

Tubería de alimentación. Conducción conectada a la acometida del edificio y que discurre por la instalación general de éste.

Tubería de aspiración. Conducción a la que se conecta la aspiración de una bomba. Puede ser una tubería simple o un colector asociado a varias bombas.

Válvula de retención. Dispositivo que impide automáticamente el paso de un fluido en sentido contrario al normal funcionamiento de la misma.

Válvula de seguridad (de alivio). Dispositivo que se abre automáticamente cuando la presión del circuito sube por encima del valor de tarado, descargando el exceso de presión.

Volumen útil del depósito del calderín. Volumen de agua en el interior del calderín en régimen permanente. 


\subsection{SimbologíA}

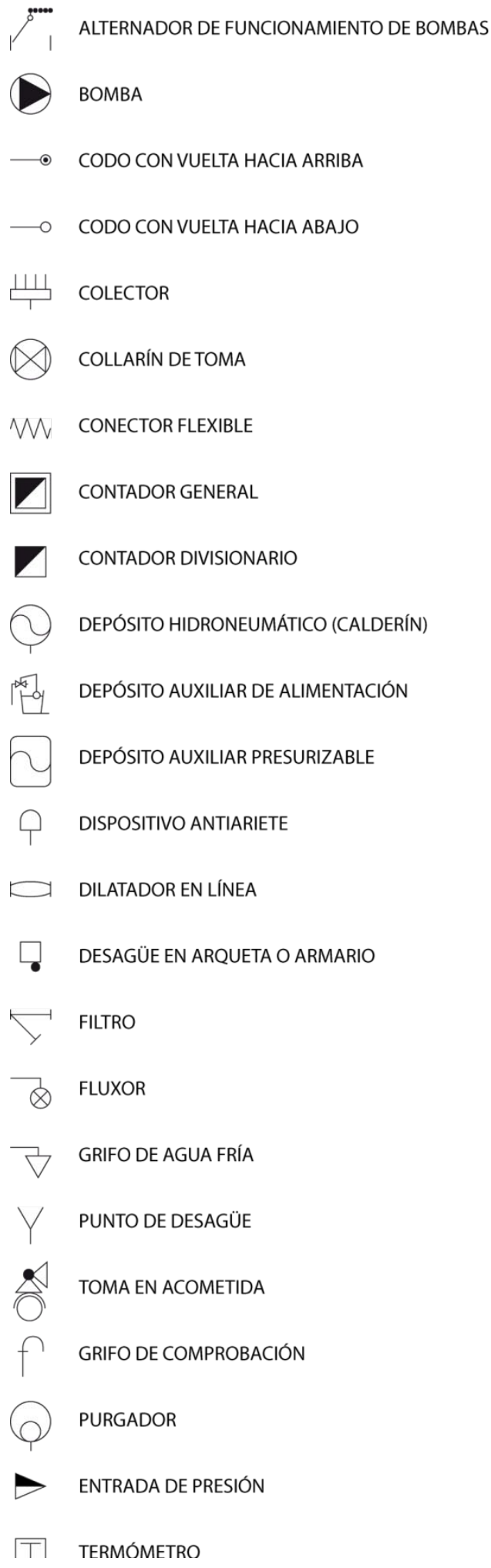

LLAVE DE TOMA EN CARGA

\# llave de compuerta

$£$ LLAVE de bOLA O de aCCIONAMIENTO RÁPIDO

1. LLAVE DE PASO CON DESAGÜE O GRIFO DE VACIADO

LLAVE DE ASIENTO DE PASO INCLINADO

$7 \quad$ LlaVe de paso con grifo de VACIADOY

DISPOSITIVO ANTIRRETORNO

(M) MANÓMETRO

(P) PRESOSTATO

(MP) MANÓMETRO Y PRESOSTATO

VF VARIADOR DE FRECUENCIA

$\varnothing$ válvula de aisLamiento

2) VÁLVULA DE ALIVIO

VÁLVULA ANTIRRETORNO

VÁlvula de dos vías motorizada

VÁlvula de tres vías motorizada

$\triangle$ VÁLVULA LIMITADORA DE PRESIÓN

$\triangle$ VÁLVULA REGULADORA DE PRESIÓN

$\searrow$ VÁlVULA DE VENTOSA

— TUBERÍA DE IDA O IMPULSIÓN DE A.F.

---- TUBERÍA DE IDA O IMPULSIÓN DE A.C.S.

-.-- TUBERÍA DE RETORNO O RECIRCULACIÓN DE A.C.S.

$-\quad$ T CON SALIDA HACIA ARRIBA

- - T TON SALIDA HACIA ABAJO

........ LÍNEA DE ACCIONAMIENTO ELÉCTRICO O ELECTRÓNICO 
Anexo 8

Referencias 


\section{ReferenCias}

Abreu J. M. y Cabrera E. (2011). "Disipación de energía en régimen transitorio: comprensión y caracterización del fenómeno físico". Jornadas de Ingeniería hidráulica, $2^{\text {a }}$ ed. Octubre de 2011. Madrid.

Abreu J. M., Cabrera E. y Arregui F. (2012). Fundamentos físicos (Capítulo 2). Transitorios hidráulicos. Del régimen estacionario al golpe de ariete. Editores Abreu J. M., Cabrera E., Espert V. B., García-Serra J. y Sanz F. Universitat Politècnica de Valéncia. ISBN: 978-84-8363-780-7.

Abreu J. M., Cabrera E., Espert V. B., García-Serra J. y Sanz F. (Edit.) (2012). Transitorios hidráulicos. Del régimen estacionario al golpe de ariete. $1^{\text {a }}$ ed. Ed. Universidad Politécnica de Valencia. España.

Abreu J. M., Izquierdo J. y Vidal Ma . R. (1995). Transitorios hidráulicos en sistemas complejos. Capítulo 6. Transitorios y oscilaciones en sistemas hidráulicos a presión, pp. 223-293. $1^{\text {a }}$ ed. U.D. Mecánica de Fluidos. Universidad Politécnica de Valencia.

Almandoz J., Cabrera E., Arregui F., Cabrera Jr. E. y Cobacho R. (2005). "Leakage Assessment through Water Distribution Network Simulation". Journal of Water resources Planning and Management, 131(6), pp. 458-466.

Allen R. (1987). "Network analysis: the real story". Illrd International Conference. Computer applications for water supply and distribution. Ed. Leicester Polytechnic, UK.

American Water Works Association (1982). Introduction to water quality analyses, Vol. 4, Denver. 
Apollino C., de Marinis G. y Leopardi A. (2009). "Water hammer in Branched SystemsBehaviour of Viscoelastic Pipes". 33rd IAHR Congress: Water Engineering for a Sustainable Environment 2009 by International Association of Hydraulic Engineering \& Research (IAHR).

Arizmendi L. J. (1985). Cálculo y normativa básica de las instalaciones en los edificios. Ed. Universidad de Navarra. ISBN: 84-313-0894-X.

Arregui F. (1998). "Propuesta de una metodología para el análisis y gestión del parque de contadores de agua en un abastecimiento." Tesis Doctoral. Univ. Politécnica de Valencia, España.

Ayto. de Sevilla (2008). Modificación de la Ordenanza Municipal sobre el Servicio de Abastecimiento Domiciliario de Agua Potable. BOP no 300 de 29 de diciembre de 2008.

Ayto. de Zaragoza (2011). Ordenanza Municipal para la Ecoeficiencia y la Calidad de la Gestión Integral del Agua. Ayuntamiento de Zaragoza. BOP nº 29 de 07 de febrero de 2011.

Beatty R., Bliss P.J. y Vintage D. C. (1996). "Analysis of factors influencing chlorine decay in piped distribution systems". J. AWWA 16, pp. 159-165.

Bergant A., Simpson A., y Vitkovsky J. (2001), "Developments in Unsteady Pipe Flow Friction Modelling". J. Hydraul. Res. 39, pp. 249-257.

Bergant A., Tijsseling A. S., Vítkovský J. P., Covas D., Simpson A. R. and Lambert, M. F. (2003a). "Further investigation of parameters affecting water hammer wave attenuation, shape and timing-mathematical tools". Proceedings of the 11 th International Meeting of the IAHR Work Group on the Behaviour of Hydraulic Machinery under Steady Oscillatory Conditions, Stuttgart, Germany, Paper 4.3.

Bergant A., Tijsseling A. S., Vítkovský J. P., Covas D., Simpson, A. R., Lambert, M. F. (2003b). "Further investigation of parameters affecting water hammer wave attenuation, shape and timing-case studies". Proceedings of the 11th International Meeting of the IAHR Work Group on the Behaviour of Hydraulic Machinery under Steady Oscillatory Conditions, Stuttgart, Germany, Paper 4.4.

Bergant A., Tijsseling A., Vitkovsky J., Covas D., Simpson A. y Lambert M. (2008). "Parameters affecting water-hammer wave attenuation, shape and timing-Part 1: Mathematical tools". Journal of Hydraulic Research. Volume 46, Issue 3, pp. 373381. 
Bhave P. R. (1988). "Calibrating water distribution network models". Journal of Environmental Engineering, 114, nº 1, pp. 120-136.

Biswas P. y Clark R.M. (1993). "A model for chlorine concentration decay in pipes". Water Res. 27, pp. 1715-1724.

Bombas Ebara. Manual Técnico. www.ebara.es.

Bombas Espa. Manual Técnico. www.espa.com.

Bombas Grundfos. Manual Técnico. www.grundfos.es.

Bombas Ideal. Manual Técnico. www.bombasideal.com.

Boorman G. A. (1999). "Drinking water disinfection byproducts: review and approach to toxicity evaluation". Environ Health Perspect,107 (Suppl. 1), pp. 207-217.

Buchberger S. G. y Lee Y. (1999). "Evidence Supporting the Poisson Pulse Hypothesis for Residential Water Demands". Proceedings of International Conference on Computing and Control for the Water Industry, Exeter, United Kingdom, pp 89-101.

Buchberger S. G. y Wells G. J. (1996). "Intensity, Duration and Frequency of Residential Water Demands". Journal of Water Resources Planning and Management, 122, $\mathrm{n}^{\circ} 1$, pp. 11-19.

Buchberger S. G. y Wu L. (1995). "Model for Instantaneous Residential Water Demands". Journal of Hydraulic Engineering. Vol. 121, $\mathrm{n}^{\circ} 3$.

Bush C. A. y Uber J. G. (1998). "Sampling design methods for water distribution model calibration". Journal of Water Resources Planning and Management, 124, n 6, pp. 334-344.

Cantor K. P., Lynch C.F., Hildesheim M.E., Dosemeci M., Lubin J., Alavanja J. y Craun G, (1998). "Drinking water source and chlorination by-products I. Risk of bladder cancer". Epidemiology, 9 1, pp. 21-28.

Chambers V. K., Creasey J. D. y Joy J.S. (1995). "Modelling free and total chlorine decay in potable water distribution systems". Water Supply Res. Technol. Aqua 44, pp. 60-69.

Charalambous B., Charalambous S. y Ioannou I. (2007). "Meter under-registration caused by ball valves in roof tanks". Water Loss 2007. Specialist Conference. International Water Association. ISBN: 978-973-7681-3. Bucarest, Rumanía. 
Clark R. (1998). "Chlorine demand and TTHM formation kinetics". J. Environ. Eng. ASCE, 1241 (1998), pp. 16-24.

Clark R., Abdesaken P., Boulos P. F. y Mau R. E. (1996). "Mixing in distribution system storage tanks: Its effect on water quality". J. Environmental Engrg., ASCE, 122(9).

Clark R., Goodrich J. A., Wymer L. J. (1993). "Effect of the distribution system on drinking-water quality". Aqua (US Environmental Protection Agency). Volume 42, Issue 1, pp. 30-38.

Clark R., Grayman W.M., Goodrich J. A., Deininger R.A. y Skov K. (1994) "Measuring and modeling chlorine propagation in water distribution systems". J. Water Resources Planning Manage.

Cobacho R., Arregui F., Cabrera E. y Cabrera E. Jr. (2007). "Private water storage tanks: evaluating their inefficiencies". Water Practice \& Technology. IWA Publishing 2008.

Covas D., Stoianov I., Mano J., Ramos H., Graham N. y Maksimovic C. (2004). "The dynamic effect of pipe-wall viscoelasticity in hydraulic transients. Part I experimental analysis and creep characterization". Journal of Hydraulic Research Vol. 42, n 5, pp. 516-530.

Covas D., Stoianov I., Mano J., Ramos H., Graham N. y Maksimovic C. (2005). "The dynamic effect of pipe-wall viscoelasticity in hydraulic transients. Part II - Model development, calibration and verification". Journal of Hydraulic Research Vol. 43, $\mathrm{n}^{\mathrm{o}} 1$, pp. 56-70.

Crane (1987). Flujo de fluidos en válvulas, accesorios y tuberías. Ed. McGRAW HILL.

Criminisi A., Fontanazza C., M., Freni G., y La Loggia G. (2009). "Evaluation of the apparent losses caused by water meter under-registration in intermittent water supply". Water Science and Technology. Volume: 60, Issue: 9, pp. 2373-2382.

CTE (2006). Código Técnico de la Edificación. Aprobado en el Real Decreto 314/2006 BOE no74, 28 de marzo de 2006 -CTE. HS 4. Suministro de Agua -CTE. SE AE. Acciones en la edificación.

DeOreo W. B., Heaney J. P., y Mayer P. W. (1996). "Flow trace analysis to assess water use". Journal of the American Water Works Association; 88(1), pp. 79-90.

DIN 1988. Part. 3. Drinking water supply systems. Pipe sizing. 
CEDEX (2006). Guía Técnica sobre tuberías para el transporte de agua a presión. Ed. Centro de Estudios Hidrográficos del CEDEX. 3a Edición. ISBN: 84-7790-431-6.

DIN 1988. Part. 5. Drinking water supply systems. Pressure boosting and reduction.

EMOTRON. Manual Técnico.

http://www.emotron.es/Documents/Documents/Applications.

Fang Hua J. R., Wset R. A., Barker y Forster C. F. (1999). "Modelling of chlorine decay in municipal water supplies". Water Research, Volumen 33, $\mathrm{n}^{\circ} 12$, pp. 27352746(12).

Farley M. y Trow S. (2003). "Losses in Water Distribution Networks". IWA publishing, Alliance House, 12 Caxton St, London, UK. ISBN: 1900222116.

García V. J. (2003). "Modelación de la demanda urbana de agua" Tesis doctoral. Departamento de Ingeniería Hidráulica y Medio Ambiente. Univ. Politécnica de Valencia, España.

García V. J., García Bartual R., Cabrera E.; Arregui F. y García-Serra J. (2003). "Stochastic Model to Evaluate Residential Water Demands". Journal of Water Resources Planning and Management. ASCE.

García-Serra J. (1988). "Estudio y Mejora de las Técnicas de Calibración de Modelos de Redes Hidráulicas". Tesis Doctoral. Univ. Politécnica de Valencia, España.

García-Serra J., Cabrera E. y Díaz J. (1996). Ingeniería hidráulica aplicada a los sistemas de distribución de agua. Válvulas de control, regulación y operación. Vol. 1, cap. 7, pp. 283-332.

Gauthier V. (2009). "Storage Tank Management to Improve Drinking Water Quality: Case Study". J. Water Resour. Plng. and Mgmt. 126, 221.

Grayman W. M. y Kirmeyer G. J. (1999). Quality of water in storage. Water Distribution Systems Handbook, L. W. Mays, ed. McGraw-Hill, New York.

Grayman W. M., Deininger R. A., Green A., Boulos P. F., Bowcock R. W. y Godwin C. C. (1996). "Water quality and mixing models for tanks and reservoirs". J. AWWA, 88(7), pp. 60-73.

Hassan I. M. y Ali A. M. G. (2011). "Effect of Cold-Water Storage Cisterns on DrinkingWater Quality". J. Water Resour. Plann. Manage. 137, 448. 
Holmboe E. L. y Rouleau W. T. (1967). "The effect of viscous shear on transients in liquid lines". Journal of Basic Engineering, ASME, Vol. 68, pp.174-180.

Ibaiondo (depósitos presurizados). Catálogo comercial. www.ibaiondo.com.

Iglesias P. L. (2001). "Modelo general de análisis de redes hidráulicas a presión en régimen transitorio". Tesis Doctoral. Univ. Politécnica de Valencia. España.

Iglesias P. L., López G. y Martínez J. (1998). “Influencia de la modulación del consumo de agua en la calidad del suministro". I Congreso Ibérico sobre Gestión y Planificación de Sequías. Zaragoza. España.

Ingeniería Hidráulica aplicada a los sistemas de distribución de agua (Vol. I). Unidad docente de Mecánica de Fluidos de la Universidad Politécnica de Valencia. 1996. Pp 74-124, 283-321.

Lansey K. E. (1988). "A Procedure for Water Distribution Network Calibration considering Multiple Loading Conditions". International Symposium on Computer Modelling. Kentucky Water Resources Research Institute. Univ. of Kentucky. Lexington.

Levesque S, Rodriguez M. J., Serodes J., Beaulieua C y Proulx F. (2006), "Effects of indoor drinking water handling on trihalomethanes and haloacetic acids". Water Research. Volume 40, Issue 15, August 2006, pp. 2921-2930.

López G. (1994). "Modelo matemático de la red arterial de distribución de agua potable a la ciudad de Valencia". Proyecto final de carrera, E.T.S.I.I. Univ. Politécnica de Valencia, España.

Manual Allievi. http://www.allievi.net.

Marchal M., Flesh G., y Suter P. (1965). "The Calculation of Waterhammer Problems by Means of the Digital Computer Proceedings". International Symposium on Water hammer in Pumped Storage Projects. American Society of Mechanical Engineers (ASME), Chicago.

Martínez F. (2005). "Pérdidas de carga en tuberías. Coeficientes de rugosidad". Ponencia en IV Jornada sobre tuberías de hormigón armado y postesado. CEDEX. Madrid. 15 de marzo de 2005.

Mayer P. W., DeOreo W. B., Opitz E. M., Kiefer J. C., Davis W. Y., Dziegielewski B. y Nelson J. O. (1999). "Residential End Uses of Water". American Water Works Association Research Foundation, USA. 
Mecánica de Fluidos. Frank M. White. Ed. McGraw-Hill. 1979.

Meredith D. D. (1983). "Use of optimization in calibrating water distribution system models". Proceedings of the ASCE Spring Convention, American Society of Civil Engineers, Philadelphia, USA.

NIA (1975). Normas Básicas para las Instalaciones Interiores de Suministro de Agua (NIA). Ministerio de Industria, Comercia y Turismo. Centro de Publicaciones (1975). Según Orden de 9 de Diciembre de 1975 (B.O.E. del 13-1-76 y corrección de errores en el B.O.E. de 12-2-76).

NIA (1990). Ampliación de las Normas Básicas para las instalaciones interiores de suministro de agua. Condensadores hidráulicos. Conselleria d'Indústria, Comerç i Turisme (Generalitat Valenciana). Resolución de 26 de septiembre de 1990.

Nieuwenhuijsen M. J., Toledano M. B., Eaton N. E., Fawell J. y Elliott P. (1999). "Chlorination disinfection byproducts in water and their association with adverse reproductive outcomes: a review". Occupational and Environmental Medicine 2000, no 57, pp. 73-85.

Normas Técnicas para Proyectos y Obras de Abastecimiento y Saneamiento en el Puerto de Santa María (1991), de acuerdo al Reglamento del Suministro Domiciliario de Agua, aprobado por Decreto de la Junta de Andalucía 120/1991, BOJA n 81, de 10 de septiembre de 1991.

Olaer (depósitos presurizados). Manual Técnico. www.olaer.es.

OMS (1985). Guía para la calidad del agua potable. Washington D. C. (US). OPS no 481.

Ordenanza de Aguas de Cartagena (1991). Contratación del suministro de agua potable. 2 de mayo de 1991.

Ordenanza fiscal reguladora de la tasa por prestación del servicio de abastecimiento domiciliario de agua potable y otras actividades conexas al mismo (2009). EMASESA BOP nº 300 de 29 diciembre de 2008.

Ordenanza Municipal para la ecoeficiencia y la calidad de la gestión integral del agua. Ayuntamiento de Zaragoza (2011). Anexo X: Depósitos domiciliarios de agua.

Ordenanza Reguladora de la Gestión del Ciclo Integral del Agua en el Municipio de Vitoria - Gasteiz (2010). Ayuntamiento de Vitoria. BOTHA, no 9 de 21 de enero de 2011. 
Ordenanza sobre la Contratación del Suministro de Agua. Ayuntamiento de Cartagena. 2 de mayo de 1991.

Ormsbee L. E. y Chase D. V. (1988). "Hydraulic Network Calibration using Nonlinear Programming". International Symposium on Computer Modelling. Kentucky Water Resources Research Institute. Univ. of Kentucky. Lexington.

Ormsbee L. E. y Lingireddy S. (2000). "Calibration of hydraulic networks models". Water Distribution Systems Handbook. Larry W. Mays, ed., McGraw-Hill, USA.

Real Decreto 140/2003, de 7 de febrero, por el que se establecen los criterios sanitarios de la calidad del agua de consumo humano. BOE nº45, 21 de febrero de 2003.

Real Decreto 865/2003, por el que se establecen los criterios higiénico-sanitarios para la prevención y control de la legionelosis. Ministerio de Sanidad y Consumo. BOE 171 4 de julio de 2003.

Reglamento del suministro domiciliario de agua en Andalucía (1991). Decreto 120/91, de 11 de Junio, Consejería de Presidencia, Junta de Andalucía.

Reglamento para el servicio y distribución de las aguas del Canal de Isabel II. Decreto 2922/1975, de 31 de octubre por el que se aprueba el reglamento para el servicio y distribución de las aguas del Canal de Isabel II (M. Obras Públicas). BOE, 13 de noviembre de 1975.

Reglamento Servicio de Abastecimiento de Agua Potable de la Ciudad de Valencia (2004). BOP, 14 de septiembre de 2004.

Reynolds T. D. y Richards P. A. (1996). Unit operations and processes in environmental engineering. PWS Publishing, Boston.

Rizzo A. y Cilia J. (2005). "Quantifying meter under-registration caused by the ball valves of roof tanks (for indirect plumbing systems)". IWA Specialised Conference "Leakage 2005". Halifax, Canada. Conference Proceedings, p.106.

Rossman L. A. (1993). EPANET User's Manual. U.S. Environmental Protection Agency. Cincinnati, Ohio (USA).

Sarrio V. (2011) "Desarrollo de un simulador para entrenamiento de operadores de abastecimientos de agua". Tesis doctoral. Univ. Politécnica de Valencia. España. 
Soriano J. (2008). "Simulación del comportamiento hidráulico en régimen permanente y transitorio de un tramo de red residencial de distribución de agua utilizando consumos reales con alta resolución". Master's thesis. Univ. Politécnica de Valencia. España.

Soriano J., Arregui F., Veiga C., y Buchberger S. (2010) "Análisis y Comparación de los Principales Esquemas de Suministro en Instalaciones Generales de Edificios" IWA Young Water Professional Conference. Barcelona. España.

Thorley A. R. D. y Chaudry A. (1996). "Pump characteristics for transient flow analysis". Proc. 7th Int. Conf. on Pressure Surges, BHRA. Cranfield, Beds. (UK), pp. 461-475.

Tijsseling A. S. (1996), "Fluid-structure interaction in liquid-filled pipe systems: a review". Journal of Fluids and Structures. Volume 10, Issue 2, pp. 109-146.

Trussell R. R. y Umphres M. D. (1978), "The formation of trihalomethanes". J. Am. Water Works Assoc., 11(1978), pp. 604-612.

UK Water Industry (1994). Managing Leakage. Report G, Managing Water Pressure. (WRcplc/ Water Services. Association/Water Companies Association, UK).

UNE 149201. Dimensionado de instalaciones de agua para consumo humano dentro de los edificios. Febrero 2008. AENOR.

UNE-EN 806-2 (2005). Especificaciones para instalaciones de conducción de agua destinada al consumo humano en el interior de edificios. Parte 2: Diseño. AENOR.

Vardy A. E., Fan D. y Tijsseling A.S. (1996). "Fluid/structure interaction in a T-piece pipe". J. Fluids Struct. 10(7), pp. 763-786.

Vasconcelos J. J., Rossman L. A., Grayman W. M., Boulos P. F., y Clark R. M. (1997). "Kinetics of chlorine decay". Journal AWWA Vol. 89 (7), pp.54-65.

Veiga C. y Soriano J. (2010). "Monitorización global del comportamiento hidráulico de un edificio de viviendas". Congreso AEAS 2010.

Vela A. (1988). "Asignación de cargas al modelo de una red de distribución de agua potable. Aplicación al caso de la ciudad de Valencia". Proyecto final de carrera, Universidad Politécnica de Valencia. España.

Villanueva C.M., Kogevinas M. y Grimalt J. O. (2003). "Haloacetic acids and trihalomethanes in finished drinking waters from heterogeneous sources". Water Research. Volume 37, Issue 4, pp. 953-958. 
Vítkovský J. P., Bergant A., Simpson A. R. y Lambert M.F. (2006). "Systematic evaluation of one-dimensional unsteady friction models in simple pipelines". J. Hydraul. Eng. ASCE 132(7), pp. 696-708.

Vítkovský J. P. (2001). "Inverse analysis and modelling of unsteady pipe flow: theory, applications, and experimental verification". Ph.D. Thesis, Department of Civil \& Environmental Engineering, University of Adelaide, Adelaide, Australia.

Water Research Center (WRc) (1989). "Network analysis - a code of practice". WRc, Swindon, UK.

Wells G. J. (1994). "Statistical characteristics of residential water demands". Master's thesis. Univ. of Cincinnati, Cincinnati (US). 